\title{
Language learning in three early childhood programs in Austria, Germany and the United States
}

\author{
Sandra Schoder \\ West Virginia University
}

Follow this and additional works at: https://researchrepository.wvu.edu/etd

\section{Recommended Citation}

Schoder, Sandra, "Language learning in three early childhood programs in Austria, Germany and the United States" (2010). Graduate Theses, Dissertations, and Problem Reports. 2958.

https://researchrepository.wvu.edu/etd/2958

This Dissertation is protected by copyright and/or related rights. It has been brought to you by the The Research Repository @ WVU with permission from the rights-holder(s). You are free to use this Dissertation in any way that is permitted by the copyright and related rights legislation that applies to your use. For other uses you must obtain permission from the rights-holder(s) directly, unless additional rights are indicated by a Creative Commons license in the record and/ or on the work itself. This Dissertation has been accepted for inclusion in WVU Graduate Theses, Dissertations, and Problem Reports collection by an authorized administrator of The Research Repository @ WVU.

For more information, please contact researchrepository@mail.wvu.edu. 


\title{
Language Learning in Three Early Childhood Programs in Austria, Germany and the United States
}

\author{
Sandra Schoder \\ Dissertation submitted to the \\ College of Human Resources and Education \\ at West Virginia University \\ in partial fulfillment of the requirements \\ for the degree of \\ Doctor of Education \\ in \\ Curriculum and Instruction
}

Joy Faini Saab, Ed.D., Chair

Patricia Obenauf, Ed.D.

Ardeth Deay, Ph.D.

Deborah Janson, Ph.D.

Cynthia Chalupa, Ph.D.

Department of Curriculum \& Instruction/Literacy Studies

\author{
Morgantown, West Virginia \\ 2010
}

Keywords: Language Learning, Early Childhood, Curriculum and Instruction Copyright 2010 Sandra Schoder 


\author{
ABSTRACT \\ Language Learning in Three Early Childhood Programs \\ in Austria, Germany and the United States
}

Sandra Schoder

In 2002 the European Union declared multilingualism and life-long language learning to be two goals that it will pursue for its citizens. As a result, member states have introduced language learning at the elementary school level, and have shown an ever increasing interest in implementing second language programs designed specifically for children under the age of seven. This is a welcome change for European educators who are already working in early childhood language programs or who plan to establish new programs and have been looking for support for their endeavors. Yet despite recent progress, scholarly research into this arena remains limited.

This dissertation attempts to address the lack of scholarship in this field by presenting the findings of a case study I conducted in three early childhood language programs in Austria, Germany, and the United States. I used aspects of grounded theory in the analysis of the data that was obtained through observation, interviews with participating educators, and questionnaires presented to teachers and parents. Through this qualitative inquiry, I analyzed several aspects of language learning while seeking a holistic description of their application. The aspects studied included multilingualism, curriculum, approach, instructional strategies, and the role of teachers and students.

The study's results showed both commonalities and differences in the programs' features, allowing for an understanding of the characteristics and complexity of early childhood language learning to emerge in relation to the approaches and methodologies imbedded in the programs. I found that the child, with his or her language competence, age, and personality, is at the center of early childhood language learning. Each child makes choices concerning the form that his or her verbal and non-verbal language participation will take while considering the situation and person involved in the application. Both teachers and children guide, facilitate, and interact throughout the applied curriculum, strategies, and program environment. These facets define each child's path on the language-difficulty continuum. The paths overlap, creating a tapestry in which the children attempt to become verbal members of the target language environment. 


\section{Dedication}

This dissertation is dedicated to my family Niklas, Marc, Susann, Thomas, Gisela, and Karl, and to the memory of my father Siegfried. I hereby thank them deeply for their love, patience, and support throughout the years. 


\section{Acknowledgment}

Warm thanks go to the children and educators for allowing me to be part of their experiences and for their support of this study. I will be forever grateful to my committee members Dr. Deborah Janson, Dr. Cynthia Chalupa, Dr. Pat Obenauf, Dr. Ardeth Deay, and Dr. Joy Faini-Saab, who supported this study and helped me to succeed in my doctoral studies. A heartfelt thank you goes to my family and friends: Warren and Avah, Miriam and Jarod, Lisa, Barbara, Bettina, Andrea and their families.

I would like to express my deepest gratitude to my husband Karl E. Schoder, who offered his support and love throughout this journey. 


\section{Table of Contents}

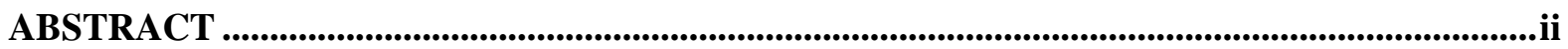

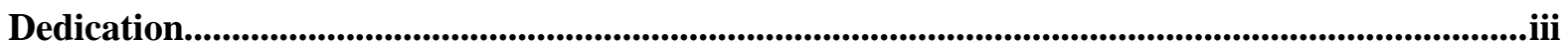

Acknowledgment …......................................................................................................................................... iv

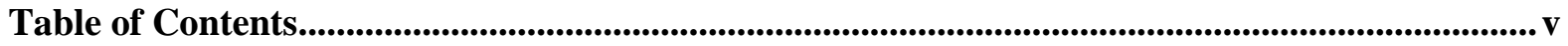

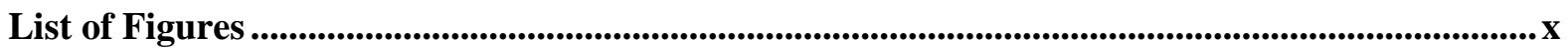

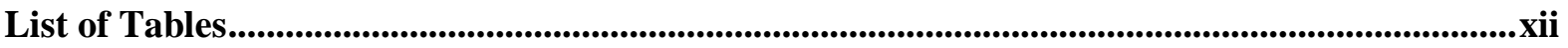

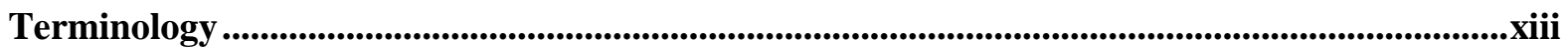

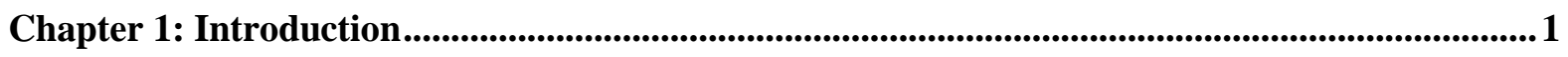

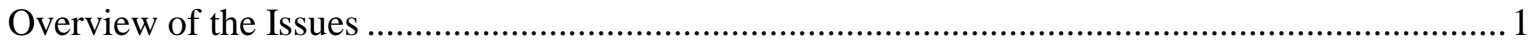

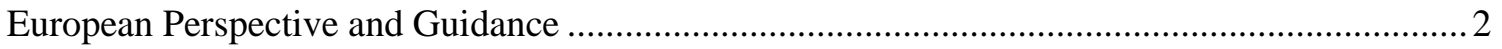

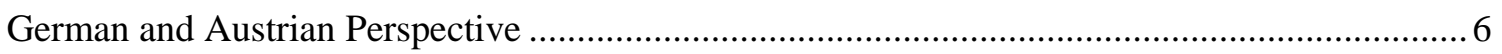

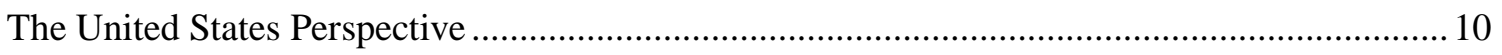

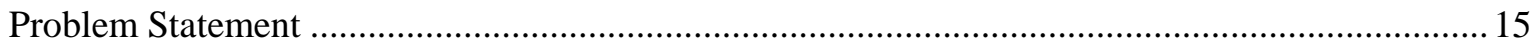

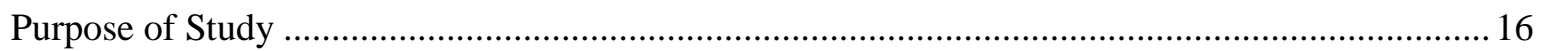

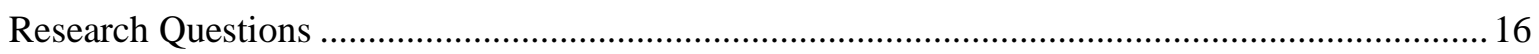

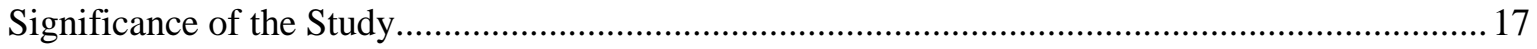

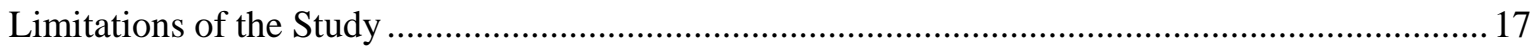

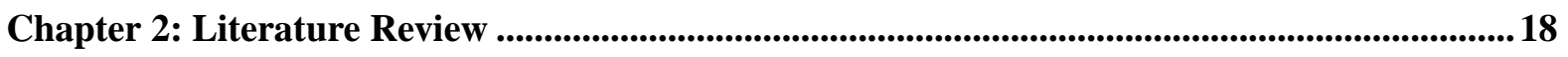

Austrian Education System and Elementary Language Learning .............................................. 18

Early Childhood Education Prior to School Entry and Language Learning................................ 19

German Education System and Elementary Language Learning .............................................2 23

Early Childhood Education Prior to School Entry ............................................................... 25

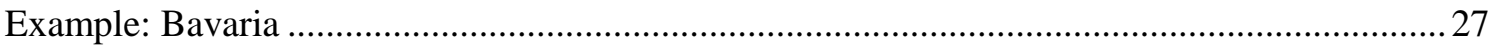

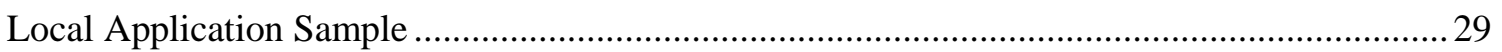

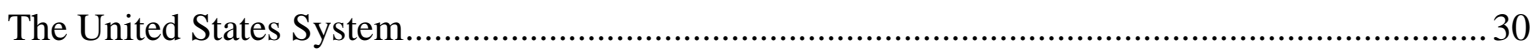

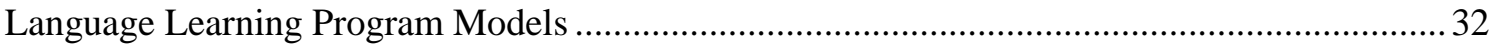

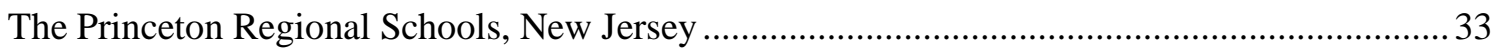

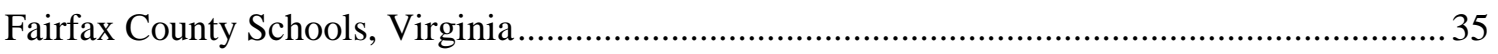

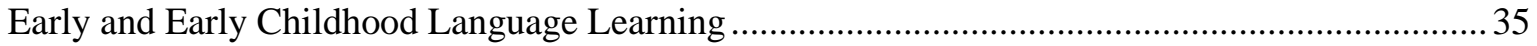

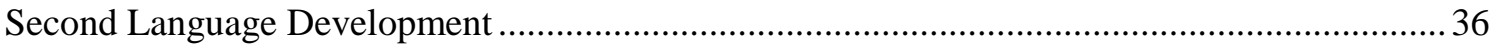




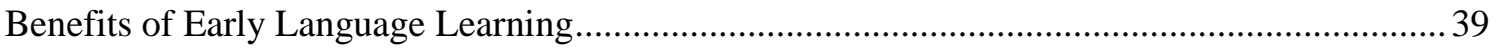

Early Childhood Language Learning In Preschool ................................................................ 40

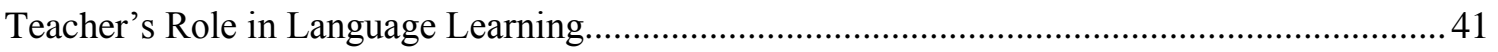

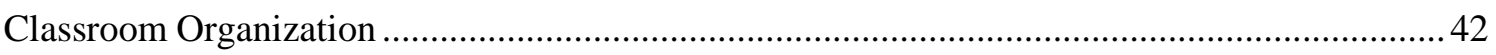

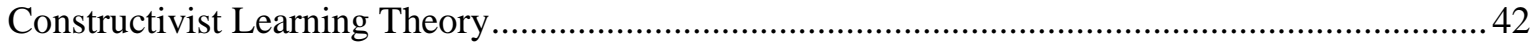

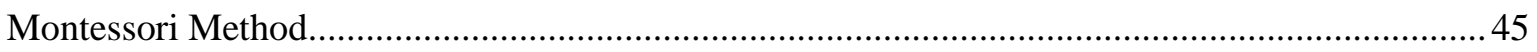

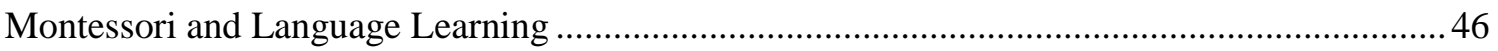

Chapter 3: Methodology …........................................................................................................................48

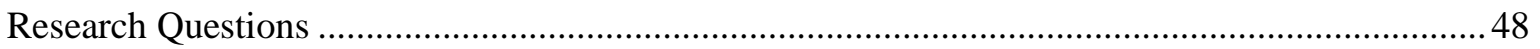

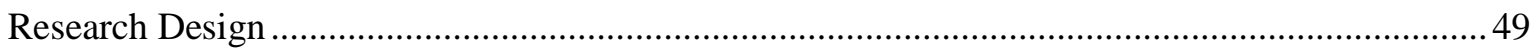

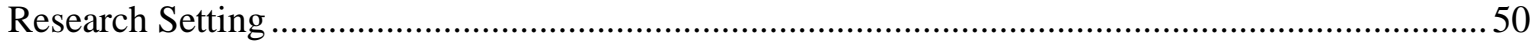

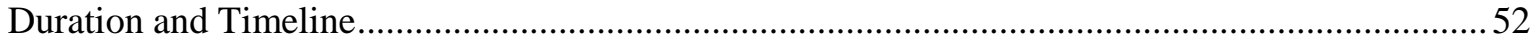

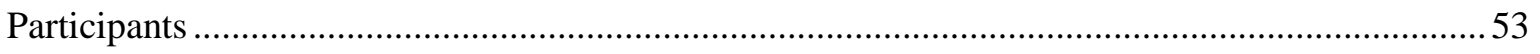

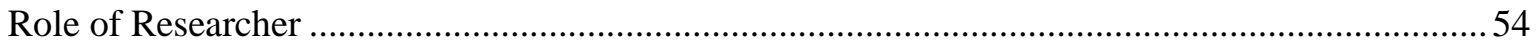

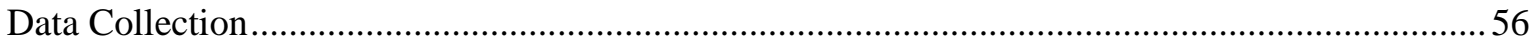

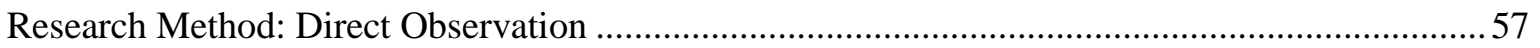

Research Method: Interview and Questionnaires ...................................................................5

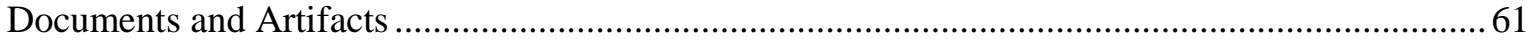

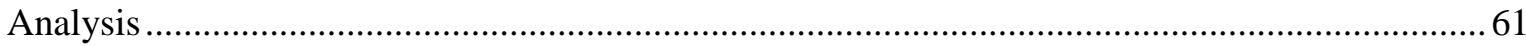

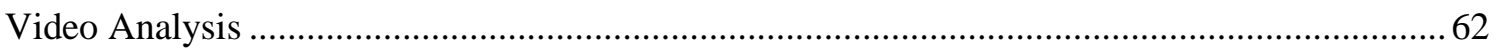

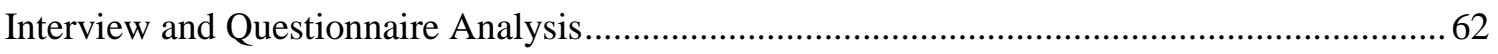

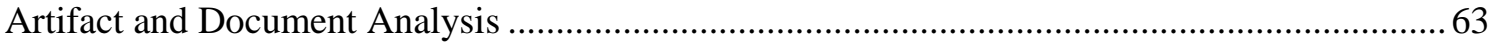

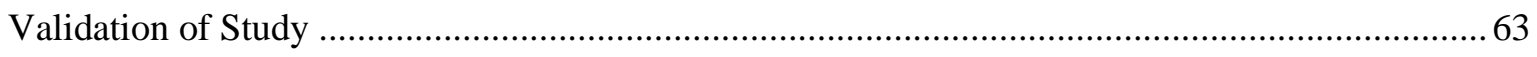

Chapter 4: Austrian Program Data Presentation - Montessori Kindergarten ..............................65

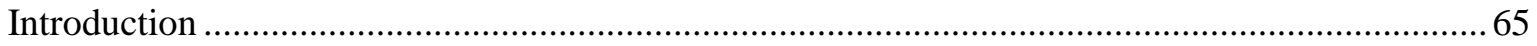

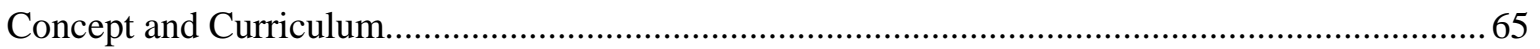

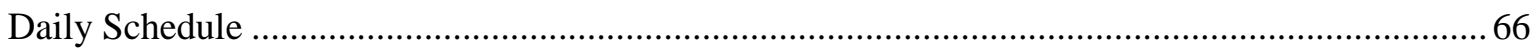

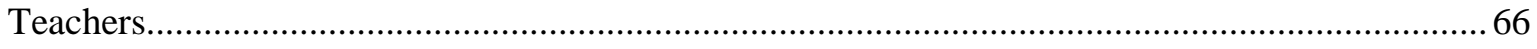

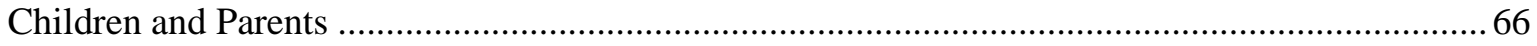

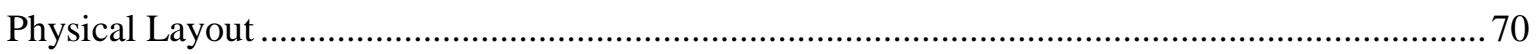

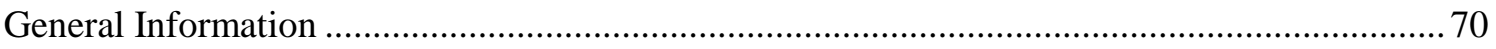

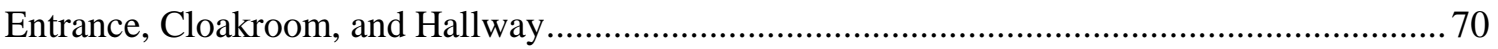

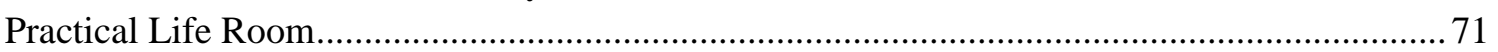




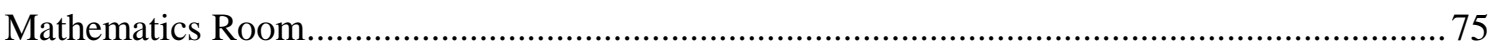

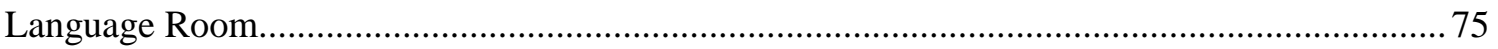

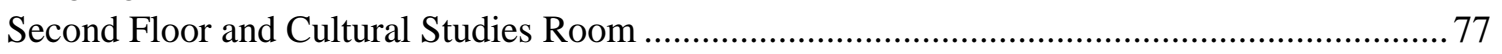

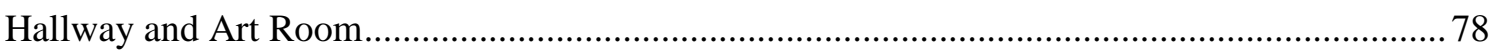

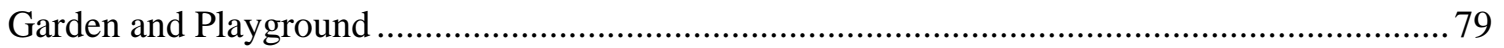

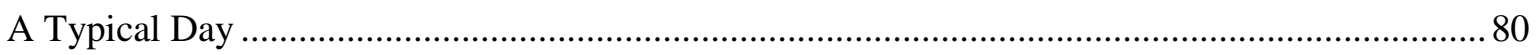

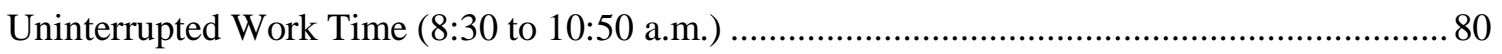

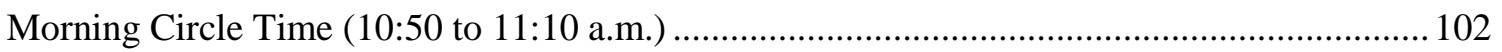

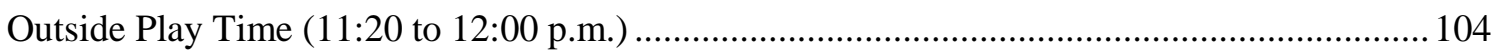

Blue Group Circle Time - 2-3year Old Children (12:10 to 1:50 p.m.) ..................................... 106

Yellow Group Circle Time - 4-5 year Old Children (12:15 to 1:50 p.m.)............................. 115

Red Group Circle and Lunch Time - 5-6 Year Old Children (12:10 - 1:50 p.m.) .................... 123

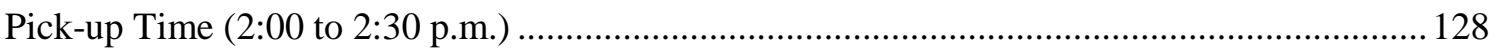

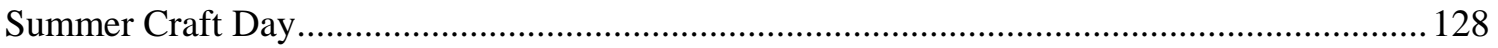

Chapter 5: German Program Data Presentation - Public Kindergarten ....................................... 135

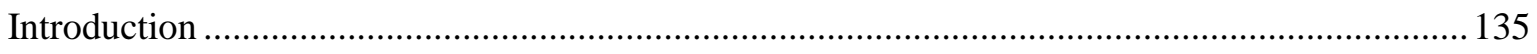

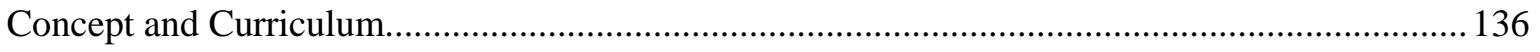

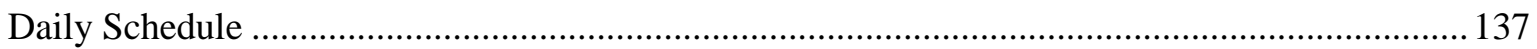

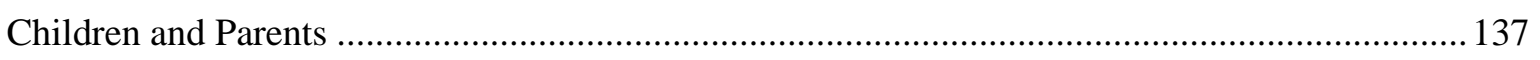

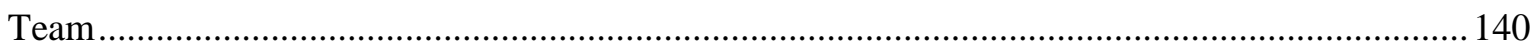

Physical Layout

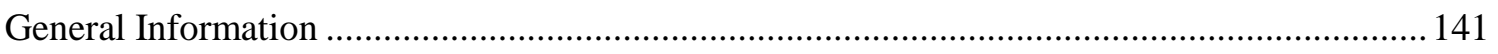

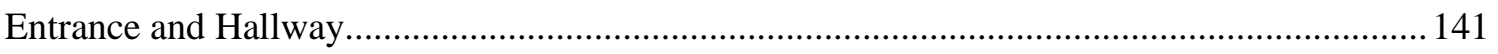

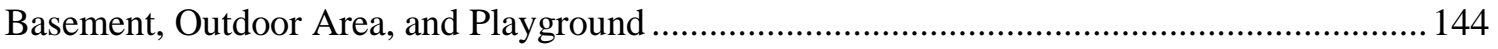

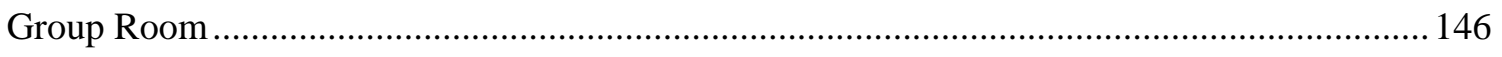

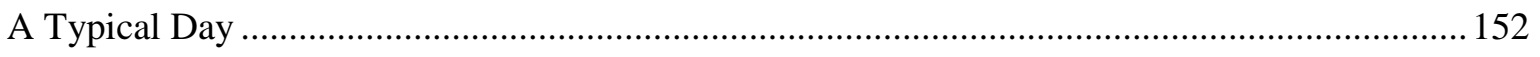

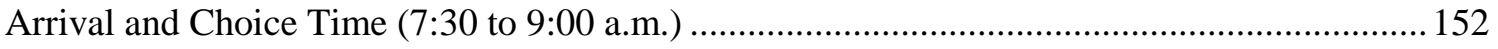

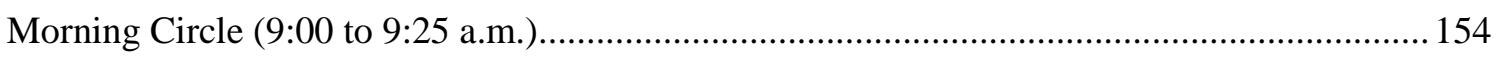

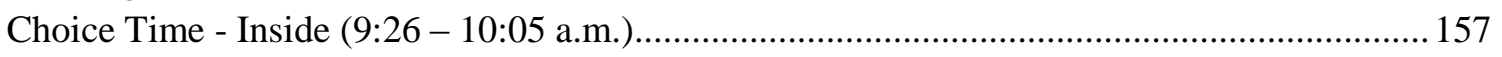

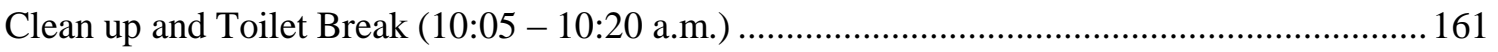

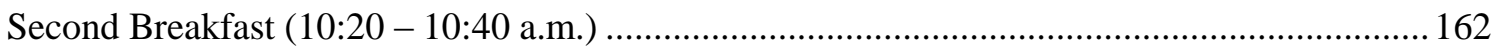

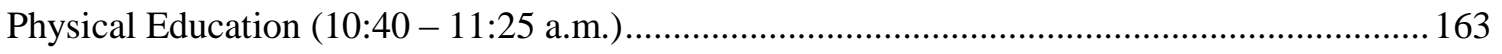

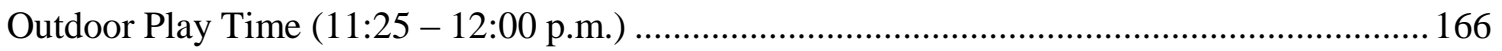

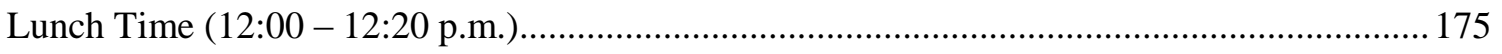

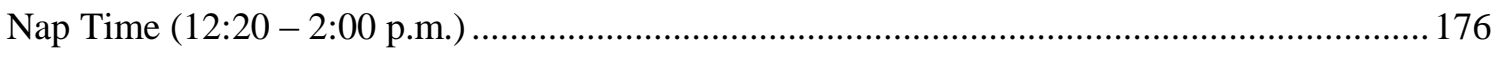

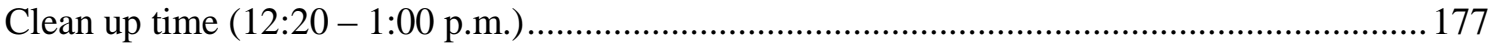

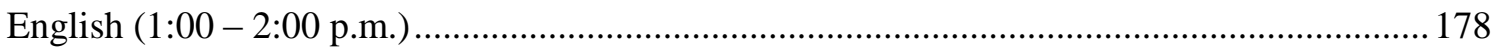

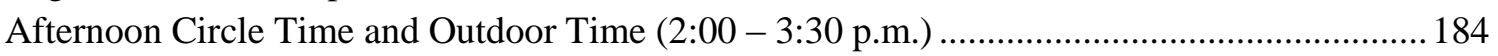




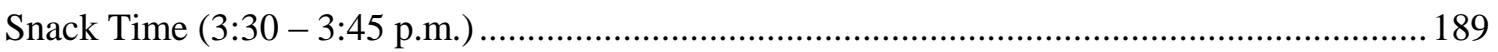

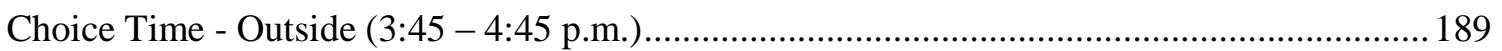

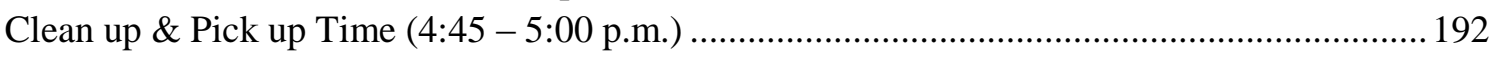

Chapter 6: Data Presentation U.S. Program - Private German Immersion School ................... 194

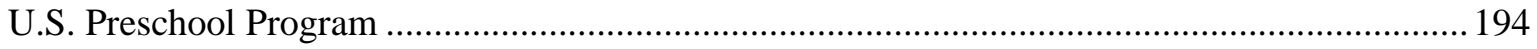

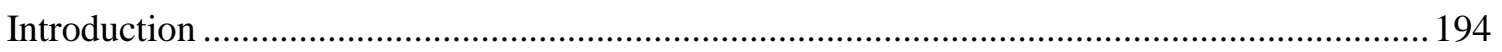

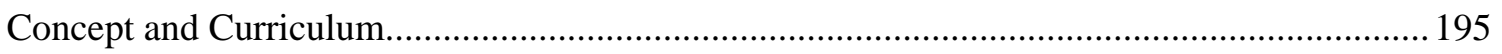

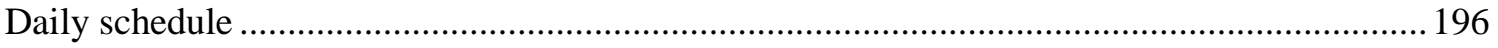

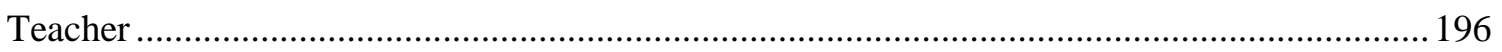

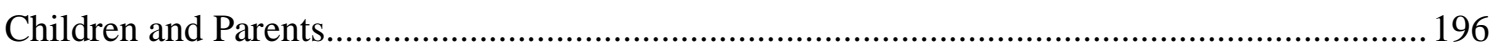

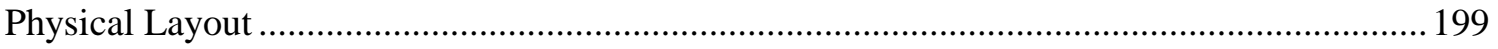

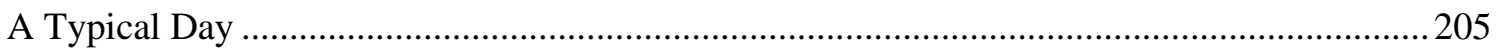

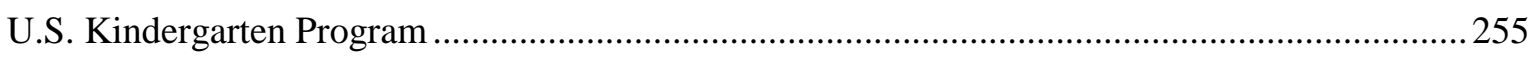

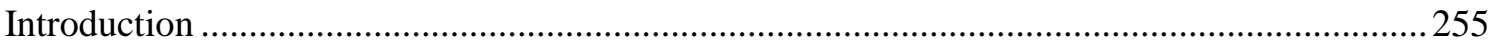

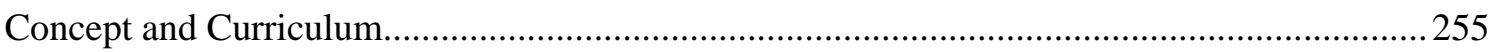

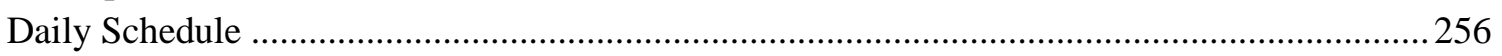

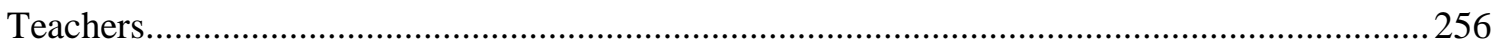

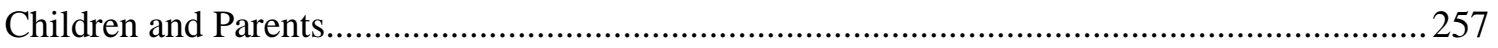

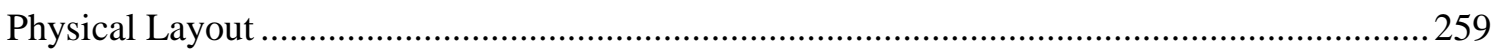

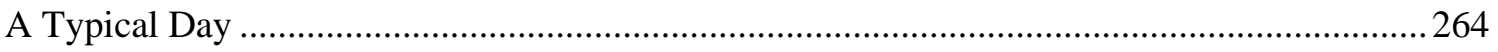

Chapter 7: Analysis and Discussion of Findings.......................................................................................315

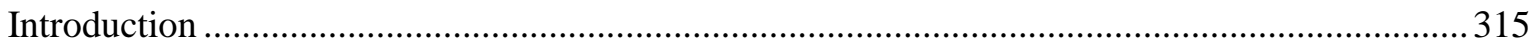

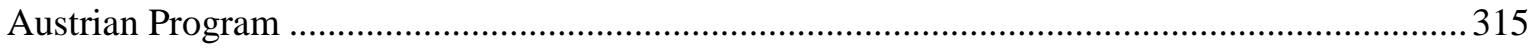

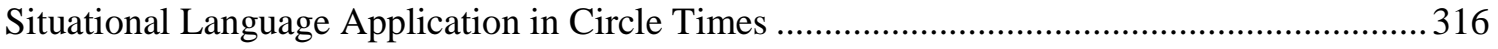

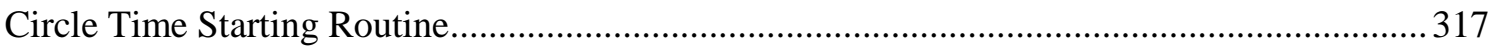

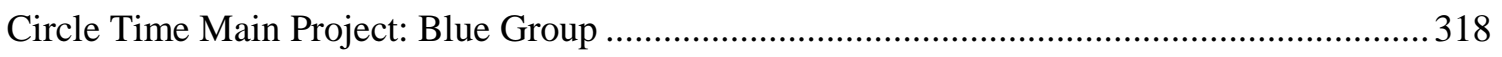

Circle Time Main Project: Yellow and Red Group ............................................................... 321

Main Project Yellow Group: Learning through Puppetry and Storytelling............................... 321

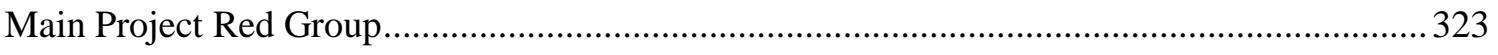

Situational Language Application during the Uninterrupted Work Time ................................. 325

Person-bound Language Application during the Uninterrupted Work Time .............................330

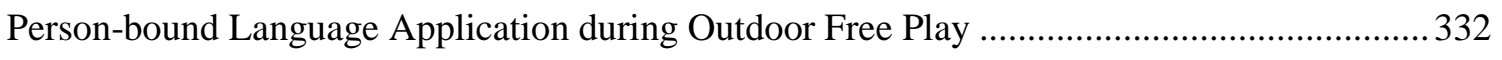

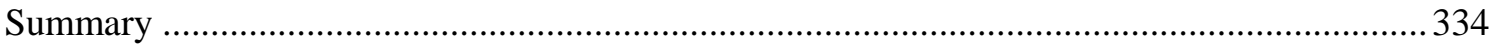

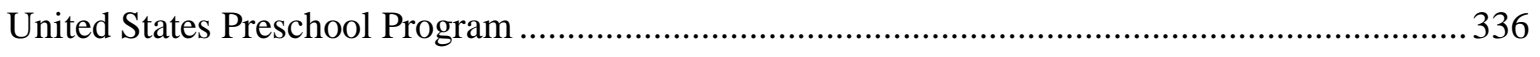

Situational Language Application during Circle Time .......................................................... 336

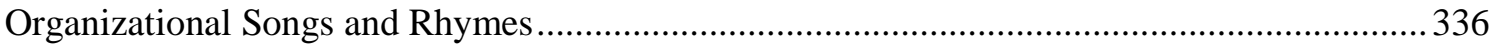

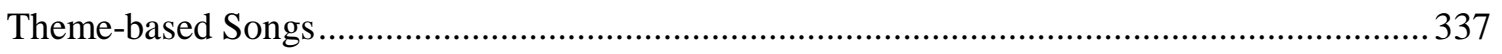

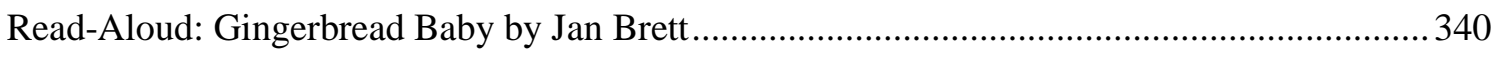

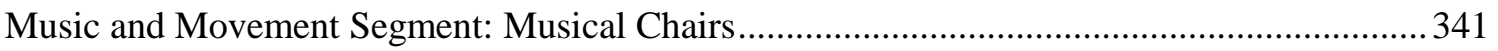




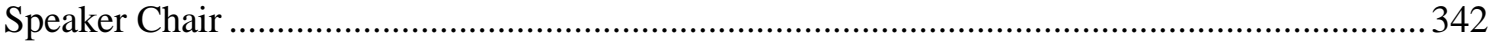

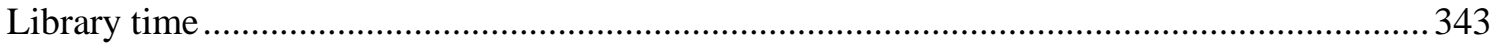

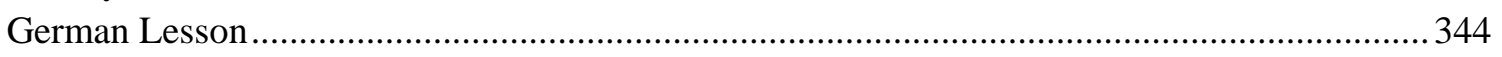

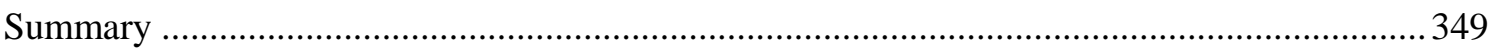

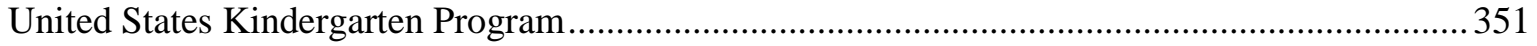

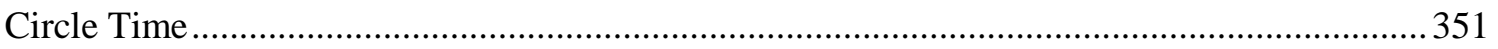

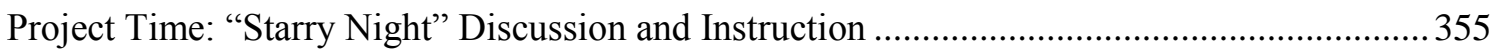

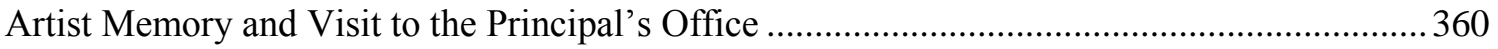

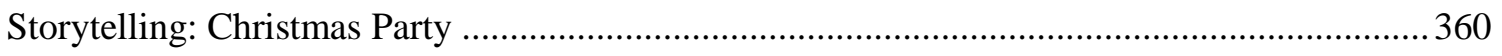

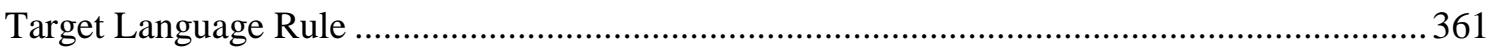

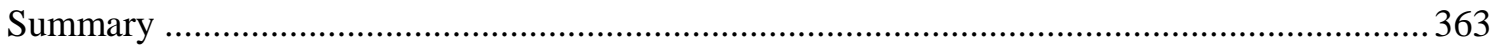

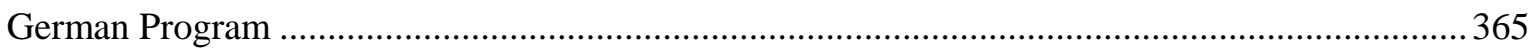

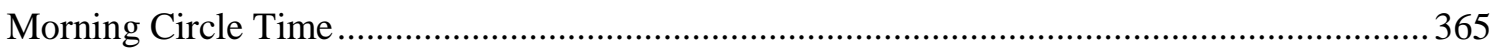

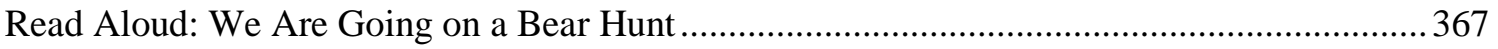

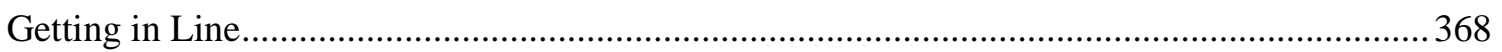

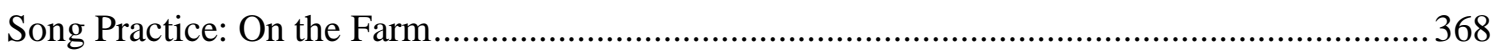

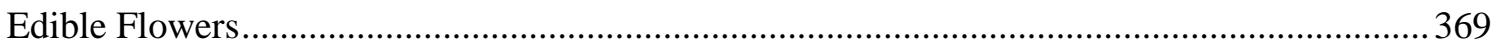

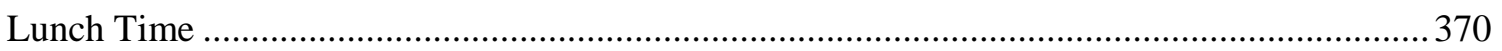

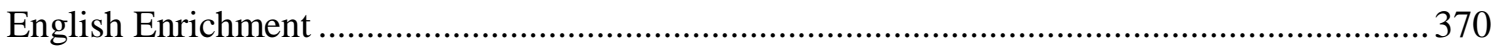

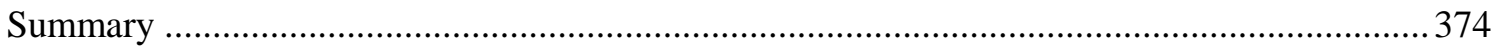

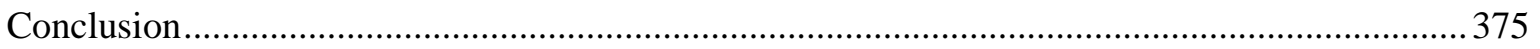

Languages and their Application by Children, Teachers, and Programs .................................... 375

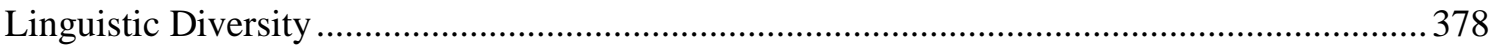

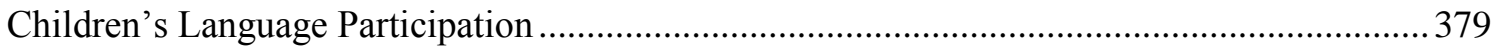

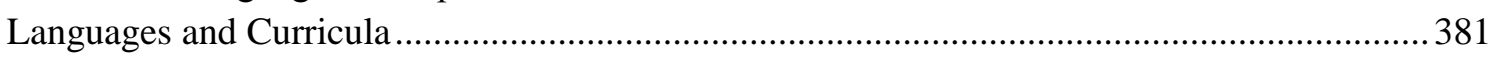

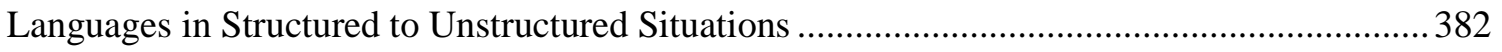

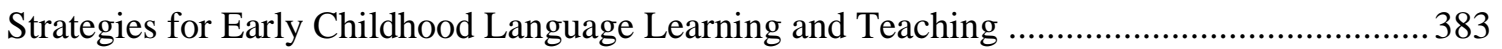

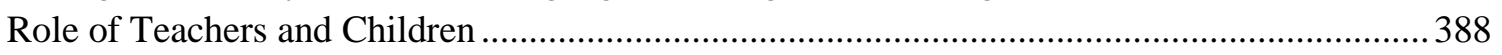

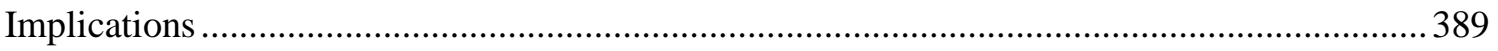

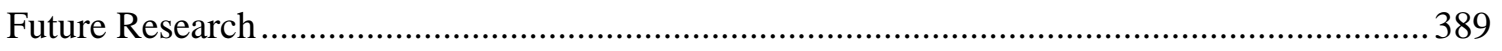

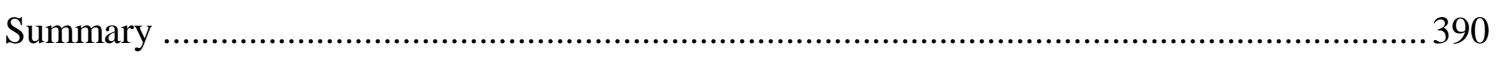

Bibliography................................................................................................................................................3 391

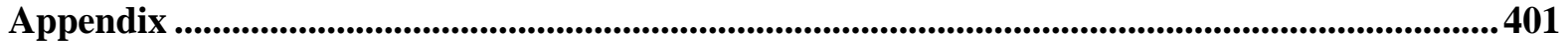

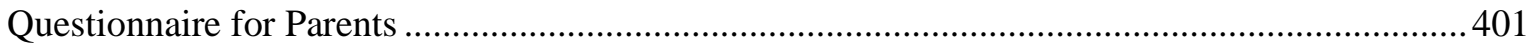

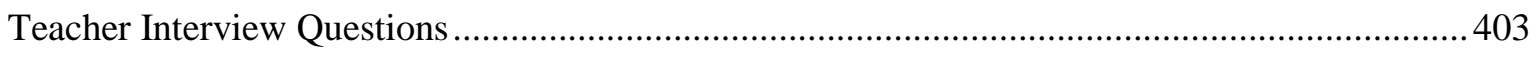

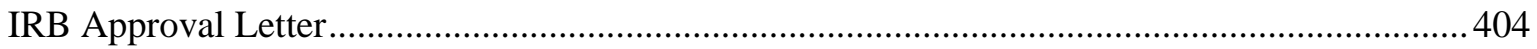




\section{List of Figures}

Figure 1. Visual representation of the data collection process.....................................................56

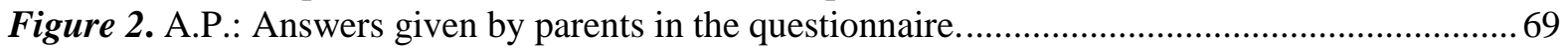

Figure 3. A.P.: Parents' answers to perceived importance of world language learning..................... 70

Figure 4. A.P.: Practical life room layout with centers and offered activities................................... 74

Figure 5. A.P.: Language room layout with centers and offered activities. ....................................... 77

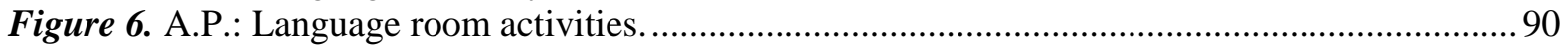

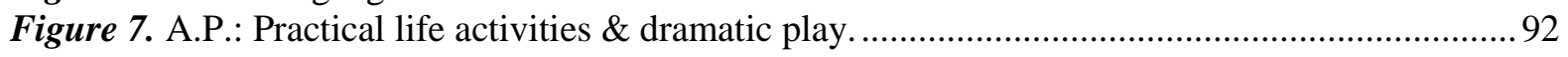

Figure 8. A.P.: Local history corner and cultural studies activities.............................................. 98

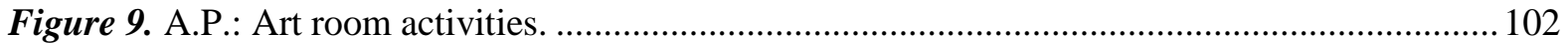

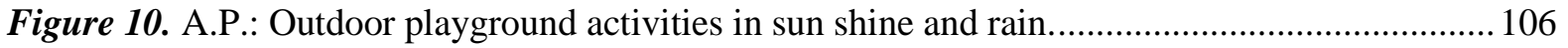

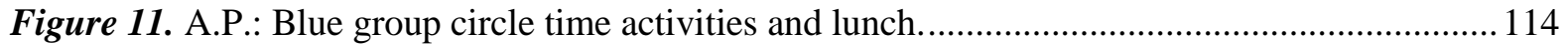

Figure 12. A.P.: Yellow group circle time activities and lunch.................................................... 122

Figure 13. A.P.: Red group circle time in the cultural studies room and lunch in the art room....... 127

Figure 14. A.P.: Craft day painting activities and artwork...................................................... 131

Figure 15. A.P.: Artwork about summer time and craft project "boat." ......................................... 132

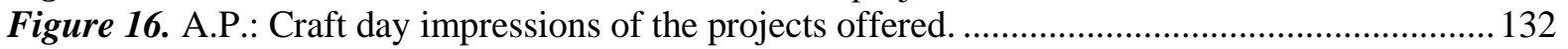

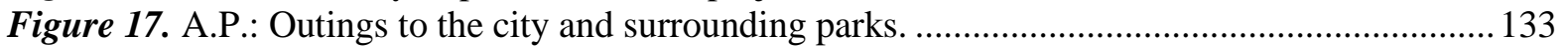

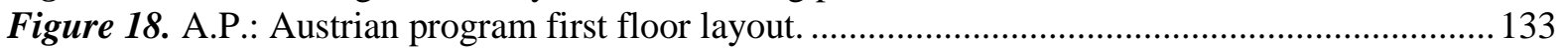

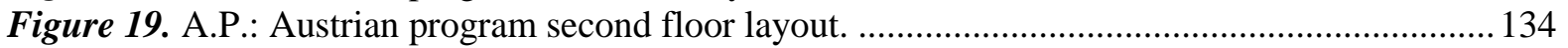

Figure 20. G.P.: Answers given by parents in the questionnaire.................................................. 139

Figure 21. G.P.: Parents' answers to perceived importance of world language learning.................. 140

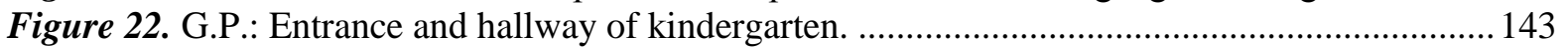

Figure 23. G.P.: Basement and outdoor area of the kindergarten and playgrounds. ........................ 145

Figure 24. G.P.: Group room impressions of the block area and manipulative station.................... 147

Figure 25. G.P.: Group room impressions of the art and craft station and children's creations........ 148

Figure 26. G.P.: Group room impressions, storage room and dreaming corner............................. 150

Figure 27. G.P.: German program group room layout. ............................................................ 151

Figure 28. G.P.: Arrival and choice time impressions of child's play or activity and read aloud..... 154

Figure 29. G.P.: Morning circle impressions of activities and discussion...................................... 157

Figure 30. G.P.: Choice time impressions of different activities................................................. 161

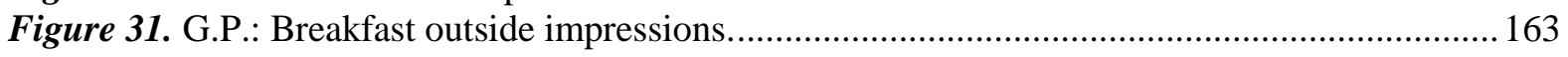

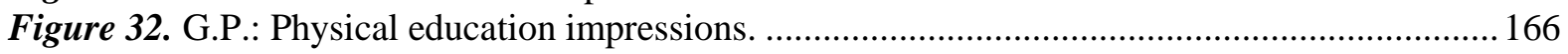

Figure 33. G.P.: Outdoor activities impressions and singing "On the Farm." ................................ 171

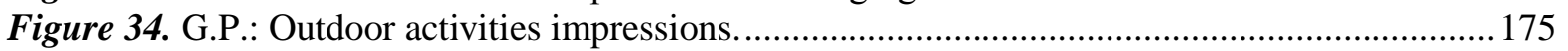

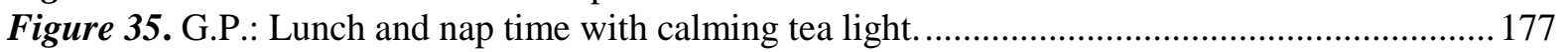

Figure 36. G.P.: Visiting a sheep herd and making herb and vegetable soup. ............................... 182

Figure 37. G.P.: English enrichment activities and artwork by the children................................ 184

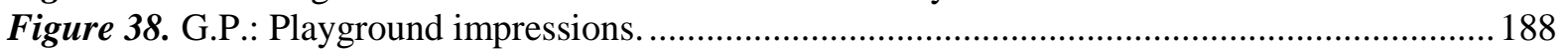

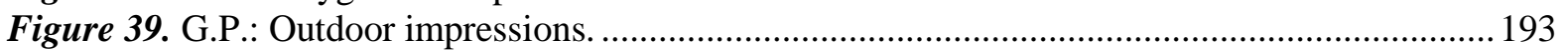

Figure 40. U.S.P.P.: Answers given by parents in the questionnaire........................................... 198

Figure 41. U.S.P.P.: Parents' answers to perceived importance of world language learning............ 199

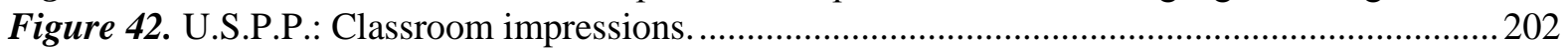

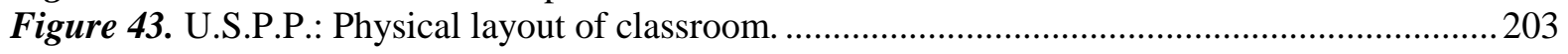

Figure 44. U.S.P.P.: Outdoor play and activity areas and playground. ...................................... 205

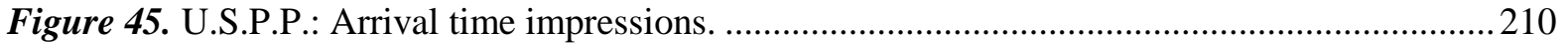

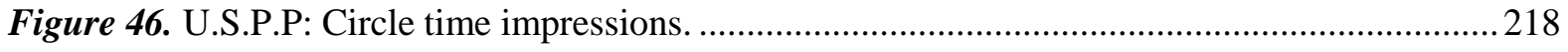




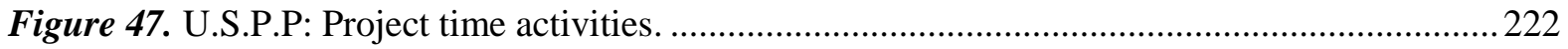

Figure 48. U.S.P.P.: Free play and guided activities. ...............................................................226

Figure 49. U.S.P.P.: Going to the school's library is a weekly event..............................................228

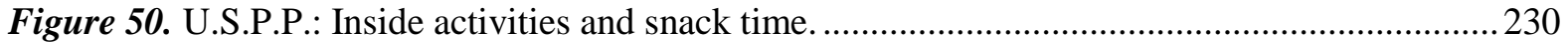

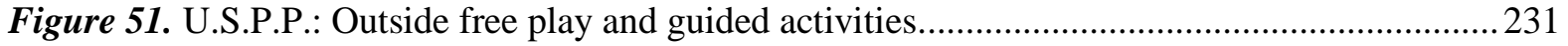

Figure 52. U.S.P.P.: German lesson and lunch impressions...................................................... 241

Figure 53. U.S.P.P.: Outdoor activities impressions of play, climbing, and bike riding..................244

Figure 54. U.S.P.P.: Outside guided activity impressions of woodworking. ................................246

Figure 55. U.S.P.P.: Outside activities impressions play and climbing. .......................................247

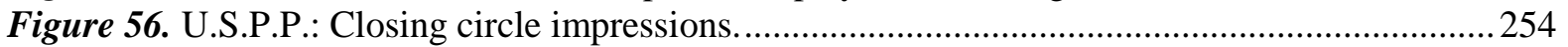

Figure 57. U.S.K.P.: Answers given by parents in the questionnaire............................................ 258

Figure 58. U.S.K.P.: Parents' answers to perceived importance of world language learning...........259

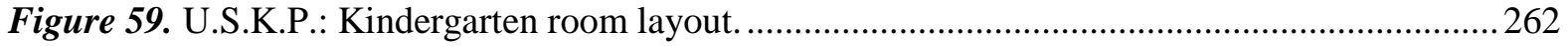

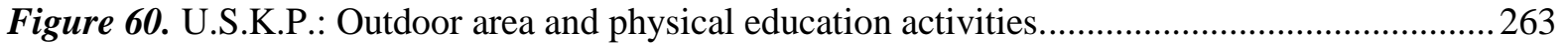

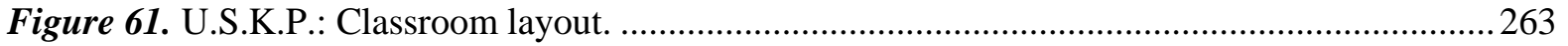

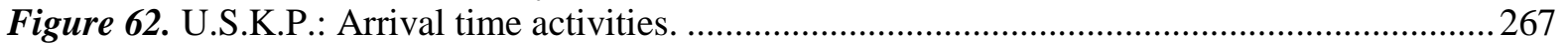

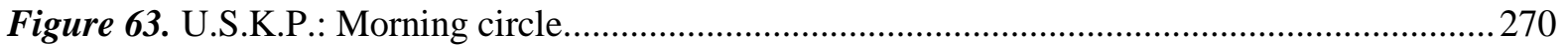

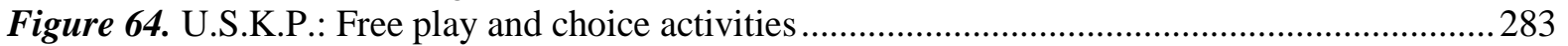

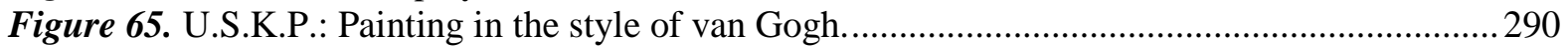

Figure 66. U.S.K.P.: Free choice activities and feedback chart. .................................................294

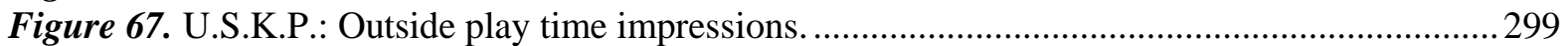

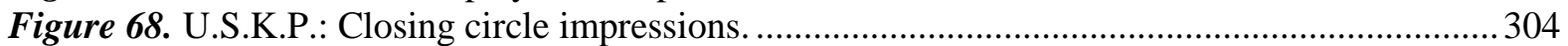

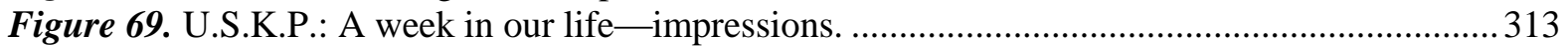

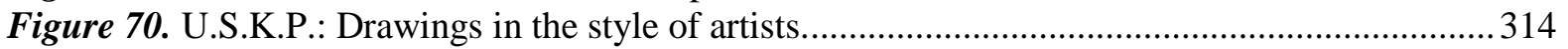

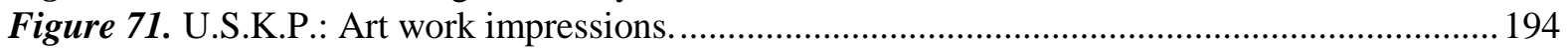

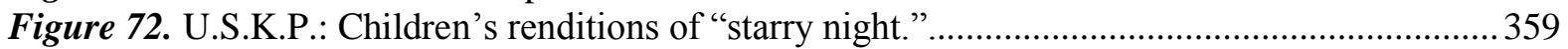

Figure 73. Guiding components and features constructing the complexity of early childhood language

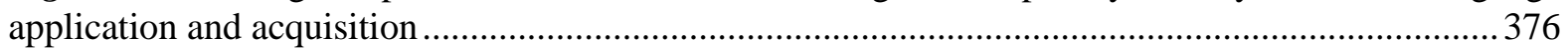




\section{List of Tables}

Table 1. Languages in Germany's educational and pedagogical curriculum .................................. 27

Table 2. G.P.: Observation schedule and data collection ...........................................................52

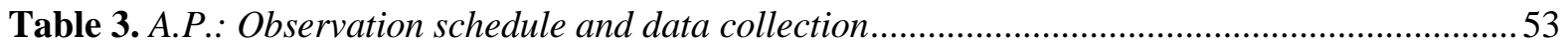

Table 4. U.S.P.: Observation schedule and data collection ............................................................53

Table 5. Research methods applied and data according to research site ........................................57

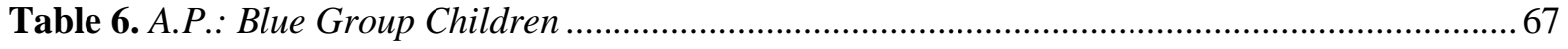

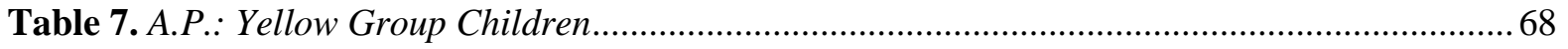

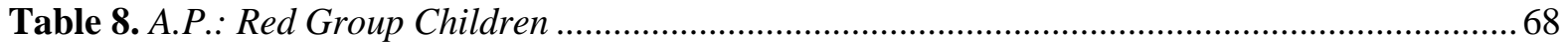

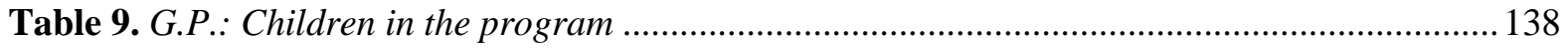

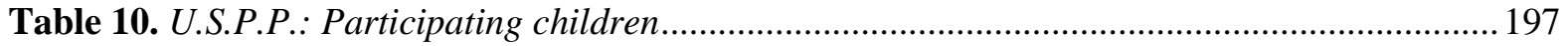

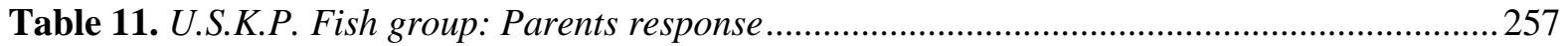




\section{Terminology}

This overview provides clarification of terms relevant for early childhood language learning and early childhood programs as used in this study.

The term language learning refers to foreign or second language learning and early childhood language learning (ECLL) is defined as language learning accomplished by children who are between the ages three and six.

Early childhood programs in Austria and Germany are Kinderkrippe, Kindergarten, and Kindertagesstätte. Kinderkrippe (crèches) is an early childhood setting that is designed for children up to the age of 3. Kindergarten is an early childhood setting and designed for children of 3 to 6 years. Kindertagesstätte is a regional or federal state defined institution for early childhood settings in which a combination of Kinderkrippe and Kindergarten, a combination of Kinderkrippe, Kindergarten, and Hort (afterschool care for children up to the age of 10), or a combination of Kindergarten and Hort may apply.

Early childhood programs in the United States include kindergarten, preschool, day care, and others. Kindergarten in the U.S. is part of the regular education system and is designed for children of the age of 5. "The term kindergarten is used to define the unit of school that enrolls 5-year-olds prior to entrance into the first grade," according to Decker and Decker (2001, p. 8). Preschool is defined as an early childhood setting that is designed for children up to the age of 5 .

A wide range of definitions exists for language learning, bilingualism, and other terminologies referring to the field of language learning. It is beyond the scope of this study to discuss these definitions, and I have chosen to present simple definitions that explain the necessities.

The first, family, and heritage language, or mother tongue (L1) is the language spoken by the child's parents or legal guardian and is acquired by the child since birth. The children whose parents or legal guardians are of different language origins and who use both languages in their household grow up with two mother tongues and are therefore recognized as bilingual.

The Second language (L2) is usually acquired when moving to another country or growing up in an area where the mother tongue is not the main language. The second language learner in Germany and Austria will learn German; in the USA they will learn English. The new term for second language learners in the U.S. that is being used throughout research and the media is English Language Learners (ELLs). This term offers a wide range of possibilities for language learners to be categorized within this group and does not exclude any population. I will use the term $\underline{\text { German }}$ Language Learners (GLLs) for children whose first language is something other than German. 


\section{Chapter 1: Introduction}

\section{Overview of the Issues}

Languages provide powerful tools with which to discover and explore the soul of this culturally and linguistically diverse world. Children begin to acquire language the moment they are born, placing them on a pathway to becoming functional members of society. Language as a means of communication allows us to explore the richness of our cultural traditions, beliefs, and history. In monolingual cultures, childhood experiences are limited to one's own culture. Yet historically, living in a monolingual culture has been the exception rather than the rule. Migration has been part of the world's development, creating societies that host a variety of languages and cultures. Children have grown up bilingual or trilingual for centuries. All along, there have been supporters of cultural and linguistic diversity within and across nations. More recently, however, policies supporting assimilation stress the importance of adapting to the new culture and leaving the heritage culture and language behind. As a result, not all societies today value cultural and linguistic diversity. This trend must be reversed if we are to create meaningful dialogue, built on trust and understanding, between nations and individuals. As Freire (2001) stated, "It would be a contradiction in terms if dialogueloving, humble, and full of faith — did not produce this climate of mutual trust, which leads the dialoguers into ever closer partnership in the naming of the world" (p. 91). To create this kind of dialogue, we must be able to communicate not only in our mother tongue but also in the languages spoken by our partners from other cultures.

In recent decades, there has been renewed interest in learning multiple languages. For example, the European Union regards its cultural and linguistic diversity as a strength, and has declared multilingualism for all citizens as one of its goals. The EU leadership understands that this unique vision will not be fulfilled easily and regards it as a "rewarding challenge" (Commission of the European Communities, 2008). The main objective has become "to raise awareness of the value and opportunities of the EU's linguistic diversity and encourage the removal of barriers to intercultural dialogue" (Commission of the European Communities, 2008, p. 5). The member states support the view that knowledge of multiple languages eases collaboration among different areas of common interest while creating a prosperous unity. This awareness opens up the possibility of meaningful and respectful engagement with other cultures.

To reach this goal of multilingualism, the EU provides guidance and policies geared towards establishing a program that supports language-learning experiences throughout a child's education. Additionally, the EU promotes languages as a part of life-long learning for each of its citizens. The 
member states have developed strong language policies that will influence the future of its citizens and allow them to find their place in this increasingly interconnected world of the twenty-first century. For the world to become a global village, not only on the Internet but on all levels of life, one must redefine education through the lenses of intercultural studies and language learning. The leadership of the EU provides a good model for other regions and societies around the world.

It is important to begin the process of becoming multilingual at an early age when the brain can most easily integrate new linguistic structures. In the United States, children in public schools do not usually begin learning a second language until they reach middle school. Some regions do not offer a foreign language until high school or college, at which point it is usually too late for an individual to become fluent in the language. In Europe, school children often begin studying a second language as early as first grade, though many do not begin until third or fifth grade. Yet because the brain of the young child is so flexible and able to absorb new information, second language instruction should really begin in pre-school. Since the languages one knows will expand one's knowledge of the world, the field of early childhood language learning has an important role to play in preparing young people to engage in intercultural dialogue and global awareness. In light of this need, the focus of this study is to explore the complexity of early childhood language learning via three programs that exist today. I have chosen programs in Austria, Germany, and the United States that reveal both commonalities and differences in terms of methodology, instruction, and language application by children and educators. My research shows that young children are indeed capable of negotiating meaning within a multilingual environment — a skill that if developed worldwide will create a more peaceful and open global society.

\section{European Perspective and Guidance}

Throughout the first decade of the twenty first century the European Union has been developing new visions for language learning policies for its citizens and identifying the goal of a multilingual society within the Union. In March 2002, the meeting of the European Union Heads of State or Government, called for a:

... sustained effort "to improve the mastery of basic skills, in particular by teaching at least two foreign languages from a very early age." At the same time, they called for a "linguistic competence indicator" to be established in this field. (Eurydice, 2005, p. 3) 
This sign of supporting early language learning can be seen as an important starting point of early language learning integration into the educational systems and as a long term commitment that has evolved within the member states.

In 2004 multilingualism became part of the European Commission's agenda. Under the leadership of President José Manuel Barroso, the commission defined its role and developed a plan of action for the European Union (Eurydice, 2008). The responsibility for multilingualism "was given to the Commissioner whose portfolio also included education and culture, given the crucial role of schools in language learning and given the central role of language in culture" (Eurydice, 2008, p. 3). The European Action Plan of 2004 to 2006, Promoting Language Learning and Linguistic Diversity, was produced by the European Commission following a request by the European Union (García, 2009). It stated that because of the growing population of "diverse ethnic, cultural and linguistic backgrounds, it will be more important than ever that citizens have the skills necessary to understand and communicate with their neighbours" (Commission of the European Communities, 2003, p. 3). The Action Plan affirmed further that "learning and speaking other languages encourages us to become more open to others, their cultures and outlooks" (Commission of the European Communities, 2003, p. 3). The main issues of the Action Plan were that the national, regional, and local authorities should support strengthening language learning with new energy, and re-evaluation of educational requirements and objectives. It presented three major objectives: 1) extending the benefits of life-long language learning to all citizens, 2) improving language teaching, and 3) creating a more language friendly environment (Commission of the European Communities, 2003, p. 6). The first aspect is of main interest to this study because it defined that "language competencies are part of the core skills that every citizen needs for training, employment, cultural exchange and personal fulfillment; language learning is a lifelong activity" (Commission of the European Communities, 2003, p. 7). Consequently, language learning should start with beginning educational programs such as crèches, kindergarten, or other early childhood programs. The action plan stated under the lifelong language learning:

'Mother tongue plus two other languages:' making an early start

It is a priority for Member States to ensure that language learning in kindergarten and primary school is effective, for it is here that key attitudes towards other languages and cultures are formed, and the foundations for later language learning are laid. ... In implementing this commitment, most Member States will be called upon to make significant additional investments. The advantages of the early learning of languages - which include better skills in one's mother tongue - only accrue where teachers are trained specifically to teach languages to very young children, where class sizes are small enough for language learning to be effective, where appropriate training 
materials are available, and where enough curriculum time is devoted to languages. Initiatives to make language learning available to an ever-younger group of pupils must be supported by appropriate resources, including resources for teacher training.

Early learners become aware of their own cultural values and influences and appreciate other cultures, becoming more open towards and interested in others. Parents and teaching staff need better information about the benefits of this early start, and about the criteria that should inform the choice of children's first foreign language. (Commission of the European Communities, 2003, p. 7)

This statement addresses several decisive points that need consideration while integrating early childhood and early language learning, for example, effectiveness, teacher training, class size, materials, cultural aspects, curriculum, and sharing of benefits. In this study the curriculum and teaching strategies, group sizes, materials used, and children's language application and the cultural connections are addressed through the data analysis in each as well as across programs.

In 2005, the European Commission published the first policy document, A New Framework Strategy for Multilingualism (2005), as enforcement of its commitment to multilingualism. The document defined multilingualism as referring "to both a person's ability to use several languages and the co-existence of different language communities in one geographical area" (Commission of the European Communities, 2005, p. 3). Furthermore, the framework outlined three aims of the multilingual policy of the European Commission: "To encourage language learning and promoting linguistic diversity in society; to promote a healthy multilingual economy, and to give citizens access to European Union legislation, procedures and information in their own languages" (Commission of the European Communities, 2005, p. 3).

The framework described several key areas for action in the educational systems that support the goal of creating a multilingual society, including the development of coherent action yielding national strategies, teacher training, early language learning, and content and language integrated learning. Additionally, the European Commission announced in the action section of the framework the plan to conduct a study about the situation and practice of early language learning. The study The Main Pedagogical Principles Underlying the Teaching of Languages to Very Young Learners was published by Edelenbos, Johnstone, and Kubanek (2006) and focused on good practices and main principles in the teaching of early language learners. It provided an overview of research conducted in the field of early language learning. However, only a small number of the reviewed studies were conducted in the field of early childhood language learning looking at age group of 3 to 6-year-olds. This was another sign that more scholarly attention needs to be given to the very young language learners. 
In 2007 the European Union welcomed Bulgaria, Romania, and Ireland as new members.

The official languages spoken within the Union rose to 23. In the same year a new commissioner was appointed, whose sole assignment is the responsibility of multilingualism. This demonstrated the commitment and belief "that the Union will not function well unless a coherent policy on multilingualism is both defined and implemented" (Eurydice, 2008, p. 3). While the second Key Data on Teaching Languages at School in Europe report provided several meaningful findings for this study, the following is highly significant: "Compulsory teaching of a foreign language is beginning at an increasingly early stage" (Eurydice, 2008, p. 10). However, almost all EU member states begin language learning in elementary education. Only two countries, Belgium and Spain, officially offer early childhood language education for 3 to 6 year-old children (Eurydice, 2008, p. 10). The data reflected that English was the main focus in the early language learning experience, which was not surprising due to the fact that it is the most studied language in Europe. This development did not fulfill the intention of the EU to learn the languages of the neighboring countries or societies, and current educational practices do not resemble the linguistic diversity present within the Union.

Another critical finding stated that teaching is often performed by non-language specialists (Eurydice, 2008).

The report's findings and the proposals offered by the Group of Intellectuals for Intercultural Dialogue, an arranged initiative of the European Commission, guided the 2008 Commission's Communication on Multilingualism: an Asset for Europe and a Shared Commitment. The tone is best described by the quote given at the beginning of the document: "Linguistic diversity is a challenge for Europe, but, in our view, a rewarding challenge" (Commission of the European Communities, 2008. p. 3). This statement also described the current position and experience of the European Union to establish a multilingual society within its members. The Communication stated:

The harmonious co-existence of many languages in Europe is a powerful symbol of the European Union's aspiration to be united in diversity, one of the cornerstones of the European project. Languages define personal identities, but are also part of a shared inheritance. They can serve as a bridge to other people and open access to other countries and cultures, promoting mutual understanding. A successful multilingualism policy can strengthen life chances of citizens: it may increase their employability, facilitate access to services and rights and contribute to solidarity through enhanced intercultural dialogue and social cohesion.

Approached in this spirit, linguistic diversity can become a precious asset, increasingly so in today's globalised world. (Commission of the European Communities, 2008, p. 3) 
The lifelong learning view is still based on mother tongue plus two with an emphasis on early childhood and early language learning. However, another interesting objective was added:

Languages are often perceived as a difficult subject and an important factor in failure at school. An effort is needed to motivate students and adapt teaching methods to their needs. The value of passive language knowledge should be further explored, and appropriate language learning methods enhanced to allow understanding and basic communication across different languages. (Commission of the European Communities, 2008, p. 10)

The above statements demonstrate the blue prints for the role of language education in the EU member states, and the tools necessary to value the multicultural and linguistic diversity within the European Union. The leadership of the EU outlined the path to constructive intercultural dialogue and awareness through multilingualism. The European Union's vision has encountered success, for example, language learning starts earlier in the member states (Commission of the European Communities, 2008), but it has also encountered problems. To fulfill the goal of a "united diversity" within the Union is a long term and intensive challenge that the members have accepted and are working towards.

Early childhood and early language learning not only involve the learning of the language system and its unique features, but also promote interest and openness toward other cultures. The resulting curiosity will pave the way to intercultural dialogue and shape future policies within the European Union. Through its guiding policies such as the action plan, the framework, and key data reports, the European Union has provided important support for early childhood and early language learning advocates and educators within Europe and the rest of the world. At the same time it has established a leadership role for all its member states, leaving them to adapt the policies according to their needs and views.

\section{German and Austrian Perspective}

Considering a historical perspective based on the last five decades, the citizens of Austria and Germany learned to understand that their cultures have become multicultural and multilingual societies. One reason is rooted in the invitation of guest workers after World War II, which helped establish very strong German and Austrian economies and industries. Additionally, Germany and Austria have experienced new waves of migration throughout the last three decades due to several negative incidents, such as the wars in the former Yugoslavia during the early 1990s, economic distress, poverty, and political and religious insecurity. The Language Education Policy Profile Austria named additional reasons for the increased multiculturalism: 
Three events in recent history have created new linguistic challenges for Austria: the fall of the Iron Curtain in 1989, Austria's accession to the European Union in 1995, and the accession of neighbouring states to the European Union in 2004. Each of these events has brought an increase in inward and outward mobility, opened up new opportunities for trade, and raised new questions to which Language education has still to find answers (Austrian Centre for Language Competence, Austrian Federal Ministry for Education, the Arts and Culture, \& Austrian Federal Ministry for Science and Research, 2009, p. 85).

The EU law of free movement of persons includes the mobility of workers across member states. This gives the citizens' the right to work and to live in the member states of their choice, while some restrictions may apply for the different states. This adds another reason to an increasingly diverse population. The provided reasons account for to current percentage of foreigners living mainly in metropolitan and urban areas of both states, as experienced by other European countries. The latest migration wave in the late 1990's reintroduced the discussion of how to educate children and students who are German language learners (GLLs).

An increasingly multicultural society can be found in Germany and Austria and it has an imminent impact on the educational needs of all children. Finally, at the beginning of the twenty first century, the problem of the twentieth century, the concentration on the official state language of German in the educational system, is being addressed. Education policies apply integration of early language learning, different approaches to and methodologies of language learning, and an introduction of intercultural aspects in the educational system.

\section{Austria}

In response to the European Union's Action Plan, Austria established a national committee for (foreign) language education (Österreichisches Sprachenkomitee, ÖSKO) under the leadership of the Federal Ministry of Education, Art, and Culture and the Austrian Center for Language Competence (Österreichisches Sprachen-Kompetenz-Zentrum, ÖSZ). Both worked together on the Austrian version of the Action Plan, which includes the main features of the European plan and defines the priority areas with its goals for Austria. These areas are life-long language learning, better language teaching, and building a language-friendly environment.

Early (foreign) language learning has had an important role and has undergone a long developmental stage since the 1980s (Jantscher \& Landsiedler, 2000). Therefore, Austria was able to fulfill parts of the action plan before the European action plan was published. The Austrian language learning policy for elementary education was already adequate for the early language learning as outlined by the European Union: 
... that (1) considering Austria introduced nationwide integrated foreign language learning starting in first grade with the 2003/2004 school year and (2) this language learning builds on the already developed materials (e.g. the teaching supplements ZOOM and KIESEL developed by the Austrian Center for Language Competence).

... dass (1) das in Österreich seit dem Schuljahr 2003/2004 flächendeckend eingeführte integrative Lernen einer Fremdsprache ab der 1. Schulstufe berïcksichtigt und (2) auf den bereits entwickelten Materialien aufbaut (z.B. auf den vom Österreichischen Sprachen-Kompetenz-Zentrum entwickelten Unterrichtshilfen ZOOM und KIESEL). (Austrian Center for Language Competence, 2004, p. 9)

This defined the understanding of early language learning in Austria with the beginning of elementary education, leaving out the age group of 3 to 6-year-olds. However, Austria has taken the European Union's focus on multilingualism and the connected policies very seriously for the good of its citizens and other EU member citizens. The Language and Language Education Policy in

Austria: Country Profile stated:

The plurilingual and reflective intercultural personality is the ideal of European language education. The development of such a personality is seen as a civic virtue, but also as a means of facilitating later job mobility, and it is a key principle of European curricula that the process of development should begin as early as possible. (Austrian Federal Ministry for Education, the Arts and Culture, Austrian Federal Ministry for Science and Research, \& Austrian Centre for Language Competence, 2009, p. 4)

Austria committed itself to the European Union's vision for language learning of mother tongue plus two languages with an early start in education and has taken a leading role in the field of language learning policy. More attention still needs to be given to language learning in early childhood education.

\section{Germany}

The Standing Conference of the Ministers of Education and Cultural Affairs of the Federal States [Kultusminsterkonferenz der Länder in der Bundesrepublik Deutschland, KMK] (2005) published an enactment report Fremdsprachen in der Grundschule: Sachstand and Konzeptionen 2004 [Foreign Languages in the Elementary School: Current Status and Concepts]. The Standing Conference cited the two decisions made in 1970 and 1994 that helped guide the foreign language learning at the elementary level in Germany and described the current policies and circumstances of the individual federal states. Further, it provided a generous list of reasons why the Standing Conference is in support of early language learning. The most significant are given here:

...changed living environment and the for the language acquisition beneficial learning conditions of the children of this age ... 
... the growing mobility of the people (employment, travel), the increasing international contacts, especially in bordering areas ..., the European unification process, the internationalization of the media,... all this led to even more children growing into a multilingual reality in Germany and that all children find a variety of foreign language elements in their living environment.

(...veränderten Lebenswirklichkeit und den für den Spracherwerb günstigen Lernvoraussetzungen der Kinder dieses Alters. ...

... die zunehmende Mobilität der Bevölkerung (Berufstätigkeit, Reisen), die wachsenden internationalen Kontakte, insbesondere im grenznahen Bereich ..., der europäische Einigungsprozess, die Internationalisierung der Medien, ... all dies hat dazu geführt, dass in Deutschland immer mehr Kinder in eine mehrsprachige Wirklichkeit hineinwachsen und dass alle Kinder in ihrem Lebensumfeld eine Vielzahl fremdsprachlicher Elemente vorfinden). (KMK, 2005, p. 2)

These reasons demonstrate that the German federal states acknowledge observations similar to Austria and correspond to the actions and initiatives of the European Union in the area of early language learning and support the bigger goal of diversity within the European Union. It is similar to Austria in that the federal government is focusing on elementary education while early childhood language learning is not mentioned. As education policies and decisions reside with each individual federal state, the guidelines established by the Standing Conference help set standards so that the states are working toward and within similar frameworks, which should increase the population's mobility.

In Germany, formal education starts with first grade. The federal government announced that country-wide the instruction of early language learning must start in third grade as of the 2006-2007 school year. Several states had actually fulfilled this requirement years earlier, for example, BadenWürttemberg in 2003-2004 and Rhineland-Palatinate in 2005-2006. In 2006, when most states started language learning in 3rd grade, these two states extended English to first and second grade (Eurydice, 2008).

\section{Early Childhood Language Learning in Austria and Germany}

The integration of early language learning in the elementary school systems, research findings, and the interest of parents had an influence on bringing languages into the kindergarten pedagogy and early childhood education. Language programs were established and geared toward integrating English or other languages, as well as programs for German language learners. A variety of similar language learning arrangements can be found in both countries. These initiatives are based on private programs or local governing bodies. So far, there is no guiding policy in Germany or Austria. Kindergartens offer the possibility of either free or paid instruction. The children 
participate once or twice a week in 30 to 60 minute lessons in commercial courses that are taught by private language schools. If the institution applies the integrated language approach it is free of charge. The educators or the aids possess target language skills and have experience and/or have taken continuing education courses to acquire qualifications. The time allocated to language learning correlates to the program goals and type of integration.

The bilingual kindergarten programs in Germany and Austria offer a combination of different languages like German-English, German-French, and others including Spanish, Danish, Czech, Polish, Russian, Turkish, Portuguese, Greek, Chinese, Japanese and Italian. These programs are often privately funded and located in urban areas. In bordering areas, for example GermanyFrance or Austria-Hungary, one can find subsidized programs by the local governments or federal states. Their implementation of languages depends on their individual philosophies and concepts, while the instruction ranges from a few minutes a day to all day. The development of introducing language learning into the kindergarten curriculum is often initiated by parents and now expected and supported by a growing number of parents.

According to a list by the German "Association for Early Multilingualism in Early Childhood Education and Schools (Verein für Frühe Mehrsprachigkeit an Kindertages-einrichtungen und Schule e.V.)," there are about 644 programs for 2 to 6-year-olds, which shows a growing trend from the 340 programs that existed in 2004. According to the maps provided (Verein für Frühe Mehrsprachigkeit an Kindertageseinrichtungen und Schulen e.V. [FMKS], 2010), these programs are mainly located in urban areas. In Austria, about 142 projects and programs are available in public and private kindergartens. Furthermore, a variety of private programs exist though a specific number has not yet been established.

\section{The United States Perspective}

The history of language learning education is rich and diverse in the United States based on the fact that the country was created by immigrants of European and African heritage as well as by Native Americans. García (2009) stated that "at the time of the European encroachment, there were approximately 2 million Native Americans speaking over 300 languages north of what is today Mexico" (p.160). Until the $19^{\text {th }}$ century, education was based on the heritage language of the people. Therefore, schools conducted the educational process in German, English, French, Russian, Spanish, Dutch, or Swedish (Brown, 1992). García (2009) provided a detailed view on the past U.S. language policy while considering bilingual education and discussing the different waves of language restriction or tolerance of indigenous, enslaved, and European languages. Additionally, Garcia 
(2009) described the linguistic diversity and language inequities in the present education system and the policy changes on bilingual education. Shrum and Glisan (2010) offered an overview of foreign language education following the applied approaches. They stated that "Foreign language instruction in the U.S. evolved historically from the emphasis on reading and writing in the $18^{\text {th }}$ and $19^{\text {th }}$ centuries to a focus on using languages for real-life, interactive purpose in the $21^{\text {st }}$ century" (Shrum and Glisan, 2010, p. 46).

The complex history of languages and the related policies in the United States built the foundation for the present language learning experiences that are approached from two angles: foreign language learning and bilingual education. Commonalities and points of overlap in these fields are far greater than their differences, which should lead to constructive collaboration enhancing language learning experiences for students at all levels of the education system. The development and history of bilingual education and foreign language learning are extensive and go beyond the scope of this dissertation. Refer to García (2009), Nieto and Bode (2008), and Bennett (2007) for an overview of bilingual education and Curtain and Dahlberg (2010) and Shrum and Glisan (2010) for foreign language education.

The field of language education has been guided by national language organizations such as the American Council on the Teaching of Foreign Languages (ACTFL), the National Association for Bilingual Education (NABE), and the National Network for Early Language Learning (NNELL) among others, as well as with research centers such as the National K-12 Foreign Language Resource Center, the Center for Applied Linguistics, and the National Foreign Language Center. These organizations and centers, along with parents, school administrations, and language specialists, are working together with the state and federal government agencies on the development of language policies and strategies.

The National Standards in Foreign Language Education Project (NSFLEP) developed the first national standards for foreign language education in grades K-12. The project was a collaboration of national language organizations such as the ACTFL, the American Association of Teachers of German (AATG), the American Association of Teachers of French (AATF), and the American Association of Teachers of Spanish and Portuguese (AATSP) that were first published in 1996 (Shrum and Glisan, 2010). The standards have been revised twice to provide standards for the languages taught in the United States such as Arabic, Chinese, Classics, French, German, Italian, Japanese, Portuguese, Russian, and Spanish. Both the Standards for Foreign Language Learning in the $21^{\text {st }}$ Century and the Performance Guidelines for K-12 Learners in 1997 have been crucial in the field of language learning. Both documents envision a platform for the continuation of language 
learning beginning in elementary education going through secondary, while the standards also consider post-secondary education. This long-term view committed to an early start was a major step for early language learning. Curtain and Dahlberg (2010) viewed the implementation of the Standards as, "For the first time in the United States, the language teaching provision had made a strong statement about the importance of instruction beginning with the earliest years of schooling" (p. 453). In May 2006, ACTFL published the following position statement focusing on early language learning:

Since research shows that an early language learning experience generally results in the development of native or near-native pronunciation and intonation, it is recommended that students be provided the opportunity to learn a second language as early as possible in school. ... promotes higher levels of proficiency if the student continues in a well-articulated sequence of language learning. Research corroborates additional benefits including strengthening of literacy in students' first language, raising standardized test scores in other subject areas, and developing comfort with cultural differences. These benefits accrue with instruction that is continuous throughout the school year, connected grade to grade, and more frequent than twice per week, adding up to at least 90 minutes per week, at both the elementary and middle school levels. (ACTFL, 2006)

This statement supports professionals as well as national language organizations active in the field of early language learning. NNELL has been established with the purpose of the furtherance and promotion of early language learning by supporting teachers in the field through providing teacher development workshops, sessions at national, regional, and state conferences, and advocacy materials supporting teachers and programs. Additionally, national language organizations such as AATG, AATF, and AATSP have special interest groups working on the advocacy of early language learning in grades K-8 (Curtain \& Dahlberg, 2010). The AATG's steering committee "Kinder lernen Deutsch (Children learn German)" has been supporting German teachers in areas of teacher training, curriculum development, program designs, and networking (AATG, 2010). Standards, guidelines, position statements, and general work of the ACTFL, as well as the work of national language organizations, play an important role in the field of early language learning and provide a vision for the future. More attention needs to be given overall to the field of early childhood language learning and the standards should be extended to include the pre-kindergarten sector and provide guidelines.

The United States government has provided funds for the elementary and secondary programs through the Foreign Language Assistance Program (FLAP) starting in 1988 (Curtain \& Dahlberg, 2010). This grant program, along with grants provided by local boards of education, state, or even foreign governments such as Germany, establish and fund elementary programs. Curtain and Dahlberg (2010) stated that "many existing elementary school language programs owe their existence 
to the receipt of a FLAP grant. ... In 2008 and 2009 these three-year grants were targeted especially at so-called critical foreign languages, including Chinese, Arabic, Russian, Korean, and Hindi” (p. 451). While grants are often an important factor in establishing programs, they can at the same time add to the phenomenon of short-lived programs that cannot continue beyond the grant supported phase. It is the intention of FLAP that local funds must be used to carry on these programs, but based on budget shortfalls over the last couple of years many programs have been eliminated and even longstanding programs that were locally funded have been affected. In the report on the national survey of teaching of foreign languages in the United States' school system that was supported by the Center for Applied Linguistics, Rhodes and Pufahl identified that:

The current status of early foreign language instruction in the United States is bleak, with a decline over the past decade of 9 percentage points (from $24 \%$ to $15 \%$ ) in the percentage of public elementary schools teaching foreign languages. This decline seems likely to continue given the number of districts that reported cutting back on foreign language programs for funding reasons. (Rhodes \& Pufahl, 2010, p. 85)

During the last decade emphasis in the field of language learning has been placed on English language learners (ELLs), and foreign language learning received very little support and funding. Rhodes and Pufahl (2010) stated as one of their research findings that "nearly one third of public elementary and secondary schools with language programs reported that language teaching had been negatively affected by NCLB (No Child Left Behind Act)" (p. xvii). Furthermore, participants provided comments of how the NCLB had affected their schools: "More time is spent on English and math than foreign language because of NCLB" and "Funds and time have been directed to reading and math. In some cases, we pull students out from foreign languages ...to provide more extensive reading and math support" (Rhodes \& Pufahl, 2010, p. 76).

The No Child Left Behind Act that was introduced in 2001 focused on three main elements: testing, accountability, and school choice. The NCLB policy included the Reading First mandate for elementary education to improve test scores in reading. The focus on reading and literacy skills can be seen in a positive light for ELLs according to Forrest (2004) for “... ethno- and linguistically diverse communities, it specifically requires the implementation of scientifically based programs that help English language learners meet the same high academic standards as other students (NCLB 2002b) (p. 41)." But at the same time, the policy does not address the important role of first language or family language skills nor reading skills, and what they could provide toward successful second language learning. Forrest stated that:

Although NCLB provides for the implementation of research-based programs to help ELLs meet high academic standards, any mention of biliteracy, bicultural, and 
bilingual programs is excluded. In fact, NCLB mentions that the act "will focus support on enabling all limited English proficient (LEP) students to learn English as quickly and effectively as possible" (NCLB 2002b). However, the transfer approach to bilingual and biliterate education is ignored. That is, the act discourages the development of first language literacy as a means of transferring content and literacy skills into a second language. The transfer of literacy skills and strategies from the first language to the second language (Baker 1996) is a widely used, effective technique that the act overlooks. (Forrest, 2004, p. 41)

The NCLB Act has been heavily criticized starting with its implementation in 2001. Arne Duncan, the U.S. Secretary of Education, stated that "the law puts too much emphasis on standardized tests, unfairly labels many schools as failures, and doesn't account for students' academic growth in its accountability system" (U.S. Department of Education, 2009). The new vision for education, The Blueprint for Reform, has been outlined by the U.S. Department of Education in 2010 that will reauthorize the Elementary and Secondary Education Act. The reform focuses on the goal of returning the U.S. education system to a leading educational system in the world by 2020 . The system needs to prepare students for college and a career, and to achieve this goal the administration proposes raising the standards for all students, the development of a new assessment system, and providing a complete education. By 'complete education' the administration suggests:

Students need a well-rounded education to contribute as citizens in our democracy and to thrive in a global economy - from literacy to mathematics, science, and technology to history, civics, foreign languages, the arts, financial literacy, and other subjects. We will support states, districts, school leaders, and teachers in implementing a more complete education through improved professional development and evidence-based instructional models and supports. (U.S. Department of Education, 2010, p. 8)

This new vision for the U.S. includes foreign language education, however, how the administration will support the field of language learning and which role it will take has yet to be seen. With the focus on well-rounded education and the goal of returning the education system to a world leading power, one can only hope that the rest of the world is being considered and the fact that language learning starts even earlier elsewhere, such as in European elementary education. These tendencies need to be reflected in the U.S. education system and implemented through guidance and legislative support by the Department of Education of the federal government as well as in the individual states. It is important that all children are able to study at least one other language during early childhood and that this learning does not only occur within the elementary education system.

Needless to say, children who grow up learning at least two languages will have advantages in both a global society and the future job market. It is interesting to see that children from diverse 
backgrounds have the chance to learn two or more languages through the proper support by their families and formal education, while children of non-diverse families usually lack this experience or the accompanying skills. Since we do not want to leave U.S. children behind, the education system needs to provide an early start for all students in the United States, preferably starting during early childhood.

The failure to teach languages has subsequently brought the U.S. into harm's way in Afghanistan and Iraq. More language support would have been useful to stabilize these countries. However, reaching a certain level of fluency, proficiency, and native like pronunciation requires time and commitment. Learning a language is a life-long process starting with the day one is born, and learning another language should start early in order to achieve a high level of proficiency that will enable the child in his or her future to engage in intercultural dialogue within and across societies.

While considering the three countries Austria, Germany, and the United States, it can be said that the phenomenon of integrating language learning into kindergarten and preschool has begun in both the public and private sectors. This can be seen as only the first steps; a country-wide implementation of programs for early childhood and early language learning is still a vision of the future. Rhodes and Pufahl (2010) recommend and support the establishment of new programs starting at the elementary level and focusing on intensive foreign language programs for the United States. This needs to be extended to early childhood education as well. Guidance and support is still needed through the cooperation of academia, the individual states within all countries, and the institutions. This notion has opened a wide field for research. Academia must use this field to explore the impact of early childhood language learning more coherently and to provide curricula that support learning and teaching. In general, a survey study, which provides a general overview of the field of early childhood language learning, is needed for all three countries. Further, only very few cross-cultural studies have been undertaken that relate to language learning, curriculum, or approaches in early childhood programs.

\section{Problem Statement}

Early childhood teachers and educators experience a growing number of children between the ages of three and six with multiple languages across all programs. These children receive support and recognition of their second language through general and language education. However, only some monolinguals are introduced to early language learning in their education, and rarely in early childhood settings. At the same time, teachers who are working in early childhood language programs are looking for assistance and tools that they could apply in their teaching. The request for 
early childhood language programs specifically for children under the age of seven is rising in the private sector and somewhat growing in the public sector. There have been limited and mainly private early language learning programs active in the field for decades. There is a need to study and to share the experiences of children and teachers alike, their practices and methods, as well as the approaches that early childhood language programs use for children under the age of seven.

\section{Purpose of Study}

The purpose of this case study is to describe and to understand the characteristics of early childhood language learning while considering the interaction of program structures and approaches used in early childhood institutions for children ages 3 to 6 years. Through this qualitative inquiry several aspects of language learning including multilingualism, curriculum, approach, instructional strategies, and the role of teachers and students were analyzed while seeking a holistic description of the ways these were used or applied. The study portrays the complexity of early childhood language learning environments with relation to the embedded approaches and methodologies applied in early childhood programs. The three participating programs were located in Austria, Germany, and the United States, and offered an abundance of commonalities but also differences through their unique features.

\section{Research Questions}

These questions evolved over the course of my research and were influenced by observations I made during my field experience, including program differences. Once I had finished analyzing the data, I realized that I was being guided by the desire to determine the factors that influence early childhood language learning and use in the selected programs. This inquiry resulted in the following questions: What influences early childhood language learning and use in the selected programs? Specifically addressing:

- What approaches and methods are used in the programs?

- What strategies and activities occur in the program to engage students in early childhood language learning?

- When and how are children using their language(s) in the early childhood program?

- How does peer support engage in language learning?

- What are the roles of teachers and students in the early language learning environment? 


\section{Significance of the Study}

The study contributes to the field of language learning with an emphasis on early childhood, defined here as the ages of 3 to 6 years. It provides important practical and theoretical findings for the general early childhood education as well. The detailed view into the daily experiences of children and teachers and the presented research findings of the three participating programs that located in Austria, Germany, and the United States, make the study rich and informative. The observed experiences and practices are set in context to the existing research and provide recommendations for integration of the findings in the field of general early childhood education concerning children under the age of seven. This study also develops the groundwork for developing a model for language learning in early childhood education. This is the first cross-cultural naturalistic inquiry that observed early childhood settings in Austria, Germany, and the United States focusing on the practices, programs, and approaches most beneficial to a child's early childhood language learning experience.

\section{Limitations of the Study}

This study investigates one early childhood program per country and is therefore not intended to be representative of all early childhood programs within these countries. Each research site has been observed over a period of two weeks. Limitations that may pertain to this study include the impact of the researcher on teacher practice, the small sample size, and the researcher bias which is addressed in detail in Chapter 3. 


\section{Chapter 2: Literature Review}

\section{Austrian Education System and Elementary Language Learning}

In Austria, compulsory education begins at the age of six and ends after nine years. This period is separated into four years of elementary education and five years of secondary education. The system is highly diversified and any kind of in-depth explanation would go beyond the scope of this study (see Austrian Federal Ministry for Education, the Arts and Culture, Austrian Federal Ministry for Science and Research \& Austrian Centre for Language [BMUKK, BMWF, \& ÖSZ] (2008) for more information). Throughout primary and secondary education the students receive foreign language instruction. Since the early 1960s step-by-step progress has been made and pilot studies carried out at the elementary level in Vienna led to the nation-wide addition of compulsory foreign language instruction in third grade in 1983. The Language Education Policy Profile: Country Report Austria stated that "Austria was among the first countries in Europe to introduce modern foreign language (MFL) learning nation-wide at primary stage ... amounting to one period per week..." (BMUKK, BMWF, \& ÖSZ, 2008, p. 37). During the mid 1990s new pilot studies were introduced in first and second grade integrating foreign language instruction into the core subjects. The success of these studies and the new developed foreign language curriculum and materials started the notion of introducing foreign language in the core subjects in 1998 applying a five year transitional period (BMUKK, BMWF, \& ÖSZ, 2008; Jantscher \& Landsiedler, 2000). Beginning with the school year 2003-2004 all students in Austria received foreign language instructions in first grade. This was a major success for foreign language instruction in Austria.

Students do not receive grades and the language is integrated across the curriculum in the first and second grades. The teacher can use thirty-two lessons per year that should be separated into smaller units and the area of concentration are listening and speaking skills and comprehension. In the third and fourth grades language teaching can be either still integrated across the curriculum or taught as a subject area. At this level students receive one lesson per week, reading and writing are added, and grades are given. An additional modern language can be offered as an elective subject (BMUKK, BMWF, \& ÖSZ, 2008).

The foreign language instruction and learning are supported by a national framework of early language learning that includes the following objectives: "to motivate for life-long language learning; to prepare the ground for communicating in a foreign language; to generate in children essentially positive attitudes towards other and languages and respect for other ways of thinking and acting" (Jantscher and Landsiedler, 2000, p. 17). 
English is the most taught world language at the elementary level with approximately $97 \%$ (BMUKK, BMWF, \& ÖSZ , 2008; Jantscher \& Landsiedler, 2000). The list of reasons for the predominant role of English includes its status as a world-wide language, the language of the united Europe, technology and the Internet, research, and the parents' desire to prepare their children for their future. The Austrian Country Report added that:

The Austrian curriculum offers a variety of languages for this first encounter, at primary school: however, English is chosen almost exclusively. This is partly due to a lack of teachers trained in other languages; partly to the fact that most secondary schools hardly offer any alternatives to English - which is itself due to parental choice, among other factors. (BMUKK, BMWF, \& ÖSZ , 2008, p. 59)

The introduction of foreign languages at the elementary level had a tremendous impact on early childhood education. Jantscher and Landsiedler stated in the introduction to their article Foreign Language Education at Austrian Primary Schools:

The manifold individual initiatives (for example, in kindergartens) to introduce a foreign language at an even earlier stage ( 3 to 6 year-olds) are not taken into account since there is no co-ordination between these initiatives and there are no efforts being made to link them to foreign language education at primary level (Jantscher \& Landsiedler, 2000, p. 13).

The missing articulation between early childhood program and elementary education seems to be the general trend in Austria and Germany. Administrators and teachers fail to make this important connection between early childhood education and formal school education. Lifelong learning, one of the objectives of the Austrian National Curriculum for Foreign Languages, could instead be started in Kindergarten rather than in first grade. There is no reason why it cannot be implemented earlier (Jantscher \& Landsiedler, 2000).

\section{Early Childhood Education Prior to School Entry and Language Learning}

Early childhood education in Austria follows the national curriculum Education and Pedagogy in Kindergarten (Bildung und Erziehung im Kindergarten) integrated in 1975 that featured eleven overlapping and interconnecting main educational objectives. These are emotional education, social behavior, sexual behavior, religious education, creativity, critical thinking, language development, physical education, learning and performance behavior, moral education, and mastering of the environment (Berger, 2005). The plan has been re-evaluated and improved twice since its implementation by the situational approach in the 1980s and recently through the transactional approach (Transaktionsansatz). The latter can be derived from a quality-oriented view of the learning 
process and understood as a two-way interaction of the development process of children and their cultural as well as social environment within and beyond kindergarten (Textor, 2003; Berger, 2005).

In 2009, a new curriculum framework was introduced nationwide in Austria that had been written by the Charlotte Bühler Institute in collaboration with all federal states. This educational curriculum provides general standards and information about the curriculum approach, curriculum areas and competence, articulation between family, early childhood programs and elementary education, as well as the quality of the curriculum. The curriculum area that is of interest for this study concerns the language and communication aspect. The curriculum framework stated:

The first language of the children has a specific significance. Thereto count also dialects and sign language. The home language is deserving of appreciation because language and identity are closely associated. Successful second language learning builds on first language competences; therefore it is important to also develop the first language continuously. The discussion of different languages promotes living together in a pluralistic society.

Der Erstsprache der Kinder kommt ein besonderer Stellenwert zu. Dazu zählen auch regionale Dialekte oder Gebärdensprache. Die Familiensprache verdient Wertschätzung, da Sprache und Identität eng zusammenhängen. Erfolgreicher Zweitspracherwerb baut auf erstsprachlichen Kompetenzen auf, daher ist es wichtig, auch die Erstsprache ständig weiterzuentwickeln. Die Auseinandersetzung mit unterschiedlichen Sprachen begünstigt das Zusammenleben in einer pluralistischen Gesellschaft. (Charlotte Bühler Institute, 2009, p. 14)

This was a needed approach, if one considers the population of children who are German language learners and recent numbers are given in the Country Report "On average, $20 \%$ of the children that attend a kindergarten have a first language other than German; in Vienna, this figure is 41\%; in Vorarlberg 22\%" (BMUKK, BMWF, \& ÖSZ, 2008, p. 36). Khan-Svik provided data dating back to 2000 in her study The attitude of employees at kindergartens towards mono/bilingual kindergarten children - a survey in Austrian kindergartens (2004) showing that in Vienna (14\%) has more than doubled and Vorarlberg's percentage rose about $9 \%$ in the last eight years. The study's findings demonstrated that employees who speak only one language promote mono-lingualism, while employees who speak two or more promote bi- or multi-lingualism, therefore "setting incentives that bi/multilingual children and personnel are integrated into the kindergarten; by that multilingualism could become the everyday experience for everyone" (Khan-Svik, 2004, Discussion section, para. 7). These findings found a resonance in the new vision for early childhood education expressed in the national curriculum framework through the recognition of the significant role of the first language and the understanding of the interwoveness or language and identity. It is intended to encourage all mother tongues within early childhood language learning in Austria's kindergartens. Reaching this 
goal however will be a challenging and long journey for children and early childhood educators that will be supported by additional training.

In Austria, the early childhood education prior to school entry is optional; however the numbers of children that need to attend kindergarten due to parental time constraints are rising, while the number of births is decreasing. According to the Country Report “...66,3\% of all 3 year olds; $89,8 \%$ of all 4 year olds; and $91,9 \%$ of all 5 year olds" attended early childhood programs across Austria in 2005 (BMUKK, BMWF, \& ÖSZ, 2008, p. 16). The general demand of parents wanting to place their children in kindergarten is greater than the actual existing programs. About $15 \%$ of the children cannot attend a kindergarten and are missing important social and educational experience and benefits, therefore they will not have the same school preparation and needed skills as children who attended kindergarten. The Country Report stated further that "75\% of Austrian kindergartens are public institutions - for the most part, council or municipal kindergartens -, while the larger part of the remaining $25 \%$ are facilities run by churches or associations" (BMUKK, BMWF, \& ÖSZ, 2008, p. 16).

According to the announcement by the Austrian Federal Ministry of Economy, Family and Youth (2010), an initiative was started to establish more early childhood programs for the 3 to 5 -yearold by 2010. Additionally, beginning with the academic year 2009/2010 the national government required that the early childhood programs will be free of charge for 20 hours per week for children attending their last year. The federal states implemented this requirement according to their needs and developed different approaches. Some states extended the offer to all children as in the case of Vienna and Steiermark by offering free early childhood education starting with two-year-old children. In the remaining states, for example, Lower Austria has already been offering the free half-day program to all children that resulted in an attendance rate of $98 \%$ for the 5 to 6 -year-old children. After the nation-wide expansion of early childhood programs that should be finished by 2010/2011, the government plans to require that the last kindergarten year will include an obligatory half-day program throughout Austria. These policies have come into existence to support and enhance early childhood education and language learning for all children but a special focus is given to German language learners. The Country Report stated:

Frühe Sprachförderung ('early language learning promotion and support'), a national project of the former BMBWK, the relevant Austrian ministry, was first carried out across Austria in the school year 2005/06: this scheme does not represent a new departure, though it underlines the importance of early language learning and promotion, and in this way supports the work of kindergarten teachers. 
As from the school year 2005/06, all children due to enter primary school the following year are assessed with regard to their communication skills in German, to see if these will be sufficient for them in the primary classroom a year later: this assessment is carried out at so-called early primary school pupil registration (between October and January of the school year that precedes a child's first entry into primary school); should the assessment (called Sprachstandsfeststellung) show an insufficiency, a child's parents or guardians will be recommended to accept a special support package, as the project is a matter of voluntary participation. To make support feasible, they will receive 'language tickets'(i.e. vouchers) issued by the federal authorities, to the value of $€ 80$ per child per year, as a part payment towards the cost of 120 units of support teaching (which is variously integrated into everyday life at kindergarten). In the 2005/06 school year, 12.591 'language tickets' (vouchers) were issued; there is as yet no all-Austrian statistical information on the rate of acceptance; nor is there an evaluation of this scheme yet (BMUKK, BMWF, \& ÖSZ, 2008, p. 31).

This support of GLLs aims to provide an equal chance in the educational experience but also to achieve better results in international assessment comparisons such as the OECD Programme for International Student Assessment (PISA). Additionally, there have been more early childhood language learning programs offered in the public sector and also the private sector has been growing. The Country Report mentioned that there are no national records of the offered programs because the early childhood education resides within each federal state. It provided some information about bilingual programs of German and a minority language such as Slovene, Hungarian, Croatian, Czech, and Slovak, and bilingual programs using non-minority languages such as English, Arabic, French, to name a few. A general list of language learning in kindergarten for each state has been included in the Country Report. The list is not complete because a survey has not been conducted to understand the field's complexity yet. (BMUKK, BMWF, \& ÖSZ, 2008, p. 141).

The federal state of Lower Austria implemented kindergarten language learning programs in bordering communities teaching Hungarian, Czech, and Slovak. These programs have been growing and in 80 kindergartens more than 3,500 children attended in 2009 (NÖN, n.d.). In 2007-2008 this language initiative was extended to English. A survey in support of the English language addition conducted by the state's government found that the about $82 \%$ of parents wish the offering of in English in kindergartens and support that their children should already start during this age to learn a foreign or second language (NÖN, n.d.). The initiative plans to provide English language learning experiences for all children taught by English teachers or native speakers applying a play-oriented approach. Additionally, the early childhood educators are offered continuing education training in the methodology of language learning to be able integrate more English language experiences throughout the day. The curricula for early childhood education have been adapted to include preparation for the 
new educators. This added to the programs' application from just learning English or another language to including studying the methods and application of early childhood foreign or second language learning in kindergartens (NÖN, n.d.). . According to the press release Lower Austria has taken a leading role in early childhood language education in Austria (Milk-Leitern, 2007). In 2010, English has been offered in over 90\% of kindergartens in Lower Austria (ORF, 2009, March 18). This is an overview of one of the states initiative for early childhood language learning. The remaining states are also providing similar initiatives, however to describe them all in detail goes beyond the scope of this review.

\section{German Education System and Elementary Language Learning}

In Germany, compulsory education starts at the age of six and ends in most federal states after twelve years. In Berlin, Brandenburg, Bremen, and Rhineland-Palatinate compulsory education ends after ten years. The system is highly diversified and any kind of in-depth explanation would go beyond the scope of this study (see Kubanek-German (2000) for more information). It is crucial to stress that there is no national curriculum due to the structure of the German education system. This approach is seen as the principle of cultural sovereignty (Kulturhoheit), which allows each of the sixteen German states (Länder) to determine its own educational framework and curriculum.

Language learning is represented continuously in secondary and post-secondary education and has been introduced into the elementary education as well to provide full foreign language education throughout the entire obligatory education experience. Additionally, the language education offerings and approaches are differentiated because education is defined by each federal state.

At the elementary level language learning was introduced in the 1980s, and by 2000 language instruction begins in third grade in different areas of the country (Pufahl, Rhodes, \& Christian, 2000; Kubanek-German, 2000). Several federal states extended English on a trial base to first and second grade, for example, Baden-Württemberg, Bavaria, and Rhineland-Palatinate. The general goal is to introduce world languages in first grade, but because of financial constraints and teacher shortages in the field of world language instruction at the elementary level, it will take a longer transition period before it can be introduced to all first grade students. Kubanek-German listed the following language program types that can be found nation-wide at the elementary level:

Type A. Playful, but relatively systematic approach (for example, Hessen, Hamburg)

Type B. Approach based on authentic materials, no systematic progression (for example, Bavaria) 
Type C. Language awareness, talking about language, presenting different languages

Type D. Encounter language / window language

(for example, North-Rhine Westphalia)

Type E. Border-Programs. Regular Encounters with Peers Speaking the Other Mother-Tongue (for example, along the River Rhine, the Saarland, in certain schools near the Czech border) (Kubanek-German, 2000, pp. 62-3).

The Kultusministerkonferenz der Länder in der Bundesrepublik Deutschland [Standing Conference of the Ministers of Education and Cultural Affairs of the Federal States in the Federal Republic of Germany] (2005), referred to as KMK in the following, published an enactment report Foreign Languages in the Elementary School: Inventory and Concepts 2004 (Fremdsprachen in der Grundschule: Sachstand and Konzeptionen 2004). In this document the KMK in alliance with the experiences and current policy tendencies of the federal states defined the goals and global content guidelines, didactics and methods, organization, assessment, and transition to secondary education. As goals for the early language learning are listed that lay the foundation for multilingualism and intercultural competence, it suggested the move from a language teaching approach to a bilingual approach, in which languages are taught across the curriculum or through different content areas. Additionally, the report provided a detailed overview of each federal state elementary language learning policy and current data considering the approach, level, languages, time, students' enrolled, state standards, teacher education and professional development, and articulation (KMK, 2005).

In 2006, the KMK released a report on bilingual instruction and education (Schulausschuss der ständigen Konferenz der Kultusminister der Länder in der Bundesrepublik Deutschland, 2006). The report provided experiences and suggestions for enhancing bilingual education with a main focus on secondary education, but it included also references concerning early and elementary education. In 1999, 336 schools offered bilingual education in Germany and this number rose to 847 schools in 2006. Additionally, the report stated that there is a rising tendency in early childhood education and elementary schools. Baden-Württemberg, Berlin, Hamburg, Hessen, North-Rhine Westphalia, Rhineland-Palatinate, Saarland, Sachsen, and Schleswig-Holstein provided bilingual education at the elementary level while offering, for example, English as working language in different curriculum areas. Other working languages are determined by their neighboring countries, for example the Saarland und Baden-Württemberg offer French, in Nordrhein-Westfalen and Niedersachsen Dutch, Schleswig-Holstein Danish, Sachsen Czech und Polish. Russian, Turkish, New Greek, and Portuguese are additional working languages found in Germany. Bilingual education uses a foreign 
language as instructional tool, similar to the working language, for different subjects and applies the same standards as if taught in German (Schulausschuss der ständigen Konferenz der Kultusminister der Länder in der Bundesrepublik Deutschland, 2006).

The federal government required that country-wide instruction of early foreign language learning would start in third grade in school year 2006/2007. Several states had actually fulfilled this requirement years earlier, for example, Baden-Württemberg in 2003/2004 and Rhineland-Palatine in 2005/2006 (Eurydice, 2008). The federal states offer two hours of English while some states included a choice of English or French and students receive grades starting in third or fourth grades. All states have standards and some provide main curriculum areas. By the school year of 2009/10 BadenWürttemberg, Brandenburg, North-Rhine Westphalia, and Rhineland-Palatine offered state-wide foreign language instruction starting in first grade with one or two hours per week according to each state's standards. Students receive a participation remark on their report cards. Languages learned are English, French, Polish, Russian, and Sorbian. The remaining states conduct pilot projects to offer foreign language in first or second grades (KMK, 2005).

\section{Early Childhood Education Prior to School Entry}

Early childhood education in Germany had reached an important benchmark on August 1, 1996 when according to the law the legal claim of a part-time kindergarten placement for children at the age of three was introduced and implemented in the Code of Social Law (see Bundesrepublik Deutschland (2006), Sozialgesetzbuch (SGB), 8. Buch, § 24). In 2006, about two million, about $88 \%$, of 3 to 6-year-old children attended an early childhood education program (Deutsches Jugendinstitut e.V. and Dortmunder Arbeitsstelle Kinder- und Jugendhilfestatistik, 2007).

The federal states of Germany have described their individual laws for early childhood institutional requirements, but these never represented an in depth view of the curriculum. In the 1970s some states introduced a general curriculum. In 1990, early childhood discussions focused on offering more early childhood education programs. The changing society with more and more families where both parents are employed resembled in the situation that there was greater demand than early childhood programs offered in old federal states of Germany. The new states however had a surplus due to falling birth rates and migration consequently programs had to be reduced (Deutsches Jugendinstitut e.V. and Dortmunder Arbeitsstelle Kinder- und Jugendhilfestatistik, 2007).

With the beginning of the twenty first century a discussion about a general transition to educational oriented early childhood pedagogy was initiated due to the unacceptable results of the German educational system in the OECD Programme for International Student Assessment (PISA) 
study of 2000 (Textor, 2003; Organisation for Economic Co-operation and Development (OECD), 2004). The KMK together with the Ministers of Youth of each federal state provided a detailed framework for the design of a new educational and pedagogical curriculum framework for each state (Jugendministerkonferenz und Kultusministerkonferenz [JMK \& KMK], 2004). The framework focused on holistic education guiding principles and is based on learning to understand the concept of learning, developmental engagement in the decision making process, intercultural education, gender awareness, specific support of children with special needs, and enrichment for gifted children. It listed specific curriculum areas such as language, social development, mathematics, science, technology, music, sports and health, nature, and cultural and social environments. Furthermore, it offered considerations for structures and the formation of pedagogical work and quality assurance, for conditions of the realization of the educational goals, and for strategic transition to elementary education. Each federal state followed its own timeline and the integration of the new educational and pedagogical curricula occurred between 2004 and 2008.

A major portion of the curriculum framework focused on the promotion of language that originated from the growing numbers of migrants in Germany and the results of the PISA study. The aim was to provide language education for the children that are learning German as a second language but also to work on literacy in kindergarten. The PISA study revealed that, "children have only remote skills and knowledge of the language of instruction" (Hovestadt, 2003, p. 65).

Jampert, Best, Guadatiello, Holler and Zehnbauer (2007) compared all curriculum frameworks with respect to the concept of language education. They found that language promotion was understood as a leading factor in all states' early childhood education. The language promotion started for all children with entering the program. Some states initiated collaboration between kindergarten and elementary schools to coordinate language promotion and ease the children's transition between institutions. Education in German as a second language received a special emphasis. Intercultural education, a more recent aspect in early childhood education, includes appreciation of multilingualism. This means that the mother tongues will not be seen as a curriculum area but rather offered a place in the pedagogical approach. The only state, so far, that considered mother tongue education is Rhineland-Palatinate. Berlin, Rhineland-Palatinate, Saarland, and Sachsen promoted early childhood foreign language learning for all children. One major change in German early childhood education was the move toward integration of emergent writing skills, which was previously the responsibility of elementary education (see Table 1). 
Table 1. Languages in Germany's educational and pedagogical curriculum

\begin{tabular}{cccccc}
\hline State & $\begin{array}{c}\text { Language } \\
\text { Education for } \\
\text { All }\end{array}$ & $\begin{array}{c}\text { Home or } \\
\text { Family } \\
\text { Languge }\end{array}$ & $\begin{array}{c}\text { German } \\
\text { Language } \\
\text { Learners }\end{array}$ & $\begin{array}{c}\text { Foreign } \\
\text { Language } \\
\text { Learning }\end{array}$ & $\begin{array}{c}\text { Appriciation of } \\
\text { Multilugualism }\end{array}$ \\
\hline Bayern & $\mathrm{X}$ & $\mathrm{X}$ & $\mathrm{X}$ & $\mathrm{X}$ & $\mathrm{X}$ \\
Berlin & $\mathrm{X}$ & $\mathrm{X}$ & $\mathrm{X}$ & $\mathrm{X}$ & $\mathrm{X}$ \\
Brandenburg & $\mathrm{X}$ & $\mathrm{X}$ & $\mathrm{X}$ & & $\mathrm{X}$ \\
Nordrhein - & $\mathrm{X}$ & $\mathrm{X}$ & $\mathrm{X}$ & & $\mathrm{X}$ \\
Westfalen & $\mathrm{X}$ & $\mathrm{X}$ & $\mathrm{X}$ & $\mathrm{X}$ & $\mathrm{X}$ \\
Rheinland -Pfalz & $\mathrm{X}$ & $\mathrm{X}$ & $\mathrm{X}$ & & $\mathrm{X}$ \\
Sachsen-Anhalt & $\mathrm{X}$ & $\mathrm{X}$ & $\mathrm{X}$ & & $\mathrm{X}$ \\
Thüringen & $\mathrm{X}$ & $\mathrm{X}$ & $\mathrm{X}$ & & $\mathrm{X}$ \\
Hessen & $\mathrm{X}$ & $\mathrm{X}$ & $\mathrm{X}$ & & $\mathrm{X}$ \\
Niedersachsen & $\mathrm{X}$ & $\mathrm{X}$ & $\mathrm{X}$ & $\mathrm{X}$ & $\mathrm{X}$ \\
Saarland & $\mathrm{X}$ & $\mathrm{X}$ & $\mathrm{X}$ & & $\mathrm{X}$ \\
Schleswig-Holstein & $\mathrm{X}$ & $\mathrm{X}$ & $\mathrm{X}$ & & $\mathrm{X}$ \\
Hamburg & $\mathrm{X}$ & $\mathrm{X}$ & $\mathrm{X}$ & & $\mathrm{X}$ \\
Bremen & $\mathrm{X}$ & $\mathrm{X}$ & $\mathrm{X}$ & & $\mathrm{X}$ \\
Mecklenburg- & $\mathrm{X}$ & $\mathrm{X}$ & $\mathrm{X}$ & & $\mathrm{X}$ \\
Vorpommern & $\mathrm{X}$ & $\mathrm{X}$ & $\mathrm{X}$ & $\mathrm{X}$ & \\
Baden- & & & &
\end{tabular}

\section{Example: Bavaria}

In Bavaria the State Institute of Early Childhood Research and the Bavarian State Ministry for Labor and Social Affairs, Families and Women designed the Bavarian education plan for children in early childhood institutions until school entry (Bayerisches Staatsministerium für Arbeit und Sozialordnung, Familie und Frauen, Staatsinstitut für Frühpädagogik [BEP] 2003). This plan represents the federal state guidelines in early childhood education which focuses on nursery schools (crèches, birth to three years) and kindergarten. The Bavarian Institute for Early Education has provided the lead in Germany in early childhood education through research and teacher support over the past 30 years.

Oberhuemer and Kieferle (2007) stated that for the last 20 years the main focus of their work at the Bavarian State Institute of Early Childhood Research was guided by their belief that "multilingualism and multiculturalism belong in the pedagogical curriculum of child care institutions - be it through people belonging to particular cultures, be it through concrete offers such as songs, multilingual role play or through tapes with bilingual storytelling” (p. 131). In the early 1980s the institute developed an approach to integration of different mother tongues into the curriculum, which 
was accompanied by materials offering bilingual aspects. This was integrated into the Bavarian education plan under the aspect of intercultural and language promotion.

Educators working within diverse institutions should reflect their work of providing the German language as a starting point for "dialogue and exchange between cultures and as such embed in and influence their pedagogical (language) work. ... In the center of intercultural work are language promotion, parental involvement, and reflection" (Oberhuemer \& Kieferle, 2007, p. 31). The aim was to situate the research in the early childhood multilingual language development, to understand the reality of the multicultural society in the view of parents, teachers, and children, and to collect materials and books according to the different mother tongues to build a rich catalogue of information and support work in the institutions (Oberhuemer \& Kieferle, 2007).

The plan offered specific recommendations for language learning. These recognized that language learning is a continuous and long lasting process. Five major points of interest are suggested (BEP, 2003, p. 155-157):

- Achievement of language learning reached through personal contact;

- Emphasis on literacy education;

- Appreciation and promotion of bilingualism and multilingualism ;

- Focus on observation and documentation of language development;

- Importance of family support for the language development of children.

Furthermore, the plan stated that early childhood institutions prior to school entry need a concept for language promotion that supports a multilingual early childhood that is not seen as risk or exception but rather as a chance and a normal case. Only then can the children can develop a positive attitude toward multilingualism. The development of acceptance and interest in their first language and other languages is today not only the task of the foreign language instruction, but should be a part of the everyday life of the children in early childhood education (Bayerisches Staatsministerium für Arbeit und Sozialordnung, Familie und Frauen, Staatsinstitut für Frühpädagogik München [BEP], 2003, pp. 163-164). This is a very strong statement that both supports language learning and promotes equality among all children and hence the possibility of an even start.

The details offered by the BEP for an appreciation and facilitation of bilingualism and multilingualism are discussed in the following. The first and important educational task is an open and integrated appreciation of the home languages by the teachers. Parents and other family members' involvement is seen as a crucial factor in this process. The plan offers a checklist of questions to understand how this appreciation can take place. Here are some examples: Are there authentic materials like music CDs, books, and computer games, and are they accessible to the children? Is there integrated bilingual and multilingual staff, and is it active throughout the 
institution? Is the staff properly trained and do teachers have an understanding of the methods and theories of language learning? Are the parents and families actively engaged in the learning process?

The pedagogical work has to be designed to challenge the curiosity of a child and support the child's interest in learning the language. The plan emphasized that there is a need for constant integration of a language, instead of programs that offered once or twice a week. Therefore, if an institution decides to integrate another language, the staff will be arranged to the needs of the language learning process because there is a natural need of using the language and understanding its existence. Teachers with limited language knowledge should show the children that they are also learners during the language activities.

\section{Local Application Sample}

The city of Munich offered parallel to the intercultural approach to language promotion the project ‘English in Kindergarten’ (Landeshauptstadt München-Schul und Kultusreferat, 2004). The global goals for the project are the expansion and quality improvement of the educational offerings as demanded and supported by the parents, the opening to the European and international language field, and use of resources. The city's early childhood education staff, as one resource, has been analyzed according to its language abilities. Over 28 languages were identified and are mainly mother tongues of the pedagogues. This diversity is seen as a crucial factor in offering help, supporting and comforting parents with limited German language skills, but more so for the application in early childhood program situations and integration aspects of intercultural education and language promotion.

The project 'English in Kindergarten' was established the early 1990s and the analysis showed a high percentage of English language knowledge among their staff. The preparation for English in kindergarten was provided by workshops in the framework of continuing education development of the pedagogues and building a network to support their work. The pedagogues should ideally have appreciation, proficiency, and competency of the English language so that they can integrate the language into their work according to the daily experience and life in the program. Parents who like to volunteer in order to provide their resources are welcomed and integrated in onsite programs.

The goals are to increase the children's awareness for languages and cultures, to provide a playful and positive interaction and contact with English, to offer motivation for language usage, to expand the competence in English, and last but not least, to assist in strengthening the children's selfesteem. The curriculum is embedded in the child-oriented pedagogy and follows the regular 
curriculum. It can also be adjusted to the applied educational concepts like Montessori or artsoriented approach. At the center of the English curriculum will be the seasonal topics and play as a foundation for the teaching of vocabulary. Teaching will be conducted in small group settings or the entire group depending on the activities.

\section{The United States System}

The education system in the United States is highly diversified due to varying federal, state, and local funding as well state and local defined policies and school curricula. The compulsory education requirements are different for each state, with the starting age ranging from five to eight years and the ending age from sixteen to eighteen (Planty et al., 2009). Foreign language and bilingual education coexist in the teaching of languages in the United States. In foreign language education several factors apply such as state and district requirements, high school graduation requirements, the presence of state standards, and the state's vision. These factors are so different from state to state that is would go beyond the scope of this dissertation to describe them all. Therefore, a selection will be presented instead.

The mainstream curriculum introduces learning foreign languages at the high school level. In general, a student has a one to two-year language requirement. Over the last two decades, changes made it possible to offer languages at the middle school level for at least one year, but there is an overall need to start much earlier and to require a long-term commitment to foreign language instruction.

According to the National Council of State Supervisors for Languages (NCSSFL, 2010), the following states have high school graduation requirements for foreign languages: New Jersey, Tennessee, Maryland, North Carolina, South Dakota, Georgia (until 2012), Florida, Hawaii, and the Department of Defense Education activity. Other states plan to implement a high school requirement, such as Connecticut, Delaware Washington, Louisiana by 2012, Michigan by 2016, and Kentucky. In Ohio and Virginia, students that want to graduate with an honors/advanced diploma are required to take three years of one foreign language or two years each of two foreign languages. Maine has a world language PreK-Diploma. New York requires two units of FL between Kindergarten and ninth grade, and one or two in high school. The following states require at least two credits for postsecondary education access but not for high school graduation: Kansas, Kentucky, Georgia, Texas, and West Virginia. Illinois has no language requirements and Minnesota's requirements for world language standards and graduation are based on local decisions. 
At the elementary level Arkansas requires that all K-4 students receive foreign languages annually, and in 5 and 6 grades it is part of the social studies curriculum. Maine requires foreign language study of at least one other language starting in Pre-K and offers an extended program throughout the entire educational experience (Maine Department of Education, 1997). New Jersey and Oklahoma require all local education agencies to offer K-8 language programs. Vermont and North Carolina have K-12 language learning requirements that are connected later to their access to funding. Wyoming has a K-6 requirement for all students. Florida requires all local education agencies to have a K-12 foreign language curriculum plan.

Jackson and Malone (2009) stated that:

Excellent language programs have been developed in different institutions and communities, in different languages, at different levels, and for different purposes. Some, such as the DLI and FSI, are institutional programs that address clearly identified functional work-related requirements, but others are often the product of the vision, knowledge, and extraordinary work of a single individual or group of individuals. Among such programs are those of the school districts of Glastonbury, Connecticut; Chartiers Valley in Pennsylvania; Fairfax County, Virginia; and Montgomery County, Maryland; and innovative statewide programs launched in such states as Ohio, Wyoming, and New Jersey. Dual-language immersion programs in elementary schools serve students from heritage, native-English and immigrant communities and support the development of language skills in both English and the heritage language. They have often emerged partly as the result of a passionate commitment from both parents and the community, and have provided important language learning opportunities in an increasing number of communities across the country, such as Key Elementary School in Arlington, Virginia. (p.16)

Rhodes and Pufahl (2010) stated in their report on the national survey of teaching of foreign language in the United States school system that "over the past decade, the percentage of elementary schools nationwide offering language instruction has decreased by 6 percentage points" (p. 22). The public school system shows a significant decrease from $24 \%$ in 1997 to $15 \%$ in 2008, an even lower figure than the $17 \%$ of 1987 . In the private school sector there was a $2 \%$ change, going from $53 \%$ to $51 \%$.

The schools used the following program structures: "in 2008, 50\% of elementary schools' language programs were categorized by the school as language focus, $44 \%$ as exploratory, and $6 \%$ as immersion" (Rhodes and Pufahl, 2010, p. 37), which showed no significant change.

Rhodes and Pufahl (2010) found a significant increase in Spanish instruction that can be linked primarily to the private school sector, noting that "in 2008 , Spanish was taught at $88 \%$ of elementary schools that offered language instruction, compared to 79\% in 1997 -a statistically significant increase" (Rhodes \& Pufahl, 2010, p. 31). French decreased by about $16 \%$ by 2008 , 
ending at $11 \%$, and German by $3 \%$, ending at $2 \%$. For the German programs it was stated that it "was the decrease for public schools alone (from 7\% to $0.7 \%$ ), . Private schools, however, showed a slight increase, from 2\% to 3\%" (Rhodes \& Pufahl, 2010, p. 31). Some less commonly taught languages rose in the last decade though they are still taught within only a few schools, for example, Latin went from $3 \%$ to $6 \%$, Chinese from $0.3 \%$ to $3 \%$, and Arabic from 0.1 to $3 \%$. Latin and Chinese were mainly offered in private schools.

\section{Language Learning Program Models}

Curtain and Dahlberg (2010) suggested that when planning a new program the designers should consider the language outcome goals of the program in the midst of the organizational decision making process. They had observed that the implementation of programs caused misunderstanding in the learning outcomes for children in the past. They introduced a new guideline for early language learning: "Elementary school language programs can be classified along the continuum, with the language focused programs at the one end and content-focused immersion and bilingual programs at the other end" (Curtain \& Dahlberg, 2010, p. 462). The central elements for all programs are language, culture, and a content-based curriculum. They set a minimum time frame of 90-120 minutes per week for the language focus, which establishes recognizable language proficiency based on the ACTFL Standards for Foreign Language Learning and the K-12 Performance Guidelines.

Furthermore, Curtain and Dahlberg (2010) offered an overview of program models according to their continuum of intensity and focus for early language learning programs leading to proficiency. Gilzow and Branaman (2000) provide a deep inside view of seven programs that applied different program models, looking at elements such as the curriculum, program evaluation, outcomes, accessibility, articulation across content areas and across continuing education, student population, professional teacher development, and community involvement.

Curtain and Dahlberg (2010) considered immersion programs as content focused or contentdriven programs, which have the general goals of students becoming functionally proficient and mastering subject content taught in a foreign language, as well as acquiring an understanding of and appreciation for world cultures. In an immersion program students are engrossed within the language(s) and culture(s). Three subcategories can be differentiated by the intensity and the language(s) used: total, two-way, and partial immersion. The last program is defined as spending at least half a school day in the foreign language while the other is in English. The students' goals are to become able to understand and learn the subject matter and to achieve a medium proficiency level in 
a foreign language. The total immersion program is taught in the foreign language all day. Its goals are similar to the partial immersion but aimed at a higher proficiency level. The two-way immersion program is defined by the dual use of languages by students and teachers throughout the day while only one is used at any given time. The main goal is to acquire the foreign language with the aim of bilingualism. The students are native speakers of one of the offered languages.

Curtain and Dahlberg (2010) referred to language-focused or language-driven programs as early language learning programs K-6. They pointed out that these have the same goals as immersion programs and recommended at least thirty to forty minutes a day and not less than three to five days a week teaching the target language, which can also be a content-based way to reach recognizable language proficiency. These programs should be well articulated within the K-6 program and with middle and high school programs available to achieve long-term proficiency goals.

The Foreign Language in the Elementary School (FLES) applied teaching a language other than English, and Curtain and Dahlberg (2010) stated that the program was:

...taught three to five times a week for class periods of 20 minutes to an hour or more ... the profession is moving away from the term in favor of more general terms such as early start programs, early language learning programs, or programs for young learners. (Curtain \& Dahlberg, 2010, p. 463-4)

The foreign language exploratory (FLEX) programs, which can be offered in Grades K-8 and over a certain amount of time, are non-continuous. The students only learn phrases of the target language because the main goal is to introduce the culture. This should develop interest in future language studies and create an awareness of cultures. FLEX programs teach less than 90 minutes per week. Though FLEX programs have a valued place in the field of early language learning, their outcome with regard to students' language proficiency would not meet the ACTFL Standards or the performance guidelines.

\section{The Princeton Regional Schools, New Jersey}

The state of New Jersey requires that all students of grades K-8 study world languages. The high school graduation requirements, at 5 credits, are the highest in the U.S. The World Languages Curriculum Framework (New Jersey State Department of Education, 1999) is detailed and organized in a very teacher-friendly way. The document stated that, "The World Languages Curriculum Framework is intended to serve as a catalyst to assist schools in making curricular decisions based on an understanding of how students learn world languages most effectively, thereby providing a blueprint for innovation in local curricula and classroom practice" (World Languages Curriculum Framework, p. 2). All the foreign language programs like FLEX, FLES, and different types of 
immersion are options for the counties to adopt. The majority of the programs follow the FLES

model. The framework lists the following components as important and vital to its intentions:

- Embracing the belief that language learning is an innate human capacity and that all students who speak one language can successfully learn from another;

- Focusing on meaningful communication with increasing accuracy of expression in an authentic, real-life context;

- Availability to all students as part of the core curriculum in a K-12 articulated sequence;

- Delivered in a student-centered curriculum based on inquiry, problem solving, and application of concepts;

- Exploring themes and issues across content areas and making connections to the multicultural world of the 21st century, thereby fostering a greater understanding of and appreciation for world cultures; and

- Supporting the systems thinking approach to learning while integrating the skills outlined in the Cross-Content Workplace Readiness Standards.

The curriculum presents student-centered and authentic classroom settings, an interdisciplinary connection, and world language implementation in science and mathematics. Through the standards-based approaches in teaching, the units are structured by themes and organized around situation teaching scenarios, and grades can be based on performance, production, and written tests. The framework also achieved an outstanding level of articulation, which means that the students are moving from elementary to middle to high school without experiencing problems in program continuation and repetition.

The Princeton Regional Schools have been selected as one of six visitation sites for the World Language model program in 2002-2004 (Greenfeldt \& Russel, 2003, p. 11). The school district shows the following demographics:

- Students represent all major racial and cultural groups, and speak many languages ranging from Arabic to Vietnamese;

- $24 \%$ of the students claim 1 of 52 languages other than English as their first tongue;

- Student enrollment of approximately 3,250 in six schools;

- Four elementary schools- Community Park (348 students), Riverside School (333 students), Littlebrook School (383 students), and Johnson Park School (410 students);

- Include full-day kindergarten through fifth grade.

Greenfeldt and Russel (2003) summarized in their article "Engaging Children in Language Learning" the kindergarten program as structured in four lessons a week with the duration of fifteen minutes each. Therefore, the program falls into the category of FLES programs. The target language is Spanish, which is the only language offered in the county wide K-5 program. This choice was based on feedback provided by the parents, who were asked in a survey prior to the program start in 2000. 
The instructions are given in the target language only, and the teachers use gestures, visuals, and activities to achieve understanding and learning. Another important feature of teaching is the creation of a risk-taking environment coinciding with a comfortable atmosphere for using the target language.

The curriculum, according to Greenfeldt and Russel (2003), is designed "to reinforce concepts from math, social studies, art, and science" (p. 12). They further list themes taught in kindergarten: identifying attitudes, feelings, and emotions, and the understanding of plant growth. Greenfeldt and Russel (2003) commented that the program could not have been successful without strong support from parents, teachers, and the county.

\section{Fairfax County Schools, Virginia}

The Fairfax County Schools have four programs of two-way immersion kindergarten, all of which offer Spanish and English. In their first to sixth grade programs in the elementary schools, they offer partial immersion in the following languages: Spanish (7 schools), Japanese (3), French (2), and German (1).

Lake Anne Elementary School in Reston, Virginia offers the two-way immersion program in kindergarten, following their arts focused curriculum. This combination offers a rich and interesting education for all their children in agreement with their school's philosophy (Fairfax County Public Schools, 2010). The program model is defined by the Fairfax County Schools:

The children are taught half of the school day in English and the other half in Spanish. The students who speak English learn literacy skills that are currently taught in English as well as literacy skills taught in Spanish. Through this exposure, they acquire the Spanish language. The students whose native language is Spanish acquire English literacy while learning literacy skills in Spanish as well, allowing them to strengthen their skills in both languages. Both groups benefit and are able to connect the skills learned across both languages. The instructional program follows the Fairfax County Program of Studies for kindergarten. (What is Partial-Immersion? Program Model section)

\section{Early and Early Childhood Language Learning}

Language learning can be explained through looking at linguistic, psychological, and social development of children and the corresponding learning and teaching theories. These need to be taken into account when implementing instruction and language learning programs.

A rich pool of identification terminologies for learners has been created in accordance with their language development and experiences. These terms include: monolingual learners, bilingual learners, multiple language learners, second language learners, foreign language learners, English 
language learners, students with limited English proficiency, heritage language learners, world language learners, learners of less commonly taught languages, and dual language learners, and all terms have been used to describe children in relation to their language learning experiences and situation. Additional terms are applied specifically to the factors of language application: societal aspect — majority and minority languages, learner's language skills — dominant and non-dominant language(s), and time frame - sequential and simultaneous language learning. These factors influence children's language learning and the proficiency they will reach in their languages.

Genesee, Paradis, and Crago (2004) defined second language children as "children who begin to learn an additional language after 3 years of age; that is, after the first language is established"; simultaneous bilingual children as "children who learn two or more languages from birth or at least starting within the first year after birth. In effect, simultaneous bilingual children have two first languages..."; and dual language children- both simultaneous bilingual children and second language learners. They may be in preschool or school aged (p. 4). Furthermore, Genesee et al. stated that "children are socialized into their culture through language, and in turn, cultural patterning socializes children in how and with whom to use the language or languages they are learning." This is called language socialization (Genesee et al., 2004, p. 27).

\section{Second Language Development}

Chomsky changed the understanding of language development in the 1950s through his theory of language acquisition device (LAD). In this theory he suggested that humans are born with an innate language processing tool, the LAD. It is similar to the computer operating system in that one can set it to work on a specific language (Lesslow-Hurrley, 2005). He argued that the LAD consisted of universal language principles that he called Universal Grammar (Chomsky, 1965). Shrum and Glisan (2010) explained that "when children pay attention to features of language they hear, the LAD is activated; it triggers and selects the innate rules specific to the language they hear" (p. 13). Resent research by Kuhl, Conboy, Coffey-Corina, Padden, Rivera-Gaiola, and Nelson (2008) has found that infants discriminate phonetic units universally. Kuhl stated that "babies are "citizens of the world' when they're 6 months old — able to hear all the sounds of every language — but lose that ability by their first birthday as their brains commit to a native tongue (Bock, 2005, para. 23). This developmental change is explained by the Native Language Magnet Theory Expanded (NLM-e) proposed by Kuhl. The theory followed four stages in the child's phonetic development: 1) universal discrimination state when born, 2) neural commitment state influenced by social factors and perception-production links, 3) enhancement of language-specific perception, and 4) neural 
commitment stable. Infants used their computational abilities to select the phonetic sounds for the languages that they are surrounded by and their social skills play an important role in learning.

The notion of a universal phonetic system with which infants are born connects into the long discussion about critical or sensitive periods of second language learning. Singleton (2005) presented the manifoldness of the research and the complexity of the field, establishing different hypothesis including one concerning onset and offset, and the connections to reasoning that apply to neurobiological, cognitive-developmental, or affective-motivational aspects. He connected these to second language acquisition or various areas such as phonology, semantics, or syntax. Earlier researchers, for example Lenneberg (1967), placed the onset at age two and the offset with puberty, while Molfese (1977) placed the offset for phonology at age one. According to Kuhl's theory, there is no onset but rather an innate system for phonology is present when the child is born and findings show that the offset occurs by age one. Other researchers have focused on the offset of language learning, such as Penfield and Roberts (1959), who considered brain plasticity, suggesting that after age nine the human brain functions become progressively inflexible, making language learning more difficult. Lightbown and Spada (1999) offered evidence that both supported and rejected the critical period hypothesis, suggesting to shift the focus onto the different learners' needs, motivation and learning context. If native-like proficiency is the goal they suggest an early start for language learning. However, if communicative ability is the goal, the early start is much less clear. Singleton (2005) cited Ross Thomson's conclusion, endorsing it with his view and connecting it to second language acquisition:

"While the metaphor of critical periods in the organization of neural systems in the visual cortex or of the imprinting in lower species may offer an attractive heuristic to students of human development, the complexity of behavior systems to which these aspects are applied in young children makes it difficult, if not impossible to identify the parameters of sensitive periods with appropriate specificity. (pp. 280-1)

This view is shared by Lightbown and Spada (2006), who presented a balanced spectrum of factors that supports a continuous second language experience during early childhood, helping children to become successful learners. They stated:

Age is one of the characteristics that determine the way in which an individual approaches second language learning (both inside and outside the classroom), the motivation to learn, and the individual differences in aptitude for the language learning are also determining factors that affect both rate of learning and eventual success in learning. (p. 74)

The field of language learning and teaching has been influenced by Hymes (1972) with his sociolinguist theory of communicative competence. This theory moved away from the Chomsky's 
(1965) understanding of competence, which was built on the natural knowledge of grammatical and syntactic rules and the operation of the linguistic system. Communicative competence was defined as knowing the rules of syntax and grammar and the rules of language application in the appropriate context (Hymes, 1972). The approach was further developed by "Canale and Swain (1980), and Canale (1980), Bachman (1990), and Celce-Murcia et al (1995), who attempted to define the specific components of the construct of communicative competence" (Usó-Juan and Martínez-Flor, 2008, p. 158). The communicative competence was defined by Usó-Juan and Martínez-Flor (2008) as having five components: discourse competence is the text in a context and is influenced by the other competences; linguistic competence is the language system; intercultural competence focused on the production of text in a socio-cultural context; strategic competence is understood as the knowledge of learning and communicative strategies; and pragmatic competence is the focus on function (Usó-Juan and Martínez-Flor, 2008, p. 161).

The second main influence was Krashen's theory of natural second language acquisition, which focuses on the acquisition-learning, the natural order, the monitor, the input, and the affective filter hypotheses. His understanding represented a difference between learning and acquisition. He defined learning as "knowing the rules, having a conscious knowledge about grammar," and saw learning as connected to an editorial function referred to as "Monitor" that checks the output (Krashen $\&$ Terrell, 1983, p. 18). The major focus in his theory stresses language acquisition and how it leads to acquiring linguistic skills. "Simply, acquiring a language is 'picking it up,' i.e. developing ability in a language by using it in natural, communicative situations" (Krashen \& Terrell, 1983, p. 18). According to Krashen, children acquire language by receiving comprehensible input that is just above their language skills and being given time to organize and process the language they hear and understanding it before using it. The children develop language skills when taught in a meaningful and interesting context while learning in a comfortable environment that lowers their affective filters. He stressed that comprehension would have to precede language production. Lesslow-Hurley (2005) stated that "Krashen's theory has gained tremendous popularity among classroom teachers and has led to the development of innovative methodology that moves away from the grammar-translation and other traditional approaches" (p. 56) present in the 1980's and 1990's. However, his approach has been criticized for the separation between learning and acquisition and the emphasis on input, among other things (Lesslow-Hurley, 2005, Shrum \& Glisan, 2010).

Cook (1997) suggested that the views of Hymes and Krashen brought about two main understandings: "Authentic/natural language is the best and is primarily practical and purposeful, 
focused upon meaning rather the form" (p. 224). He discussed these premises coming to the conclusion that formed his vision of twenty first century language learning:

A recognition of the complexity of language learning: that it is sometimes play and sometimes for real, sometimes form-focused and sometimes meaning-focus, sometimes fiction and sometimes fact. This would be a real change of fashion: one which could provide the richer and more complex environments for learning, which after a century of being pushed and pulled in all directions, both learners and teachers deserve. (Cook, 1997, p. 231)

While discussing the second premise he connected language learning with play, suggesting the phenomenon of language play is connected to enjoyment, imagination, relaxation, and fun, as well as seeing play as a form of intelligence. He described two areas of language play: the formal and the semantic level. The formal aspect referred to play with sounds, grammatical structures, and patterns. The semantic aspect connects play with "units of meaning, combining them in ways which create worlds which do not exist: fictions" (Cook, 1997, p. 228). These types of language play would include "explicit attention to form, manipulation of form, repetition, rote learning, recognition that language classrooms is not real world where behaviour has serious consequences but ... a play world in which people can practices and prepare," and, "saying things without understanding them, producing and receiving language which communicates little" (Cook, 1997, pp. 229-30). According to Cook (1997) these were all "things that contemporary approaches would have us avoid" (pp. 22930).

Broner and Tarone (2001) studied language play in the elementary classroom while applying Cook's view, understood as fun or ludic, and Lantolf's view, represented as rehearsal. Lantolf, according to Broner and Tarone, referred to Vygotsky's notion of private speech setting play as a fundamental aspect of a child's development. The research results showed that both forms of play are present in the classroom. Language play seen as a form of private speech gives the second language learner ways to practice and internalize new language. Ludic language play was found to be supportive of second language acquisition. Shrum and Glisan (2010) stated that "private speech, mental rehearsal, and language play foster flexibility and change within the inter-language system of the learner, resulting in its growth and development" (p. 29).

\section{Benefits of Early Language Learning}

Robinson (1998) reviewed studies conducted in the field of early language learning, reaching from bilingualism to second language learning, and concluded that "It is clear from the research on cognitive, academic, and attitudinal benefits of early language learning that all children can profit 
from participation in foreign language programs" (p. 42). She stressed that the outcome of the academic oriented studies showed strong evidence that all students at different abilities enhanced their skills in the areas of language arts, reading, and math. Met (1991) stated that "students that learn another language in childhood score better on measures of cognitive functioning than their monolingual peers" (p. 88). Taylor-Ward (2003) studied the academic achievement of children in elementary foreign language programs in Louisiana. One research finding showed that "foreign language students significantly outperformed their non-foreign language peers on every test (English language arts, mathematics, science, and social studies) of the fourth-grade LEAP 21" (Taylor-Ward, 2003, p. 170). The other two main findings presented in the study show that foreign language students at every level outperformed their peers and that these results were connected to a sustained enrollment in the foreign language program. Caccavale (2007) discussed early second language research concluding that bilingual and monolingual children enrolled in continuous, long-sequence language programs can benefit measurably in terms of mathematical and linguistic development.

The field of second or foreign language research agrees that learning another language as a second or foreign language during childhood assures higher proficiency and stronger language acquisition (Met, 1991 and 1998; Curtain \& Dahlberg, 2010, Genesee et al. 2004). Shrum and Glisan (2010) summarized research findings in second language oral and literacy proficiency, listing results for elementary school children such as: gains in pronunciation, long-sequence programs supporting proficiency, benefits of an early start, young learners (K-3) carry a positive attitude toward language study, and literacy can start with the beginning of language study. Research findings support the idea that the earlier children start another language the greater their chance of being successful in language acquisition and the learning process. Curtain and Pesola (1994) stated, "when language learning begins earlier, it can go on longer and provide more practice and experience, leading ultimately to greater fluency and effectiveness" (p. 4).

Additionally, the students who learn another language prior to adolescence were more open toward learning about cultures and were more likely to develop positive interest in cross-cultural learning (Met, 1991 and 1998, Robinson, 1998).

\section{Early Childhood Language Learning In Preschool}

A child learning its first language will acquire the main linguistic apparatus by the age of five. There are several levels during this process. Tabors (2008) described that during the preschool years a first language learner acquires the idea of explanations, argumentation, and narration as well as the understanding of adjusting toward a different audience. ELLs who arrive in preschools with 
very limited English language knowledge based on their non-English speaking home environments have to master several situations, including new social and linguistic demands.

ELLs are second language learners in their second language domain and are therefore sequential second language learners. This means they have partially mastered their first language knowledge by preschool entry and are starting to learn another language (English in the U.S.). Tabors stated: "For these children, then, second language acquisition is not a process of discovering what language is, but rather of discovering what this language is" (2008, p. 12).

She observed four phases in the second language development. They are: 1) the application of the home language for a certain period of time, 2) a nonverbal period when a child is acquiring the program language and may conduct sound experimentation, 3) a short application of the program language through use of words or memorized phrases, and 4) the productive period in which children start to construct their own phrases (Tabors, 2008). Genesee et al. (2004) added the phase of interlanguage that starts during the productive phase and lasts until the child reaches language proficiency, defining it as, "a systematic and rule-governed linguistic system, but it does not have the same characteristics as the target system, the L2" (p. 121). He provided two reasons for the difference: the influence of the first language with its structure and pronunciation, called transfer errors, and “developmental, target-deviant patterns are a typical part of language learning" (Genesee et al., 2004, p. 121)—so-called developmental errors.

Another common belief is that during preschool and kindergarten the children learn a foreign language with ease, but this is disputed by Genesee et al. (2004) who stated:

Some people think that when young children learn a new language they "soak it up like a sponge." There is considerable research evidence showing this popular belief to be false, and it is important for professionals working with L2 children to be aware of how long it can really take to acquire native-like competence in a second language, in order to have realistic expectations of children's performance. (p. 133)

\section{Teacher's Role in Language Learning}

Tabors (2008) recommended the communication strategies that evolved from her observation of and work experience with second language learning children in preschools. The teacher should start by connecting to the children's knowledge, slowly building up vocabulary, and using language repetition so that children have the chance to learn the vocabulary through frequent use. She suggested the strategy of "Buttressing Communication," which she defined as "additional information delivered by a gesture, an action, or a directed gaze [which] adds another dimension that helps the child tune in to exactly what is being talked about, making it easier to get the message" (Tabors, 2008, p. 92). She advised using the focus on "here-and-now" so that the learner can demonstrate 
what they are talking about, which limits the field for the learner allowing direct connection to the new information to be made. The expanding and extending of language in communication situations is another strategy that a teacher can apply. This strategy is closely connected to "Upping the Ante," which she recommended and described saying:

One of the difficult judgment calls that teachers have to make when communicating with second-language learners is when to be more insistent that the children get beyond the nonverbal techniques that they have developed and actually use language to get their point across. (Tabors, 2008, p. 94)

The last strategy she suggested was "Fine Tuning," in which the teacher rephrases the original and not understood message so that it will be more understandable for the child. Tabors (2008) noted that these strategies are rarely used alone but rather appear to be combined in communication with second language learners.

\section{Classroom Organization}

Tabors (2008) suggested that the classroom environment should be child friendly and that there are places where children can feel competent and comfortable. The use of routines helped the language learner to become part of the group. She stated that:

The social aspect of the ... classroom that proved most helpful for the secondlanguage learners ... was the fact that the teachers established a consistent set of routines for the children. These routines meant that, with a little observation, the second-language-learning children could pick up cues as to what to do and when, using the English-speaking children as models, even before they could understand the language being used around them. The daily schedule of arrival, free play, cleanup, snack time, outside play, and circle time gave the second-language learners a set of activity structures to acquire ... which immediately allowed them to act like members of the group. (Tabors, 2008, p. 97)

\section{Constructivist Learning Theory}

Piaget's cognitive developmental theory is grounded in the activity of the child and developed out of "a laborious effort to make sense of children's efforts to understand the physical world" (Piaget, 2001, p. xii). He stated that "the world is filled with tendencies and intentions which are in participation with our own. This is what we have called dynamic participation..." (Piaget, 2001, p. 245). Therefore, the exploration of learning is seen as a construction by the child's participation in the environment, building on assimilation and accommodation. The balance of these two notions, he proposed, would lead to intellectual growth. In his theory, he rendered four classifications of a child's development. The second stage he categorized as the pre-operational level for 2 to 7 -year-old children. This stage is characterized by the application of language and the 
development of symbolic and one-way operational thinking, as notes that the child has difficulties in recognizing other people's point of view (Piaget, 1970). In the field of second language learning, accommodation has been taken into consideration and received the label "restructuring - used to refer to the re-organization of mental representations of language" (Cameron, 2001). Piaget's theory does not consider the child in its social environment and has been criticized for this among other things (Cameron, 2001). Vygotsky stated that "The relations discovered by Piaget turned out to be valid only for the social milieu in which his subjects live. One may imagine how substantial must be the differences in data collected in Genevan and Soviet kindergartens (Vygotsky, 1986, p. 56).

Vygotsky expressed that children need to be studied and understood in relation to their different social and cultural backgrounds, leading to more complex findings of the cognitive development process (Vygotsky, 1986). The major contribution of this learning theory is Vygotsky's aspect of the zone of proximal development (ZPD) that was connected to school age children. It is defined as: "the distance between the actual developmental level as determined by independent problem solving and the level of potential development as determined through problem solving under adult audience or in collaboration with more capable peers" (Vygotsky, 1978, p. 86). This notion provided a new vision for education and provided direct application possibilities in teaching. He observed that during the preschool years the role of play was central and a child's imagination evolved. Vygotsky (1978) found also in play a created zone of proximal development stating: "As in the focus of a magnifying glass, play contains all developmental tendencies in a condensed form and is itself a major source of development" (p. 102). Additionally, he understood language as a tool of communication that reflects upon the environment and internally to build cognitive structures. Vygotsky (1978) described that:

"The acquisition of language can provide a paradigm for the entire problem of the relation between learning and development. Language arises initially as a means of communication between the child and the people in the environment. Only subsequently, upon conversion to internal speech, does it come to organize the child's thought, that is, become an internal mental function." (Vygotsky, 1978, p. 89)

The current application and misinterpretation of constructivism in education have been criticized by researchers such as Fosnot (2005), who remarked that "many educators who attempt use such pedagogical [constructivist-based] strategies confuse discovery learning and 'hands-on' approaches with constructivism" (p. 278), and argued that constructivism was a learning theory. Fosnot and Perry (2005) emphasized further that "constructivism is a theory about learning, not a description of teaching“ (p. 33), and suggested that teachers apply general principles of learning originating from constructivism when teaching. For example, learning is understood as development 
that needs to be organized by the learner; making errors is seen as an important part of the learning process and affirming and contradictory views need to be explored; reflective abstraction is the driving force of learning; and dialogues in the learning environment encourage deep thinking.

The constructivist view emphasizes that the students view their environment, including all learning and teaching materials as well as the teacher, differently than the teacher might have intended. Therefore, the teacher constructs a hypothetical model of the topic taught and can long for the inducing of change in students' thoughts (von Glasersfeld, 2005). Considering the language used in teaching, Glasersfeld (2005) stated:

...the consideration of how meanings are constituted, and how, consequently, linguistic communication works, would dismantle the still widespread notion that conceptual knowledge can be transferred from teacher to student by the means of words. This is not to say that language is not important. In fact, it is the most powerful tool available to the teacher, but it does not transport meanings or concepts. Language enables the teacher to orient the student's conceptual construction by precluding certain pathways and making others more likely. (p. 7)

These two notions moved the goal of instruction toward centering on cognitive development and deep understanding, which are viewed as construction of active learner recognition and represent learning as complex and nonlinear (Fosnot \& Perry, 2005).

Mayer (2009) connected to Fosnot's (2005) critique and defined it as the "constructivist teaching fallacy" (p. 184). He referred the problem as "drawing on a distinction between high cognitive activity during learning (which according to constructivist learning theory leads to deeper understanding) and the high behavioral activity during learning (which according to a constructivist teaching theory leads to deeper learning)" (p. 184). He explores active and passive methods in the field of learning and instructions while considering high and low activity in either learning and instructions. After analyzing these areas he arrived at the conclusion that the constructivist understanding of the learning process "can be caused by passive instructional methods (such as principled presentations) and can be hindered by active instructional methods (such as pure discovery)" (p. 195). He recommended that if applying the constructivist learning theory in teaching, teachers should locate an instructional method that promotes cognitive processing during learning by supporting it with providing useful materials, connecting it to prior knowledge, and supporting the organization of the information.

The implications that derived from this constructivist understanding of learning for teaching and learning situations are a combined responsibility. This responsibility encourages the student's autonomy and initiative in the analyzing, creating, and classifying of information while offering raw 
data along with manipulatives and physical material. Teachers and students drive the learning situation according to their natural curiosity, while there is flexibility in the intended content or strategies. Teachers explore student's understanding of content and concepts before offering their own understanding. In this process open-ended questions and inquiry are applied while seeking elaboration of initial responses and encouraging discussion through confirming and contradicting view points. Time plays a crucial role in the process of constructing meaning and metaphors (Brooks \& Brooks, 1999).

\section{Montessori Method}

Maria Montessori (1914) described the Montessori method in her book, Dr. Montessori's Own Handbook, and stated that the school "ought to be a real house that is to say, a set of rooms with a garden of which the children are the masters" (p. 10). She elaborated on the description of the garden, providing a play area, shelter, and tables to eat and do their activities, seen in this approach as "work." While describing the house she defined the main room as used for "intellectual work" (Montessori, 1914, p. 10), the use of child-sized furniture, and the presence of only didactic materials

for the children. She discussed each room and its content in detail and reasoned that education should create a mental picture of a child friendly environment. She felt this environment was absent from the current system, and therefore started to develop her own approach to early childhood education. Lascarides and Hinitz (2000) stated that in present early childhood programs the physical setting was taken from the Montessori children's house, naming for example, large open rooms, child sized furniture, and low shelves with didactic materials.

Furthermore, Maria Montessori outlined her method and explained how to use the essential materials she intended for a child's education. Wentworth (1999) stated that “...neither her teaching aids, ...called the Montessori material, nor the technique of presenting them to the children, were her own inventions. Their originators were her French predecessors, Itard and Seguin, ...” (p. 10).

Gitter (1970) described the three-period lesson that was adapted from Seguin. The first step is to link the sense-perception with the name while the teacher articulates well and shows the object. "This is a car. This is a bike." In the second step the recognition of the object by the name is in the center. "Point to the bike. Point to the car." The third and final step is remembering the name that corresponds to the object. The teacher then asks, "What is that?" and the child replies "This is a bike," and this sequence is repeated for the second object. Lillard (2007) summarized the steps as “association, recognition, and recall" (p. 178). This kind of lesson is used during primary education because Maria Montessori believed that a child needs to learn the precise terms for explaining the 
world. Additionally, she defined a child's first five years as the major period for learning vocabulary and language as a whole, defining it as a sensitive period (Lillard, 2007). By sensitive period, Montessori meant the time when a child is interested in "particular stimuli that aid psychological development" (Lillard, 2007, p. 123). She referred to the ages from 3 to 6 as the conscious absorbent mind and stated about language:

....is a very clear example, for its spontaneous development goes on till the age of five or so. Already it has existed since the child was two and a half, and it was then complete, for the child could not only form words but use sentences grammatically correct. But there still remains the special sensitiveness (the sensitive period for language, ...) that goes on urging the child to fix its sound ever more accurately, and above all to enrich it with an even greater repertoire of words. (Montessori, 1967, p. 167)

Lillard (2007) describes the main characteristics of the Montessori education and curriculum. When movement and cognition are interwoven they can enhance thinking and learning. Choice and interest should lead the construction of learning while extrinsic rewards need to be avoided which leads to training the child for a reward instead of engaging in a meaningful construction of knowledge. Creating meaning and building knowledge is supported by learning with and from peers, learning in rich and meaningful context, and through order in the environment order in the mind is supported.

The curriculum for the primary years, ages 3 to 6 , is generally built on five subject areas: 1) practical life exercises that develop social skills and to engage in activities of daily life which will support independence; 2) sensorial education providing experiences in the development and enhancement of the senses while using contrasting strategies; 3) language focuses on the spoken and written while using activities that develop speech, reading and writing; 4) mathematics includes experiences to explore size, shape, dimension, and beginning quantity understanding; and 5) cultural studies (Humphryes, 1998). Humphryes (1998) described the cultural study area as the part of the curriculum that:

...offers children a wealth of experiences in various topics: for example people and their cultures and beliefs, the arts, ...geography, biology, physical science, cooking, astronomy, botany. ... [are] not specifically ethnically oriented, but it does incorporate multicultural experiences that promote respect and appreciation for similarities and differences among people. (p. 14)

\section{Montessori and Language Learning}

Lillard (2007) noted that Maria Montessori did not include the learning of other languages in her method. However, many Montessori programs do include languages in their curriculum. 
Concerning foreign language learning, Maria Montessori (1914) stated that "Early childhood is, in fact, the age in which language is formed, and in which the sounds of a foreign language can be perfectly learned" (p. 54).

Ceo-DiFrancesco (2007) traced back the combination of the Montessori method and foreign language instruction to the 1960s in the United States and provided guidelines for Montessori foreign language programs while applying recommendations by Curtain and Dahlberg to use more thematic planning. She stated that "Montessori educators around the world have for years employed strategies and techniques in the Montessori environment that can significantly enhance the child's acquisition of another language (p. 197).

Crane-Fisk (1987) described the experience and the instruction in a foreign language in a Montessori environment starting with preschool through junior high. The language focus was French and used the lesson and conversation approach. Once a week the French specialist taught a lesson and her second weekly visit was based on spontaneous interaction during the uninterrupted time, during which children could approach her themselves. The classrooms had French materials integrated, and she did the following with the preschool children: felt board activities, tapes with songs were used often, and beginning labeling activities for the topics taught, for example, clothes. She stated that "as a result of having placed these materials within the classroom environment, we have found that a wonderful undercurrent of French is present in the classroom throughout the day" (Crane-Fisk, 1987, p. 3). 


\section{Chapter 3: Methodology}

This chapter introduces and explains the applied study methodology. There have been discussions about whether a case study is a research strategy or a research approach. Yin (2003), for example, understands a case study as a comprehensive research strategy and not as methodology while Croker (2009), Creswell (2007), Hatch (2007) and Merriam (1988) understand case studies as a research approach. Creswell (2007) defines a case study "as a methodology [same meaning as research approach], a type of design in qualitative research, or an object of study, as well as a product of the inquiry" (p. 73). This definition captures the guiding approach for this study.

This dissertation is a qualitative observational case study and applied aspects of the grounded theory in the analysis. The purpose is the exploration and understanding of the characteristics and complexity found in early childhood language learning while considering the interaction with program structures and approaches used in early childhood institutions for children under the age of seven. The programs were located in Austria, Germany, and the United States. The report of the case study provides a holistic description of the experience as well as a case-based theme discussion that initiated a preliminary model of the complexity of early childhood language application and acquisition connected to the educational environment.

The research questions already presented in chapter one are given again here to clarify the study's goals. This is followed by a description of the study design, which offers the methodological background of the research process. The chapter further explores the research process by describing the research site selection, the site itself, and the duration and time-frame. This is followed by relating data and data collection with the applied research methods, and an explanation of the data analysis. The last section of this chapter provides a discussion on the validation of the study.

\section{Research Questions}

The overarching research question guiding this study was: What influences early childhood language learning and use in the selected programs? The proposed questions have been extended to fully represent the language used in the participating early childhood settings. I therefore refined the questions in their wording and broadened their meaning to address all program realities. To change or to adapt the research questions is a common practice in qualitative research. Hatch (2002) commented that "research questions are often refined and sometimes changed during the course of qualitative studies, but without them, studies can lack direction, focus, or the means to evaluate their 
effectiveness" (p. 42). However, the intended content and focus of the proposed questions was not compromised by the changes. This study was guided by the following questions:

What influences early childhood language learning and use in the selected programs?

- What approaches and methods are used in the programs?

- What types of strategies and activities occur in the program to engage students in early childhood language learning?

- When and how are children using their language(s) in the early childhood program?

- How does peer support engage in language learning?

- What are the roles of teachers and students in the early language learning environment?

In conducting the qualitative case study I applied these questions to explore the field of early childhood language learning in the participating programs and to understand their realities while learning from their experiences.

\section{Research Design}

This qualitative inquiry was designed as an observational and multi-site case study. I applied the case study methodology as described by Creswell (2007). He wrote:

Case study research is a qualitative approach in which the investigator explores a bounded system (a case) or multiple bounded systems (cases) over time, through detailed, in-depth data collection involving multiple sources of information (e.g. observations, interviews, audiovisual, documents and reports), and reports a case description and case based themes. For example, several programs (a multi-site study) or a single program (a within-site study) may be selected for study. (p. 73)

For a case study researcher it is often difficult to define the bounded system (the case). Merriam's (2007) explanation: “I can 'fence in' what I am going to study” (p. 40) and Stake's (2006) graphic design of a case study were most helpful in designing this case study. The bounded system was defined by the phenomenon of early childhood language learning while observing different programs: one in Austria, one in Germany, and one in the United States.

Hood (2009) stated, "regardless of the type of the case study one chooses to conduct, cases are selected because they possess certain characteristics - psychological, linguistic, institutional, socio-cultural, or biological..." (p. 71). The emphasis of this observational case study was on linguistic characteristics, primarily those concerning early childhood language learning, and on sociocultural characteristics noted while observing children and educators in their learning environments. 
Patton (2002) described qualitative studies as “...naturalistic to the extent that the research takes place in the real-world settings and the researcher does not attempt to manipulate the phenomenon of interest (e.g., group, event, program, community, relationship, or interaction)" (p. 39). The changes in early language learning policies and implementation in Europe and the United States have initiated the focus of my research and I therefore chose to include a global aspect in this observational case study. Another aspect that influenced the study was that I am German, married to an Austrian, and living in the United States. As such, it was my intention to shed light on the work of teachers, early childhood language learners, and programs that taught German or English. These factors directly led to the design of a multi-site study in which I conducted research in Austria, Germany, and the United States.

The research methods for collecting data were observation, interviews, questionnaires, and documents. Additionally, different types of media were utilized to support the data collection process within the classrooms and institutions, including multi-media technologies such as cameras, tape recorder, camcorders, microphones, and a dictaphone. Computer technology was utilized in the process of transcribing the collected data from field notes, audio recordings, and video tapes. Patton stated that "contemporary researchers,..., have available to them a number of technological innovations that, when used judiciously, can make fieldwork more efficient and comprehensive" (2002, p. 307).

The case study design provided a good foundation for in depth exploration of early childhood language learning situations in these selected programs while constructing a holistic picture of their realities and experiences. This view has been supported by Merriam (1988), who stated that "the qualitative case study is a particularly suitable methodology for dealing with critical problems of practice and extending the knowledge base of various aspects of education” (p. xiii).

\section{Research Setting}

The method of purposeful sampling is a common strategy applied in qualitative research (Merriam, 2009; Creswell, 2007, Bogdan \& Biklen, 2007, Patton, 2002). The reseacher finds research sites that will support exploration of the research topic and the studied phenomenon. Patton (2002) provided a wide selection of different sampling strategies from which I had selected the strategy of typical case sampling. In this study I wanted to present distinctive public and private programs that include early childhood language learning in their program structure.

In the U.S. early childhood programs are mainly private enterprises, while in Europe a good balance of public and private programs can be found. This was one reason for choosing a private 
program. In order to recognize if a program was typical or not, I visited possible sites beforehand. I conducted an international study tour to Germany and Austria in the summer of 2004, visiting several metropolitan areas and establishing contacts and possible partnerships in these countries.

One German city's Department of Education and Culture supported my quest by providing a guide who showed me different public kindergartens. I found the sites to be a reflection of distinctive metropolitan public programs. Making the decision to choose the city's early childhood program, I contacted the department after the proposal had been accepted. Their office of early childhood education provided a research site that met all the described criteria. The criteria were that the institutions use early childhood language learning as part of their regular daily schedule, are located in a metropolitan area, use a child-centered approach, operate on an all-day schedule, have a culturally diverse population, and that the children are between the ages of 3 to 6 years. The German kindergarten used an integrated English language concept.

In Austria I mainly visited private programs in different metropolitan cities because I had selected a public program in Germany and wanted to represent private and public kindergartens in Europe. I chose a program in the eastern part of the country. I established a connection with one kindergarten and its program director showed interest in participating in this research project. The setting fulfilled the above mentioned criteria and applied the English immersion approach.

In the United States I considered several metropolitan areas, looking for German language programs in these areas. I was not able to locate a public program that included German for children between three and five years. Therefore, I searched in the private sector and found several programs which fit the study criteria. After careful consideration I chose a program located in a metropolitan area in the western United States. This program had both preschool and kindergarten classes and used the German immersion approach.

I chose to refer to each country's program by the respective first initials and abbreviations to protect the participants' privacy. I used the abbreviations G.P. for the German program, A.P. for the Austrian program, U.S. P.P. for the United States preschool, and U.S. K.P for the United States kindergarten in the tables and figures. Similar programs to the ones chosen in Germany and Austria can be found in both countries, and I feel both are good representatives of public and private early childhood education programs. Similarly, the U.S. program can be seen as a representative for the U.S. private sector of early childhood language programs. I came to this conclusion due to my experiences and studies in the field of early childhood education. Nevertheless, the final decision lies with the reader and the individual institutions will not be further advocated in this study. 
The administration of each research site determined the classroom or group that would participate in the study and distributed the consent forms to the parents or guardians, which I received signed upon arrival. Each program supported the study within their means and offered help whenever I needed something or had questions. I am very grateful for their assistance and cooperation.

\section{Duration and Timeline}

As anticipated, I spent at least two full weeks at each location to observe, explore, and interview teachers, administrators, parents and children. Therefore, I spent 35 days in the field collecting data for this observational case study. The first program I observed was the German program from June 13 through June 30, 2005, then the Austrian program from July 1 through July 15, 2005, and the U.S. program from December 5 through December 16, 2005 (see Tables 2-4).

Observation days lasted for the full duration of each facilities program: in Austria from 8:30 a.m. to 2:30 p.m., in the United States preschool program from 8:30 a.m. to 1:45 p.m., and in the U.S. kindergarten program from 8:30 a.m. to 1:55 p.m. In the German program I had to set the beginning of the observation according to the means of transportation. Mondays I observed from 7:30 a.m. to 5 p.m., Tuesdays through Thursdays from 8:30 a.m. to 5 p.m., and Fridays from 7:30 a.m. to 4 p.m., which was the closing time.

Table 2. G.P.: Observation schedule and data collection (FN-field notes, P-photos, V--video, Aaudio)

\begin{tabular}{|c|c|c|c|c|c|c|c|}
\hline Days & Date & Time & & FN & $\mathrm{P}$ & $\mathrm{V}$ & $\mathrm{A}$ \\
\hline 1 & $6 / 13 / 2005$ & 7:30 to $5: 00$ p.m. & & $\mathrm{X}$ & $X$ & & $\mathrm{X}$ \\
\hline 2 & $6 / 14 / 2005$ & $8: 30$ to $5: 00$ p.m. & & $X$ & $X$ & & $X$ \\
\hline 3 & $6 / 15 / 2005$ & $8: 30$ to $7: 00$ p.m. & & $X$ & $X$ & $X$ & \\
\hline 4 & $6 / 16 / 2005$ & $8: 30$ to $5: 00$ p.m. & & $\mathrm{X}$ & $\mathrm{X}$ & $\mathrm{X}$ & \\
\hline 5 & $6 / 17 / 2005$ & 7:30 to $5: 00$ p.m. & & $\mathrm{X}$ & $X$ & $\mathrm{X}$ & \\
\hline 6 & $6 / 20 / 2005$ & 7:30 to $5: 00$ p.m. & & $\mathrm{X}$ & $\mathrm{X}$ & & $\mathrm{X}$ \\
\hline 7 & $6 / 21 / 2005$ & $8: 30$ to $5: 00$ p.m. & Interview 1 & $\mathrm{X}$ & $\mathrm{X}$ & & $\mathrm{X}$ \\
\hline 8 & $6 / 22 / 2005$ & 8:30 to $5: 00$ p.m. & Interview 2 and 3 & $X$ & $X$ & $X$ & \\
\hline 9 & $6 / 23 / 2005$ & 8:30 to $5: 00$ p.m. & Interview 4 and 5 & $X$ & $X$ & & $\mathrm{X}$ \\
\hline 10 & $6 / 24 / 2005$ & 7:30 to 5:00 p.m. & Interview 6 & $\mathrm{X}$ & $\mathrm{X}$ & $\mathrm{X}$ & \\
\hline 11 & $6 / 27 / 2005$ & 7:30 to 5:00 p.m. & & $\mathrm{X}$ & $\mathrm{X}$ & & $\mathrm{X}$ \\
\hline 12 & $6 / 28 / 2005$ & 8:30 to $5: 00$ p.m. & & $X$ & $X$ & $\mathrm{X}$ & \\
\hline 13 & $6 / 29 / 2005$ & 8:30 to $5: 00$ p.m. & & $X$ & $X$ & $X$ & $X$ \\
\hline 14 & $6 / 30 / 2005$ & $8: 30$ to $5: 00$ p.m. & & $X$ & $X$ & $\mathrm{X}$ & $X$ \\
\hline
\end{tabular}


Table 3. A.P.: Observation schedule and data collection (FN-field notes, $P$-photos, $V$--video)

\begin{tabular}{ccccccc}
\hline Days & Date & Time & & FN & P & V \\
\hline 1 & $7 / 1 / 2005$ & $8: 30$ to $2: 30$ p.m. & & X & X & \\
2 & $7 / 4 / 2005$ & $8: 30$ to 2:30p.m. & & $\mathrm{X}$ & $\mathrm{X}$ & \\
3 & $7 / 5 / 2005$ & $8: 30$ to 2:30p.m. & & $\mathrm{X}$ & $\mathrm{X}$ & $\mathrm{X}$ \\
4 & $7 / 6 / 2005$ & $8: 30$ to 2:30p.m. & & $\mathrm{X}$ & $\mathrm{X}$ & $\mathrm{X}$ \\
5 & $7 / 7 / 2005$ & $8: 30$ to 2:30p.m. & & $\mathrm{X}$ & $\mathrm{X}$ & $\mathrm{X}$ \\
6 & $7 / 8 / 2005$ & $8: 30$ to $2: 30$ p.m. & & $\mathrm{X}$ & $\mathrm{X}$ & $\mathrm{X}$ \\
7 & $7 / 11 / 2005$ & $8: 30$ to $2: 30$ p.m. & Interview 1 & $\mathrm{X}$ & $\mathrm{X}$ & $\mathrm{X}$ \\
8 & $7 / 12 / 2005$ & $8: 30$ to $2: 30$ p.m. & Interview 2 & $\mathrm{X}$ & $\mathrm{X}$ & $\mathrm{X}$ \\
9 & $7 / 13 / 2005$ & $8: 30$ to $2: 30$ p.m. & Interview 3 & $\mathrm{X}$ & $\mathrm{X}$ & $\mathrm{X}$ \\
10 & $7 / 14 / 2005$ & $8: 30$ to $2: 30$ p.m. & Interview 4 & $\mathrm{X}$ & $\mathrm{X}$ & $\mathrm{X}$ \\
11 & $7 / 15 / 2005$ & $8: 30$ to $2: 30$ p.m. & & $\mathrm{X}$ & $\mathrm{X}$ & $\mathrm{X}$ \\
\hline
\end{tabular}

Table 4. U.S.P.: Observation schedule and data collection (FN-field notes, $P$-photos, $V$--video)

\begin{tabular}{ccccccc}
\hline Days & Date & Time & FN & P & V \\
\hline 1 & $12 / 5 / 2005$ & $8: 30$ to $1: 45$ p.m. & X & X & \\
2 & $12 / 6 / 2005$ & $8: 30$ to $1: 45$ p.m. & X & X & X \\
3 & $12 / 7 / 2005$ & $8: 30$ to $1: 45$ p.m. & X & X & X \\
4 & $12 / 8 / 2005$ & $8: 30$ to $1: 45$ p.m. & X & X & X \\
5 & $12 / 9 / 2005$ & $8: 30$ to $1: 45$ p.m. & X & X & X \\
6 & $12 / 10 / 2005$ & $8: 00$ to $1: 00$ p.m. & X & X & X \\
7 & $12 / 12 / 2005$ & $8: 30$ to $1: 55$ p.m. & X & X & X \\
8 & $12 / 13 / 2005$ & $8: 30$ to $1: 55$ p.m. & X & X & X \\
9 & $12 / 14 / 2005$ & $8: 30$ to $1: 55$ p.m. & X & X & X \\
10 & $12 / 15 / 2005$ & $8: 30$ to $1: 55$ p.m. & X & X & X \\
11 & $12 / 16 / 2005$ & $8: 30$ to $1: 55$ p.m. & X & X & X \\
\hline
\end{tabular}

\section{Participants}

The children, teachers, and programs were assigned new names and their location has not been disclosed to protect their personal and institutional privacy and to comply with the regulations of the West Virginia University's Institution Review Board for the Subject Protection of Human Research Subjects. The children in the participating programs were generally between the ages of 3 and 6 years, with the exception of four 2-year-olds who attended the Austrian program. The teachers and pedagogues were experienced educators and had been working in the field of early childhood education for at least three years. Please refer to Chapters 4 to 6 for more details and information about all participants. 


\section{Role of Researcher}

The researcher is the key instrument to the study by taking on many different roles (Creswell 2007). In this study I had the tasks of designer, fieldworker, observer, interviewer, analyzer, and reporter. These roles have been influenced by my personal beliefs, my education, and my experience in the field of language and early childhood education. In the following section, I will discuss and ponder philosophical assumptions, the paradigm, and the framework of this study. As Creswell (2007) stated, "good research requires making these assumptions, paradigms, and frameworks explicit in the writing of a study, and at a minimum, to be aware that they influence the conduct of inquiry" (p. 15). I will discuss how my assumptions, dedication, and background apply to this case study.

Philosophical assumptions are developing, changing, and overlapping, as well as conflicting. They are the guiding thoughts of the world's evolving philosophies and of one's life and experiences, however both shape and tangle personal views. My experience of different world views has certainly impacted my assumptions and views. I lived in a communist country until the age of 17 , teaching me socialist and Marxist world views and leaving me with an interesting and unique experience and perspective. I formed mainly dualistic assumptions, which were based on a social-cultural understanding. When experiencing the changes within the German society of two German countries, there were multiple perspectives on how Germany became united. After a long reflection on the reunification of Germany in 1990, I understand now that these multiple perspectives were not discussed in a meaningful dialogue based on intercultural experiences, and in turn were not allowed room and time to develop as a process. Many sacrifices were made on either side but looking back, the feeling of being neither necessary nor useful to the new German society discouraged many East Germans and could perhaps be considered the biggest sacrifice. However, the unification between the people is ongoing and will continue for generations to come. German identity is based on so many different experiences and views that it can be defined only through a wide-angle lens while taking multiple perspectives of its society members into consideration.

I apply the same understanding to my personal identity search, which is an ongoing and everchanging process connecting the past, present and the future to life in the now. Therefore, the ontological view of reality is constructed out of multiple and subjective perspectives while creating a whole which is in the end smaller than its individual parts.

My educational experiences in Germany and the Unites States guided me in designing this study. At West Virginia University, I had the chance to experience the role of the learner and the teacher, both of which were embedded in courses I took or taught. Combining the roles of teacher 
and student into one person has been one of my educational foundations since the day I became a student at the Magdeburg University, and it has evolved and received a theoretical foundation in the paradigm of constructivism.

In the WVU German graduate program, I had the chance to explore teaching the communicative approach that is linked to the constructivist paradigm. From a student's perspective I had the chance to explore German literature and the meaning of identity, the latter of which has become a very important part of my personal teaching philosophy. Still, it felt that there were several pieces missing.

In the Department of Curriculum and Instruction/Literacy Studies, WVU, I learned about paradigms and their meaning for education, which helped me to understand the construction of society embedded in the field. Educational theories are founded on philosophical beliefs. After exploring different theories and approaches I came to the conclusion that I am an eclectic teacher and person. This means that there are truths, knowledge, and reasons for the application of all of these frameworks. In my life and work I have to make meaningful selections according to the situation and environment. I understand learning in accordance with the constructivist view as active engagement of the mind to reach deep understanding. Learning is building a rich complex structure that is nonlinear in its existence (Fostnot, 2005). To engage in learning, students and teachers alike should apply passive and active behaviors and instructional methods.

From a postmodern perspective, the world is a complex system in which these theories and practices coexist. However, modern views such as polarization and dualism will remain present within each society. The postmodern view expresses that past, present, and future coexist and influence each other continuously. Therefore, I believe that in early childhood education one has to study all approaches to construct a meaningful program as well as teaching and learning environment. Montessori, Reggio Emilia, Bank Street, Waldorf, Forest, or Summerhill methodologies exist presently, and some have a long and rich history while others are new. They have important characteristics and I as a teacher must make meaningful choices according to their application while taking into consideration the circumstances and the environment of the educational system. I also have to look to other fields to see how their knowledge and findings can be useful in the field of early childhood education. Endless possibilities and areas are available for consideration. In this study I considered the fields of linguistics, neuroscience, psychology, history, politics and policy making, and early childhood education, borrowing from them any aspects I found useful in understanding the characteristics and complexity of early childhood language learning. 
I have chosen the constructivist paradigm and how it relates to education, applying it to the educational settings and to the design of the study. I applied direct observation in the settings, while being an active participant during interviews by asking questions that informed my study as well as listening to the stories and perspectives of those interviewed. During the analysis and transcription phase I was very detailed and tried to accurately reconstruct the events as children and teachers experienced them. It is my representation of the data that was filtered through my objective perspective, and I therefore included as many voices as possible to let their realties come alive. In the analysis I applied aspects of grounded theory to present the case. While comparing my data and grounding the findings I connected them to the theory to construct a meaningful body of work. This allowed me to conclude by offering a preliminary model for early childhood language learning seen in its complexity.

\section{Data Collection}

In a qualitative case study it is crucial to collect data from different research methods.

Creswell (2007) listed observations, interviews, documents, and audiovisual materials, all of which are applied in this study. Tables 2-4 show a general overview of when and what data were collected, Table 5 provides the amount of data that was collected, and Figure 1 demonstrates how the fieldwork intertwined observation, interviews, questionnaires, and documents.

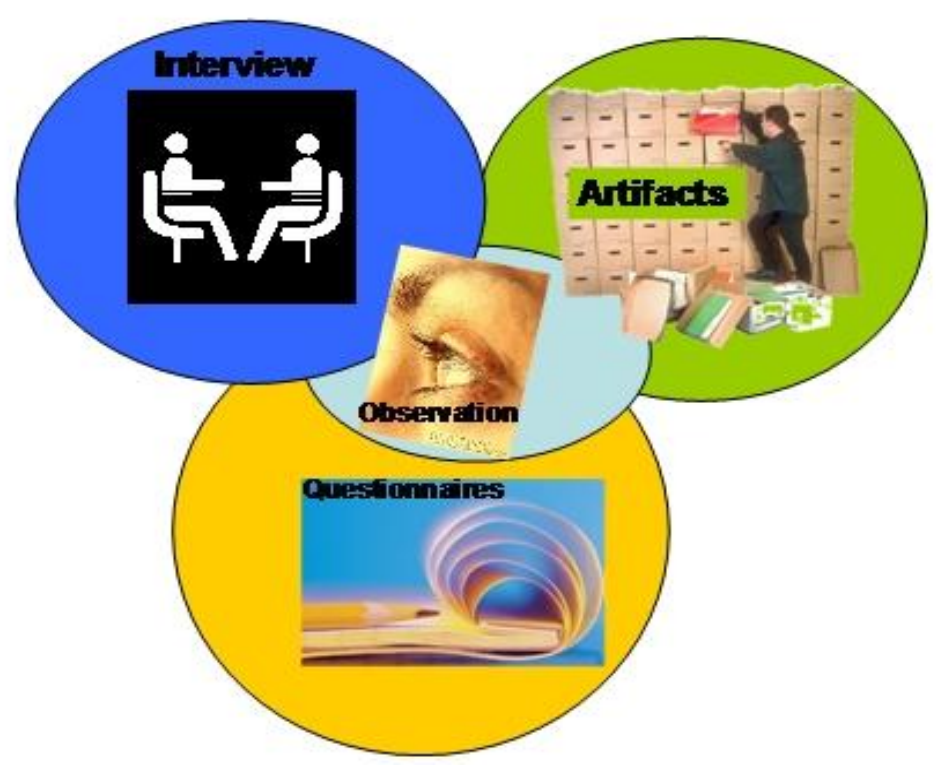

Figure 1. Visual representation of the data collection process. 
Table 5. Research methods applied and data according to research site

\begin{tabular}{|c|c|c|c|c|c|}
\hline $\begin{array}{l}\text { Research } \\
\text { Method }\end{array}$ & Germany & Austria & $\begin{array}{c}\text { United States } \\
\text { Pre-K }\end{array}$ & $\begin{array}{c}\text { United States } \\
\text { K.P. }\end{array}$ & Total \\
\hline $\begin{array}{c}\text { Days of } \\
\text { Observation }\end{array}$ & 14 & 11 & 5 & 5 & 35 days \\
\hline $\begin{array}{c}\text { Video } \\
\text { (hours of tape) }\end{array}$ & $\begin{array}{l}10 \mathrm{hr} \\
25 \mathrm{~min}\end{array}$ & $\begin{array}{l}19 \mathrm{hr} \\
6 \mathrm{~min}\end{array}$ & $\begin{array}{l}11 \mathrm{hr} \\
27 \mathrm{~min}\end{array}$ & $\begin{array}{l}11 \mathrm{hr} \\
11 \mathrm{~min}\end{array}$ & $\begin{array}{l}52 \mathrm{hr} \\
9 \mathrm{~min}\end{array}$ \\
\hline $\begin{array}{c}\text { Audio } \\
\text { (hours of tape) }\end{array}$ & $\begin{array}{l}\text { about } \\
8 \mathrm{hrs}\end{array}$ & NA & NA & NA & about $8 \mathrm{hrs}$ \\
\hline Digital pictures & 184 & 60 & NA & NA & 244 \\
\hline Analog pictures & 578 & 420 & 654 & 300 & 1952 \\
\hline $\begin{array}{l}\text { Interviews } \\
\text { (teacher) }\end{array}$ & 6 & 4 & only informal & only informal & 10 \\
\hline Field Notes & daily & daily & daily & daily & \\
\hline $\begin{array}{c}\text { Parent } \\
\text { Questionnaire }\end{array}$ & 18 & 5 & 15 & 13 & 51 \\
\hline $\begin{array}{c}\text { Teacher } \\
\text { Questionnaire }\end{array}$ & 3 & 3 & 3 & 1 & 10 \\
\hline
\end{tabular}

\section{Research Method: Direct Observation}

The direct observation method I applied to explore the daily schedule was built on a combination of video or audio-taping, taking field notes, and photographing the daily schedule and events. Moments of participant observation were present in correlation to when children were approaching me or in their conversations with the teachers.

In all three programs I applied an ease-in phase before using the video camera. This means that, depending on the group and suggestions by the educator, I would wait between one to three days before using the video camera for the first time. On the first day in the program I took field notes and pictures. Since I did not want the children to be disturbed by flash photography, and the light conditions mostly cooperated, I did not use the flash at any time to be respectful of the children and their environment.

In the German program I collected the most field notes due to the fact that I used the video tape only during outings and the enrichment program of the 5 to 6-year-olds. I collected audio files in combination with the field notes and took photographs, both of which were referenced in the field notes. During the outdoor free play time it was more difficult to take field notes due to the size of the 
open area. This was the case in all programs and all research methods. In the Austrian program, the head teacher and I agreed to wait for three days before using the video camera. I took field notes and pictures for the first three days and video-taped the daily schedule from the fourth day until the end of the study. In the U.S. program, where I first observed the preschool program, I waited for one day only because I had only four days left to collect the data before moving to the kindergarten program. The teacher and I had decided that I could start using the video camera on the first day of observation.

My initial plan of how and when to use the video camera was to alternate between afternoons and mornings starting on the first day. However this needed to be changed because not enough data would have been collected. For example, the Austrian program's layout consisted of five different rooms and three different simultaneous circle times. If I would have alternated I would not have collected enough data for each setting or part of the day. Since I spent some days upstairs and others downstairs, and observed different circle times, not all children were observed at all times. In the U.S. program, because I observed one week in preschool and one in kindergarten, I decided to use video-taping all day and every day after the phase-in period.

The reason for scheduling the video-taping was to alternate media present in the room and to identify whether students' behavior is altered through the use of multi-media. In the end, there was no reason for concern since the children were very accustomed to many different kinds of media. When parents observed their children they took pictures and video-taped the daily schedule for their personal use. At the U.S. institution, parents wanted to send this home to their families in Europe. The children were sometimes impacted and interested in what their mother was doing. In my case the children's learning was not disrupted nor did they pay particular attention to my presence. If they did, it was not during the instruction or during focused free play time. I observed little or no change in their participation and behavior during planned activities. Since the students had time to ask questions and were introduced to the study on the first day, there were no major variations in their normal behavior. This corresponds to the experience presented by Patton (2002), who stated:

We had great success taking videos of mothers and children playing together in early childhood education centers. Of course, use of such equipment must be negotiated with program staff and participants, but the creative and judicious use of technology can greatly increase the quality of field observations und the utility of the observational records to others. (p. 308)

Another organizational aspect that had to be changed was my plan to use a tripod and place it in different areas prior to the daily arrival of the students. However, my intentions of using a tripod proved impossible due to space confines and my unwillingness to disrupt the children's environment 
and also due to the size of the room itself or the fast pace of the early childhood environment. I decided instead to hold the camera, thus opening up much more space and retaining flexibility in the recorded view point. Therefore, my ability to take notes or pictures was impacted in situations where I was not able to put the camera down. There are situations and moments when I wanted to take a picture or write down notes but could not do so while filming. Instead, I added field notes after the particular event. Generally, I was able to take a few notes or pictures and video-tape at the same time.

The participating research sites were not in my local area. Therefore, I did not have sufficient equipment while traveling to transfer the video tapes onto DVDs. I had to begin this process after returning home using a DVD recorder to burn DVDs of the data so that it would be viewable on a bigger screen and easier to analyze. For each program, I organized the data according to the day and schedule while creating titles for each segment for better accessibility. I collected about 52 hours of data, which is described in more detail in Table 5. I made additional copies for data protection and backups and for each program. The programs' administrators eagerly accepted my offer to send copies of all photographs and video data for their records. I sent these copies once I had all the data transferred and the photographs developed.

\section{Research Method: Interview and Questionnaires}

The interviews were administered to gather information beyond what was taped and written. The scheduled interviews with administrators and teachers were formal guided conversations. I used a partially structured approach with open-ended questions that the participants where familiar with because I had provided these prior to the interview. I used the questionnaires to prepare myself and also to add specific questions I had derived from the questionnaire or my observation.

In the German program, I scheduled the interviews according to the program director's suggestion, during the second week of observation from 1 to 2 p.m., when the children had naptime or enrichment period. The interviews lasted between 30 to 45 minutes depending on the person interviewed. I applied the method of purposeful sampling in choosing all educators working with the group. I also invited the other educators to participate, and they agreed. Thus, I conducted six interviews of which I lost the information of the first one due to technical problems. Fortunately, I was able to reconstruct the main points with the help of the interviewee and my notes. The interviews were conducted in a small room on-site which offered privacy and assurance that there were no interruptions (see Appendix). 
In the Austrian Program I conducted four interviews. These were scheduled after 2:30 p.m. once the official schedule was over. I interviewed the teachers responsible for the three circle times and then asked the other teachers if they would like to participate. One other teacher had the time to do so. The interviews were conducted in the cultural studies room.

In the U.S. program I interviewed the two main teachers but, due to a mistake during the data transfer onto my computer, I lost the files and these were not retrievable. However, I had many informal interviews about which I had taken notes and with the help of their questionnaires, I constructed the main information during the analysis process.

Questionnaires were used for collecting data from the administrators, teachers, and parents (see Appendix). The use of questionnaires is not a common practice in qualitative research due to their connection to the positivistic research paradigm. Merriam (2007) stated that "unlike experimental, survey, or historical research, a case study does not claim any particular methods for data collection or data analysis. Any and all methods of gathering data, from testing to interviewing, can be used in a case study" (42). I found that the information about the students' languages, their preferences, learning experiences, and surrounding environment provided by the parental questionnaires was essential to conducting meaningful data analysis.

The questionnaires were designed with the constructivist paradigm in mind, using openended questions, while only a small portion of information drew on multiple choice answers. I utilized the questionnaires for administrators and teachers as a preparation for the interviews and asked questions about specific information I needed clarification on and had further interest in. Not all teachers had the time to fill out the questionnaires prior to the interview, which had no effect on the interview.

In the German program I handed out the questionnaires to the educators in the program on the first day of arrival, and to the parents or guardians of the observed group during the first days. It was my intention to introduce myself to the parents and answer questions they might have. There were rarely questions due to the support and preparation of the study which was given by the program director and pedagogues. For the group I was not observing, the pedagogues handed out the questionnaires. In the Austrian program, the process was different because of the organization, structure, and schedule of the program. I handed out several questionnaires directly to parents and left the rest on the bulletin board for the remaining parents, but I only received 5 of the 45 . This led me to change my strategy for the U.S. program, where I attached the questionnaires to the parental or guardian consent and information forms which were mailed to the program four weeks prior to the start of the fieldwork. The teachers collected the consent forms prior to my arrival and I received the 
30 consent forms with only two questionnaires missing and two that were only answered partially (see Table 5).

\section{Documents and Artifacts}

Documents were provided by each program. In the German program the director provided the kindergarten's concept, general information about the city's program that included statistics on the staff, fees, and approach, and information about the project "English in kindergarten." The Austrian program provided some event schedules and a summary of their concept, and from the U.S. program I received the parent guide book that they publish every year.

I took pictures of the artifacts, such as student paintings, craft projects, and evaluation charts. These pictures provided information on how children liked the main project of the day while at the same time showing how the development of building projects grew throughout the week to demonstrate the learning process. The researcher-produced photographs were taken daily in combination with using audio-visual and/or visual equipment and field notes to accommodate future referencing.

The study gained on validation, credibility and transferability through the triangulation of these research methods in the data collection and analysis. It is important to understand that the different types of data collection do not have to reveal the same findings, but rather offer a deeper and more realistic understanding of the studied phenomenon.

\section{Analysis}

Observation and analysis were difficult to separate while conducting this study, supporting Patton (2002), who stated:

...the fluid and emergent nature of naturalistic inquiry makes the distinction between data gathering and analysis far less absolute. In the course of fieldwork, ideas about directions for analysis will occur. Patterns take shape. Possible themes spring to mind. ...earlier stages of fieldwork are generative and emergent ...later stages ...confirming (or disconfirming) patterns that seem to have appeared. (p. 436)

Therefore, I applied aspects of grounded theory to engage in the analysis process. Glaser and Strauss (1967) defined grounded theory as a "general method of comparative analysis" (p. 1). This method receives theory from the obtained data that is then demonstrated by the characteristic examples of the data. They defined the need for combining data collection, coding, and analysis to generate theory. The constant comparative aspect has four stages: "1) coding leading to categories 
and a description of the categories, 2) integrating categories and their properties, 3) delimiting the theory, and 4) writing the theory (Glaser \& Strauss, 1967).

I applied grounded theory to the analysis in this study through finding general codes and structures and reducing the number of codes to derive categories within the obtained data. I made conscious choices in the selection of observational situations throughout the data collection. With this method I found, through the application of systematical comparisons of the data results, a preliminary model of the complexity of early childhood language learning in relation to its features and components.

Therefore, I approached the analysis of the collected data from two angles: 1) a general emerging theme-based approach while located in the field and 2) a specific theme-based approach established during transcription, transferring, and analysis of collected data. The first angle was applied to the observation of the German and Austrian programs that were scheduled from June 16 through July 15, 2005. I looked for emerging themes that were connected to early childhood language learning and created a list. I then used the list of themes as a starting point for the second angle. This is a very long-lasting and intensive process in which careful application of coding leads the researcher to understand the collected data.

\section{Video Analysis}

I started the extensive screening process of the video tapes after returning from the first two research sites. I watched the tapes several times while taking notes in order to narrow the selection to the information provided in Chapters 4 to 6 , keeping in mind the research questions and themes that had emerged during observation and adding new codes and themes. Afterwards the data was transcribed in detail which demanded additional watching of each part several times. I reviewed the material one final time to check for errors before I began the detailed analysis using the list with themes as codes and adding new ones as necessary. I then narrowed and organized the codes according to nine categories: program, language used, situation, language medium, language function, language characteristics, content, role of teacher, and role of student.

\section{Interview and Questionnaire Analysis}

I transcribed the interview data from tapes or digital recordings in their original language, either English or German, into Excel worksheets noting the time and applying the codes I had established or adding new ones as needed. The transcribing process was long. First, I entered rough notes while screening for important information and adding codes from the established list. When I 
returned for fine editing I concentrated on the coded areas while checking the encoded ones to see whether my opinion had changed. The final read through checked editing and the un-marked areas. If the quote of a German speaker was to be used in the study I added the English translation as needed.

For the questionnaire data I also used electronic spreadsheets and made graphics for sections concerning the language spoken and used at home. I translated the German information for consistency of language.

\section{Artifact and Document Analysis}

I analyzed the provided documents according to the information that would yield general information about the program and information that was concerning early childhood language learning, which I included in Chapters 4 to 6.

The photographs taken of the daily schedule, learning situations, and rooms were selected according to each component of the daily schedule. As needed, pictures were scanned, labeled, organized according to school, and separated in folders. I had decided to take an abundance of pictures in order to provide a visual support of the events for my personal records. However, this has developed during the analysis into the idea that the inclusion of photos throughout the dissertation will allow the reader to create her own storyline or fact check the presented description.

\section{Validation of Study}

Creswell (2007) lists the following procedures under validation: prolonged engagement and persistent observation, triangulation, peer review or debriefing, rich and thick description, negative case analysis, clarifying of researcher bias, member checks, and external audits. He suggests that researchers utilize at least two of the following procedures to add rigor to the study. In this study three of these procedures were implemented.

Triangulation has been explained under the section on data collection and analysis. The second aspect that I have selected is the thick and rich description of each participating research site. The portrait of each early childhood program can be found in Chapters 4 to 6. It was my intention to give the educators and children their own voice and allow them to come to life through the use of dialogue. Additionally, readers should have the chance to create their own story not only through the provided dialogue synapses but also through the use of photographs; I have included collages as a visual representation of the daily events, programs, and artifacts. Through the interlacing of the dialogue, photo collages, and narrative descriptions of events, settings, and programs, I have tried to 
offer different angles in the written and visual storyline, providing a detailed and meaningful description.

As third aspect of validation I have selected identifying the researcher's bias. At the beginning of the study, I have stated my views and beliefs of the enrichment of education and personal growth for any student through learning language at any stage of their lives. This study focuses on early childhood language learning and multicultural education because I am a strong advocate of both. It is understood that my views and beliefs may influence the collection and interpretation of data, which makes it even more necessary to implement other elements of trustworthiness to reach validation. 


\section{Chapter 4: Austrian Program Data Presentation - Montessori Kindergarten}

\section{Introduction}

The kindergarten is a private institution in a metropolitan city that was founded in 1992. The program started with nine children in a one family home that was converted into a kindergarten. As the demand grew and the neighboring house became available, a second house was added. In November 2004 the kindergarten received the Montessori Quality Seal by the German and Austrian Montessori Society. Today, the program facilitates up to 110 children in the two houses during the regular school year, which starts in September and ends at the end of June. In the summer months the attendance changes daily due to vacation time and new children entering into the program. The tuition fees run about $€ 510$ per month per child with available afternoon care at additional cost.

\section{Concept and Curriculum}

The program applies the English-language immersion approach. The teachers use the target language all day and are native speakers or have native-like language abilities. Through the application of the target language rule the children are asked to use English inside the house while they can use their mother tongues or English according to their needs in the garden.

The curriculum is based on the Montessori method and the learning activities for this year were guided and arranged in accordance with this year's theme: "From the Milky Way to our city." The head teacher, also the founder and owner of the kindergarten, describes some features of the Montessori method and the program's personalized approach:

For me the most important things they do here ...is the idea of deciding and thinking for themselves. Being independent. Doing things for themselves. Learning things by doing them. By using their hands. By working things out for themselves and also by helping others. A very important part is the consideration for others. The respect for others. ... Also the idea of creativity used in a very useful way. Being able to put things together, work them out, and explain what they did. ... Their opinions are very important to us and respected by all children. Each one gets their turn and everyone is listening.

The program offers regular outings in the city and its surroundings (see Figure 17), cultural celebrations like important heritage festivals, one yearly scheduled weekend trip, and organization of plays and concerts. These outings and events are strongly supported and aided by the students' parents. 


\section{Daily Schedule}

The kindergarten opens everyday at 8 a.m. and all children should be present by 8:30 a.m. The day starts with uninterrupted work time that lasts for $2 \frac{1}{2}$ hours during which the children work on activities alone or participate in small groups. Around 11 a.m. the morning circle takes place lead by one of the teachers. The children greet each other through a welcome song then the teacher takes attendance, makes announcements, and birthdays of the children or teachers are celebrated. This is followed by outdoor play time that lasts about 40 minutes. The group circle times start just after 12 a.m. and last for about one hour. The groups are coordinated according to age: the blue group (BG) ages 2-3 years, the yellow group (YG) ages 4-5 years, and the red group (RG) ages 5-6 years. After circle time the children have lunch in their groups, then outside play time from 2:00 to 2:30 finishes off the kindergarten day.

\section{Teachers}

Six teachers are in the house where I conducted research. The head teacher holds a Montessori International Center Nursery Teacher Diploma and a B.A. in German and French. The other teachers are certified and hold an Austrian early childhood educator certification or certifications from other countries such as Britain, South-Africa, and New Zealand. All teachers need to have or are working on their teaching practice certification by the Montessori International Center, which is based in London and offers long distance certification. The overall student-teacher ratio is 9 to 1 but it is influenced by segments of the daily schedule. For example, during the uninterrupted work time the children follow their interest in which subject area they would like to work. Therefore in the mathematics room there may be only five children working on activities while in the art room there may be twelve.

The teachers are each responsible for one of the thematic rooms: practical life, mathematics, language, culture studies, and art. One additional teacher works in the practical life room. For three weeks they have all the responsibilities that the room brings with it including caring about the activities, changing activities at the end of the week, and planning and leading the group circle time. The circle time for the blue group is in the practical life room, the yellow group's is in the math room, and the red group's is in the cultural studies room.

\section{Children and Parents}

The children enrolled in the study went to house one and attended the program from 8:30 a.m. to 2:30 p.m. They address their teachers by first name. Fifty-one children were enrolled and, 
due to the summer program, a few newcomers were admitted. Their age ranged from $2 \frac{1 / 2}{2}$ to $6 \frac{1}{2}$. The children are grouped by age only during group circle time and lunch (see Tables 6-8). They come from a wide range of international backgrounds. The children are accepted into the program after an application process. The children are mainly dual language learners and speak two or more languages. The list of mother tongues includes German, English, Spanish, Japanese, Korean, and several others. The information about the languages of the children was provided by the programs' records and documentation of the children.

Table 6. A.P.: Blue Group Children

\begin{tabular}{cllcc}
\hline & Name & Languages & Age & Gender \\
\hline 1 & Ann & 1. German (English) & 2 & $\mathrm{~F}$ \\
2 & Annina & English/ German & 3 & $\mathrm{~F}$ \\
3 & Daniel & German/ English & 2 & $\mathrm{M}$ \\
4 & Johannes & 1. German, 2. English & 3 & $\mathrm{M}$ \\
5 & Christine & 1. German (English) & 3 & $\mathrm{~F}$ \\
6 & Domonkos & 1. Bulgarian, 2. German, 3. English & 2 & $\mathrm{M}$ \\
7 & Paula* & 1. German & 3 & $\mathrm{~F}$ \\
8 & Almaz & 1. Amharic, 2.English & 3 & $\mathrm{~F}$ \\
9 & Manuel & German/ English & 2 & $\mathrm{M}$ \\
10 & Liam & 1. Malayalam, 2. English. & 3 & $\mathrm{M}$ \\
11 & Monika* & 1. German & 3 & $\mathrm{~F}$ \\
12 & Ji-Sung & 1. Korean, 2. Swedish, 3. English & 3 & $\mathrm{M}$ \\
13 & Oliver & English/ German & 4 & $\mathrm{M}$ \\
14 & Sophia* & 1. German & 3 & $\mathrm{~F}$ \\
15 & Tamila* & 1. German & 3 & $\mathrm{~F}$ \\
16 & Toni & 1. German, 2. English & 4 & $\mathrm{M}$ \\
17 & Zachariah (Zach) & 1. English & 3 & $\mathrm{M}$ \\
18 & Cloe* & 1. German & 3 & $\mathrm{~F}$ \\
\hline
\end{tabular}

Explanation: 1. Fist language, 2. Second Language, 3. Third Language;

Language/Language: bilingual family while first language is the one preferred by the child; (language) some language skills, * just started in program, ** only attending during the summer month; 
Table 7. A.P.: Yellow Group Children

\begin{tabular}{cllcc}
\hline & Name & Languages & Age & Gender \\
\hline 1 & Dimitar & 1. Bulgarian, 2. German, 3. English & 5 & $\mathrm{M}$ \\
2 & Marlene & German/ English & 5 & $\mathrm{~F}$ \\
3 & Alexandra & 1. English & 4 & $\mathrm{~F}$ \\
4 & Jasni & 1. Malayalam, 2. English, 3. German & 5 & $\mathrm{M}$ \\
5 & Juliane & 1. German, 2. English & 5 & $\mathrm{~F}$ \\
6 & Jonas & German/ English & 5 & $\mathrm{M}$ \\
7 & Christopher & 1. German, 2. English & 4 & $\mathrm{M}$ \\
8 & Chung-hee & 1. Korean, 2. English & 5 & $\mathrm{M}$ \\
9 & Dana & 1. German, 2. English & 4 & $\mathrm{~F}$ \\
10 & Maria & 1. German, 2. Hebrew, 3. English & 4 & $\mathrm{~F}$ \\
11 & Molly & 1. English, 2. German & 4 & $\mathrm{~F}$ \\
12 & Emma & 1. English & 5 & $\mathrm{~F}$ \\
13 & Alicia & 1. Spanish, 2. English & 4 & $\mathrm{~F}$ \\
14 & Conrad & 1. German 2. English & 4 & $\mathrm{M}$ \\
15 & Adam & 1. English & 5 & $\mathrm{M}$ \\
16 & Severina & 1. English, 2. German & 4 & $\mathrm{~F}$ \\
17 & Ramona & 1. English, 2. German & 5 & $\mathrm{~F}$ \\
18 & Dileep & 1. Malayalam, 2. English, 3. German & 5 & $\mathrm{M}$ \\
\hline
\end{tabular}

Explanation: 1. Fist language, 2. Second Language, 3. Third Language;

Language/Language: bilingual family while first language is the one preferred by the child; (language) some language skills, $*$ just started in program, $* *$ only attending during the summer month;

Table 8. A.P.: Red Group Children

\begin{tabular}{cllcc}
\hline & Name & Languages & Age & Gender \\
\hline 1 & Andy & English & 6 & $\mathrm{M}$ \\
2 & Micheala & 1. German, 2. English & 6 & $\mathrm{~F}$ \\
3 & Chendra & 1. German, 2. English & 6 & $\mathrm{~F}$ \\
4 & Vicky & 1. English, 2. German & 5 & $\mathrm{~F}$ \\
5 & Emilia & German/ English & 5 & $\mathrm{~F}$ \\
6 & Nanako & Japanese (English) & 5 & $\mathrm{~F}$ \\
7 & Lea** & German & 6 & $\mathrm{~F}$ \\
8 & Mindy & 1. English, 2. French, 3. German & 5 & $\mathrm{~F}$ \\
9 & Natalie & 1. German, 2. Hebrew, 3. English & 6 & $\mathrm{~F}$ \\
10 & Rico & 1. German, 2. English, 3. Spanish & 6 & $\mathrm{M}$ \\
11 & Nadine & 1. German, 2. English & 6 & $\mathrm{~F}$ \\
12 & Lucas & 1. German, 2. English & 6 & $\mathrm{M}$ \\
13 & Teresita** & 1. Spanish, 2. English & 5 & $\mathrm{~F}$ \\
14 & Matti & 1. German, 2. English & 5 & $\mathrm{M}$ \\
15 & Avah & English & 6 & $\mathrm{~F}$ \\
\hline
\end{tabular}

Explanation: 1. Fist language, 2. Second Language, 3. Third Language;

Language/Language: bilingual family while first language is the one preferred by the child; (language) some language skills, * just started in program, $* *$ only attending during the summer month; 
From the parental questionnaire distributed to all caregivers and parents of all children in the program, I received five questionnaires representing five children. The responses show that the German language has a dominant role in the lives of four children (see Figure 2). However, since this is a very small sample it is not representative for the entire program. One child is growing up bilingual at home using both German and English, while one child uses, according to the parents, Korean language only.

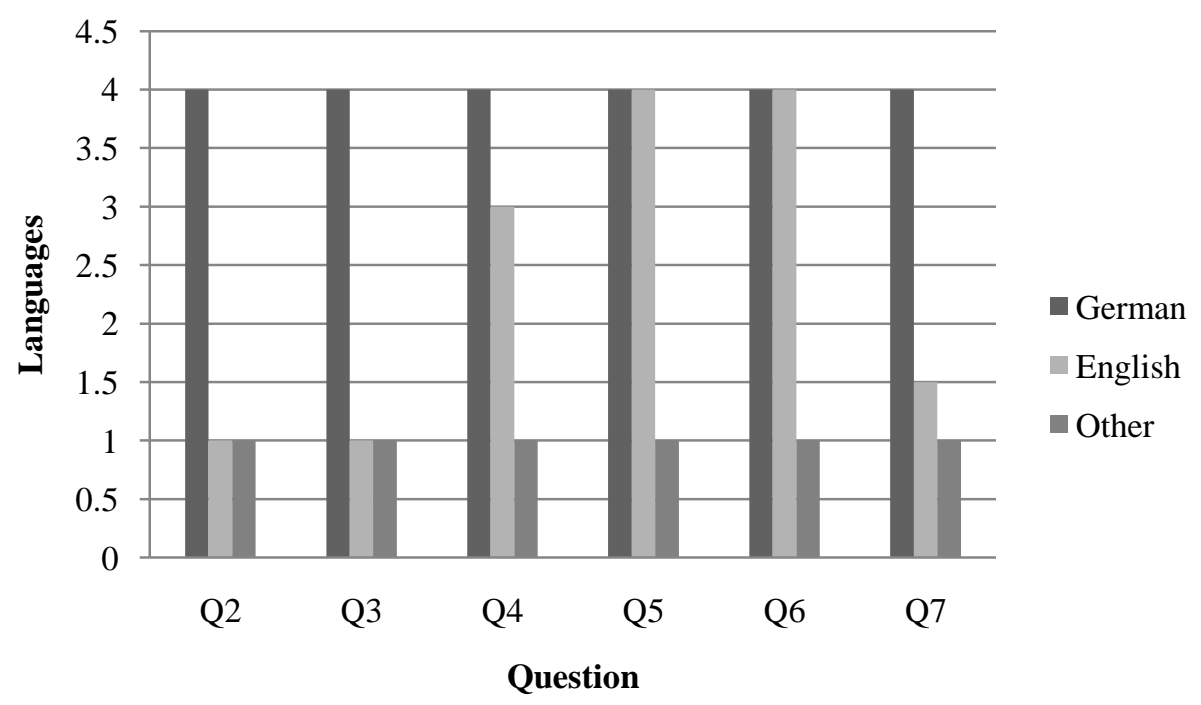

Figure 2. A.P.: Answers given by parents in the questionnaire. The following questions were asked: Q2: What language(s) are spoken at the child's home? Q3: What language(s) did your child know prior to kindergarten? Q4: What language(s) are mainly used in conversation with your child? Q5: What language(s) does your child understand? Q6: What language(s) does your child speak? Q7: What is your child's language preference? Under Other languages the following language were listed: Q2, Q3, Q4, Q5, Q6, and Q7: Korean.

Parents answered the question "Why did you choose this program for your child's education?" by giving the following reasons:

- $\quad$ Since English is the \#1 world language and will possibly remain that way, she will surely have an advantage one day when she is able to speak fluently. A part from that, the Montessori approach meets my own values and ideals.

- $\quad$ 1. Montessori, 2. Foreign language, 3. Cosmopolitan world view through multicultural children

- To get advice how on my child uses English more efficiently.

- Language, location Montessori, proximity, English

Parents see the role of early childhood language learning in the program as very important (see Figure 3), and predominantly name it as the main reason for selecting the program for their child's education. 


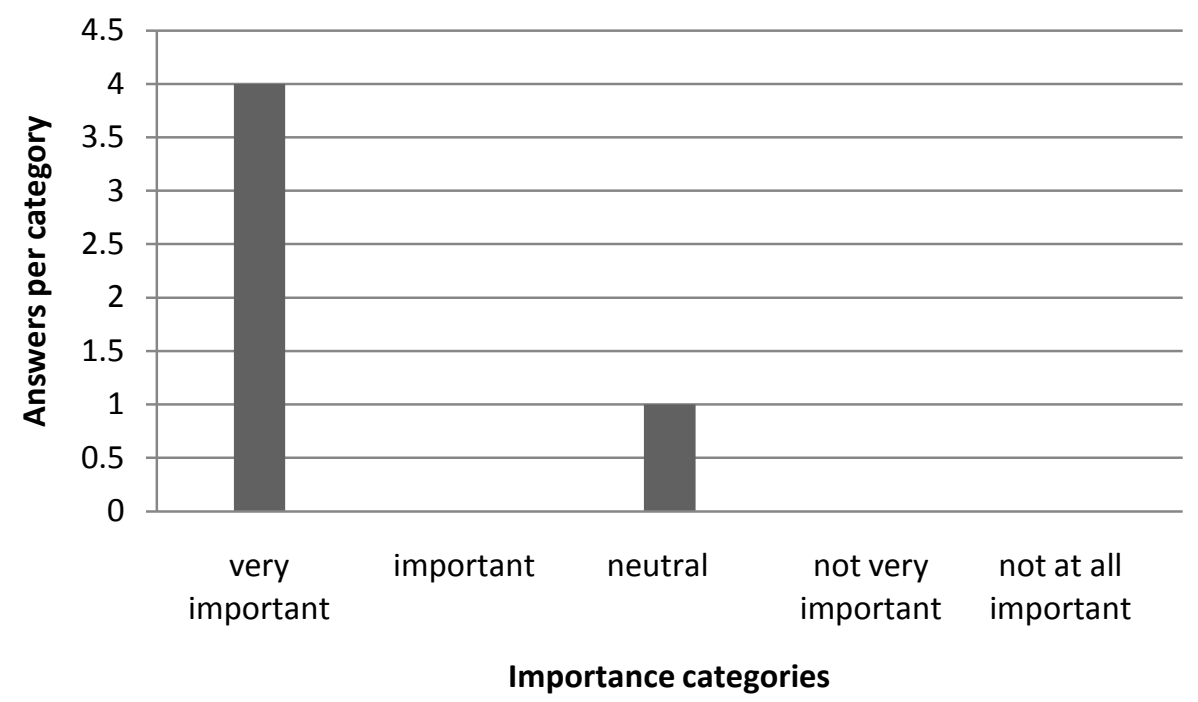

Figure 3. A.P.: Parents' answers to their perceived importance of world language learning in kindergarten.

\section{Physical Layout}

\section{General Information}

The house has five instructional rooms. Each of the rooms features a different Montessori curriculum subject area. On the first floor (see Figure 18) are practical life, math and language. Cultural studies and art are on the second floor (see Figure 19). The art room is a unique component of this school because normally art and music are integrated in the general Montessori curriculum rather than taught separately. The sensorial curriculum activities are spread out across all rooms. Each room has low open-shelves with activities according to the room's theme, a few sensorial activities, child-size furniture, baskets with rugs for activities, and art work including pictures or posters on the walls. None of the instructional rooms have doors. The rooms have a nice natural glow due to the big windows.

\section{Entrance, Cloakroom, and Hallway}

At the entrance of the kindergarten, the children take their name card out of the alphabetized card organizer and place it in their group basket. A magnetic white board that has information about the monthly outings, group structure, and other needed information greets the parents. Then they walk half a staircase down to the cloakroom that is located in the basement. On the walls are $5 \times 7$ portrait pictures of the children with their names below and a drawing by the child of themselves above. These are organized by age starting with the oldest and ending with the youngest, which is a 
great idea because one only has to move the numbers of the age forward when the children have a birthday. On the opposite staircase wall a poster of a political world map is displayed with the countries' flags, the native language, and the expression for "welcome" in the country's language. A piece of thread starting on the flag leads to the country on the map. The pictures and the world map lead the parents and children from the rain boot shelf to the left into the cloakroom where each child has a small cubby area with their name. The room is filled with cubbies around all the walls. The children can store their coats, snack boxes, their shoes, and whatever they bring. It is custom to wear different shoes in the house than they wear outside. More art work of the children is on display above the coat hooks and the windows are open to let in fresh air.

Returning to the entrance a poster displays the kindergarten's visit of an outdoor play, drawing the visitor's attention. Up another half staircase leads to the first floor and another political world map shows each child's national flag such as Australia, Austria, Egypt, Ethiopia, Great Britain, Canada, Germany, India, Iraq, Lebanon, Nigeria, South Korea, Sweden, and the USA.

In the hallway of the first floor you can see six entrances leading to language, mathematics, kitchen and storage, imaginary play, practical life, a rest room, and next to it the stair case to the second floor. Only the kitchen and the rest room have doors. In between the kitchen and imaginary play area is a shelf with small cubby trays for the children, on top of which are beautiful seasonal flowers and an orchid. On the wall is a picture frame with great close-up shots of a yellow dandelion, a pretty daisy, and a bunch of chamomiles.

\section{Practical Life Room}

The practical life room (see Figure 4) is the biggest room and expands from the front to the back of the house. Two tall windows are on either side and plants lie on the window sills. As one enters the room, a basket with rugs is to the left and next to it a taller shelf. The top part is used for teacher's materials, and above is a pin board for documentation and teacher information. The lower half has wooden knob puzzles and a basket with a butterfly sorting activity. The attached shorter shelf has one of the knobbed cylinder block sets on each tier, sound cylinders - red and blue, and next to it stands the piled up pink tower. Another shelf lies a couple of feet away, placed perpendicular extending into the room to serve as an area divider. On top of the shelf are the teacher's small circle time preparations and the CD player; below are the brown stairs, the introductory color tablet set, and several shape puzzles. Above the area hangs the growing weather calendar. Just below the ceiling hang six differently colored panels about 6 inch by 8 feet representing January through June. Each 
panel has the days of the month and weather symbols attached for each kindergarten day. The July panel is still on eye level with the children so that they can attach the symbols.

A carpeted play area (about $5 \times 5$ feet) is in the corner with a big window above. It has two stacked boxes filled with wooden building blocks, Lego blocks, and toys. Three stacked dressing frame cubes and a pillow basket serve as area divider on the other side. Next to this are a chair and a child-sized sofa standing on a small runner, above which is another window. A tall but slender fichus tree is placed in the corner and a book shelf sits next to it. The book selection includes: Let's Go Home Little Bear, Kipper's Toy Box, Red Is Best, My Granny's Motor Car, Monkey Puzzle, Ketchup Your Cornflakes, A Quiet Night In, to Brown Bear, Brown Bear, What Do You See?. A table with one chair provides an individual workspace and closes off the reading area. On the table are a cork frame and a basket with colorful glass gems.

A big rectangular table is placed lengthwise against the wall and provides seating for four children. A writing area is next to the table. On the top shelf are baskets, trays, and markers and big colored pencils in color coordinated jars. Below are two wooden organizer stands with scissors and glue, and a big basket with scrap paper and letters. The next tier has two trays, each holding a container with play dough and a basket with a rolling pin and letter cookie cutters. On the lowest tier is a collection of different papers in baskets.

The next two shelves host different practical life materials such as pouring, scooping, sorting, and polishing activities. Each activity is displayed on a small tray. For example: a mirror and a silver bowl polishing set, a two big plastic pitcher set with glass gems, a lentil pouring set with saucer and small bowl, a color sorting scooping set with color bowls, a marble sorting set, a clothes pin set, and a few other similar activities.

Next to the shelves is a table with dish washing activities where the children can wash and dry their used dishes from snack time. There are two dish washing bowls, one with soap and one with clear water, a drying rack, a small basket with a wash cloth, and a drying towel hung on a hook on the wall. The snack table is next to this in the corner and has two benches and two chairs. The table is covered with a tablecloth and a small plant sits in the center. One window oversees the table, where the children can enjoy a view into the garden while eating their snack. The access to the dish washing station is from the snack area. Tea and water pitchers, glasses, plates, cutlery, and napkins are placed on a smaller shelf in front of the station.

On the other side of the snack table and closing off the snack area is the hand washing activity with a plastic bowl, a pitcher, a soap dish with soap and hand brush, and a folded guest towel. Next to it is the laundry station that has two rectangular bowls, one with a wash board and the other 
one empty, two small baskets, one with wash soaps and the other with clothes pins, and a towel. Below the station are buckets with clean and soapy water. Next to the station is the laundry drying rack.

In front of the next window is the ironing board with a small cordless metal iron and a few articles of clothing. In the corner is a door leading into a small bathroom containing all the toothbrushes of the yellow group. Next to the door and across from the washing station is the art station - an easel with paper and red, yellow, green, and blue paint with color coordinated brushes ready to go. The art apron hangs across the easel and on the wall next to it is a hook with a thin rope that leads up to the ceiling where drying pictures hang around the drying rack. Next to the easel is a table with four chairs, and on the wall are two more shelves. One shelf has art supplies such as big bottles of paint and baskets with paint brushes and palettes, small and big buckets, cleaning cloth, and so forth. The other shelf has more activities for children such as a water transferring set with two small bowls, a baster, and a sponge; a color writing set; more color sorting and water activities, a lacing set with yarn and lacing boards, and a bead lacing set. The middle of the room remains empty to provide space for the big circle time around 11 a.m., when all the children in the house congregate in this room. Off to the side of the washing station is another rectangular table that seats six children.

The play area is $4 \times 6$ feet and has two mirrors on the opposing walls, a table in the corner, a small chair, and a stool. Across from these is a small dresser with a phone on the top. Next to this lies a small wooden bed in which two baby dolls, one white and one black, are resting, and a coat rack with hangers and dress up clothes. 

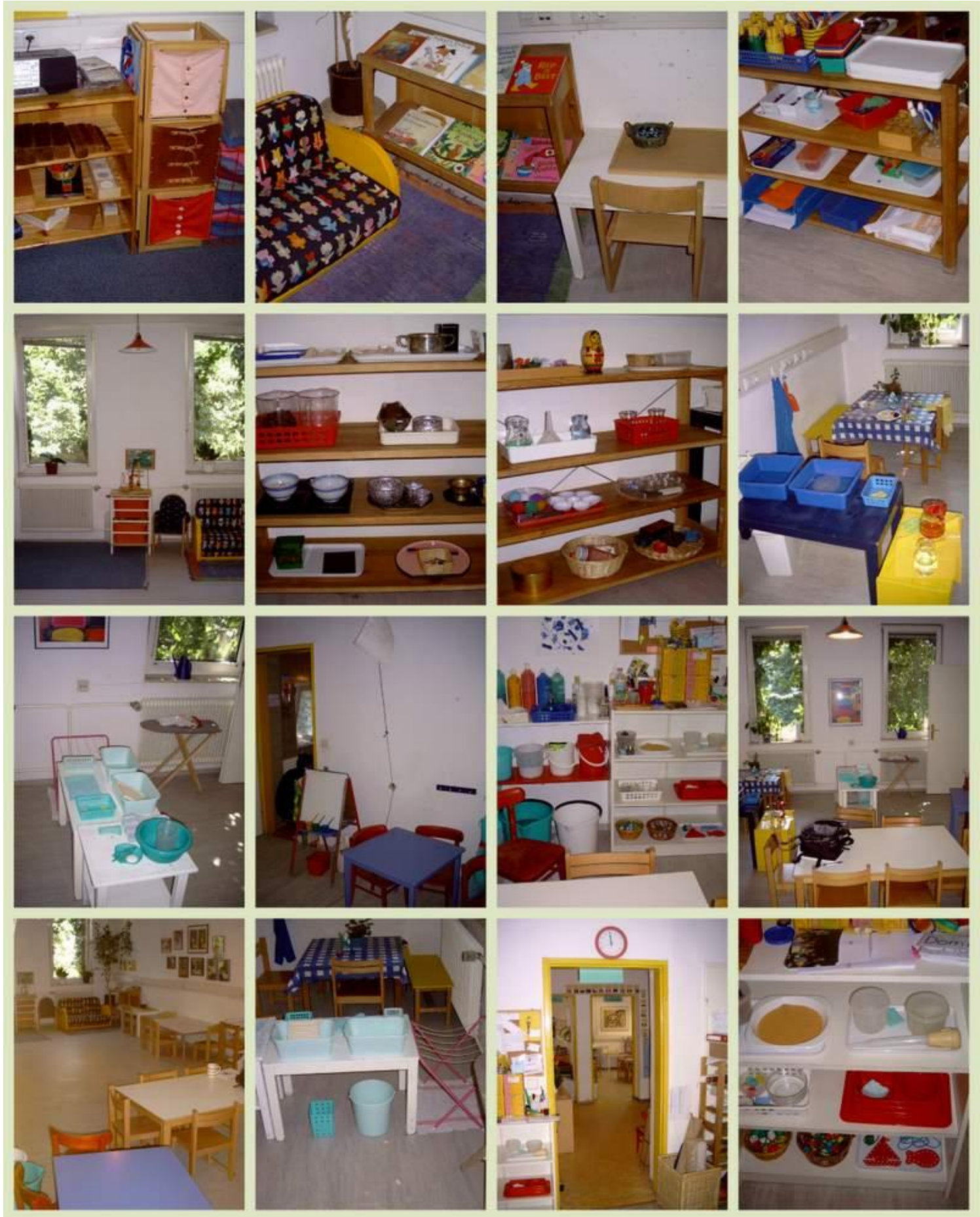

Figure 4. A.P.: Practical life room layout with centers and offered activities. 


\section{Mathematics Room}

As one walks into the Math room, there is a basket with pillows to the right and a shelf with math activities in small wooden boxes such as number cards with counters, wooden number blocks, number boards with and without circles, a multiplication and a division bead board set, and the Bank Game. A second shelf has red and blue rods with numbers, a spindle box, and a small one hundred board, addition strip board, addition working chart, subtraction strip board, and subtraction working chart and other Montessori math activities. Above are numbers posters from 1-10 and in front of the shelf stands a table with four chairs. A small fichus tree stands in the corner next to the window and below is a small white table with a paper organizer. A two tier shelf is placed next to it and has metal fractions circles on two stands and two baskets on top. On the tier below is a geometric cabinet with metal insets and a tray, and on the bottom tier is a basket with blue geometric solids and several cubes such as the power of two, the binomial, and the trinomial. Above the shelf is a poster with a variety of triangles.

In the window bay, which is similar to the one in the language room, is a child-sized wicker bench, a small book rack, and another two tiered shelf below the middle window. It has long wooden rods on top, and a Constructive Triangles set with five different shaped boxes and a set of weight cylinders in four boxes with activity charts. The next window sill has colored pencils arranged in their color-coordinated stands and below stands a very small shelf that has placemats on top, pencil holder baskets, and a paper tray with different copies. Next to it is a taller shelf that has baskets with pattern blocks, trays with pattern block activity charts, a bear counting activity, a WEDGiT ${ }^{\mathrm{TM}}$ starter set, sorting activity, and more wooden block activities.

The wall next to the window bay has bead chains hung on a rack and above additional beads are placed on a small shelf. A small bathroom is off the corner of this room. Another shelf is next to it which has several activities such as apple tree counting set and geoboard sets. Next to it is a table placed against the wall and three chairs. There are two tables with four chairs each next to the activities areas.

\section{Language Room}

As you enter the language room (see Figure 5) an alphabet poster with pictures is displayed on the wall at the children's eye level. Above hangs framed art work, next to which is a hatch that holds a green fern and allows teachers to look into the Math room next door. Below the hatch is a shelf with metal insets, baskets, trays, paper, color-coordinated glass pencil holders, and a few other writing utensils. Next to the hatch are big crayon cutouts with the name of the color and a symbol in 
the same color. A table with two stools and an orange sofa fill the rest of the wall space. A small moveable book stand is placed next to the sofa and has about twelve books such as Aaron's Hair, Noisy Nora, Sing, Sophie!, and Bear on a Bike. The window above has three plants and provides natural light for the small reading area. Another small table and stool is placed next to the shelf that hosts the listening station with a CD player and a basket with audio stories and books. There are several language activities such as labeling of everyday kindergarten objects, storytelling kits, songs, finger play, rhyme activities, and word puzzles.

The window bay area contains three shelves as well as a basket of rugs and provides the majority of natural light for the language room. The first shelf has a big collection of beginning readers books and the second has a moveable alphabet and pink and blue boxes with word card activities. Next to the window is a small step stool at the bye-bye window. On the wall below are five small lists containing words for each of the vowels. On the window sills are more small plants and in the third shelf is a collection of green box word card activities.

The next shelf has sandpaper letters - blue for consonants and red for vowels - and small containers with matching objects. Other activities on the shelf are sand writing and drawing boxes, initial sound recognition with matching objects muffin tray, a chalkboard tray, and a world building tray with alphabet. Above the shelf the alphabet signs are hung at the children's eye level. There is one table with four chairs in front of the shelf and another table a few feet away in front of the teacher and organization shelf, which contains the name cards of the children present throughout the day. 


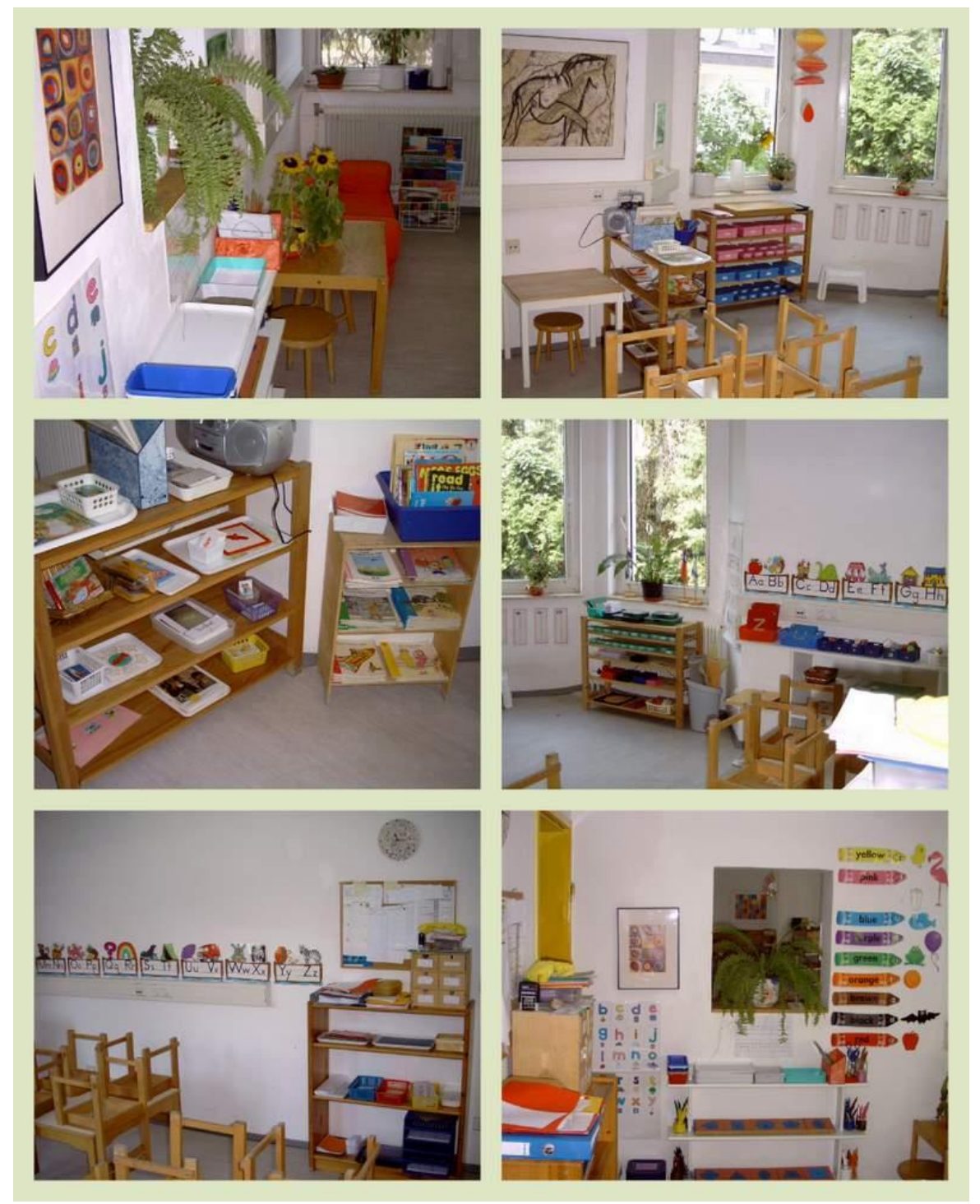

Figure 5. A.P.: Language room layout with centers and offered activities.

\section{Second Floor and Cultural Studies Room}

Two sets of stairs take you to the second floor with its art and cultural studies rooms, a kitchen, a big restroom, the main office, and storage space. As you turn right at the top of the stairs you enter the cultural studies room. A shelf covers two thirds of the wall space and flags of several countries from around the world and Montessori Bells are placed on the top tier. Other activities on this shelf include letter writing, labeling, and sorting activities for science and cultural studies. Above the shelf self-made posters of impressions of different continents such as Africa, Asia, Oceania, Europe, South America and North America are hung and also a map of the kindergarten. A group of wooden elephants are placed below the posters. 
Next to it is a table with four chairs placed in the corner and a window on the adjoining wall provides natural light. A shelf stands next to it and has the geography activities such as knobbed world and continent maps and knobbed land and water form puzzles. A basket with rugs is situated next to this. Three Poäng chairs are placed against the wall, a runner in front of them and a reading station is attached to the left on the wall. It features children's books about artists such as Picasso, Van Gogh, Marc Chagall, and Klee, and topics such as world flags, animals and birds, story books and a child's world encyclopedia. A cage with two gerbils closes off the reading area and provides some privacy.

Next to the reading area is the calendar and date station with a small shelf that has all the materials in little baskets, one basket with all the children's addresses, and a CD player on top. Two dustbins are placed here, one for paper and the other for "other rubbish" so that students learn recycling early. Next is the computer station with printer and paper. The beams of the roof are used as a shelving unit in the corner and host CDs and teacher materials. Below are two smaller shelves with a writing station and more teacher materials. A tall shelf has activities for cultural studies and science in plastic envelops with different labels as well as matching activities, and on the bottom tier is a cabinet with animal knob puzzles. A table with two chairs above which hangs a poster entitled "world of flags" lie next to this shelf. Planets painted by the children hang just below the ceiling.

\section{Hallway and Art Room}

In the hallway is a shelf standing against the railing with a two-pan beam balance scale, a basket with objects to be weighed, and small weights on the top tier. Below you have a life cycle puzzle, a 100 piece puzzle called "In the City", a basket with a silver polishing activity, a floating activity, and more puzzles. Across from the shelf is a small work space for two students and above on the wall is a display called "We live in ...." with nice birds-eye pictures of the city, the current city map and an older map, and pictures of the former royal family members. On the table are a miniature fair wheel and a city guide for children. A few steps away is a small imaginary play area with a blackboard with an integrated abacus.

As one enters the art room the big window on the side wall draws immediate attention because it fills the room with an abundance of natural light. A big oval table that seats 8 to 10 children is placed in front of it. In the corners on either side of the window are deep built-in shelves that accommodate art supplies, books about art and cooking, a CD player, and recycled materials.

On the right side of the window is a small dresser containing different kinds of paper. Another open shelf holds several different practical life activities arranged on trays. For example: 
two wooden cutting board sets with a fruit knife and two bowls each, and a bowl of apples in between; a China tea pouring set with a tea pot and four small cups; a wooden coffee grinder with coffee and a bowl; a pipette with a bowl and two small jars; smelling bottles with bowls of water; a decanter pouring set with a funnel; a color mixture set with a rack of test tubes, bottles of yellow, red, and blue color, a funnel, and a small pitcher; a glass pitcher pouring set with two small and one big pitcher; a scooping set with three different sized bowls and a scoop; and a bubbling whisk set including two small glass pitchers with water and soap, a bowl, and a whisk. A smaller shelf is attached and labeled "Snack Boxes." The children can store their snacks here. Above this shelf is an art piece that shows the continent of Africa with individual animals painted and cut by the children and glued together into a collage. It is very beautiful.

The table next to the shelf has a colorful tablecloth and is mainly used for snack time. It has two benches in the corner and two chairs. Above the table is intriguing art work by the students displayed on a black bulletin board, showing painting with strings and understanding of symmetry. There are two doors on the next wall with a tall shelf in between them. One door leads into the adultsized kitchen and onto the balcony that oversees part of the outdoor play area. The other door goes into a bathroom that has a table with a drying rack for art work. The shelf in between the doors has compartments for tablecloths, cooking aprons, a bowl with water and a rag for the snack and lunch tables, and three buckets for water and used water.

The shelf at the entrance has small baskets, trays, round containers with markers, rulers, scissors, erasers, and chalk on the top shelf. The second tier is labeled "drawing" and has two cutlery trays with colored pencils and chalk. The third is labeled "collage" and has a variety of different materials for collages. The bottom tier is labeled "play dough" and has two trays, each holding a container with play dough, a child-sized rolling pin, and a basket with cookie cutters. Above the shelf hangs Miró's painting "People and Dog in the Sun."

\section{Garden and Playground}

The playground is large and has a living tree and bush fence in addition to a wall or lattice fence in front of the house. The trees provide shade for the children to play and also protect against the rain. Along the living fence different play areas are offered such as two wooden walk-in play houses, a climbing tree with soft soil below, a big six foot high, two-sided A-frame wooden ladder with an attached tire swing and an eight foot wave slide, a double turning bar, a bird's nest swing, and a tree trunk for balance activities. Several child-sized benches and chairs are available and children carry them around to define their play areas. The center area of the playground is open for running 
and children can play soccer and basketball in the back. There is a hoop for the children. In the middle is a $12 \times 12$ foot rubber tile area on which two trampolines and a small plastic slide are placed . In the front is a paved area for cycling. Other materials that can be found include old tires, wheelbarrows, sand play toys, and several different sized tricycles.

\section{A Typical Day}

\section{Uninterrupted Work Time (8:30 to 10:50 a.m.)}

\section{Language Room}

\section{Music and Language}

At the beginning of the school day the atmosphere is calm and the children seem a little sleepy. The sound of children's music and the teacher's voice quietly fill the air. There are five children in the room who are working with different materials or listening to a story. The brothers Dimitar (YG) and Domonkos (BG) are working on a song matching activity. They have placed the CD player, five picture cards, and a small tray on which the puzzles are spread out on a rug just in front of the window bay. The task at hand is to listen to the first verse of a children's song, then choose the right symbol and place it on a picture card showing part of the song's story line. The older brother sits on the floor in front of the rug and listens to the songs while the younger brother stands holding his sippy cup observing his brother's movement. The first song is Twinkle, Twinkle Little Star and Dimitar searches for the star symbol to place on the picture card, which has a white star. Several other traditional children's songs follow. At about two years old, Domonkos is one of the youngest children in the program. He is happy and moves slowly to the music occasionally pointing at the $\mathrm{CD}$ player when there is no music between the songs.

\section{Reading and Read Aloud}

Nanako (RG) holds the book The Bear on a Bike in her hands and carefully thumbs through it. She turns the pages slowly and examines the pictures (see Figure 6). She sits at the table next to the reading area where the teacher is reading the story of Noisy Nora. On the sofa to either side of the teacher are Adam (YG) and Severina (YG) listening to the story, their eyes glued to the pictures. Meanwhile Nanako has finished her book and returns it to the book stand under the window. She selects a new book, Aaron's Hair, and returns to her seat. Adam seems to have gotten lost in the story and the teacher goes back several pages to discuss some pictures and the story line. After they have finished the story Adam picks a new book, Sing, Sophie! The teacher starts reading the story 
and sings some parts, which the children enjoy very much. Toward the middle Adam joins her when she is singing and toward the end Severina also joins their singing.

Meanwhile more children are in the house and the sounds from the other rooms get louder, but the language room is still quiet and calm. Molly (YG) enters and walks over to the bye-bye window and steps onto the little stool standing at the window to wave her family good bye. Nanako finishes her book, returns it to the book stand, and leaves the room. The brothers have been working all along and are almost finished listening to Mary Had a Little Lamb.

\section{Name Cards Reading Activity}

Molly returns from the window and goes to the organizing shelf next to the entrance. On the shelf are three baskets with laminated name cards. Every time I observed in the language room during the uninterrupted work time, the children would read through the name cards. It is a very popular activity.

Meanwhile, Michaela (RG) comes in, greets the teacher, and takes a tray, paper, and pencils. She takes a seat at the table next to the sofa and starts drawing. Toni (BG) enters, goes to the bye-bye window, waves, and watches as his family leaves. He takes a chair and joins the read-aloud at the sofa. Molly takes the yellow basket, puts it on the table next to the shelf, and takes a seat. She starts a conversation across the room with her peers from the yellow group, Adam and Severina.

1. Molly: I I am in the yellow group now. Let's see if I am in the yellow group now, maybe I am in the blue group again.

2. Adam: $\quad$ You are in the blue group.

3. Molly: $\quad$ Smiles and nods. I know.

4. Teacher: Are you checking the names there?

5. Molly: Nods and puts three cards down. Hey, Christine is in the yellow group?

6. Teacher: Returns to the sofa Christian, Christ-ian.

7. Molly: It looks like Christine.

8. Teacher: Yes, it does. They look very similar those two names.

9. Molly: Alex card says Alexandra

10. Adam: Alex is in the yellow group.

11. Michaela: Has interrupted her activity, stands at the table listening to Molly reading the card. Says A-lex-an-dra, Alexandra.

Michaela is watching while Molly goes through the cards placing one card after another on the table without reading them aloud.

12. Molly: My name is not there! She gets up and takes the blue basket, grabs the cards, and starts looking for her name and builds one pile with all cards. I need to find my name card, my name is not there. 
13. Dimitar: Who was observing what Molly is doing with some interest, comes to the table. Are you mixing the cards? You are not supposed to mix them. Lucas is not in the yellow group. Picks up the card.

14. Molly: Finds her card. There, I am in the yellow group. She puts her name on the pile. Christopher is now in the blue group. She returns the rest of the blue group cards back into the blue basket and places the others in the yellow basket.

15. Dimitar: Looks through the blue group cards, takes Maria's name out and hands it to Molly. Maria is in the yellow group now.

Dimitar and Molly mix now according to their standards the cards.

Meanwhile, more children have come in and gone to the bye-bye window, the younger ones have been accompanied by a teacher, and then left the room. Toni picked a book of his choice, Bear on a Bike, to be read next and waits patiently for his turn while listing to the current story. The teacher reminds Dimitar and Domonkos to clean up their activity and set it back onto the shelf if they are finished. They clean up while Molly starts counting the name cards quietly to herself. As the teacher notices that she wants to put the baskets away, she asks her, "Are you going to separate them again?" The girl nods her head and starts separating cards into the two baskets. As she is finished JiSung (BG), a three year old boy, walks by with his snack box and she says, "Pick one" holding the name cards like playing cards in her hands. She repeats, "pick one" and he does. Molly takes the card and reads "Conrad." He smiles and takes another card, but this time she just puts the card into a basket.

Alicia (YG) and Teresita (RG), sisters who used to go to this kindergarten and now returned for a month to Austria from their home in Spain enter the room. Alicia reads silently and very shy through the cards of the yellow group while her sister reads through the red group. Teresita taps the teacher carefully, who is standing with her back to her. The teacher turns to her and reads the card she is holding. The teacher says, "This is Chendra. She was here yesterday and got very long hair," showing how long the hair is. She nods to show that she understands and returns to reading the names and occasionally smiles at a name, then slowly finds her English voice and starts very quietly to read name by name. She needs the help of the teacher a few more times and asks her every time, "What stands here?" After she finishes and has warmed up, she chooses a different language activity - an alphabet wooden puzzle - and takes a seat at the neighboring table. Alicia, on the other hand, remains intrigued by reading all the names and moves on to a new basket, the blue group names, but since these are all unknown to her she has even more problems reading the names. The teacher reads slowly the names to her when Johannes (BG) joins the group. He is also three years old and has been 
in this kindergarten for a year. The teacher knows that he is very familiar with the names and asks, "Who is that?" He reads, "An-ni-na." Alicia puts the card down and takes the next one, he reads, "Ju-Sing." Ji-Sung (BG) hears this and comes over with a big, warm smile from the sofa where he was looking at a picture book, and he starts observing the reading activity. The teacher nods with a smile that expresses well done Johannes. He continues to read the next cards, "Almaz, Paula, Manuel" and says, "Christine is a nice name." The teacher smiles and replies, "Yes, a nice name." Alicia holds up the next card and he reads "O-li-ver" and smiles. His mouth was wide open, as open as it can be while reading the name. He noticed that Oliver had folded his card a couple of times and says, "it does not look nice anymore." The teacher agrees and they move on to the next card.

Johannes reads the card of his group in an amazing speed. His face, body, and voice formed each letter and syllable into a name, which was amazing to watch. When he finds the teacher's name, Emma, takes the name card and brings it to the teacher, who is in the hallway, saying, "Emma. This is your name." She agrees with him saying, "Yes, that is my name. Thank you very much." He returns with the name card in hand and puts it into the blue basket. He leaves the activity and Alicia goes through the names one more time with the help of the teacher, repeating the names after the teacher each time.

The teacher encourages Cloe (BG), who is three and has been in the kindergarten only for three days, to participate in reading the name cards. She mainly speaks German and says to her new friend Paula, who is very shy and also new to the program, "Komm mach mit, Paula (Let's do it together, Paula)" while placing the blue basket on the table which the teacher had given her. Both of them know very little English at this point and communicate in German in the kindergarten, while the teachers speak mainly English with them. Paula (BG), who started the same day as Cloe and is of the same age, takes a basket and takes a seat at the table. The teacher tells Cloe, "Let us find Cloe. Can you find your name?" and starts reading the name cards Cloe shows to her. The girl places them on the table and when they get to her name, the teacher emphasizes her name with a smile "Cloe." While the girl proudly shows it to everyone around her. She spreads the names out on the table and so does Paula. A mix of the names has been created and the teacher tells the children that they have to separate them again later.

Cloe holds up a name card and the teacher reads "Jo-han-nes." Johannes comes over to the table and reaches for his name card, looks at it with a big open smile, presses it against his proud chest, hugs his name card lovingly, and puts it back into the yellow basket. Paula looks at the same names as Cloe and ignores her own basket. 
Teresita comes over and shows the teacher her finished alphabet puzzle and points out the problems she has with the $\mathrm{p}, \mathrm{b}, \mathrm{q}$, and $\mathrm{d}$. They finish together and she smilingly returns the puzzle onto the shelf. She looks for a different material she likes to work with next. Meanwhile, the girls are mixing the cards and Johannes reads the names he recognizes. As the teacher returns her attention to the name card reading activity she asks "Where is Paula's name?" and a few seconds later Johannes finds it and hands the card to the teacher. She says, "Oh here is Paula's name. Pau-la" and hands the card to the girl repeating her name. Paula seems not very attached to her name card while looking at it and puts it right away into the red basket. The teacher explains to her, "Paula you are in the blue group" pointing to the blue basket and the child places the card into it. While the children are sorting the cards into the basket the teacher reads the names and adds in which group they are to help the children identify the colors of the basket and where they should put each card. Then the teacher asks them to return the baskets to the shelf. Cloe gets up and talks, but it seems like practicing different sounds, "ce, be ba, me..." Paula places her basket onto the shelf the teacher has shown her. Cloe seems to leave the room and the teacher asks her, "Can you put the basket back on the self?" pointing to where it belongs. She puts the basket where it belongs and declares in German, "Ich gehe jetzt raus. (I am leaving the room)." The teacher asks her to push her chair in and she picks up the name cards that are lying on the floor. The teacher takes Paula's hand and helps her to push her chair in. Cloe follows her example after the teacher reminds her to push her chair in too.

Sophia (BG), who is carrying the blue basket, sits down at a table and reads the names she is able to recognize from the blue group cards, which she does very well. After she has read all the names she returns them to the basket and counts each card, counting first in English (L2) as high as she is able to count. When she reaches the number twelve, she counts it twice in German and in English and continues in German (L1) up to 14 when she stumbles and understands that there are more cards than she can count in either language. She takes the remaining cards and puts them all together in the basket, then gets up and returns the basket to the shelf.

\section{Labeling, Sorting, and Matching}

The teacher introduces a new activity to Johannes $(\mathrm{BG})$, who has been reading all the names effortlessly. They go to one of the shelves in the window bay and take out a tray with pictures and name labels of things in their kindergarten environment. They then take a seat at the table and she explains, "You have got the names and I have the objects here, Johannes." He shows her a label and she points her finger at the label: "play dough." She looks for it in the picture pile. Sophia (BG) observes what they are doing and the teacher tells her to join them. The teacher goes through the 
pictures and asks, "Is this play dough?" Johannes says "No" twice and then recognizes it with a big "Yes." He puts the label next to the picture and they read together with Sophia, "play dough." The teacher goes through the pictures as they look for 'glue.' Sophia looks at a picture and shakes her head saying "no", but the next one is right. She points with her finger at the picture and says "glue." The teacher responds with "this is the glue. You are right, Sophia." Johannes places the label besides the picture and they read together "glue." He shows her the next label and she reads "cushion." He moves the label closer to him and reads it again, while the teacher hands the pictures to Sophia.

The teacher asks her "can you find the cushion?" She starts looking through the pictures and shows a picture to the teacher who replies, "that is an apron." She takes the next picture and the teacher tells her one after the other that these are "paper, scissors, paper bin, and cushion. This is a cushion." Sophia places it on the table and Johannes adds the label. Together they say twice "this is a cushion." The teacher points to the picture and says, "Look, the cushion is on the line like during circle time." The group smiles and continues with searching for the next word by carefully looking at each card.

The teacher reads "paper" and the girl starts looking through the pictures. Again, the teacher helps her by telling what things are: "This is a paper bin, scissors, mat, paper." They place the piece on the table and go on looking for a tray. Sophia shows her a mat and searches further - "felt pen, chair, table, pencil, tray," the teacher tells her. They found the match and Johannes picks the next label. "Sharpener," she reads and adds, "like sharpening a pencil" while showing the movement. They continue the activity with six additional picture objects: scissors, paper bin, felt pen, chair, table, and pencil. Michaela (RG) comes over with a book, points to the title, and asks, "What stands on it?" The teacher reads, "Spot bakes a cake." The girl repeats the title, "Spot bakes a cake," a couple of times as she goes to Daniel (BG), who is crying, to read him the book.

Johannes is pointing to the word 'paper' and the teacher reads, "paper," pronouncing the initial sound several times. Johannes repeats this twice. The teacher points and says, "play dough, they both start with p," and he repeats the word. Sophia decides that she has finished the activity after matching nine pairs. She gets up, pushes her chair in, and leaves the room. The teacher asks Johannes if he would like to continue, but Daniel's crying has taken its toll on everyone's concentration. It takes Johannes a while to make one pile of pictures and one of labels. He puts them on the tray and returns it to the shelf where it belongs, while the teacher takes care of Daniel through hugging and reading a story to Daniel and Michaela. 


\section{Initial Sound Recognition}

Several sorting and labeling materials are available on the shelves in the language room. Teresita works with the consonant initial sound, object matching, and labeling material. She has a muffin tray that has a round red paper piece with one consonant on it in each muffin opening. The tray has twelve openings and some of the letters are c, b, f, j, l, m, n, and r. In the basket she has several small objects that start with the needed consonants: a bottle, a ladybug, a jaguar, a cow, a marble, a fox, a nut. A stack of labels are between the tray and the basket.

Teresita takes the ladybug, looks for the corresponding label, and places them into the opening that has the $L$. She looks through the stack of labels, stops at the cow label, looks for the cow in the basket, and places the cow in the letter $C$ opening. She takes the small perfume bottle out of the basket, opens it, and smells it. Meanwhile her younger sister has been sitting next to her and working with the letter box with integrated laying tray. She wrote her name Alicia with the letters and starts with the $T$ for her sister's name. She is looking for the letters as her sister comes over and helps her to write Teresita. She puts most of the letters onto the line and asks her sister to find an "a" while making the sound. Alicia finds it and places the $a$ next to the other ones, finishing the name. Teresita returns to her seat and places all the objects in their place. She takes the labels and shows them to the teacher who reads each one to her. Then they go over to the table and check the tray together. While the teacher reads the labels, Teresita points to each corresponding object on the tray. When they finish the girl puts the objects back into the basket, stacks the labels, and returns the tray to its place on the shelf.

\section{Phonetics}

Natalie (RG) and the teacher take a seat at the corner table and the teacher holds a few lowercase sandpaper tracing boards with vowels and consonants. The girl picks a letter and places it in front of her while the teacher traces the letter with her finger. She follows her and they make the $O$ sound.

1. Teacher: O. What can we think of that begins with the $\mathrm{O}$ ?

2. Natalie: Thinks but nothing comes to her mind.

3. Teacher: Do you see the dot with the blue sticker?

4. Natalie: Nods her head and looks right into the video camera. She is the first one who seems aware of it.

5. Teacher: Can you find the basket with the blue sticker and pick something that starts with $\mathrm{O}$ ?

6. Natalie: She gets up, turns around, and searches for the basket. As she finds it, she takes an object out, returns to the table, places it on the 
letter, and says: $\mathrm{O}$ for orange.

7. Teacher: Yes, $\mathrm{O}$ for orange. $\mathrm{O}$ is in the beginning of orange. She directs her attention to the letter signs on the wall. Do you see the animal up there above the $\mathrm{O}$ ?

8. Natalie: Yeah.

9. Teacher: What animal is that?

10. Natalie: O... Octopus moving her finger around the letter again.

11. Teacher: Takes the next letter $Q$ and makes the sound $\mathrm{Q}$

12. Natalie: She feels the letter with her finger and makes the $Q$ sound.

13. Teacher: Do you know anything that starts with a Q? Making the sound.

14. Natalie: She goes to the shelf looking for a basket with a green sticker. It takes her a while. She turns around asking, What is this?

15. Teacher: This is a little lion. They search together and return with a stone. That is quartz. It is a mineral.

16. Natalie: Quartz

Teacher: Also, do you see there that sign? Not so easy to recognize? That is 'question?'

17. Natalie: Question looking up to the question mark

18. Teacher: There is something else that starts with a Q. What is the princess' mom called?

19. Natalie: Queen, she says and notices the video camera again.

20. Teacher: She also starts with the sound of Q.

21. Natalie: Takes the next letter and places it next to the $Q$.

22. Teacher: This is the sound E. She moves her fingers along the letter and repeats the sound a few times.

23. Natalie: Repeating the sound each time. Gets the basket and places it on the table.

24. Teacher: Takes out a small mat. Is there an $\mathrm{E}$ at the beginning of mat?

25. Natalie: Both shake their heads. No. finds an egg E for egg.

26. Teacher: Yes, please put the basket back on the shelf. Do you remember anything else that starts with an E?

27. Natalie: She gets up, goes to the baskets, takes an object, and asks What is this one?

28. Teacher: That is a dice.

29. Natalie: Taking another object That is a rabbit.

30. Teacher: Yes, that is a rabbit. Can you think about a big animal that you might find at the zoo?

31. Natalie: A tiger.

32. Teacher: Bigger. It is gray and has a trunk showing a trunk in her face.

33. Natalie: Elephant.

34. Teacher: Yes, an elephant. So here we have the letter that makes usually the sound... 
35. Natalie: Orange.

36. Teacher: O for Orange. This letter makes usually the sound $\mathrm{Q}$ for quartz or queen, and this letter stands usually for E. E as in egg or elephant.

37. Natalie: Repeats the sounds and phrases.

Natalie turns the letters upside down and mixes the cards on the table. The letters make scratching sounds while moving due to the sandpaper. She makes the sounds of the letters and the teacher picks one up and guesses " $E$ " and is right. Together they say, "E for elephant and egg." They continue playing for a short while before the teacher helps her to put everything back in its place.

\section{Movable Alphabet and Writing}

Michaela (RG), who has been looking at books for a while, now stands in front of the movable alphabet shelf. She calls to the teacher a few times, "Can I do this." The teacher turns around and says, "You can set it up on a rug. I will come and help you." Michaela has set the movable alphabet on the top two rugs. Daniel (BG) joins her, taking a seat on the rugs, and grabs a few letters. The teacher walks over looking at the wooden boxes with the letters that they have not put away in a very organized manner. They sort all the letters and the teacher asks Daniel to hand her the letter he is holding, which he does. Daniel observes the next steps while Michaela takes a pink box with the vowel $a$ on the front, opens it, and takes out a pile of vocabulary words and a pile of pictures. The teacher takes the labels and shows the pictures to her. She says the name of each object as the girl lines them up vertically under the left letter box. Daniel, Teresita, and Alicia watch and listen to the teacher repeating each object again "can, pan, van, tap, yak." The sisters take a seat at the table and read through the name cards while the teacher finishes the activities with Natalie. Michaela comes over to the table and asks the teacher, "Can you help me?" The teacher tells her the name of the picture she is holding a couple of times: "can."

Daniel is intrigued by the letters and plays with them again. As he takes an $O$ Michaela tells him in German, "Du kannst damit Oma schreiben. (You can write the word Grandma with this letter)." She continues, "Du brauchst ein $M$ und ein $A$. (You need an $M$ and an $A$ )." She shows him each letter, then places them under the right letter box on the rug, and reads the word a few times. Daniel likes her attention and she teaches him how to write mother (mama) and father (papa) in German. She writes the German word with a natural ease and impersonates a teacher. A couple of children are watching them and the teacher comes over to help Michaela. She has started the object can and spells it kan. The teacher tells her the name of the next picture, "pan," and she puts the letters on the rug next to the picture while repeating the name a few times, $p$, $a$, and 
searches for the $n$ a little longer. "And this?" the girls asks, showing the next picture to her. "Van," the teacher replies while sorting some letters in the boxes. Daniel, who has been observing, repeats "van" a couple of times.

Michaela asks the teacher, "What did I write for Daniel?" She tells her, "You wrote Oma, Mama, and Papa," reading them in German and pointing to each noun. Michaela finishes the word van without any problems. She asks, "What is this?" "Tap, tap, tap," the teacher replies. The girl takes a $t, a$, and $p$. She remembers the yak and takes a $y, a$, and $c$. She looks at the words and changes the kan to can and calls out, "I did it." The teacher asks her, "Shall we go outside? Daniel can come with us." The three leave the room and take a seat on the stair case going up to the second floor. The teacher shows her a label, reads "tap," and hands it to her. She goes into the language room and places it next to the word she wrote. They continue in the following order: tap, van, and can. Michaela takes away the letter $y$ from her word so that only $a$ and $c$ remain. As she returns with the label for $y a k$ she places the $y$ back and says in German, "So, jetzt bin ich fertig. (Now, I am done)."

The girl goes over to the writing shelf by the entrance, takes a piece of paper, a mat, and a pencil, and returns to write the words. She prints the German words first, shows them to the teacher, and says in German, "Schau mal, was ich für Daniel geschrieben habe. (Look, what I wrote for Daniel)." She tells her, "very nice." Michaela returns to her activity and cleans up the German words by placing each letter into its designated place. She continues to print the English words in the order she placed them on the rug. After finishing she goes over to the teacher who tells her that yak is spelled with a $k$ and they change the word. The girl stamps her work proudly with the date and places the paper into her paper cubby in the hallway. She returns to clean up her activity and is very organized. 


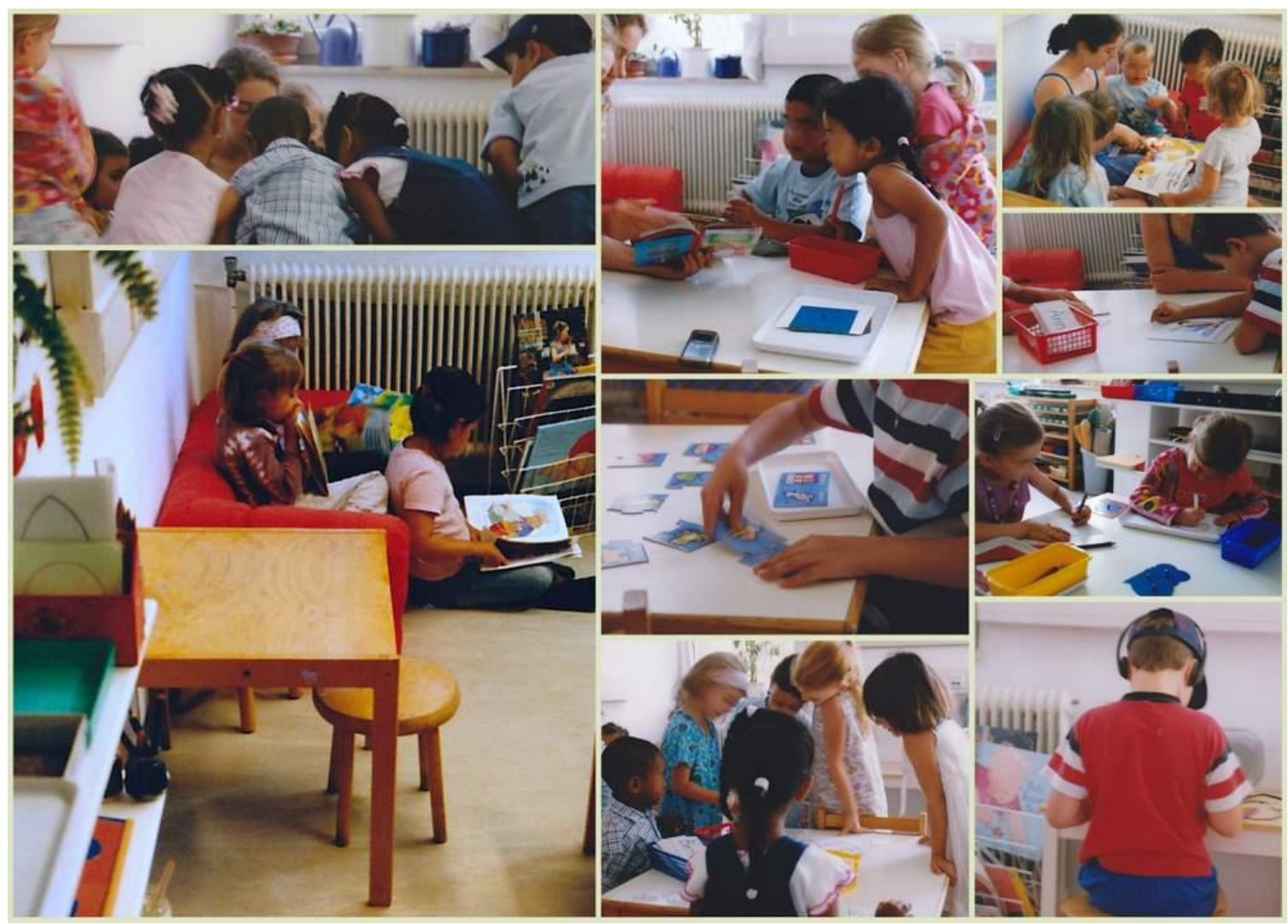

Figure 6. A.P.: Language activities such as read-alouds, independent reading, interactive story reading, language puzzles, and name card activity.

\section{Practical Life Room}

\section{Individual Lesson - Brown Stairs - Sensorial Activity}

Monika (BG) walks around the different shelves looking at the activities. Then she walks over to the rug basket and takes one, places it on the floor, and carefully checks all the edges. She goes to the brown stairs activity and takes the smallest piece, then runs back to the shelf to get the next piece. She places them together. She goes back and takes the biggest block, then the second largest. She places all of the pieces out of order but in line on the rug. She looks at her work and picks two blocks up, the two smallest ones, holds them like an instrument, and starts drumming the bigger one with the smallest.

The teacher comes over and explains to her that these blocks are the brown stairs. The teacher asks her, "Should we build the stairs?" Monika replies in German "Ja (Yes)." The teacher spreads the brown blocks out on the rug and Monika takes her two music instruments and also places them apart on the rug. She seems to want to play with them and puts a different block on top of 
another one. The teacher takes the piece off and says, "Let me show you how to build the stairs." The girl still moves the blocks on the rug but stops after a short while. The teacher shows her how to find the biggest block first, takes and compares it with other blocks, finally defines it as the biggest, and places it in the corner of the rug. She repeats "the biggest" while the girl observes the teacher's work. The teacher moves on and states, "the next biggest", takes another block, and compares it again. This time Monika also takes a block and helps compare it.

Together they build the stairs, checking each time which one is bigger or smaller. Monika seems to have understood the concept and wants to skip the checking phase but the teacher always holds another piece that they will check together. After finishing the brown stairs they get up, walk around their work to observe it from all sides, and the teachers says, "small and big," pointing from one side to the next. The teacher goes to the shelf, gets a marble, and places it onto the biggest block. She lets it run slowly down the stairs, which makes pleasant sounds. Monika catches the marble and places the marble back on the biggest block. She glides with her hand down the stairs while holding the marble, creating a range of dark to light sounds step by step.

Christine (BG) comes over and Monika says in German, "Christine, schaul mal. Das is für di. Ich hab das extra gebaut für di. (Look here Christine, that is for you. I have built this for you)." She waves her hand and places the marble on the biggest block and lets it carefully go. It sounds beautiful like a wooden xylophone. Annina (BG) comes over and takes a look at the stairs, while Monika checks where Christine went. The teacher tells Monika to take the stairs apart and rebuild it herself. They spread the blocks out and Annina observes their work. Monika tells Annina in German that she can join their play. The teacher encourages her to start with the biggest one, but she still moves the pieces on the rug around. She has lined up the blocks out of order and tries to let the marble run down but it does not work well. Almaz (BG) and Christine have joined her activity. Christine understands that the marble will not run down these stairs, therefore, she shows her how to build the stairs. She speaks in German as she moves the blocks while Monika is helping a little and Almaz is observing. They have finished the brown stairs again and now it is time to let the marble run down the stairs. After a while they return the blocks to the shelf and rebuild the stairs in their original location.

Meanwhile Annina reads a book in German to herself, but the book is in English. She adds the last phrase in English saying, "Then they all leave". Toni (BG) had joined reading the book Monkey Puzzle. Smiling, he says, "look, a monkey and a snake, a snake" while she is screaming and acting a little scared. She finishes her book and joins Monika who is now playing with a butterfly puzzle. He finishes reading his jungle book, takes another one, and reads while looking on the cover, 
"Brown bear, brown bear what do you see?" He goes over the first couple of pages rather fast, then returns to the beginning and reads, "Brown bear, brown bear what do you see?" turns the page and reads, "I see a red bird looking at me. Red bird, red bird, what do you see?" now looking into the room and saying, "I see a yellow duck, looking at me. Yellow duck, yellow duck, what do you see?" He turns the page, waiting to see the picture as a clue, and continues, "I see a blue horse, looking at me." He holds up the book to show the picture, but no one is in the reading area to listen to him. He glances at the camera for the first time, recognizing that I am there, and is a little confused but continues reading two pages very quietly. Then he is back to his read aloud, showing the pictures while turning each page. He finishes the entire book, stopping only on a few pages to see the pictures as clues. Additional impressions from the practical life room are shown in Figure 7.
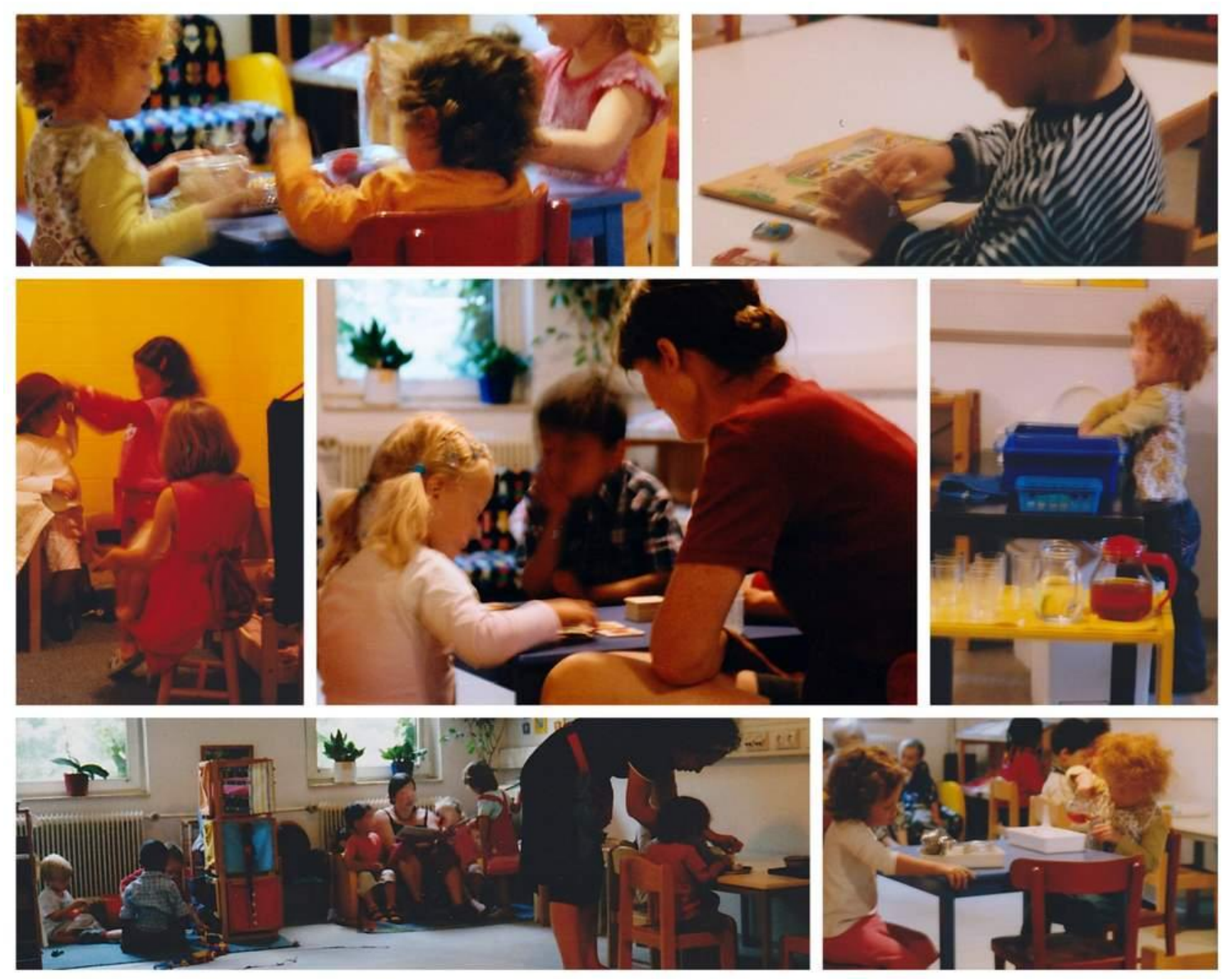

Figure 7. A.P.: Practical life activities \& dramatic play during uninterrupted morning time. 


\section{Cultural Studies Room}

In the cultural study room are Nadine (RG), Lucas (RG), and Johannes (BG). The teacher helps Nadine, who is wearing a headset, to get the DK learning program started. She creates a letter picture with A's, B's, C's, and others in different colors, while her brother Johannes and Lucas are watching what she is doing. She starts a different activity in the literacy program while the teacher turns on classical background music.

\section{Address Book Activity}

Lucas decides to do something else asking, "Can I look at the names?" The teacher asks, "Do you want also the addresses?" which he does. "Do you want to make an address book, so when you are going to school in the fall you have all the addresses of the children, your friends? Do you want to?" "Yes," he replies while taking a rug, placing it on the floor and putting the materials-a yellow paper card collection with the addresses and paper-on it (see Figure 8). He gets a black marker and asks the teacher, "Can I write all this inside?" showing the cards. The teacher answers, "Yes, you need the addresses and the phone numbers, so you can contact them." "Phone them?" he checks and she agrees repeating his choice of words, "Yes. Phone them." Then he says proudly, "I am making an address book," and starts working. Nadine finishes at the computer telling the teacher, "I don't want anymore." She agrees and Nadine helps to put the headset on her brother who has been waiting very patiently in line. She joins Lucas on the floor and observes what he is writing busily, while Johannes tries to get onto the computer chair. He is still too small and the chair rolls away with every try until his sister holds it in place. Johannes pushes the keys on the keyboard and turns around to signal proudly, "I am using the computer."

Nadine, astonished, asks in German, "Willst du das alles schreiben? (Do you want to write all of these)?" while flipping through the cards. He tells her "Ja (Yes)." The first street name he writes has 18 letters and is written in one word, "Plankenmaisstrasse." She continues in German asking "Machst du auch mich? (Will you make mine to?)" He answers, "Ja, aber nur meine Freunde. (Yes, but only my friends)." The teacher asks Nadine whether she would also like to make an address book and she agrees. Lucas looks through the cards and selects the ones he likes to put into his book. Johannes makes funny noises in the background. Lucas needs two lines for the long street name he is working on. She joins him on the floor starting her own address book. 


\section{Cultural Studies Activity}

Nanako (RG) enters, looks around the room, examines a few activities, and decides to work on a flag drawing activity. She picks the flag of Singapore, gets a worksheet, a basket with colored pencils, and a ruler. On the worksheet she starts sketching the flag. She draws a line, looks at the flag, thinks, draws another line with the ruler, looks at it again, grabs an eraser, and erases the line. Nanako is drawing the crescent moon and the five stars with the help of the stencil ruler. She looks over what Nadine and Lucas are doing on the floor and continues to color the upper part of the flag red. Since the address cards do not have the phone numbers, the teacher reads the one Lucas is working on to him. Johannes stops working at the computer and Nanako looks at the poster "World of Flags" to look for her flag. As she finds the name of the country she writes it on the worksheet that states "This is the flag of

\section{Montessori Bells}

Johannes runs to the teacher, gives her a big hug, and goes to the musical scale bells. She helps him to organize the bells on the shelf. Nanako, who has finished her flag, puts her materials back on the shelf, pushes her chair under the table, and leaves the room. Bell sounds fill the room. They take two white bells and bring them over to the table. Johannes bangs a bell with the stick he is holding in his right hand. In his left hand he has the stopper that the teacher wants him to use as she explained to him that this was a high pitch. He bangs it several times and the teacher repeats "high" and demonstrates how to use the stopper. Then he bangs the low one and she tells him that it is low while he stops the bell sound. He enjoys this activity and his smile shows it.

While the teacher is looking for more bells he continues to bang the bells and says "low," and bangs the other one and says "louder," while holding his hands over his ears. He seems not to have quite understood the concept of high and low pitch yet, focusing instead on loud and louder. The teacher returns with two brown bells that she would like him to match. He does it very well after a short amount of time. She encourages him to sing the low sound with her, then the high one, which is

a little more difficult. He plays the sounds again, but after some time he loses interest in the bells and uses the stick like a microphone. The teacher asks him a few yes-or-no questions, like: "Are you upstairs?" "Are you sitting close to Elephants?" "Are you sitting at a table?" and he agrees with "Yes." After a short time he starts to ask her, "Are you sitting on a chair?" She replies, "No." Annina (BG) is watching the interview and Nadine and Lucas are still working on their address book. The interview ends with "Thank you very much and bye-bye." 
Meanwhile Toni (BG) has entered the room and chooses a labeling activity about animals. The teacher reads the labels of the animal labeling activity to him so that he learns about different animal families and their members including cattle, caw, bull, and calf. He places the matching family member next to the card. Dileep comes in and picks up his library bag that he will bring to the cloakroom. Toni repeats the words the teacher reads off the cards and learns the terms for animal families. They also talk about the animals, what these animals do, and the families. He tells her that he likes horses very much.

Chendra (RG) has been working on a puzzle map of the world that she has placed on a red rug, and is tracing each continent where it belongs onto the paper. She looks at her work as the teacher points to Australia, expressing that it is missing, and Chendra takes the piece out and traces it. After she has traced all continents she goes to the shelf, takes a blue pencil, and colors the bodies of water blue. She shows focus and concentration while working on her map.

\section{Reading and Computer Area}

The teacher asks Manuel (BG), "Would you like to read a book?" "No, I want computer," the two year old says. He returns his activity to the shelf and runs to the computer. The teacher reminds him to push in his chair. He takes it for a ride around the room and returns to where the teacher is pointing. "I am going to computer," he says while passing, then he climbs up into the chair and the teacher places the head set onto his head. She opens a program appropriate for his age and stands behind him to help him navigate a little, while Severina (YG) is watching him.

Several children are sitting in the reading area. Nanako (RG) is focused on her book, Where's Waldo: The Wonder Book. Jasni and Adam are talking about animals and which one they would like to be while thumbing through a book about animals. Adam asks the teacher while sitting in the reading area, "Can I be after Manuel?" Since she does not answer, he goes to the computer and asks again. She says, "Yes," and he waits there watching every move on the screen. Jasni calls “Adam, look a tiger. I am going to be a lion. What is a young lion called?" and continues to thumb through the book. "Yes. Adam, I am this lion and what are you?" while pointing to his lion. Adam is still watching the computer screen, but turns around and tells him, "I am a leopard." "Leopard, but I am the king," states Jasni. Adam adds, "No, I am the king." "No, I am the king because I am the lion." "No, I am the king. Lions are not the king only leopards are the king." Adam adds, "I am going to be a king for Halloween." The teacher passes on the computer to Adam and the conversation is put on hold. After a while Jasni joins Adam at the computer, continuing the conversation about 
animals, but Adam is wearing a head set and does not hear much. Occasionally, Adam points to animals on the screen and says their name.

Nanako, still focused on the same book as Severina, takes a seat next to her and thumbs through another story book for a while. As Teresita (RG) and Alicia (BG) enter, Nanako leaves her seat to Alicia. Severina watches the gerbils in the cage and tries to pet one. Michaela (RG) enters, goes to the book stand, and takes the book that was read during the last circle time, The King of Capri. She takes a seat at the table because all chairs are full.

\section{Photo Surrounding Activity}

The teacher engages Manuel (BG) and Severina (YG) in an activity, which Manuel chose. She asks, "Do you know where that is?" Severina nods, "It is right by the train." "Do you go home by the train," she continues and the girl nods her head again. Manuel takes another photo out of the envelope and the teacher asks, "What is that?" He shrugs his shoulders and she tells the children, "That is where the cars go to get petrol. It is a petrol station, just around the corner." He places the card on the table, takes the next out, and looks at it. "You know what this is? This is the kindergarten. This is the bye-bye window where you say bye-bye to papi," says the teacher and both nod their heads. "Did you say good bye to papi today?" His sister says, "Yes," but he gets up to go downstairs to the window. Both tell him that papi has left already and he had said good bye earlier, but nothing can stop him and he is gone. The teacher asks Severina, "Would you like to look at the other photos?" She nods again and takes out the next laminated purple card with a photo glued onto it.

The teacher attends the need of a different child as Severina keeps taking out more cards and laying them on the table. She recognizes something and says, "Billa," the name of a supermarket, while pointing to the photo. When the teacher returns she takes a card and asks Manuel, who also just returned, "What is that?" He replies, "Water," and she tells him, "Yes, that is the Donau (Danube)." Severina finds another picture she recognizes: "The Baker." The teacher takes another picture with water and boats and shows it to them. The girl tells her, "We went on a boat." The teacher listens interested and tells her that it was a nice experience but has to leave again to help at the computer station. Severina spreads out most of the cards on the table and a few others on the chair, while her brother goes downstairs. She says, "No more space," returning first the left over pictures then all others to the envelope. The teacher holds a clip board to take notes of the children's activities so far this morning. Chendra is still working focused on her world map, Adam continues to work at the computer, and Conrad (YG) and Jasni watch the screen. 


\section{Neighborhood Design Activity}

The teacher encourages Nanako (RG) to choose an activity from the shelf. As she picks a partner activity Teresita (RG) is asked to join her. The activity tray has two maps and two baskets with small wooden buildings, trees, and several other shapes. They sit next to each other and the teacher tells them that they should design two cities that look alike. Teresita's sister Alicia (YG) joins them and she helps her sister to place the trees, bridges, and different buildings. They work well together following one another's choice at different times. There could be a lot of language interaction but there is not. Instead, Teresita, whose first language is Spanish, and Nanako, whose first language is Japanese, check each other's maps carefully to design the same city. Almaz (BG) watches their activity from behind and waits for her turn. Teresita checks her design and changes one building, and then they call the teacher. She comes over and looks at their city and tells them she likes the bridge over the lake with a person on it. Then they clean up by placing all parts back into the baskets and Alicia carefully pulls her sister Teresita of her chair. She takes the seat and starts designing her own city while coordinating and compromising with Nanako. They work well together and their city does look alike, which the teacher recognizes by saying, "That is a nice city,very nice." Immediately, they clean up the activity.

Meanwhile Chung-hee (YG) has been tracing continents of the world puzzle map to make his own world map. Chendra is still working on hers, coloring all parts in colors similar to the puzzle map. Jasni works with the animals from 'Around the world activity.' He matches the animals to the pictures and talks to Adam, who is still at the computer browsing through an alphabet-letter matching activity. "I am this lion," he says, while pointing to the lion standing on a laminated card. He takes the labels and starts arranging them. He calls for the teacher and together they check his work by reading the arranged labels. He did very well and while he cleans up the activity he repeats the animal names when returning them into the basket.

Jasni and Adam decide to do the neighborhood design activity and they build similar cities but argue about what goes where and use the activity to start a story line about castles and horses. Jasni says, "Now they are tired and go home to sleep," and places their horses in the castle to sleep. Adam says, "Now they are awake. Hello. Let's go boat riding," while placing the horse onto the lake. Jasni is trying to assert the idea but Adam is focused and declines Jasni's idea to go back to the house. Then Jasni takes his horse and places it onto the lake. Adam says, "I am horses riding," while jumping about with his horse. Jasni suggests, "Can we go to your house now?" They agree and the story goes to having sleepovers. 


\section{Tortoise Activity}

Teresita (RG) takes out the tortoise puzzle and a yellow plastic envelope. Then she takes a seat at the table by the entrance. She opens the envelope and takes out the materials. There are two sets of yellow laminated cards, which each have a picture of the tortoise with different highlighted body parts; one has the name of the body part and the other does not.

The teacher introduces her to this activity. She takes a card, points to it, and says, "Claws." Then she takes the next card, points to the highlighted body part reading "neck," and shows the word below. She takes the matching card which has no word and points to the neck, "This is the neck. Each card matches." She takes a card and asks, "What are those?" The teacher points to the claws, Teresita does not answer but points rather to the matching card. So the teachers says, "Claws," and places the card next to its match. Nanako and Alicia are watching her and Chendra comes over to ask, "Where she can put her map, because she wants to finish it tomorrow?" The teacher shows her a good place, and Teresita continues with her activity taking the next card and finding the matching card. Then she takes the tortoise puzzle apart and returns the puzzle pieces carefully back into the wooden puzzle tray, which is more challenging than anticipated. As she finishes she puts all cards into the envelope and places the activity back where it belongs.
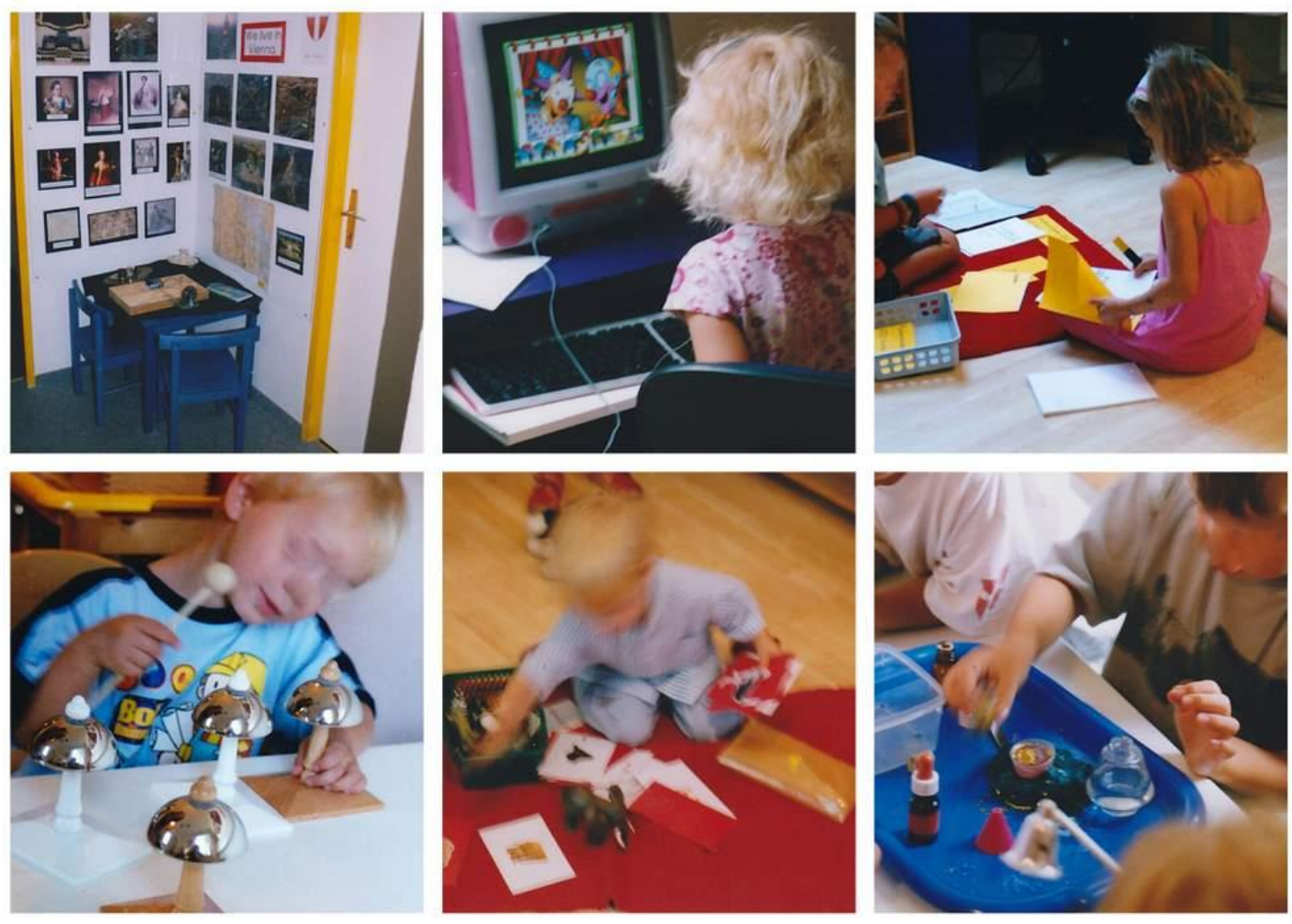

Figure 8. A.P.: Local history corner and cultural studies activities such as Montessori bells, sorting activity, creating a volcano, and address book activity. 


\section{Art Room}

The teacher prepared the table with an activity that allows children to create pattern paintings with objects of different shapes and sizes such as lids, caps, and squares. The tray has red and yellow paint, the objects in a box, and paper towels to wipe off the paint from the objects. The second activity is similar but it uses cookie cutters and different colors of paint: red, yellow, green, blue, black, and white.

Another teacher is baking a cake with Nadine (RG), Mindy (RG), and Lucas (RG) for the upcoming birthday celebration during the big circle time. She collects all the utensils needed for the cake while in the kitchen the children put on aprons and start singing "stir up the porridge." Lucas examines the scales the teacher placed onto the table. The teacher brings the ingredients and Lucas asks, "Is today your birthday?" Nadine answers, "Tomorrow," and the teacher agrees with her, "Tomorrow is my birthday." She asks, "Would you like to pour in the sugar?" while pointing to the scale. He points at Mindy saying, "You do it" while the others are watching the scale. It takes a while for them to measure the sugar. They add the measured ingredients into a big mixing bowl and stir the batter.

Adam (YG) walks in with his snack box and takes a seat at the snack table in the corner. Marlene (YG) joins him. She goes into the kitchen, takes a plate for her snack out of the cabinet, and returns. Dimitar (YG) and Molly (YG) take a seat at the snack table. They communicate in English, but since their table is across the room the conversation is difficult to follow. However, they seem to enjoy their food, talking and laughing as they eat.

As Avah (RG) enters the room she goes over to the oval art table, looks at the art activities,

and turns around to ask, "What are you doing?" Lucas answers her, "We are baking cake for Emma's birthday today. No, tomorrow." Then she says, "I am in the red group." And he says, "What?" Nadine adds, "Yes, she is in the red group because it changed." She continues in German holding the recipe and says, "Als nächstes kommt Butter, als nächstes kommt Salz rein. (Butter is next, then comes salt)." The conversation at the baking table switched into German. Severina (YG) turns around, walks to the oval table, and puts an apron on, and so does Marlene. Together they take a seat at the baking table. There are more and more children at the baking table and they come and go.

\section{Practical Life Activities}

Lucas (RG) grinds coffee, Rico (RG) pours tea into very small cups, and Nadine (RG) joins them at the art table. She has a pouring, sorting, and sieving activity. They work focused and concentrated in silence; only the baking table is talking. Lucas gets up to fill the coffee box and 
informs the teacher. Rico finishes his activity and returns it to the shelf. Nadine returns her activity and takes the tea pouring activity, while Rico waits for the coffee grinding activity as Lucas has not finished yet. If there is a conversation between the three children then it is in German. Since the cake baking has finished, the teacher asks Lucas to move to the other table so the children can do the prepared art activities.

Johannes (BG) and Lea (RG) each take a cutting activity and the bowl with apples over to the small table. Rico and Lucas speak in German as Johannes and Lea take their seats. Lucas teases Lea in German, "Schau der Johannes weiß, wie es geht und die Lea nicht. (Look, Johannes knows how it works and Lea doesn't).” Johannes asks in German, "Kannst du mir helfen, Lucas? (Can you help me, Lucas?)" Rico gets up and says in a mixture of German and English, "Ich kann dir helfen. Du hast die carrot. (I can help you. You have the carrot)," then tries to get to his place in the corner. He cannot access it; therefore he takes the fruit knife and the apple and starts cutting at his seat. As the teacher walks by she takes the cutting board and places it under his apple. She watches him cutting until he has cut the apple in halves.

Johannes announces in German, "So geht das! (That is how it's done)." The teacher explains in English how he can cut the apple and asks, "Are you cutting the apple or are you just helping Johannes?" Rico replies, "Just helping." The table has become very quiet while each of the children works on their activity. Lucas asks Johannes, “Can I take one apple?" He nods "yes." The teacher goes over to Johannes and starts cutting the second half with him together. Lea and Johannes, who have finished cutting their apple, walk around offering everyone a piece, which the children accept with a smile. Lea returns with another apple to cut. Lucas, having just finished the coffee grinding activity, pours the coffee into a little bag, brings it into his cubby, and returns the activity onto the shelf.

Johannes cleans up his activity, returns it to the shelf, takes the coffee grinding activity, and returns to the table. Carefully, he spoons the coffee beans into the grinder opening, fills it up, and takes the grinder off the tray. He tries to move the handle using his chin as additional support, but that does not work. So he stands up, presses the grinder into his body, and moves the handle by rocking back and forth. He then takes a different approach, placing the grinder on the table and turning the grinder instead of the handle. It must work because he adds more coffee into the opening, but it looks like hard work. He takes a break and the teacher comes over to the table and takes a seat. He moves the grinder closer to her and asks, "Can you hold?" He places one hand onto the grinder and moves the handle with the other while the teacher helps holding the grinder in place. It really is hard work for him. He says, "The coffee is for my mommy" which the teacher repeats and he adds, 
"She likes it. It is so hard." Then he checks the little drawer pulling it out and showing it to the teacher, "Look how much I got. We can drink it." Lea, who just cleaned up her activity, passes by. He shows her proudly what he has grinded. He is checking the drawer more often, checks the opening and says, "No more beans" then fills the drawer with more beans. When all the beans are gone he takes the drawer, pours the coffee into a bag, and returns the activity to the shelf. Apple cutting and coffee grinding are very popular activities in the art room, which has several practical life activities.

\section{Paint Shape Impressions with Objects}

The teacher greets the three girls, Annina, Almaz, and Christine, who are in the blue group, by asking, "Would you like to do something in here? Paint or do an activity?" Annina says while jumping "I want to paint" and the other girls join her jumping: "I want to paint." The teacher tells them to put on an apron and take a seat at the art table, so they sit down. She helps them to tie their aprons in the back. At the table they explore the activity, start dipping the objects into the paint, and onto their paper in front of them. Almaz, who has a small glass with red paint in her hand, says to the teacher while pointing to the red circle on the paper, "Look, here," and she acknowledges it with a nod (see Figure 9).

Other children have entered the room and are sitting at the activity table. Molly (YG) works on peeling and cutting a carrot, Michaela (RG) works on the bubbling whisk activity, and Johannes (BG) works with the coffee grinder again. Zach (BG) sits at the art table and needs help cutting an apple. The teacher washes her hands, shows him how to cut the apple, explains where to place the apple pieces that he can share with the children, and where to place the leftovers. Then they cut together while she is placing her hand on his.

Molly and Michaela are observing the girls painting with their different objects. Christine says, "I need yellow," but has difficulties expressing the $y$ properly. Molly, holding the carrot in her left hand and the peeler in the right, corrects her by saying, "Not, yellow (mispronouncing it) but yellow." Then asking, "What are you doing with that?" and Annina answers, "We are painting with these." Michaela asks, "What are you doing with that cup, Almaz?" She replies, "Because, we do like this.... We stamp like this. Look," pointing at the red circles the cup makes. Michaela returns her tray and tells the teacher, "Sanne, I want to do one of those," who replies with, "Yes, but you have to wait a little bit." Afterwards, the teacher lets her join the activity and tells her to sit next to Annina. They work on the activity, but they are running low on paint and the teacher adds more. Lea (RG) comes in and observes the art activity standing behind Michaela. Molly comes over sharing her work 
and telling the children, "Carrots." The girls each take a piece and thank her. Michaela and Lea put on an apron and the teacher helps tying. Lea takes a piece of paper and joins the painting activity. Michaela takes the small glass heart and makes yellow and red shapes on her paper by pressing the heart onto the paper. The five girls, who are doing the paint activity, are working quietly on their papers and share the materials well. Annina finishes and the teacher writes her name on the back, while Michaela says, "I have finished, but I want to do another one," passing the paper to her. A line of the girls formed at the drying rack in the bathroom, only Lea is still working by pressing different objects onto her paper. Michaela returns and starts another one. The other girls are cleaning up their area and washing their hands.

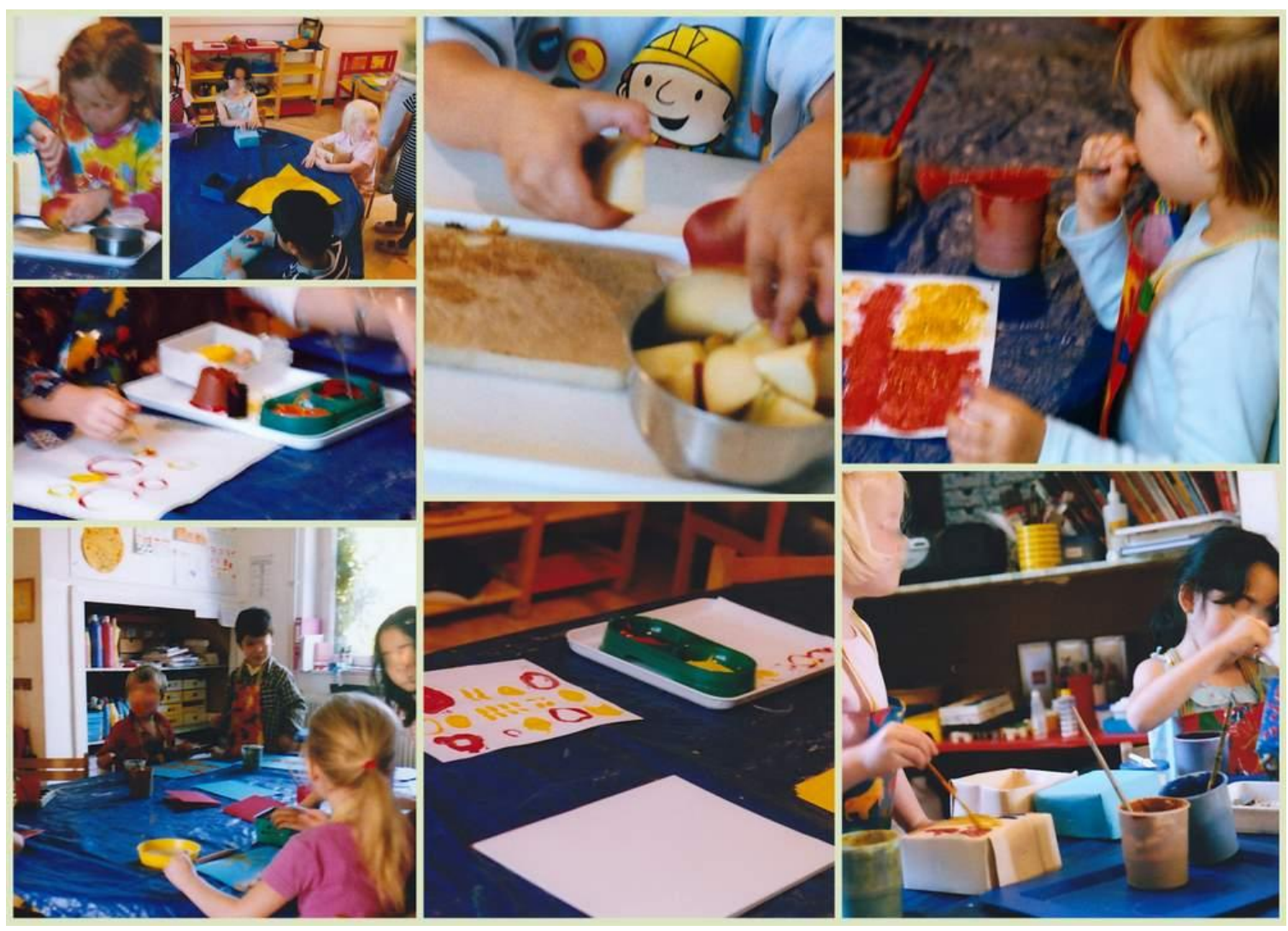

Figure 9. A.P.: Art room activities such as pattern making with objects, painting, creating boxes, and practical life activities such as apple cutting.

\section{Morning Circle Time (10:50 to 11:10 a.m.)}

The sounds of the triangle or rain stick make the children aware that circle time is going to start soon. The girls hurry to finish the coffee grinding activity, clean their work area, and return the tray onto the shelf. Johannes walks in with a rain stick in his hand to signal the circle time on the second floor. All children walk or run into the practical life room. The teacher starts taking 
attendance after most of the children are in the room and have taken a seat in the circle. She calls out the first names alphabetically of the children in this house. Each child replies with "yes." If there is no answer she asks the group if they have seen the child in case he or she might be late for circle time. The children are usually full of energy and lively at this time because outdoor play follows in a few minutes. She makes a few comments about absent children, explaining for example that someone is on holiday or is sick so that children know why their friends are not here.

The teacher chooses Vicky to start the Welcome Song explaining her reason, "because it is her last day before she is going on vacation." Everyone gets ready, sits up straight and starts tapping their knees as they sing "Tic Toc, Tic Toc, the clock says tic toc ... It is time to say hello. Hello Vicky, hello Avah. Hello Michaela. It is time to say hello..." The song moves around the circle and the children get up to show their presence. Some children forget to get up or are too shy but that is fine unless they misbehave. Sometimes she repeats a name and they get up on the second chance.

On birthdays the welcome circle lasts longer, like today, because they celebrate teacher Emma's birthday. Three of the older children carry in the cake that was baked in the morning. They are proud of their accomplished work. Nadine (RG), Mindy (RG), and Avah (RG) helped baking the cake in the morning. The teacher wants them to also take a seat in the circle because they are going to start celebrating the birthday now. She lets the children guess how old Emma is and where she is from. The children guess 18, 20, and one child says 28 , which is correct. Someone else answers the origin question and says "England," which is true. Emma holds a globe beach ball in her hands and shows each child in the circle where England is located.

The teacher says, "Let's celebrate her birthday. We start with the month of the year. January, February..." The children speak with her in a chorus and she places the months on the floor, which creates a colorful circle, sets a candle in the middle and lights it. She says, "The candle represents the ..." and the group says "sun" and "What Emma is holding is the..." "Earth." She asks the children, "How long does the earth take to go around the sun?" "One whole year, and how many times had the earth to wonder around the sun for Emma to celebrate this birthday?" and some reply, "28 times." The teacher tells a short story about her life while the birthday girl walks slowly around the circle counting each year when she gets to July. Some of the children give her their drawings that they made for her earlier and she shows them to all children around the circle. Afterwards the candles on the cake are lit and they all count together as each one is lit. Then the group sings "Happy Birthday" and the second verse asks her "How old are you now?" The verse is repeated to a melody and then she sings her answer: "I am 28 years old now." The group replies, "She is 28 years old now," and show with their hands the number. 
Cloe (YG) seems confused and just shakes her arms to the melody. Emma blows out the candles and the teacher says, "And now we give her 28 claps for each year she was on this earth." The children and the teachers clap and count. Cloe counts a few numbers then she gets lost, makes a longer sound and claps very quickly, by the upper 20's she returns to the rhythm. Finally, it is time for cake and after the children finish their piece they can go downstairs with a partner to change their shoes and go outside. The teacher chooses the partner, sending Lea (RG) with Ann (BG) to the cloakroom. The principal is to pair the children so that an older child can help the younger child to get their shoes changed or put on a jacket if needed. Then she sends the three year olds like Cloe, Toni, and others to the toilet. The room is soon empty and the children are downstairs. There are two teachers who help to get all the children outside.

\section{Outside Play Time (11:20 to 12:00 p.m.)}

As the children leave the house, different languages are spoken and plans on what to do are made. A few children from the blue group, Tamila, Sophia, Domonkos, Zach, and Johannes, are riding tricycles on the paved area. Cloe tries to ride one too by asking Sophia in German, "Krieg ich dein Dreirad? (Can I get your tricycle?)" Sophia does not react and she asks someone else, but the teacher tells her to wait a little longer while the others ride along. Cloe does not wait for long and she gets her snack box, joining other children at the outside snack table.

Annina (BG), Almaz (BG), and Monika (BG) are playing in the sand pit. They are filling a red bucket with their yellow shovels and pile the sand up high while Molly (BG) and Avah (RG) are standing and swinging on the bird nest swing. The teacher tells them that they are high enough and that they should be careful. Nadine (RG), Adam (YG), and Dimitar (YG) are walking through the jungle with sticks in their hands to clear their path. While Chendra, Lucas, and Matti, all from the red group, are climbing a climbing tree (see Figure 10).

Three girls play at the small house and a bench is standing attached to the left of the house. Michaela (RG) and Lea (RG) are trying to attach a hula hoop on the entrance to the little house. Natalie (RG), who is sitting on the bench with a small shovel in her hand, leans back and gets some dirt. The hula hoop turns out to be a problem and cannot easily be attached. The girls try several different ways to attach it on the door hinge, but this does not work either. German is the language spoken because it is their first language.

Bakers are busy four feet to the right of the house: Two chair seats are being covered with a dirt-sand mixture by the sisters Alicia (YG) and Teresita (RG), who communicate in Spanish, their

mother tongue. Smaller and bigger sand shovels help to flatten the dirt on the seat of the chairs. Lea 
carries a green sand bucket and goes over to Alicia, who is sitting on a child sized plastic chair and using both a big and a small shovel. She poured the sand from one shovel to the other. This pouring activity is similar to the practical life activities that the children can do inside. Lea takes the small shovel from Alicia, who calls for her sister in Spanish. Lea immediately knows that she is doing something wrong. As the older sister comes over, Lea returns the shovel without any words spoken.

Michaela is smiling and demonstrating a winning posture with folded arms because she was able to find a way to attach the hula hoop to the entrance of the house. If one would like to enter the house one would have to climb under the hoop or over it. Now since she attached it her fascination about it seems gone, and she and Lea are starting to climb the tree branches under which the little house is located. Natalie and Alicia are still playing with the dirt on the seat - filling in the ditch and flattening the dirt. Michaela has a bucket and asks Teresita in English, "Could you come with me into the house?" Teresita replies, "Yes." They climb through the hula hoop to enter the house and start filling the bucket with dirt with their bare hands. Michaela tries to leave the house but it is more difficult to exit through the hoop and therefore she places two 4 by 4 inch cobble stones in front of the door. She climbs through the hoop by placing her legs onto the stones. Lea is still climbing in the tree branches and swings on them from time to time.

The younger children of the blue group, Cloe (BG) and Paula (BG), are jumping with joy and full of energy on the small trampolines placed in the middle of the playground. They practice to keep balance and coordination. Cloe steps onto the big one and Paula remains on the smaller one. Sophia (BG) is watching for a few minutes before placing one foot onto Cloe's trampoline to express that she would also like a turn. But both Cloe and Paula continue. She runs to the rocking crocodile and starts moving front and back. Monika (BG) is climbing up the small plastic slide stairs and slides down with delight: Conrad follows her and they take turns. Meanwhile Michaela, Lea, and Natalie are running around the play ground and only Teresita and Alicia are still playing at the small house with the dirt on the chairs. A big group of children is playing soccer in the middle of the play ground while the remaining play areas have only a few children. Dodo, the tortoise, is walking around in its home - an old wooden sand box overgrown with green leave plants that it likes to nibble.

Occasionally, a child stops by and looks at it before running of again.

Some children of the yellow group are playing by the bunny cage. There are four big bunnies in a good-sized cage. Three girls are visiting the bunnies in the cage while three boys are outside and are planning a little plot. Adam, Dimitar, and Jasni decide to lock in the girls in the bunny cage. They run to the door, Adam immediately locks it, and they run off again. Now the girls are standing inside but would like to get out. They are not able to do so on their own. They look for the bunnies 
and explore the cage some more. Severina pets a bunny that is hiding under the bunny house. Their focus has returned to the animals and Dana and Monika are now petting the bunnies. The teacher comes and opens the cage, and together they feed the animals-carrots and cucumber peels are on the menu for the bunnies. Fresh water is poured into the feeding bowls by the girls. They leave the cage and everyone has forgotten the boys prank.

The conversations are difficult to understand because many children are playing and running about screaming. All languages can be heard: for example, German by its native speakers Michaela, Lea, Cloe, Paula, and English by the children whose first language is other then German or Spanish. The playground is a place for any and all languages that the children are comfortable with and a place for them to relax.
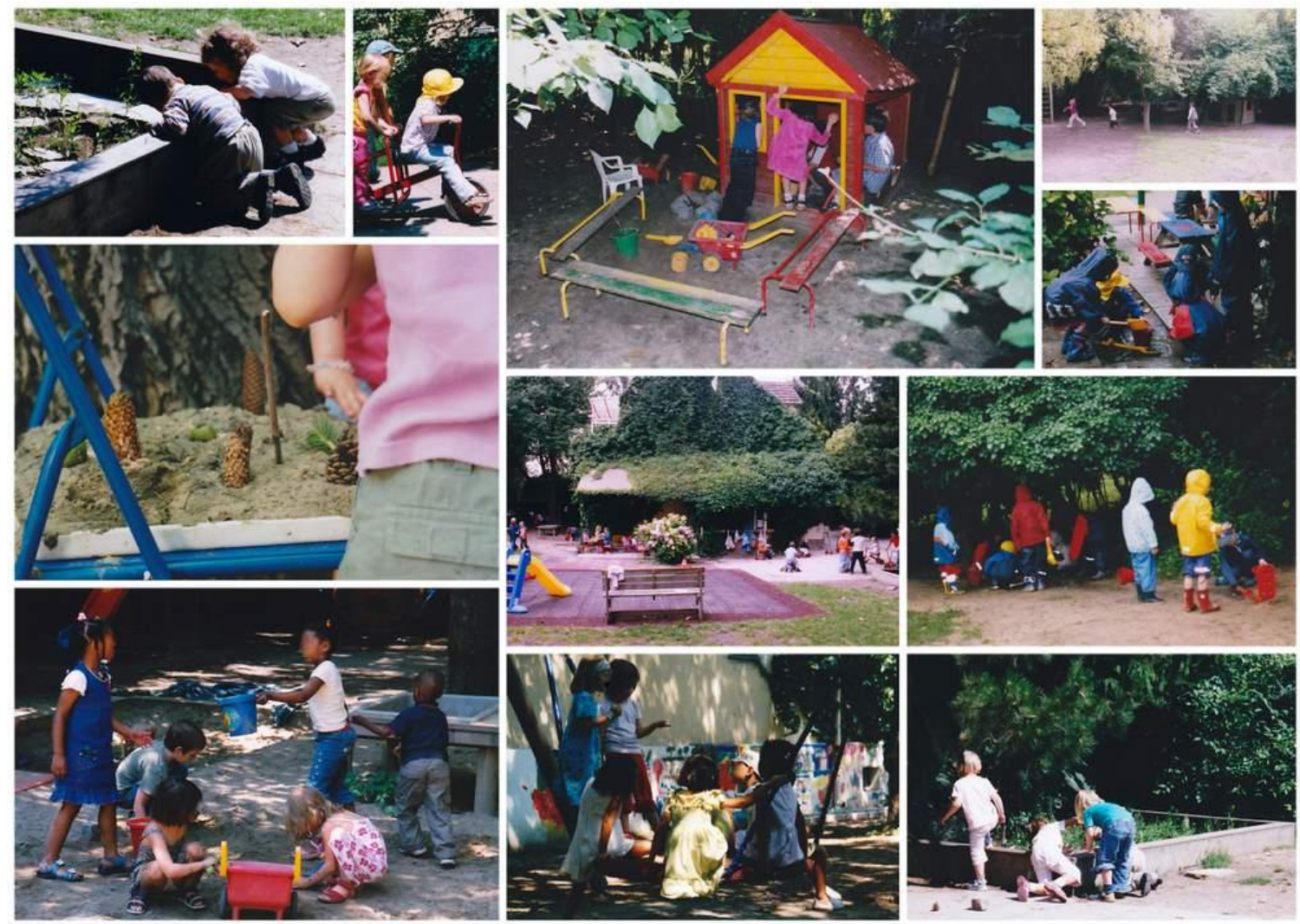

Figure 10. A.P.: Outdoor playground activities in sun shine and rain.

\section{Blue Group Circle Time - 2-3year Old Children (12:10 to 1:50 p.m.)}

\section{Getting Ready for Circle Time}

Today the children experienced an art-rich morning (see summer craft day) and worked on different projects in the garden. This is the first time today that they are inside and the small circle 
time is going to start after everyone goes to the bathroom and washes their hands. The teacher, Annina,, and Sophia are inside while the other children are still outside or using the bathroom. The two girls are playing with their pillows as I enter to observe the yellow group. The teacher explains to Annina, who is concerned about her birthday as it is not until November, that she is a little older than Sophia. The girls are playing with their cushions, moving them front to back, back to front, and pressing them into their tummies. Zachariah enters and runs to the basket with pillows that has been placed between the windows. He takes one and starts looking for the perfect spot in the circle to sit. The teacher explains that Sophia's birthday is in January, and therefore, Annina is older. Sophia says, "Yes, right after Christmas" with a big smile. The teacher turns to Zachariah and asks him to show the wanted behavior: "Please, take a seat on your cushion right on the line." She turns the lights on and reminds the children who are wandering about with their pillows to sit down on the line (see Figure 11).

However, the line is difficult to see as it has worn down through the kindergarten year. The children keep walking around in the circle to find their perfect spot on the line. The smaller oval is used every day for the blue group's circle time. More children enter the room, get their pillow, and take a seat on their favorite spot or next to the person they would like to sit with. The teacher helps the children to find a seat. Zachariah wants to sit next to Sophia, but Annina complains in a highpitched voice, "I want to sit next to Sophia." The teacher comes over and tells Johannes, who just took his pillow, to sit next to her. She also asks Christine to sit to her left, while Annina takes a seat left of Sophia, with Zackary to her right. More children come into the room, run to the pillow basket, take a pillow, find a spot on the smaller ellipse, sit down on their cushion, and join the circle of children waiting for the circle time to begin. Seven children are seated, which is almost half of the group. The conversation starts to shift into German because the mother tongue of six of the seven children is German. Only Zachariah's mother tongue is English, but he has turned his back to the circle and is playing with material placed on the open shelf. Annina says in German, "Du bist meine Freundin. Und du auch. (You are my friend. And you too).," while pointing with her smiling face to Sophia and Tamila, who still stands, looking for a space before taking a seat where she is standing. The conversation continues in German about their age and how to show it accordingly using their fingers. Zachariah is still playing on the shelf as Domonkos, who is two years old, enters slowly and looks around the room. Numbers three and four can be heard in German, while Domonkos toddles into the conversation and immediately turns around and returns to the door. The teacher reminds Zach to leave the material on the shelf alone. 
The conversation about age continues. I can hear phrases that combine German and English in one statement, for example, "Jetzt bin ich old" while showing 3 or 4 fingers using two hands because their fine motor skills are not well developed yet. Domonkos wanders to the basket of pillows, takes one, and sits down next to Zach. Sophia moved her pillow more into the middle and therefore cuts of Zach and Domonkos view. The teacher comes and helps the children to arrange their seats while reminding the children to speak English, which is the major rule in the house for children and parents. Ann, who is two, enters and the teacher asks her, "Do you need to go to the toilet?" She answers, "Nein." "No, okay go and sit in the circle please." The circle is getting full with more children taking a seat. The children around the circle sit cross legged with the exception of Tamila, but after the teacher sits cross-legged Tamila follows her example.

\section{Circle Time Starts: Name Cards, Register, Calendar, and Weather}

The teacher starts circle time by handing out the name cards. She says, "Let's see who is here today." She holds up a name card and shows it to all the children in the circle. Tamila reaches with her arm to take the name card at the first glance and the group says "Ta-mi-la." She takes the card and places it in front of her. The teacher takes another card and repeats, "Whose name is this one?" Johannes says "Emma," and a few join him. She places it in front of her and goes on showing a new card. The group says in a nice chorus "Za-cha-riah". He takes his card and places it in front of him. Cloe goes to the bathroom and the teacher gets up to help her to wash her hands then returns quickly. "Whose name is this one?"-"Do-mon-kos" fills the room and he gets up, toddles to her, and takes his card. She asks him to return to his seat and to sit on his cushion. One child expresses that Domonkos and Ann are only two years old, and the teacher says, "You are right. They are still two year olds." Johannes says "Domonkos is smaller" with a smiling face. Ann gets up while a few children say her name: “Ann.” The teacher taps on Sophia's knee and asks her, "Can you speak English, please?" and Sophia puts her hands on her mouth.

The girls next to the teacher answer any question immediately, and give no one else a chance to talk. Therefore, she asks them to give Zach a turn, who asks quietly and softly spoken, "Do you know where Almaz is?" "She is in the bathroom," the teacher replies. Cloe, Toni, and Adela enter and get their pillow. Cloe hands a pillow to Adela, who is a guest and will maybe start later this year when she turns three. The teacher asks, "Who's name is this?" while showing the name card around the circle. "Clo-e." She gets her card and the teacher tells her, "Then you get back on your seat, place the card in front of you please." She takes a seat between Ann and Adela and places her card 
just in front of her checking with the other cards in the circle. As all name cards are passed out, the teacher goes over the register and the children return their cards to her.

"So let's count how many children are here," the teacher says and starts counting the name cards placing one after another in a pile on the floor. "One, two ...." continues until thirteen and the last name card is counted. "We are fourteen with Adela who is visiting us today," the teacher explains. Some kids turn around to look at her and Cloe, who herself has been here only for a few days, has been helping her like a big sister. "Let's look at the days of the week," she continues and takes the cards to place them on the floor in the middle of the circle. She calls out each name while some children repeat them after her: "Monday, Tuesday, Wednesday, Thursday, Friday, Saturday, Sunday." A few of the children are still looking at Adela, who is at the table where her mom is sitting. The teacher goes on to ask, "And today is?" Toni crawls fast into the middle to point to Thursday and says "Thursday." The other children repeat the day with the teacher, "Thursday." She says, "Very good, Toni," who is sitting on his pillow again with a proud smile. One child says, "Yesterday was Wednesday." "Yes, you are right. Yesterday was Wednesday and tomorrow is?" continues the teacher. "Fri-day" the children scream into the circle.

The teacher gets up and points to the calendar line of numbers that shows the weather symbols for the first 13 days. She counts the days and some children join her, and she expresses the date, "July 14th, 2005." After taking a seat in the circle again she says, "I have to tell you something. My daughter Rachel, it is her birthday and she is 18 years old today." Some of the children smile and others say "Happy birthday, Rachel." Then she goes on and says, "It is Annina's turn to do the weather, today on July 14, 2005. Let's sing: What will, What will the weather be? ... What will Annina say? Will it be sunny, rainy, windy, cloudy? What will Annina say?" The children add a hand drawing or movement for each weather expression.

Tamila observes the children and their visual expression. She does not sing with the children but tries to understand the hand motions that go along with the song. The teacher asks Annina to go to the window and check the weather, which she does. The children, who are sitting further away from the teacher and closer to Adela, the guest, have difficulties focusing on circle time. The teacher reminds Domonkos to sit on his cushion. Cloe is shaking her curly, shoulder length hair. Annina returns and says "sunny." The teacher says, "It was quite warm today," and hands her a small picture of the sun that she sticks on the $14^{\text {th }}$ on the calendar. Meanwhile, she collects the days of the week and reads them again while some kids join her. Domonkos is reminded one more time to sit on the cushion. Adela taps Cloe on her shoulder and points to her cushion. Domonkos and Cloe take a seat on their pillows. 
Circle Time Main Activities: Story time, Colors, Numbers, Movement to Music, and Singing

The teacher asks Almaz how her little brother is and what he eats. Almaz shows the children how to hold a baby so that it can burp after drinking milk. Then the teacher says, "Now, let's read this book and it is also about a baby. It is a monkey baby looking for its mommy. It is called 'Monkey Puzzle.' What is this here?" She points with her finger to the little monkey on the cover page, and a few kids answer, "a monkey." She repeats several times "a monkey" while pointing to the picture on the cover and the children join in. Then the teacher reminds the group while reading a story to listen and to keep their fingers to themselves. She opens the book asking, "What types of animals can you see there?" The children call out animals as the book is shown around the circle. "A butterfly," says Zach. The teacher replies, "Yes, we can see a butterfly and a snake and a frog. Where is the frog?" Sophia leans forward and points with her finger to the frog and says, "There is the frog," while the other children look at the book page to check for the frog. The teacher tells her that this looks more like a lizard and it is not a frog. The other children agree with the teacher and they go on to the next page, the beginning of the story. She shows the first pages asking, "Does the monkey look happy or sad? The children say in a chorus, "SAD." She follows with the question, "Why do you think the monkey is sad?" and Almaz offers an answer, "Because he can't smile." The teacher asks, "Why can't he smile?" and waits a few seconds for an answer, when the children do not answer she offers the answer: "The monkey is looking for his mommy."

She starts reading with a sad child-like voice, "I lost my mom," showing the pages around the circle so that each child can see. One child says quietly with a sad voice, "Oh, no," while another says, "I see it crying." The teacher reads on " 'Hush, little Monkey don't you cry. I help you find her,' said butterfly. 'Let's have a think. How big is she?' 'She is big,' said the monkey. 'She is bigger than me.' 'Then I have seen your mom. Come little monkey. Come, come, come.' "She shows the picture and turns the page. "No, no, no. That is an elephant..." As the teacher goes through the following pages, she uses different voices for the butterfly and the monkey, and she adds gestures for words like big, bigger, tusks, trunk, tail, legs, nose, beak, claws, and others. The children repeat the animal names and words she empathizes strongly without being asked by the teacher. The story has a nice rhythm and flow, which allows the children to interact with the story. As the story line crosses a spider, Cloe is confused. She gets up and points to the spider in the book and says in German, "Das ist eine Spinne (This is a spider)," and the teacher nods her head. Then she goes back to her seat while Sophia turns to her and repeats several times, "That is a spider, a spider," but this does not convince Cloe. She insists in German, "Nein, eine Spinne. (no, a spider)." The teacher continues the story and Cloe is off and on listening like some of the other German speaking children. 
The story line and pictures keep them interested most of the time. Toward the end the butterfly tells the monkey that none of her babies look like her, which is the reason she did not know that monkey babies and their mothers look alike. The children identify the caterpillars as the babies of the butterfly and on the last page of the book they name all the animals they have met in the story as well as their colors. "This is how the monkey found its mother, by visiting all these animals and describing its mother to the butterfly," concludes the teacher while putting the book behind her.

Then the teacher takes a small tray with a colored dice and says, "Now, we will look at some colors." While holding up and turning the color dice she asks the group, "and here we have some different colors. See, what color have we got on there?" She points to one of the sides and the children say, "blue," which she repeats. "What color is that?" and some children say, "red." Then she wants them to look carefully but they stay with red. She turns the dice to the red side and says, "That one is red and what is this one?" turning it back to the orange side. A few children say carefully "orange" which she agrees with by nodding her head, "Yes, you are right that is orange." The activity repeats with the colors blue, brown, and green.

Afterwards, the teacher rolls the dice and says, "What we do with it is, this is a dice and you roll it. And what do we have on top?" The children say "blue" and Cloe says in German "blau (blue)." The teacher goes on to explain, "Then you take something blue out of the basket," and holds up a blue object. She places the dice in Monika's hand and she rolls the dice. The children say "green." The girl takes out a green object and places it in front of her. Next is Sophia who rolls orange and takes out a red cube. The teacher asks her, "Is this something orange?" and she sticks with her choice at first but finds a different object which is orange and places it in front of her.

Cloe is next and rolls the dice. The teacher asks her "What color is that?" and Cloe says in German "gelb (yellow)" while the teacher says, "Yellow. Can you take something in yellow?" She looks through the things and Sophia points to an object and says to her, "This is yellow." Cloe takes the object and places it in front of her. Flora is next, rolls the dice, and the teacher tells her "brown. Can you find something brown in there?" and Flora takes a brown bear. The teacher says in agreement, "the bear is brown." When all children have rolled the dice and taken an object out of the basket the teacher tells Monika to hold up her object while holding up her arm to show what "hold up" means. Then she asks the children, "What color has Monika got?" and some of the other children name the color. Every child gets a chance, then they hold up their object and the group expresses the colors one last time before they return their objects to the basket.

"So here we have the number?" the teacher asks and shows a card with a number. The children reply, "One." “Annina, can you get one bear?" The girl gets up, takes a bear, and places it 
next to the card on the floor. The teacher shows the next card and asks, "Here we have the number?" "Two," the children reply happily. She asks another child to place two bears next to the card. The child does a good job and so do the other children that follow. As they reach the number five, some children are getting upset because they think that they will not get a turn but that is taken care of by the teacher immediately, showing her little basket and telling the children that they will each get a turn. Now she hands out cards with dots on them and asks Johannes to place his at the right number, which he does well and fast. Cloe gets the next card but she needs more help to find the right match. After all of the cards with dots have been handed out the teacher gives the children a plastic number and the children have to match these numbers also. They do this correctly and quickly. The teacher asks five children to place all numbers back into the basket, and finally the bears, out of order starting with three, five, two, four, and one. During the last step some children seem to get tired of the task and start to talk while one child starts to sing quietly.

After everything is back in the basket, the teacher asks the children to get up and put the pillow behind them. Cloe, who is new and has more difficulty staying on task, takes her neighbor's and her pillow and wants to return them into the pillow basket, but notices soon that this is not the task and returns with the pillows to her space. The teacher says, "Let's sing a song and move to the music." The first song is "One, two, three" from the Bend and Stretch with the Sticky Kids CD, which reviews the numbers the children went over during the math portion of the circle time. The teacher sings the song and models the movements. The next song is Wiggles \& Jiggle, which asks the children to move certain body parts like fingers, toes, nose, ears, and so on. The teacher demonstrates these motions while singing together with a few children. The children enjoy the movement to the music and seem to have fun. The last movement song requested by the children is The Journey to the Moon. Some children mainly show the movement to the song and do not sing, while others watch what these children are doing.

The teacher leads into a musical activity by handing out instruments and telling each child the name of their instrument, for example, "Here is a shaker. Zach." She hands out shakers, tambourines, and drums. "Remember we are doing the volcano and the shakers start first. You have to be quiet for now; wait for the music," she says while turning on the CD player. The piece is a version of "In the hall of the Mountain King" by Grieg. The children join the classical music piece that expresses a volcano eruption. Each group of instruments has a different starting point according to the loudness and instruments used in the musical piece. The teacher gives them a sign signaling when to join. Some children have done this activity before and know what to do or expect while the new children are a little confused and orient themselves on their peers. After the activity is finished the teacher 
tells the children that they did a great job and each child returns its instrument into the instrument box as called on by the teacher. She reminds them to place them carefully into the box, as Cloe throws her instrument in. The teacher lets her take it out and put back in carefully.

"Now we can do a volcano dance as well," the teacher announces to the children while getting out the yellow and red scarves. She tells each child whether they get "a red scarf" or "a yellow scarf" and asks them to "hide it first." As the teacher sits down she shows the children how to hide the scarf in their hands, to kneel down, and to bring their heads to their knees. The children start to get into the position and some have to look at their peers to check if they are doing it right while the teacher gets up again to turn the music on. The scarf is quite big and some children have problems hiding it in their small hands, but as they hear the music start they just hide it with their body. First, their movements are small up and down scarf waves according to the pace of the music. The teacher instructs students to do very little. Some children like to talk during the activity but the teacher tells them to listen to the music and follow the sound. As it gets louder the movements grow higher and faster. What started as a low and slow body movement had turned into a high and fast one as the volcano erupts in the end of the piece. Some children start to dance with their scarves. The teacher encourages the children to follow the drum beat and make the highest movement every time the drum bangs. After the volcano had erupted the children return to their initial pose. The teacher acknowledges that everyone did wonderfully as she collects the scarves.

\section{Circle Time Closing and Lunch}

The teacher asks everyone to take a seat and tells Zach and Toni that they are the helpers today. They get up and help setting the lunch table with plates, forks, spoons, and napkins while the others start singing The Itsy Bitsy Spider. The children sing it with different expressions for big and tiny spiders. The children are singing joyfully and like to make the expressions. The next song is Three Little Monkeys and last is Where is Thumbkin. The children are still on task and love singing the songs.

The teacher dismisses the children one by one for lunch. They put their pillows away and look for their name cards at the different place settings. The three lunch tables have real child- sized plates, forks, spoons, table clothes, and two smaller bowls - one filled with apple slices and grapes, the other with sliced cucumber and carrots. A small name card is placed on the plate for each child. After the children have found their lunch seat for the day the teacher goes around and collects their name cards. The cook places the food—spaghetti with tomato sauce — on each table and the children start serving and passing the bowls around the table. They wish each other "Guten Appetit" and start 
eating at their own pace and talking about different things. The teacher gives each child a glass filled with water or tea. As the children finish their lunch they individually clean their plate, spoon, and fork. Then the children go to the bathroom in the corner of the room to brush their teeth. One of the teachers usually helps the children and checks if they brush properly and long enough. The children who finished their tasks can get ready for outside play or stay a little longer inside but by two o'clock all children are expected to be outside playing on the playground.

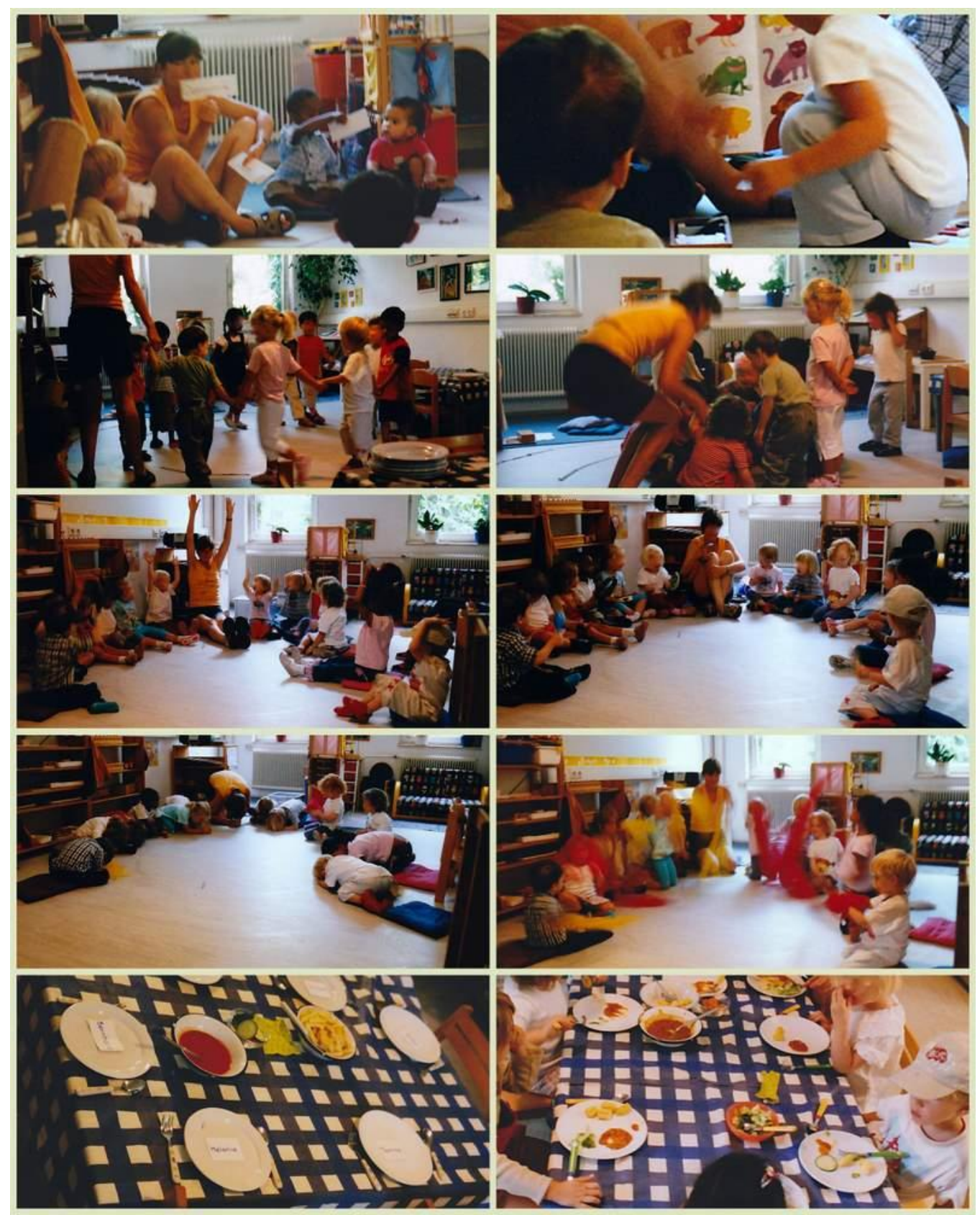

Figure 11. A.P.: Blue group circle time activities and lunch. 


\section{Yellow Group Circle Time - 4-5 year Old Children (12:15 to 1:50 p.m.)}

\section{Getting Ready for Circle Time}

The children return inside after their outside play time and four children are sitting very close to the teacher's spot in front of the middle window. The teacher placed three toy-sized recycle bins, green fabric with flowers, a plastic lunch bag with paper inside, a tin can, and a few other things on the shelf. The children do not notice the prepared material; they talk and sit on their pillow. Adam, Dimitar, Marlene, and her friend, who is visiting for the day, are waiting for circle time to begin, while other children come in, take a pillow at the entrance, and take a seat in the circle. Alicia, Conrad, and Maria are talking with each other, which is difficult to understand as many conversations are filling the room. The teacher enters the room with more materials for the circle time, sets everything on the window sill, then leaves again. Dana enters and forgets to bring her pillow. There is a discussion among the children that they should not change their seat after picking a space, but Molly does not play by this rule and changes her seat. This behavior upsets Dimitar, who gets up and says, "I am the teacher," while taking the spot of the teacher to which Adam replies, "You are not the teacher." He wants to make sure that the teacher sits next to him.

The room is filled with conversations, discussions, and laughter but only the English language can be heard. The teacher returns with a big purse on her shoulder and asks the children to spread out in the circle so that she can sit in her spot. Adam tries to tell the teacher how Dimitar should not sit next to her because he was there first. Dana returns with a pillow on her head, while the teacher explains how Adam could sit next to her tomorrow, but he is getting very upset about that and starts crying. Adam explains to her what happened and how Dimitar had taken his seat on purpose, now she asks Dimitar to find another spot in the circle and he takes a seat across from her a little sad. The children like sitting next to the teacher and discuss this problem on a regular basis in all three groups. Severina and Juliane come in and several conversations continue as the teacher asks the children to spread out some more.

\section{Circle Time Starts}

The teacher starts circle time by placing a hula hoop in the middle of the circle. She asks Maria to hand her the sphere from the basket on the shelf behind her (see Figure 12). She says, "Thank you, here is our magic ball," holding it up for everyone to see and continues, "Our magic ball has a special name..." Molly holds her arm up before the teacher can even ask the question: "What is the name of the magic ball?" She takes the turn and says "sphere." The teacher repeats, "Its name is 
sphere, sphere," while Adam is wondering when the clown is coming back in reference to the puppet. The teacher tells them that they have to wait and see; maybe later. "The clown is a funny man," insists Adam and Molly supports his view with a clear "Yes." The teacher rolls the sphere in the hula hoop. While the magic ball is rolling around the hoop she sets the expectations for the children's behavior: "No talking, only listening, otherwise your friend might not visit today." Everyone is very quiet and sits straight on the pillow. The room is filled with total silence.

The ball stops rolling in front of Severina and the teacher sings her name according to the syllables "Se-ver-i-na-." She invites her through a gesture to set the magic sphere in motion.

Severina leans forward and gives the ball a nice push as Michaela, who is in the red group, comes into the room looking for her name card. The teacher finds it in the stack of cards and hands it to her. Meanwhile the ball stops and she sings "A-dam" with a soft, calm, and pleasing voice. He gets up and pushes the ball but it rolls out of the hoop. She explains to the children to be very gentle and careful. On his second trial, unfortunately, the sphere goes out again. Marlene receives the ball from the teacher, pushes it carefully, and resumes her seat. The teacher sings "Da-na" and reminds her to be very gentle. All children have had their turn and the room is very quiet and still. The blue group is singing the weather song and the sound can be heard from across the hallway. The teacher asks, "Who would like to put the magic sphere into its basket?" and many arms go up immediately. Molly gets to put the sphere back.

\section{Handing Out Name Cards}

"Now, everybody look at my hands and listen - touch your ears everybody." All children have the hands on their ears and wave with their fingers, looking rather funny. The teacher has arranged all the name cards in the hula hoop upside down. She sings and claps the first name, "Sever-i-na." The girl gets up and turns a card over. The teacher asks, "Whose name does she have?" Adam answers "Severina." "That is right," says the teacher, "She has found her own name; that was lucky." Severina takes her card, sits down on her pillow, and places it in front of her. "Now listen," the teacher points to her ears and starts singing and clapping "Di-mi-tar." He gets up, looks at the cards, takes one, turns it over, and reads "Adam," handing it to him. Adam had been smiling when he heard his name and he turns over a new card, reads the name, and hands it to the child. The teacher always sings and claps the names after the children read them. Only a few children have problems reading the names but the group helps each one reading their card. 


\section{Taking Register, Weather, and Calendar Time}

After all students have received their name card, the teacher looks around the circle to decide who will do the register, while taking the register clipboard. Arms go up and she says, "Let's see. The register will do... Severina today." She takes the clipboard and looks through the list of names. The noise level gets louder again, the teacher reminds everyone to be listening to the register. Severina, a very shy girl, receives help from her friend Juliane and asks, "Is Dimitar here today?" Dimitar comes over and turns in his name card. The other children are talking and giggling and the teacher reminds the group to be listening for their names. "Is Marlene here today?" asks Severina's soft and shy voice. Marlene says "Yes" and turns in her name card. "Is Alexandra here today?" her voice is whispering and Adam replies with a loud "NO." The teacher expresses that Alexandra is absent. Severina is talking with her neighbor again, and it takes some time to decipher the names. After a while the teacher suggests that she should sit next to her so she can help her. Now the registering goes much faster. As Severina gets to her name she gets up, gets her name card, places it on the pile of name cards, sits down and continues with the registering. After all the children are accounted for, the teacher starts counting each name card and the group joins in. She places the cards one by one on the floor and as they have counted the last card she announces, "We have eleven children here today and let's see who will do the weather today?" The teacher rolls once again the magic sphere in the hula hoop and the children watch, full of anticipation, as it finally stops in front of Juliane. The girl gets up and the teacher points to the window where she will go to check the weather.

The teacher reminds the children to sing and not to scream the song. The children are tapping their knees with their hands to support the rhythm of the song: "What will, what will the weather be? ... What will Juliane say? Will it be sunny, rainy, windy, cloudy? What will Juliane say?" The children add hand movements to each weather expression. The teacher turns to her and asks her, "What is the weather like today?" Juliane replies "sunny" and takes a seat in the circle again. The other children state that they like sunny weather and the sun. One of the children says that she likes both sunny and snowy weather. One of the boys adds that he likes everything.

Meanwhile, the teacher takes the cards for the days of the week and asks the group, "What day is today?" Several children answer at the same time "Saturday," and they seem to insist that it is Saturday. The teacher places the days of the week in a row on the floor starting with Monday and the children join her in saying them. The actual day is moved outward so that the children can see the day of the week. "Today is Monday, July 11, 2005. Monday through Friday we go to kindergarten and Saturday and Sunday we stay home." Severina comes forward and points to Sunday and says, "I 
go to church". The teachers nods and agrees with her. Some of the other children agree and Molly says, "On Sunday I go to Sunday school."

\section{Circle Time Main Activity}

The teacher moves on with asking whether they remember the guest they had the last time while placing a bag in front of her. The children smile and say, "Yes." Some sit up straight on their pillow in anticipation of another visit. The teacher says, "He likes to come to kindergarten. He really enjoyed last time visiting all the children, and I think he wants to come back. Do you like him to come back?" All children straighten up on their pillows and are focused on the teacher. An eager "Yes" comes out of their mouths. The teacher uses this opportunity to remind them to stay quiet and be nice. Adam remembers and says, "He goes home then," and the teacher helps to explain his comment for children who had not been there: "He goes home when it is loud. He does not like kindergarten when it is too loud and when children tease him or the children are not nice."

While opening her bag she pushes her hand in carefully and whispers "Kasperle, Kasperle are you in there?" All eyes are on the bag and for the first time tranquility fills the room. "Kasperle, I think we woke him up," and the puppet comes out of the bag yawning and looking around to see where he is. The children are happy to see him and smile because of Kasper, who wears a pink and turquoise jelly bag cap with a small bell and a darker pink-red suit. He acts surprised while looking about the room, noticing and saying, "There are many children here today." His voice is high pitched and he starts counting the children saying, "There are eleven children here today." The group seems transformed, not talking anymore but watching every move Kasper makes. "Would you like to go on a walk with me? Let's go to the park." "Yesss," the children reply still in a state of wonder. "Everybody, close your eyes. We go to the park," requests Kasper and most of the children close their eyes on their next blink. Only two children want to see what is going on, but soon after their eyes are closed too. The teacher spreads out a green fabric with a few colorful flowers printed on it in the middle of the circle. Kasper has been talking about the park and wants the children to open their eyes again. He tells the group that this is his favorite park where he likes to come a lot to play, to run around, to lay in the grass, and to look into the sky. He eats a sandwich and throws the paper, plastic lunch bag, carrots, cucumbers, and a can on the lawn. "Hmm that sandwich was good. Oh, I did not share my food with you, maybe tomorrow, Krawutzi-Kaputzi. Would you like to play with me?" Kasper asks the children who reply with a loud "Yes." "Let's go! Oh, can I leave the park like this?" "No," shout the children. Maria tells him, "You have to put everything in a Mistkübel (trash can)," and the teacher helps her, "You need to throw everything in a bin, Kasperle." "Yes," says Maria. 
"This is why I like you to play with me because you know what to do when I forget things.

Krawutzi-Kaputzi. I wonder where I put these things. Who knows what this is made of?" he asks. The children tell him, "It is paper." "Hmm, paper. Would you like to feel the paper?" "Yes." The teacher gets up with Kasper, who is holding the paper in his hands, and everyone touches and feels the sandwich paper. The children smile at Kasper, and one child tells him, "You are so sweet," to which he replies, "Thank you." After the teacher with Kasper in his hands sits down again, he asks the children, "Where do I put the paper?" Molly says "In that bin," pointing to three bins lined up on the shelf behind the teacher and adds "In the red one." "How do you know?" asks Kasper. The teacher explains, "There is a special bin for paper, Kasper." Molly repeats that the bin with the red lid is for paper. The teachers nods, "Molly is right," and takes the bin off the shelf, shows everyone the bin, and explains that the symbol on it stands for paper. Kasper takes a good look and says, "Krawutzi-Kaputzi, yes that is paper. Can you help me to throw the paper away?" "Yes." The children and Kasper speak in chorus "Pull, pull... open," repeating it several times until the red lid is open. The next steps are "Throw, throw away..." and "Pull, pull ... close." It is amazing to see how the group supports Kasper through their words and help him succeed at his task of cleaning up the park. He receives a flower token that he places in the grass because he helps to make the park a nicer place to be. He feels ready to move on but the children remind him that he needs to clean up the other things he left behind. "Krawutzi-Kaputzi, I forgot them. Who knows in which bin carrots and cucumber belong?" Kasper asks the group. Dana tells him twice that they need to go into the compost bin. One child tells him the green bin, but a different child tells him to use the brown bin. The teacher calls on Severina as everyone else is debating the matter with a partner in the room. The noise level is rising and Kasper is not happy and hides behind the teacher's back.

Adam sees him hide and says, "He is gone." All the children get quiet again, sit back on their pillow, and wait for him to return. He comes out very shy, looks around and says, "KrawutziKaputzi, what bin do I use for carrots and cucumbers-Severina?" She tells him the brown bin. The other children nod to show their agreement and repeat, "In the brown bin." The teacher takes the brown bin off the shelf and Kasper looks at the symbol on the bin, "Can you tell me what the picture shows?" "An apple," answer the children and it echoes in the room. He puts the plastic vegetables in the brown bin with the verbal support of the children. Molly, who has been very engaged, tells Kasper that there is a bin like that next to her house. The teacher asks Kasper if he knows now where the compost goes. He replies, "Oh yes, I know. This bin here, the red one," pointing to it. The children immediately scream "No, the brown one" in a jumble of voices. "The brown one? Oh," he 
says, "silly me Krawutzi-Kaputzi." The children take pleasure in every time he uses the phrase "Krawutzi-Kaputzi," which is a rhyming nonsense word creation.

"That was hard work, Kasper," the teacher tells him and presents him with another flower he can plant in the park. "Oh, Krawutzi-Kaputzi," he says happily as he plants the flower, "I like flowers. Can I go home now?" "No, you have to throw away the can," the children tell him. The teacher explains that the can is made of tin and lets the students touch it. The sound and singing of the group across the hall is loud and strong and starts to distract a few students. "Where do I put my can?" Kasper asks the group and Adam tells him, "In the blue bin." The teacher takes the blue bin and checks with Kasper. "Oh, I can see the symbol. It is a can. This is where I have to put my can. Krawutzi-Kaputzi," he says and the children smile at him. Kasper gets his can and wants to throw it in the wrong bin, but the children remind him immediately, "Blue is the right one." The children help him through verbal support and even by going through the same hand motions. He thanks them for all the help and receives another flower from the teacher, which he plants.

The teacher asks Kasper, "Since you are here in the park with the children of the yellow group, would you like to sing and move with us?" "Yes," everyone answers and gets excited while the teacher takes the materials out of the circle and sets them aside. She turns on the CD player and they start singing and moving to the song I travelled over land and sea. As they finish Kasper asks the children, "Can I go home now?" and they tell him "Yes" loud and clear. He is not ready to leave yet and says, "Oh, I like to lie in the grass with my flowers. That is nice. ... so nice. Children look into the nice blue sky, too. It is so nice. Krawutzi-Kaputzi." They do look up onto the ceiling of the room which has become a blue sky. He gets up and says, "I think, I have to go home now. It was very nice being here with you. Can I come back another time?" All the children say "Yes" with happy faces and tell him "bye, bye." He goes back into the bag and tells the children "bye, bye" and that he needs to rest now from the long time in the park.

\section{Circle Time Closing and Lunch}

The teacher reminds the children to stay quiet since they could be sleeping now, and asks Alicia and Conrad to help with setting the three tables for lunch. They get up, get the plates, spoons, and glasses on the tables while the other children lie down with their heads on their pillows and listen to relaxing music. She tells them that they are still in the park lying in the green grass and the children start to relax. She continues telling them that there is a butterfly flying around and landing on their shoulder to signal them to get up and go to lunch. One by one the children get up slowly and 
climb through the ocean of bodies lying around in the park, return their pillow to the basket, look for their name card, and sit down.

The weather outside is very bad as it is raining very hard at the moment. Marlene found her seat and says in German, "Let's eat." Some children wander about, looking for their name cards, while the teacher collects the cards of the children who are already seated. Adam and Dimitar notice that the food is not there yet and call "Julia" while wandering into the small kitchen next door to check if the food is ready. They return with a bowl of rice each and set it on the tables.

The other children are sitting and talking with each other. Since the food is here they start serving themselves and pass on the serving bowls. They express that the rice is very hot due to the steam and start puffing the food so that it will cool down. The same happens with the vegetable sauce. Giggling takes over the puffing. German can be heard in the room. Dana and Conrad seem to talk about birds in German but since all the children are jumbling it is difficult to understand who uses it and what is being said.

The children at the wall table have finished serving their food and hold their hands now, wishing each other "Enjoy your meal." The table at the entrance has nicely decorated plates with sauce on top of the rice, a slice of carrot, and two slices of cumber. They hold hands and also wish each other to enjoy their meals. At the wall table Severina speaks in English while Dana and Conrad reply in German, but everyone seems to understand and enjoy the conversation. The tables are mainly quiet because the children are all eating. At one table Molly and Dimitar are talking about her birthday party list and the children she will invite while Maria and Juliane are day dreaming. The plates and bowls are becoming empty and Dimitar takes the serving bowl and goes into the kitchen where the teacher has been helping, returning with more food.

Music has been a companion throughout lunch but as the children finish their meals it disappears in the background. The children bring their plate into the kitchen next door and clean the tables. They go to the bathroom to brush their teeth and then some prepare for outside play while others stay inside doing an activity off the shelves. 


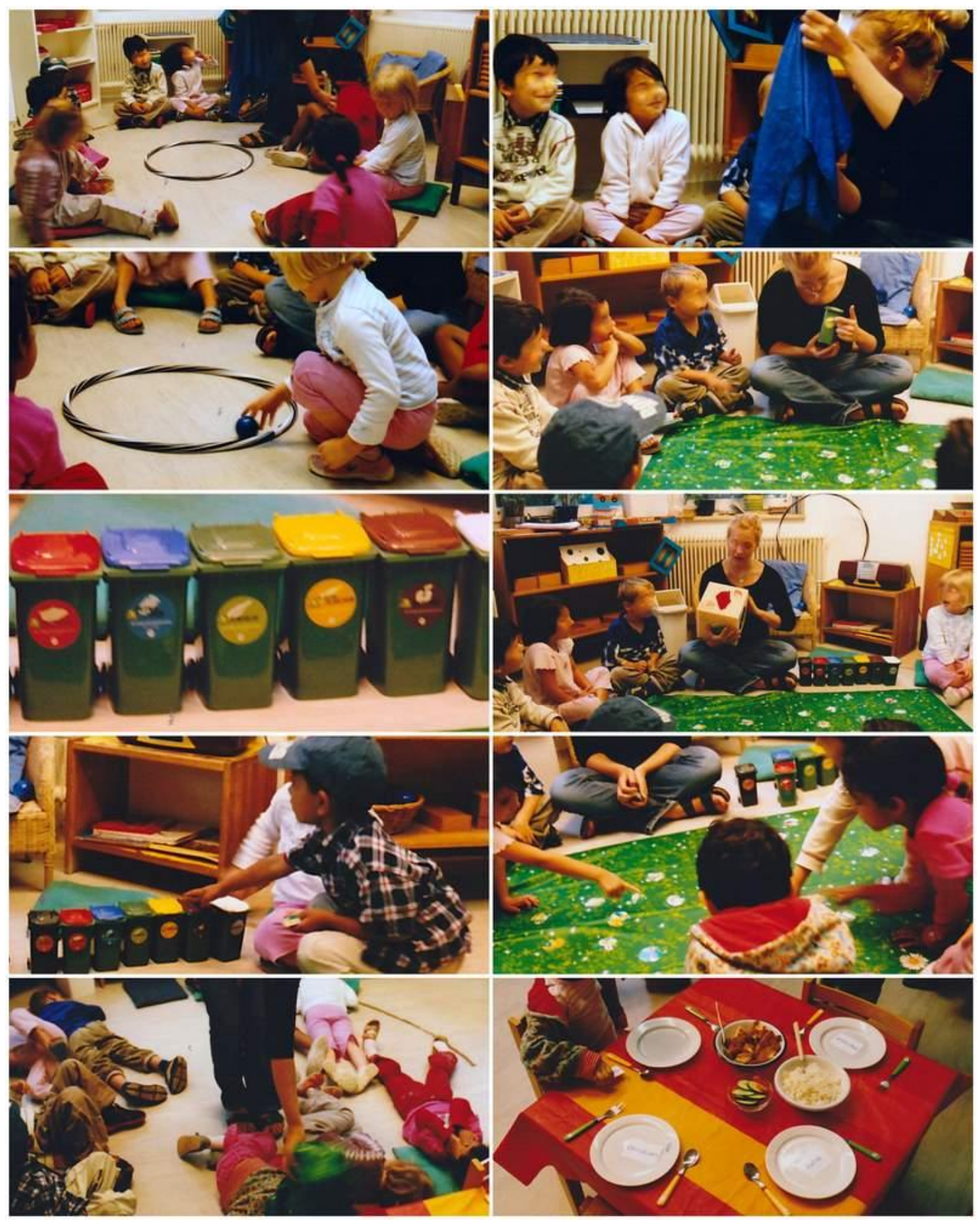

Figure 12. A.P.: Yellow group circle time activities and lunch. 


\section{Red Group Circle and Lunch Time - 5-6 Year Old Children (12:10 - 1:50 p.m.)}

The children come upstairs, some by themselves, others in small groups. The teacher helps Mindy to tie her bow on the back of her dress. The group is quite lively today and many demands are made toward the teacher, who takes the register clipboard and takes a seat in between the children in the circle. Yesterday, the red group together with the yellow group went on an outing into town, therefore some of the children did not get their turn to be a helper or do the calendar. These children would like to have their turn, so the teacher suggests that they move all the jobs forward one day from yesterday to today. Therefore Mindy and Rico will sit next to her.

\section{Circle Time Stars: Name Cards, Register, Weather, and Calendar}

The teacher takes the name cards and holds them like a fan, calling on the children to take a name card (see Figure 13). She asks Teresita to start and she gets up, pulls a card, reads "Lucas," and places it in front of him. Lucas leans forward, takes the next card, reads "Emily," and places it in front of her. She gets up, takes the next card, reads "Nanako," and hands it to her. As all name cards are passed out and placed in front of the children, Natalie starts reading through the register: "Is Allen here today?" The children reply for him with "Yes" because he is in the other room with a teacher trying to relax. She continues down the list, "Is Claudia here today?" and checks each child off as she or he turns in their card. As the register is finished they start counting the children in English and when they get to three, Natalie asks, "Can we count in Hebrew, today?" The teacher agrees. She starts counting, "Achat, shtayim, shalosh, arba, chamesh, shesh, sheva, shmoneh, tesha, eser, achat, shteyim esreh." The teacher repeats each number and some of the children do too. Lucas observes her mouth closely, almost seeing the words the teacher says before repeating them. Then they count in English and Natalie asks, "Can we do it now in Deutsch (German)?" They start counting in German, "Eins, zwei, drei, ..." The room fills with German numbers and it ends in a pure counting contest while the task to count the children seems to be forgotten. Teresita, Nanako, and Avah watch the native German speakers as they run off. The teacher says, "There are twelve children here today," and writes the number into the air while reminding Lucas to behave and stop counting.

Lucas starts working on the calendar while the group sings, due to a request by Mindy, the "Weather song." "What will, what will the weather be? ... What will Mindy say? Will it be sunny, rainy, windy, cloudy? What will Mindy say?" Some of the children express the words with their hands while others just sing. Mindy tells the group that the weather is "cloudy and rainy." The teacher helps him working on the calendar as he asks her to check. Then he says the weekdays and dates for today, yesterday, and tomorrow with some help from the teacher who tells him the numbers 
and initial sounds for the weekdays. Next, the children sing the song: "Rain, rain, go away, Teresita and Nanako want to play. Come again another day." The song goes around the circle until each child has been sung about. The children are very lively because they could not go outside due to the heavy rain.

\section{Circle Time Main Activities: Music and Movement, Story Time, and Experiments}

The teacher asks the children, "Would you like to hear a story about our city?" They tell her "No" in different nuances and Nadine says, "I want to stretch my legs," placing her legs into the middle of the circle with everyone copying immediately. The teacher asks surprised, "No?" She decides to let them move and dance to a few songs like the Chicken dance and Stir up the porridge. The children enjoy the movement to the lyrics and stay on task. She looks for the next song while the children have already started singing loudly and moving all about to Stir up the porridge. Lea goes right into a few ballet steps like a sissonne, small jumps, and turns with her arms in the air, then returns to her seat. The song starts, some children decide to be the porridge, and step into the middle of the circle. While the children sing and make movements to the song another teacher has joined them singing and dancing. Lucas and Rico are getting a little wild but the teacher sends both a meaningful and strong look and they pull themselves together. The children hold their hands in front of them and make stirring motions as they turn around. Nanako opens up and makes a couple of turns smiling happily, while Lea makes a couple of small pirouettes.

The teacher tells the children the next request; Michaela has requested the Hokey Pokey. She wants the children to make a nice circle so that everyone has space to move about. They start singing and do the movements. The joy is written all over their faces, but toward the end some get a bit to rowdy while others decide to sit down and rest for some time. Instead of getting too concerned about the behavior, the teacher suggests another singing and movement activity: Singing in the rain. The children participate very well and enjoy this funny song that also practices a few body parts: feet, legs, knees, thumbs, and several others.

The children are a little exhausted and when the teacher asks, "Would you like to hear the story now?" They are excited and say "Yes." Some children are lying down, but they agree on sitting with their legs stretched out instead of crossed. The teacher reminds them to sit still because otherwise the children might interrupt the story time. She reads the title, The King of Capri, and also tells the children about the author and that the story takes place in Italy. She shows the first page, which has a funny looking bike on it, around the circle and starts reading the next page. The children close to her watch interested the pictures in the book. The faint singing of Stirring up the porridge 
can be heard from the first floor, immediately diverting a few students attention away from the story, and some singing can be heard in the room. However, this does not interrupt the reading and stops when the song is finished.

The page the teacher is showing has several tiered cakes and is very colorful, and the children are amazed by all the food. One is saying "So much cake." Michaela has been concerned since the dancing and movement activity is over because she has lost her hair clip, and she interrupts the story carefully. The teacher tells her she has not seen it and will help her find it later. Chendra asks her, "How look like it?" and she tells her, "A butterfly." Though the teacher stops occasionally to ask short questions, she focuses mostly on reading the story as a whole. The story is about a king who is living on an island, only concerned with how he can eat more, and wasting a lot of food. All the while the people living across from his island are very poor and worry about feeding two or more people with one meal. One day there is a storm that blows so hard that all the things of the island fly to the poor. The king becomes poor and lonely and decides to set his pride aside and go to the queen across the sea to ask for help. She reads on, "Si, si, si by which Italian cats mean "Yes." Mindy interrupts by asking, "Si means yes?" and the teacher agrees. Teresita tells the group that it would be the same in Spanish, her mother tongue. The story teaches the king how to be more humble, less wasteful, and to work for himself. After he has understood these concepts, the queen asks him if he would like to marry her. The teacher asks the children what they think will happen, and they believe that he will marry her. She turns to the last page to check and finishes the story. The story taught some words in Italian like hello, bye, yes, and a few others. The children enjoyed the story and many of them stayed on task.

Next the teacher asks the children if they have done the experiment with the $\mathrm{CD}$ and balloon before. They are giving mixed answers as some of the group have, while others have not. "What we need for this is one ...." holding one CD up into the air, Natalie ends her statement, "CD." The teacher continues, "Do you think it is a new CD?" "No," say the children and she asks, "Would it be a good idea to do an experiment with a new CD?" "No." "What might happen? Do you think you can still listen to the CD?" "No." "No, you will not. That is right. So when you do it at home you want to ask your mother or father or brother or sister for an old CD." Then she shows the other materials needed for the experiment. "You need a cap of a drinking bottle that opens and closes like this," opening and closing it. "You need ...," the teacher pauses and Dileep says, "A balloon." "And this as well, you know what this one is called?" Avah answers, "Play dough." "It is a bit like play dough. Its name is uni-tack," and some of the children call out "blue tack." "Which it is called in England," the teacher adds as she passes the tack around the circle for the children to feel the mass. 
From downstairs one can hear the blue group making a volcano eruption with their instruments, but the children do not seem disturbed by the music. The teacher rolls the tack into a slim roll and Michaela says, "A snake." She agrees saying, "It looks like a snake. So, now you have to seal it that none of the air can get out while otherwise this will not work." The children watch carefully and focus while she presses down the tack connecting the lid and CD. "I hope that no air can get out of there and also very important to close the lid" she says, to which Lucas adds, "And then you open it."

The teacher places the CD-lid in front of her while asking the children, "What do you think will happen when I blow the balloon up?" Avah interrupts her, "I can blow it up. Can I please blow up the balloon?" "Can you blow up a balloon?" the teacher asks. "Yes, I can," Avah replies, and the teacher hands the girl the balloon. As she starts the other children are watching her and it looks like she is having some difficulty but the teacher encourages her, "That's it. Keep blowing. That is enough," while taking the balloon. She gives it a couple of turns, places it on the lid, and un-twists it carefully as Lucas raises the question, "What is going to happen?" She holds and passes it to the children who are shy and not answering the question at first. She asks again, "What do you think is going to happen?" and Avah replies, "It is going to fly around," showing circular motion upwards with her arm. Michaela, Chendra and a few others agree with her. Dileep predicts, "It will fly around and then it will fly into the blue group." When Nadine is asked she says, "I don't know," and Nanako and Teresita are also unsure.

Now the teacher says, "We need to pull the lid up," and the CD moves slowly along the laminate floor, which the children enjoy and find funny. It stops just in front of a shelf and Avah takes the creation. She says, "I am going to blow it up again" while taking off the balloon but the teacher asks her to let everyone have a turn. Teresita is next and this time the balloon moves in the same direction, but stops under the shelf, which the group finds very funny. As the activity goes around the circle there are still some children who cannot blow up a balloon yet, and the teacher tells them that it took her some time to learn how to blow up a balloon.

The children are a little tired and ask her to do the Sleeping Dinosaurs Song. She sits in the middle of the circle while the children lie with their head on the pillow, their legs pointing out of the circle. After a while she starts singing, "Sleeping Dinosaurs, till it's nearly noon, come let us wake them, with a merry tune. Oh so still, are they ill? Wake up little Dino's! (Shout) Stomp Little Dino's (stomps on the ground) Stomp, stomp, stomp (stomps on the ground)," and the stomping is repeated a few more times.

Then the teacher asks the children to take a seat on their cushion and she sends them one by one to lunch, which is taken in the art room at the big oval table and the snack table in the corner. 
The teacher in the art room has set up the tables and the children find their name cards and take a seat. They fill their plates, wait until everyone has served him- or herself, and wish each other a nice meal. The children hold conversations between them or with the teacher. When they have finished they wash their plate in the kitchen, clean the table, and go to the bathroom to brush their teeth. Now, it is time to get ready for outside play and the children can go to the cloakroom in the basement to change their shoes and put on jackets if needed.

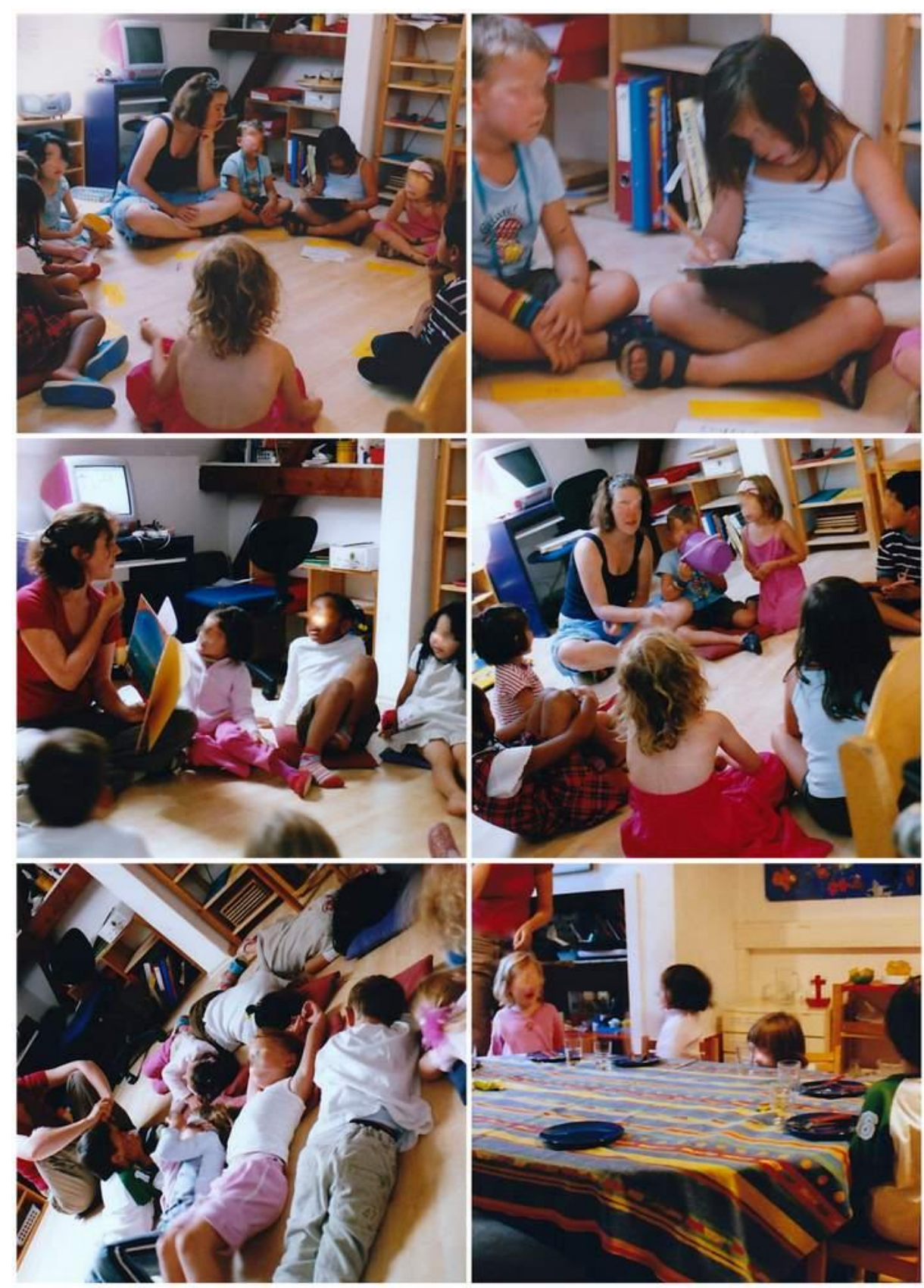

Figure 13. A.P.: Red group circle time in the cultural studies room and lunch in the art room. 


\section{Pick-up Time (2:00 to 2:30 p.m.)}

The parents, caregivers, and nannies can pick up their children between 2:00 and 2:30 p.m. Today several parents are very early so the teachers or parents call for the children who are playing on the playground. The parents call the children in the language with which they usually address their children. This creates an interesting mix of languages such as German, English, Japanese, and Spanish. The morning teachers are in the garden, and one after another the afternoon care teachers arrive, greeting parents, teachers, and children. Many children are also attending the afternoon care program where children mainly play in the garden or participate in outside guided activities and games.

\section{Summer Craft Day}

One day is used for an outdoor "craft day" with several different activities offered in the garden (see Figure 14, Figure 15, and Figure 16). It was rather unusual for the children to be in the garden first thing in the morning. Additionally, the children are not supposed to be playing in any playground areas in the beginning. Seven different stations are set up by the teachers and supervised throughout the morning. All stations are hands-on and of a creative nature. The students design a foot print art runway to guide them through the stations, starting with the one closest to the kindergarten building and the turtle house. The children's feet are painted by the teachers with colors of their choice. Cloe, who loves this activity, has a red and a pink foot. She sits with stretched out legs and laughs as the teacher paints with cold paint on her right foot. The teacher explains to her what she is doing, taking her feet in her hand, asking her to turn around, and helping her find the right position to get up slowly and walk carefully along the newsprint runway.

Cloe is almost running at the end, gets off the paper and turns around to come back to the station while Almaz and Teresita watch her attentively. The turtle takes a sun bath on a stone enjoying the company. The teacher asks them, "Are you ready to get your feet painted" and Teresita says "Yes," immediately taking off her shoes. Meanwhile Cloe puts her feet in a water container to clean them. The teacher asks Teresita which color she would like and she replies very quietly "Blue." Her sister steps closer to the teacher, who has already started to paint one foot, to see the blue foot. The other foot is painted pink. She carefully moves to the runway, gets up, walks along the newsprint stepping wherever her feet take her, turns around, goes a little faster and almost slips on the runway. As she walks one can hear the squishing of paint onto the paper with every step she takes. She returns and sits down for another turn. This time she picks brown and orange as the teacher asks her for the colors. Cloe stops playing with the water as the teacher asks her if she would like another 
turn. She agrees and points to the colors she likes and says in German, "Das da und das da (that one and that one)." After she takes a seat the teacher asks her again and says, "That is red and this is blue." The newsprint paper is filling up slowly and cobblestones are placed along the edges to secure it against the wind.

The station has become busier with the arrival of more children. Paula, Sophia, Dana, and Almaz are waiting for their turn as Cloe cleans her feet again. Parents watch the activity with smiling faces, dropping off more children. One parent states, "That looks like fun!" and wishes to be young again. A mix of German and English could be heard from the children, parents, and teachers. The wooden boat building station is next and has two woodwork benches set up were two children can work at a time. This means that the children must be very patient. It turns out to be a popular station throughout the day. German is used almost the entire day because the husband of the owner is Austrian. The children have to saw a thin round stick to serve as a mast on their boat. The next step is to find the properly fitting drill bit from the drill bit set that the teacher shows the students. The students will use a cordless, handheld drill to attach the "mast" to a wood piece of their choice. They are learning about the different types of drill bits - wooden, metal, and concrete. After they have found the wood bits they have to choose which size the bit needs to be. One boy takes his stick and puts it in the set where he took the drill bit out that he thinks might work. He checks the number on the drill bit and both he and his teacher agree that this is the right one. The next step is to learn how to insert the drill bit into the drill and the children predict how to do it. The teacher shows them how to do it and lets each child try it on their own. Next he must mark the boat at the location for the mast hole. The teacher shows how to hold, switch on, and use the drill. As the boy takes the drill and tries to repeat the steps the teacher watches closely and provides support. The boy is a natural talent and does a very good job. The last steps are to clean away the dust, adhere the mast to the boat, decorate the ship with sea shells, and cut and attach the sail. The children are able to accomplish these tasks without much help. All ships are placed for drying on the bench close to the woodworking station. After the boy has finished the construction of his wooden boat, he walks proudly, singing with his boat in his hands while the waiting children watch him with a smile. He then places his boat on the drying bench, where it sits alone though many more will follow.

At the three dimensional summer collage station the children can work rather independently with a very thick sand-glue mixture. The paint is mixed with sand, small sea shells, and scrap paper with interesting colors and textures. As Tamila starts at the station she has a hard time working with the sand-glue mixture because the brush does not carry enough onto the picture. The teacher suggests that she use her hands and scoop the mixture out onto the paper, but after the first scoop that she 
smashes onto the blue paper she feels the mixture with both hands and does not like it very much. She tries to wipe her fingers off on the art apron, but the teacher goes and gets a few paper towels to help her get it off. She moves on to the glue bottle and put dots of glue onto the paper, covering them with sea shells. The teacher puts a few dots of the sand-glue mixture onto her paper and she puts the sea shells on top. She encourages Tamila to draw a fish with red, blue, orange, purple, or yellow paint. She picks blue and starts painting a circle.

At the second boat station for the younger children, they can make a boat out of recycled styrofoam trays like those used for selling tomatoes, sticks, play-dough, and a piece of fabric. Many start with picking the color of the fabric for their boat's sail. Everyone at the station is two or three, so the teacher decides to cut the sails for them in their choice of white, red, or blue. The children start to paint their sail with images of their imagination. They use fabric paint in jars and a brush. Maria tells the other four girls drawing with her, "I made a boat," holding up the white fabric for everyone to see. The teacher tells her "You made a sail for your boat. That is wonderful," and encourages Alicia to take any color she likes for her sail. Next to the table the younger girls are waiting to paint their sails and Paula tells Cloe in German "Das mache ich später. Ich male eins später. (I will do that later. I will paint one later)." The other five children are very busy with their sail drawings and it looks like she has to wait for a while.

The paint-your-own-painting station has a canvas for each child of the blue and red group, a palette, a smock, and oil paint. The teacher encourages all of the children to start by painting over the entire canvas so that no white can be seen, referring to other paintings they have seen before. As Lucas shouts that he is finished the teacher comes over and looks at his picture, telling him that it will be a very nice one; he should just fill in the background a little more - all the white bits. She suggests to mix white with some other colors or to draw something else. She also shows him how to wipe off the paint brush on a cloth, dip it into turpentine carefully, and wipe it off again. Lucas chooses pinkred to fill parts of the background, which is a nice color addition to the blue sky line on top of the painting and the green grass on the bottom. The sun is just under the blue sky, and in the middle lies a brown circle with a black edge and short back lines similar to sun rays. The children have a hard time with the idea at first but create beautiful paintings in the end.

Another station offers a colorful bead activity. The children need little help at this station, making their own necklaces or bracelets. The girls wear their beautiful creations immediately, while making more for friends or their mothers. At the last station the children can make leaf impressions using leaves, paint, paint rolls, and trays. They place a leaf on their paper, take a paint roll, and roll it 
over the leaf. While removing the leaf the children can see the patterns a leaf makes.
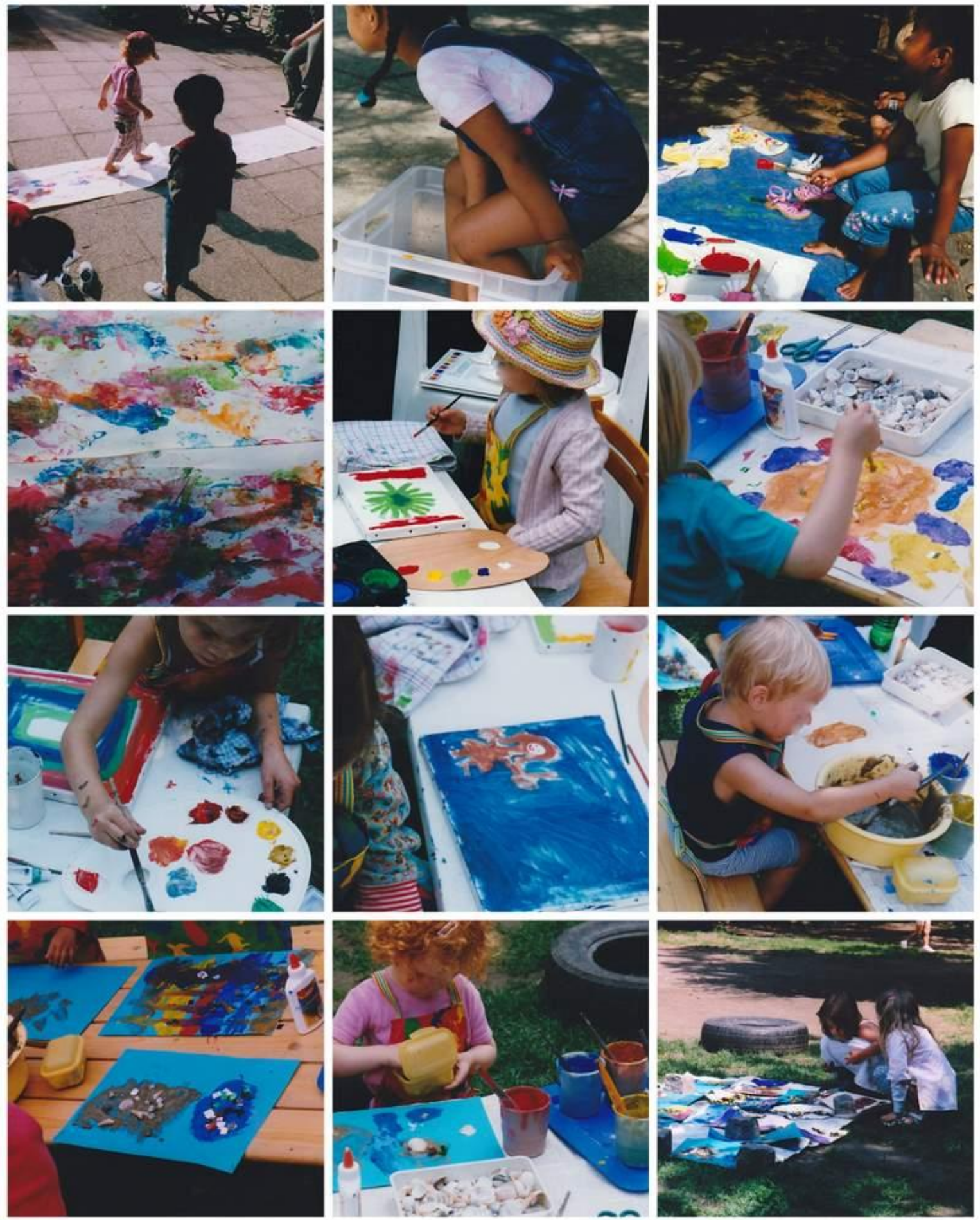

Figure 14. A.P.: Craft day painting activities and artwork. 

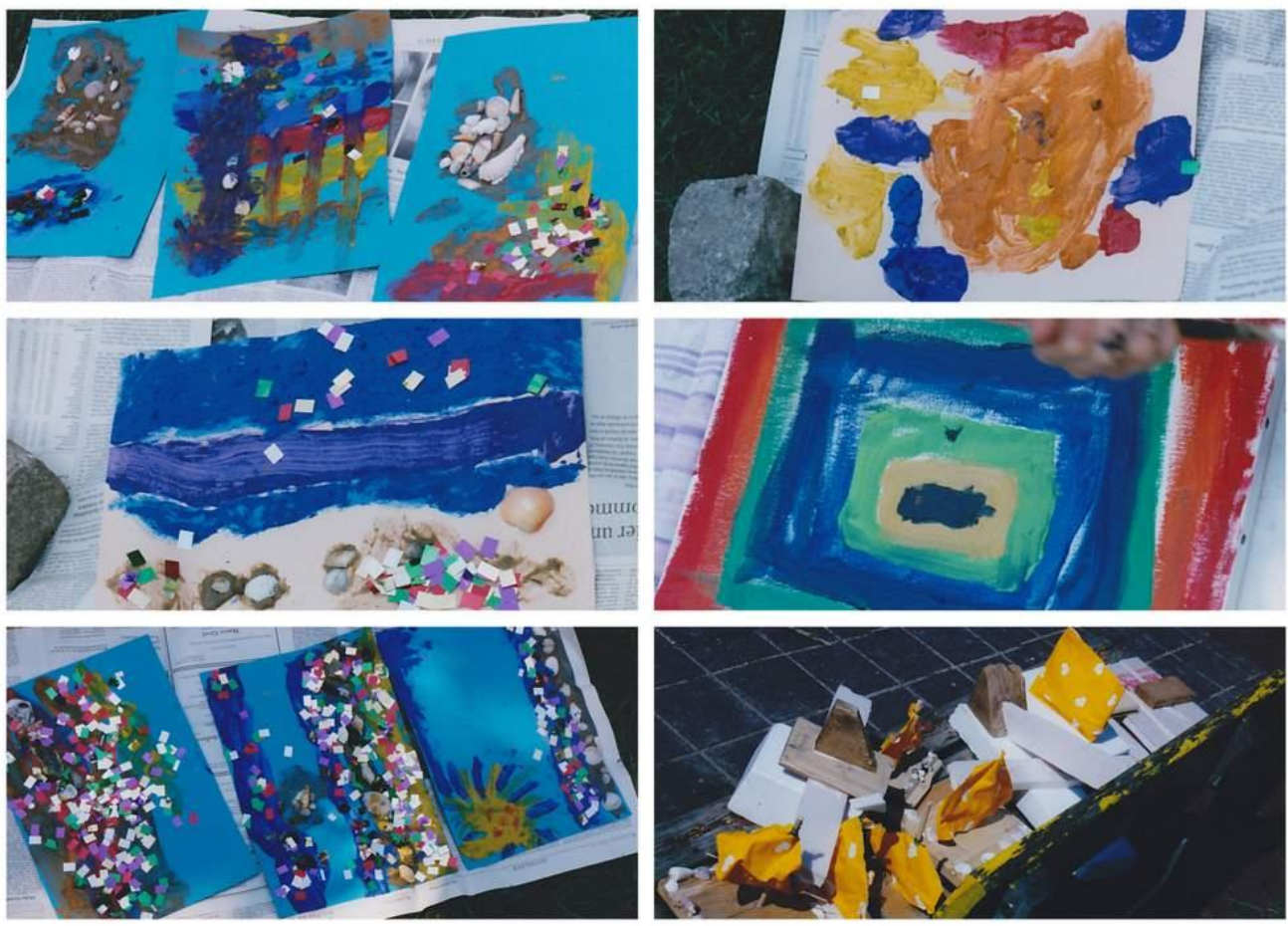

Figure 15. A.P.: Artwork about summer time and craft project "boat."
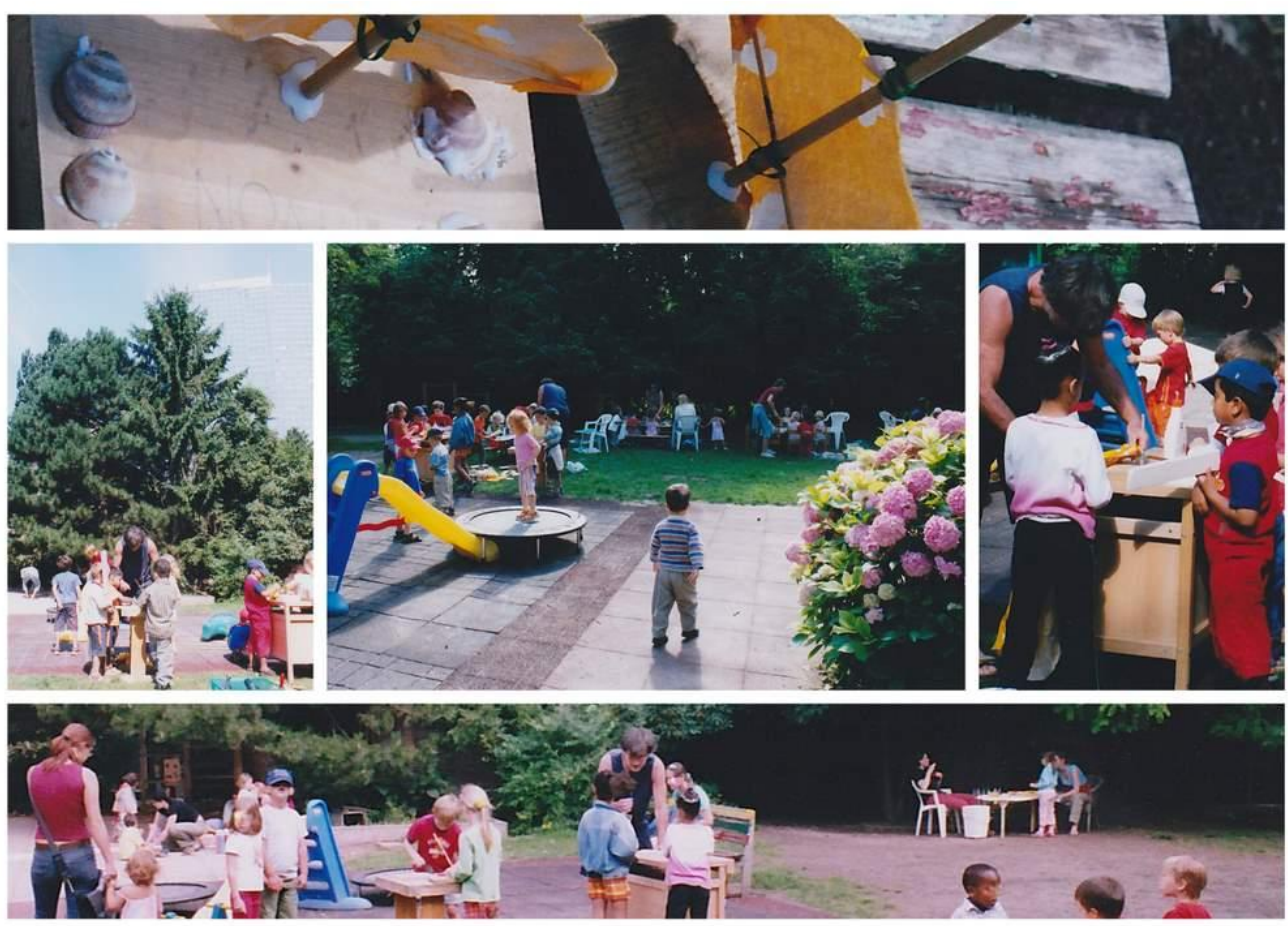

Figure 16. A.P.: Craft day impressions of the projects offered. 

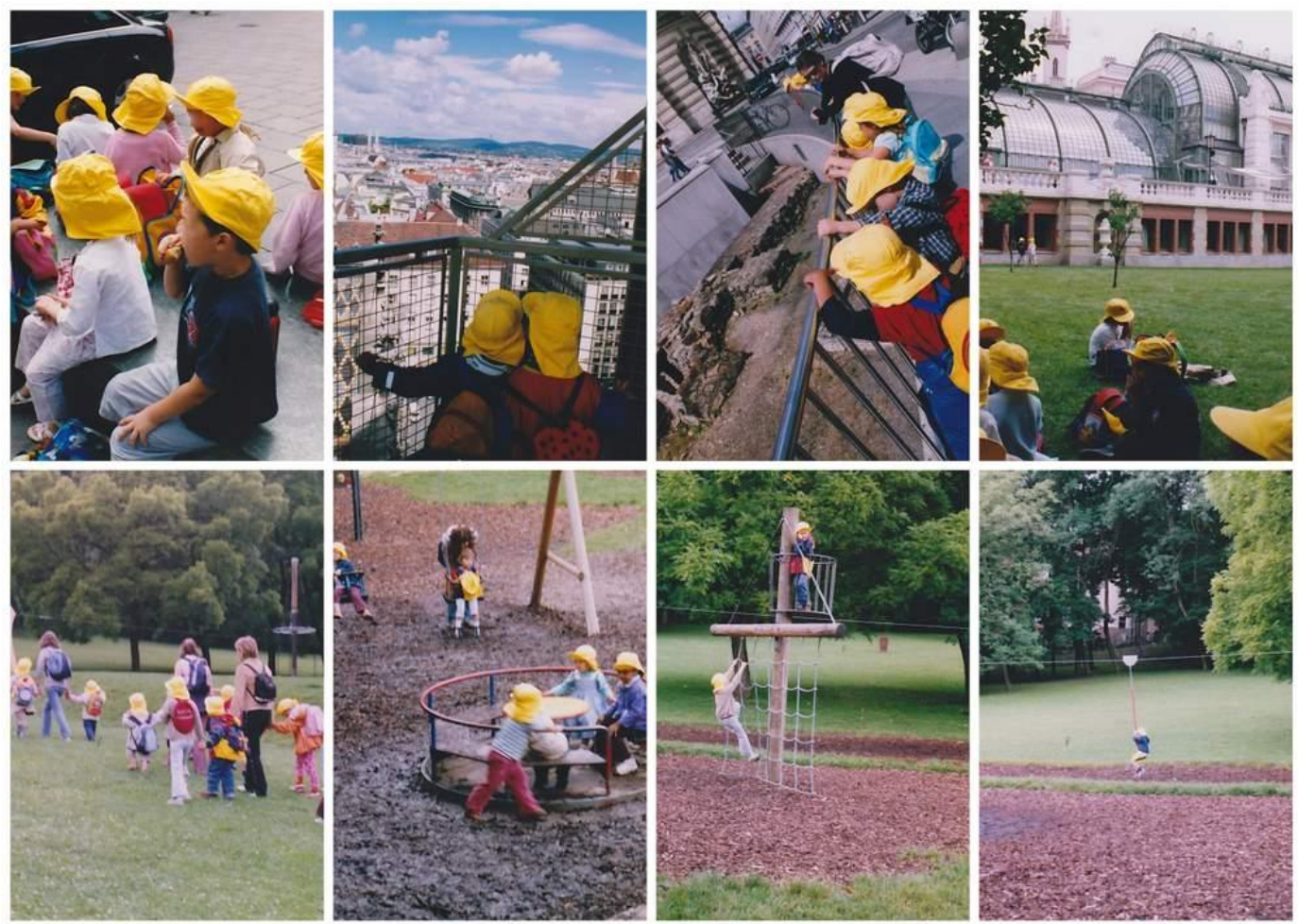

Figure 17. A.P.: Outings to the city and surrounding parks.

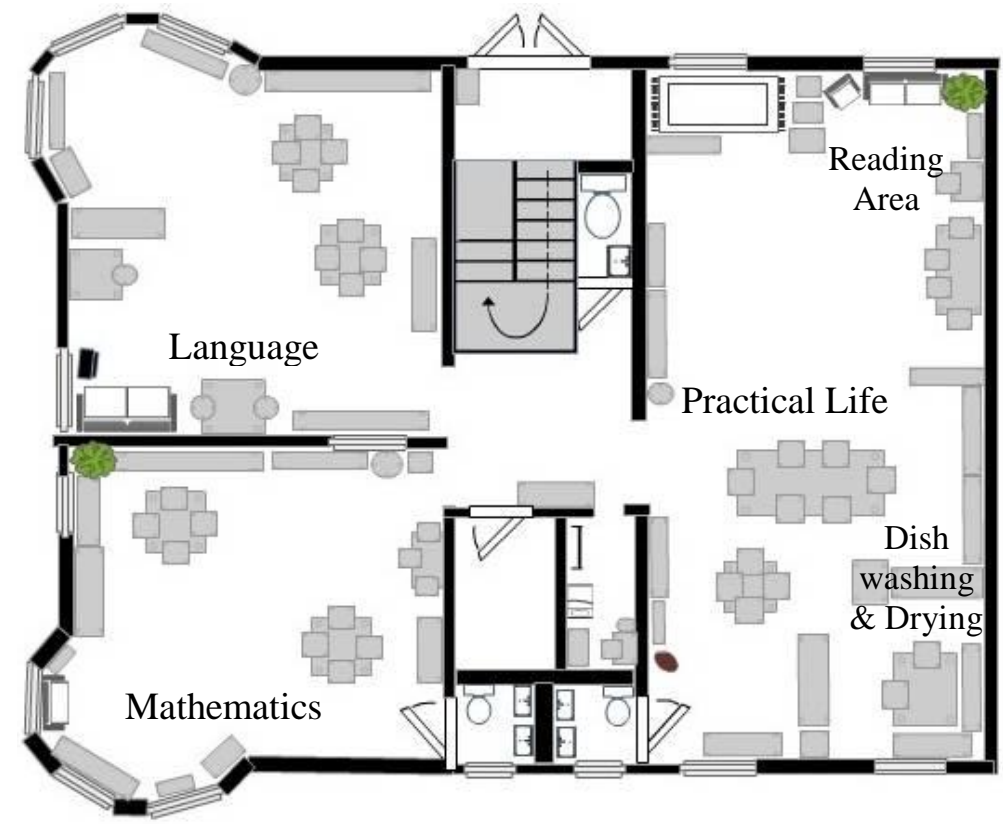

Figure 18. A.P.: Austrian program first floor layout. 


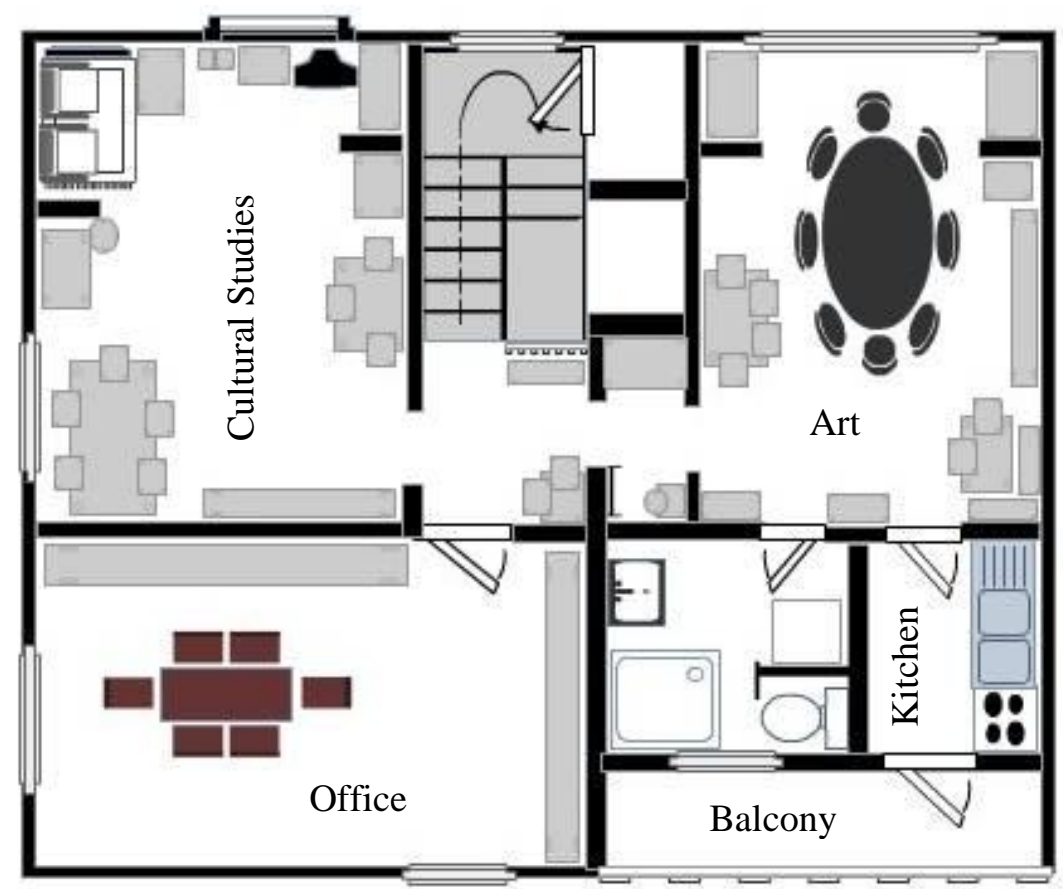

Figure 19. A.P.: Austrian program second floor layout. 


\section{Chapter 5: German Program Data Presentation - Public Kindergarten}

\section{Introduction}

The metropolitan municipality emphasizes integration and intercultural relationships in their leadership and politics to assure the principle of equal opportunities for all migrants in the city. Integration is viewed as a long-term process through which migrants become active participants in the core community and societal branches. Both non-migrants and migrants are responsible for a successful integration, embracing the community's cultural diversity while at the same time unifying on common interests. Furthermore, the city has focused on creating a child-friendly and familyoriented atmosphere through its communal policies such as education, transportation, and city planning.

The state's early childhood policies shape and influence the city's department of education through its division of early childhood education and afterschool care. Due to changes in the city's population, the office of intercultural pedagogy was established in the 1990s to supervise the professional development and performance of city education employees. The office's main focus is to place the importance of languages at the heart of intercultural pedagogy, since language is considered the door to equal educational opportunities for the children. The office of intercultural pedagogy has defined three major building blocks: the academic enhancement and furtherance of children with either German as their mother tongue or a different mother tongue and the enrichment of children in a foreign language. These basic principles evolved and were integrated between 2002 and 2009. However, the main focus has been placed on the enrichment of children with a mother tongue other than German.

The kindergarten program utilizes the situational or emergent approach and intercultural pedagogy in its professional work. It has included English since the late 1990s, long before the development and integration of the three building blocks. The English integration takes place throughout the day and as desired by the children, as well as in the enrichment program. The program director has been working together with the division of early childhood education for about twenty years to bring English into the cities' kindergarten pedagogy. Educators have also been trained in intercultural aspects and methods. Languages and their cultures are welcome and applied or theme-based according to the needs of the children.

The main language of the program is German. Therefore, the observations have been translated into English, and the original German or other language will be provided with the 
translations in parenthesis as needed. When English or languages other than German were used during the day, the text is typeset in bold and italic.

Following the program's concept, it is open all year from 7:30 a.m. to 5:00 p.m. on Monday through Thursday, and until 4:00 p.m. on Friday. The kindergarten has two family-oriented groups with 25 children each, and the children are between the ages of 3 and 6 . Each group has two certified teachers and one certified aid. The parents can enroll their child as an all-day, morning (7:30-12pm), morning and lunch (7:30-2pm), or afternoon (2-5pm) participant.

At the time of observation, the expenses for the families were scaled according to the income of the household. For example, for an income below $€ 15,000$ the kindergarten is free of charge, an income of $€ 30,000$ requires a monthly fee of $€ 80$, and above $€ 150,000$ the fee is $€ 160$ per month. Additionally, the parents have to pay a daily fee of $€ 2.90$ for food and drinks. However, the morning and afternoon snack must be provided by the parents.

\section{Concept and Curriculum}

Each city kindergarten has to write and submit their educational concept and information for parents to the city's supervising office. This concept provides an overview of the facility and its opening hours, the rights of children, the teaching team, educational goals and objectives, the yearly schedule with traditional celebrations and educational projects, information for parents, collaboration and parental involvement, and public relations.

The curriculum is based on the following educational goals and objectives, which are listed and described in the concept: social development, language development, creativity, music and eurhythmy, nature and environment, health and nutrition, tradition, meditation, and relaxation. Special offerings are theme-based projects, English in the kindergarten, music enrichment, language enrichment, parental or family counseling, projects with regular parental involvement, and school preparation and enrichment for 5 and 6 year old children who are in their final year of the program.

The teachers describe their expectations of the children upon completion of the program and explain their role as pedagogue as follows:

They [the children] should be able to solve conflicts, find their way in their later life, and be ecologically aware; practice tolerance and helpfulness, that means to learn about all areas of life. We [the pedagogues] define that as the pedagogy of the whole child. (Sie sollen Konflikte bewältigen können, sich im späteren Leben zurechtfinden, umweltbewusst sein, Toleranz und Hilfsbereitschaft üben, d.h. aus allen Bereichen des Lebens etwas lernen. Wir nennen das Ganzheitspädagogik). 


\section{Daily Schedule}

\begin{tabular}{|c|c|c|}
\hline 7:30 - 9:00 a.m. & Arrival and Choice Time & $\begin{array}{l}\text { 7:30 to } 8: 00 \text { care provided by one } \\
\text { educator in one of the group rooms } \\
8: 00 \text { to } 8: 30 \text { the groups will separate } \\
\text { during this time }\end{array}$ \\
\hline 9:00 -12:00 p.m. & $\begin{array}{l}\text { Morning Circle Time } \\
\text { Choice Time inside and outside } \\
\text { Guided activities } \\
\text { Clean up and Toilet break } \\
\text { 2. Breakfast }\end{array}$ & $\begin{array}{l}\text { Mondays: Physical Education } \\
\text { Wednesdays: School Preparation } \\
\text { Education Activities ( } 6 \text { year olds) }\end{array}$ \\
\hline $\begin{array}{l}\text { 12:00 -12:20 } \\
\text { p.m. }\end{array}$ & Lunchtime & \\
\hline $\begin{array}{l}12: 20-2: 00 \\
\text { p.m. }\end{array}$ & Naptime (3 to 5 year olds) & \\
\hline $\begin{array}{l}12: 20-1: 00 \text { p.m. } \\
1: 00-2: 00 \text { p.m. } \\
2: 00-5: 00 \text { p.m. } \\
(2: 00-4: 00 \text { p.m. } \\
\text { on Fridays) }\end{array}$ & $\begin{array}{l}\text { Clean up ( } 6 \text { year olds) } \\
\text { English or project time ( } 6 \text { year olds) } \\
\text { Afternoon Circle time } \\
\text { Choice Time inside and outside } \\
\text { Guided activities } \\
\text { Snack time }\end{array}$ & \\
\hline
\end{tabular}

\section{Children and Parents}

The children attending the kindergarten live in the same neighborhood and are selected through an application process and interviews by the team. An "ease-in" concept is applied. Siblings have preference because of the educators' belief that it is important for siblings to be in the same group or institution. Another reason for this is to ease the parents commute. Children come from diverse family structures, different cultures, and different socio-economic groups to establish a good representation of the greater community and encourage social learning.

The age range is from just 3 to almost 7 due to the early summer observation time frame. Each older child has a younger buddy who he or she helps throughout the entire year. They look after one another throughout the day and walk together on outings. Especially in the beginning of the year, the older children help their partner learn the daily schedule and get dressed. The older children are role models for the younger children, which develops responsibility and empathy among the children.

There are twelve dual language learners, using two or more languages on a daily basis, though the main language within the program is German. The list of mother tongues includes German, English, Russian, Tibetan, Farsi, and several others (see Table 9). 
Table 9. G.P.: Children in the program

\begin{tabular}{|c|c|c|c|c|c|}
\hline & Children & Language & Age & Gender & $\begin{array}{l}\text { Comments \& } \\
\text { What do you think is a reason for the } \\
\text { preference? Please explain. }\end{array}$ \\
\hline 1 & Matthias & German & 5 & Male & $\begin{array}{l}\text { Mornings only, German is spoken by all } \\
\text { guardians and surrounding }\end{array}$ \\
\hline 2 & Heiko* & German & 5 & Male & \\
\hline 3 & Vivian & German & 6 & Female & FG, mother tongue \\
\hline 4 & Lana & German & 3 & Female & mother tongue \\
\hline 5 & Kevin* & German & 6 & Male & \\
\hline 6 & Chhang & German / Tibetan & 4 & Male & He has many friends who speak German. \\
\hline 7 & Zaid & German / English & 4 & Male & $\begin{array}{l}\text { The kids were born in Germany and they } \\
\text { grew up with German language! They } \\
\text { started crèches at an Early stage so that's } \\
\text { their main language. }\end{array}$ \\
\hline 8 & Malika & German / English & 6 & Female & $\begin{array}{l}\text { FG, The kids were born in Germany and } \\
\text { they grew up with German language! } \\
\text { They started crèches at an Early stage so } \\
\text { that's their main language. }\end{array}$ \\
\hline 9 & $\mathrm{Nico}^{*}$ & $\begin{array}{c}\text { German / (Polish, } \\
\text { Thai) }\end{array}$ & 6 & Male & FG \\
\hline 10 & Sara & German & 6 & Female & FG \\
\hline 11 & Michail* & German / Russian & 7 & Male & FG \\
\hline 12 & Anielle* & German & 4 & Female & \\
\hline 13 & Sophia-Maria & German / Slovak & 3 & Female & \\
\hline 14 & Antje* & German & 4 & Female & \\
\hline 15 & Nassir* & German (Arabic) & 5 & Male & \\
\hline 16 & Conrad* & German & 5 & Male & On vacation \\
\hline 17 & Lena & German (English) & 5 & Female & mother tongue \\
\hline 18 & Mario & German & 6 & Male & FG \\
\hline 19 & Lucas* & German & 4 & Male & \\
\hline 20 & Thomas & German (Farsi) & 6 & Male & $\begin{array}{c}\text { FG, focus is German, German is the } \\
\text { mother tongue, language of the } \\
\text { environment }\end{array}$ \\
\hline 21 & Patrizio & German / Italian & 5 & Male & $\begin{array}{l}\text { German is more spoken at home, friends, } \\
\text { family, grandparents, kindergarten ... }\end{array}$ \\
\hline 22 & Victor* & German / Russian & 5 & Male & \\
\hline 23 & Danush & German / Farsi & 5 & Male & \\
\hline 24 & Janesa* & $\begin{array}{l}\text { Macedonian } \\
\text { (German) }\end{array}$ & 3 & Female & \\
\hline 25 & Manja* & German & 4 & Female & $\begin{array}{c}\text { Mornings \& Early Afternoon } \\
\text { On vacation }\end{array}$ \\
\hline 26 & Marie* & German & 5 & Female & Afternoon only \\
\hline 27 & Rosi* & German & 5 & Female & Afternoon only \\
\hline
\end{tabular}

Explanation: Language/Language = language use in kindergarten / at home; (language) some language skills, * information provided by the program; FG: Participation in in-house enrichment program prior to school 
The parental questionnaire that was distributed to all caregivers and parents of all children in the program shows that children live multilingual lives in their homes and that German has a dominant role (see Figure 20). At the same time a wide variety of languages are spoken. I received 18 questionnaires representing twenty children due the fact that there were two pairs of siblings whose parents filled out only one questionnaire for both children.

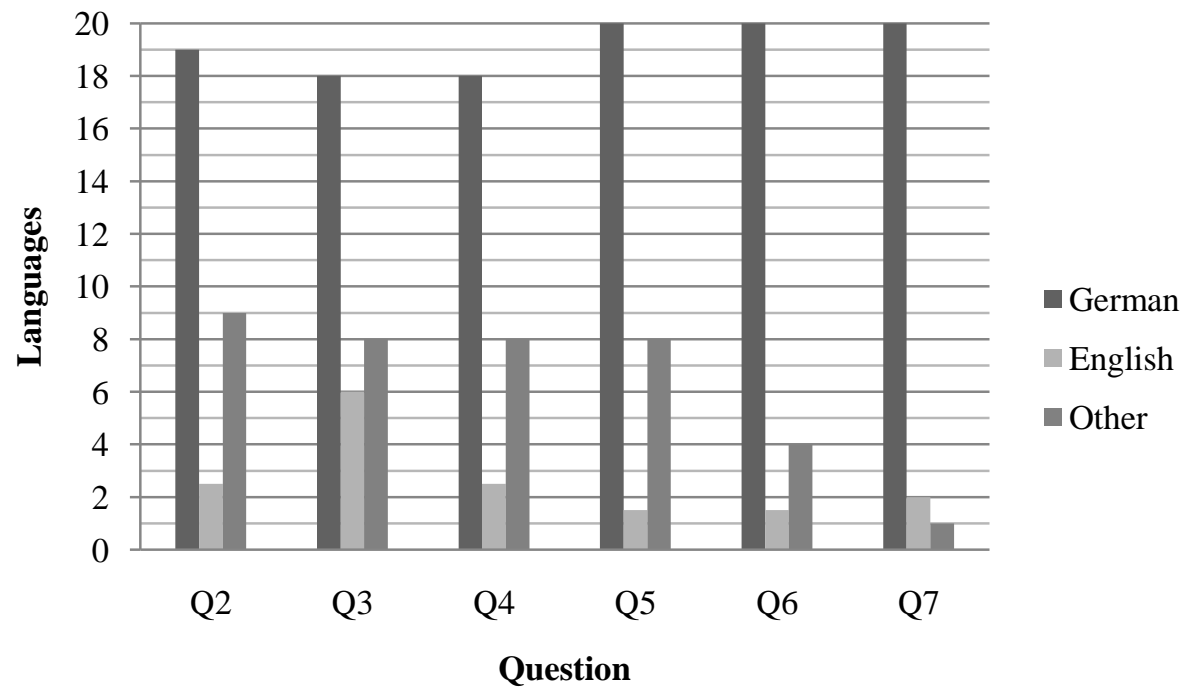

Figure 20. G.P.: Answers given by parents in the questionnaire. The following questions were asked: Q2: What language(s) are spoken at the child's home? Q3: What language(s) did your child know prior to kindergarten? Q4: What language(s) are mainly used in conversation with your child? Q5: What language(s) does your child understand? Q6: What language(s) does your child speak? Q7: What is your child's language preference? Under Other languages the following language were listed: Q2: Farsi, Italian, Farsi, Tibetan, Slovak, Spanish, Russian, Italian, French; Q3: Farsi, Italian,

Farsi, Tibetan, Slovak, Spanish, Russian, Italian; Q4: Italian, Farsi, Tibetan, Slovak, Spanish, Russian, Italian, French; Q5: Farsi, Italian, Farsi, Tibetan, Slovak, Spanish, Russian, Italian; Q6: Farsi, Tibetan, Spanish, Italian; Q7: Spanish.

Parents provided the following reasons for sending their child to this program: multilingual focus, English integration, proximity to their homes, and simply by accident. The parents' answers included the following language specific motivational aspects:

- because languages are very important

- $\quad$ Foreign languages $=$ the future!

- The English-project is part of the main concept of the kindergarten, which was the main reason to send my child to this institution.

- closeness and multiple languages

- As an advocate for foreign language learning, I think that children need to start as early as possible.

- because languages are very important

- $\quad$ to provide the possibility to learn English 
Additionally, parents see the role of world language learning in the program as either very important or important (see Figure 21). Only two parents state that is has no significant role in their eyes.

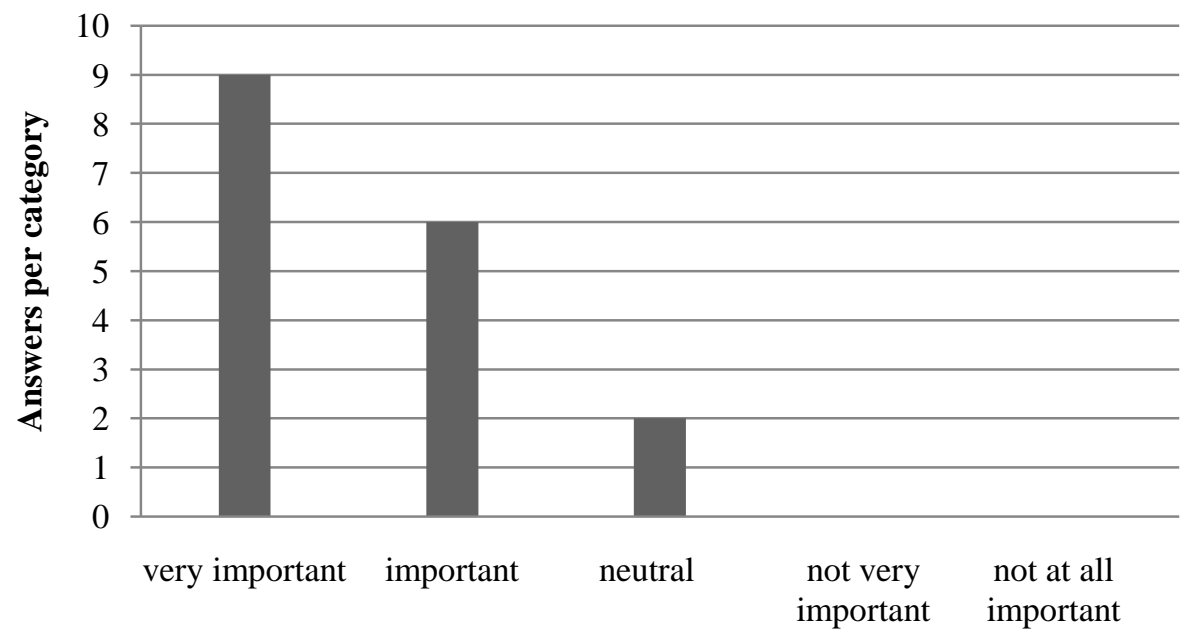

Importance categories

Figure 21. G.P.: Parents' answers to their perceived importance of world language learning in kindergarten.

\section{Team}

The observed group has two state certified full-time educators and one full-time certified assistant. The educators have a high school diploma or equivalent, and have a diploma as educator, which involves a three year program: two years of theoretical education at a public academy for social sciences with accompanying internship, and one year of work experience. The assistant has a degree as a childcare worker, an education program which can last from two to three and a half years according to the school diploma and work experience. The first part focuses mainly on theory and lasts for 18 months, while the second part focuses on work experience.

The head educator is also the program director and therefore attends to administrative tasks according to demand. She conducts regular meetings for the committee for English in Kindergarten, and offers workshops through the city's professional development program. The second educator assumes the role of group leader. 


\section{Physical Layout}

\section{General Information}

The kindergarten is part of a large apartment and business building complex. The demand for a public/city kindergarten in the area led to remodeling a small part of the ground and basement floors of this facility in the mid 1980s, and the kindergarten opened its doors in the summer of 1994. The facility has two large education rooms, each with a preparation and storage walk-in closet; a small education room; an office; a kitchen; and a children's bath- and restroom on the ground floor. The basement has a huge all-purpose room and three storage rooms. The outdoor area provides a sand area with willow igloo, a water play area, and open space.

\section{Entrance and Hallway}

While approaching the entrance you find several children's bicycles and scooters parked to the right just under the kitchen window. To open the glass door one has several bell choices, including the office, kitchen, or group rooms, all of which are connected through an intercommunication system. The narrow window next to the door provides information about upcoming parent events. There is a rotating sign attached to the door that has been created by the children. It is a collage representing the forest project and announcing when the next forest day will take place. A tall yucca plant and an umbrella bucket are placed to the right of the entrance. On the walls are several different big collages celebrating birthdays, good-byes from the school children, innumerable small and big picture frames, and additional information sheets. On the right is the office for the program director and meetings. To the left is a fully functional kitchen where lunch is freshly prepared daily by the lunch help. Next to the kitchen door is a blue, child-sized bench (see Figure 22).

Above the second door a sign stating Warm Welcome (Herzlich Willkommen) is attached and as you step through the open wings you enter the main hallway, which is long and curves to the left. The hallway feels inviting, happy, and alive, and it looks colorful and carefully decorated with children's art hanging on bulletin boards or cloth lines. The well designed bulletin boards fill the wall space above child-sized benches and cubby areas, which provide a shelf and hooks for the children's clothing. Each child's place is marked by a symbol chosen by the child, providing storage for their indoor and outdoor shoes.

The first two bulletin boards inform about English projects and the current headline reads Our Discoveries in the Forest. Drawings of the forest with, for example, trees, leaves, and pine cones 
are placed below and natural materials such as branches, pine cones, and roots with their German and English names are just beneath these drawings. An explanation on the board, written by the English coordinator, describes the project activity. On the clothes line are the children's colored drawings from the farm trip.

The first room is next on the left and belongs to the Squirrel group. The door has a big painted tree with a squirrel sitting on a branch and the leaves feature pictures of the children in the group. The photos present the pairs of children: an older child with a younger one, paired to help and support each other throughout the year. To the left of the door is a pin wall with information about up-coming events, news, song text copies to take, and a map that shows the forest area. Underneath stands the wooden food cart which has hooks for the children's snack boxes. Right across is the parental information area set up by the parent advisory committee for the kindergarten. The committee is introduced by their names, professions, and photos on a boat's sail,, representing how their support for the educators allows the kindergarten to function smoothly. There is a lot of information for the parents about the kindergarten, the city's department of education, the division of early childhood education, afterschool care, and other organizations that offer support to parents in raising their children.

Along the left side of the hallway, between the first and the second room, tables with orange velvet table cloths are set up and a food train is displayed. The wooden train engine is first and the following carts are made by the children, carrying samples of different healthy food groups, which range from fruits and vegetables to drinks and animal products just to name a few. Across are more cubbies and benches, above which are two bulletin boards concerning the development of the 6 year olds, with pictures of their projects and their visit to a bakery. A big poster of an oak tree on a blue background lies in between the bulletin boards. The leaves are wishes made by the children. A clothes line is strung in a zig-zag-pattern from one side of the hallway to the other, and examples of self-made paper hang in the entrance area. Toward the end of the hallway is a summary of a weekend trip to a farm.

Next are a gate and a railing securing the path to the basement, across from which is the door to the Root children's room along with their pin wall and food cart. Along the adjoining wall are more cubbies and benches; above is a 10 foot bulletin board that has a huge house on it with drawings by the children representing a window into their thoughts. There is a storage room and across is the woodworking station. The work bench has an organized tool system and several boxes with wood pieces of different sizes, shapes, and thicknesses. Each tool is painted on the backdrop so that the children know where it belongs. A few steps past the station is the children's restroom. Each child 
has his or her own towel, which is washed by the kindergarten. Across is the adult restroom with a shower and teacher cubbies. Another tall yucca plant is placed next to the door leading to the outdoor area.
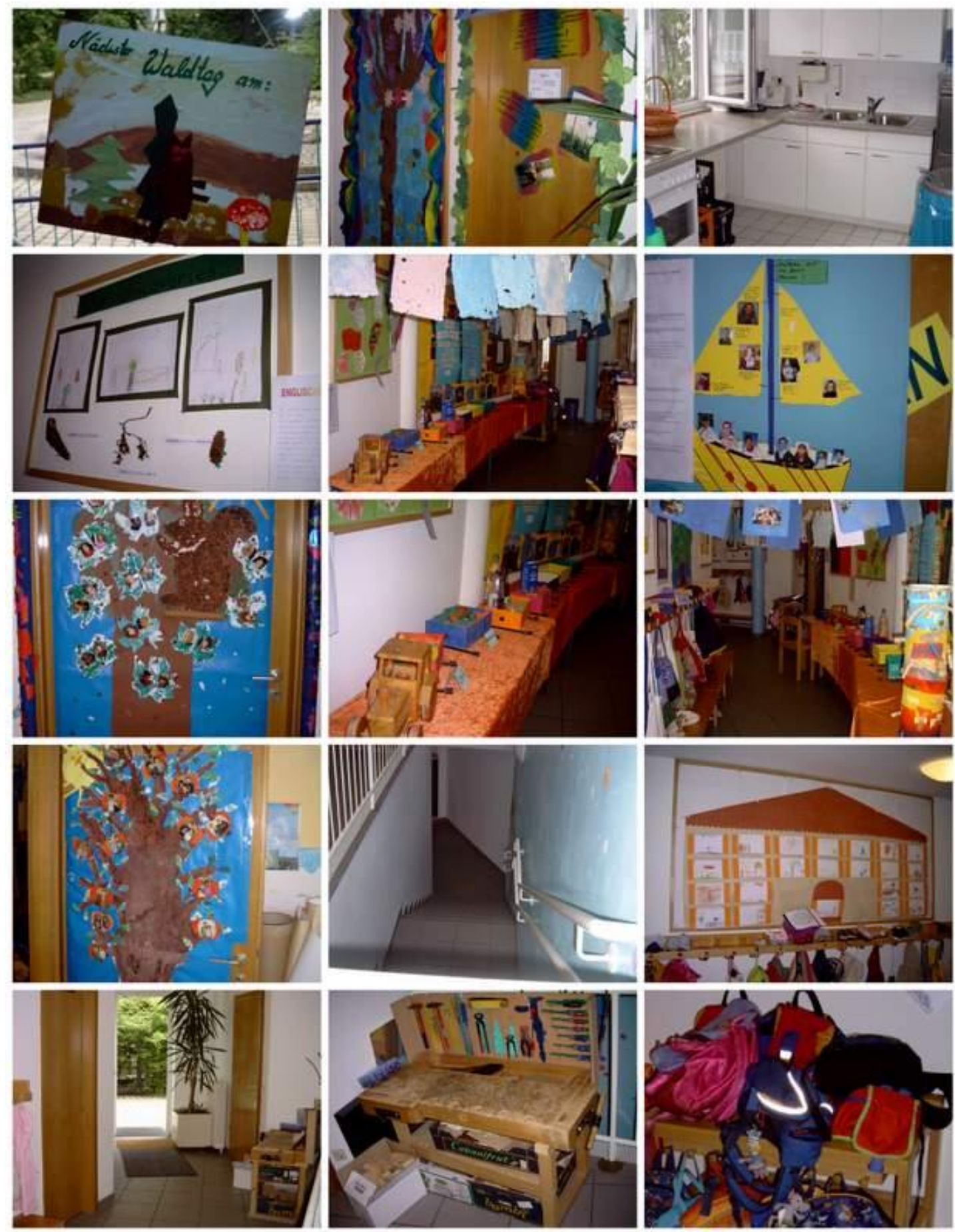

Figure 22. G.P.: Entrance and hallway of kindergarten. 


\section{Basement, Outdoor Area, and Playground}

A metal gate leads downstairs a big painting fills the wall space with a rainbow, butterflies, bees, lots of bubbles in the colors of the rainbow, and a child holding her arms into the air. The hallway has several doors that lead into small storage rooms or a large multi-purpose room (see Figure 23). On the walls hang posters made by parents and teachers to express their educational expectations of one another. At the end of the hallway is the market center where two children are allowed to play. The last door, which is to the right of the market center, leads into the largest room of the kindergarten. This room is used for physical education, nap time, choice time, and other group events. The center of the room is open and all materials and furniture are placed along the walls. As you enter the room two white boards are attached to the wall on your left. A double stall bare is next; it is attached to the wall but can move at a 90 degree angle into the room and anchored to the floor. A couple of feet away a beam is attached to the ceiling on which ropes, now hidden in the wall space, can be lowered into the room. A gymnastic bench (about 13 feet long) is placed on the wall and next is a door that leads into a storage room with sport materials and outdoor play materials such as tricycles and scooters. On the next wall is a puppet theater stage high enough for adults to stand while presenting a show. It is as tall as the ceiling and the front is covered with blue felt material. The window opening is about six feet wide and two feet high. The curtain is closed and in the back are traditional German puppets on a puppet rack. Next are deep storage shelves that hold blankets, pillows, and mats for nap time. These items are organized by the children's names. On top of these shelves are mats.

A teacher's desk is next, then another bench (about 10 feet long) is placed under the window. Thick, rolled up mats are placed along the wall and two mats (about a foot thick) are strapped to the wall. There is another bench under the second window of the room. A gymnastic bench (about 13 feet long) is placed on the adjoining wall and leads to the entrance door. There are a few support pillars set about four feet in from the wall to provide support for the weight of the building. The

ceiling is painted light blue with a sun and white puffy clouds, and the wall to the right of the entrance is painted light blue with a rainbow.

The outdoor area is V-shaped with a good sized willow tree igloo, a sandbox area, a water play area, a potting and plant area, and a paved area for playing, biking, running, and so on. Due to the small playground size, several city playgrounds are visited regularly, providing an interesting and unique playground experience for the children. During my observation time, three different playgrounds were visited within a walking distance of 3, 10, and 15 minutes respectively. The closest playground is part of the apartment building complex and is rarely visited in the mornings because 
children are at school or in kindergarten. The other two are part of the city and community park system. The playgrounds have climbing equipment of different shapes, slides, swing sets, sand pits, water play and water pipe systems, and towers.
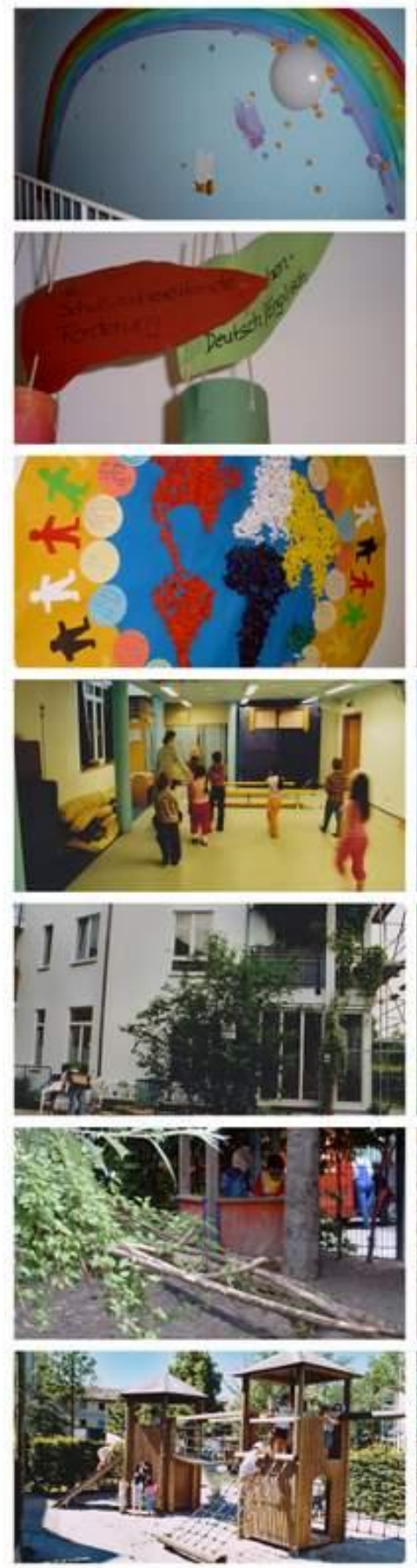
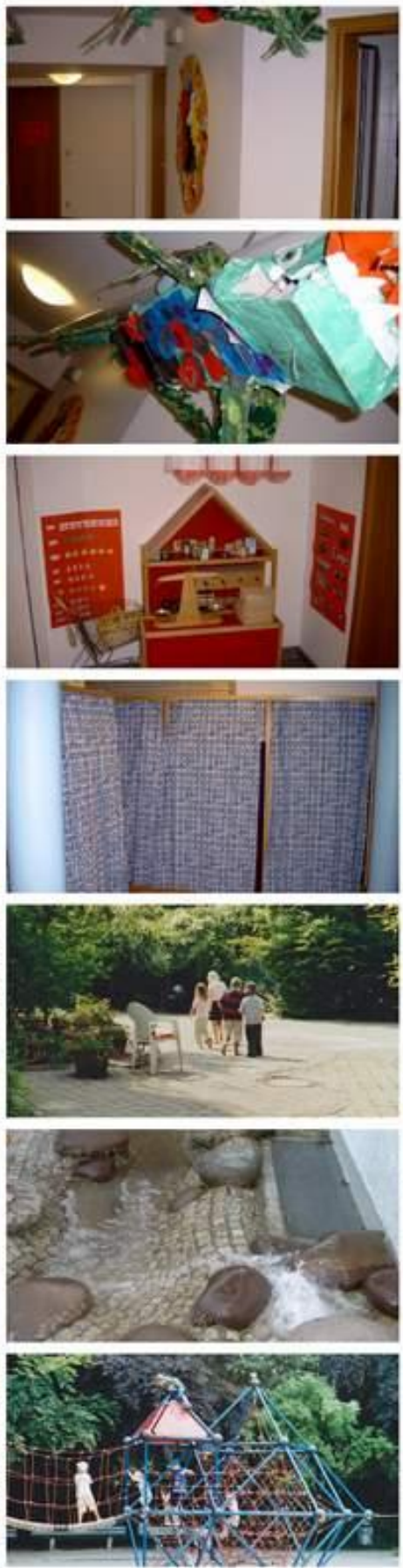

Figure 23. G.P.: Basement and outdoor area of the kindergarten and playgrounds in the surrounding area. 


\section{Group Room}

The group room was light, airy, soothing, and stimulating at the same time (see Figure 24 and Figure 27). Through the interesting, theme-oriented decoration the room felt friendly, open, and welcoming. The children and educators work together to decorate the room week by week. On the door is a big painted tree with pictures of children to introduce the group to visitors and families. Each photo has two children, an older and a younger child, representing the peer partners. Every year the older children adopt a younger child as they start kindergarten at the age of three and help them to get dressed and go to the bathroom while going on walks or trips. During the first parent evening the parents of the grouped children get the chance to get to know each other.

The two exterior walls are filled with windows and French doors that open to the outdoor space, which makes the room feel even bigger. The room features several activity centers and play

areas. As you enter the room, a small reading station with books about animals and their biotopes and farm and animal stories are displayed. Next to this station is a storage unit with 20 drawers. Each drawer has the name of a child and their sign. For example, Vivian has an apple tree as her sign and it tells me immediately what she likes. The signs help children who cannot read yet to locate their storage space, clothes, or bathroom towel. Some of the younger children share their cubby drawer though there is another storage area for each child right outside the door in the hallway where jackets, changing clothes, and shoes are kept.

The carpeted block area is enclosed by shelves that provide cubbies and storage space for art materials, books, and blocks. Two willow baskets are filled with natural blocks made from branches or tree trunks. These blocks have different sizes and shapes, but all have one side with bark.

Between the two baskets an interestingly shaped branch is located. All blocks are traditional natural or colored wooden blocks, and additional differently themed accessories are provided such as farm and zoo animals, trees, transportation (train tracks, trains, stations, cars, trucks and tunnels), castles, and people.

The manipulative station on the left half of the window sill across from the block area has natural materials such as chestnuts, small and large pine cones, acorn caps, beech tree nut shells, pumpkin seeds, sea shells, small bark pieces, colorful glass gems, and geometric wooden pieces. These wooden pieces are natural color or blue, green, yellow, or red and are circles, triangles, diamonds, hexagons, small rods, or bell-shaped. They are arranged in round trays with individual compartments. Different fabrics offer a good background for the patterns and designs of the children.

The art and craft station occupies the right half of the window sill with a variety of paint, paint brushes, colored pencils, sharpeners, and markers. The storage unit has five large drawers, one 
has additional markers, crayons, pencils and more, the second has a variety of paint products - finger, water, tempera the third has a variety of different color and patterned paper, the fourth has a variety of white-shaded and textured paper, and the last drawer has scrap paper. In ten smaller drawers a variety of materials is stored such as different fabrics, wool, yarn, thread, weaving materials and needles, cotton, cork, wooden pieces, felt, and cutting tolls. The attached shelf stores plastic place mats and table cloths, a box with sponges, a box with recycled yogurt cups, a box with white paper, and a bucket with differently sized palettes. On top of the storage unit several things are arranged on a light blue runner: the book of the week, "Prince Franz in Love;" several instruments including a small xylophone, singing bowl, melody harp, and 8-note wooden tong drum; a Magic Tin, small plants, and candles. A big display bowl filled with green leaves, pink and white flowers, candles, and water stands on green tulle with origami paper flowers to create the impression of a beautiful meadow.
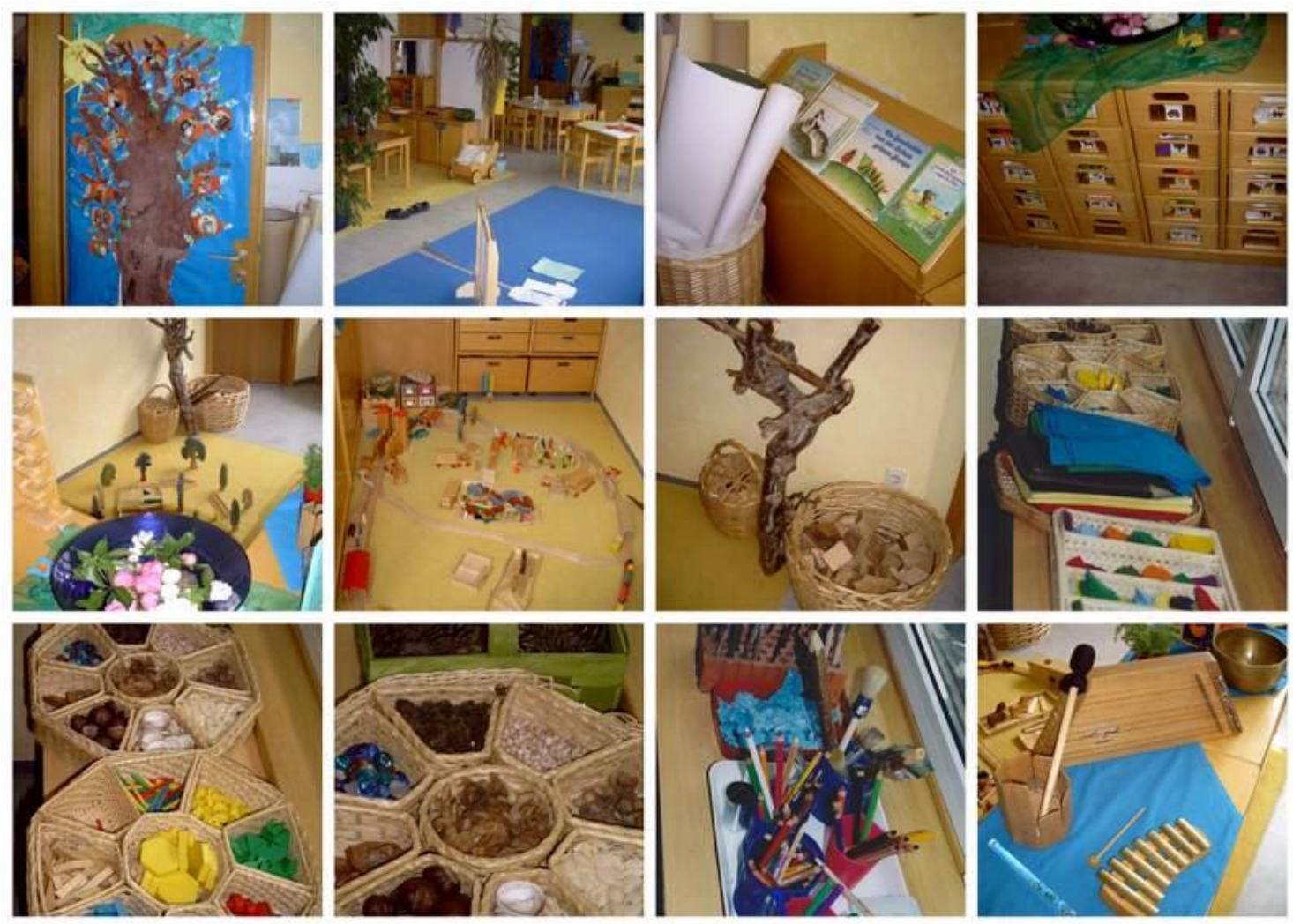

Figure 24. G.P.: Group room impressions of the block area and manipulative station.

The four tables provide seats for 22 children in the center of the room (see Figure 25). There are two rectangular tables seating six each, one square seating four, and two semi-circle tables seating a total of six. These tables are used for breakfast, lunch and snack time, as well as for arts and crafts and similar activities. The French door niche offers space for plants and smaller corner shelves that 
have yarn, needles, and baskets. In the middle of the general carpet area stands a big hanging octave chime instrument with hand-made paper and forest festival invitations to the right next to it. On the window sill stands a jade plant and a triangular shaped piece of bark with salt dough snails made by the children. An animal game is leaning against the window. Another plant separates the weaving center which has a small basket with yarn, thread, needles, and four child-sized weaving looms. The weaving projects show differently paced work and materials used. Another plant and the tree trunk marble roller lead to the doll house area. High above this area hangs a long branch with a colorful caterpillar, which is made of different paper circles, each of which have the name, birth date, and picture of a child in the group.
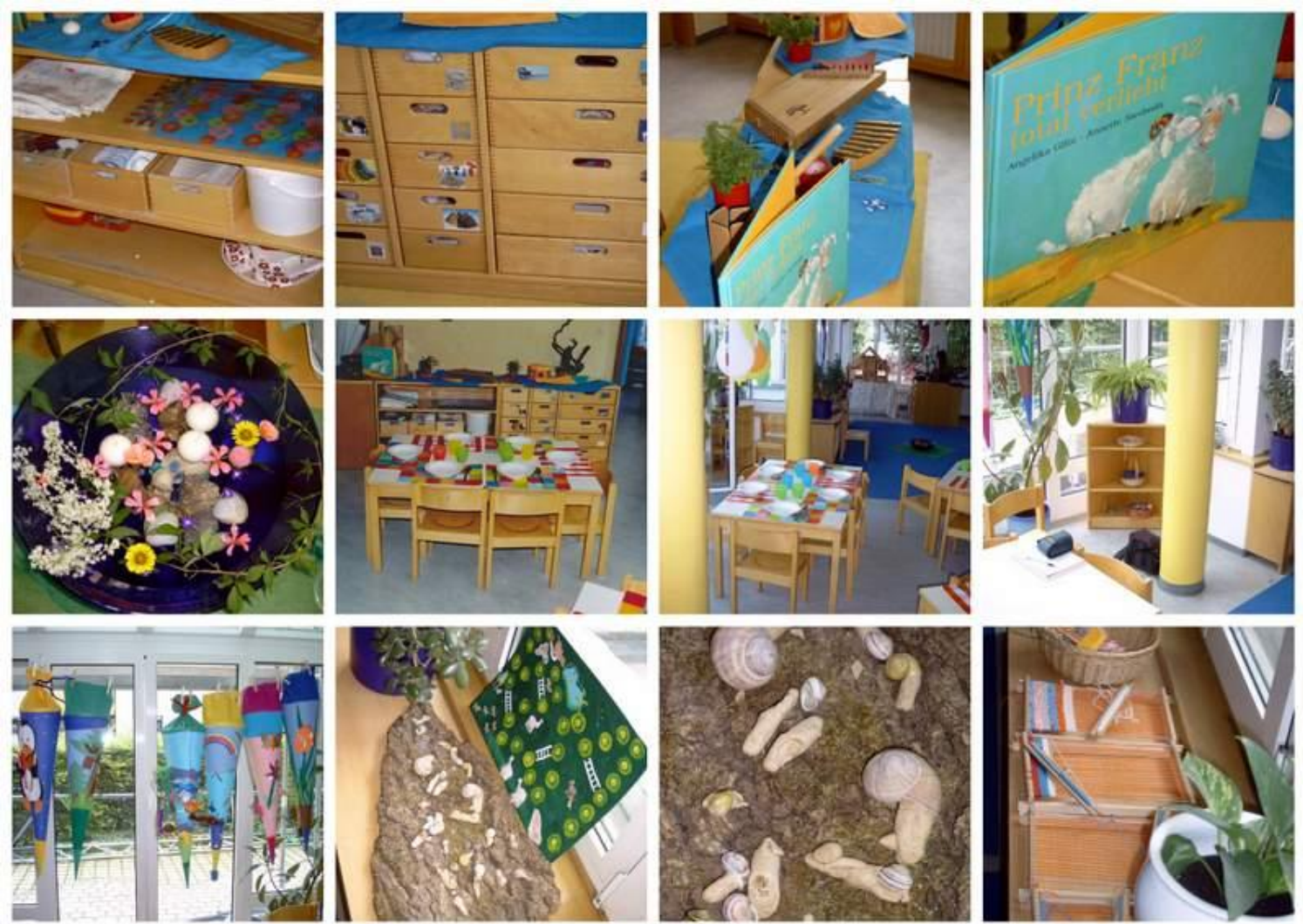

Figure 25. G.P.: Group room impressions of the art and craft station and children's creations.

A wooden doll house is in the center of the window niche, which is furnished with wooden toy furniture and dolls (see Figure 26). It has several bedrooms, a kitchen, a living room, a bathroom, and an attic. The area has window benches and oriental shawls hanging from the ceiling, which creates a unique lighting when the sun is shining through the windows. A large wooden xylophone is placed on the bench. 
To the left of the area are two shelving units, one with small drawers and one with open shelves. The shelves are filled with square and round colorful wooden parquetry pals pattern blocks activities, and big wooden puzzles with, for example, a farm theme. A variety of games such as memory, tic-tac-toe, and others are placed in the individual drawers. On top of the units is the magic or treasure table filled with treasures found in the forest, hand-made, or brought back from trips or vacations. Aladdin's lamp and oriental shoes are displayed as well as a box made by one of the children with her favorite things, a glass bowl with moss, small pieces of bark and twigs, large and small pine cones, three wooden mushrooms; several larger pieces of bark with moss and branches, plants and branches in a vase, coconut shells filled with colorful flat glass stones and marbles, and white sea shells in a plastic bag.

One table is placed in the kitchen block area, which has a sink with running water, several cabinets, a few shelves, and a stove. The cabinets and shelves store plastic cups and place mats, cutting boards, cloth napkins, water buckets, wash cloths, towels, decoration materials, the birthday surprise candle tin, and more. On top of the kitchen unit are several plants, a watering can, a small chalk board with the helper list, and a play clock.

The dramatic play area is separated by a large dream catcher hanging above a wooden trunk filled with dress-up clothes. From the ceiling hangs a large blue tulle canopy with yellow stars attached. On the floor is a yellow carpet with small blue patterns. A play table with four chairs and flowers is in the center. There are two doll cradles and one baby buggy; each with a doll, a pillow, and a blanket; a blue suitcase, and a play kitchen with pots, pans, plates, a stove, two phones, and a few cabinets. Two dividers, a mirror, and a white board separate this area from the rest of the room. There are two big plants: a palm and a fichus tree.

The backside of the room dividers holds magnetic chalkboards with colorful, shaped magnets and a funny mirror. The parental letterbox is hanging on the divider. It is used for questionnaires, communication, or problems. The door to the preparation and storage room is between the divider and teacher's cabinet, which has a phone and organizational materials. Above hangs a bulletin board with a calendar and postcards sent to the group. Another smaller fichus tree is placed right next to it. Next to the entrance door is the door intercom system, which allows teachers or children to open the front door so that the children can be picked up by their parents.

The children have painted the lower part of the windows with a brown background, resembling soil, and red, yellow, and pink flowers. Just above the table in the French door area hang seven school cones attached with clothes pins on a clothes line made by the children who will begin school in the fall. 

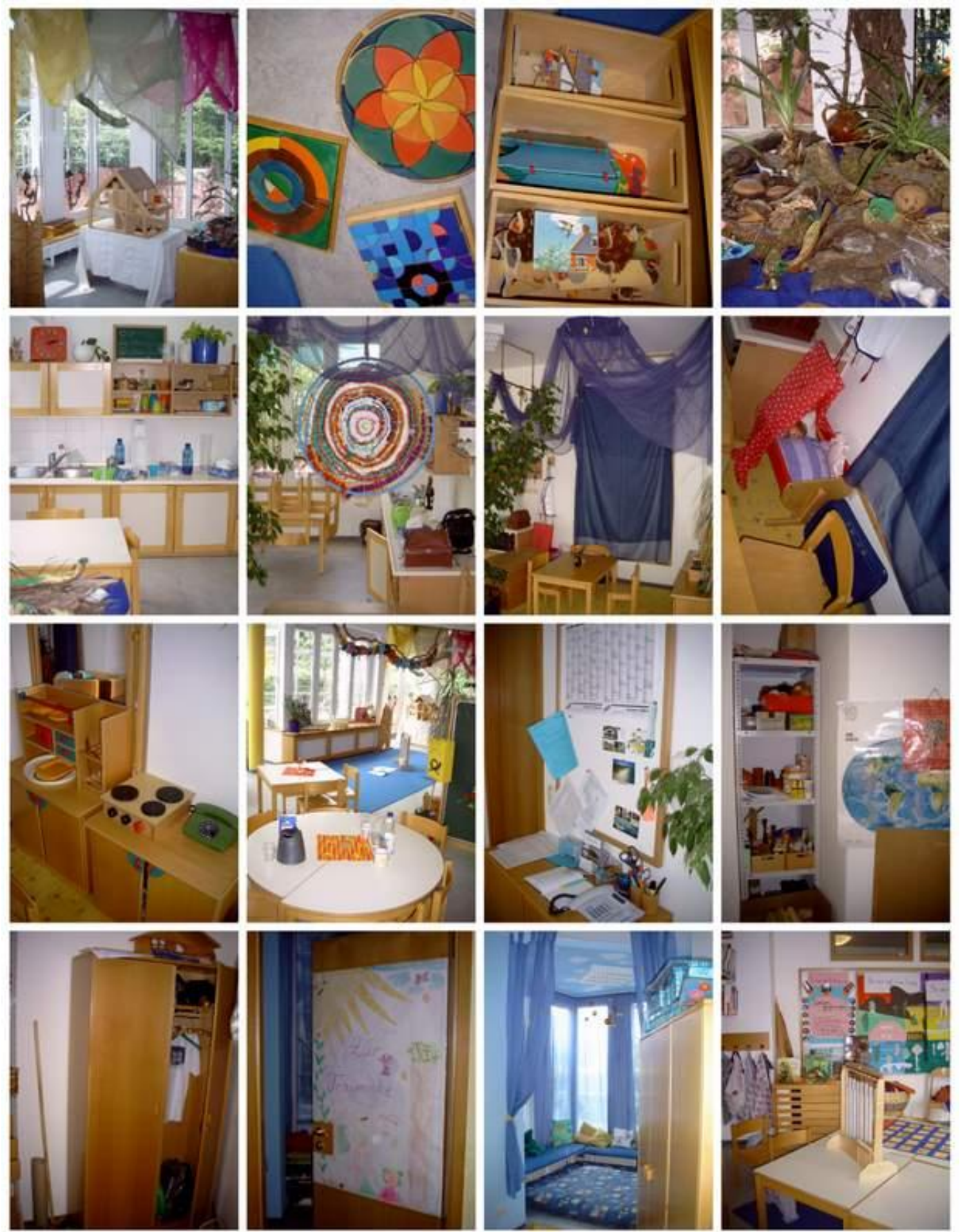

Figure 26. G.P.: Group room impressions, storage room and dreaming corner. 


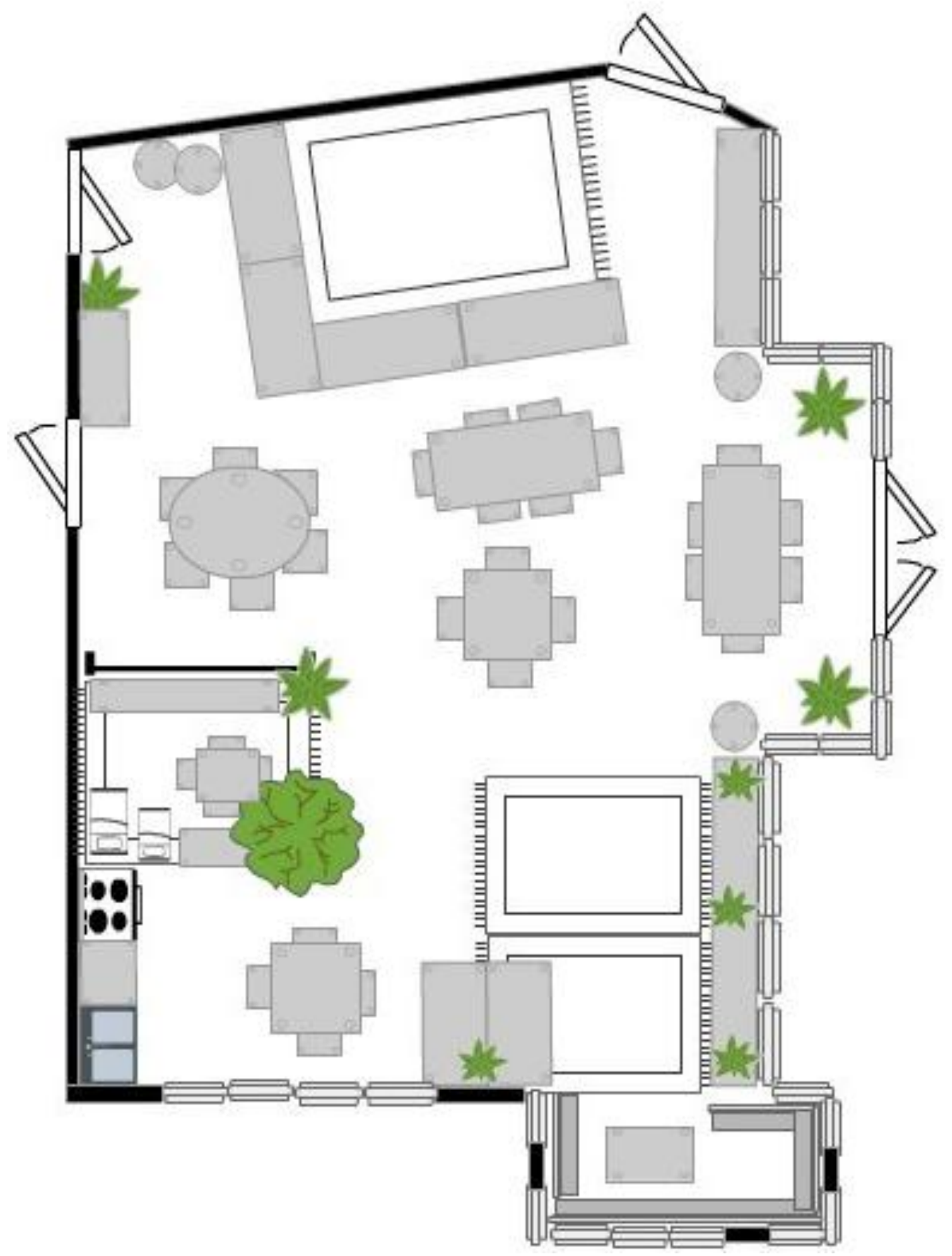

Figure 27. G.P.: German program group room layout. 


\section{A Typical Day}

\section{Arrival and Choice Time (7:30 to 9:00 a.m.)}

Today is Monday and the children seem to arrive later then during the rest of the week. At 7:40 there are only three children in the room. One child is drawing a picture while the other two boys quietly play in the block area (see Figure 28). The room feels sleepy and the children walk in quietly with some acting shy while others seem tired. They wave their parents good-bye while the teacher greets the parents in a friendly manner. The early arrival time from 7:30 a.m. to 8 a.m. is usually taken care of by one educator, and this week it is Mrs. V., who will be looking after the children of both groups until the others arrive according to their schedule.

Sophia-Marie enters with a sleepy smile and greets the educator. Her mother stands at the door observing her for a few moments, then waves good-bye and shuts the door. Meanwhile, the educator asks her if she has made a flower for Mrs. J., whose birthday is coming up. The girl shakes her head to show that she has not made one. Mrs. V. offers that if she likes to she could do it now, while pointing to the materials on the rectangular table in front of the French windows. Sophie-Marie takes a seat and the educator joins her so that she is able to see the entrance and welcome arriving children. Mrs. V. takes a piece of origami paper and guides Sophia-Marie, who has chosen a red piece. The educator leads her through the folding process by explaining each step. The girl follows the instructions, watching Mrs. V.'s hands carefully but she does not communicate; she is focused on following the demonstration. As other children join the activity a conversation starts about what they did yesterday. Meanwhile Sophia-Marie waits quietly to continue her flower and observes the other children. More children arrive and by 7:50 a.m. there are nine children present, of which five are creating origami flowers. The educator continues to explain how to fold the paper to create a flower.

Mrs. S. enters the room with a group of children. She greets the children and her colleague. She then goes into the preparation room to store her belongings. The noise level rises from sleepy to awake but still the room feels fairly quiet. The children disburse around the room, watching activities that are going on or just start playing with their friends. When the children finish their flowers they either go and color something or play with the small group in the dramatic play area. Four children are in the block area and a few more watch them. Five children are listening to the book Prince Franz madly in love, which Mrs. S. reads aloud, discussing the pictures with the group. Presently there are about 20 children in the room.

At 8:00 a.m. Mrs. R., the main educator from the other group, enters through the dream corner and announces that the children of the Squirrel group can now also play in their room. She 
reminds them to clean up their area and adds that if they would rather continue their play that would also be fine. The program has an open door policy which means that the children can play in the room of their choice during certain parts of the day, but they have to let an educator of each group know that they are leaving or coming. The children from Mrs. R's group give her a hug to greet her. Some return to their activities while others follow her into their room. Heiko enters, greets the teacher, takes paper from the art shelf, and takes a seat at the table across from the arts center where Anielle and Lena are drawing pictures of the summer: flowers, the sun, trees with cherries, and grass. He takes a seat across from the girls and starts folding the paper. After staring at his paper for a while he starts creating a paper airplane. Meanwhile, a few more boys enter and watch what he is doing. Finally, he says, "This is an airplane and it can fly very high." The other boys Matthias, Patrizio, Victor, and Danush get their own piece of paper and return to the table to create their own paper airplanes. As they return the girls finish, get up, and join the reading on the blue carpet to listen to the rest of the story. After the boys have finished their airplane and are ready to let them fly, Mrs. V. reminds them that they can do this outside later and for now they can place their planes into their drawer, which they do without hesitation.

By 8:50 almost all children are present with only a few of the older children having not yet arrived. Mrs. S. calls the children into the clean-up circle and asks them where they were playing and what they need to clean up. The children then return to their play areas, putting things away and cleaning up the area. After all things are put away, Mrs. V. places the flowers in a basket and covers it so that Mrs. J. does not see her surprise from the children. Mrs. S. tells the children to get a chair and to make a circle on the carpet so that they can start circle time in a few minutes. 

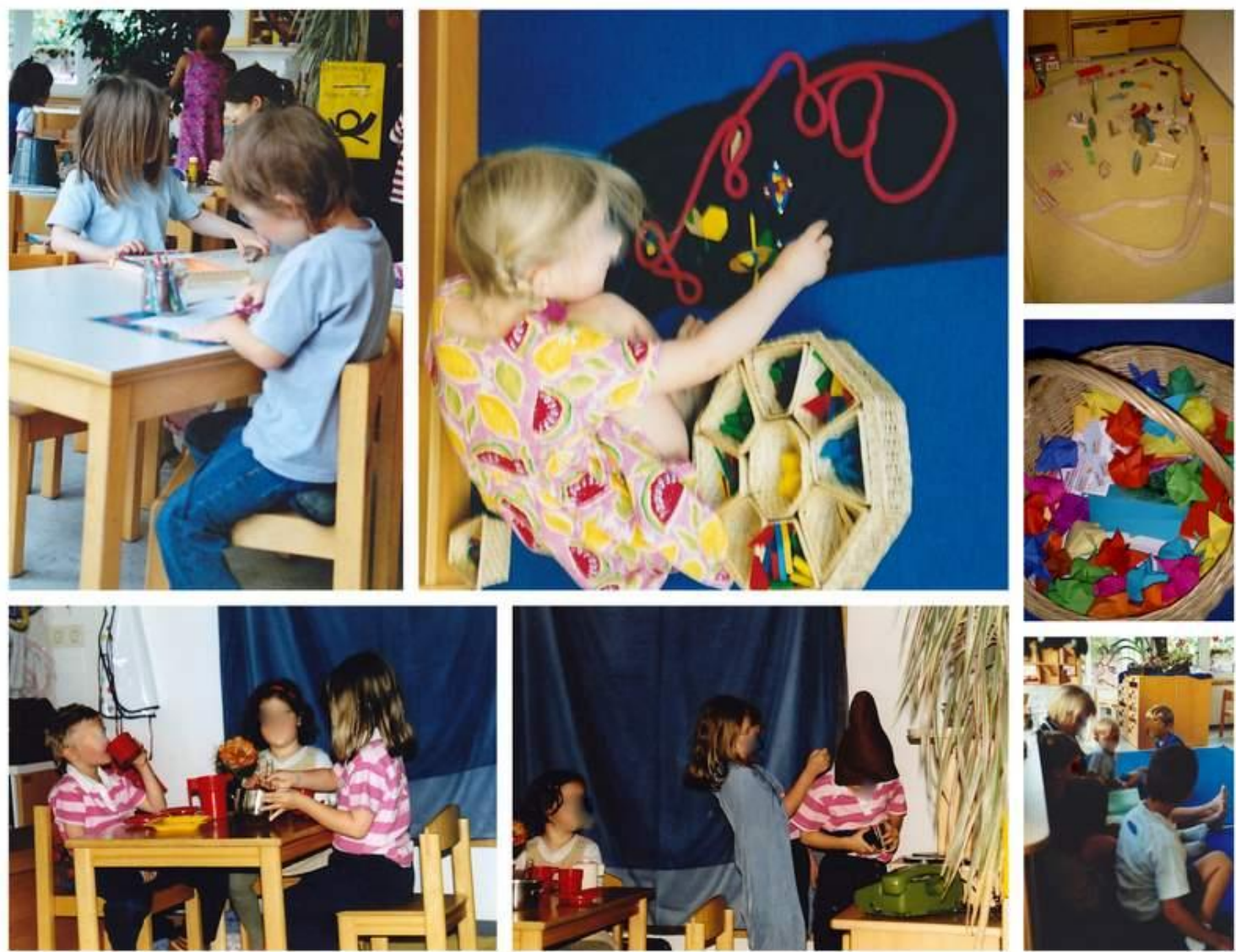

Figure 28. G.P.: Arrival and choice time impressions of child's play or activity and read aloud.

\section{Morning Circle (9:00 to 9:25 a.m.)}

(German is in Roman script and English or other languages are italicized and bold).

Mrs. J. tells the children that they are very quiet and that she likes this behavior. She has prepared the circle time by placing her red bag into the center next to the book the group was reading last week and the chimes (see Figure 29). The group and the three educators sit in a circle and wait for Malika, who comes in late. Her mother waves to the group as she closes the door. The girl takes a seat on the last empty chair in the circle and the educator says in English, "Good morning, good morning," and everyone replies, "Good morning," and she repeats in Italian, "Buongiorno," in Spanish, "Buenos Días," and in German, "Guten Morgen," and the children repeat the greeting with joy and lots of energy. The room fills with languages and wakes up every dreaming soul.

Mrs. J. then takes her basket and says, "I promised you to bring something connected to a wedding like the wedding in the book we have been reading. I have a surprise for you in here. What 
could be in here? Could it be sheep wool?" Everyone says "No" without hesitation and Sara adds "sheep?" "No, there are no sheep in here," answers the teacher while peeking into the bag and everyone laughs. Vivian seems to remember and says carefully, "a wedding dress," and the educator filled with joy says, "Yes, a wedding dress. The two were so in love. Actually, what is the name of the two?" Lena says "Gerda," and Michial adds "Franz." Mrs. J goes on to retell the plot of the book, Prinz Franz total verliebt (Prince Franz madly in love), with the help of the children who fill in the blanks or finish a sentence. She summarizes: Franz decides to get married and is on the search to find a women, but he has forgotten his glasses and can therefore not see all of the beauties lined up at his door step and must make his decision based upon how nice the girls are. The moral of the story is that beauty is not as important as a person's inner self.

Now, the educator asks Anielle to help her to take out the wedding dress, "my wedding dress, I also have a veil, but I forgot to bring it." A big "Oh" can be heard in the circle. The dress is white, long and has stitched tiny white daisies and green leaves starting at the knee and going to the floor. Anielle and the educator walk around the circle and show the dress to each person, many of whom take a long look and feel the material. She says, "You can try it on later during free play in the dramatic play corner, but you have to be careful because it is so long." Malika asks her, "Is this your wedding dress?" and the educator replies, "Yes, this is my wedding dress. You can play with it later and try it on. You cannot run with it because it is too long because you don't get married when you are little but when you are older. What do you do with a wedding dress? Do you wear it every day?" and the children answer in a chorus "No." "When do you wear a wedding dress, Mario?" and he tells her that you wear it when you get married. "Yes, when two people have decided that they would like to stay together," she adds.

The teacher moves on to the next activity, which the children will be working on throughout the week, by asking the children, "What did we plan to create for our festival in the forest?" Marius answers, "To make arrows and signs." "Yes that is right. That is what we will make when we are in the forest so that your parents can find us in the forest. What else will we make?" "Hats," says Mario proudly and she agrees, "hats and chaplets, the girls wear a chaplet and the boys a hat. So Chhang will wear a hat, and so will Heiko, Zaid, and Lucas. Janesa will wear a chaplet, and so will Lana, Anielle, and Sophia-Marie. What will Matthias wear?" and the children tell her a hat. She tries to mention every child in the circle and moves on to how to decorate either chaplets or hats. Vivian tells her that she will decorate hers with trees and butterflies, while others talk about animals, flowers, and birds. 
The next part focuses on attendance and the day of the week. The educator asks the children in English, "Who wants to count the children?" and Sara counts in English, Victor in Russian, and Antje in German. The children count slowly so that some have a chance to repeat the numbers and many children join in. After it is established that there are 23 children here today and only two are sick or on vacation, she moves on to the day of the week.

She asks the children, "What day is today?" and after a while a few children say "Monday." Then she asks, "Lena, can you set the day clock?" which she does without problems and the educator praises her. She starts saying "and in English today is ..." "Monday," the children reply in a loud and proud chorus. Naturally, they go through the days of the week in English: "Monday, Tuesday, Wednesday, Thursday, Friday, Saturday, Sunday - every day is a special day." The chant has a nice easy rhythm to it so that it is very easy for the children to learn and she strikes the chime for each day, adding a pleasant sound. Afterwards, they run through the days of the week in German, to which the teacher also adds the chime. Now she requests that the children close their eyes, hold their hands in front of their face, and listen to the sounds. After playing the scale twice she asks the children, "Was each sound the same?" They recognize that these sounds were different by saying "No." She asks, "What are the notes creating? Who knows that already?" and Mario answers, "Some sounds are dark and others are lighter." "Good some notes are low and others are high and they sound long and short," and she invites him to play some notes and lets him decide whether the note was high or low and long or short. He plays the chimes and the children are pleased, clapping for him after he finishes.

The next focus is on the weekly chore chart. Every Monday the children can choose one of the three chores they would like to do. The chart has both symbols and name labels so that the children are able to decide for themselves. A cup and a plate symbolize helping to set the table during lunch and snack time as needed. A bucket represents the table chore, where the children are responsible for wiping the tables after activity, lunch, or snack time. The final chore is the plant chore, shown as a pot with flowers, and indicating that the children are expected to water the plants in the room.

As the educator takes the chore chart and wipes off the names from last week, many hands of the children go up to signal that they would like to take on a chore. She asks, "Who would like to do the plate and cup chore?" She looks around the circle and chooses Lucas and Thomas with the explanation that they have not done a chore in a while and that she is glad to see their interest in taking this one. As she moves on to the table chore some of the hands go down and she chooses Victor and Michail, and for the final chore of watering the plants more arms go up and Anielle and 
Lena are chosen. Then she dismisses the children by asking them where and with whom they would like to play. Small groups form within seconds and she reminds the children that only 4 or 5 children can play at a center at a time as they return their chairs to the tables.

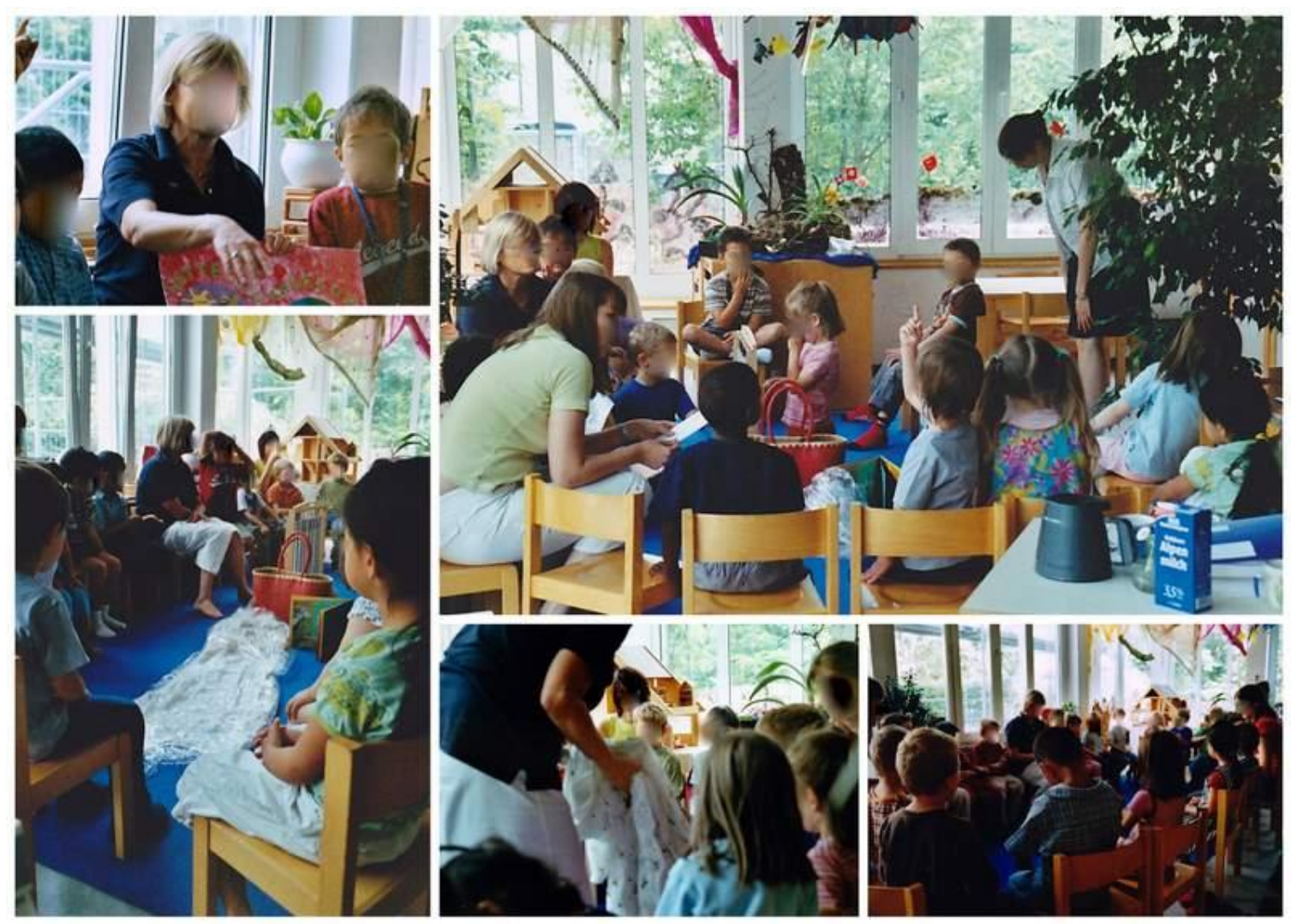

Figure 29. G.P.: Morning circle impressions of activities and discussion.

\section{Choice Time - Inside (9:26 - 10:05 a.m.)}

The children disperse to their chosen play areas in the room, in the hallway, or in the basement. Only Marius and Conrad want to play with children in the other group and go next door. Vivian and her younger sister Lana chose to play at the market center, leaving the room to go downstairs into the basement where the center has been set up. Thomas and Michail go into the hallway where the woodworking station is located. Chhang, Victor, and Danush go into the block area (see Figure 30). Malika, Zaid, Janesa, and Sophia-Marie go to the dramatic play area and also include the blue carpet area in their play. Lucas and Patrizio wander around the room to decide what they will do, looking at different activities and games. 
Mrs. J. shows Sara, Anielle, Antje, and Lena how to make a circlet for their summer forest festival. Mrs. S. demonstrates to Heiko, Nassir, Mario, and Matthias how to make and design their hats.

\section{Block Area}

Three boys, Chhang, Victor, and Danush, who each have a different mother tongue but share German as their common language, play in the block area. Danush's mother tongue is Persian and Victor's is Russian; both children are five years old. Chhang is four and speaks Tibetan. As they enter the area the carpet is empty and they talk about building a farm with stalls for the animals. Victor pulls out a drawer with animals. He turns to the other boys and says, "We will build a farm - a stall for horses and lions, a big stall for hippos and crocodiles." Chhang nods and adds, "We also make a train," while Danush seems to play by himself building an airplane.

Victor places all the animals into the stall while Chhang takes out the tracks for the train and starts building a train track. Soon everyone helps him to build the track. After finishing they set a train on top and play while Nassir and Heiko watch from the edge of the carpet area. Chhang finds a figure in the drawer and shows it to Victor saying, "A person - das Mensch." Victor tells him the right expression, "A person - der Mensch," takes the figurine, and places it next to the animals in the stall. Danush is now playing with the wooden truck. There is not a lot of speaking going on because the children are focused on their play. The main interaction is between Chhang and Victor, who guides their play expressing what he is doing in German with a slight Russian accent.

\section{Dramatic Play Area}

The children who play together have different mother tongues. The siblings Malika and Zaid speak English, Janesa's mother tongue is Macedonian, and Sophia-Marie's is Slovak. Their common language is German but they use very little language. They are playing family; Sophia-Marie is the mother, Janesa is the daughter, and Zaid is the father. Zaid jumps in between his self-chosen parts from father to dog to baby while Malika is the big sister just like in real life. Sophia-Marie pulls the wooden baby buggy onto the blue carpet and talks to Zaid - the baby - who is kneeling next to the buggy. She says, "sleep, sleep, baby has to sleep," while patting his back. He looks into the buggy and Sara interrupts their play telling her that Zaid does not fit in the buggy. Then Maria says, "Mama and papa go to work," puts the camera over her shoulder, and walks about the room.

Meanwhile, Mrs. V. has come over to the group and Malika tries to ask her if she can wear Mrs. J.'s wedding dress but her speech impairment makes it difficult to understand. After the initial 
stutter she catches her language and repeats the question, "Can I wear the wedding dress?" Mrs. V. says, "yes, sure," then she carefully helps Malika put on the dress. Sophia-Marie and Janesa watch her get dressed. The dress is very long and Malika has to hold it up so as not to step on it. Janesa smiles and Sophia-Marie, carrying a photo camera over her shoulder, says "pretty." Mrs. V. searches the dress-up-chest for a veil, which she puts on the girl's head. Malika walks in front of the funny mirror. Her big smile shows that Malika likes what she sees, as do Lucas and Patrizio who tell her that she looks pretty.

Sophie-Marie returns from 'work' and tells everyone it is time to sleep, spreading out blankets in the dramatic play area. Zaid and Malika, who still wears the wedding dress, go to bed in the corner, while Janesa and Sophie-Marie lie down in the front area. The children change their activity according to their interests and needs. Lucas and Patrizio wander about for a while until they decide to play a self-made memory game about the children of the group and their different activities. Mrs. S. shows a group of boys - Heiko, Nassir, Mario, and Matthias - how to fold a hat, encouraging them to decorate it the way they like using colored pencils and crayons. After a while, Heiko gets up and goes to the craft cabinets on which several instruments are placed. He chooses the wooden tong drum, moves the stick, and the sound signals all children that someone feels the noise level is too loud in the room. The children recognize the complaint, and it becomes quieter in the room as he returns to his place. After Nassir has finished his decoration Mrs. S. holds his hat into which he punches two holes with a hole-puncher. Next, he attaches an elastic band in each hole and the educator tells him to write his name on the inside. She takes the hat and hangs it on the clothes line where a few others are already hanging. Meanwhile, the boy wanders about the room to participate in a different activity or to find something to play.

Mrs. J. works with a group of girls, to whom she gives a 2 inch wide dark green strip of colored paper, asking them to decorate it with flowers or whatever they like. On the tables are scissors and a drawer with scrap paper of all colors. Antje chooses pink and yellow paper for her decoration patterns, while Anielle uses light blue and orange. After they have cut out small shapes of flowers, suns, squares, and so on they glue the pieces onto the strip. Antje and Anielle finish soon and the educator helps them to cut their strip to the size of their head, staples the strip together, and covers the staple with tape. The other girls spend almost the entire inside choice time at their craft stations, while the boys finish faster and Mrs. S. offers a read-aloud. 
Read Aloud: We Are Going on a Bear Hunt

Mrs. S. introduces a new book We are going on a bear hunt to Heiko, Nassir, Anielle, Antje, and Mario. She first shows the cover and some pictures which they discuss in German. The children tell her that there is a boy, a father, a baby, and a girl. Nassir asks, "Where is the mother?" and Anielle shows her and says, "She is on the back, here," while pointing to the mother. Heiko adds, "There is a dog," and Mrs. S. nods her head. She says in English, while pointing to the pictures on the cover, "There is a boy, a father, a baby, a girl, a mother, and a dog." The children carefully watch her mouth saying the words as she repeats the sentence, and some children repeat the words after her. Then she reads the title "We Are Going on a Bear Hunt” and translates it into German "Wir gehen auf Bärenjagd." She asks the children a few questions in German like "Where do you go on the hunt for a bear?" Heiko says, "in the forest," and others agree. The next question is "Have you been on a bear hunt?" and all shake their heads and say "No."

Then she says, "Let's see what happens in this book." She repeats the title, "We Are Going on a Bear Hunt" and turns to the first page. "We are going on a bear hunt. We are going to catch a big one." She supports her words with hand motions to demonstrate catch and big. "What a beautiful day! We are not scared." Her intonation supports the story and she looks bravely into the room when reading "not scared." She reads each line in English and then asks or tells the children what it means. The first line they remember and they tell her. The next line is told by Antje, "Big ist groß (big is big)," and Mrs. S. says in German, "Great, Antje. They are going to catch a big bear." Then she anticipates that they will know this sentence: "What a beautiful day!" Heiko tells her that "day ist Tag (day is day)." Anielle adds in German, "ein schöner Tag (a beautiful day)." "Yes, Anielle. Was für ein schöner Tag! (What a beautiful day,)” says Mrs. S. She then reads the last line and translates it for them. On the next page she first reads the whole text with hand motions and discusses this in a similar way to the first page. The children know the words grass and long, and she sets them into context. The following page gives the children a small break because it is just the sound of walking through grass. On the next page the educator first tells the children that the word river means Fluss in German and then starts reading the text. Anielle and Heiko start to say a few words together with Mrs. S. and all of the children make the movements accompanying the words catch, big, scared, over it, under it, and through it. They read a few more pages until they get to the forest. Mrs. S. suggests taking a break from the book and reading the rest tomorrow morning. The children look exhausted, but have enjoyed the read-aloud and agree on waiting until tomorrow to finish the story since Anielle will be picked-up after nap time. 


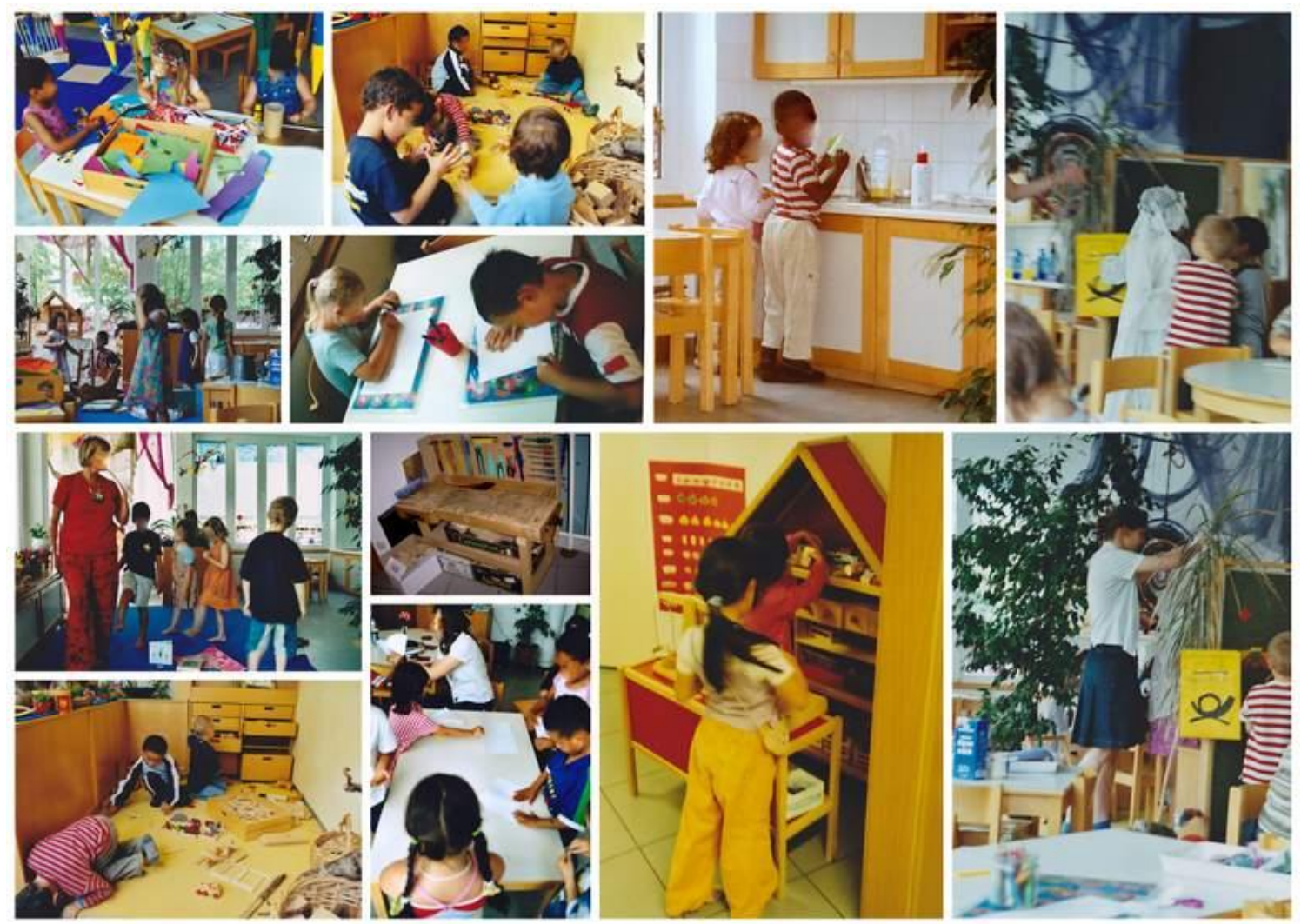

Figure 30. G.P.: Choice time impressions of different activities.

\section{Clean up and Toilet Break (10:05 - 10:20 a.m.)}

The calming sound of the singing bowl fills the room, signaling the end of the indoor choice time, and Mrs. S. calls the children onto the blue carpet. The children stop their play and go to the blue carpet finding a place in the circle. When each child has a place, Mrs. S. asks the children, "What does this circle mean?" A mixture of answers are given by a few including "clean up," with others saying, "It's a clean-up circle. We clean up after playing." Then Mrs. S. reminds children what needs to be done: everything on the table has to be returned to its place or to the trash can in the dramatic play area, the suitcases have to be put away and the table needs to be cleaned, the puzzles have to be returned in order to the shelf, and in the block area everything that is not needed should be returned to the baskets or drawers. She reminds the children that if everyone helps then clean up is done faster and they can have their thieves' breakfast.

As the children finish their cleaning efforts, she asks them to line up next to the shelves at the entrance. Once everyone is in line she asks the children, "How should we go to the bathroom today?" The children call out different animal names and the group agrees on ladybug. Mrs. S. tells them the English word and they repeat it in English, "Ladybug, Ladybug." Then one by one they slowly fly 
off, with their arms at shoulder-height while repeating the word "Ladybug." Anielle lifts her arms and dances slowly toward the bathroom, where Mrs. V. waits to help the children, reminding them to wash their hands before breakfast.

\section{Second Breakfast (10:20 - 10:40 a.m.)}

The children go excitedly into the hallway, take their backpacks from the cart next to the door, and run outside into the shade, which is right outside their group room during the morning. Eating breakfast outside is a nice summer treat and the children like it very much. The educator calls it "thieves' breakfast" (Räuberbrotzeit, see Figure 31). The weather is warm, but the wind offers a nice cool breeze. The leaves and branches of the living fence, the willow igloo, and the trees are waving in the wind. The educators have placed blankets and pillows in a big circle on the paved ground. Plastic cups with tea sit on a bench in front of the room windows.

As the children come outside they take a seat, some search for their friends, while others wonder who to sit with. There are several little groups: older boys, older girls, three year olds, and a mix of four and five year olds.

After all the children have found their seat, Mrs. S. goes into the middle of the circle and says, "Let's start our thieves' breakfast with a saying. Roll, roll, roll, the plate is so full, the stomach is so empty, it growls like a bear, it buzzes like a bumblebee. Good appétit! (Rolle rolle rolle, der Teller der ist volle, der Magen ist so leer, er brummt wie ein Bär, er brummt wie eine Hummel, guten Hunger!)" The children join the saying, and then she wishes everyone good appétit and takes a seat at the table where the educators eat their breakfast. The parents send food for the second breakfast or afternoon snack, which the children now eat. The children are expected to ration their food so that there will be some left for the afternoon snack.

Everyone is talking, eating, or drinking. Occasionally there is a quiet moment, which ends rather quickly by new conversation or street and city noise. The conversations overlap with different voices and birds singing in the background, creating a unity of sound and making it impossible for the observer to understand any of their important conversations. Once an entire little group of children has finished, the educator allows them to put their backpacks away and to play outside until everyone else has finished. The teacher asks the children to go inside, take their physical education bag, and go into the room. 


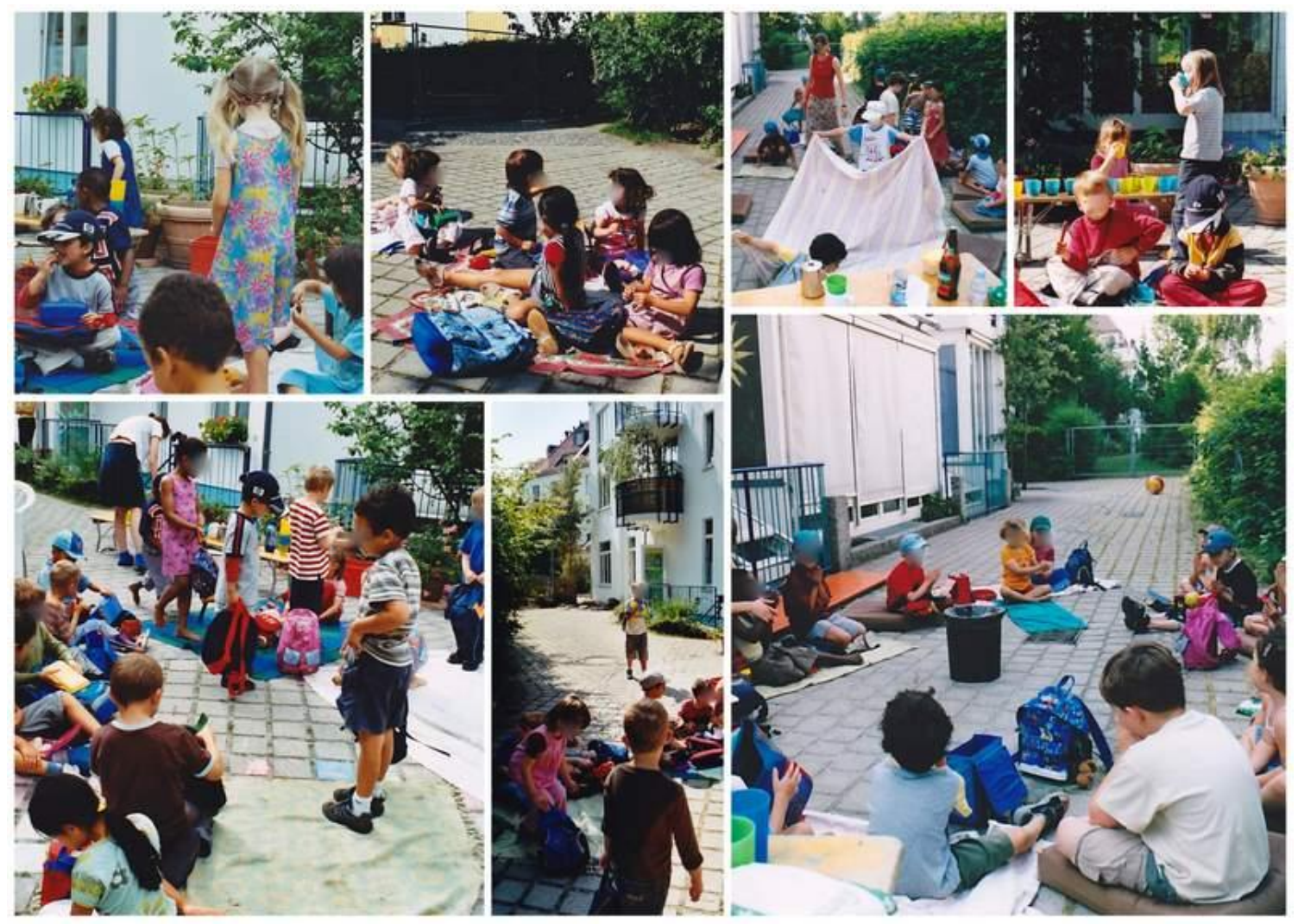

Figure 31. G.P.: Breakfast outside impressions.

\section{Physical Education (10:40 - 11:25 a.m.)}

Most of the children know what they are expected to do in preparation for physical education, but some of the younger children get help from Mrs. V., who explains that they should take a chair and place it in a circle on the carpet. Other young children observe the older children and follow their lead. Mrs. S. enters and asks the children to "only wear their gymnastic shoes and not their entire physical education outfit because we will be doing an imaginary walk through the woods." The children react happily and make sounds like "yeah." They then line up in the hallway to go downstairs into the basement where the PE room is located. After the group is lined up and quiet, Mrs. V. opens the gate, walks down the staircase with the children following one by one holding onto the upper or lower handrail, and Mrs. S. follows behind to close the gate.

When everyone is lined up in front of the PE room door Mrs. J. asks the children to share a few rules about behavior in this room (see Figure 32). Marius says that they should not climb up the stall bars. Sara adds that they should not climb the mats because they could fall over, and Nassir says that you should not hide behind the storage curtains. The children are very quiet and listen to their peers. Just before the group enters the room Mrs. S. tells the children to make a circle in the middle 
and sit with their legs crossed. Mrs. V. lets a few children enter at a time, and they find their seats and talk with their neighbors. When all children are in the circle, Mrs.V. strikes the triangle, which is the sign to listen prompting the children to stop talking. Mrs. S. reminds a few to cross their legs and asks the group what they did last week in PE. Several children talk at the same time and Mrs. J. reminds them that one can only listen to one at a time. She asks Thomas, who tells her that they were gliding on the benches. Victor gets the next chance and says that they were climbing the stall bars and then sliding down the bench. Next is Anielle, who explains how they did a forward roll with the help of the teacher. The last reply comes from Michail, who adds that they also used the benches as a balance beam. Mrs. S. agrees with their answers.

Mrs. J. says that today they will do something different because something special is happening in a couple of days. The children tell her excitedly that there will be a picnic with the parents. She continues their answer and adds more details: The picnic will be in the forest area where they have been going throughout the year and their entire families are invited. "We will sing our English song On the Farm and perform the traditional dance which we have been practicing. Today we will visit the forest in this room through our imagination. Who can tell me how we can do that?" Marius says, "Children can stand tall and be the trees." "Great idea and what else do we need in the forest apart from the tree, Janesa?" She smiles and looks very shy. Sophia-Marie turns to her and says something quietly, but then she says "animals" into the circle and Janesa nods her head. The other children agree and repeat "animals," and Mrs. S. summarizes, "We have children who will stretch their arms high into the sky as trees and children who are animals. What else can there be in the forest?" Malika says, "Children who walk through the forest," and Mrs. S. tells her, "What a great idea, like us when we are in the forest."

Mrs. V. asks, "Who would help me to get the material in the box?" The children's arms fly into the air and she chooses Mario with the comment that he had such a nourishing breakfast this morning. They get the box and place it into the middle of the circle, while Mrs. J. wonders what could be in the box. Zaid lifts the lid and tells the group, "scarves." Marius has a burning thought and says that the children who are trees can use the scarves. The scarves are the leaves." Mrs. S. adds, "The children who would like to be trees can also move their arms like branches and the scarves as the leaves in the wind." Most of the girls, Sophia-Marie, Janesa, Sara, Malika, Lena, Vivian, and two boys, Nassir and Chhang, decide to be trees while most of the boys want to be the animals. Two boys, Heiko and Lucas, are the children who take a walk in the forest.

They discuss what trees and animals can be found in the forest and the following words are called out by the children: spruce, chestnut, oak, basswood, birch, pine, wolf, wild boar, fox, and 
rabbit. Mrs. S. calls the children who want to be trees into the middle and they each take a scarf and find a place in the room. She asks, "How can the animals be different from the trees?" and Michail says, "They could be like the animals on four legs." She tells the animals to also spread out in the room.

Two children remain in the middle and Mrs. S. starts the narration: "It is a nice summer day. The sun is shining high in the sky. The sky is blue with a few white puffy clouds." She points up to the painted ceiling and wall. "The wind is blowing. The summer breeze smells of flowers, moss, and forest soil. The wind blows slowly and the branches with their beautiful green leaves dance in the wind. The animals are everywhere and play with their friends. The people are walking through the forest quietly and carefully because they want to see all the animals living in the forest. The wind blows harder and the branches dance faster in the wind. There is a rabbit hopping from one tree to the next and the people smile. There in the corner by the oak tree is a wild boar digging for food. The people are very careful not to interrupt the wild boar. There is a fox strolling proudly through the forest and the wolf is on the other side. The animals are playful and happy and the people know to keep a safe distance. The rabbit just hopped in front of the people and they carefully step aside to let it pass. The people have been walking through the forest for quite some time and the wind has been blowing harder and harder. As they get tired, hungry, and thirsty they to decide to go home while the animals get ready for a good night's sleep in their dens. The wind slows down and the trees can rest too."

The triangle sounds with three strokes, symbolizing the end of the imaginary walk. Mrs. J. comments positively on the roles the children took on: The trees swayed their arms in the wind, the animals moved realistically, and the children walked through the forest and did not touch the wild animals because that is something they should never do. If they find a sick animal they should call the forester or an animal hospital. She tells the children that they can choose new roles, and another imaginary story similar to the first one starts. The children participate with interest, focus, and role engagement.

When the triangle sound fills the air again Mrs. S. asks the children to return to a circle and sit quietly. She tells the children that they can change their shoes and play outside until lunchtime. She dismisses the children by striking their heads with a scarf. They get up and go upstairs to change their shoes. On the way upstairs some children stay in their roles as animals and walk up on their hands and feet. The children go into the room to get there P.E. bags, into which they place their shoes while sitting on the benches in the hallway and changing into their outdoor shoes. 

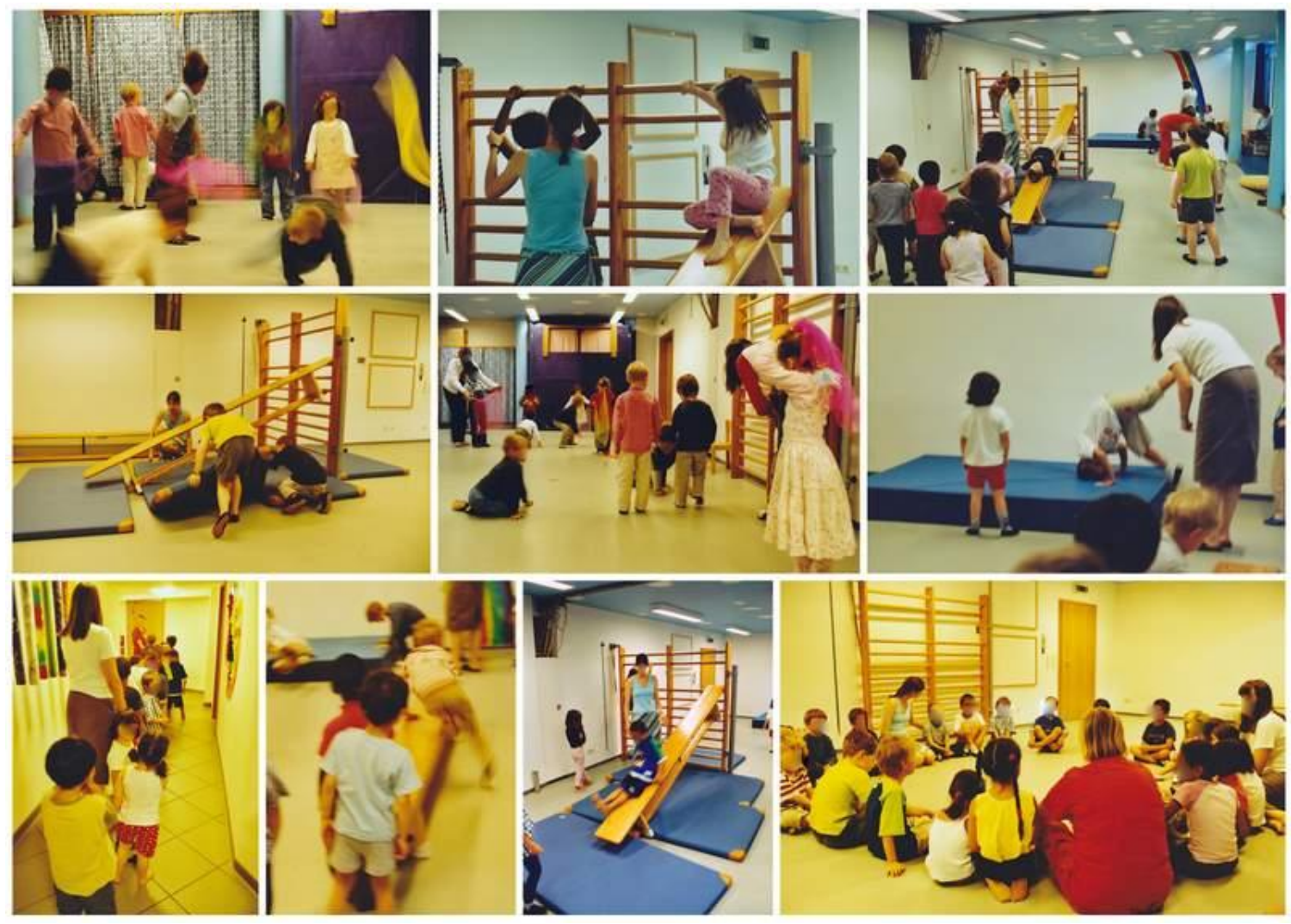

Figure 32. G.P.: Physical education impressions of an imaginary walk in the forest and PE activities.

\section{Outdoor Play Time (11:25 - 12:00 p.m.)}

\section{Song and Dance Practice}

As the children come outside some minds are still in the forest pretending to be foxes, wolves, or rabbits while they are running around the play area (see Figure 33). The Squirrel group has been outside for a little while and these children are playing in different areas. The educators call the children to make a big circle in which both groups can join together. The children look for their friends in the circle and stand next to them. The groups are mixed within the circle. Malika stands next to her brother Zaid, who is next to Sophia-Marie, who is next to Janesa while other children picked any place. Mrs. R. asks the children to take their neighbors' hands and to spread out a little more because they need more space while they are practicing their traditional dance to the song $\boldsymbol{O n}$

the farm, and tells them they can return to their activities afterwards. As the children wait for the CD player, which has not yet arrived, some children start singing on their own and uninhibited. Malika knows the song well, unintentionally leading the singing. The children close to her watch and slowly join in singing. The teachers then join in, singing well even without CD player support. The children do the gestures and seem to enjoy themselves while singing the song. Some of the younger children 
watch the older ones to see their gestures. By the time Mrs. F. brings the CD player, the group has almost finished the song and does not need it anymore. Mrs. J. praises the children for how well they sang and how well they knew the song already.

Song

On the farm in the barn,

There are many animals.

On the farm in the barn,

There are many animals.

Turn around and see,

What could these be?

Cluck, cluck, cluck, the chicken goes

And it's pecking with its nose,

With its nose.

The duck can swim and the duck can fly, Put your hands up in the sky.

Quack, quack, quack, quack, quack, quack.

On the farm in the barn,

There are many animals.

On the farm in the barn,

There are many animals.

Turn around and see,

What could these be?

Oink, oink, oink, goes the pig,

And the pig is very big.

Little mouse, little mouse,

Living in a little house.

Peep, peep, peep, peep, peep, peep.

On the farm in the barn,

There are many animals.

On the farm in the barn,

There are many animals.

Turn around and see,

What could these be?

One, two, three, one, two, three.

How many animals can you see?

Chicken and duck, pig and mouse,

All live in the farmer's house.

One, two, three, one, two, three.

On the farm in the barn,

\section{Movement}

Move arms in front bringing hands together (farm).

Move arms over head bringing hands together (barn).

Wave with fingers (animals).

Turn with one hand on forehead.

Move arms to the sides with hands out.

Move arms to the back bringing hands together

(chicken).

Pointing to nose.

Move arms in front bringing hands together (swim).

Move arms over head (sky).

Move hand in front of the chest and move arms (duck).

Move arms in front bringing hands together (farm).

Move arms over head bringing hands together (barn).

Wave with fingers (animals).

Turn with one hand on forehead.

Move arms to the sides with hands out.

Move hands around on chest and belly (hungry).

Move hands to show big belly (big).

One hand shows a little mouse with fingers.

Both hands make a little roof (house).

Move arms in front bringing hands together (farm).

Move arms over head bringing hands together (barn).

Wave with fingers (animals).

Turn with one hand on forehead.

Move arms to the sides with hand out.

Count numbers on one hand.

Move arms to the sides with hand out.

Make movement for the animals.

Move arms over head bringing hands together (house).

Count numbers on one hand.

Move arms in front bringing hands together (farm). 
There are many animals.

On the farm in the barn,

There are many animals.

Turn around and see,

What could these be?

Three, four, five, three, four, five.

Mother's baby looks so nice.

Every baby on the farm,

Loves to be in mummy's arm.

Kiss me sweet, kiss me sweet.

On the farm in the barn,

There are many animals.

On the farm in the barn,

There are many animals.

Turn around and see,

What could these be?
Move arms over head bringing hands together (barn).

Wave with fingers (animals).

Turn with one hand on forehead.

Move arms to the sides with hand out.

Count numbers on one hand.

Cross arms and move to the sides.

Blow a kiss with the hand on mouth.

Move arms in front bringing hands together (farm).

Move arms over head bringing hands together (barn).

Wave with fingers (animals).

Turn with one hand on forehead.

Move arms to the sides with hands out.

Some of the children want to sing it again, but Mrs. S. reminds the children that they also need to practice the traditional Seven Jump dance. She explains that for the dance a boy and a girl dance together; the boys are inside of the circle and the girls are outside. Then she asks the boys to step two steps into the middle while the girls stay where they are. The two children closest to one another are partners. Since the boys have not yet moved, Mrs. R. shows that Sara is next to Heiko, who steps into the middle next to her and takes her hand. Some of the other children follow their example while the educators help the younger children to find partners. Slowly, everyone finds a partner and the pairs spread out around the circle. Mrs. R. comments that everyone has enough space for the dance. The dance is connected with a song the children will sing. Mrs. J. then asks, "What will the girls wear when we do the dance for the parents at the summer forest festival?" They tell her circlets. "And the boys?" she asks. The children say in a chorus, "hats," with which Mrs. J. is in agreement and she reminds the children that if they have not yet made a circlet or a hat, they need to do so throughout the week. Mrs. R. gives a sign to start and counts "one" as everyone joins her "two, three." The group starts singing and moving:

\section{Song: Seven Jump}

One, two, three, four, five, six, seven.

Cock-a-doodle-doo.

One, two, three, four, five, six, seven.

Cock-a-doodle-doo.

\section{Movement}

Walk the count forward.

Take both hands and turn once.

Walk the count forward.

Take both hands and turn once. 
And the right foot, and the left foot.

And cock-a-doodle-doo.

And the right foot, and the left foot.

And cock-a-doodle-doo.

One, two, three, four, five, six, seven.

Cock-a-doodle-doo.

One, two, three, four, five, six, seven.

Cock-a-doodle-doo.
Place the right foot forward.

Place the left one forward.

Take both hands and turn once.

Place the right foot forward.

Place the left one forward.

Take both hands and turn once.

Walk the count forward.

Clap hands with your partner.

Walk the count forward.

Clap hands with your partner.

The stanzas are repeated several times and the movement during the "cock-a-doodle-doo" changes according to the announcements by the leader, Mrs. S. When they finish the dance Mrs. R. and Mrs. J. compliment the children on their nice dance moves. Mrs. J. tells the groups that they can play now until lunch time, which is in about 20 minutes.

\section{Planting Geraniums and Sunflowers}

The planting materials - pots of different sizes, organic potting soil, garden trowels, and watering cans - have been placed outside in the early morning by Mrs. V. Now, a few children are interested in planting flowers while other children water the plants standing in the area.

Anielle, Antje, and Janesa are watching Vivian, who uses the small trowel to fill up a 6 inch pot by transferring soil from the soil bag. Mrs. V. shows them the Geranium that needs a bigger pot and brings them the sunflower seeds and a few smaller pots. Lucas takes a pot and finds a bug inside. He observes the bug for a while and shows it to children passing by. After a while he goes to Mrs. V. and asks what kind of bug he has found. She tells him that it is a woodlouse and that you find them under rocks and wood that have being lying on the ground for a while. He keeps observing the woodlouse and continues to show the bug to other children.

1 Vivian: Here is the soil. I have to go very deep into the bag. Using the shovel she fills up the small pots.

2 Anielle: I give you always soil. Passing a pot to Antje.

3 Antje: She sieves the soil through the holes of the pot carefully into the big planter.

4 Nassir: Who has been observing their work. Could I have one, too? Meaning a small pot to transfer the soil.

5 Vivian: Gives him one and the group starts humming a melody while they are working.

6 Antje: Day dreams while sieving the soil.

7 Nassir: Complains. Not on my arm. Can I have the shovel? 
Vivian: No, not yet. The children wait patiently for their turn. Their hands are getting muddy but they work focusing carefully. Some of the soil ends up on the ground around the planter.

After a while Vivian goes over to participate in the forest footbath experience and Mrs. R. asks around if someone would like to try to eat these edible flowers. She holds a few nasturtium flowers in her hand. Several children from both groups surround her and some wonder about the idea of eating flowers. Michail asks her skeptically, "Can you really eat these?" and she says, "Yes, you can eat this plant. The leaves you can eat in your salad and actually also the blossoms. We planted these in the spring and now they are ready to be eaten. Would you like to try one?" He is still a little confused, but some of the younger children have tried one and as he is ready. Mrs. R. asks him, "What colors are the blossoms?" He tells her "yellow, orange, and red," and she asks "Which one do you like?" and the answer is "yellow." He takes the flower, tastes it, and it seems it is not bad. He does not say much and wanders off to his friends in the sand pit while some other children get their second flower and some seem to enjoy it quite a bit.

Meanwhile, Anielle, Antje, and Nassir have emptied the potting soil bag and they pick up what they have spilled on the ground. Vivian returns and they start planting the Geranium in the smaller planter while Mrs. V. gives each child a few sun flower seeds. She tells them that they should not push the seeds to close to each other, but rather a little farther away and only a finger deep. The children then push their seeds into the soil one after another, cover the tiny holes they made, and water the soil in each planter. Mrs. V. asks the children to help her clean up, and the children do so without hesitation. They collect the small pots, take the plastic bag and place it into the big trash can, and return the watering can to the storage room. 


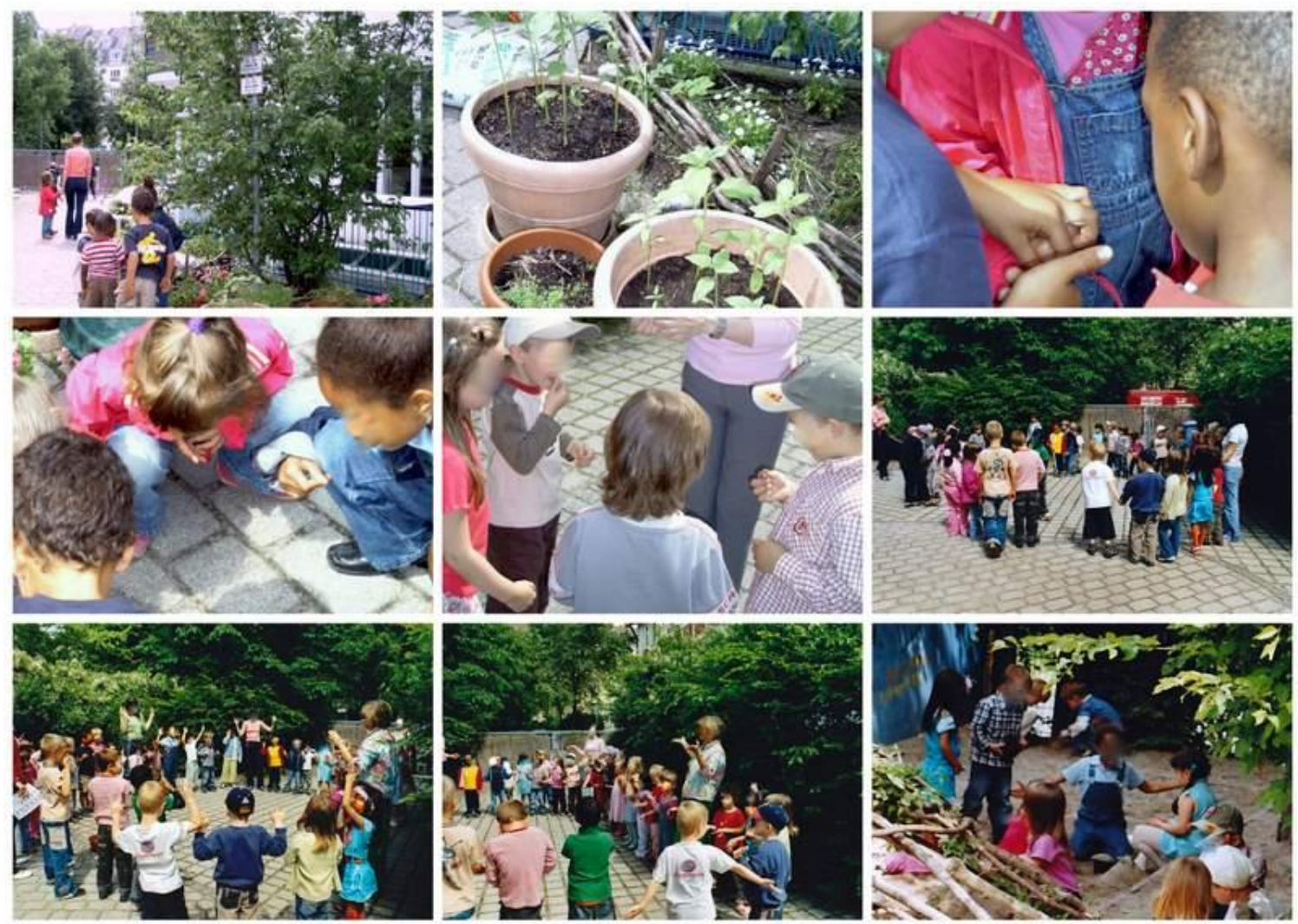

Figure 33. G.P.: Outdoor activities impressions and singing "On the Farm."

\section{Sandpit and Willow Tree Igloo}

Most of the sand pit area is in the shade due to the bushes and trees planted along the edge.

In the willow tree igloo are a few children: Chhang, Lana, Heiko, Lena and Victor. Chhang and Lana are lying on the ground and Lena says, "Sleep well, until we get back from work. Bye children." The two on the ground wave their good-byes and Lena and Victor leave the igloo while Heiko stays seated on the tree trunk like an observer. Meanwhile, in the sandpit, Michail is showing his Judo knowledge to Sara, Thomas, and Markus. Lena and Victor play in the sand and make a few baked goods with forms, bucket, and shovel.

As I move the camera back into the igloo the two resting on the ground notice me and Chhang gets up and wakes Lana. He sits legs crossed, places his arm on her shoulder, and says, "Look she takes us picture. (Schau die macht uns Foto)." His smile reaches over his entire face and she also smiles into the video camera. Their parents are back from work and as they enter from the side both return quickly to their resting position. Lena goes over to their children and tells them to wake up and that the meal is ready. Slowly they get up and they go to the tree trunk seats and table 
where Victor placed the filled sand forms. They all sit together and pretend to eat while Lena empties the forms one by one behind her back, dumping the sand on the ground.

The sandpit becomes quite loud because Michail has gained a much bigger audience for his Judo movements. He is rather careful and no one gets hurt. The children slowly wrestle each other. Other children are running around while others stand and talk or smell the flowers blooming in the outdoor planters. In the igloo, Lana is resting on the ground again, pretending to be sick and receiving treatment by two girls, while Chhang is on a tree trunk table which has a carved hole on top. He takes out sand, twigs, and leaves with his hands and throws all on the ground.

Janesa and Sophia-Marie are moving a blue, sand-filled, plastic sun umbrella stand, which others have brought into the sand pit, closer to their play area next to the igloo in partial shade. They rotate it on the ground as it is too heavy for the two three-year-olds to carry. They do not speak during this entire time. They start filling each opening with sand and turn it over. When Janesa sees the round cylinder, she screams of joy and both laugh happily. Janesa does not touch the cylinder but moves her fingers close. Meanwhile, Sophia-Marie has filled the stand again and they turn it together. She jumps up onto the stand again. This time they have a hard time lifting the stand, but after a while they muster enough strength. When they turn it over the cylinder appears again and they laugh happily. This play goes on for some time until Janesa decides to sit on the stand while SophiaMarie is trying to lift it. She says, "Janesa, get up, (aufstehen)," and repeats it a couple of times.

\section{Forest Footbath Experience}

Mrs. S. places three bowls in a row a couple of feet away from each other (see Figure 34). One is filled with water, one with forest items such as pine cones, moss, twigs, and soil to represent the forest floor, and one with river stones. There are arrows painted on the floor to show which direction to follow.

The children are watching the preparation of this guided activity with interest, and when Mrs. S. has finished she says, "This is a forest footbath. Who would like to experience the bath? Please, line up at the line painted on the floor." The children get in line immediately, and the activity starts with Michail.

\section{Teacher Mrs. S.}

1 Is it good for walking barefoot, on the river stone?

2 What is it?

3 Is this good for the feet?

\section{Children}

Michail Yes.

Hmm,...right. That is water. It is pleasantly cold and good too.

Yes. 
Now, it is Marius turn. Marius prepares himself well. He folds up his pants. So, what is this?

5 On what are you standing at the moment?

6 Absolutely right. And where do you find moss?

7 Right, in the woods.

8 Hard? And is it easy to walk on?

9 Why not?

10 And in what are you stepping now?

11 How do you recognize that?

$12 \mathrm{Hmm}$, very good. Sara, now it is your turn. How does that feel? Can you describe it?

13 Right. And in the next one?

14 Absolutely, the stones are grey and hard. And in the next one?

15 Step through it? You mean walk through?

16 Thanks, Sara. Very good and now it is Vivian's turn. You should tell me what you are feeling stepping into the tubs.

17 And where can you find it?

18 And what is it?

19 Where can you find so many stones?

20 Absolutly, at the Isar.

21 And is it pleasant for your feet?

22 Chhang, please start over again and tell me what you are feeling? What can you recognize with your feet? What is that? On what are you standing? Where did you see this before?

23 In the wood? Did you see this in the woods?

24 And what is that?

25 Moss.

26 Moss. And how does the moss feel?

27 Well done. The moss is soft. Please, step into the next bowl. This one, you know
Marius It's a little soft. A little hard.

On moss.

In the woods.

So hard, it is hard.

No, not really.

Because you can slip easily.

In water.

Because it is cold and wet, and you can walk through it. Also, it is not hard but rather very soft.

Sara It feels very soft. A little hard, too.

Only hard and grey.

This is so cold and one can step through it.

Yes, and stepping through it.

Vivian

This feels soft and also a little hard. In the woods.

Moss .....stepping into the next one

Hard and...

At the Isar.

Cold and water. Cold water.

Yes.

Chhang Very quiet and shy.

Yes, in the woods. He repeats eagerly. Very quiet and shy.

Moss.

Soft?

A stone. 
what it is, or? What is that your standing on?

Stones, exactly. And how does that feel under your feet.

Can you walk on this well?

$29 \mathrm{Hmm}$ ? Is that good for your feet?

30 Well, then step into the next one and tell me what you feel.

31 That is water?

32 And how is the water?

33 Very good, Chhang and now it is Lena's turn. On what did you step now?

34 How do you know that?

35 Good. Can you step into the next one? Can you tell, on what you are standing now?

36 Can one run on it easily?

37 Hmm, can you? And into the next bucket. What is it?

38 Really? How do you know that this is water?

39 And what else? Does the water look like the stones?

40 What does it look like?

41 Exactly, the water is transparent. You can see your feet in the water. Great, well done. And now, it is Lana's turn. Step into this. How does it feel?

42 Haha, like summer?

43 It feels like summer and what is this?

44 This is moss. We found that in the forest by the trees. This is moss.

45 And what is this?

46 Stones. Right, these are the stones. How do they feel?

47 In what are you stepping now?

48 Yes, right. When it is summer then you can go bathing. And how is the water?

49 Right. The water is cold.
Lana

Hard.

Yes

Yes.

This is a water.

Yes.

Soft.

Lena On moss.

I know that because it is soft.

Stones.

Nods her head.

This is water.

Because this is cold.

Hmm, no.

It looks, it looks, it looks ....

transparent.

Like summer.

Yes, like summer.

Tree.

Moss.

A stone.

Hard.

Into the summer. Into the water.

Cold. 
After all the children who had lined up went through the forest footbath experience, Mrs. S. offered a second turn to the children who wanted. She mixed the tubs so that it would be a different order and experience every time. She held the hands of the younger children to guide each one along the experience path of forest materials. Most children were able to do the activity two or three times.

Some children played tag and hide and seek while others colored the paving stones with chalk, creating a checkered pattern of color. Just a few minutes before lunch time the educators walk around and tell the children that they should clean up their play areas because they will be eating lunch soon. They tell them to wash their hands and to go to the bathroom if they need to.
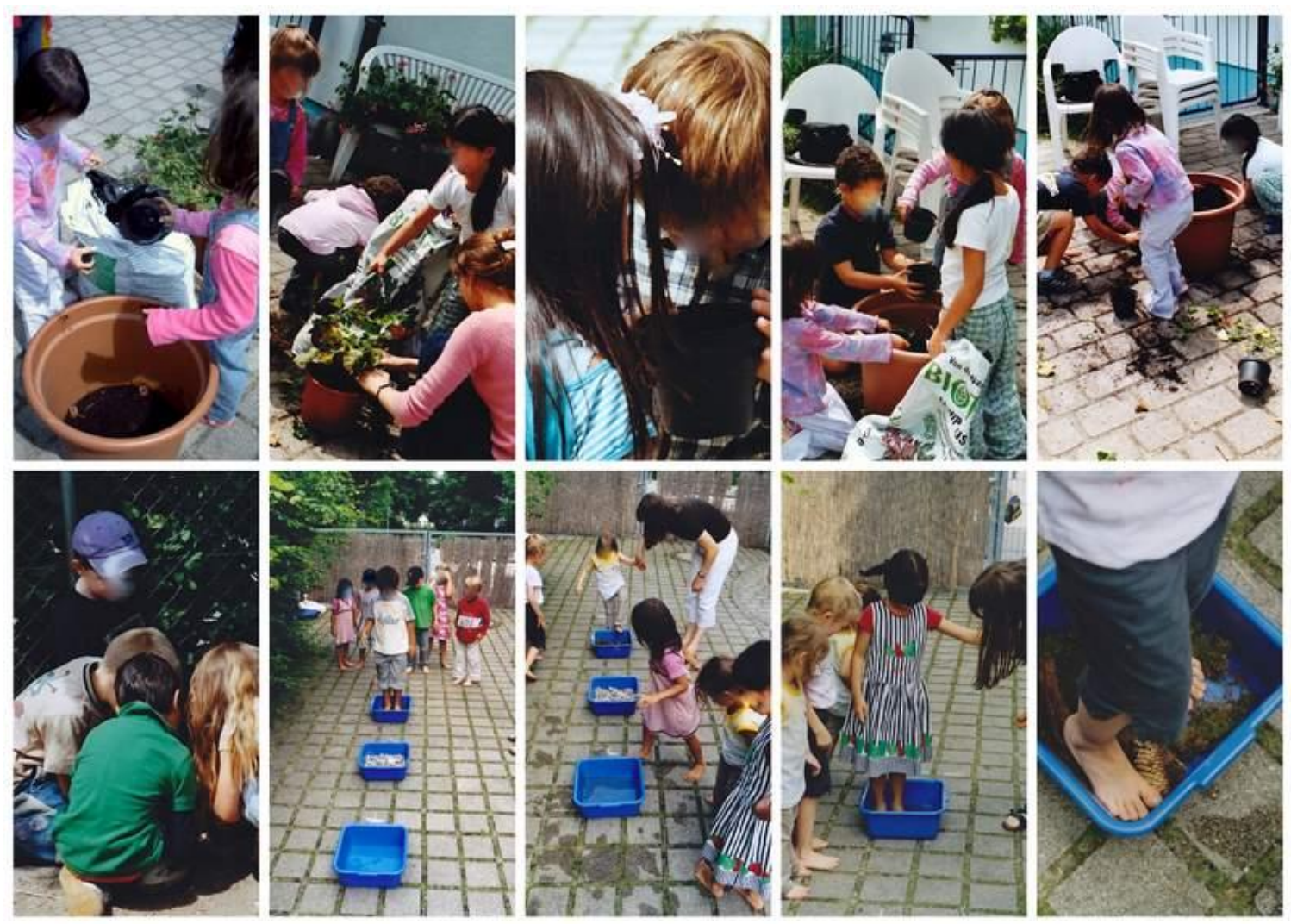

Figure 34. G.P.: Outdoor activities impressions of planting and the forest footbath experience.

\section{Lunch Time (12:00 - 12:20 p.m.)}

On the menu today are cheese Späztle with vegetables, green leaf salad, and freshly cut fruit. The tables have been set by the lunch helpers Thomas and Lucas, and the lunch lady, who also prepares the food daily. On the tables are colorful plastic place mats, cutlery; fork, knife, and spoon; a soup plate, and a plastic cup. In the middle stands a silver tea pot (see Figure 35).

As the children enter the room each finds a seat at the table of their choice. Meanwhile Lucas places glass bowls for the salad on each table and Thomas brings a serving bowl with salad. Then the 
boys place a serving bowl with the entree on each table. The children start serving themselves and take as much as they want, which is in most cases very little but in a few cases a lot. If children take too much food the educators remind them that the food is for everyone.

After everyone has food on their plate they say a lunch saying and wish each other good appetite. Today it is: Elbow, elbow, don't be so ornery, you are not allowed on the table, all children eat pleasant, peep, peep, peep, bon appetite (Ellenbogen, Ellenbogen, sei doch nicht so ungezogen, auf dem Tisch darfst du nicht sein, alle Kinder essen fein, piep piep piep, guten appetit). Afterwards the children start eating and enjoy conversations among themselves and an educator, who sits with them. As children finish the salad and entree they return their plates to the lunch cart and sit down again. When everyone at a table has finished their salads and noodles, the table can have dessert.

The fruit looks fresh, ripe, and delicious - strawberries, cherries, peaches, and apples. The conversation has moved to finding the names for each fruit in English and Russian. While the teacher helps with English, Michail provides some of the words he knows in Russian. He knows only a few, which are his favorites including strawberries, cherries, and mangos. The children repeat the words for strawberries, cherries, peaches, mangos, watermelon, and apples in English and Russian. Each child has added their favorite fruit. Similar conversations can be heard on every table. When all the fruits are gone the children go to wash their hands and use the bathroom. Mrs. V. helps the children and tells the younger children to take a seat on the benches in the hallway.

\section{Nap Time (12:20 - 2:00 p.m.)}

In the big room downstairs, Mrs. K. prepares the mats for the children. She places the mats a good distance from each other, keeping in mind the children she places next to each other. After all the mats are on the floor she carefully places pillows and blankets one each mat. Each child has their own regularly washed set. While handing out the pillows and blankets the first children arrive quietly. Mrs. K. shows some of the children their places while other children enter and know exactly where to go. One child wants to be close to the teacher, but Mrs. K. tells him that Zaid's mat must be close because he cannot fall asleep easily.

Today a few six year olds also decide to nap, which they always have the option to do. Mrs. V. enters, which is the sign that all the children are in the room for their nap. She helps to hand out pillows and blankets for the waiting children. The children know the rule during nap time well, and the teachers know which children have trouble sleeping. As Mrs. K. hands Lana her pillow and covers her with the blanket, she reminds her to sleep today and stay on her mat otherwise she will have to sleep closer to the teacher tomorrow. Lana is placed right next to me in the back of the room. 
The room is getting quieter and it seems that everyone has found their mat, rested on their pillow, and been covered with a blanket. The educators darken the room some and one takes a triangle, striking it three times, which is the sign for no more talking. The room has become very quiet and a whisper of classical background music flies through the air. Some children still toss and turn, but within 15 minutes most of the children are asleep with a few still daydreaming.

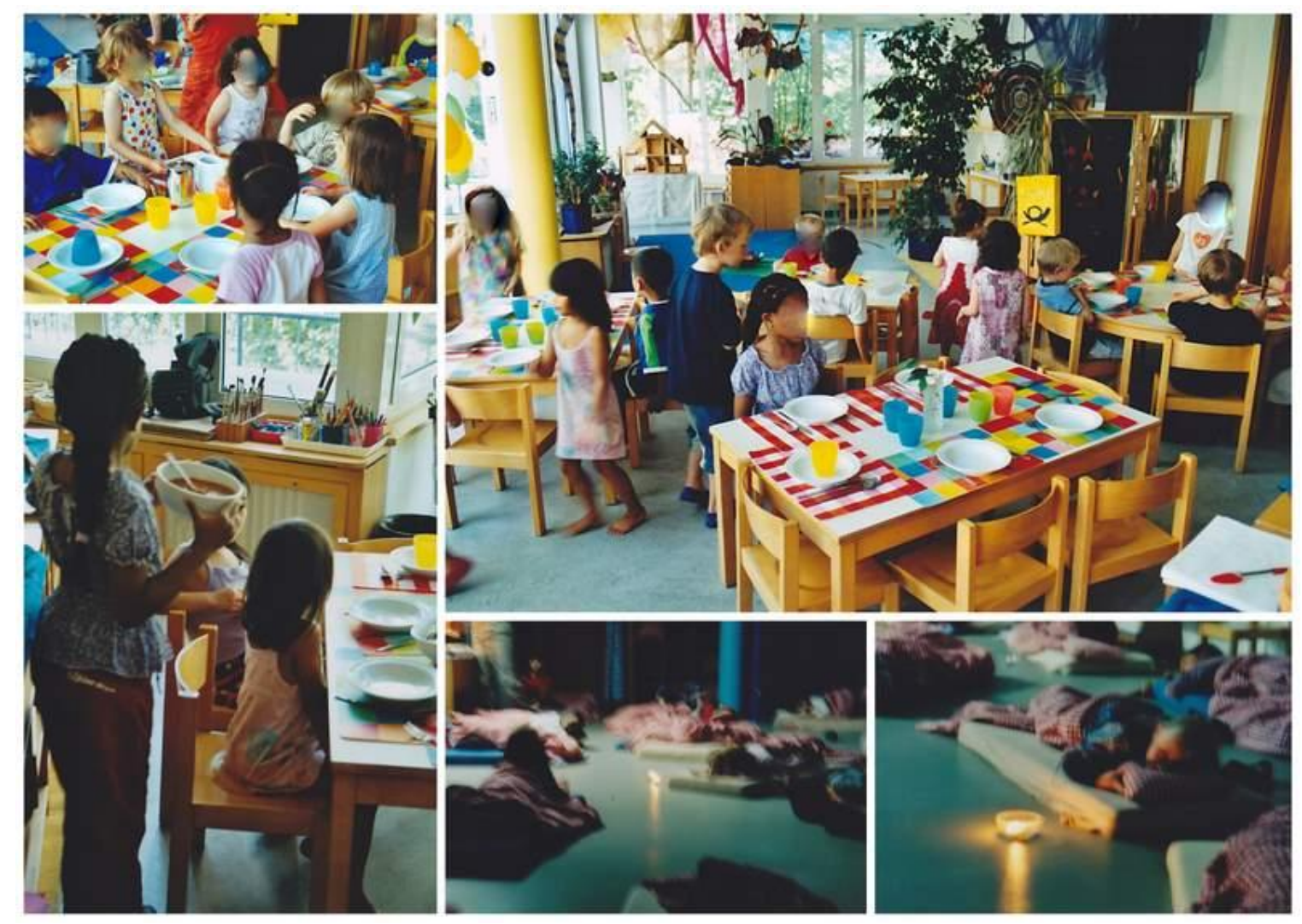

Figure 35. G.P.: Lunch and nap time with calming tea light.

\section{Clean up time (12:20 - 1:00 p.m.)}

The six year olds together with the educators clean up the room after lunch. Vivian wipes the placemats with a wet cloth. Sara dries them with a dish towel. Michail collects them and returns the pile onto the hanging shelf in the kitchen area. Marius and Malika clear the dishes off the table. Mario sweeps the floor and Thomas uses the dust pan and brush to sweep the little dust mountains that Mario creates for him. Mrs. S. returns the food cart with the dishes into the kitchen. When she returns the children have finished their chores and she asks them to check the rest of the room. They pick up some remaining paper, but overall the room looks fine. She tells the group to relax for a 
while in the room or in the dream corner before English begins. The boys go into the building area and the girls go into the dream corner to relax and talk.

\section{English (1:00 - 2:00 p.m.)}

During naptime the children who will start school in the fall have English. They gather in the room of the observation group on the blue circle-time carpet. The children are from both groups and are excited for the educator to arrive. Mrs. St. enters to put cups in the kitchen area, and tells the children that Mrs. R. will be here soon and that she is just finishing her preparations. There are ten children on the carpet, most of which are seated with only a few still moving about. Sara is dancing, Paula is galloping, Niklas is running, and Marius is making some acrobatic movements. Their movements start to converge and they are walking around in a circle. First they walk slowly but then they get faster and faster until they all seem to jog slowly. As Mrs. R. enters they stop and she asks the children to make a circle. English starts with everyone greeting each other and asking how everyone is feeling.

1 Mrs. R.: Hello, Marius.

2 Mrs. R.: How are you today, Marius? I am fine, good, not so good, okay. She makes impressions for each word.

3 Mrs. R.: Good. Thank you. How are you today, Rico?

4 Malika: Whispers the options he can choose from. Good, fine, bad.

5 Mrs. R.: Good. Thank you. How are you today, Malika?
Marius: Hello.

Marius: Good.

Rico: Looks at her shyly.

Rico: Fine.

Malika: I am very fine. She says with confidence.

6 Mrs. R.: Very fine. That is good. I like that.

(English italicized and bold and additional information is italicized).

As this continues around the circle most of the children are fine or good. She explains in English that it is very hot today and uses her hand as a fan to show the meaning before translating it into German. They sing the song Head, Shoulders, Knees and Toes as a warm up song while touching the body parts they are singing about.

She then takes the folders, which are in front of her, and hands them to the children while asking what color their respective folder is. All children know this very well. She holds a pile of pictures in her hands that the children made earlier. 
did you draw, Rico? Then she repeats it in German. Was hast du gemalt?

8 Mrs. R.: Weißt du auch wie das in English heißt? (Do you know what this is called in English?)
Tannenzapfen.

(leaves, roots, and pine cones)

Malika: A tree. She is saying the word over and over again.

9 Mrs. R.: Good, Malika. She goes on and reviews all words, which the children repeat. These are roots. That is a pine cone, and this is a tree trunk. Very good.

(English is italicized and bold, German in Roman script, translations in (brackets) and additional information is italicized).

She hands the children their work and they add it to their folder. After each one has organized their folder they make a pile of folders in the middle of the circle. Then they reflect on their outing experiences from last week.

10 Mrs. R.: Rico, wir waren bei den Schafen. Und was haben wir da gesehen (see Figure 36), what did we see Vivian?

11 Vivian: Wir haben Schafe gesehen. Tausende.

12 Michail: Nein, nicht tausende, sondern dreihundert.

13 Mrs. R.: Waren es wirklich dreihundert?

14 Michail: Ja, es waren dreihundert. Ich habe gefragt.

15 Mrs. R.: Three hundred sheep. Schafe nennt man sheep. Es ist sehr einfach im Englischen, da ist ein Schaf - sheep und zwei Schafe heißen auch - sheep. We saw so many sheep - three hundred sheep. Und was haben wir noch gesehen, Michail?

16 Michail: Ein Zelt.

17 Mrs. R.: A tent. Ja, ein Zelt haben wir gesehen, $\boldsymbol{a}$ tent. A tent for children? War das ein Zelt für Kinder?

All: Nein.

19 Mrs. R.: What else did we do? Was haben wir noch gemacht?

20 Thomas: Wir waren bei den Schafen.

21 Mrs. R.: Ja, richtig. Für was haben wir die Stöcke gesammelt?

22 Michail: Für das Lagerfeuer.

23 Marius: Für das Brot.

24 Mrs. R.: Was haben wir mit dem Brot gemacht?

25 Michail: Gegessen.
Translation

Rico, we were by the sheep. And what did we see there, Vivian?

We saw sheep. Thousands.

No, not thousands, but three hundred.

Where there really three hundred?

Yes, there were three hundred. I asked.

Three hundred sheep. Sheep are called sheep. It is very easy in English. There is one sheep - sheep and two sheep are also called sheep. We saw so many sheep three hundred sheep. And what else did we see, Michail?

A tent.

A tent. Yes, a tent, we saw a tent. A tent for children?

No.

What else did we do?

We were with the sheep.

Yes, right. For what did we collect the sticks?

For the bonfire.

For the bread.

What did we do with the bread?

Ate. 
Mrs. R.: Gegessen haben wir des she says smiling. We ate that.

Sara: Und die Gemüsesuppe.

Mrs. R.: Wie ist denn die Gemüsesuppe entstanden?

29
Vivian: Wir haben die Kräuter gesammelt.

Mrs. R.: Yes, we collected herbs. Wer weiss wie die Kräuter hießen? Das waren ganz schwierige Namen, aber eins ist ganz leicht. Vivian?
And the vegetable soup.

How was the soup made?

We collected the herbs.

Yes, we collected the herbs. Who knows the name of the herbs? They were quite difficult names, but one was rather easy. Vivian?

(English is italicized and bold, German in Roman script, translations in last column and additional information is italicized).

The children tried to remember the names of the herbs - nettle, field balm, herb bennet, and salvia, and the educator helps them in this task. The discussion took place in German only and they return to a mix of German and English as they count how many different herbs they collected.

31 Mrs. R.: Wer kann bis vier zählen?

32

\section{All: One, two, three, four.}

Sara: bir, iki, üç, dört Russisch. anderen Sprache zählen?

All: Sheep.

All: Shepherd. der shepherd dabei?

Thomas: Die Hunde.
Mrs. R.: Four herbs. Die Kräuter sind herbs.

Sara: Ich kann bis vier auf Türkisch zählen.

Mrs. R.: Gut, dann lass es uns mal hören.

Mrs. R.: Excellent. Michail, du kannst ja auch auf Russisch zählen. Zähl mal bitte bis vier in

Michail: Один, два, три, четыре.

Mrs. R.: Wow, excellent. Wer kann noch in einer

Michail: Ich kann auch noch weiter zählen.

Mrs. R.: Ich glaube es dir. She says and smiles. Wer kann sich noch daran erinnern wie ich die Schafe in Englisch genannt habe?

Mrs. R.: Sheep. Excellent. Da war ja auch noch ein Schäfer, eigentlich eine Schäferin. Shepherd.

Mrs. R.: Dann haben wir schon sheep - ein Schaf, sheep - zwei Schafe, shepherd - Schäfer. The children repeat each word using choral reply. Und was hat es noch gegeben? Wen hat denn

Mrs. R.: Hund kennt ihr schon in Englisch. Das haben wir schon gelernt.
Who can count to four?

The herbs are called herbs. I can count to four in Turkish. Great, let's hear it.

One, two, three, four.

Excellent. Michail, you can count in Russian. Please, count in Russian.

One, two, three, four.

Wow, excellent. Who can count in another language?

I can count even further.

I believe you. She says and smiles. Who remembers how I called sheep in English.

Sheep.

Sheep. Excellent. There was also a shepherd.

Then we have sheep - a sheep, sheep - two sheep, shepherd shepherd. And what else was there? Who did the shepherd have with her?

The dogs.

Dog, you already know in

English. We learned that already. 


\section{Küken.}

Vivian: A hen. Mrs.

Mrs. R

Ein Schaf oder Schafe Mrs. R: Die Katze, was noch? Mrs. R:

Der Hund, was noch? Counts animals on her fingers.
Niklas:

Michail: Ein Huhn A worm.

Mrs. R.: Ein Wurm. Richtig. Da sind wir aber ziemlich gut. Zehn Tiere. She says while showing ten fingers. Was haben wir noch?

Marius: A bull.

Sara: Eleven.

Mrs. R.: Eleven animals. We know a lot of animals.

Paula: A cow.

Malika: A duck.

Mrs. R.: We know a lot of animals. Excellent. Weil das so ein schöner Tag war, wollen wir heute ein Bild basteln - eine Collage darüber basteln. Wer möchte, kann selber die Englischen Wörter schreiben.
Should we review the animals we learned already?

Yes, no, yes, no, yes.

A sheep or sheep.

The cat, what else?

The dog, what else?

The mouse, what else?

The pig, what else? noch? chick?

A chick.

A hen.

A worm. Right. We are pretty good. Ten animals. What else do we know?

\section{Because that was such a nice day, we will make a picture - a collage. Whoever likes can add the words in English.}

(English is italicized and bold, German in Roman script, translations in last column and additional information is italicized). 

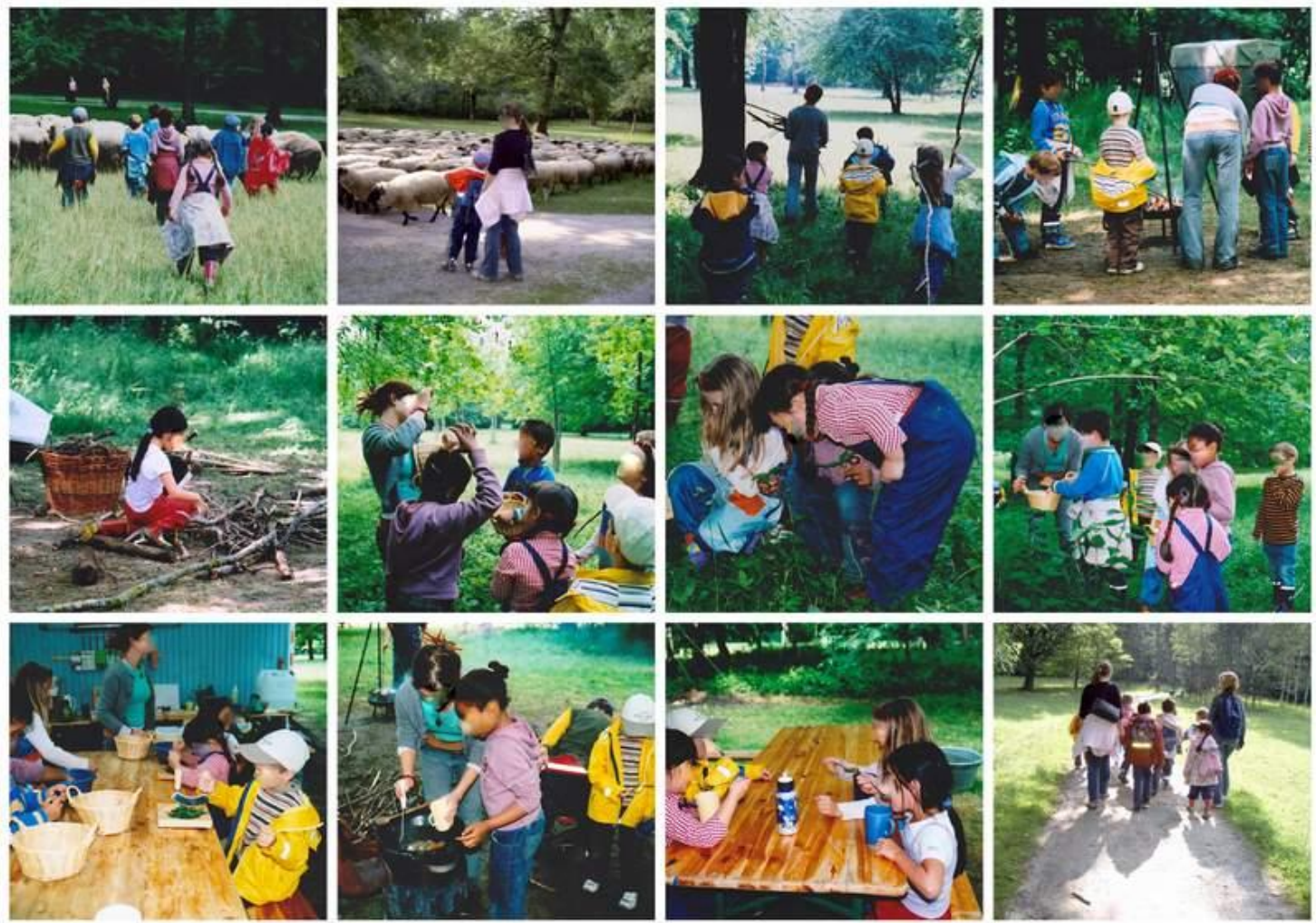

Figure 36. G.P.: Visiting a sheep herd and making herb and vegetable soup.

The children react with mixed feelings. Some really like this activity while others have a harder time enjoying it. The educator reminds them about the different experiences they had such as how they made the soup, how they collected the herbs on the outskirts of the woods, how they shepherd the sheep, and how they collected sticks and branches for the fire. She tells the group that they can choose whatever they liked best and that they should express that in their picture. The door opens and Paula's mother waves at her to come. The children take a seat at the prepared table and some discuss what they will be doing. The door opens again and Paula returns saying that she is able to stay longer. The educator starts handing out the paper to the child sitting next to her and goes around the table (see Figure 37).

69 Mrs. R.: What color do you want? Dark or light green?

70 Marius: Dark green. Takes the dark green paper.

71 Mrs. R.: What color do you want? Dark or light green?

72 Thomas: Dark green he whispers and takes the dark green paper.

73 Mrs. R.: Dark green. Good. What color do you want? Dark or light green? Vivian.

74 Vivian: Light green. Takes the light green paper.

(English is italicized and bold, German is in Roman script, translations in last column and additional information is italicized). 
As the question moves around the table they choose their paper: Niklas - light green, Sara light green, Michail - dark green, Paula - light green, Mario - light green, Malika - light green, and Rico - dark green. The educator reminds the children to write their name on their paper before they start. In the middle of the table are colored pencils and a wooden box with combed wool pieces, cotton balls, wooden recycled ice cream sticks, and other useful materials.

Since some of the children decide to use glue, the educator hands out placemats to prevent any mess on the table. The children focus on their reflective collage or picture while the teacher writes the vocabulary on pieces of paper so that the children can write it themselves. Everyone is busy working and the room is quiet as quiet can be for a few moments. After a while Sara says that she will include the German shepherd dogs in her picture. The children were fascinated by the dogs on the outing and some had long petting sessions with the dogs.

75 Mrs. Who remembers the name of the dogs?

R.: Kennt ihr denn noch die Namen der Hunde? Michail?

76 Marius: Reminds Michail. Wo wir nicht weg wollten. which is so true because the children had a hard time to leave and everyone wanted to take the dogs home with them or never leave the park at all.

77 Mrs. Ihr ward doch so traurig in der S-Bahn, R.: weil ihr den Hund nicht allein lassen wolltet. Ich glaube einer hieß Caro.
Who remembers the name of the dogs? Do you know the names of the dogs? Michail?

We did not want to leave them.
You were so upset on the train because you did not want to leave the dog. I believe one was called Caro.

(English is italicized and bold, German in Roman script, translations in last column and additional information is italicized).

Then they seem to remember and start the same discussion as the day before repeating "my Caro, No, my Caro, No, my Caro," which goes on for a little while. As the children are working the educator points out the great work some of them are doing and the children take the time to look at their peers' work. They work for about 15 minutes on their collages or pictures. Sara tells Mrs. R. that she would like to add a dog but that she cannot draw one. Mrs. R. tells her that she could look at a picture in a book and she gets up to look for the book On The Farm, which is in English with pictures and vocabulary words. She tells the girl that they will find a dog in this one for sure. Sara, Marius, and Mrs. R. look through the pages together. Meanwhile, the other children finish their work, get up, and wait close to Mrs. R. to show their collages or pictures. As they have chosen the right dog, the educator places the book on the table so that the girl is able to look at a sample and starts drawing her dog. Then the educator listens to the explanations of the children about their work. 
Vivian tells her about her drawing: the fire place, the sheep behind the fence, and the blue sky and the sun, while Tomas tells her about the trailer, the fire place, and the people in his picture. When the educator asks why there are not any sheep on his work he replies that they did not fit, and both smile. The children who have finished return to the blue carpet and rest or look through the books placed on the carpet.

Sara has finished drawing her dog and Mrs. R. places the book on the carpet. Vivian, Marius, and Niklas thumb through the pages and open some of the hidden pictures. Michail and Thomas are playing memory. Paula creates a pattern with colorful wooden blocks. Malika and Mario are looking at the book We Are Going On a Bear Hunt. After a few minutes the children join the educator who wants to sing the action song On the Farm in the Barn. Everyone joins the circle and the teacher counts to three and starts singing while expressing the meaning with gestures and movement.

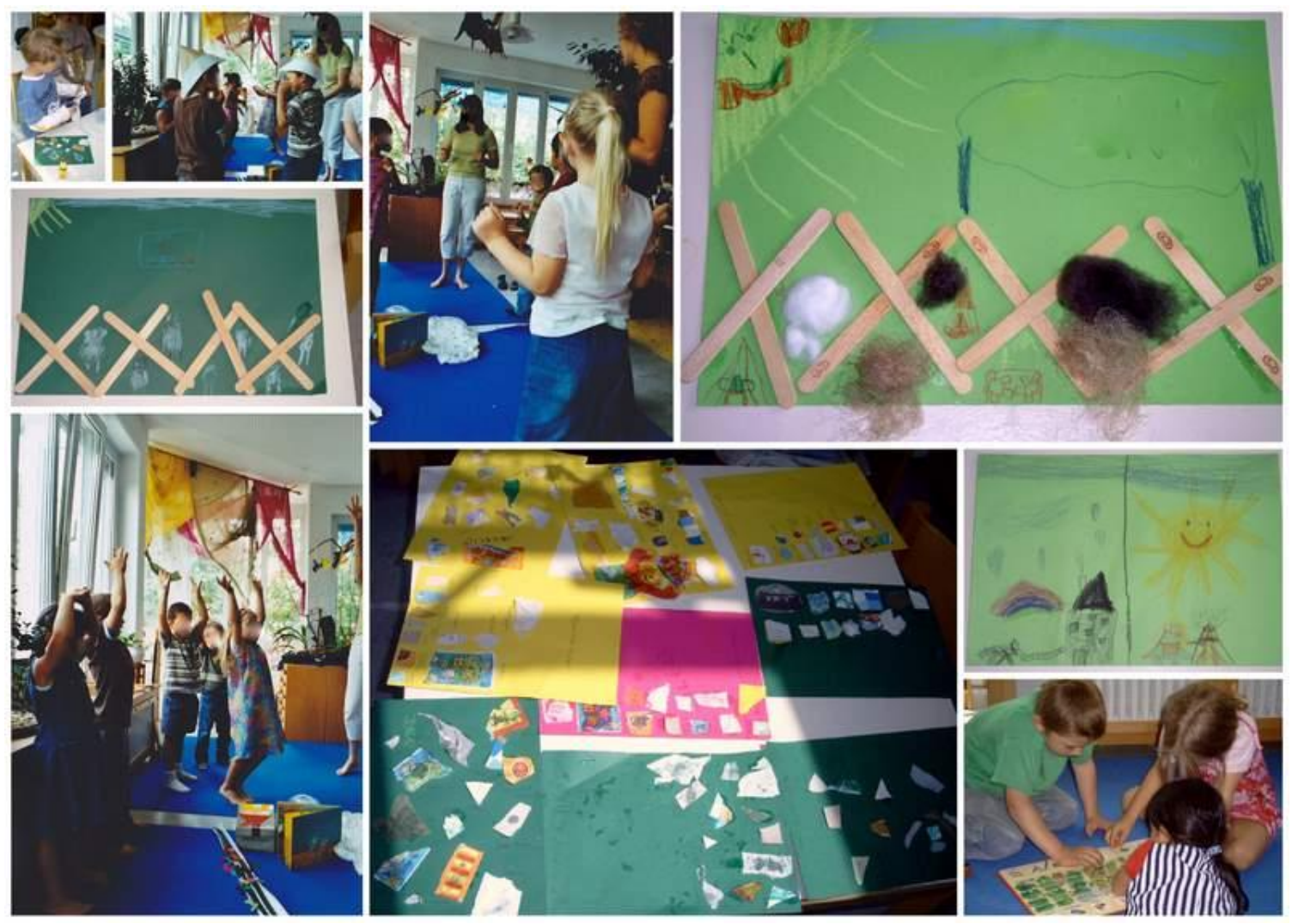

Figure 37. G.P.: English enrichment activities and artwork by the children.

\section{Afternoon Circle Time and Outdoor Time (2:00 - 3:30 p.m.)}

Mrs. S. gathers the children on the blue carpet for a very short afternoon circle time. As usual, Matthias was picked up just before lunch and Anielle has gone home too. When everyone is in the circle, Mrs. S. and the morning children welcome Marie and Rosi, who are five year old twins and 
have been attending for only a few weeks in the afternoon. Then she explains what they will be doing this afternoon, and the children are very excited about the plan to visit a nearby playground. She sends a few children, who show that they are ready, into the hallway to change their shoes and put on a sun hat. She comments on the children's behavior to signal that the children who are still excited should be quieting down and sitting cross-legged on the carpet. Mrs. S. goes to the door, checks on the children outside, and tells them to get a partner and line up at the hallway door once they are finished. Then she calls all of the children who are waiting on the carpet. Meanwhile several parents pick up their children early today and a total of eight children leave. It is not usual for so many children to leave at the same time, but the weather is wonderful and many families are going swimming or to a park.

When both groups are lined up, Mrs. S. goes over the behavior and traffic rules and then they leave. There are twenty eight children and three educators. One educator leads the group, one is in the middle, and one is at the end pulling a cart with a parachute, snacks, drinks and a first aid kit. The walk is rather short, taking only about five minutes along smaller and bigger roads, and crossing one main crossroad. The children are well behaved, alert to the traffic, and know the way well. Without a problem the group arrives at the playground, which is part of a small park (see Figure 38).

The educators lead the group to the middle lawn area and Mrs. R. asks the children to form a circle. Meanwhile Mrs. S. and Mrs. F. get the parachute and open it up in the circle. Mrs. R tells the children to take the parachute with both hands and to hold it tight. Next, she asks the children to slowly move it up and down and up and down, which the children enjoy very much, laughing happily. Moving the parachute makes a calming sound which all enjoy. Mrs. S. asks the group to hold the parachute very low and then very high over their heads. Then they move fast and slow and after a while Mrs. R. invites the children to take a seat in the middle, beginning with Marius. At first he is tentative, but soon he sees what happens and relaxes and smiles. Afterwards, small groups of children enjoy the experience and the educator calls the children into the middle while the children call out names of children who did not have a turn yet. When they start moving the parachute wind blows the hair of the children providing a nice breeze on a hot summer day. After the children come off the parachute, some children call out that they would like to have another turn, but Mrs. R. tells them that the children who did not have a turn yet will go next. When the younger children have a turn, the educators tell them to climb on carefully and walk slowly into the center, while providing positive feedback when they do this well. Mrs. S. reminds the children to wait until everyone is in the center before moving the parachute. Moving the parachute creates a sound of thunder that fills the air. The educators praise the children because they are moving the material so well. After everyone 
has had at least one turn Mrs. R. announces that they now have to clean up, which means here in the park to put the parachute away. Mrs. S. walks with the children on her side to the middle and slowly brings the material to the waiting children, then they fold the parachute a couple more times while guiding the children.

Mrs. R. reminds everyone that playing in this park and on the playground means that they have to stay together and play in the distinct area the group usually plays in. The children nod their heads and some run to the playground set that is shaped like a pyramid and connects two towers by a long rope bridge. This equipment is focused on climbing and balancing. Marius is the first to climb to the top of the pyramid, then the first on a tower. He is very fast and seems to have experience, while the other children, Vivian, Michail, Marie, and Rosi, take their time while climbing the playground set. Lena and Lana play in the sand baking cakes and bread or stirring soup close to the manual water pump play area where Heiko, Lena, Malik, Zaid, Janesa, and Sophia-Marie are playing. Heiko moves the handle of the pump up and down several times, and the children are astonished and upset and say "no water" several times. Marius comes over and tries to help Heiko, but it will not work until Michail pumps several times. The water comes with every move of the handle. The first part of the wooden pipe line is filled and they open it so that the water can flow to the next tier. Malik pumps some more and now all barriers are open and the water runs down to the sand. The children are very excited about their work and Janesa and Sophia-Marie are playing with the mud.

Victor and Chhang have been playing in the park behind the benches where they are squatting close to a fallen tree trunk with sticks in their hands. Carefully, they move leaves, branches, and dirt to the side looking for bugs underneath. As they do not find anything they move further along the tree trunk. Victor takes a big piece of bark, feels it, looks at it, and places it carefully back on the tree, but it falls off again. There is no bark left on the upper part of the tree trunk, and the children use it as a balance beam. Victor says, with a slight Russian accent, "he continues to work," pointing to Chhang, who carefully removes bark from the tree trunk close to the floor. Victor asks him, "Did you find something?" They find a few bugs and observe them for a while before they go onto the playground and climb up the rope jungle gym. Carefully, Chhang balances across the big rope to the other side of the gym. The children enjoy climbing in the rope jungle gym and try to get from one side to the other and to the highest point.

A group of three year olds, Sophia-Marie, Janesa, and Zaid, are playing together in the shade under the trees. Sophia-Marie is the leader and has given each one their role by telling them who they are: Janesa is the baby, Zaid plays the dog, and she herself is the mom. 


\section{Translation}

1 Sophia- Komm wir gehen nach Hause. Holding

Let's go home. ... with car, with car.

Marie: Janesa's hand, walking away, and saying bei

Come on dog!

Auto, bei Auto. Hund komm!

2 Zaid: Is on hands and knees pretending to be the family dog and crawls behind them

3 Sophia- Grosse Schwester, grosse Schwerster but her

Marie: call is unheard and Janesa sits on her lap while Zaid sits next to her.

4 Zaid: Wir sind beim Auto.

5 Malika: Comes by and tells the group "Mama, ich kann nicht mehr arbeiten. Ich gehe jetzt zur Schule" and walks off again.

Big sister, big sister.

We are at the car.

Mom, I cannot work anymore. I am going to school now.

Zaid watches her for a while before returning to their play. Sophia-Marie tries consistently to keep Janesa on her lap and treats her like a baby. The conversation is short and phrases are repeated.

6

Zaid: Sits down in front of the girls "Wir sind schon bei Auto. Wir sind bei Auto sein." Meanwhile the mother feeds her baby with leaves from the ground and he adds "Wir gehen bei Arbeit." He gets up and says "Wir sind schon bei Arbeit"

7 Sophia- "Okay"

Marie:

8 Zaid: Demands loudly "Aussteigen."

9 Janesa: The baby shakes her body and says "nein, nicht aussteigen."

10 Zaid: He puts his hand out to help the baby up and she grabs it and both girls get up.

11 Sophia- The mom wipes the dirt and leaves off of the

Marie: babies back and bottom telling Zaid that

"Baby ist schmutzig."
We are already at car. We are at car. ....We walk by work. ... We are already by work.

Step out.

No, don't get off.

Baby is dirty.

As she wipes everything off, the mother takes the baby's hand while the baby holds their hats and Zaid returns to the floor as their dog. The mom has her hand on his t-shirt, pretending to walk the dog as they walk off to a different tree.

12 Sophia- Says several times "Der Hund hat The dog has a nosebleed.

Marie: Nasenbluten." She wants him to lie down.

13 Malika: The big sister re-appears hearing the mother's statement and carefully checking the dog's nose - her brother's in real life. 
14 Sophia- Tells the big sister "Hol Arzt, hole Arzt, Marie: schnell."

15 Malika: Replies "Ich komme gleich."
Get doctor, get doctor, quickly.

I will be right there.

The big sister does not return for a while and they are back in their baby-mother-dog formation.

16 Sophia- Says "Wir gehen nach Hause." Marie:

17 Janesa: Replies several times "nicht nach Hause."

18 Sophia- Gives in and says "wir gehen bei Geschäft"

Marie: which makes the baby happy and they walk a few steps.
Zaid: Gets up and says "Hier ist unsere Hause."
Let's go home.

No, not home.

We go by the store.

Here is our home.

The girls follow him but Janesa seems to want to stay and cook something. She takes a seat at the next tree and the other two run off to the playground. While the children drink some water the educators spread the word that it is soon time to return to the kindergarten. The children do not like to hear it but they still have a couple of minutes to play while Mrs. V. places all the cups and materials into the cart. After about five more minutes of play Mrs. S. calls the group to line up at the path in front of the playground. She asks if everyone has their partner and the children call out "yes" while Mrs. R. counts the children to make sure that every child is returning to the kindergarten. It takes the group about 5 minutes to reach the kindergarten as the streets are not too busy yet. The children behave well on the walk home.

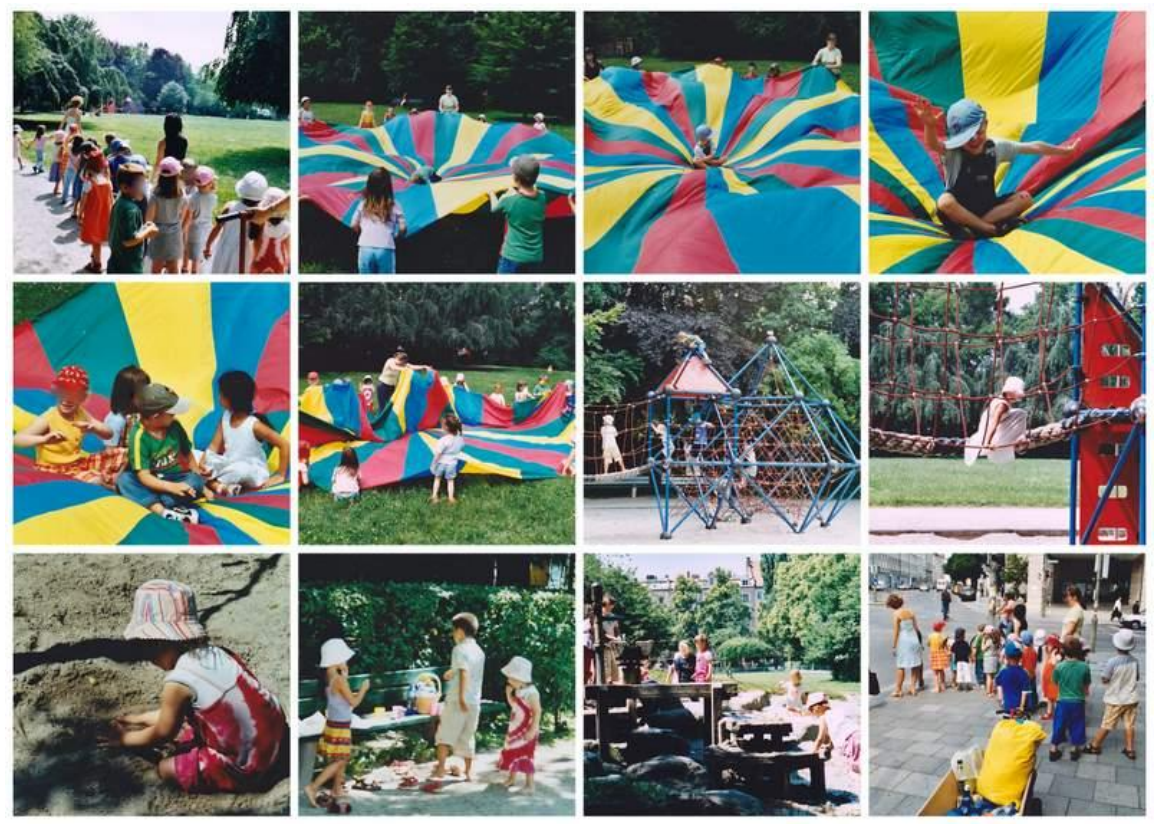

Figure 38. G.P.: Playground impressions of parachute activity, climbing, and water pump play area. 


\section{Snack Time (3:30 - 3:45 p.m.)}

In the kindergarten Mrs. S. tells her group that they should go to the bathroom, use the toilet if needed, wash their hands, take their backpack, and return to the group room. Mrs. V. puts placemats and cups on the tables and when the children enter they find a seat, take something to drink, and wait until everyone is present. Mrs. S. starts an eating saying, "My stomach is so empty, it growls like a bear. It drones like a lobster, therefore good hunger! (Mein Magen ist leer, er brummt wie ein Bär. Er brummt wie ein Hummer, drum: Guten Hunger!)” Then the children eat their snacks and talk with their peers. There are thirteen children in the group as it leaves to go outside. Mrs. V., Rosi, and Josi clean the tables, finishing quickly, and together they join the children outside.

\section{Choice Time - Outside (3:45 - 4:45 p.m.)}

The children are scattered throughout the outdoor play area (see Figure 39). A group of girls creates patterns by coloring cobble stones with different colors on the ground, but after closer observation it is evident that they are drawing by themselves and merely share the chalk. They are focused on their work and do not talk much. Close by is the forest footbath experience, and it is still the main attraction of the day. The children get in line and some interrupt their activities to have another turn. Mrs. S. has added a tub with sand to the existing water, forest soil, and stones. The children love this activity and even play this by themselves while Mrs. S. gets the blind fold from inside. The first child to try blindfolded is Paula. It is difficult for her, though the educator guides her and Rosie also holds her hand. Mrs. S. asks questions concerning their experience and the children answer them. Vivian and Lana run, pretending one is a horse and the other is riding in a buggy.

\section{Clay Station}

At the table close to the igloo the teachers placed clay and some of the boys created airplanes and other figurines. At the moment Chhang, Sophia-Marie, and Lana, who just joined the other two, are kneading the clay while adding some water. Sophia-Marie does not stay very long and does not say anything while kneading the clay.

\section{German}

1 Observer Was machst du denn da?

2 Lana Dideldum, die sind im Krankenhaus.

3 Observer Was ist das da?

4 Lana Wir sind im Krankenhaus. Da sind die Babys

\section{Translation}

What are you doing?

Dideldum, they are in the hospital.

What is this? 
drin. Pointing to a similar bed clay figurine.

$\begin{array}{ll}5 & \text { Observer } \\ 6 & \text { Lana }\end{array}$

\section{Ahmmm}

Changing her mind. Nee, da sind nicht die

Babies drin. Da sind die Babies drin pointing to another figurine. Und hier ist Vivian.

7 Observer

8 Lana

$9 \quad$ Chhang

10 Observer

11 Lana

12 Observer

13 Lana

14 Observer

15 Lana

16 Observer

17 Lana

18 Chhang

19 Lana

20 Chhang

21 Observer

22 Chhang

23

24 Chhang
Und was ist das?

Das is ein grosse Burg. Starts kneading and says das ist so hart.

Das ist nicht so hart handing her clay that is softer.

Da ist noch welcher, der nicht so hart ist. Damit kannst du noch spielen. Was soll das sein?

Was ganz lustiges.

Ist das ein Elefant oder Elefantenhaus?

House collapses suddenly. Jetzt ist alles hin.

Schau mal was ich für Babys mache?

Und was für Babies?

Von Elefanten ein Baby.

Aha, ein Elefantenbaby.

Hier kannst du haben Chhang. Handing him small pieces of clay.

Oh, cool.

Und wenn ich noch was brauche dann musst du es mir gleich geben. Okay?

Ja. Kneading and shaping the clay. A Wurst he says with Bavarian accent.

A wurst?

Ja and kneads on. Wir haben ein Flugzeug gemacht. Wir haben ein Flugzeug gemacht. Victor und ich und Heiko. He drowns out Lana with his statement.

Auch aus Ton?

Ja, auch aus Ton. Frau S. and Frau V. auch. Frau S. aber ein grosses. Ein Wurst. Ein grosse Salami haben wir. Singing grosse Salami, grosse Salamie haben wir, grosse Salami, grosse Salami. are the babies.

Ahmm

No, the babies are not in there.

The babies are in here. And

here is Vivian.

And what is that?

That is a big fortress. This is so hard.

This is not so hard.

There is some more which is not so hard. You can play with that too. What is this?

Something really funny.

Is this an elephant or an elephant house? Now, it is all gone.

Look what kind of babies I am making?

And what kind of babies?

A baby from elephants.

Aha, an elephant baby.

Here you can have this,

Chhang.

Oh, cool.

And when I will need some then you have to give it back right away. Okay?

Yes. A sausage

A sausage.

Yes We have made an airplane. We have made an airplane. Victor and I and Heiko.

Also from clay?

Yes, also from clay. Also Mrs. S. And Mrs. V. But Mrs. S. a big one. A sausage. We have a big salami. Starts big salami, big salami we have, big salami, big salami. 
25 Lana

26

27 Chhang

28 Lana

Chhang

29

30

31 Lana

32 Chhang

33 Lana

34 Chhang

35

36

37

Lana

Chhang

Lana

Chhang

Lana

Chhang

41 Lana

42 Chhang

43 Lana

44 Chhang

45 Lana

46 Chhang

47 Lana
Backe, backe Kuchen, she says unaware while kneading. Then she repeats a part that an educator is saying in the background. Laufen lernen and adds Wir können doch schon laufen.

Ja, ihr könnt schon laufen.

Eine Salami und eine Brot und ...eine Brot und ...

\section{Eine Bretzel.}

Eine Bretzel sieht aber anders aus. Egal, keine Bretzel.

Ja. Noch was fehlt? Eine, eine, hmm, eine... Wie heißt trinken?

\section{Was ist das Chhang?}

Trinken, trinken. Was ist das, Chhang?

Trinken, trinken, was trinken? Bitte. Singing while thinking. Welche willst du?

Das hier.

Brot oder Wurst oder ...

Das da.

Das Brot. Ich nehm was von der Wurst hier. Ist das Wurst. Na, gut. Gut. He looks astonished at Lana.

Ja.

Washes his hands in the water bowl for the clay and says jetzt hab ich saubere Hände.

Saubere Hände. Nass he says proud and shows them Lana and drips water on hers. She laughs and he asks nochmal?

Ja.

Sings nasse Hände, nasse Hände, nasse

Hände ...And drips more water on Lana's hands.

Nicht auf mein Kleid, nicht auf mein Kleid.

Entschuldigung, he looks on his clothes and says meine auch.

Nein, du hast doch kein Kleid.

Doch, ich hab.

Nein, kein Kleid. Du bist doch kein Mädchen.
Bake, bake cake.

Learning to walk, We can walk already.

Yes, you can already walk.

A salami and a bread und a bread and...

A pretzel.

But a pretzel looks different. Doesn't matter, not a pretzel.

Yes. Something is missing? A, a, hmm, a ... What is it called

to drink?

What is that, Chhang?

Drink, drink.

What is that, Chhang?

Drink, drink, drink what?

Please. Which do you want?

This one.

Bread or sausauge or ...

This one.

The bread. I'll have something from the sausage here. Is it sausage? Well, then. Good. Yes.

Now I have clean hands. Clean hands. Wet. ... Again?

Yes.

wet hands, wet hands, wet hands

Not on my dress, not on my dress.

Sorry. Mine too.

No, you don't have a dress.

Sure, I have.

No, not a dress. You are not a 
She says laughing. Then they play by themselves girl.

for a while.

48 Chhang Sings nasse Hände while playing with his hands in the water bowl for a while and says

Wet hands ...That is yours das ist deine Lana pointing to the different Lana. foods he made from clay.

49 Lana Nein, nein, nein. She rejects all his offers.

No, no, no.

Chhang runs off to the forest footbath activity and takes several turns. Zaid and SophiaMarie are watering the flowers and plants. In the sand pit three girls are playing, pushing sand with their bare hands onto a big piece of carton. A group of boys is discussing secrets in the willow tree igloo while telling each other to whisper. A different group of boys has been playing with gymnastic bands trying to draw circles in the air. One by one mothers, fathers, or siblings appear to take their children or siblings home. Often the children tell the parents to wait a few minutes as they are not yet ready to leave. Unless they are in a hurry, they usually wait or join in their children's play for a few minutes. Many use this time to talk to the educators.

\section{Clean up \& Pick up Time (4:45 - 5:00 p.m.)}

The educators spread the word to the children, of which about 15 are left, that it is time to clean up. Each educator has taken a specific area and calls for the children to bring certain materials. Mrs. S. asks Chhang, Paula, Vivian, and Janesa to bring a tub from the footbath to her. She is standing by the outdoor storage room and the children bring her the tubs. She empties the water into the water play area. Girls from the other group hand her the bucket with chalk and she places all the items onto the shelf in the storage room. The outdoor area is cleaned up and more and more children are picked up. Soon there are only two children left and they walk inside with the educators, who lock the backdoor behind them. The children take their backpacks and walk with the educators to the front door and everyone checks that all the windows are closed. Just before 5 p.m. the last children are picked up by their father and everyone goes home. 

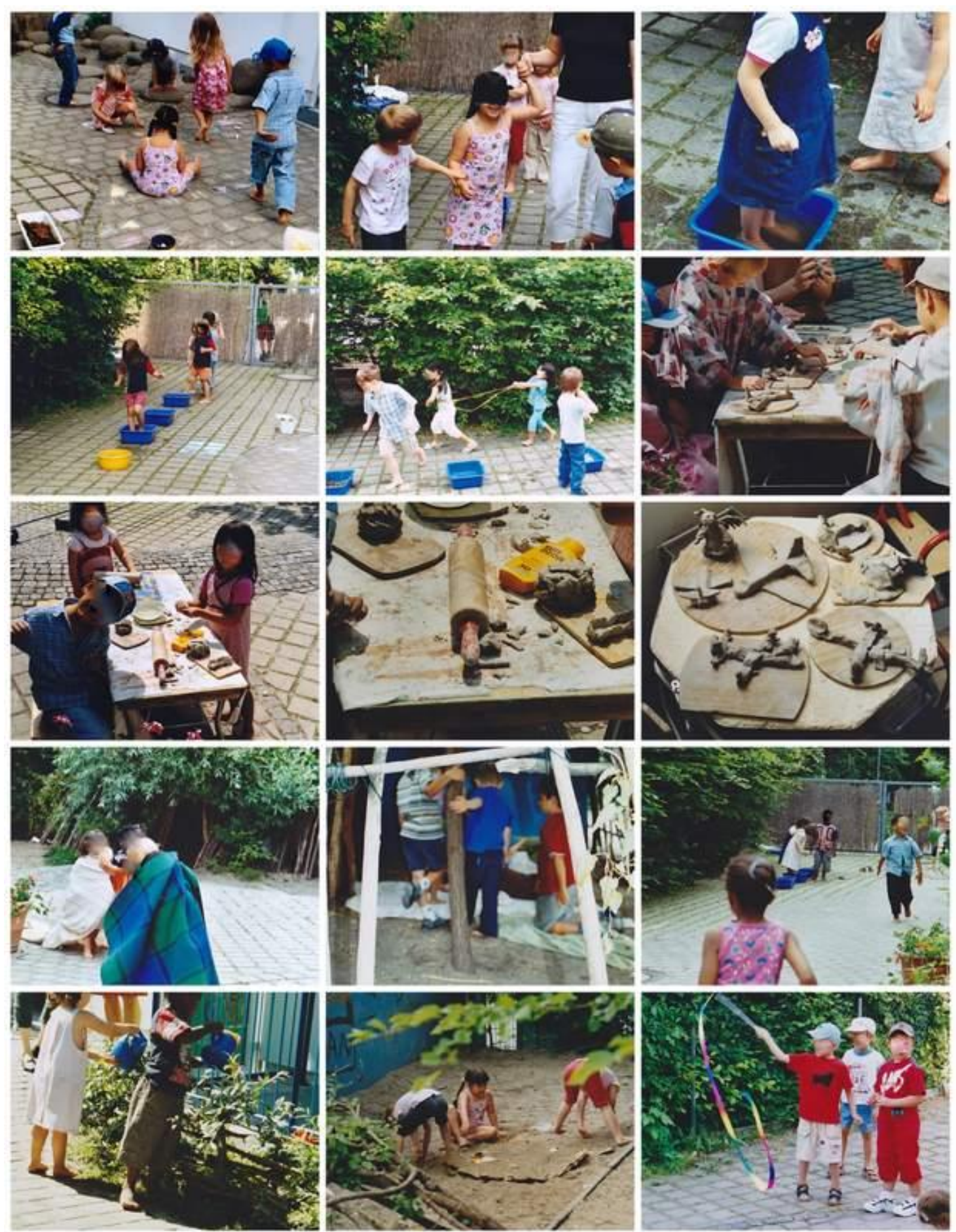

Figure 39. G.P.: Outdoor impressions of forest footbath experience, clay activity, and play. 


\section{Chapter 6: Data Presentation U.S. Program - Private German Immersion School}

The school opened its doors in 1988 as a private non-profit school in a highly populated area on the West coast with two major cities close by. During the first years the kindergarten program included preschool and kindergarten children in age-mixed groups similar to the German or Austrian systems. The school started to consider using the International Baccalaureate (IB) Program guidelines to improve and widen their program in 2000-2001.

Together with the new IB program structures and the rapidly growing program, the decision was made for the 2002-2003 school year to separate 3 and 4 year old children from the 5 year old children during parts of the day, such as circle and project time. The trail year was very successful and led to a full time separation of the 5 year old children for the following year, when they got their own two classrooms and playground area. The school re-structured its programs into a preschool program and a K $-8^{\text {th }}$ grade program which has about 280 students today.

In 2007 the school received the International Baccalaureate program authorization for the Primary Years Programme. This includes children aged 3 to 12, with the main emphasis on developing the whole child in and outside the classroom while inquiring about life and learning. The IB program offers a transdisciplinary, international framework for all subjects including knowledge, skills, attitudes, concepts, and action synthesized in the learner profile. It has an intercultural focus and simplifies comparison and transfer of educational degrees around the world.

Currently, the annual fees for the preschool program are about $\$ 10,975$ per year and $\$ 12,475$ for the kindergarten program. Cost reductions are provided if siblings are attending the program. The rates are higher in the event the employer is paying the educational fee, about $\$ 13,100$ for the preschool and about $\$ 15,080$ for the kindergarten.

\section{U.S. Preschool Program}

\section{Introduction}

The Preschool has four rooms, two groups that attend all day from 8:30 to 1:45 p.m. for five days a week, two groups that come on Mondays, Wednesdays, and Fridays, and one group that comes on Tuesdays and Thursdays. The groups are named after animals - whale, beetle, frog, mice, and snake. Only one group is named differently: little star. The group that I observed is an all day, everyday group and is called the beetle group (Käfergruppe). 
The main language used during the day is German. However, children can address teachers in German or English and use both languages among each other. Additional German lessons are provided as a daily six week long course for small groups of children depending on their needs. If English language support is needed then courses are offered. The children address the teachers by their first name.

\section{Concept and Curriculum}

Their philosophy includes the following characteristics and beliefs: the importance of developing the whole individual; the equality and connectedness of social, physical, emotional, and cognitive growth; that the development of a positive self-image will lead the child to reaching his or her full potential; and that an environment providing opportunities to learn, explore, cooperate, share, and build friendships will support the development of all children.

According to the parent guide book (2005 - 2006), the main curriculum aspects as described by the teachers are to:

... plan the curriculum as the year progresses (child emergent curriculum). The curriculum may include events of the month or season, current situations in the group; themes initiated by the children or personal life experiences of the children.

According to the theme, the teachers prepare activities such as games, plays, experiments, cooking, songs, books, observations, outside activities, field trips or visitors, parties, arts \& crafts, and room decorations. Examples of themes are: Animals, fire-water-earth, families, seasons, international holidays, professions, different countries and customs.

Many of our themes address the many cultural backgrounds of the children. The curriculum of the kindergarten is kept flexible. It can and will be adjusted and changed to meet the needs of the children and the group.

At the beginning of the school year, circle times are sometimes held in both languages to familiarize new children with no prior German skills and to get them comfortable with their new environment. As the year progresses, English explanations decrease. Matters concerning safety and other essential information will always be announced in both languages.

During my observation the main focus of the curriculum was the theme: winter and the holidays. Circle time focused on practicing the songs for the Holiday festival in small and big groups. Most of the afternoon circles where joined with the other present groups, and on Friday a dress rehearsal was held in the gymnasium. During project time the activities focused on the decoration of the gymnasium or the head bands for the children to wear. 


\section{Daily schedule}

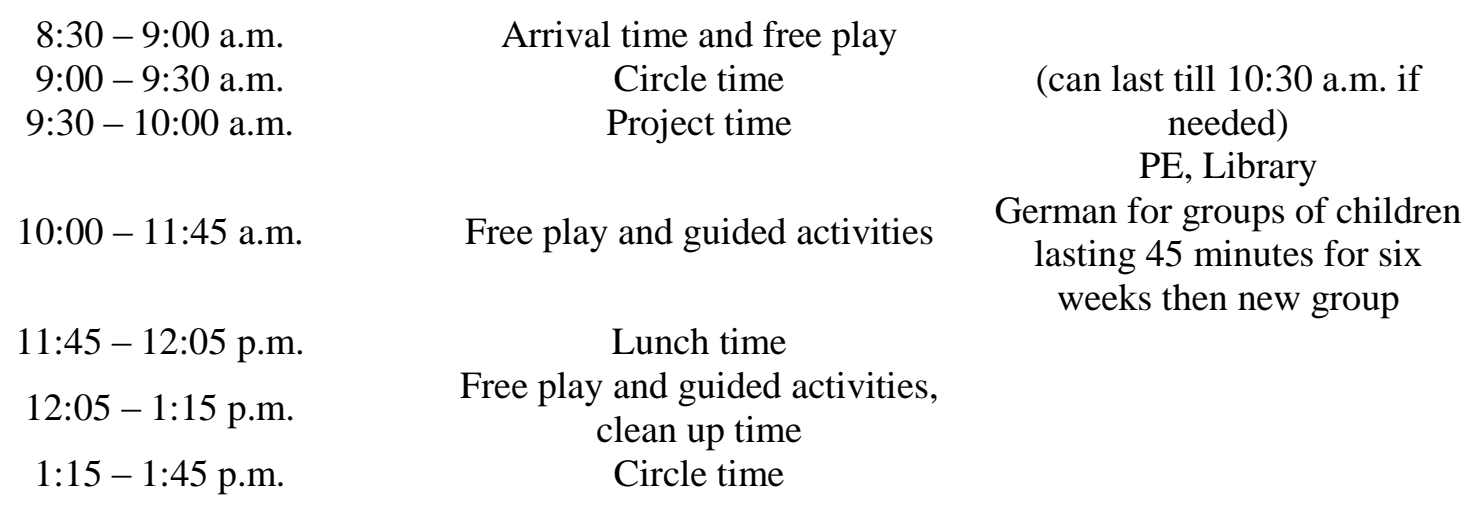

\section{Teacher}

The group has one teacher, one assistant, and one student teacher, resulting in a studentteacher ratio of 5.3 to 1. The head teacher is bilingual in German and English, while the other teachers are German native speakers who have a good knowledge of English. The head teacher has been working for this program since 1991 and is also the current preschool director. Therefore, she commits Mondays and Fridays to administrative work while another teacher substitutes for her. All teachers are certified, the head teacher is educated in the U.S., the second teacher is educated in Germany holding a state accredited educator degree, and the student teacher is still working on her degree as an educator in Germany. She conducts part of her teaching experience in the U.S. The head teacher holds a B.A. in Developmental Psychology and an Early Childhood Education Certificate. Previously, she ran her own day care and worked in other preschools in the area.

\section{Children and Parents}

There are sixteen children in this group, but one child is visiting his grandmother in Germany during the Christmas season. The children are between three and five years old. They come from a wide range of international backgrounds and affluent families. The children are accepted into the program after an application process which includes an interview. Eleven children use English as their preferred language and three use German, while one child uses German and Finnish and another uses German and English. All are able to understand German and use it in the educational setting if engaged in the German language. The children are mainly dual language learners and speak two or more languages. The list of mother tongues includes German, English, Spanish, French, and Chinese. The information about the languages of the children was taken from the questionnaire or provided by the program (see Table 10). 
Table 10. U.S.P.P.: Participating children

\begin{tabular}{|c|c|c|c|c|c|}
\hline Children & Age & Gender & $\begin{array}{l}\text { Preferred } \\
\text { Language }\end{array}$ & $\begin{array}{c}\text { Other } \\
\text { Languages }\end{array}$ & $\begin{array}{c}\text { Comments of Parents on Questionnaire } \\
\text { What do you think is a reason for the preference? } \\
\text { Please explain. }\end{array}$ \\
\hline Amy & 4 & Female & English & $\begin{array}{c}\text { some } \\
\text { German }\end{array}$ & $\begin{array}{c}\text { Though I know some German (grandparents } \\
\text { spoke \& studied in school) up until she attended } \\
\ldots \text { She spoke \& heard English almost exclusively } \\
\text { in preschool, play with other children \& at home. } \\
\text { My German isn't so good anymore, so it is still } \\
\text { easier for us to speak English. }\end{array}$ \\
\hline Kacey* & 3 & Male & English & $\begin{array}{l}\text { very little } \\
\text { German } \\
\text { some }\end{array}$ & no info \\
\hline Christian & 4 & Male & English & $\begin{array}{l}\text { German, } \\
\text { Swiss, } \\
\text { Chinese }\end{array}$ & mother speaks English to him \\
\hline Mira & 4 & Female & English & German & $\begin{array}{l}\text { father only speaks English, mother speaks } 90 \% \\
\text { German to them, has a twin sister, who also } \\
\text { prefers English, so their conversation is English. } \\
\text { Big changes since they enrolled.... They started } \\
\text { to use German when they are talking to mother. }\end{array}$ \\
\hline Vanesssa & 4 & Female & German & English & uses German most at school \& with the nanny \\
\hline Marianne* & 4 & Female & English & German & \\
\hline Daniela & 4 & Female & English & $\begin{array}{c}\text { some } \\
\text { German* }\end{array}$ & $\begin{array}{c}\text { mother speaks English only, so father speaks in } \\
\text { English as well even though he can speak } \\
\text { German, }\end{array}$ \\
\hline Jeth* & 3 & Male & English & & \\
\hline Michel & 5 & Male & German & English & $\begin{array}{l}\text { German is the language that my child is mainly } \\
\text { surrounded by. Most people speak German with } \\
\text { him. He is able to switch to English at anytime } \\
\text { and is able to continue the conversation. When he } \\
\text { went to an American Kindergarten for two years, } \\
\text { and only } 2 \text { days in the German Kindergarten, he } \\
\text { spoke more English at home. }\end{array}$ \\
\hline Marc & 4 & Male & English & $\begin{array}{c}\text { some } \\
\text { German }\end{array}$ & English is the main language spoken since birth. \\
\hline Warren** & 5 & Male & German & English & $\begin{array}{c}\text { More exposure to German. Mother speaks } \\
\text { German and stayed home for } 4 \text { years. German } \\
\text { preschool. }\end{array}$ \\
\hline Cloe & 4 & Female & English & $\begin{array}{c}\text { some } \\
\text { German* }\end{array}$ & no info \\
\hline Sarina & 4 & Female & $\begin{array}{l}\text { German } \\
\text { Finnish }\end{array}$ & $\begin{array}{l}\text { some } \\
\text { English } \\
\text { some }\end{array}$ & level of fluency, home languages \\
\hline Liam & 5 & Male & $\begin{array}{l}\text { English } \\
\text { German }\end{array}$ & $\begin{array}{l}\text { French, } \\
\text { some } \\
\text { Spanish }\end{array}$ & $\begin{array}{l}\text { Highly motivated to learn German because of } \\
\text { school - which he loves }\end{array}$ \\
\hline Lea & 4 & Female & English & German & more spoken at home + elsewhere \\
\hline Sophia & 4 & Female & English & $\begin{array}{c}\text { some } \\
\text { German }\end{array}$ & home language \& environment \\
\hline
\end{tabular}


The parental questionnaire was distributed to all caregivers and parents of the observed group. I received 15 of 16 questionnaires but two had either no information or only the first part was filled in (see Figure 40). English, being the culturally dominant language, is also the preferred language of eight children. This agrees with the answers to questions 2,3 , and 5, which were asking for the language used at home and the language used with the children. However, nine children are able to understand German and English, while four understand only English, which is connected to the children's age. The younger children, for example Kacey and Jeth, still have very rudimentary language skills.

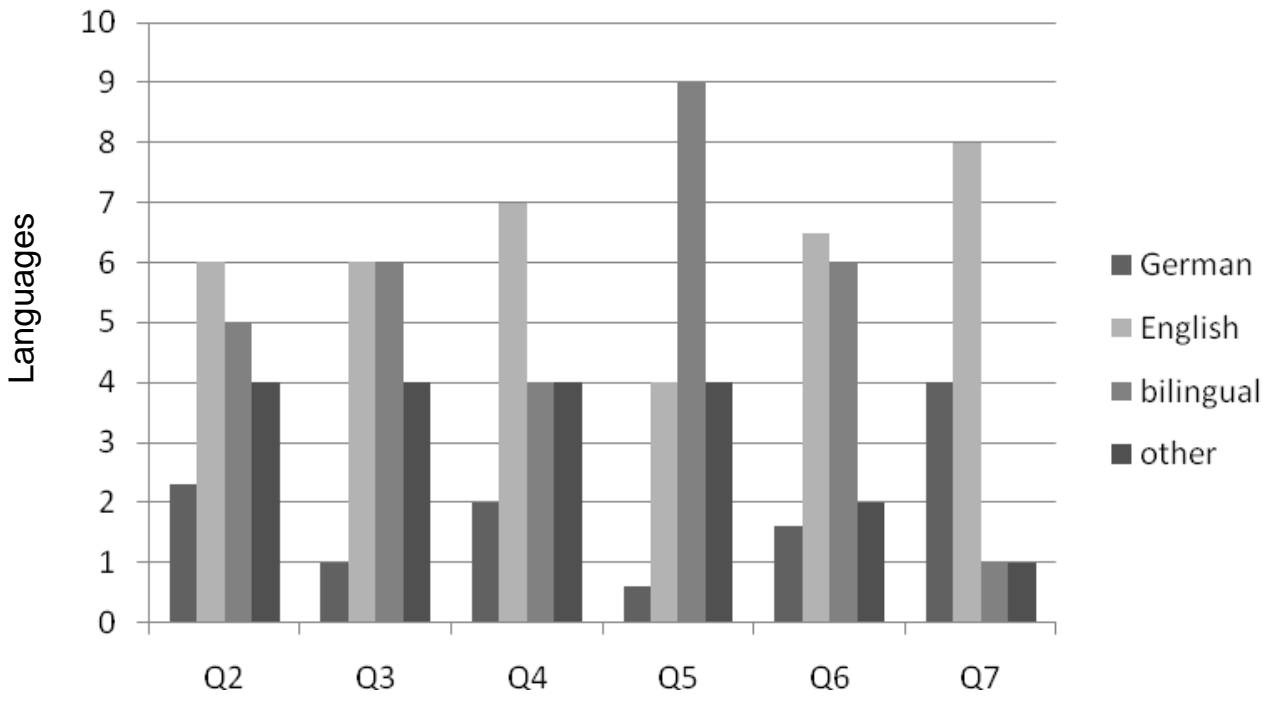

Figure 40. U.S.P.P.: Answers given by parents in the questionnaire. The following questions were asked: Q2: What language(s) are spoken at the child's home? Q3: What language(s) did your child know prior to kindergarten? Q4: What language(s) are mainly used in conversation with your child? Q5: What language(s) does your child understand? Q6: What language(s) does your child speak? Q7: What is your child's language preference? Under Other languages the following language were listed: Q2: Chinese, Finnish, French, Punjabi; Q3: Chinese, Finnish, French, Spanish; Q4: Chinese, Finnish,

French, Spanish; Q5: Chinese, Finnish, French, Spanish; Q6: Finnish, French; Q7: Finnish.

Parents named a wide variety of reasons why they have chosen to send their child to this program, to list a few: the German immersion program starting in preschool, the diversity and cultural experience, outstanding program and staff which leads to excellent test scores, great in- and outdoor facilities, a play-based focus, and heritage language connections to German.

Below are listed samples of the parents' comments:

- German language, teachers, the learning philosophy of play based learning, large very nice outdoor facility; 
- want him to be fluent in languages other than English and feel immersion from Pre-K is the only real way to achieve this;

- play-based, great facilities, wonderful teaching staff;

- believe in the benefits of bi/multilingualism; program content; school's philosophy, community and values.

Additionally, almost all parents see the role of world language learning in the program as very important (Figure 41).

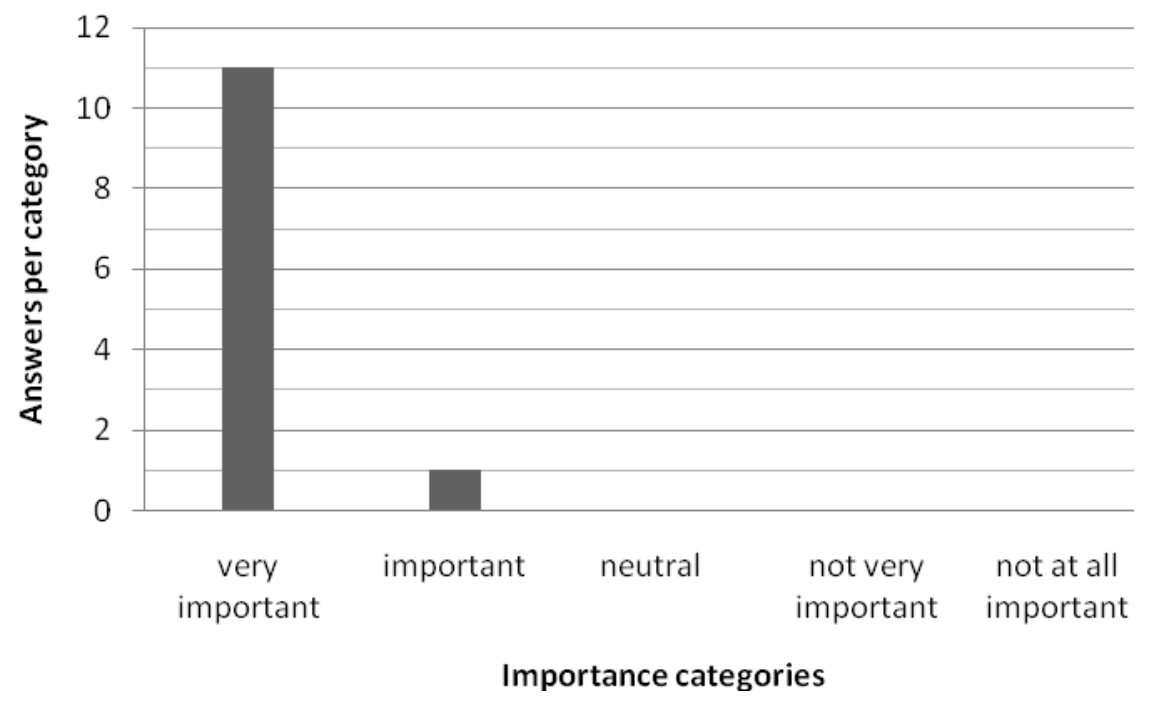

Figure 41. U.S.P.P.: Parents' answers to their perceived importance of world language learning in preschool.

\section{Physical Layout}

As one enters the classroom the room offers a warm and welcoming feeling through the arrangement of the centers and the decorations in the areas and on the walls (see Figure 42 and Figure 43). Children's art projects, posters of artwork, and the combination of natural and florescent lights create a warm and alive atmosphere even in the absence of the children. Natural elements such as plants, pumpkins, pine cones, branches, and colorful corn cobs as well as the animal corner together with the artwork of the children offer a first impression of the program's curriculum and learning focus. The classroom's unique feature of a moveable center wall provides the possibility to enlarge the room and offer a different set of areas for the children. To the right of the front door stands a red painted box with children's portfolios, allowing the parents easy access to their children's work, which they can take home. The portfolios are labeled with the children's names and are arranged in alphabetical order. They are made out of two A3 card stock papers which are stapled on three sides. 
A yucca plant stands right next to the box and above is an information board for parents and caregivers.

The writing, animal, exploratory, building, and circle areas are to the left along the window wall. The writing area has a paper recycling box and a shelf filled with writing materials such as different kinds of paper, magazines, pencils, crayons, markers, scissors, glue sticks, and rubber stamps. The tabletop paper dispenser on top of the shelf allows the children to define the paper size needed for their projects. A round table with four chairs is placed two foot away from the shelf.

An aquarium with several fish is placed on a cabinet and the exploratory table closes off the writing area while providing a shield from the happenings in the rest of the room. The exploratory table is filled with different items such as small and big yellow, black, or orange pumpkins, small and big pine cones, Indian corn, moss, bark, and branches. Several magnifying glasses are placed close to the table on a cabinet, which is next to the aquarium and two terrariums. One is unused while the other is the home of a spider - a tarantella. A blue carpet defines this area and the area is further framed by the animal cabinet on the left side and an open shelf on the right side. The shelf has different building materials, a variety of manipulatives in boxes, a big palm tree plant on top, a basket, and an advent wreath with four candles that are used during circle time.

The windows above provide plenty of light for the building and all of the animals. A third terrarium is placed on a smaller table in front of the window and it is the home of a snake. A small porcelain plant and a lamp are placed in the remaining space on the table. On the edge of the carpet extending into the room is a brick-building table, which is shared with all groups and rooms and therefore is not always in this room.

The circle area has a rectangular carpet with an earth works theme and the world in its center, which is framed by icons of nature. The wall is decorated with a tree that is as tall as the children can reach. It still has a few green leaves and functions also as a bulletin board holding the information about the new curriculum. In the windows four drawings of trees show the seasons and above are fish made by the children and labeled in German and English with keywords of behavior and rules such as tolerance, creativity, confidence, curiosity, commitment, respect, independence, appreciation, enthusiasm, integrity, empathy, and cooperation. A rattan shelf and cabinet combination has material for circle time and two baskets on top. Next to it stands the speaker chair. Another stair shelf is located on the side bordering the reading area and has additional manipulatives and puzzles. A guitar is placed in the corner. A box filled with wild animals stands in front. In between the circle and reading area stands a big ficus tree that is almost as tall as the room. 
One enters the reading area through a small book stand on the left side and a large one on the right. It is sectioned off by two soft walls. A sofa that fits about four children is placed against the wall and above is an art print of an African painting with three women dancing and two children running in the foreground. A green mesh toy storage unit hangs from the ceiling in the corner at the soft wall. It is filled with small stuffed animals. A child-sized armchair stands right next to the net. Christmas lights are hung from the ceiling and attached to the four corners of the soft walls. Books are offered in English and German (G): The Snowy Day, The Big Snow, Millions of Snowflakes, When Winter Comes, In the Snow, Footprints in the Snow, Stellaluna (G), The Beetle, The Best Book of Bugs, The Adventures (G), The Big Picture Book - Countryside (G), and several more.

The backdoor allows the children easy access to the playground, but also to the cubbies and clothes that are attached on the outside wall of the classroom. The small wall space between the door and the movable wall is filled with art - a painting of African women dancing in a circle wearing colorful traditional dresses and the village huts in the background - at the eye level of the children. Above are three wall file holders for paperwork, checklists, and parental information.

Just in the middle of the movable wall about a foot or two away stands a big, wooden playhouse that has a sheet as a roof to provide more privacy. The window has curtains, which allows its additional use as a puppet theater. Inside are a mat, pillows, and a child-sized armchair. Next to it stands a birthday easel with pictures of a birthday child. It shows his growing up and friends and family. On the other side of the house stands the drying rack for the children's artwork and creations. Attached to the movable wall are life-sized, painted silhouettes of the children.

The kitchen nook is big and has a rectangular table that seats eight children. On the left wall are cabinets and the sink, and children's artwork is posted above. There is a water cooler, and a microwave is available for the children and the teachers to heat their lunch. The back wall has lower and upper cabinets which host a collection of books on top. Teachers use some cabinets as their personal storage area, while others house teaching materials. In the right corner is a door that leads to a small storage room which is used for additional or currently unused materials. Next to the door are a dishwasher and a fridge, which is hidden through a bookshelf that is full of books.

The craft center is a small nook that has a table from wall to wall, some storage below, and two shelves above. Both are filled with arts and crafts materials. There are plenty of recycled materials below the table and several boxes with a mix of all kinds of materials that the children can use for their creations. Glue guns are ready to use along with scissors. Just a couple of feet toward the middle of the room are two tables pushed together providing seating for six. To the right of the craft center is a small hallway that leads to two bathrooms that have privacy curtains, and on the 
opposite wall are more storage cabinets and a big sink. The center area is open facilitating easy access from one area to the next and plenty of room for movement.
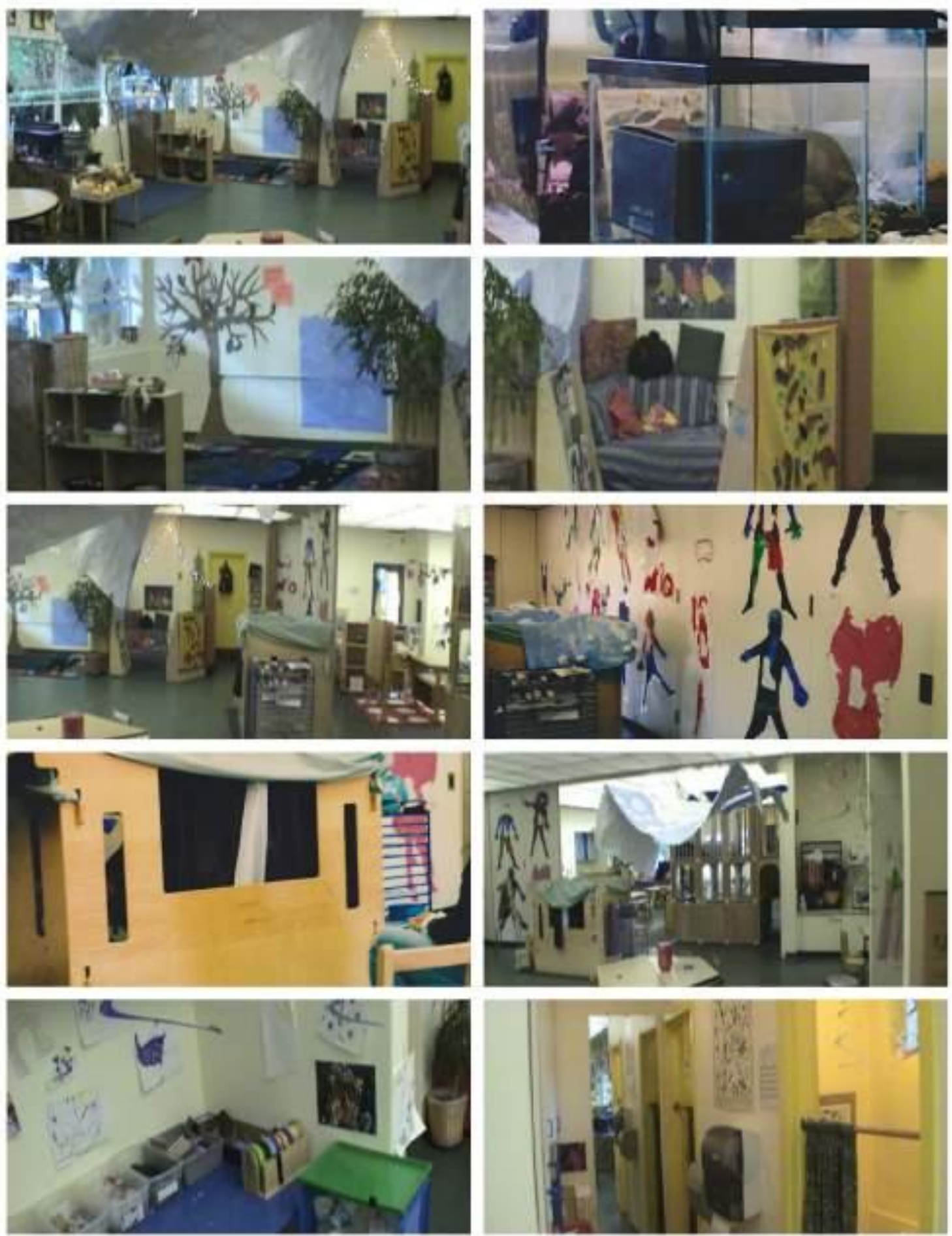

Figure 42. U.S.P.P.: Classroom impressions. 


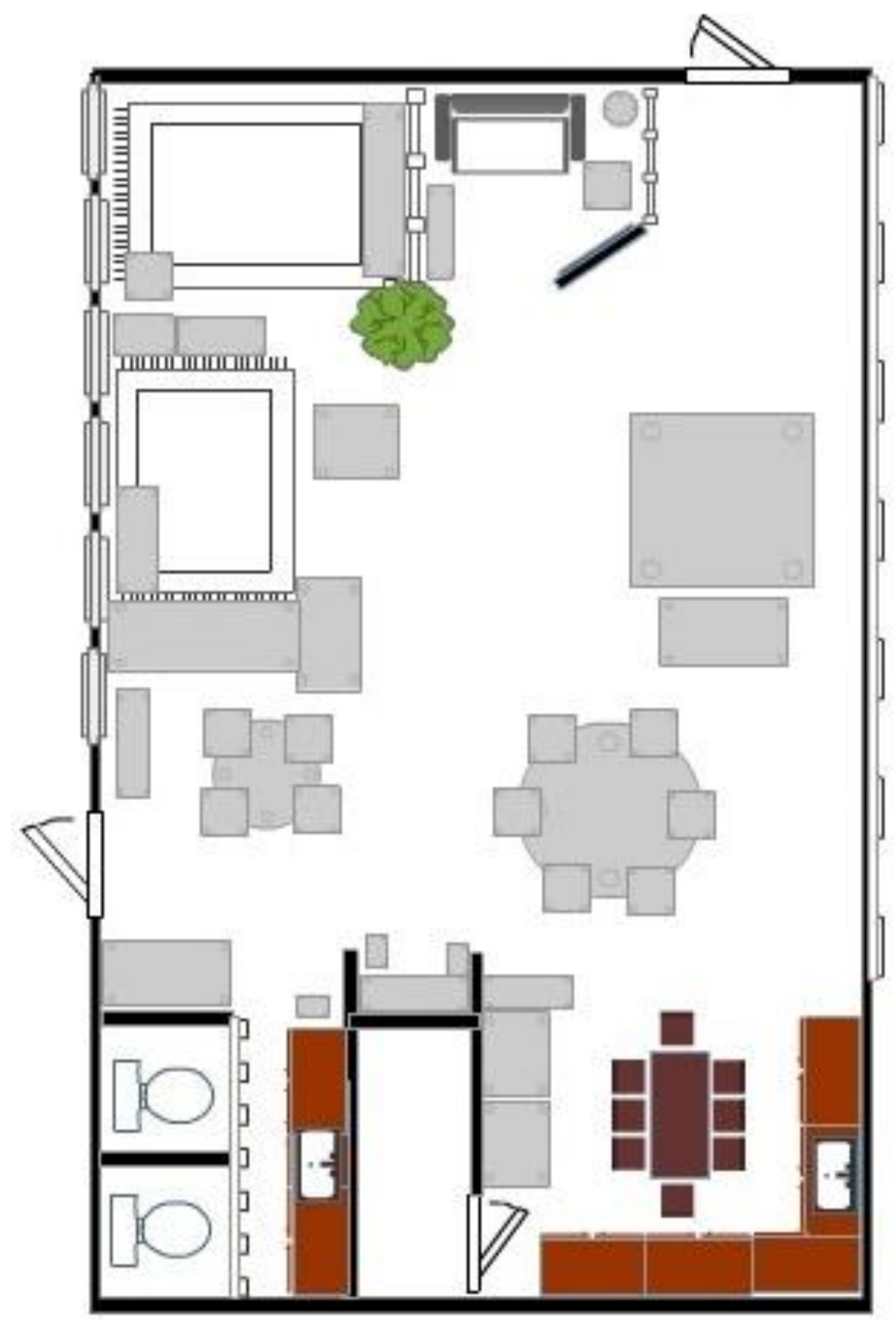

Figure 43. U.S.P.P.: Physical layout of classroom. 


\section{Outdoor Area and Playground}

Right outside the backdoor are cubbies and coat hooks for the children's clothes and materials, and a wooden picnic table stands a couple of feet away (see Figure 44). The area has several storage cabinets for the outdoor activities. On the wall are two big paintings of past projects: the night sky and the jungle. A bulletin board for parents is right next to the door and it displays the daily schedule, copies of songs and rhymes the children are learning, and the monthly calendar. All of these items can be taken home by the parents.

To the left is a small wooden play house and a couple of smaller trees, and at their feet is a collection of car tires of which some are painted in blue and pink. Next to them live the rabbits and guinea pigs in different cages with access to a fenced free running lawn area. A smaller wooden playground set with a slide, a swing, and rings is next, and below the outlook are hanging pans with which the children can make music. A wooden giraffe and a zebra are placed close to the set and used for riding. Just behind the small playground set begins the tree area including several taller trees with swings attached. The tree area is located in the back of the playground and provides shade for the sand pit, the big playground set, the forest stage, which is a small meeting area, and a playhouse. Several bushes separate the sand pit area from the bike riding area to the left. The sand area has a water source, different kinds of pipes, a couple of low benches, and big wooden bins with pots, pans, buckets, and sand forms. The big playground set has two slides, different climbing activities, and a covered outlook.

Behind the bushes of the tree area is the riding lane, which is marked on the concrete with yellow paint and arrows indicating the direction of traffic. The 'street' passes by the swing set, the triple horizontal bar system, and the balance walk, which is made of differently sized tree trunks, and turns just before the entrance area of the neighboring group. On the way back the lane passes by the fence that separates the preschool from the school playground, the gym trailer, and the storage container for the outdoor toys and riding vehicles. Just behind the container is a small ramp which makes the street more challenging, and at the end of the ramp are a few small garden beds.

If one would take away the balance activity, the children could also ride to the backdoor area of the beetle group, which I am observing.

Back at the house the backdoor area of the other group is the work bench area for wood working and other activities. There are a couple of big sinks on the walls and more tables are close by. The playground has been framed by the different activity areas which leave the middle open providing a nice lawn area. 

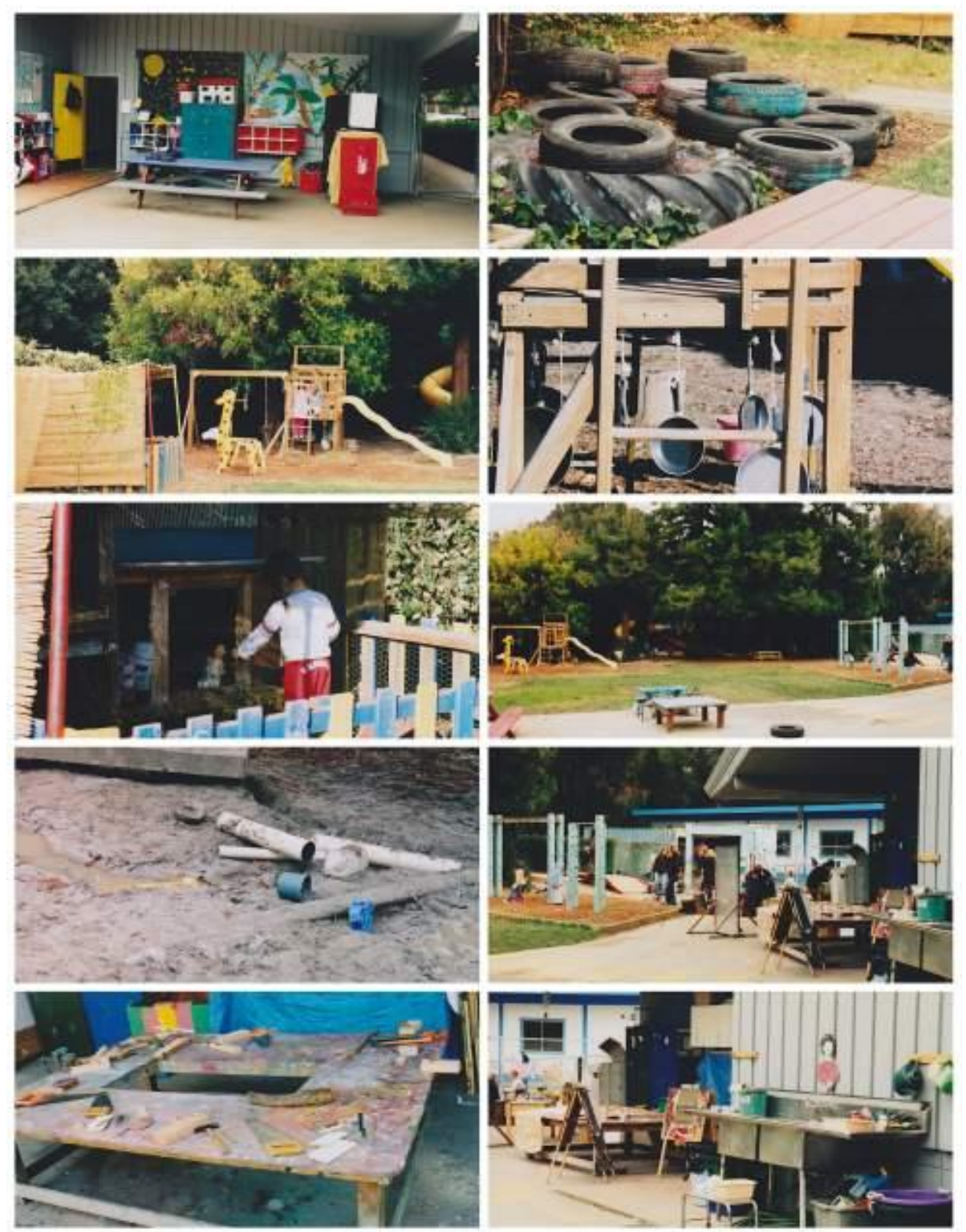

Figure 44. U.S.P.P.: Outdoor play and activity areas and playground.

\section{A Typical Day}

The daily schedule starts at 8:30 a.m., when parents can start bringing their children. During this time the children can play in the room while parents have a chance to talk with the teacher. By 9 a.m. all children should be present because the morning circle starts and runs until approximately 9:30 a.m. Project time follows, lasting from 30 minutes to one hour. Afterwards, the children have guided activity time and free play which can be inside or outdoors from about 10:00 a.m. to 11:45 a.m.

Children can choose their snack time according to their needs. At 11:45 a.m. the group has lunch 
together and after lunch the children have additional guided activity time and free play time indoors or outdoors. At 1:45 p.m. the afternoon circle time ends their busy day at the preschool. The teacher uses mainly German, but in the beginning of the year or according to the needs of the children English explanations or translations are offered.

\section{Arrival Time and Free Play (8:30 - 9:00 a.m.)}

The children are dropped off by parents or caregivers who sign their children in and out at the backdoor of the room. As the children come in they are greeted by the teachers in the room. Mira is the first child today and enters a little shyly, returning the teachers greeting with "Guten Morgen (good morning)." She goes to the set up activity consisting of a plastic container one third filled with red gak and a box of materials (see Figure 45). She starts turning the big plastic jar with red gak, but it does not move much to the top so that she can get it out. While she experiments with the jar, turning it upside down and shaking it, Sophia enters and joins her at the table. They shake it, turn it upside down on the table, and hit the bottom of the container with their hands several times. The red gak gravitates slowly toward the table and in this moment the head teacher comes over and asks them, "Siehst du was? Ich sehe was. (Do you see something? I see something)." The children look closer as some of the mass in the center moves down and they start banging on the bottom of the jar again. When Sophia turns the container around the teacher turns it on its side and Mira reaches in and grabs some gak. The teacher turns the jar one more time and the red lump falls slowly onto the table. As she leaves the table, she says smilingly, "Schaut mal was ihr jetzt geschafft habt. (Look what you have achieved)."

Mira holds the jar carefully to the side while Sophia pulls the doughy mass out. Once they have a few pieces each Mira moves to the box with cookie cutters, spoons, rolling pins, spatulas, and meat tenderizers that had been on the table with the jar. She presses her dough onto the table and takes a spatula to cut it into small pieces. Mira touches her friend and says, "I am cutting the dough." Both smile. Mira goes back to the jar that is lying on the table and says, "We need all of the play dough, right?" "Yes," nods Sophia. "I'm getting it all out," says Mira and puts her hands into the big jar, moving the mass toward her and onto the table. It seems difficult for her, and she tells her peer, "You are going to cut." She has been using the spatula to cut everything that comes out of the jar. Mira pulls out bigger and bigger pieces, while more and more children have entered the room and play in different areas. 


\section{Tarantula}

Meanwhile, the head teacher went to the animal corner and took out the spider, which is now crawling on her hands and a little bit up her sleeves. Sarina and she are sitting on the blue carpet while Michel and Cloe are watching how the spider moves onto Sarina's hands.

\section{Translation}

1 HT: Wir haben sie wachgemacht. Warte mal. Vorsichtig.

We woke it up. Wait a second. Careful.

2 Sarina: Holding her hands to receive the spider. Sie hat sich so lange versteckt.

3 HT: Hallo, wie geht es dir denn? Speaking with a high pitched voice as the spider walks toward Sarina.

4 Sarina: Warum kommt die nicht auf meinen Arm?

It was hiding for quite a while.

Hello, how are you?

Why doesn't it crawl up my arm?

5

6 HT:

8 HT:

9 Sarina:
Marianne comes over into the building area to observe.

Willst du sie auch mal halten, Marianne?

Marianne continues to observe the event.

Stetz dich hin und halt deine Hände wie Sarina. Dann kannst du sie auch mal halten. Oder möchtest du einfach nur hallo sagen? Taking her finger and greeting the spider very carefully by moving one leg up and down. Hallo.
Would you like to hold her, Marianne?

Take a seat and hold your hands like Sarina. Then you can hold her too. Or would you rather just say hello. Hello.
She is only three years old, therefore she doesn't have the heart to hold it yet. This tickles.

Marianne's mother, who has been talking with a group of mothers, enters and the girl runs to her and gives her a hug and kiss. Then she goes into the circle time area and takes the guitar. She pulls the strings carefully and the guitar sound fills the air.

10 HT: Ja, richtig, weil sie so kleine Häkchen hat.

11 Sarina: Das ist lustig. Spider returns to the teacher's hand. Warum kannst du sie nur mit einer Hand halten?
Yes, true, because it has very small claws.

That is amusing. .... Why can you hold her only with one hand? 
12 HT: Weil ich weiss, dass ich sie nicht fallen lasse. Ich habe es nur ein Mal gemacht, dass jemand sie nur in einer Hand gehalten und dann ist die Spinne runtergefallen. Man erschreckt sich manchmal einfach ein bisschen, aber ich kenne sie gut. Oh, schau hier sie macht

Spinnengewebe. Sie macht keine Spinnenweben wie andere Spinnen, diese macht es auf dem Boden. Nun geht sie wieder nach Hause. So jetzt kann sie sich ausruhen.
Because I know that I will not drop it. I have let only one hold it with one hand and then the spider fell down. One is sometimes just a little startled, but I know it well. Oh, look it makes its silky thread. It does not make a spider web like other spiders, it makes it on the ground. So now, it will go home and get some rest.

The second teacher has been reading an English book Moongame by Franc Asch in German to Christian and Cloe who are sitting on the sofa in the reading area. She is kneeling on the carpet and holds the book for the children so they can see the pictures. Michel, Marc, Sarina, and Marianne are in the circle area when the head teacher joins. Michel and Marc are playing with manipulatives, while Marianne and Sarina are playing guitar with the head teacher. Meanwhile, Kacey enters and waves his hand, greeting the group in the reading area. The second teacher returns the greeting, smiles, and says "Guten morgen (Good morning)," and he offers a big smile. The head teacher turns around and greets him with a big smile, "Hallo Kacey. Wie geth es Dir? (Hello, Kacey. How are you?)" She puts her hand toward him and they shake hands. Now, Jeth's mother enters with Jeth in her arms, sets him down in the circle time area, kneels, and plays with him for a moment hoping that he will join Michel and Marc's activity.

In the background a boy is singing "Kreiszeit, es ist so weit (Circle time, it is time)," but the sound must be coming from the other room because no one moves, not even the teachers. Kacey, Jeth, and his mother all join the manipulative activity.

\section{Gak Activity}

Sarina, who had been playing in the circle time area, walks across the room joining the play dough activity where Mira and Sophia are still engaged in manipulating the gak.

1 Sarina: Du Kneads das jetzt? Looking at Mira while playing with a little piece of gak on the table.

2 Mira: Ja. Ich mache das so.

3 Sarina: Was? Playing with more gak.

$4 \quad$ Mira: Now, can I cut?

5 Sophia: No, I have to cut. Busy cutting the gak with spatula.

6 Mira: Looking for a spatula in the box.

\section{Translation}

Are you kneading this now? Yes. I do it like this. What? 
7 Sophia: Is there another knife? Looking into the box.

8 Mira: Yeah. Taking out a bladeless peeler.

9 Sarina: Hier. Offering Mira a tiny piece of gak. Here.

10 Mira: Ich brauche keins mehr. I don't need any more.

11 Sophia: Okay. Now we get to cut.

12 Mira: You know, we are making cake.

13 Sarina: Repeats we are making cake.

14 Sophia: Cutting for a few moments and adding,. No, we are making pie.

15 Mira: Yeah, we have to first cut. Right?

16 Sophia: Yeah, we are gonna bake.

17 Mira: Yeah, we bake. We need to five pieces. Right?

18 Sophia: We have to make everything. For real. I am making pie.

19 Sarina: Has been observing the two girls doing their activity and leans over and whispers something in German to Mira and then to Sophia. ... du musst mir dann echtes Geld geben.

20 Mira: Okay. Both girls keep working on cutting the gak.

21 Sarina: Leans over again. Dann können wir Eis holen. Okay? Dann haben wir kein Geld mehr. Okay?

... you have to give me real money.

22 Mira \& Both girls keep working on cutting the gak until they are Sophia: interrupted by the call to circle time and run off.

Sarina stays at the table, which is filled with plenty of little red gak pieces, for a few seconds and then runs off to the reading area where only a few pages remain unread in the book the teacher is reading to the children. With their arms crossed on their shoulders Michel and Marc come out of the circle time area and sing loudly "Kreiszeit, es ist so weit (Circle time, it is time)" a few times. Mira and Sarina join the rhyme, walking around the room to announce that circle time is next. Behind me a loud noise starts and as I turn around the teacher next door is closing the movable wall. When Jeth, his mother, and Kacey have finished cleaning up the manipulatives, both boys follow the group of singing children while Jeth's mother leaves the room joining the group of mothers talking outside by the backdoor. 

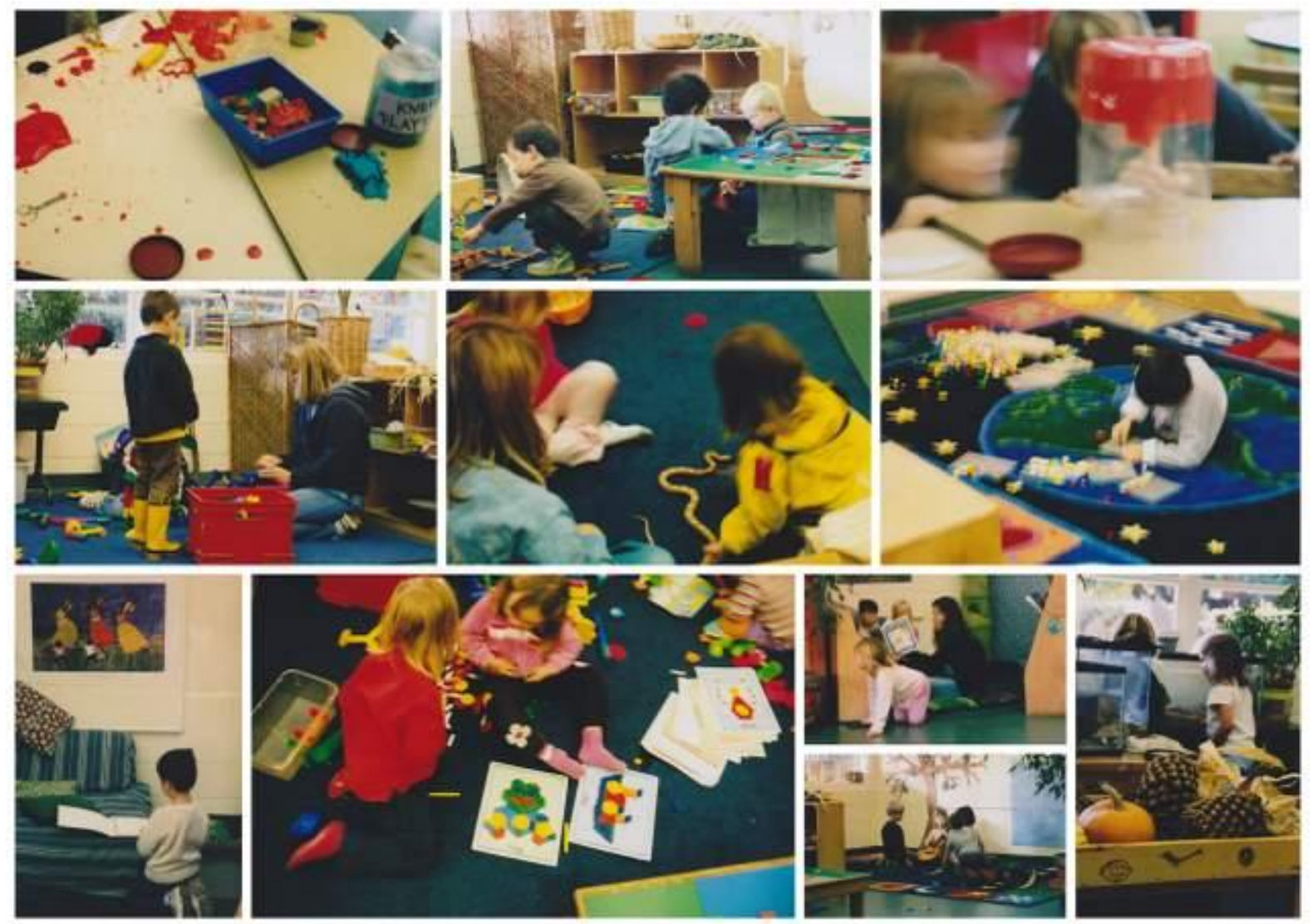

Figure 45. U.S.P.P.: Arrival time impressions of gak and pattern block activities, pet care, and reading.

Circle Time (9:00 - 9:35 a.m.)

The room is filled with German, English, and singing (see Figure 46). The head teacher encourages the children to make a circle of chairs in the center of the room. Sarina starts to move chairs away from the table, while Kacey seems confused and puts one chair back under the table. The second teacher asks Christian, "Hol Dir mal einen Stuhl und setz dich dann in den Kreis (Go and get a chair and take a seat in the circle)," which he does. Jeth takes Kacey's chair and pulls it back into the circle. Kacey steps back and watches what the other children are doing.

The second teacher explains again, "Heute machen wir einen Kreis mit Stühlen. Hier in der Mitte. (Today we are making a circle of chairs in the middle of the room)." The children go to the tables, get a chair, and place it in the center of the room. Jeth's mother comes inside and goes to her son, who sits in the circle already, gives him a few kisses, says good-bye in German, and tells him, "Ich liebe Dich. I love you," then leaves the room. The second teacher, using German, encourages 
the few children who have no chair yet to get one and take a seat. Marianne comes over and says, "Ich sitze bei dir (I will sit next to you)," while pointing to the teacher.

During circle time the children are expected to sit girl, boy, girl and so on. Marc checks the order and says "boy, girl, boy, girl" while pointing at the children. While the second teacher gets up again Michel holds his hand on her seat to make sure no one else will take her spot. She and the head teacher return with more chairs. Then the head teacher hands out four pieces of white paper with symbols - sun, wind, bird, and child - to the children.

\section{Circle Time}

As the teachers sit down the head teacher starts to sing and the children join her.

Song

1 Guten Morgen sagt die Sonne.

2 Guten morgen ruft der Wind.

3 Guten Morgen ruft der Vogel

4 Guten Morgen ruft das Kind.
Translation

Good morning says the sun.

Good morning says the wind.

\section{Movement}

Marc holds up the picture of the sun.

The teacher helps Kacey to hold up the picture of the wind and the children make wind through blowing air from the top of their lungs.

Good morning says the Mira holds up her sign of a bird and the bird. children make bird sounds.

Good morning says the Jeth holds up the picture of a child. child.

Good morning. All scream good morning.

$5 \quad$ Guten Morgen.

They sing the song twice before the head teacher takes the papers and hands them to Michel, Marianne, Lea, and Cloe. Meanwhile, the third teacher has joined the group and they start singing again. Each child holds up their paper when it appears in the song, with only Marianne receiving some help from the second teacher. They finish after each child has had a turn and in walks Sophia, who takes a seat next to Cloe. The head teacher greets her with "Guten Morgen, Sophia (Good morning, Sophia)," and so do the children.

The second teacher collects the papers while the head teacher hands out the snowflakes that are hanging on a clothesline across the room. She counts the snowflakes in German as she hands them to the children. Vanessa walks in and takes a seat next to Sarina and the second teacher, handing the snowflakes to the head teacher, greets her in friendly German. When the head teacher reaches "neun (nine)," Michel joins in and counts really fast in German, much higher and faster than needed. He stops at 25 but the teacher continues her counting and stops at twelve because there are 
twelve children in the circle. She tells the children in German that she is putting a snowflake on the two empty chairs in case the missing children come later. She comments on everything she does so that the children know what is happening. When the head teacher sits down another girl walks into the circle and she greets her very friendly and happily, "Guten Morgen, Daniela (Good morning, Daniela)." The girl smiles and hands her a piece of paper while the other children talk in German and English. The head teacher takes the paper and says, "Ich habe eine Botschaft (I got a message)." She reads it and puts it in her pocket.

The second teacher brings a basket with additional materials for the circle time and takes her seat. The children are holding their snowflake while she says, "So, Schneebälle verteilen (So, hand out the snowballs)," and throws each child their paper snowball. The head teacher asks the children, "Wer hat noch keinen Schneeball? (Who does not have a snowball?)" A few children call out "I, I, I." She gets a few pieces of paper and the children make their balls. Now, she holds up the snowflake high in the air and so do the children. She looks at hers and asks, "Was sind das noch mal? (What are these again?)" The children call out "Schneeflöckchen (little snowflakes)," one after another, and a few at the same time. The head teacher replies while showing, "Ja, das ist eine Schneeflocke und im Lied heißen sie dann Schneeflöckchen. Das sind dann kleine Schneeflocken. Manchmal sind sie groß and manchmal sind sie auch klein. (Yes, this is a snowflake and in the song they are called little snowflakes. Sometimes they are big and sometimes they are small)." Some children are ready to sing the song and the teacher reminds them that they will start together, then she counts backwards "drei, zwei, eins (three, two, one)."

\section{Song}

1. Schneeflöckchen, Weißröckchen, wann kommst du geschneit, du wohnst in den Wolken, dein Weg ist so weit.

\section{Komm setz dich ans Fenster,} du lieblicher Stern, malst Blumen und Blätter, wir haben dich gern.

3. Schneeflöckchen, du deckst uns die Blümelein zu, dann schlafen sie sicher in himmlischer Ruh.

\section{Translation}

Little snowflake, little snowflake, when do you fall, you live in the clouds, your way is so far.

Come sit on my window, you darling star, drawing flowers and leaves, we love you so much.

Little snowflake, you cover the little flowers for us, then they can sleep safely in heavenly peace.

\section{Movement}

Move their arms down slowly to show the falling of the snowflakes, reach up into the sky again, and move slowly down again.

Pretend to put their snowflake into the window and draw a flower.

Move arms down and lay the snowflakes onto the floor to cover the flowers. 


\section{Schneeflöckchen, Weißröckchen komm zu uns ins Tal, dann bau'n wir den \\ Schneemann und werfen den Ball.}

Little snowflake, little snowflake, come to us in the valley, then we'll build a snowman and throw a snowball.
Their arms are in the air again and go down setting the snowflake on the floor. They take their paper snowball and throw it on signal which starts a snowball fight.

During the song Jeth and Kacey look around at what the others are doing and copy their movements carefully. As everyone has thrown their snowball the children giggle happily and they continue the paper snowball fight by taking the balls in front of them. Everyone has fun and smiles. Then a few of the children get up to find their balls, which were flying around the room. Michel calls proudly in German "Mein Ball ist hier (My ball is here)," pointing under the terrarium while Marc does the same. He seems proud that his flew the farthest. The head teacher brings the children back into the circle by saying, "Ihr habt aber weit geworfen (You threw it quite far)." The second teacher collects all the snowflakes, puts them with the snowballs into the basket, and thanks each child when they put theirs into the basket. With a smile the head teacher cautions the children that they should be careful so that their snowballs do not melt in their hands and to return to their seats.

After everything has been collected the head teacher gets up und says, "Und jetzt brauchen wir noch einen Sandmann, oder? (And now, we need a sandman, don't we?)" The children call out "Einen Schneemann (A snowman)." She says, “Ja, richtig. Einen Schneemann. Wer wird den Schneemann heute bauen? (Oh, yes. You are right a snowman. Who will build the snowman today?)" and starts a counting rhyme. The rhyme finishes at Jeth and she asks him, "Jeth willst du einen Schneemann bauen? Would you like to build a snowman, Jeth?" Now, she remembers that he built the snowman yesterday and she tells him in English that he did it yesterday and she would like someone else to do it today. So, she counts again.

Counting Rhyme

Eins, zwei, drei, vier, fünf, sechs, sieben, eine alte Frau kocht Rüben, eine alte Frau kocht Speck, und du bist weg!

\section{Translation}

One, two, three, four, five, six, seven, an old lady cooks beets, an old lady cooks bacon, and you are gone!

\section{Movement}

Pointing with her finger to the children for each syllable.

This time it is Mira's turn and she moves at once into the center of the circle. The head teacher then counts off only the boys, and the rhyme stops at Christian. She asks him, "Möchtest du mitbauen? (Would you like to help?)" but he seems a little shy and shakes his head to says no. Michel comes into the middle to help Mira. She is holding a blue and a black hat and asks, "Welchen 
Hut braucht ihr für das erste Lied? (Which hat do you need for the first song?)" Mira gets up and chooses the black hat and returns to the snowman pieces in the center. The teacher counts "drei, zwei, eins (three, two, one)," and they start singing the song.

\section{Song}

1. Kommet her und seht, vor dem Hause steht, ein dicker Mann und lacht, der ist aus Schnee gemacht.

2. Einen blauen Topf, trägt er auf dem Kopf,

das ist sein neuer Hut, und der gefällt ihm gut.

3. Wenn die Sonne scheint, unser Schneemann weint, das ist ihm gar nicht recht, denn das bekommt ihm schlecht.

\section{Translation}

Come here and see, who stands in front of the house, a big man and smiles, he is made of snow.

A blue pot, he carries on his head

that is his new hat und he likes it very much.

When the sun shines, our snowman cries, he does not like it very much and it is too bad for him.

\section{Movement \& Action}

Two children build a snowman

that has a black pot on his head.

All children put the hands on their head.

All children draw the sun and show crying by wiping their eyes.

The children sing only a little with the teachers and the head teacher tells the children, who are more focused on watching, what Mira and Michel are building. She counts again and the children sing. After the second verse the teacher stops and one of the children says, "eines schwarzes Hut (a black hat)," noticing that they are singing about a blue hat in the song. Mira and Michel are focused on building the snowman and do not listen to the suggestion. The teacher wonders, "Hm, irgend etwas stimmt nicht mit dem Schneemann. Wer weiß es? (Hmm, something is not quite right. Who knows it?)" There is no reaction and they continue singing the song to the end. The head teacher repeats her statement, "Ich habe noch ein Problem mit unserem Schneemann. Ich singe noch einmal eine Strophe vor. Hört mal genau zu (I still have a little problem with our snowman. I will sing a verse again. Listen very carefully)," moving her hand to her chin and looking puzzled about the snowman. As she starts singing some of the children join her, "Einen blauen Topf, trägt er auf dem Kopf, das ist sein neuer Hut, und der gefällt ihm gut. (A blue pot, he carries on his head that is his new hat und he likes it very much)." Afterwards she asks the children again, "Was passt nicht mit diesem Schneemann? (What does not fit with our snowman?)" Sarina answers, "der Hut (the hat)." Kacey points to the hat and says, "blau Hut (blue hat)." Mira and Michel change their black hat to the blue pot. The head teacher asks, "Hat er jetzt einen blauen Hut auf dem Kopf? (Does he have a blue pot on his head now?)," and the children call out "ja (yes)." On the floor is a tall snowman which has a blue pot on his head, a smiling face, and many buttons. She praises their good work and Mira and Michel sit down. Then the second teacher puts the snowman away. 


\section{Read-Aloud Gingerbread Baby by Jan Brett}

The head teacher calls the children to take a seat in the circle time area where she has placed a book on the speaker's chair. It is a big book and the illustrations are large so that all children are able to see the pictures that go along with the story.

1. HT: Ich habe ein Buch gefunden, dass möchte ich euch vorlesen. Als ich es mir angeschaut habe, habe ich gedacht auch in diesem Buch ist ja ganz viel Schnee. Points to the back cover showing snow. Kennt Ihr das Buch?

2. Group: Ja, nein, nein.

3. HT: Allerdings ist diese Geschichte ziemlich lang und in Englisch. Ich lese sie in Englisch vor und übersetze dann zwischendurch in Deutsch.

\section{Translation}

I found a book that I would like to read to you. When I thumbed through the book I thought well this book has a lot of snow. Points to the back cover showing snow. Do you know the book?

Yes, no, no.

Though this story is rather long and in English, I will read it in English and translate in between into German.

The children sit close to the book in theater style. Jeth kneels and is therefore taller and some of the children start complaining that they are not able to see, which the teacher addresses immediately.

4. HT: Jeth, you have to sit on your bottom or in the

very back row. What would you like to do?

He takes a seat on his bottom and the children stop complaining. It is getting quiet very quickly, and Cloe moves to the back row, standing against the wall.

5. HT: Reads the title "Gingerbread baby."

Gingerbread is like gingerbread. Do Gingerbread ist so wie Lebkuchen. Kennt ihr Lebkuchen?

6. Michel: Nein, aber ich weiß, dass Gingerbread immer gut schmeckt.

7. HT: Aha. Cloe, setz dich bitte hin. Das ist das Gingerbread Baby. While turning the first page Was ist denn das?

8. Michel: Das ist ein Haus.

9. HT: Ja, das ist ein Haus. Bitte - Zippe diu: der Mund ist zu, wenn wir das Buch lesen.

you know gingerbread?

No, but I know that it tastes good.

Aha. Cloe, please sit down. This is the gingerbread baby. Und what is this?

This is a house.

Yes, this is a house. Please, zippe dioo: the mouth is shut, when we read the book.

She reminds the children that there is no talking during the story and moves her hand across the mouth like a zipper and some of the children join her in the movement. Before she starts reading the story they discuss some of the illustrations prior to the story and then the children turn very quiet.

10. HT: It was cold outside. It was warm inside. A fine day for gingerbread, Matti thought. Matti's mother put the big blue bowl on the table and lit the stove. Matti took down a worn-looking cookbook with old-fashioned writing on the cover. He opened it up to the page that said "Gingerbread boy." Es war ein sehr guter Tag, um Lebkuchen zu backen. Dann haben sie ein ganz altes

It was a great day to bake gingerbread. Then they got a very old cookbook from the shelf because it had a recipe for gingerbread. 
Kochbuch vom Regal genommen, weil da das

Rezept drin war für den Lebkuchen.

The book is about a little boy who is baking a gingerbread boy following a recipe from a very old cookbook that tells him not to peak into the oven for 8 minutes. The boy waits only five minutes...

11. HT: Matti couldn't wait any longer. He opened

the oven door to take a peak. Instead of a gingerbread boy out jumped a gingerbread

Matti was not able to wait. He baby. I am the gingerbread baby fresh from opened the door and the gingerbread the pan. If you want me, catch me if you can. Matti konnte nicht mehr warten, da hat er die baby jumped out and said "catch me Tür aufgemacht und Gingerbread Baby ist if you can."

herausgesprungen und hat gesagt ,fang mich falls du kannst.“

... and off runs gingerbread baby outsmarting everyone who wants to catch it. The boy stayed inside and continued baking. The villagers and animals followed the gingerbread baby up a hill to catch it, but when they reached the top they only found crumbs and a candy cane.

12. HT: I am the little gingerbread baby, lucky as can

be. Living in the house that Matti made for me.

Matti wollte ihn gar nicht essen. Er hat nur ein Haus für ihn gebaut. Da kann das Gingerbread Baby leben.

Matti didn't want to eat it. He built a house for him where the gingerbread baby could live.

The teacher uses a storytelling voice and rhythm when the story melody allows her to and the children are glued to the reading and the translation. The children ask a few questions, which is answered if connected to the plot of the story, but if they lead away the teacher ignores them because it is a long story. Afterwards the children tell her in English that they have a similar book while she tells them the title of the book.

\section{Musical Chairs}

The head teacher announces, "Alle brauchen einen Stuhl. Everyone needs a chair. Wir stellen alle Stühle jetzt mal zusammen (We will place all the chairs together)." She takes two chairs, placing the backs of the chairs together, and the children copy her example and take a seat. This looks challenging for some of the younger children. The teachers help to create a somewhat straight line. She asks a couple of times, "Haben alle Kinder einen Stuhl? (Do all children have a chair?)" The children sit on their chairs and the head teacher goes over the rules of the game - musical chairs - in German, repeating each part in English: "Ich werde jetzt Musik anmachen. I will turn on music. Und jedes Mal wenn die Musik ausgeht, dann müsst ihr euch auf einen freien Stuhl setzen. Every time the music goes off, you sit on an empty chair. Wenn kein Stuhl mehr da ist, dann müsst ihr euch bei 
einem anderen Kind auf dem Schoß setzen. Then you have to sit on somebody's lap, wenn kein Stuhl da ist."

One of the children says in English that this game is called musical chairs. She agrees and nods her head. Amy says in English, "I knew that it is musical chairs," and repeats it a few times, confused with the rules, and says, "or you have to go out of the game, right?" looking to get a response from the head teacher.

The head teacher turns on classical music and shows the children what to do. "Alle aufstehen. Auf, auf. Alle aufstehen und rumgehen (Everyone get up, up, up, everyone get up and walk around the chairs)." She goes to Christian and helps him up and shows him what to do. He is a little upset today and misses his mother. Then she helps the youngest children, Jeth and Kacey, who are still sitting on their chairs while the other children seem to understand what to do. The classical music playing is the theme song of the nutcracker. She asks the children if they can hear the music and some nod their heads, focusing on the activity, while others say "ja (yes)." As the music stops she helps the younger kids - the three year olds, Jeth and Kacey — to find a chair while saying "Stuhl suchen (find a chair)" and "hinsetzen (sit down)" several times. In the first round all children were able to find a chair and she announces, "Habt ihr alle einen Stuhl gefunden? (Did everyone find a chair?)" Some of the children answer her question with "ja (yes)," and she tells them, "Jetzt mache ich es schwerer (now I will make it harder), weil jetzt nehme ich einen Stuhl weg. Now, I will take one chair away." As the music is on again she tells the children "Alle wieder aufstehen und im Kreis gehen. (Everyone get up and walk in a circle)."

The children walk and some march to the rhythm of the music, and she helps the younger children again to find a chair as the music goes off. Cloe cannot find a chair; now she has to look for a lap and she takes a seat on Sophia's lap. The teacher comments, "Cloe sitzt bei Sophia auf dem Schoss (Cloe sits on Sophia's lap)," and turns the music back on. The third teacher takes two chairs away and some children march while others walk or dance to the music around the chairs. As the music goes off the children find a seat and Marianne and Liam are left without a chair. Marianne takes seat on Sophia's lap while Liam looks for a boy and takes a seat on Michel's lap. Then the head teacher announces to the group who is sitting on whose lap in German.

Christian enjoys this activity and engages himself happily while the two year olds Jeth and Kacey don't seem to want to sit on somebody's lap but enjoy jumping about to the music. Then the two hide in the play house and peek through the curtain. The children have lots of fun piling onto one-another. Cloe sits on Mira's lap, Sophia on Mira's, and Amy on Sophia's. Amy counts the children and says, "Wir sind vier (We are four)." All children laugh and smile happily. The piles get 
larger and larger and the teacher names all the children sitting in a pile. When one chair is left the children all sit on top of each other and the room is filled with the children's joyful noise and laughter. The transition to project time runs smoothly.
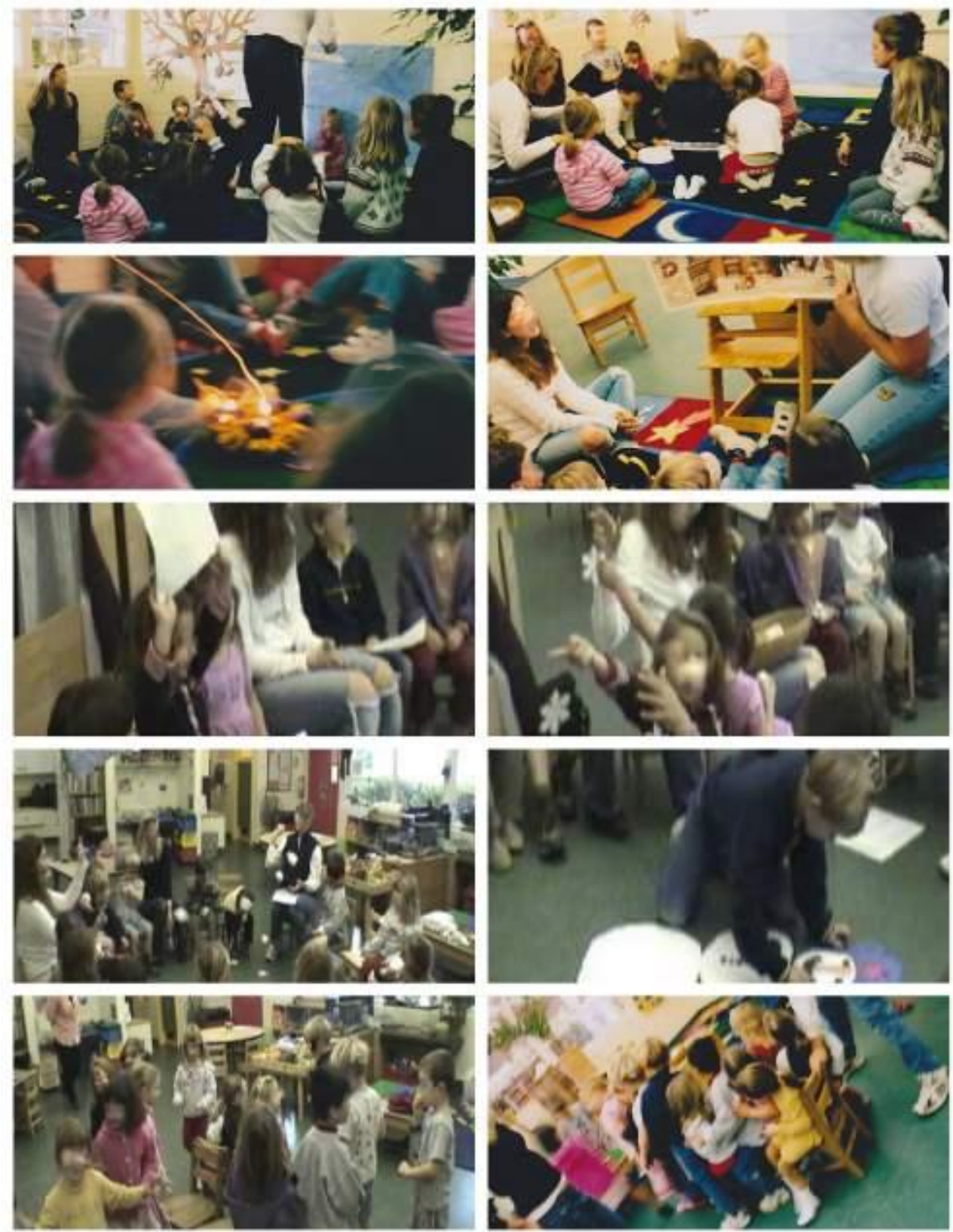

Figure 46. U.S.P.P: Circle time impressions of read aloud, singing songs, and musical chair game. 
Project Time (9:35- 10:05 a.m.)

The head teacher announces the offered activities and all are encouraged to help finish preparations for the Holiday Festival on Saturday by creating big snowflakes with cutting and glitter, finishing decorating the wall panel, and designing wintery head bands (see Figure 47). Some of the projects have been offered previously, like the wintery head band and the panel decoration. Each child needs to make a head band but not all have made one yet. The teachers finish preparing the activities and the children can participate according to their interests and needs. Christian goes into the book area, chooses one, and starts thumbing through the book. Daniela joins him and picks a book while Christian returns his to the book stand. Christian looks across the room at what the other children are creating for the festival. He seems unsure of whether to join them and keeps observing from the distance. Michel, Marc, and Liam are in the building area playing with cars and manipulatives. Jeth and Kacey are playing in the house.

\section{Panel Decoration}

The third teacher takes the approximately seven foot long wall panel, decorated by the children with different shades of white and blue, from the clothes line. Lea and Cloe stand close to her and observe what she is doing with interest. Lea repeats "Ohh, kuck mal (ohh, look here)" several times while pointing to the hole in the panel as the teacher places it on the floor in the middle of the room. Amy holds a snowman in her hand, and Marianne watches the activity. Lea places her snowman on the panel where it was broken off while the teacher gets glue for the children. She returns with a box of glue and tells Amy, "Du kannst deinen Schneemann schon mal drauflegen and dann aufkleben (You can place your snowman on the panel and then attach it)." Lea and Marianne

join the snowflake activity and Cloe takes over her spot, gluing the snowmen onto the panel together with Amy. Cloe has trouble with the bottle because no glue comes out. She hands the bottle to the teacher, who tries to the fix the problem. It takes a few seconds and the girl decides to take another bottle out of the box. They work focused and silently, carefully placing the glue onto the three feet tall snowmen.

Daniela and Christian are still in the book reading area, but he is looking across the room on and off to see what activities the children are doing. When Amy has finished she points to the snowman and says, "Das ist meine Schneemann (That is my snowman)." The teacher replies, "Ja, das ist dein Schneemann (Yes, that is your snowman)." Then a group of boys, Michel, Kacey, Jeth, Liam, and Marc, walk by the wall panel and look at it. Kacey points to one of snowmen and laughs happily while the others just watch. Amy tells them, "This is mine and this is Cloe's," while pointing 
to the snowman on the panel. The teacher asks the boys, "Möchtet ihr auch mitmachen? (Would you like to join?)," but Michel tells her, "That is too boring."

\section{Glittery Snowflakes}

Meanwhile a group of girls, Mira, Marianne, Lea, Sophia, Sarina, and Vanessa, have been creating large snowflakes out of large special paper, which has a sticky side. The head and second teacher are helping the children to cut off the edges to make a circle while the children wait patiently for their turn. Only Marianne, the youngest girl, tries to cut it herself while Sophia asks the second teacher, "Kannst du das schneiden? (Can you cut this?)" When the paper is cut she hands it to Sophia and goes to Lea who has been waiting for hers to be cut. The other teacher placed more circles into the middle of the table, and the second teacher gives her a piece and says, "Hier kannst du schon eine Schneeflocke schneiden. Schön am Rand einschneiden (Here, you can cut this one already. Cut off the edges)." Marianne has a hard time cutting her paper with the scissors. The paper is more diamond shaped than round. The head teacher finishes a paper and tells Marianne that she will join her in a minute.

Sophia says, "Kuck mal (Look here)," showing the little area she cut off of her snowflake to the teachers. The head teacher replies, "Super. Ja, den ganzen Rand so machen. Das ist super (Great. Yes, cut the whole edge like that. That is great)." Amy, who just joined the group, needs some reassurance asking, "We are doing these all around, right?" The second teacher tells her while demonstrating her words, "Ja, den ganzen Rand einscheiden. So (Yes, cut off the whole edge like that)." Mira points to the girl across from her saying "Look what they are doing," and the head teacher tells her, "Ja, richtig. Am Rand einscheiden. Kuck mal wie die Mira, hier am Rand schön einschneidet (Yes, good. Cut into the edge. Look here, how Mira cuts nicely into the edge).” Showing it to Lea who has a hard time cutting the thick paper with the small scissors, the teacher then says, "Ihr macht das alles ganz super (You are doing a great job)." The teachers hold the paper for the children so that they can cut easier, even folding it over so that they can also cut in the middle of the circle. The girls are all focused on their cutting and it has become rather quiet at the table. As the group of boys - Michel, Marc, Liam, Kacey, and Jeth - make their second round to see what the girls are creating, the teachers encourage them to make their own snowflake but they return to the building area.

After a while the first children, Sophia, Vanessa, and Sarina, have finished their snowflakes and Vanessa holds hers up into the air and repeats twice, "Kuck mal, ich bin fertig (Look, I am done)." "Sehr schön. Warte bitte einen Moment (Well done. Please wait a second).," she replies, "Ich 
helfe gerade Sophia und muss auch noch den Glitter holen (I am helping Sophia and I have to get the glitter too)." However, the girl observes them for a few seconds and says, "Ich kann das auch alleine machen (I can do that by myself)." The second teacher answers her, "Ich zeige dir mal schnell einen Trick. Kuck mal hier. Siehst du das. Da kannst du anfangen (I will show you a trick. Look here. Do you see this. There you can start)." Then she leaves the table to get the glitter from the upper shelf in the craft area and returns with hanging folders and the glitter. She places the folders under the snowflakes of the children who have finished peeling off the paper and demonstrates the next step, "Schön vorsichtig mit der Hand den Glitter auf die Schneeflocke streuen. Lass uns mal schauen, ob es auch klebt (Very carefully sprinkle the glitter with your hand onto the snowflake. Let's check, if the glitter stays)," while holding up the snowflake showing that nothing falls off. "Ja, es klebt, aber nur ein bisschen nehmen (Yes, it sticks, but always use only a little)," she says, pointing to the glitter.

More and more children finish cutting their snowflakes. They clean off their areas and place a folder under the snowflake, peel off the paper, and start sprinkling the glitter over their snowflake. Glitter seems to get everywhere but that does not matter too much. Occasionally the teachers remind the children to use only a little of the glitter and that they can also use the glitter which is on their folder. Accidentally, Amy sprinkles a handful onto the floor and the teacher shows her how she can pick it up easily by placing the sticky side onto the floor. Amy says to Sophia, "This will be very pretty. Right Sophia?" and she nods her head to agree. Sophia has placed some glitter on her snowflake, shows it to the teacher, and says, "Ich bin fertig (I am done)." Since the snowflakes are big there is a lot to cover and the goal is that there is no blue sticker paper left, only white and silver glitter as the teacher explains to the group. Vanessa and Sarina speak softly in German with each other, while Mira and Marianne are not saying much at all because their main focus is the project. Lea, Amy, and Sophia speak in English to each other. They keep working on their projects and after a while the snowflakes sparkle in white and silver in the light of the room.

\section{Wintery Head Bands}

The head teacher has placed the materials for creating a head band on the table in the kitchen area. On the table are stripes of turquoise construction paper, glue, cotton balls, paper, and scissors. She asks a few children who are not participating in one of the offered projects, "Hast du schon eine Krone gemacht? (Did you make your crown already?)" Marc, Liam, Michel, and Daniela answer "Ja (Yes)."

She looks for Kacey and Jeth in the play house and tells them, "Kommt mal her (Come over here)." She goes with them to the table, but the third teacher asks her something and off they go 
again as if playing a chasing game. She calls for them again, "Kacey und Jeth, ich brauch euch zwei hier. I need you two here. Setzt euch mal hier hin. Please take a seat right here.” Then they return to the table while Michel asks her several times, "Können wir Briefe machen? (Can we write letters?)," and since project time is almost over she tells him "ja (yes)." He goes to the writing area where Liam joins him. Marc has been creating his headdress - a wintery crown — and has almost finished.

Kacey and Jeth are sitting at the table and the teacher fits the strips to their heads and then tells them, "Hier sind Kleber und Wattebällchen, die könnt ihr aussen ankleben. Here are glue and cotton balls. You can glue balls as snow on the outside." Kacey and Jeth are making their headdresses now with the help of the head teacher, while Mira is still working on hers, and Marc has just finished his. Kacey places his undecorated crown onto his head because he is not able to get glue out of the bottle, but after the teacher opens it he chooses to glue cotton balls onto the crown. Jeth joins him gluing when the teacher has finished his crown, and both work very well with the glue and cotton balls. It takes them a while to finish their crown, on which they work intently.
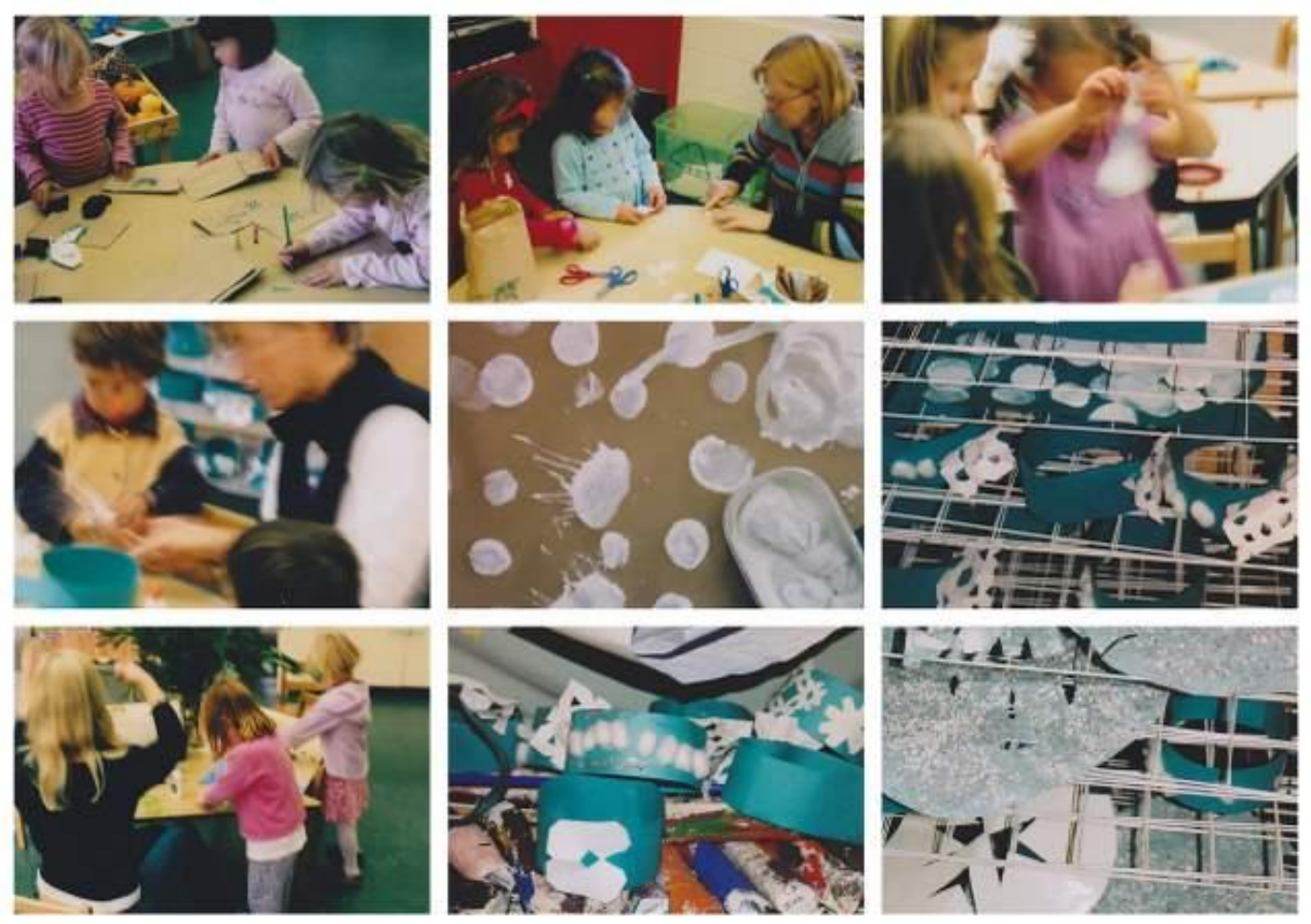

Figure 47. U.S.P.P: Project time activities stamping lunch bags, cutting snowflakes, sock painting, and artwork. 
Free play and guided activities (10:05 - 11:45 a.m.)

\section{Free Play and Read-Aloud (10:05 to 10:20 a.m.)}

The third teacher is in the reading area, reading a Christmas story in English to Daniela, Christian, Sarina, and Vanessa. Liam and Michel are writing letters to Santa and put them into a box in the circle area (see Figure 48). After Mira has finished her wintery crown, she goes to the writing station and scribbles on paper. Then she runs off while saying, "I am going potty." Liam and Michel are talking in English and then Liam runs off saying, "I have got to put it in his mailbox," while Michel is still licking his envelop to close it. Then he goes to the circle time area where their mailbox is standing. He carefully and very slowly drops the letter into the big wooden box through the side opening and returns to the writing table. The head teacher has taken a seat next to Liam and starts a conversation. While she uses German he replies in English, rarely using German throughout the day.

\section{Head teacher Liam \\ 1 ... Könnt ihr nicht mit ihm No.} sprechen?

2 Warum nicht?

$3 \quad$ Vielleicht müsst ihr einen Übersetzer finden. You got to find a translator - einen Übersetzer.

$4 \quad$ Und ihr könnt das nicht?

5 Das ist natürlich schwierig.
It is too hard to speak with him because he speaks a hard language. The only language he knows is Mandarin. That is this language pointing to his scribbles.

Only some. The only way we can speak to him is Ian and he is not here.
Translation ... Can't you talk to him?

Why not?

Maybe you should find a translator.

And you don't know it? That is rather difficult.

She gets interrupted by Marc, who asks her, "Can we get the snake out?" She tells him, "In ein paar Minuten gehen wir in die Bibliothek und danach können wir sie rausholen (In a few minutes we will go to the library and we can take it out afterwards)." Meanwhile, Marc has managed to have five different strings of gak run down onto the floor, creating five little hills. Kacey and Jeth are also playing with the play dough and the second teacher helps them. Jeth is cutting the play dough, which is pressed onto the table, with a spatula. Some of the girls are playing in the house and the conversation is in German and English, but it is very difficult to follow because they talk at the same time about different things, and in different areas. Amy and Marianne notice what the boys are doing and wonder if they should also write letters. Meanwhile, Michel has gotten all Santa's letters out of the box. Liam and he decide to place them outside in their cubbies. Now the girls, Amy, Mira, Marianne, and Sophia, also write letters to Santa. 
Liam says in English, "Amy, you cannot play with us because we are making hard language letter. You know what I mean?" Amy does not really respond to his statement. She rather talks to the girls next to her and explains in English that she is writing in cursive. Liam responds, "I am writing in Mandarin." She continues to explain to the girls that it is easy, while pointing on the paper which has wavy lines from top to bottom. "I learned it from my friend Andrea," she adds. Michel listens too and tells her, "I know what cursive is but I don't understand that." Liam expresses, "Mandarin is so easy to learn. All you got to do is..." but he does not finish his sentence and Amy continues to speak about cursive, "See, it is easy for me." "Can you give it to me because I want to put it in the letter box?" says Michel. Mira uses a counting rhyme: "Eeny, meeny, miny, moe, catch a tiger by the toe. If he hollers let him go," to see whom she will give her letter to, then she goes over and hands it to Amy. Marianna insists that she is also writing Mandarin as the head teacher calls for the children to get ready for library time.

Kacey and Jeth have returned to their play at the small house. Kacey has a keyboard in his hands and pretends that it is pizza, taking a big bite and says, "Hmm, pizza." Then he goes inside the house while Jeth runs two rounds around the house before entering. The second teacher takes a seat in front of the window and engages in their pretend play situation when Kacey hands her the keyboard and says "pizza." She asks him, "Ist da auch Ananas drauf? (Is there pineapple on top?)," and they nod their heads. "Hmm, lecker. So lecker. Wieviel kostet denn die Pizza? (Hmm, delicious. So delicious. How much is the pizza?)," she asks but there is no response. She continues to ask questions, "Kann ich ein Wasser haben? (Can I have some water?), and Kacey says, "ja (yes)," reaches out, and gives her the water. "Kann ich einen Salad haben? (Could I have a salad please?), she orders and Kacey tells her, "We don’t have this." "Keinen Salad? (No salad?)," she asks again and Kacey insists, "We don't have this." He says something about baking and the teacher says, "Ich möchte gern zwei Brötchen (I would like two rolls, please)," and he keeps saying, "We don't have that." She orders now two rolls in English and repeats in German, but Kacey insists, "We don't have this." "Ein Brot, bitte (One bread, please)," and both tell her, "We don't have that." Then she asks, "Was haben wir? (What do we have?)" They scream at her "all is gone" and go searching the small house repeating several times "all is gone." She asks, "Alles ist weg? Es gibt kein Essen mehr? (All is gone? There is no more food?)," and they tell her "ja (yes)." But the teacher does not give up and asks, "Habt ihr Trinken? (Do you have something to drink?)" and again they reply with "ja (yes)." So she orders, "einen Apfelsaft (one apple juice)," and the boys run outside the house, pull the tap to fill each a cup with apple juice, return inside, and hand the cup through the window to the teacher who says, "Danke, hmm schmeckt der Apfelsaft gut (Thank you, hmm the apple juice tastes great)." She 
continues to order different drinks and the boys bring it to her. As they bring her things she did not order she asks them, "Was ist das? (What is this?)," and Kacey tells her "pineapple" and she translates it saying, "Hmm, Ananas, wie lecker Ananas (Hmm, pineapple. How delicious pineapple)."

Sophia joins and takes a seat next to the teacher who asks her, "Willst du auch was essen? (Would you like some food too?)," and she replies "ja (yes)." The teacher asks the boys, "Gibt es noch Pizza? (Is there pizza left?)," and they nod their heads. "Was möchtest du essen? (What would you like to eat?)," she asks Sophia again, but before she can answer Kacey hands her a piece of pizza saying, "here, pizza." The girl pretends to eat it and the teacher asks her, "Was ist auf deiner Pizza? (What is on your pizza?)," while offering some choices, "Käse? (Cheese?)" "Käse (cheese)," repeats Sophia and "Salami? (Salami?)," asks the teacher while Sophia says smilingly “ja (yes)." "Und Schokolade? (And chocolate?)," and the girls says "ja (yes)" again while the astonished teacher rephrases her question, "Schokolade ist auf deiner Pizza? (Chocolate is on your pizza?)" "Ja (yes)," insists the girl copying the teacher who placed her hands on her waist to emphasize her statement. Kacey adds, "We don't have Schokolade auf Pizza. We don't have this today." The boys find this very funny and it ends this pretend play because they start running around the house and through the middle area of the room. The teacher asks them, "Was bist du Kacey? (What are you Kacey?)," and he tells her, "einen tiger (a tiger)," pronouncing the animal in English. She repeats, "Ein Tiger. Und du Jeth. Was bist du? (A tiger. And you Jeth? Who are you?)," and he says to her, "tiger." While they run around the room she says to Jeth "ein Tiger (a tiger)," then she returns her chair to the table and walks off.

Christmas music has been playing in the background during project time and free play. The head teacher walks around the room to inform the children that they must finish up because they are going to the library in a few minutes and they need to change their shoes. 

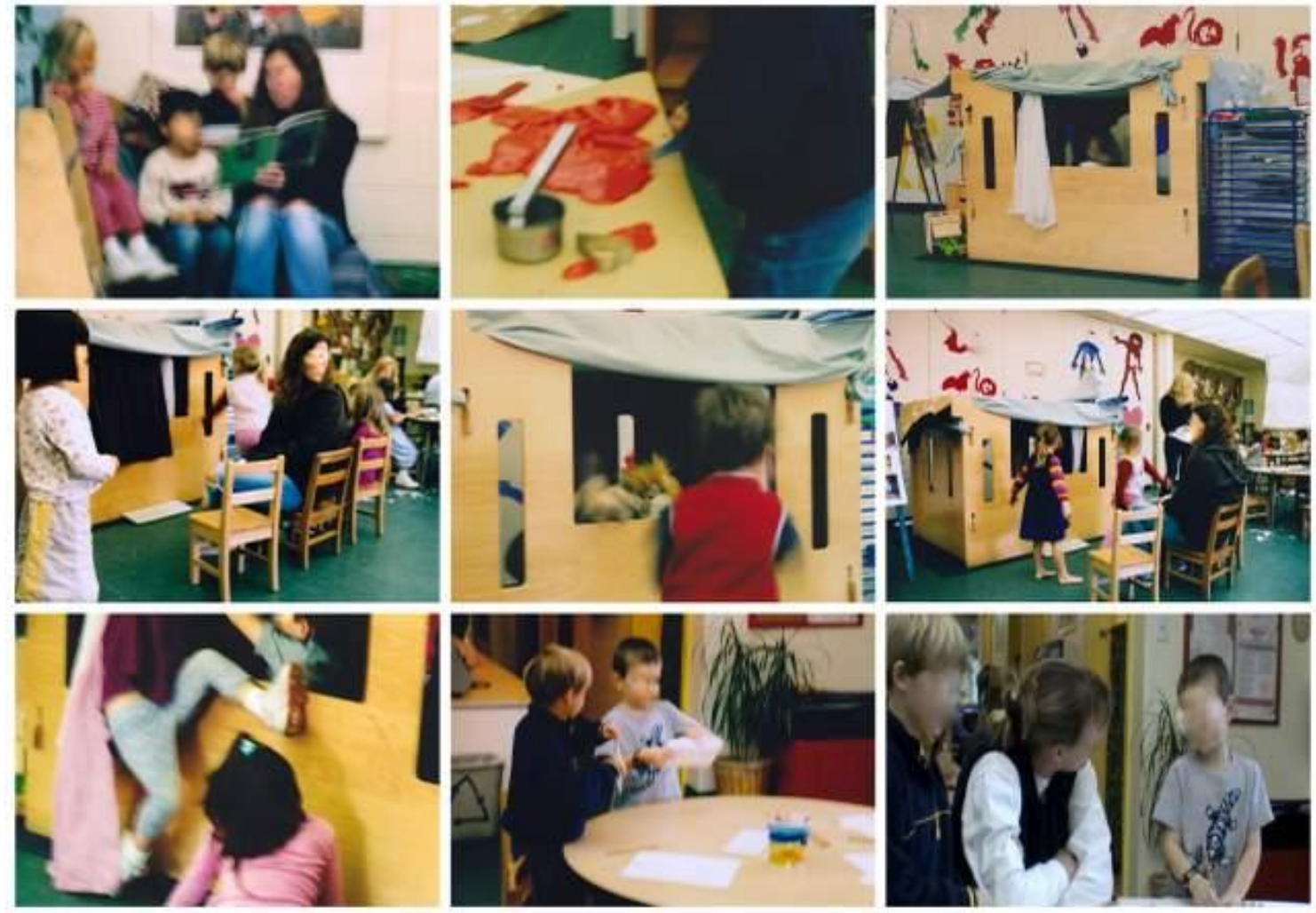

Figure 48. U.S.P.P.: Free play and guided activities.

\section{Library Time (10:20 - 10:45 a.m.)}

The head teacher calls for all children and tells them to put on their shoes and return to the classroom because they will use the front door to go to the library. The head teacher comes to the front door and asks in German and English several times, "Who has to go to the bathroom?" No one answers and she asks again. The teacher asks the boys to line up with a girl. In the room are the three teachers and Amy's mother who will help in the library. Once everyone has lined-up the head teacher explains the library rules in German and in English, "Amy's mother will read out the names who are allowed to get a book because they have returned their old one."

Amy's mother then reads eight names from the list. The head teacher reminds the group, "Die anderen Kinder können sich Bücher anschauen. They can look at some books." The children who have not returned the library book from last week cannot borrow a book this week. Through the window one can see the whale group returning from their library time, which is the sign for the beetle group to go. The library is not far from the classroom (see Figure 49) but the group has to leave the preschool area through the big blue painted entrance gate, pass by the teacher's office, then enter the next door into the library. It looks as if this was the main entrance before the school was rented by 
the German school. The mother is the last in line and carries the book box with today's returned book bags. As the group enters, most of the children know very well where the children's book section is and walk quickly to the shelves. The second teacher helps Kacey and Jeth to focus on the books by showing them where the shelf with their age group is by saying, "Kuck mal, hier sind eure Bücher. Look, here are books for you." Vanessa and Sarina select a book and take a seat on the sofa. They try to turn the pages together and look at the right page with a big picture.

The head teacher takes a seat at the round table, the children present their chosen book, and she writes the title and author into a thin book. Michel is the first who hands his book to her and after she has all the information she hands the book back to him and tells him in German, "Thank you very much. Now you can go over to Amy's mother."

Next in line is Christian, who hands her a German book about fire stations. She engages him in a conversion about fire trucks, talking in both German and English. He speaks mainly in English and includes a few German words that he knows. She reads the title of the book, "Mit der Feuerwehr (With the fire fighters)," and asks him, "Magst du die Feuerwehr? (Do you like fire fighters?)" He nods his head and tells her, "I have visited a Feuerwehr and saw how they dress for an alarm." "Stimmt. Mit Heidi und Uschi. Was hast du da gesehen? What did you see there? (Right, with Heidi and Uschi)." "Fire trucks. We saw how they dressed up," he explains to her and she adds, "Sehr schön (Great)," and then she tells him to join the other line now.

Daniela is next in line holding her book and the teacher reads her the title, "Unsere Katze (Our cat)." Then she asks, "Hast du auch eine Katze Zuhause? (Do you have a cat at home?)" The girl answers "nein (no)." "Einen Hund? (A dog?)" "Nein (no)." "Einen Elefant? (An elephant?)" "Nein (no)." “Einen Tiger? (A tiger?)" "Nein (no)." "Ein Schwein? (A pig?)" "Nein (no)." "Schwestern? (Sisters?)" She answers with a big smile and a wide open mouth, "Ja (yes)." Both laugh in agreement. The teacher then moves to the other line where Marianne and Christian are waiting patiently.

Liam comes very excitedly to the table and shows his choice to the head teacher. "Kommst du jetzt zu mir? (Are you coming to me now?)," she asks him and he replies, "ja (yes)." Then he says, "Dinosaurier (dinosaurs)," and she asks him, "Magst du Dinosaurier? (Do you like dinosaurs?)" He nods his head and says, "Ja (yes)," while she asks him, pointing to the book cover, "Weisst du was für einer das ist? (Do you know the name for this one?)" It takes a few seconds before he says, "Tyrannosaurus," pronouncing it in English and she is unsure and asks him, "Weisst du wie das auf Deutsch heist? (Do you know what it is in German?)" Liam is unsure and shows it with his hands, turning them inside out. Amy listens and says, "Nein (no)" a couple of times. The cognates are 
causing some confusion and the teacher pronounces the dinosaur names in German, but it is too close to English for Amy who says, "That is English." He says, "hmm, I am not sure." Then they agree that the teacher will check with the other teacher and let him know later in the day.

The second line, where the children get their book stamped and a card put into it, moves a little slower because they return their old books also. A mixture of German and English can be heard in the library. Some children sit quietly and look at the pictures in their books while others talk about the choice they have made and why they like it. The second teacher reads German Christmas poems to Kacey, Jeth, and Sarina. Sophia and Cloe are looking through a few books quietly in between the last two shelves. After about 20 minutes, all children have returned their books and lent new ones, and some children start to line up at the door. The second teacher tells the children that it is time to leave in a few minutes. Jeth and Kacey are playing tag and running while the older children are focused on their books about dinosaurs, storms and weather, or story books. It is time to return to the classroom and the head teacher tells the children to find their partner and to line up at the door where she is waiting. The second teacher reminds the children to put their books into their linen bags.

When everyone is ready the head teacher opens the door and the group returns to their classroom.
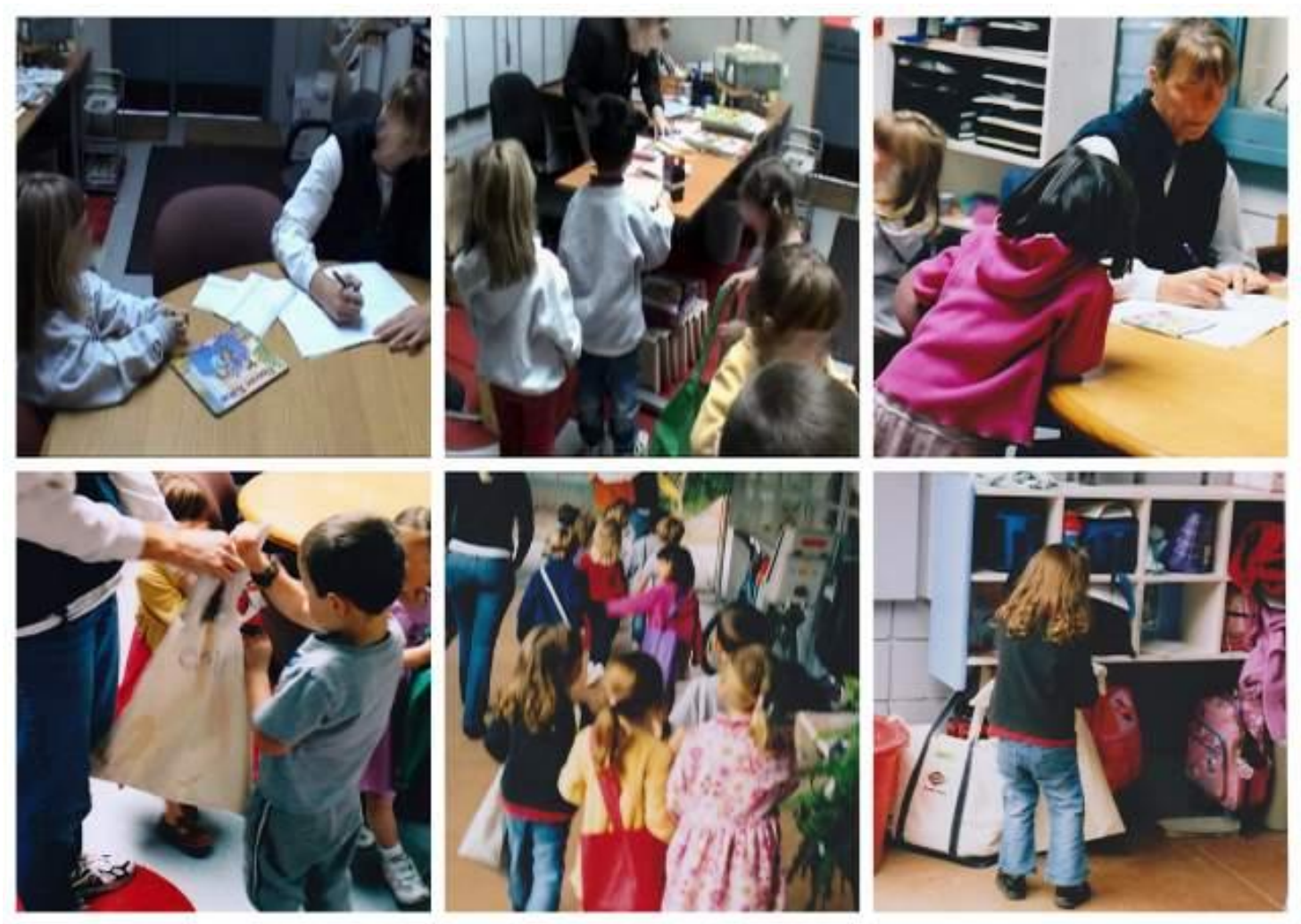

Figure 49. U.S.P.P.: Going to the school's library is a weekly event. 


\section{Free Play Inside and Snack Time (10:45 to 11:00 a.m.)}

Back in the room, the children go to the bathroom and wash their hands, while others start to play again (see Figure 50). The head teacher cleans off the table so that the children can have their snack, and Amy, Mira, and Marc take a seat with their lunch bags along with Lea, Cloe, Kacey, Sophia, Jeth and Marianne. The head teacher tells the children, "Nehmt eure Sachen aus der Lunchbox heraus (Take the things out of your lunchbox)." Amy asks the teacher, "Bitte, aufmachen? (please, open?)," while she asks a question in return, "Was ist das denn? (What is this?)" "Ein Mandarine (a tangerine)," the girl says and the teacher replies, “Aha, eine Mandarine. Gib mal her (Aha, a tangerine. Give it to me)." She starts to peel it for her and returns it to Amy, who removes the rest of the peel.

The second teacher then joins the group of nine children at the table. Marianne holds up her banana and says to the children, "I have the biggest banana." Jeth holds up his to compare it to hers, but his is smaller. The second teacher helps Marianne to express her need to throw the peel into the organic waste basket, which is in the middle of the table and difficult for her to reach. Cloe understands her and places the basket right in front of her so that she can discard her banana peel. The second teacher smiles and tells the children, "Die Cloe hat gemerkt, was die Marianne braucht und hat den Eimer zur Marianne gestellt. Vielen Dank, Cloe (Cloe has noticed what Marianne needs and put it right in front of her. Thank you very much, Cloe)." The girl looks very proudly at the teacher and smiles. Meanwhile, the head teacher works at the dishwasher and talks with the children at the other end of the table in German and English. The children ask the teacher to help them open their little packages. Michel, Liam and Christian are in the building area and work independently on their flying objects. They communicate mostly in English while Liam repeats rhyming phrases that have no meaning in German or English over and over again. The third teacher is in the reading area and reads a book in English to Vanessa and Sarina. Daniela works with play dough at the table.

When the children are about to finish their snack, which is a little later than normal because of the library time, the teacher asks, "Wer möchte mit mir nach draussen gehen? (Who would like to go outside with me?)," slowly starting to open the movable center wall. Michel hears her question and says to Liam very excited, "draussen, nach draussen (outside, going outside)," and Liam replies, "Klasse, nach draussen (Great, going outside)." They are very excited about this idea, but first they help the teacher to open the wall along with Daniela, Marc, Marianne, and Christian. Afterwards, most of the children disappear outdoors where the teachers are observing their play. Vanessa and Sarina stay inside in the circle time area where they are creating patterns and they converse in German about colors and shapes. 

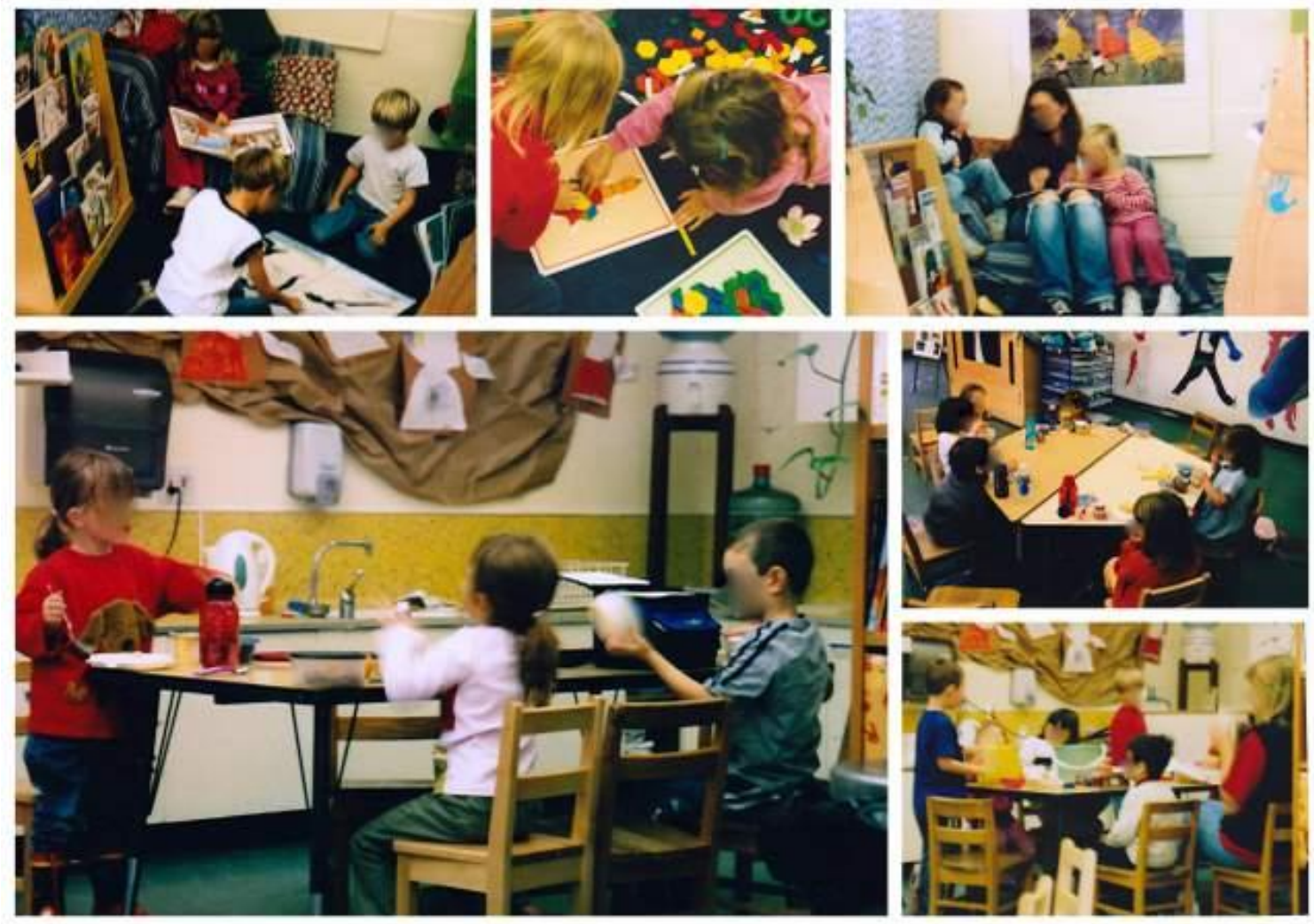

Figure 50. U.S.P.P.: Inside activities and snack time.

\section{Free Play Outside (11:00 to 11:45 a.m.)}

Amy and Sophia are swinging high in the air while Daniela waits for her turn. Many voices of the children can be heard all at once. The head teacher and a big group of children are working in the sand pit (see Figure 51). Each of the children has some sort of shovel, while the head teacher has the biggest one. They are standing at the edge of the wood framed sand pit. The sandbox is filled with water up to the edge and some children are standing with their rain boots in the water. On the outside of the frame the boys are digging a big hole. The teacher says, "Grabt tiefer (Dig deeper)" several times and the children join her saying the phrase over and over as support for the diggers. They measure how deep the hole is and one boy says while showing his shovel, "It is about so tief (so deep)." Then she asks, "Was machen wir jetzt? (What are we doing now?)," and the children answer all at once in German and English. Some seem to add sand while others take the mud out again. Each child has their own idea about the problem. The water runs into the deep hole, but does not run into the outside hole which is still dry. Then she walks off and reminds a child who is shoveling so hard that he is throwing the sand everywhere not to do that. While the other children continue to 
work on their phenomenon of water on both sides of the wooden frame, Jeth, Kacey, and Christian are very busy filling the outside hole with sand.

The water sinks into the sand and a few children place a pipe from the faucet a couple of feet away from the holes, which are now half filled with water. The head teacher reminds all the children, "Das ist eine Baustelle und wir tragen Gummistiefel (This is a construction site and we wear rain boots)." A few children run to their cubby and change their shoes.

Lea and Marianne are helping the teacher to feed the outdoor animals by giving them salad and apples. The teacher asks, "Was mag es lieber Apfel oder Salat? (What does it prefer, apples or salad?)" Lea answers, "Sie magen lieber Salat (They rather prefer salad)." They pet the rabbit together, agreeing that it has very soft fur. Marianne and Lea like to pet the bunny and take turns. After they return the rabbit the teacher takes out the two guinea pigs and places them in each child's lap. They continue to pet the animals until other children want to, and both girls leave so that the others get their turn.

The German teacher comes outside and looks for Mira, Amy, Sophia, Lea, and Cloe. She will be working with this group of girls for about 45 minutes a day over the next $51 / 2$ weeks. She gathers the girls and takes them to the library while the other children remain outside.

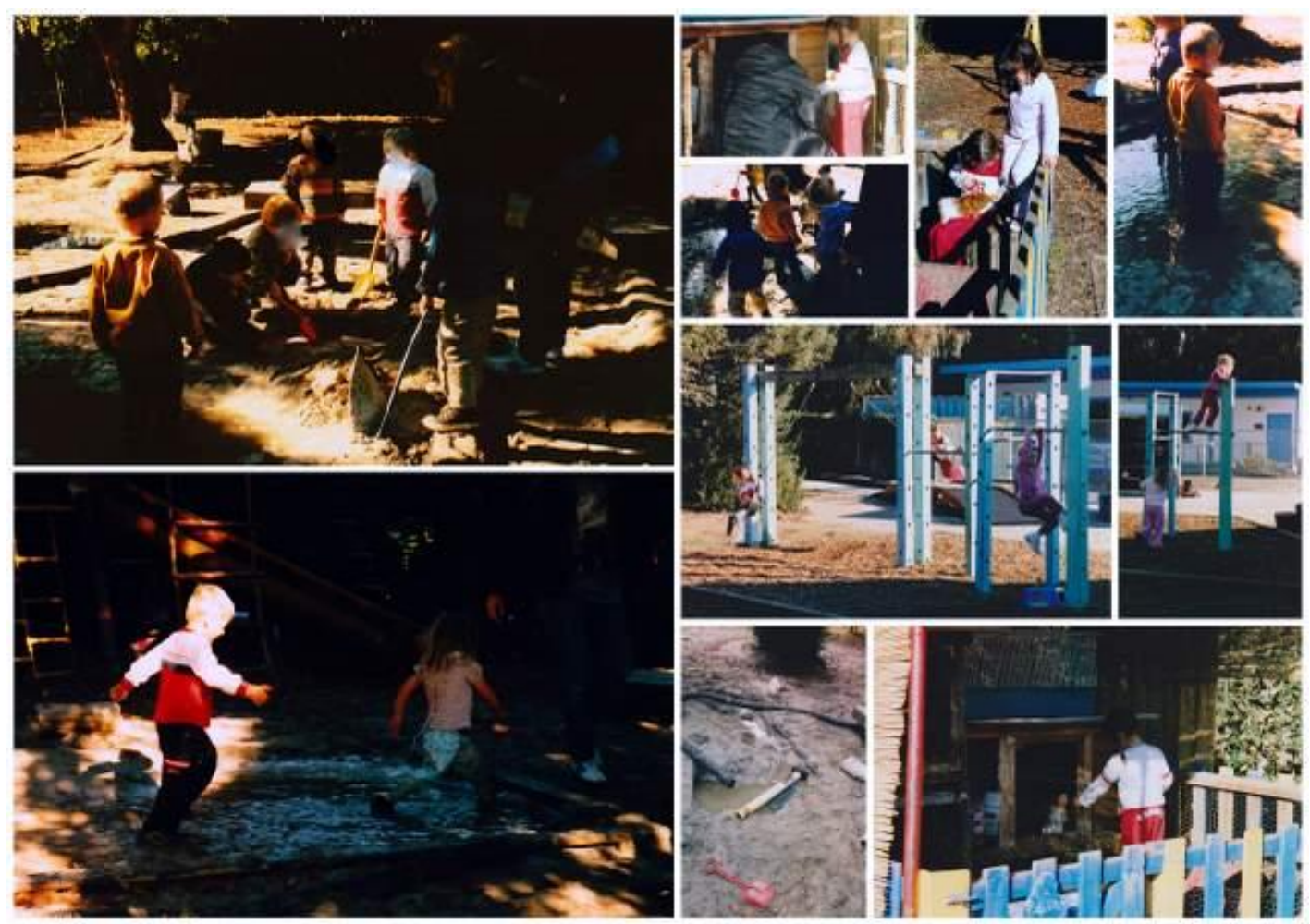

Figure 51. U.S.P.P.: Outside free play and guided activities. 


\section{German Lesson (11:10 - 11:50 a.m.)}

The German teacher speaks mainly in German and comments on everything she does to motivate the children to engage in and speak German. She asks, "Was brauche ich um die Tür auf zu machen? (What do I need to open the door?)," and Mira answers, "Schlüssel (key)." As she pulls the key out of her bag she says, "Einen Schlüssel. Ist das ein Schlüssel? (A key. Is this a key?)" The girls answer in a chorus "ja (yes)," and she continues, "Was machen wir jetzt? Tür ... (What are we doing now? Door ...)." They fill in "aufmachen (open)."

\section{Warm-up Activities}

As the girls enter the room the teacher asks, "Wo setzen wir uns immer hin? (Where do we usually sit?)" The children answer, "roten Teppich (red carpet)," and she repeats, "auf dem roten Teppich (on the red carpet)" several times as everyone takes a seat on the carpet. The teacher places her small suitcase and bag next to her and says, "Wem ist denn auch kalt. Mir ist kalt (Who is also cold? I am so cold)," while rubbing her hands on her arms (see Figure 52). The children are not that cold but the room is very cold. The teacher suggests to do the carrousel song and game. The group gets up. Amy is so excited and tells the teacher in English that "tomorrow is toy day and we can bring a toy from home." She asks, "Was ist morgen? (What is tomorrow?)" Amy starts, "Spielezeug," and Lea helps her, "Spielzeugtag (toy day)." "Aha, morgen ist Spielzeugtag, und was bedeutet das? (Aha, tomorrow is toy day. And what does that mean?)," the teacher asks. Amy says very happily in English and German, "We're gonna bring Spielzeug (toys)." Lea also states briefly but happily, "Spielzeuge (toys)." "Ihr dürft schon wieder Spielzeug mitbringen? (You are allowed to bring toys again?)," and in a chorus the girls say loudly, "ja (yes)." "Wer bringt denn mich mit? Bin ich ein Spielzeug? (Who will bring me? Am I a toy?)," and three girls say "no" and two say "yes." The teacher acts surprised and goes on to tell the group, "Wir reden gleich darüber was ihr mitbring, aber jetzt wollen wir uns aufwären (We will talk about what you will bring in a minute, but we want to get a little warm)." She stretches her arms out and takes Cloe's and Sophia's hands, and the children follow by taking the hands of their neighbors. She starts singing and the children join her.

\section{Song}

Auf der grünen Wiese

steht ein Karussell.

Manchmal fährt es langsam, manchmal fährt es schnell, schnell, schneller.

Anhalten, einsteigen, gut festhalten. Das Karussell fähr los. Wer sich nicht festhält, der fällt.

\section{Translation}

On the green meadow stands a carrousel.

Sometimes it goes slow, and sometimes it goes fast, fast, fast, faster.

Stop, get on, hold on tight. The carrousel starts; who does not hold on, falls off.

\section{Movement}

Hold hands and walk in a circle. Walk very slow. Walk faster and faster

Stop, pretend to get on, hold each other tight with their arms and try not to fall. 
They sing the song and move according to the words. After everyone has held on tight, no one falls off and all shout several times in a chorus, "Ich bin nicht gefallen (I did not fall)."

Then the teacher leads the group to the little walkway in the library which has red carpet circles. She tells the children to jump from one to the next and that they should repeat the word jump for every jump they make. She is the first in line and shows them what to do, saying, "hüpf (jump)" for each jump. The children follow her and the word "hüpf (jump)" fills the room. In the back she asks the children to jump on one leg on their way back. Jumping on one leg is much harder for the children and some tire easily. The teacher tells the girls, "und noch mal zurück mit zwei Beinen hüpfen (and back again jump with two legs)." The group has a harder time saying the word "hüpf (jump)," while Sophia likes to jump in a different direction than she is supposed to. "Und zurück auf einem Bein (And back on one leg)." The teacher wants them to repeat the phrase while they are jumping back, but they have to focus on jumping on one leg more than they are able to repeat the phrase, therefore she repeats it with each jump. Mira, who is last in line, tells the teacher, "Ich kann nicht auf einen Bein (I cannot jump on one leg)," and continues in English, "because." The teacher helps her and says, "weil ... (because)," and the girl goes on in German, "weil ich kann es noch nicht (because I cannot do it yet)." The teacher replies that she is sure that she will learn it soon.

As they are back on the red carpet, the teacher asks, "So wer kommt jetzt? (So who visits us now?)," grabbing the small suitcase and placing it into the middle of the circle. Mira says, "Schnuffi," but Amy says "nein (no)."

\section{Conversation}

1 Teacher: Gestern habt ihr ja eure Barbies mitgebracht, und da habe ich gedacht, da bring ich heute mal ein paar Tiere mit. Habt ihr Angst vor den Tieren?

2 Group: Nein.

3 Teacher: Sind die lieb oder böse? Was meint ihr? Oder sind sie gefährlich?

4 Group: Nein.

5 Teacher: Das sind die Freunde vom Schnuffi, die sind bestimmt nicht gefährlich. Erst mal müssen wir den Schnuffi rauslocken. Wisst ihr wie wir den Schnuffi rauslocken?

6 Lea Nein.

7 Teacher: Ich werde ihn mal fragen, was wir tun können. Schnuffi? She holds the suitcase to her ear and seems to listen to his answer. She nods her head.. Er

\section{Translation}

Yesterday, you had your Barbie's with you, and today I thought I should bring something too, so I brought you a few animal hand puppets. Are you afraid of the animals

No.

Are they good or bad? What do you think? Are they dangerous?

No

These are the friends of Schnuffi, and therefore, for sure not dangerous. But first we have to elicit Schnuffi. And do you know how we will do that?

No.

I will ask him what we can do. Schnuffi, he is awake, would you like to hear which toys the children will bring tomorrow? Yes. Can you tell Schnuffi what toys you 
ist wach. Möchtest du Hören, was für Spielzeug die Kinder morgen mitbringen? „Ja“ Könnt ihr das dem Schuffi erzählen und mal sehen, ob er dann rauskommt. Hmm, Schnuffi ich bring morgen mein Auto mit. Was bringst du mit, Sophia?

8 Sophia: Mein Barbie.

9 Teacher: Ich bringe meine ...

10 Sophia: Ich bringe meine Barbie.

11 Teacher: Was bringst du mit Cloe? Bitte sage es dem Schnuffi. Pointing to the suitcase to put her hand on top.

12 Cloe: Which she does and says Ich bring meine Barbie mit!

13 Teacher:

The teacher smiles and says $\mathrm{Na}$ so was? Die gleiche wie gestern?

14 Cloe: Ja, die gleiche.

15 Teacher: Was brings du mit, Amy?

16 Amy: Ich bringe meine Katze mit.

17 Teacher: Du bringst deine Katze mit. Und du, Mira?

18 Mira: Ich bring mei Barbie.

19 Teacher: Lea, und du? Was brings du mit?

20 Lea: Weisst du was ich bring? Ich bring ... bring ... meinen Lippenstift.

21 Teacher: The teacher makes a surprised and funny face, and says Du bringst deinen Lippenstift. Wisst ihr noch von gestern Lip-pen-stift. Wofür war ein Lippenstift? Das war ein Stift .... Moving her finger along her lower lip.

Amy: Für die Lippen.

Teacher: Ja, super. Schnuffi, möchtest du jetzt rauskommen? Opens the suitcase and puts her hand into the hedgehog puppet which had been hiding in the suitcase. will bring tomorrow and we will see if he comes out. Hmm, Schnuffi. I will bring my car tomorrow. What will you bring Sophia?

\section{My Barbie.}

I will bring my...

I will bring my Barbie.

Cloe what will you bring? Please, tell Schnuffi.

I will bring my Barbie.

Oh really. Exactly the same as yesterday?

Yes, the same one.

What will you bring, Amy?

I will bring my cat.

You will bring your cat. And you, Mira?

I will bring my Barbie.

Lea, and you? What will you bring?

You know what I will bring? I will bring ... bring ... my lipstick.

You will bring your lipstick.

Do you remember from yesterday? What is a lipstick? It is a pen for ...

For the lips.

Well, great. Schnuffi, would you like to come out now?

The children get very excited and Cloe waves at him. Schnuffi looks at the teacher and asks her, "Das ist ja spannend. Kannst du mich vielleicht mitbringen? (How exciting! Can you bring me maybe?)," and the teacher asks the children, "Kann ich Schnuffi bringen? Ist er ein Spielzeug? Was meint ihr? (Can I bring Schnuffi? Is he a toy? What do you think?)” Sophia looks at Schnuffi and says "ja (yes)." Amy says, "meine Freund (my friend)," and Sophia is so excited, giving him a good hug. Lea is next to give him a hug and Amy leans forward and says, "Das ist mein Freunde (This is 
my friends)." Schnuffi enjoys his hugs and says, "You are so nice to me." Mira is last and says, "Das ist auch mein Freund (This is also my friend)," and last is the teacher who says, "Du bist auch mein Freund (You are my friend too)," giving him a big hug on her shoulder. "Wisst ihr wer alle meine Freunde sind? (Do you know who all my friends are?)," he asks and the group says, "nein (no)." The puppet tells the children that the German children are all his friends and starts a group hug. The children are very happy. The teacher asks the girls, "Sind wir alle Freunde? (Are we all friends?)," and they reply with "ja (yes)." She says very happily, "super," and prepares the next activity.

\section{Introduction of a New Action Song}

She tells the children that Schnuffi can show you who he brought. Holding up a cat puppet, she asks, "Wer ist das? (Who is this?)" The children move very close to her and one says, "eine Katze (a cat)." “Ja, eine Katze (Yes, a cat)," repeats the teacher and continues, "Das ist eine besondere Katze. Wisst ihr, was die gut kann? (It is a special cat. Do you know what it is good at?)" One girl answers, "nein (no)," while Lea says "sprechen (speaking)." The teacher agrees with her and says as the cat, "Ja, ich spreche sehr gut Deutsch so wie ihr. Wisst ihr was ich noch machen kann? (Yes, I can speak German very well, like you. Do you know what else I can do?)" The children look at the moving cat and Lea calls out "tanzen (dancing)." "Ja, aber tanzen kann doch jeder. Schaut noch mal her (Yes, dancing, but everyone can dance. Look here one more time)." The teacher lets the cat puppet dance on one leg. One of the girls says "ballet," and the teacher says, "Ja, es sieht wie Ballett aus. Wie viele Beine benutzt sie zum Tanzen? (Yes, it looks like ballet. How many legs does it use for dancing?)" She hums a familiar tune and lets it move on one leg. Lea says, "auf einem (on one)," and she repeats, "Auf einem Bein. Richtig, auf einem Bein. Und tanzt sie mit jemandem? (On one leg, correct, on one leg. And does it dance with someone?)" "No," the group replies and the teacher starts singing:

\section{Song}

Und die Katze tanzt allein, tanzt und tanzt auf einem Bein.

Kommt der Igel zu der Katze:

Bitte reich mir deine Tatze!

Mit dem Igel tanz ich nicht. Ist mir viel zu stachelig.

\section{Translation}

And the cat dances alone, dances and dances on one leg. The hedgehog comes to the cat. Please give me your paw. I am not dancing with the hedgehog that is far too prickly.

The teacher uses different voices to distinguish the animals, applies meaningful intonation to stress the cat's excuses, and expresses the storyline through the movement of the puppets. She asks the children if they are also able to dance and encourages them to try together to dance on one leg. 
Mira decides to take a seat on the couch and says, "Ich möchte schauen (I would like to watch)." The teacher encourages the other girls to dance and says to her that she might decide to join the dance later. "Sind wir nun alle Katzen und tanzen auf einem Bein? (Are we all cats now and dance on one leg?)," she continues while dancing on one leg and starting to sing the first verse again. The children try to move on one leg, hold their balance with their arms in the air, and watch the teacher as she asks them if they can sing it already. She starts singing again and the children join while Mira is sitting on the couch but singing the lines. The next animal that comes out is the hare and the teacher sings slower and with a different voice. The children join her on "paw" because it does rhyme.

$\begin{array}{ccc}\begin{array}{c}\text { Und die Katze tanzt allein, tanzt } \\ \text { und tanzt auf einem Bein. }\end{array} & \text { And the cat dances alone, } \\ \text { dances and dances on one leg. } & \text { Dance on one leg. } \\ \text { Kommt der Hase zu der Katze: } & \text { The hare comes to the cat. } \\ \text { Bitte reich mir deine Tatze! } & \text { Please give me your paw. I am } \\ \begin{array}{cc}\text { Mit dem Hasen tanz ich nicht. Ist } & \text { not dancing with the hare -it } \\ \text { mir viel zu zappelig. } & \text { is far too fidgety. }\end{array}\end{array}$

She stops to repeat the word "zappelig (fidgety)" and shakes the hare to show what the word means. She asks the children, "Tanzt die Katze mit dem Hasen? (Does the cat dance with the hare?)," and they say loudly "Nein (no)." She repeats singing the verse. Lea, Amy, and Cloe are dancing on one leg as the line comes up, while Sophia and Mira watch. Now she encourages the children to sing the first lines alone, which they do quite well.
Und die Katze tanzt allein, tanzt und tanzt auf einem Bein.
Kommt der Hamster zu der Katze:
Bitte reich mir deine Tatze!
Mit dem Hamster tanz ich nicht. Ist mir viel zu fusselig.
And the cat dances alone, dances and dances on one leg. The hamster comes to the cat. Please give me your paw. I am not dancing with the hamster - it is far too fuzzy.

She introduces the next animal, which is a hamster. One of the children says this is a horse and the teacher tells her that is a good idea, but it is a hamster. As she asks them whether they know a hamster, they reply with "no." She explains, "A hamster is a rodent and is similar to a mouse or guinea pig." The teacher starts the song and pauses a little. Lea, who stands like a singer, sings by herself "Bitte reich mit deine Tatze! (Please give me your paw!)" The teacher continues with the next lines and repeats the new word "fuzzy" while petting his fur. When she takes out the next animal and asks, "Was ist das? (what is this?)," everyone says "ein Hund (a dog)" and she explains, "Das ist der Hofhund, weil er immer auf dem Hof Wache hält (This is the yard dog because it watches the yard all day)." The children sing the first lines alone: 
Und die Katze tanzt allein, tanzt und tanzt auf einem Bein.

Kommt der Hofhund zu der Katze:

Bitte reicht mir deine Tatze!

Mit dem Hofhund tanz ich nicht, denn der bellt so fürchterlich.
And the cat dances alone, dances and dances on one leg. The yard dog comes to the cat. Please give me your paw.

I am not dancing with the yard dog, because he barks so horribly.
Dance on one leg.

Teacher barks.

She joins singing and Lea sings, "Bitte reich mir deine Tatze (Please give me your paw)."

Mira, who is still watching from the couch, is encouraged by the teacher to use both legs but she stays seated. The next animal that appears is recognized as "Katze (cat)" or "Maus (mouse)" by the children as they call into the room. It looks a little odd for a cat. The teacher asks the children if they know what a tomcat is but they are not sure. She explains, showing the cat and the tomcat, and says that one is a girl and the other is a boy. She repeats "tomcat" a couple of times so that they can hear and say the word.

Und die Katze tanzt allein, tanzt und tanzt auf einem Bein.

Kommt der Kater zu der Katze:

Bitte reich mir deine Tatze.

Streichelt sie und küßt sie sacht, und schon hat sie mitgemacht.

Und nun tanzen sie zu zwein, tanzen über Stock und Stein.

Und nun tanzen sie zu zwein, tanzen über Stock und Stein.
And the cat dances alone, dances and dances on one leg.

The tomcat comes to the cat.

Please give me your paw.

Licked her paw, lovingly, stroked her, and kissed her softly, and fondly she joins him. And now they are dancing twosome, over hill and dale. And now they are dancing twosome, over hill and dale.
Children sing and dance on one leg.

Teacher sings and moves the puppets.

Lea sings this line alone.

Teacher sings and moves the puppets while the children dance in pairs.

The children recognize the meaning of two and start dancing in pairs all by themselves, which the teacher praises, repeating the line a few times. After they finish the song the teacher asks, "Tanzt die Katze immer noch allein? (Does the cat still dance alone?)" They tell her "Nein (no)."

\section{Practicing the Song}

She asks the children to choose an animal they would like to portray and sing their part with it. After some discussion, Lea chooses the hare, Cloe the hedgehog, Sophia the tomcat, Amy the cat, Mira the hamster, and the teacher is left with the yard dog. The teacher asks, "Wer kam zuerst? (Who was first?)," and Sophia says Schnuffi, which is a hedgehog, as the teacher adds and reviews the word and meaning of "stachelig (prickly)." The teacher lets the children practice their lines, and offers support when needed. She explains the meaning of the word "zappelig (fidgety)" through movement, encouraging them to join the motion. More words like "Hampster, fusselig, (hamster, fuzzy)" and 
phrases like "Der Hund bellt wau, wau (The dog barks woof, woof)" are practiced and repeated in a chorus several times. Then they repeat the song one more time and the children perform their parts. In the end everyone is dancing with a partner and she tells everyone that the cat is dancing with the tomcat, the dog is dancing with the hamster, and the hedgehog is dancing with the hare. Mira, who sat on the couch during the introduction of the song, gets up and dances on one leg throughout the practice.

\section{Drawing Activity}

The practice went very well but the children seem a little exhausted at the moment. Mira asks the teacher as soon as the song has finished, "Can we malen heute? (Can we draw today?)" The teacher asks her, "Möchtest du gern malen? (Would you like to draw?)," and Lea joins saying "malen, malen (drawing, drawing)." A chorus of voices fills the room with "malen, malen (drawing, drawing)." The teacher holds her ears because the children scream quite loudly, and shakes her head slowly to express her disagreement. The children become quiet and Lea says, "Können wir malen, bitte? (Can we draw, please?)" The teacher tells her to share the phrase with her friends. She whispers the phrase to Sophia, who turns to the teacher and says, "Können wir bitte haben malen? (Could we please have drawing?)" Lea, who continued to teach the other girls, turns around and says "Nein (no)" to the teacher and then repeats her phrase, "Können wir bitte malen? (Can we draw, please?) It seems to be a sign for the group to repeat it together, "Können wir bitte malen? (Could we please draw?)" The teacher praises Lea for being a good teacher and the others for being good students. She tells the children that they can draw today and asks them what they need for drawing.

As the children find a seat at the round table, the teacher challenges the children and asks again, "Was brauchen wir denn zum Malen? Einen Lippenstift? (What do we need for drawing? A lipstick?)" The girls shake their heads saying "Nein (no)," and Amy says, "Stifte (pens)." A mix of words can be heard, "Malenstifte, bunte Stifte, Stifte (drawing pens, colored pens, pens)." The teacher places a box with different markers and pens on the table asking, "Sind das Stifte? (Are these pens?)" The group agrees and she continues to explain, "Wir schauen uns mal an, was wir schon in der Mappe haben (We will check our portfolios to see what we have worked on)." She picks a folder, takes out a page, and asks the children, "Wisst ihr noch wie die ganzen Tiere heißen? (Do you remember the names of the animals?)" Then she calls on Amy to name all the animals in the upper row, "Maus, Hund, Katze, Schwein (Mouse, dog, cat, pig)." Sophia does the bottom row but she cannot answer so the other girls help her. Lea says, "ein Pferd (a horse)," and Sophia repeats the word. Cloe recognizes the next one saying, "ein Teddybär (a teddy bear)," which the entire group 
repeats. Then the teacher is asking, "Und wer ist neben dem Teddybär? (And who is next to the teddy bear?)," and in a chorus the girls reply, "Ente (duck)." "Und wer ist hier unter der Katze? (And who is under the cat?)," she goes on and Cloe says first "Kuh (cow)," with all the others following her.

The teacher says, "genau (right)," and checks her own ring binder for the copy with the text of the song. She explains it to the children and asks, "Könnt ihr die Katze sehen? (Can you see the cat?)" "Ja (yes)," they respond. She asks, "Was machen die Katzen hier? (What are the cats doing here?)," while pointing to the picture and the girls say, "tanzen (dancing)." "Tanzen sie allein? (Are they dancing alone?)," and Lea answers, "Nein, zusammen (No, together)." "Wer ist das denn? (Who is this?)," the children take a long look, and Cloe says quietly, "I-gel (hedgehog)." After she has reviewed all of the animals that appear in the action song, she asks the children who would like to color parts of the song page or a blank piece of paper. Sophia, Amy, and Mira want the paper with the song and the pictures, telling her one after the other, "Ich möchte dein Papier (I would like your paper)," and she hands them the paper. Cloe tells her, "Ich will nicht das (I don't want that)," and the teachers asks her, "Möchtest du ein weißes Papier? (Would you like a white piece of paper?)" The girl does not understand this and replies, "Ich möchter ein anderes Papier (I would like a different piece of paper)." The teacher repeats her phrase while giving her a piece of paper and asks the next girl, who repeats Cloe's statement. After everyone has their paper the children tell the teacher what color they need. Cloe tells her, "Ich brauche rot (I need red)," and she hands it to her and says, "Rot, bitte schön. Hier ist rot für dich (Red, here you go. Here is red for you)." Mira decides to finish the animal paper that she has in her portfolio and they reviewed earlier saying, "Ich mache fertig (I will finish)," while showing it to the teacher. She tells her that it is a good choice and asks her, "Welche Farben brauchst du? (What colors do you need?)" Since everyone likes a few colors, the teacher is busy and Mira repeats, "Ich brauche pink (I need pink)" a couple of times. With each repetition her language becomes more articulate. The teacher hands out the colored pencils and names the color that she hands to the children. Mira calls the teacher and says, "Kuck mal, deutsche Sabine, Kuck mal (Look here, German Anke, look here)," pointing to her pink pig. The teacher tells her, "Oh schön. Das rosa Schweinchen (Oh, nice. A pink pig)," and praises her for good pencil holding skills, "Du hältst den Stift schon wie eine Schulkind (You are holding it like a big school kid)." The other children check how she holds the pencil and call for the teacher to check their pencil holding skills. Cloe says, "Kuck hier (Look here)," and the teacher praises her too, but gives a suggestion on how to improve, "Mach den Mittelfinger mehr unter den Stift (Move your middle finger more under the pencil)." She tries to change the position of the pencil; meanwhile Sophia shows the teacher how she is holding the pencil. The teacher repositions the pencil in her hand, then she takes a pencil to show 
Cloe, who is sitting in a more difficult seat for the teacher to reach. Now, she demonstrates holding a pencil for the whole group of girls, expressing in German that the thumb and pointer finger are on top and the pencil rests on the middle finger - like that. The girls are watching her, with only Mira continuing to color her animals. The teacher praises each girl one after another while comparing them to the school children, which makes the girls proud and happy. Then Amy asks, "Bitte haben rot..., schwarz..., orange (Please, have red, black, orange)," and the teacher replies, "Du möchtest bitte orange haben? Ist das ein schönes Orange für dich? (You would like to have orange? Is this a nice orange for you?)," and she tells her "Ja (yes)."

The children show a good understanding of the names of the colors and also the nuances, such as light and dark color names. Amy asks her out of the blue, "Where sind deine Kinder? (Where are your children?)," and she turns the question back to them, "Ihr wißt, wo meine Kinder sind? Kuck mal, das sind doch schon große Kinder (You know where my children are. Look here, they are already big children)," showing a key ring picture of her children to the group. Then Lea answers, "Schulkinder (school children)," and Amy adds in English, "I know them from after care." "Der Junge kommt am Nachmittag in den Hort (This boy goes in the afternoon to the afterschool program)," she tells the group and Amy agrees with her "ja (yes)."

The children enjoy drawing and coloring, and the teacher tells them that they have a few more minutes. She asks them if they would like to play the animal card game that they played on Monday tomorrow, but no one answers because they are still focused on their work. Sophia is the first one who finishes her drawing and the teacher asks her to take the cat puppet from the table and help her put all the animals into the bag. The teacher asks her the names of the animals and she knows them all. The last one is Schnuffi, who has to go back into his suitcase home. The teacher announces the final minute for the children to finish their work, and returns to the table to check on the girls. Sophia has Schnuffi in her hand and hugs him in front of my video camera. She tells me, "Ich mag Schnuffi (I like Schnuffi)," and hugs him again. The teacher collects their blue portfolios and brings the children once more to the carpet. Schnuffi says, "Good bye," and so does the group. Now they line up at the door holding on to the shoulder of the person in front of them and sing as they walk back to their room.

\section{Lunch Time (11:45 to 12:05 p.m.)}

Just before lunch the center wall is closed again to provide more privacy during the lunch. Back in the room, the children are getting their lunch boxes out of their cubbies and they have to find their seat, which is labeled with their name card. Before the children can start eating, they say a table saying together and hold their neighbor's hand, "pie, pie, pie Mäuschen ist in seinem Häuschen. Isst 
so gerne Mittagbrot macht dabei die Wangen rot. Pie, pie, pie, guten Appetit (Pee, pee, pee, the little mouse is in its little house. Loves to eat its lunch, turns its cheeks red. Pee, pee, pee, bone appétit)."
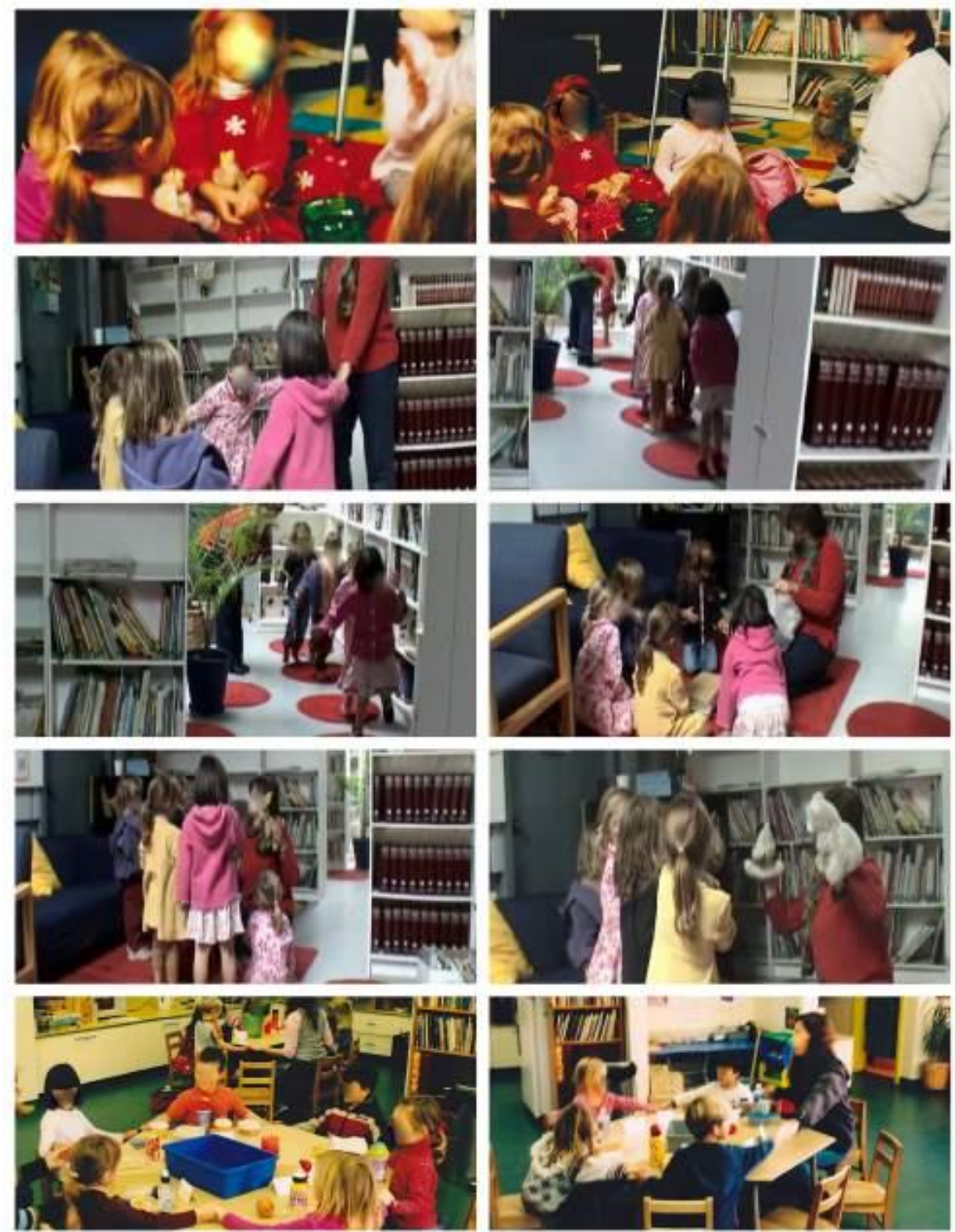

Figure 52. U.S.P.P.: German lesson and lunch impressions.

After lunch-Outdoor Play (12:05 - 1:00 p.m.)

A group of girls plays on the play ground set and screams "Alle Mädchen (all girls)" several times. Vanessa and Sarina are sitting on the vertical ladder and Amy tries to join them (see Figure 53). Vanessa just started explaining in English to Amy how they got to sit up there when a group of boys, who are playing follow-the-leader with Michel as their current leader, interrupts them. The 
girls are singing, "Nur die Mädchen (only the girls)," and Amy says, "Only all the girls are up here," while the boys slide undisturbed down the slide, one after another with Michel in the lead.

Kacey, who had also been playing here, now joins the boys but he does not seem to want to use the slide. He rather climbs down the ladder net very carefully and is now last in line. Michel is telling the boys while running, "I am over here everybody. Please come with me." He comes out of the bushes, jumps across the sandpit, runs twice around the bushes, and stops on the grass area where he waits for his followers: Christian, Marc, Liam, two boys from a different group, and last in line Kacey. When everyone is in the circle on the lawn area he whispers something and the boys run after two girls from the other group, who run screaming into their classroom followed by the boys. At the same time, Lea is swinging on the swing set and Mira is climbing up the triple horizontal bars, which are attached to the swing set. Back on the big playground set, Amy, Sarina, and Vanessa are talking about tomorrow's toy day.

1 Amy: Tomorrow is gonna be Spielzeug day you know. Morgen. Tomorrow. You get to bring your favorite toy.

2 Sarina: I ... I don't know what ... when is tomorrow.

3 Amy: Yeah, it is tomorrow. It is really tomorrow. Es ist nach dem Tag.

4 Sarina: Turning to Vanessa Es ist nach diesem Tag. Dann ist tomorrow.

5 Amy

6 Sarina:

7 Vanessa: Vanessa shares her happiness and repeats the same

7 Vanessa: Vanessa shares her happiness and repeats the same

It is Spielzeugtag. I know because Lea told me. Ist nach dem Tag tomorrow? Asking Amy again, who nods her head and happily tells Sarina twice Nach dem Tag is tomorrow. phrase Nach dem Tag ist tomorrow. Then asking Amy Is tomorrow when this day is over?
8 Amy: Yeah. It is tomorrow for real. Sarina and Vanessa are very happy and excited.
9 Amy: I will bring my Felix. What is your favorite toy?
10 Sarina: I don't know.
11 Amy: All your toys?
12 Sarina: Yes.
13 Amy: But you can bring only one.
14 Sarina: Ich gehe heute zu einer Lady Michel und die hat eine Katze und weisst du was meine Schwester. ... Amy tries to say something in English but Sarina speaks louder to continue her story. Meine Schwester, meine Mutti... Looking at Vanessa Sie kann mich nicht verstehen, wenn ich das sage. Meine Mama started a meeting. ....(whispers difficult to understand)

\section{Translation}

... toy ...

... It is after this day.

It is after this day. Then is tomorrow. ... toy day ...

It is after this day tomorrow? It is after this day tomorrow.

After this day is...

I am going to a lady Michel who has a cat. And you, what my sister... My sister, my mom... She cannot understand me, if I say that. My mom ... 
15 Vanessa: Can you get up here?

16 Amy: I can get up here.

17 Vanessa: Can you get up here? Pointing to the higher part.

18 Amy: I don't want to. Moving to a different area. This whole thing is easy for girls. Right?

19 Vanessa: Yes.

20 Sarina: Aber für dich ist es schwer. Oder? Kuck mal, wie ich es mache. Dann kannst du es auch.

But for you it is too difficult. Look here, how I am doing it. Then you can do it too.

21 Amy: Do you want to go down that slide?

22 TT: Mira, sei vorsichtig, weil Vanessa da sitzt, dass sie nicht runterfällt.

Mira, be careful, because Vanessa is sitting there so that she will not fall off.

23 Vanessa: Kuck mal. Ich habe Platz gemacht. Look here, I made some space.

24 TT: Super, Vanessa

25 Amy: Alle Mädchen. Alle Mädchen.

Great, Vanessa.

All girls. All girls.

The conversation is interrupted by the boys who come by and they talk loudly about different things while the girls climb or go down the slide then run off. Michel pulls a wagon, on which Christian, Liam, and Kacey are sitting and Marc pushes from the back. It looks like hard work. Daniela and Marianne are in the street area where they and other children are riding tricycles, scooters, and bikes. Daniela is riding the taxi tricycle while Marianne pushes it from the back. Marc pulls the wagon up the ramp and Michel pushes, however they are creating a traffic jam. Therefore the other children on their vehicles have to wait in line behind them. When it takes too long, the bikers see that they can pass by and they do so. The younger children on their scooters wait in line, but it takes quite some time and the bikers have finished their round already. The second teacher reminds the boys that they should hurry because there are a few children behind them along with Marianne, who is riding, and Daniela, who is scooting in the back. When the wagon goes down the ramp the boys get off track and stuck in the corner while the others stay on the painted street. 

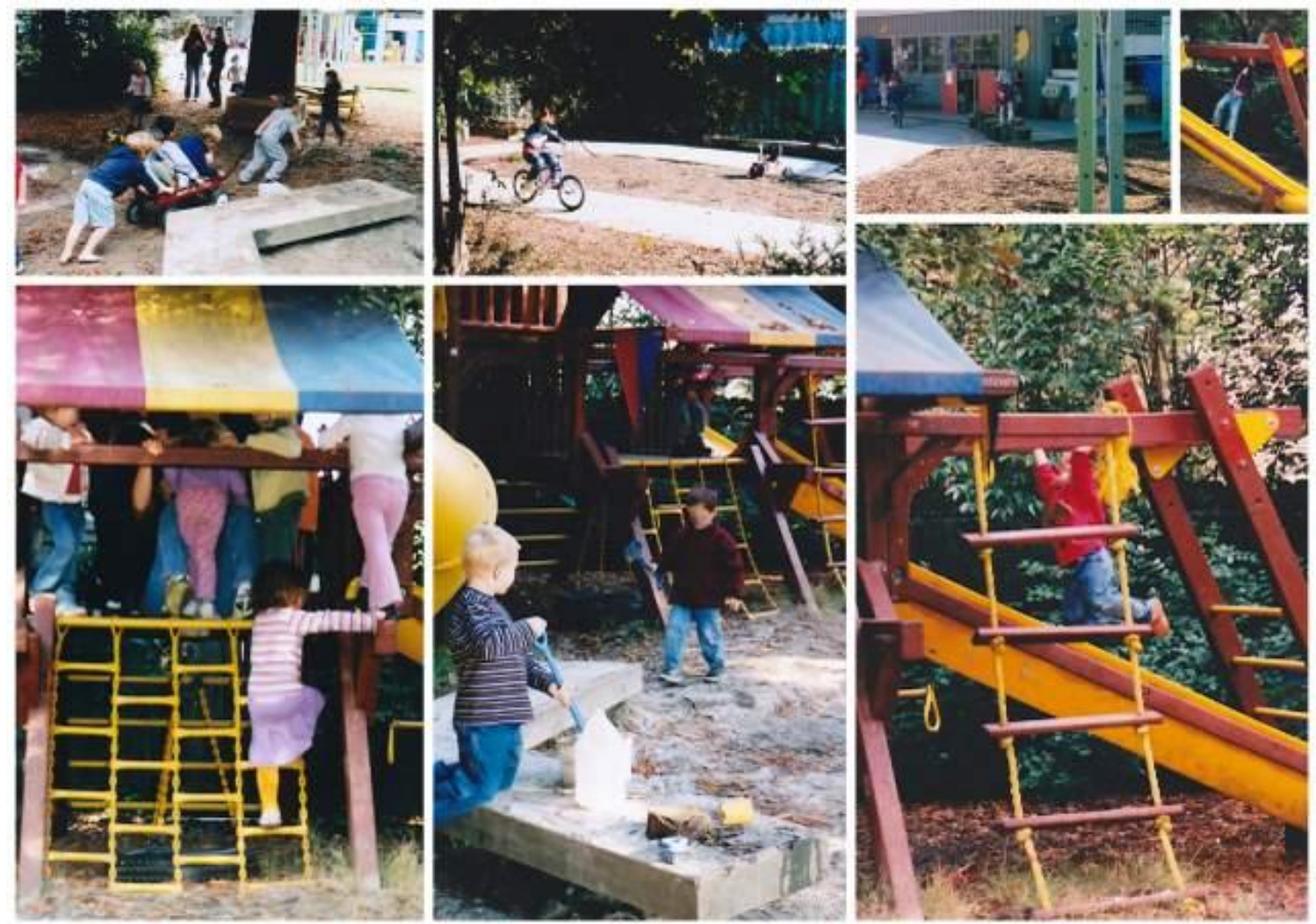

Figure 53. U.S.P.P.: Outdoor activities impressions of play, climbing, and bike riding.

\section{Guided Activity: Wood Working}

The head teacher opens the storage cabinet, places some wood pieces onto the table, and takes out backsaws, crosscut saws, a hammer, and nails (see Figure 54). Mira comes over and would like to do some woodworking and says, "Kann ich auch einen? (Can I do it, too?)" "Natürlich, kannst du auch hier was machen (Sure, you can do something here)," says the teacher pointing to a piece of wood clamped onto the table. "When die Säge dir zu schwer ist, dann haben wir auch noch eine leichtere (If the saw is too heavy for you, we also have one that is lighter)." But Mira does not mind and starts working on her piece of wood. The teacher asks if she can help her get started, to which the girl agrees by handing the saw to her. Together, they mark a line which Mira can follow while cutting off a piece of wood. She continues alone and the teacher asks her, "Geht es oder möchtest du eine andere Säge mit kleineren Zähnen probieren? (Does it work or would you like to try a different saw with smaller teeth?)" She wants to try the other one and the teacher hands it to her. "Hallo Sophia, möchtest du etwas mit Holz arbeiten? (Hello, Sophia, would you like to work with wood?)," and she nods and finds a place at the table next to Mira. When the teacher asks her, "Möchtest du hammern oder sägen? (Would you like to hammer or to saw?)," Mira turns to the teacher to let her 
know, "Ich möchte hammern (I would like to hammer)," while placing her saw onto the table. But the teacher walks off to find a pen to write the names of the children onto their wood pieces. The girl follows her and repeats her request in German. Then the teacher points to the hammers lying on the table, showing her several that she can use, while Sophia decides to use a saw. She writes the name of the children and when she is at Mira's piece she shows her the nails she can use, "Hier sind die Nägel (Here are the nails)."

The table fills slowly and the children work focused on their piece, either nailing or sawing. Not much is spoken unless the teacher explains something or the children need help. The children who use a hammer almost hit their nails at the same time, creating a nice beat that is enriched by the rhythm of the saw. It sounds nice, but it is rather loud and the children are not talking much and are difficult to understand. Mira has hammered two nails into her wood piece and seems to enjoy using the hammer. Sophia is sawing and does a great job. Vanessa, Daniela, Michel, Marc, and Sarina have all joined the activity. Sophia, who works next to Vanessa, tells her, "Das ist Arbeit (This is work)." Mira, who was just talking to a friend from the other group in English, turns to the teacher saying, "Ich bin fertig (I am finished)." The teacher asks her if she should take the piece out of the clamp. The girl takes her piece of wood and places it into her cubby and plays with her friend who was waiting. Another child takes her spot. The children tell the others who stop by to observe or wait in line for the next opening and to be careful so that they will not get hurt. "Careful" and "vorsichtig" can be heard several times.

The teacher walks around the table and comments on or praises each child's work while encouraging each one to continue. She counts with Sophia how many nails are in Sophia's wood piece. There are twelve. After much sawing Daniela has cut off a three inch piece of wood, which, though it has taken her a while, she is the first child to cut off such a large piece. The teacher and the children celebrate with clapping and positive words for her. The teacher says, "Schau mal da war ein Loch drin (Look here, there was a hole inside)," pointing to it while showing all the children at the table. Then Daniela hammers some nails into the cut off piece but not all nails fully sink into the wood. Vanessa cuts off the small tip of her triangle shaped piece of wood, which is also praised, then she adds two nails, almost fully sinking them into the wood. Marc and Michel look for different wood pieces in the wood chest, then start creating little objects by nailing these different pieces together.

The sound of a helicopter interrupts their work and the teacher says, "Oh, ein Hubschrauber (Oh, a helicopter)." The children all call out, "Hubschrauber (helicopter)" at different times as its sound gets louder and it gets closer. The children watch, excited to spot the helicopter in the air. 
When it is gone the hammering and sawing fills the air again. The children who are still working have now spent more than 30 minutes at this table and a few have spent almost the entire time since lunch on this activity, which is rather popular with the children. About eight can work at the bench at the same time.
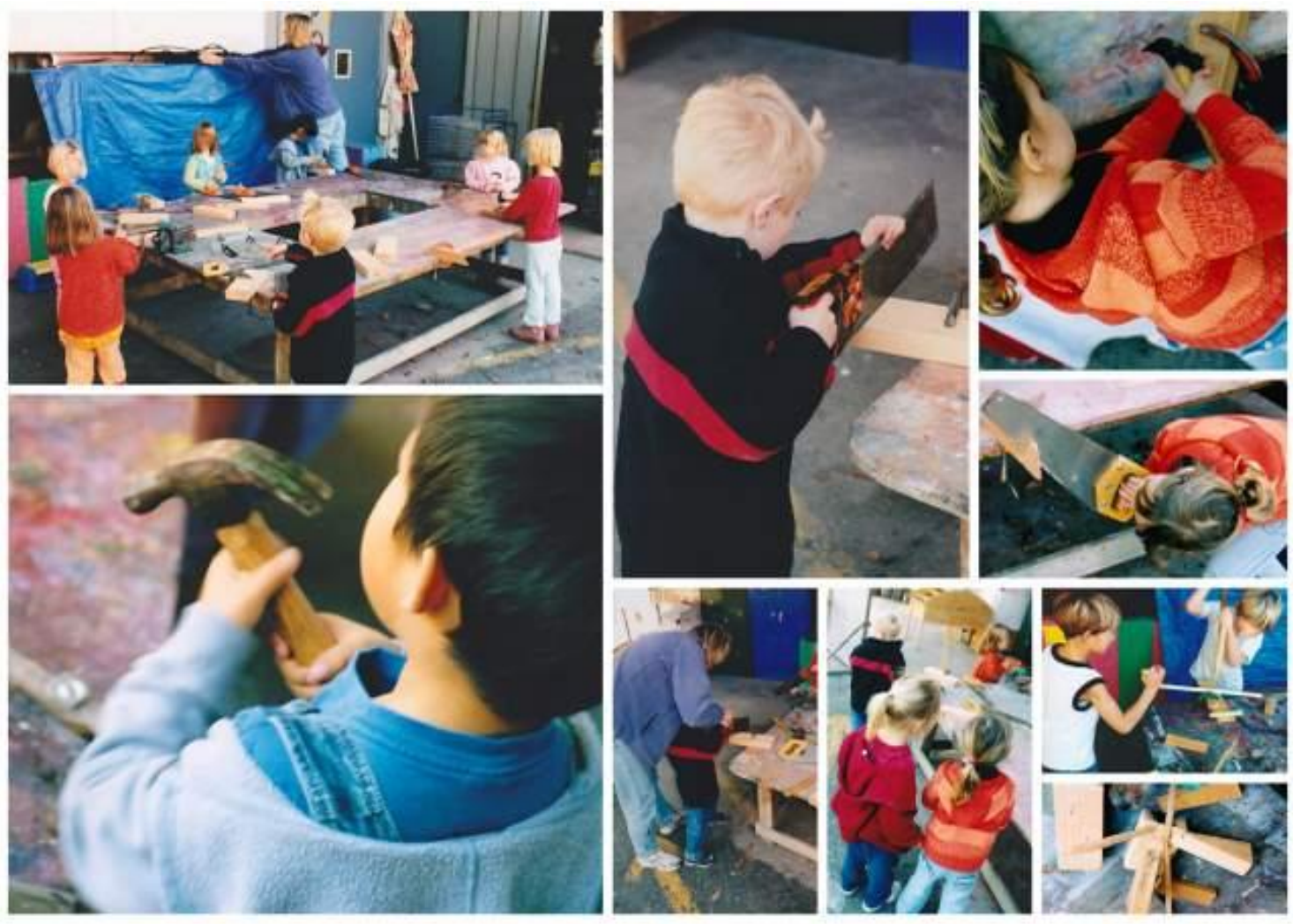

Figure 54. U.S.P.P.: Outside guided activity impressions of woodworking.

Cloe, Marianne, Lea, and Sophia are playing on the swing set and the bars while many children from the other two groups are riding different vehicles, playing in the sand pit, and creating a big mud area with the pipes, making rivers and lakes of water (see Figure 55). The teachers observe their play or participate and initiate, and they also interfere when necessary to prevent or stop negative behavior. At the moment observing is their main task on the play ground. The girls walk over to the smaller playground set and tree swings. Sophia gets up onto the tree trunk, takes the swing between her legs, and swings back and forth. The other children are climbing up on the outlook area or swinging on the attached swing while their conversation is in English. It is difficult to follow because there are about eight girls now with different interests. Vanessa and Sarina, who joined the group just a few seconds ago, talk in German with each other and Vanessa says to Sarina, 
"Komm wir gehen woanders hin (Let's go somewhere else)." They walk over to the animal cages. Cloe climbs up to the outlook and plays with Lea for a while and Marianne goes up and down the slide several times. Then Sophia gets onto the outlook and Cloe comes down to play on the moving bar. She notices that it is quite high, goes to the tire area, and returns pushing a tire. She places it below the bar and can reach it now easily.

Amy is swinging on the swing set by the riding area and receives a big push from the teacher, as does Marianne who is playing over there now. Amy then gets her helmet, takes a tricycle, and starts riding. Cloe practices several turns forward and backwards on the moving bar. Amy joins her just when she starts singing, "Kommet her und seht, vor dem Hause steht, ein dicker Mann und lacht, der ist aus Schnee gemacht (Come here and see, who stands in front of the house, a big man and smiles, he is made of snow)." Amy continues with the next few lines before she returns to the swing set on the other side of the playground.
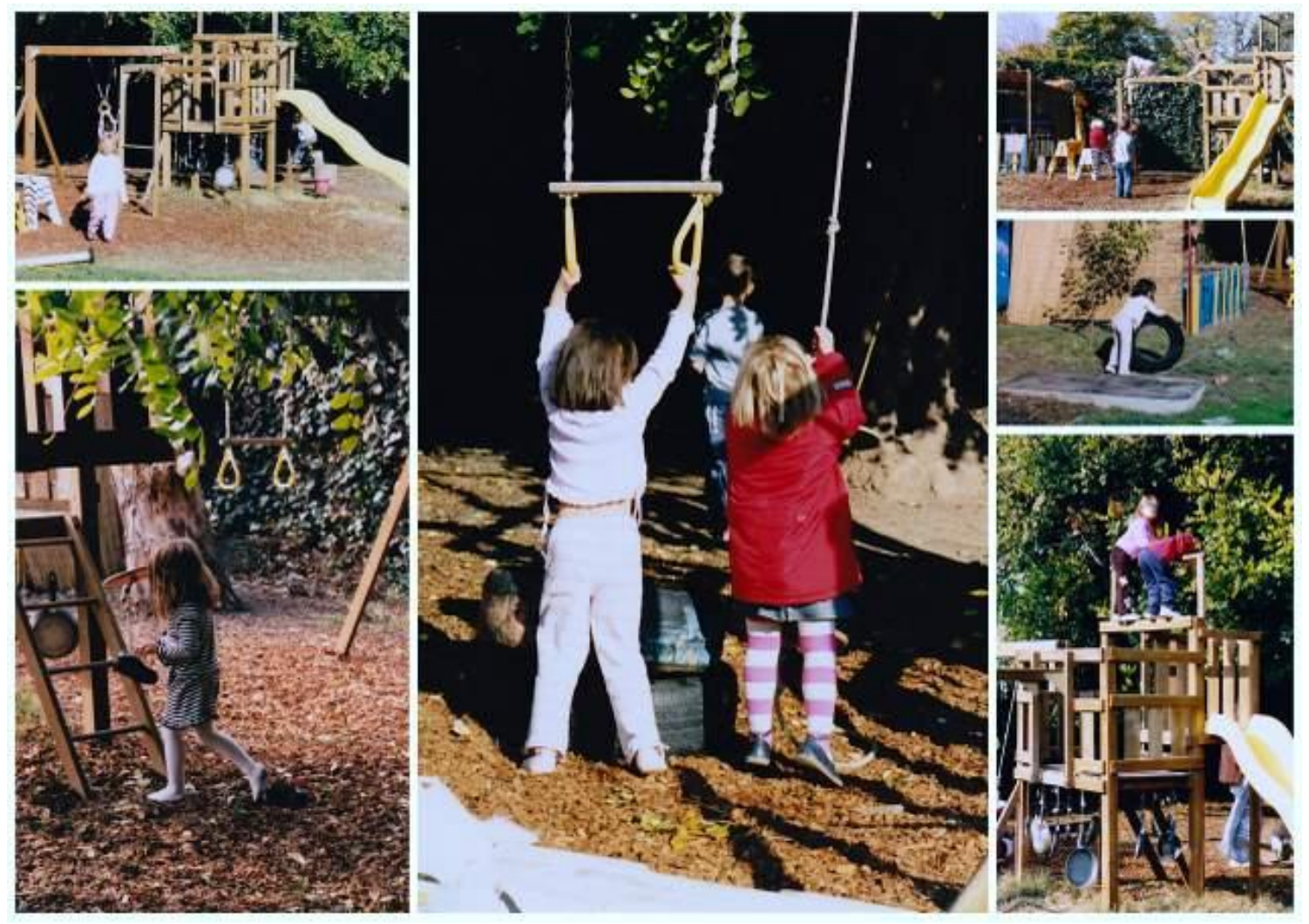

Figure 55. U.S.P.P.: Outside activities impressions play and climbing. 


\section{Clean-up Time (1:00 - 1:15 p.m.)}

In the room, Kacey and Jeth are playing at the Lego table for a while before they move to the reading area and then into the house. They talk in English with each other, and though Kacey likes to tell Jeth what to do, Jeth makes his own decisions most of the time. Kacey walks back to the building area, takes a bin, and takes two block pieces out. Following him, Jeth takes the bin and empties the entire bin onto the floor saying, "There you go Kacey." Then he spreads them out and the first teacher walks into the room singing, "Aufräumzeit ist es nun hier im Zimmer. Aufräumzeit ist es nun, helft alle mit (Clean up time is now here in the room. Clean up time is now, please everyone participate)." The teacher goes to the back door and closes it while saying, "Alle hier im Raum räumen drinnen auf und alle draussen draussen. Wir machen es heute mal anders, weil es so viel drinnen zum Aufräumen gibt. We are doing it differently today, all children inside clean up here, and all outside, outside." The teachers remind the children that they should not play but rather clean up and everyone seems to be helping. Amy, Sophia, Vanessa, Daniela, and Cloe, who all came inside, are cleaning up the circle time area where plenty of small pattern pieces with which the girls played earlier are lying around. The head teacher says, "Kuck mal, die Elektra gähnt gerade. Wir müssen ihr mal wieder eine Maus kaufen. Sie braucht ja alle zwei Wochen mal eine Maus (Look here, Elektra is yawning. We have to buy a mouse. She needs to eat a mouse every two weeks)." The girls come over to the snake and then go back to finish cleaning up their area. Amy says, "I don't like cleaning, I will go and change into a dress," but the teacher asks her to first help clean up all the little pieces on the floor.

While the group is cleaning the teacher has to remind Kacey and Jeth constantly of what to do and not to play. The back door opens and the second teacher and the other children enter; they cleaned up the outside area and returned all play utensils into the storage container. In the room they are still picking up pieces and the other children join to help. The children in the circle time area start singing songs while picking up the last few pieces and then wait for circle time, which is next on the daily schedule.

\section{Circle Time (1:15 - 1:45 p.m.)}

"Kreiszeit es ist so weit (Circle time is now)" sounds through the room, and children join in and go to the circle time area where most of the children are already (see Figure 56). The head teacher tells the children, "Käfer, setzt euch bitte alle hin (Beetles, please find a seat now)." Then she tells the children that soon there will be our Holiday Festival, for which we have been practicing 
singing the songs during the morning circle this week and last, and on Friday will be our dress

rehearsal.

\section{Speaker Chair}

1. HT: Käfer, ich wollte heute den Sprecherstuhl gebrauchen. The children raise their hands and are ready to go. Stop, stop. Ich wollte aber nur über das Holiday Festival sprechen. Wenn irgend jemand etwas über das Holiday Festival sagen will oder eine Frage hat, dann meldet euch. Amy, you have something to say about the festival?

2. Amy: Ja

3. HT: Gut, dann komm her.

4. Amy: We have to go to the gym and sing for all our parents, because we really don't go to school on Saturday or Sunday.

5. HT: Stimmt. Da hast recht. Samstags und sonntags gehen wir nicht in die Schule. Aber diesen Samstag gehen wir zur Schule.

6. Amy: Ja. And it is really silly, right? Laughingly, the teacher agrees with her comment and is not really sure how to respond while she continues to make her point.

7. Amy: Because usually you don't go, right? It is usually a break.

8. HT: Ja, da hast du recht. Amy. Okay, Amy. Dankeschön. Kacey, möchtest du was sagen?

9. Kacey: Ja. He gets up and takes a seat on the chair enjoying that as the youngest and shortest he can look down on the group now. He looks around in the circle and enjoys his view while the others patiently wait.

10. HT: Weisst du was du sagen willst? Do you know what you want to say? She asks him to move along.

11. Kacey: No, I want to say a name.

12. HT: Willst du jemand aufrufen, der jetzt dran kommt? Okay. Wer kommt jetzt dran im Sprecherstuhl?

13. Kacey: Hmmm. Still looking around the circle and says after a few seconds while pointing to the person. Michel

14. HT: Dankeschön, Kacey. Michel du bist dran.

15. Michel: Takes a seat Kommen dann alle Mamas und

\section{Translation}

Beetles, I wanted to use the speaker chair. Wait, wait. I wanted to talk about the holiday festival. If someone would like to talk about the festival or has a question, please raise your hand.

Yes.

Good, then come over here.

Right. You are so right. Saturdays and Sundays we don't go to school. But this Saturday we are going to school.

Yes. 
Papas?

16. HT: Nicht alle, aber ganz viele.

17. Michel: Bestimmt, meine Mama.

18. HT: Ja, deine Mama kommt. Machmal müssen Mamas und Papas arbeiten, oder die sind vielleicht in Deutschland, dass kann sein. Machmal kommen Omas und Opas, oder Tanten und Onkel, aber es kommen viele Mamas und Papas. Dankeschön Michel. Mira du bist daran komm.

19. Mira: Hmm, hmm. My mommy and daddy are gonna come.

20. HT: Deine Mama und dein Papa kommen?

21. Mira: Ja.

Some off the children call out meine auch (mine too) or mine too.

22. HT: Wenn eure Mamas und Papas kommen werde ich bestimmt Hallo sagen. Dankeschön Mira. Cloe, du bist daran. Schnell komm.

23. Cloe: Meine Mama und Papa kommen. Und meine Mamas Mutter.

24. HT: Deine Oma kommt auch?

25. Cloe: Nein, meine Mamas Mutter und auch meine Mamas Vater.

26. HT: Dankeschön Cloe. Marianne, komm schnell.

27. Mari- Meine Mama und Papa kommen und meinen anne: Bruder.

28. HT: Deine Brüder. Du hast zwei.

29. Lea: Auch, meine Mama und Papa kommen.

30. HT Gut, Lea. Danke fürs Sagen. Sophia, komm schnell.

31. Sophia: Meine Mama, mein Papa, and meine Schwester kommen auch. Gets of the chair quickly.

32. HT: Dankeschön Sophia. Komm schnell Marc.

33. Marc: Meine Mama, mein Papa, meine sister, meine sister und ich komme.

34. HT: Ja, du kommst natürlich auch. Super. Möchte noch irgend jemand ander etwas sagen?
Not all, but very many.

Certainly, my mom.

Yes, your mom will be there.

Sometimes moms and dads have

to work, or they are maybe in

Germany that can be. Sometimes

come grandmas and grandpas, or uncles and aunts, but there will be many moms and dads. Thank

you, Michel. Mira, you are next.

Your mom and dad will be there? Yes.

When your moms and dads come I will make sure to say "hello." Thank you, Mira. Cloe, you are next. Come quickly.

My mom and my dad will be there. And my mom's mother. You grandma will come too? No, my mom's mother and also my mom's father.

Thank you, Cloe. Marianne, come quickly,.

My mom and dad are going to come and my brother.

Your brothers. You have two. Also, my mom and dad will come.

Good, Lea. Thank you for sharing. Sophia, come quickly. My mom and dad, and my sister will be there too.

Thank you, Sophia. Come quick, Marc.

My mom, my dad, my sister, my sister, and I will be there.

Yes, for sure you will be there also. Would someone else like to say something?

The children answer "Nein (no)" and demonstrate through getting up on their knees that they are ready to move on to the next part of circle time. 


\section{Song: ABC, the Cat Ran into the Snow}

The head teacher has a plastic bag in her hands and unpacks a white round table cloth while saying, "Ich habe euch Schnee mitgebracht. Hier ist Schnee. Schnee (I brought you some snow today. Here is the snow. Snow)." A few children call out, "Nein, das ist ein Tuch (No that is a sheet, a sheet)," and a chorus of children repeats several times, "ein Tuch, ein Tuch, ein Tuch (a sheet, a sheet, a sheet)." She wants each child to grab a little area and reminds them to stay seated.

\section{Translation}

1. HT: Jetzt es ganz nah auf dem Boden halten. So. Now, hold it very close to the floor. Und jetzt machen wir das so, dass sich der And now, we are doing it like this, Schnee sich ein bisschen bewegt. so that the snow will move a little.

2. Marc: Wie Winter. Wie winter.

3. HT: Und jetzt mal ganz hoch gehen wie ein Schneesturm. Könnt ihr euch unten drunter sehen?

Like winter. Like winter.

And now move it far up like a snow storm. Can you see each other underneath?

The children enjoy this activity very much and are laughing and smiling.

4. HT: Hallo Cloe. Ich sehe dich. Hallo. Nun gehen wir wieder runter und wieder hoch und wieder runter. Okay, Ich brauche aber jetzt noch zwei Kinder, die Katzen sein wollen. Many hands go up. Ich brauche eine Nummer eins Katze und eine Nummer zwei Katze. Amy, komm mal her.

5. Group: Children's voices call out Ich will. Ich will. I want. I want.

6. HT: Und eine Nummer zwei Katze. Lea, komm mal And a number two cat. Lea, come her.

The teacher tells them quietly what to do and carefully hands Lea two pairs of white socks. Then Lea crawls under the cloth and the teacher tells her to say "Meow" when she has finished dressing herself. The children try to lift the table cloth to check what Lea does, but the head teacher tells them, "Nicht kucken (No peeking)." The teacher suggests that Lea should first dress her feet and then her hands. While the children patiently wait for her to be ready, the head teacher decides to sing the song once to see if they still remember. She states that Vanessa knows this song quite well and starts singing:

Song

A B C, die Katze lief im Schnee, und als sie wieder raus kam, da hatt' sie weiße Stiefel an, A B C, die Katze lief im Schnee.
Translation

$\mathrm{ABC}$, the cat ran into the snow, and as she returns again, There she had white boots on, $\mathrm{ABC}$, the cat ran into the snow. to me.

Hi, Cloe. I can see you. Hello. Now, we will move it back down and up again and down. I need now two children who would like to be cats. I need a number one cat and a number two cat. Amy, come to me. 
As the group waits for Lea, the third teacher climbs under the white cloth to help her get dressed. The children start to simulate a snow storm through moving the cloth up and down very fast. It takes a couple of minutes before the teacher appears again, the "Meow" sound of the cat can be heard, and the group starts singing. Amy the cat walks under the cloth and appears with four white paws walking across the white cloth while the children move the cloth up and down. Several children get a turn and several snow storms take place during the waiting time. The head teacher tells the other children who did not get a turn today that they will do this again tomorrow.

\section{Detective Basket}

1. HT: Oh, die Amy hat noch was in unserem Detektivkorb. Amy halt mal was hoch.

\section{Translation}

Oh, Amy has something else in our detective basket. Amy, hold up something.

2 Amy: Wem gehört das? Wem gehört das ding?

Whom does this belong too? To whom does this thing belong?

3 Three boys, Marc, Liam, and Michel, are searching for small pieces under the carpet and have a difficult time getting them out.

$4 \quad$ HT: $\quad$ Alle Augen auf die Amy ganz kurz who is holding a wooden car. Aha. Marianne weiß

All eyes on Amy. Aha. Marianne knows it.

es.

5 Marianne: Gets up, takes the car, leaves the area

6 HT: Hast du noch was? Wem gehören die weißen Socken?

$7 \quad$ Marianne: Goes to the playhouse, turns around and asks twice Where is the Puppenhaus?

8 HT: Oh, das gehört auch zum Puppenhaus? Gib mal her. Ich bring es nachher weg.

9 Amy: Wem gehören die Socken?

10 ST: $\quad$ Sind das nicht deine Socken? Du hatest heute weiße Socken an.

11 Amy: Nein while placing the socks back into the basket. Wem gehört das? Holding a hair band that belongs to Lea who takes it. Wem gehört das? Showing the last piece from the basket.

12 HT: $\quad$ Clarifies the questions for the group Wem gehört das. Who does this belong to? Wo gehört das hin? Where does it belong?

13 Amy: Wo gehört das hin? Saying it very slowly and repeats it faster. Wo gehört das hin?

14 HT: Oh, das gehört alles ins Whale Zimmer. Ich nehm das alles und bring es dann hin. War das alles? Ist es leer?

15 Amy: $\quad$ Turns the basket over to show that it is

Do you have something else? Whose white socks are these? Where is the doll house?

Oh, does this belong into the doll house? Give it to me. I will return it later.

Whose socks are these?

Are these not your socks? You were wearing white socks today?

No. Whom does this belong too?

Where does this belong?

Oh, that belongs into the whale room. I'll take it and return it later. Was that all? Is it empty?

Yes. 
empty. Ja. She returns to her space on the carpet.

16 HT: Dankeschön, Amy. So und nun zu morgen. Bitte vergesst nicht, dass morgen

Spielzeugtag ist. Da könnt ihr ein Spielzeug mitbringen, aber nur eins. Showing one with her thumb.
Thank you, Amy. So and now to tomorrow. Please don't forget that it is toy day. You can bring one toy, but only one.

The children are very happy about toy day and all talk at the same time, telling each other what they will bring.

\section{Good-bye Song}

The head teacher starts waving her hand to signal to the children that they will now sing the good-bye song as the last part of the afternoon circle. She counts "eins, zwei, drei (one, two, three)" and the group starts singing.

\section{Song}

Salut, mitein'nand

Schau mitein'nand

Good bye, Auf Wiedersehen.

Salut, mitein'nand

Schau mitein'nand

Good bye, Auf Wiedersehen

Lebe wohl und viel Glück,

bis morgen früh auf

Wiedersehen.

\section{Translation}

Bye, bye everyone.

Bye, bye everyone.

Good bye, Auf Wiedersehen.

Bye, bye everyone.

Bye, bye everyone.

Good bye, Auf Wiedersehen.

Good bye and good luck,

Until tomorrow morning

Good bye.

\section{Movement}

Wave at each other.

Wave at each other.

Wave at each other.

"Auf Wiedersehen, Käfer. (Good bye, beetles)" she tells the children who are leaving the circle time area and running outside to their waiting mothers, fathers, or caregivers. Mira says, "meine Mama holt me ab (my mother picks me up)." The second teacher replies, "Deine Mama holt dich ab, dass ist ja aber super (Your mommy is picking you up, that is great)." Daniela adds, "meine auch (mine also)," and everyone leaves the area with the head teacher going last. The day is over for the children and they hug their families outside where they have been talking for a few minutes. The head teacher also goes outside so that the parents and caregivers can talk to her if they need too.

Slowly, the families leave the school and the teachers clean up and prepare for the next day. 

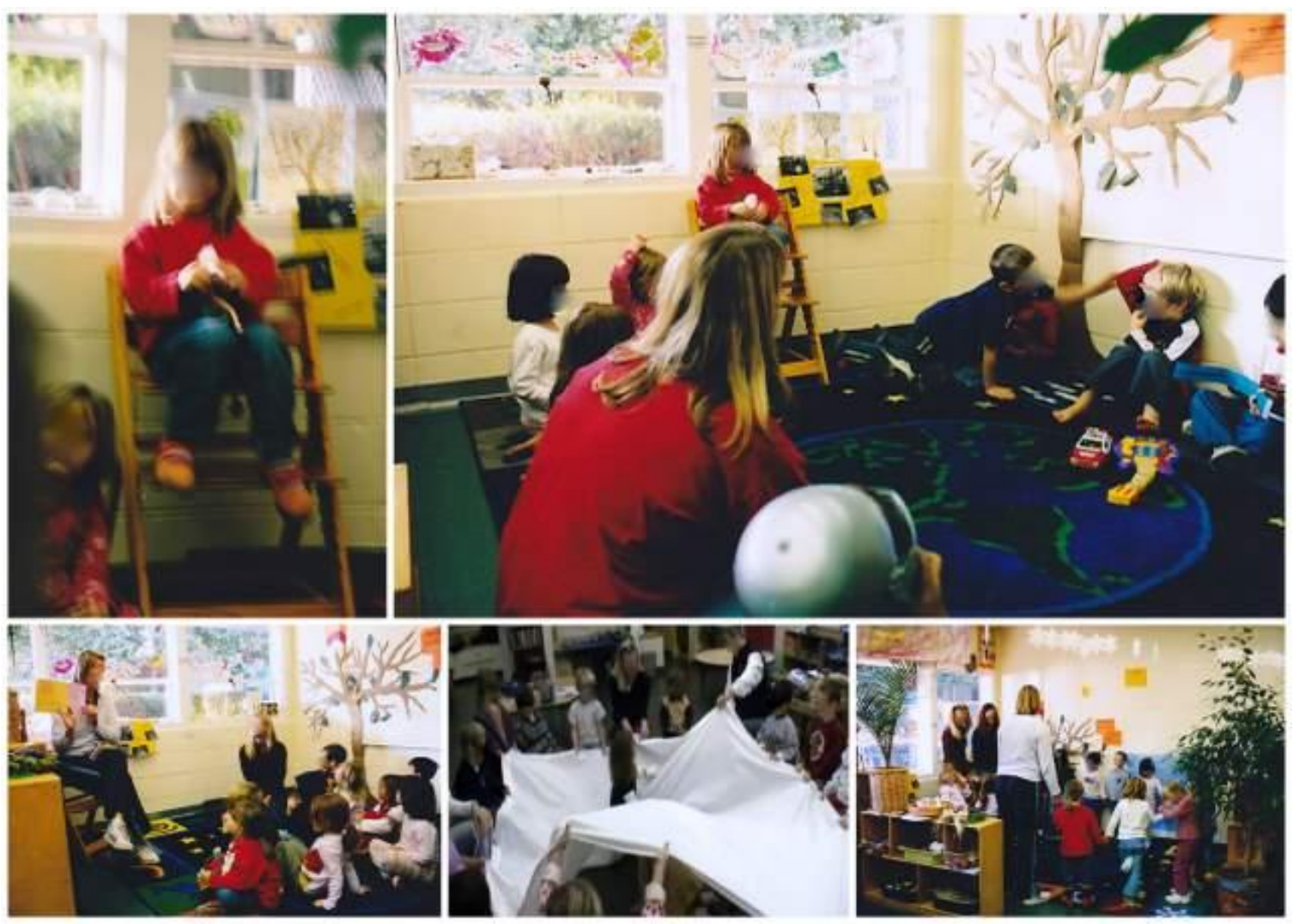

Figure 56. U.S.P.P.: Closing circle impressions, speaker chair, read aloud, songs and movement activity. 


\section{U.S. Kindergarten Program}

\section{Introduction}

The kindergarten program is referred to as "die Vorschule (the preschool)," which refers back to the original German or Austrian education system and meaning where children one year prior to school entry receive special enrichment activities geared toward school entry. While the U.S. educational system's "kindergarten" is part of the school system, the German's and Austrian's are not. If the teachers or children refer to the preschool in the following sections then they mean this kindergarten program for 5 to 6 year olds.

At the time of observation two kindergarten groups attended the full day program from 8:30 to 1:55 p.m. for five days a week, with a total of 31 children. The classrooms had themes and corresponding names. One was the jungle and the other the aquarium. The children who attended the jungle were called the parakeets while the children who attended the aquarium where called fish. The children of the fish group participated in this study.

The main language used during the instructional day is German. Teachers address children only in German. However, while students were encouraged to use German inside the classroom all languages were used in the outdoor areas. Parents were also encouraged to use as much German as possible inside the classroom to model the behavior and enforce the rule that was agreed upon with the children at the beginning of the year.

\section{Concept and Curriculum}

The head teacher's teaching philosophy summarizes the concept of the kindergarten program quite well. She states in her teacher questionnaire:

Teaching children has to happen in a hands-on, fun environment. Children learn best when they can relate to the subject, and can make a connection to their own life. Even at an early age, it is important that they understand about themselves in the context of a bigger world. Developing their social competence is another major focus during their life-long learning. Every student also learns in different ways, at a different pace, and has different strengths and weaknesses which need to be considered in the teaching methods.

Her philosophies and the IB framework, together with the interests of the children, influence the curriculum. The parent's handbook shares the following information about the curriculum:

This program is divided into six themes, with the time and flexibility to explore these in considerable depth. We practice math via measurements, estimates, concepts, sequencing and science projects rather than simply memorizing numbers. We improve 
our language skills - in German and in English - through presentations, stories, reading, music, theater and self-initiated, teacher assisted writing introduction.

The unit that the children explored during the study was called "In the footsteps of great artists," which included artist such as Henri Matisse, Vincent van Gogh, Friedensreich Hundertwasser, Pablo Picasso, Frieda Kahlo, Louise Nevelson, and Keith Haring. The students learned about the artists' life stories, their art, and their contribution to the field of art, and discussed how feeling can be expressed through the art (see Figure 69, Figure 70, and Figure 71). They created individual and group paintings and turned their classroom into an art exhibition. Furthermore, the unit included visits to art museums, an art show for parents and the community, and a fundraiser for the program by selling their art pieces.

\section{Daily Schedule}

$\begin{array}{ll}\text { 8:30 - 8:45 a.m. } & \text { Welcome and Arrival Time } \\ \text { 8:45 - 9:15 a.m. } & \text { Circle Time and Discussion } \\ \text { 9:15 - 10:00 a.m. } & \text { Free Play, Choice Activities, and Snack time } \\ & \text { Mo/Wed/Fri: Jungle opens Tue/Thur: Aquarium opens } \\ \text { 10:00 - 11:30 a.m. } & \text { Main Project of the Day (Science, Art, Theater or Linguistics) } \\ \text { 11:30 - 12:00 a.m. } & \text { Lunch at Outside Tables and Recess } \\ \text { 12:00 -1:15 p.m. } & \text { Free Play and Activities } \\ & \text { Mo/Wed/Fri Aquarium opens, Tue/Thur Jungle opens } \\ \text { 1:15 - 1:20 p.m. } & \text { Clean-up } \\ \text { 1:20 - 1.50 p.m. } & \text { Closing Circle: What did we learn today? What did I particularly like today? } \\ \text { 1:55 p.m. } & \text { Good-bye and Pick-up }\end{array}$

\section{Teachers}

The group has one teacher and one teacher assistant who also works with the jungle group. The student-teacher ratio is 10 to 1. Both are bilingual in German and English; they are German native speakers and learned English as a second language in the German school system.

The head teacher has been working for this program since 1994 as a teacher and was also the Primary Years Program (PYP) coordinator, guiding the program through the IB World School application process while I conducted my research. She does administration work on Mondays and Fridays. The teacher who substitutes for her on those days has been the preschool director for several years and has kindergarten teaching experience. All teachers are certified while the head teacher holds a B.A. in Early Childhood Education, a Child Development A. A. degree and certificate, and participates in professional development workshops in the field of IB. The assistant was educated in Germany and holds a Diploma in Music as well as music teaching credentials from the University of Heidelberg and the University of Mannheim, Germany. 


\section{Children and Parents}

The group consists of 15 children, but one child has been home sick the entire week. The children are between five and six years old. According to their parents, eight children use English as their preferred language and six use German. The children are mainly dual language learners, speaking two or more languages. The list of mother tongues includes German and English. The children are able to understand German and use it in the educational setting if engaged in the German language (see Table 11). The information about the languages of the children was taken from the questionnaire or provided by the program.

Table 11. U.S.K.P. Fish group: Parents response

\begin{tabular}{|c|c|c|c|c|c|}
\hline Children & Age & Gender & $\begin{array}{l}\text { Preferred } \\
\text { Language }\end{array}$ & $\begin{array}{l}\text { Other } \\
\text { Languages }\end{array}$ & $\begin{array}{l}\text { Comments of Parents on } \\
\text { Questionnaire: What do you think is } \\
\text { a reason for the preference? }\end{array}$ \\
\hline Leon & 5 & Male & German & English & $\begin{array}{l}\text { We speak mostly German at home. It's his } \\
\text { mother tongue. }\end{array}$ \\
\hline Katja & 5 & Female & German & $\begin{array}{l}\text { Some } \\
\text { English }\end{array}$ & $\begin{array}{l}\text { For the first } 5 \text { years of her life, she lived in } \\
\text { Germany. Since August } 2005 \text { we live in the } \\
\text { USA, so my daughter just started to learn a } \\
\text { second language. }\end{array}$ \\
\hline Leoni & 6 & Female & English & German & $\begin{array}{l}\text { Peer groups, daddy only speaks English, } \\
\text { TV; }\end{array}$ \\
\hline Emilie & 6 & Female & German & English & $\begin{array}{l}\text { We speak only German with her and she } \\
\text { considers it to be her primary language. }\end{array}$ \\
\hline Hannah* & 6 & Female & English & German & \\
\hline Lisa & 5 & Female & German & $\begin{array}{l}\text { some } \\
\text { English }\end{array}$ & $\begin{array}{l}\text { Only here for a year now, goes to the } \\
\text { German school, the environment is } \\
\text { German-speaking; not enough knowledge } \\
\text { of English yet; }\end{array}$ \\
\hline Luca & 5 & Male & English & German & $\begin{array}{l}\text { More English-speaking peers; realizes that } \\
\text { main languages around us is English; }\end{array}$ \\
\hline Marie & 6 & Female & English & German & more exposure; \\
\hline Jonas & 5 & Male & English & German & $\begin{array}{l}\text { English-speaking environment and this is } \\
\text { what he is accustomed to. }\end{array}$ \\
\hline Finn & 5 & Male & English & $\begin{array}{l}\text { German, } \\
\text { Spanish }\end{array}$ & $\begin{array}{l}\text { He speaks each language to the people he } \\
\text { knows speak the language. Spanish with } \\
\text { part of the family, English with the other } \\
\text { and German with this father and at school. }\end{array}$ \\
\hline Lea & 5 & Female & German & English & $\begin{array}{l}\text { She prefers to speak German with her } \\
\text { parents and English with her brother and } \\
\text { friends. }\end{array}$ \\
\hline Sophie & 5 & Female & English & German & $\begin{array}{l}\text { Mother is English speaker and spends more } \\
\text { time with the child and father is native } \\
\text { German speaker. }\end{array}$ \\
\hline Niklas & 5 & Male & English & German & $\begin{array}{l}\text { English with American mom. German is } \\
\text { now preference with German dad. }\end{array}$ \\
\hline Jan & 5 & Male & German & & parents speak German, native language; \\
\hline
\end{tabular}


The parental questionnaire was distributed to all caregivers and parents of the observed group. I received 13 from 15 questionnaires (see Figure 57). The graph shows that most of the children are bilingual in German and English.

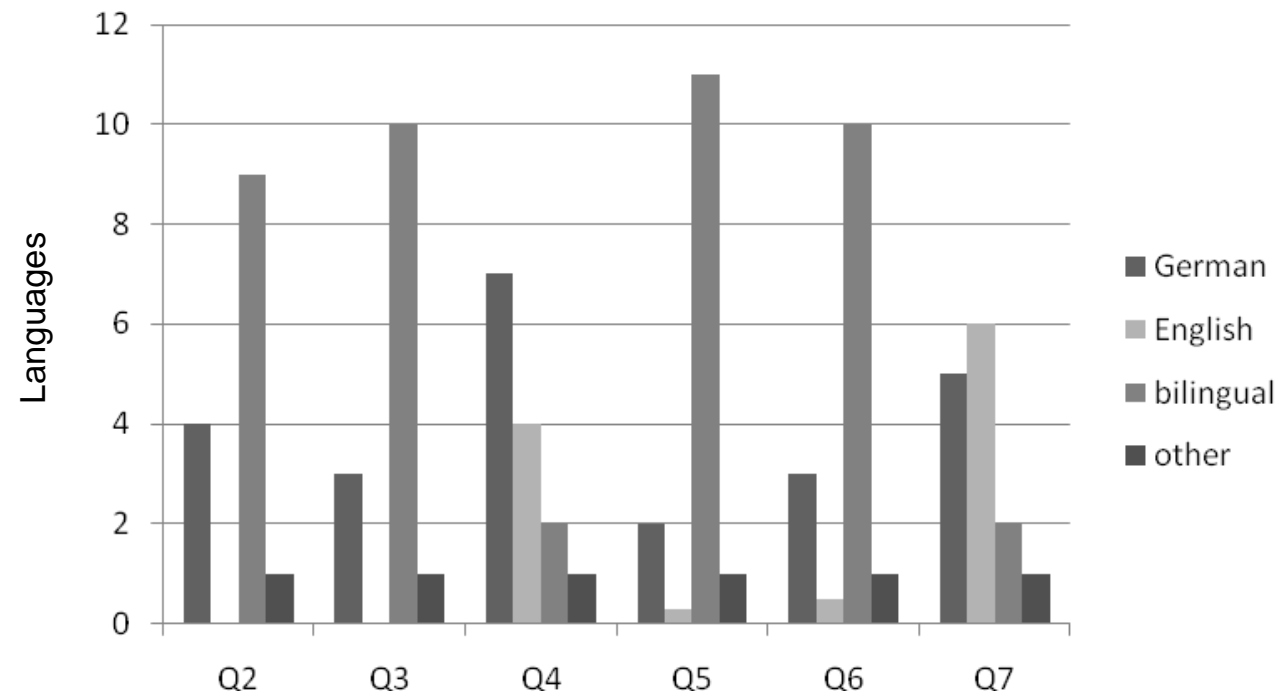

Figure 57. U.S.K.P.: Answers given by parents in the questionnaire. The following questions were asked: Q2: What language(s) are spoken at the child's home? Q3: What language(s) did your child know prior to kindergarten? Q4: What language(s) are mainly used in conversation with your child? Q5: What language(s) does your child understand? Q6: What language(s) does your child speak? Q7: What is your child's language preference? Under Other languages the following language were listed: Q2, Q3, Q4, Q5, Q6, and Q7: Spanish.

Parents named a wide variety of reasons why they have chosen to send their child to this program, to list a few: German language program and bilingual possibilities for children; the great educational program and new IB framework; outstanding staff and teaching philosophy, and heritage language connections to German. Below are some of the parents' comments:

- It's fabulous. We love the language, but it's the staff and programs that sold us $100 \%$. It's a wonderful place for the whole child.

- Cause my husband and I are already bilingual by enrolling our son in a bilingual school means he sees the benefit of both languages outside of the home and learns.

- Move to the US should not become a Trauma = nightmare because of no knowledge of English

- German background. Love the kindergarten philosophy where there is no emphasis on sitting and learning. Love the IB.

Additionally, parents see the role of world language learning in early childhood program as important (four) and very important (8), see Figure 58. 


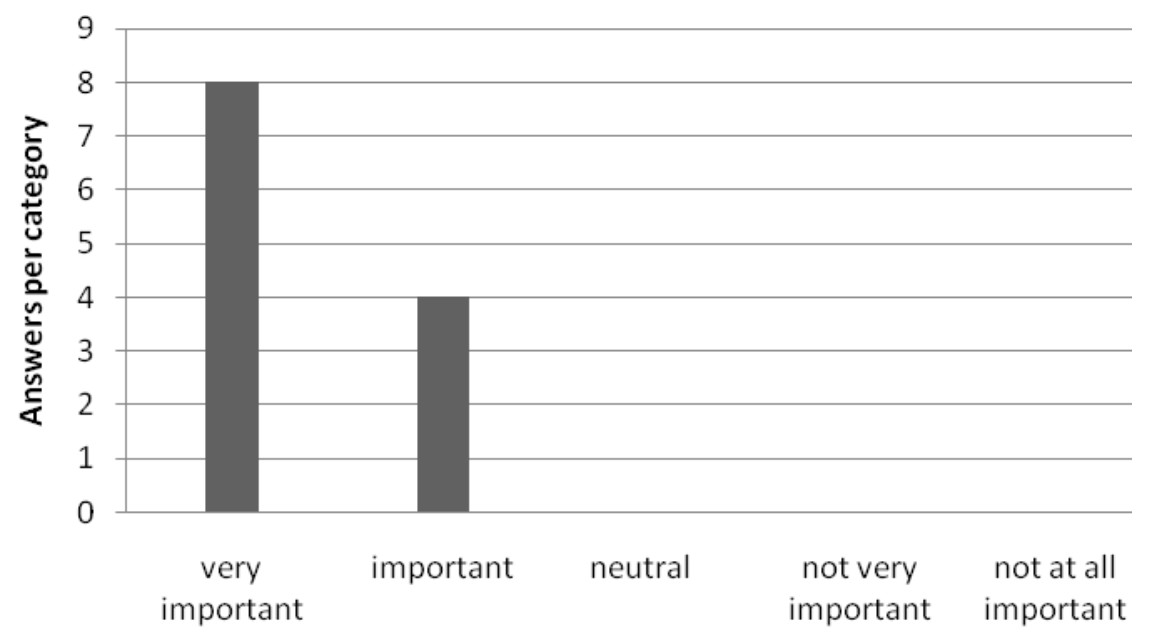

Importance categories

Figure 58. U.S.K.P.: Parents' answers to their perceived importance of world language learning in kindergarten.

\section{Physical Layout}

Inside

The kindergarten room is filled with natural day light and neon lights that cover the ceiling. The room gives the feeling of being busy and every area in the room has its own stories to tell. As you enter, to the left stands the teacher's desk with a chair (see Figure 59 and Figure 61). It is filled with teaching and organization materials and a tabletop water cooler. Just behind is the building area with a small table for one or two children. Next to it is a smaller open shelf with plastic see-through boxes that are filled with manipulatives. A slim open shelf packed with big blue, green, yellow, and red building blocks extends into the room as a divider between the building and circle time area. There is also a movable and foldable divider.

The circle time area is in the corner between the window wall and a solid wall. The blue carpet with underwater motives and fish resembles the water of the aquarium and gives the room its name. The children are the fish who live in the aquarium. The children have made their own colorful fish, which are attached to a fish net hanging from the ceiling, and a few more fish are spread throughout the rest of the room. The wall below the window is painted blue to resemble water. An interesting selection of art books is lined up on the window sill and it goes along with the current art unit. Below is a number line from one to one hundred. Just above the window hangs a metal string 
with clips for hanging pictures, but for now it accommodates Christmas lights. Several paintings of Christmas trees and beautiful stars created by the children decorate the windows.

At the adjoining wall, just below the ceiling, hangs a big blue bulletin board with white and blue note cards with word-processed concepts: key words and questions in German with small English captions. The blue paper represents the general ideas and questions that guide all learning inquiries throughout the year: Form - what is it like? Function - how does it work? Causation -why is it the way it is? Change - how does it change? Connection - how is it connected to other things? Responsibility - what is our responsibility? Reflection - how do we know? The white paper shows student questions about the current unit, for example: "Was kann man benutzen, um Kunst zu machen?" (What can one use to make art?), or, "Wie können wir durch Kunst zeigen, wie wir uns fühlen?" (How can we show through art, how we feel?) The yellow paper shares information about the current unit such as the title "In den Fußstapfen der großen Künstler" (In the footsteps of great artists).

Below the board is a world map with pictures of artists the students have learned about, such as Matisse and Van Gogh. Next to the map hangs the weather chart. A green poster board with the headline "student's profile" is surrounded by keywords and their explanations including photos of children who gesture these keywords. The keywords are: inquirer, thinker, communicator, risk-taker, knowledgeable, principled, caring, open-minded, well-balanced, and reflective; and are posted in German with small English captions. The corresponding explanations were created by the children in form of I-statements.

Below is a time line that displays when each studied artist was alive or born. A picture is attached for each one. To the side stands a soft room divider. It is covered with a fishing net that has several colorful fish, each with one of the students' desired attitudes - commitment, confidence, cooperation, creativity, curiosity, empathy, enthusiasm, independence, integrity, respect, toleranceattached in German with small English captions. The divider closes off the circle area and in front of it is a table that has a blue table cloth, an advent wreath, and several tea lights glued to yellow stars. Below are boxes with instruments such as triangles, cymbals, tambourines, bells, castanets, a toadshaped guiro, wood blocks, drums, and many more. Two low selves join the divider.

The IB concept - keywords and questions, learner profiles, and student attributes are part of the framework of the International Baccalaureate program. The school is trying to become recognized as a world IB school, which is discussed in more detail in the introduction of the U.S. program in this chapter. 
The dramatic play area has a plastic log cabin with a fire place, a doll in the bed, and a few pillows inside. Next to it are dress-up cloths such as hats, bags, suits, dresses, and different types of shoes that hang on hooks or are placed on a small shelf. A slim mirror is attached to the wall next to it. Baskets with more clothes and dishes stand in the corner. A broom leans against the wall. Above the dress-up clothes hang drawings by the children showing the Matisse way of painting. On the ceiling above hang a white sheet and more Christmas lights, which help to define the area.

In the next corner is a built-in closet that is used for storage of materials. Along the wall are several built-in open and closed shelves and kitchen facilities with a sink. On the countertop are a small fridge, a microwave with a CD player on top, and a kettle. A mirror hangs above the countertop at eye-level with the children. The reading area has one loveseat and one sofa standing opposite each other, which have blue slip covers, several pillows, and stuffed animals. Two open shelves, one with books and the other with puzzles, activities, and games, divide the kitchen and reading area. Above the bigger sofa, which stands along the wall, are built-in shelves filled with books hidden behind a curtain. A drying rack stands in the corner next to the sofa.

The next area is the creativity-recycle station. The workbench is at the children's height and one can measure the popularity of this area by the condition of the surface area, which is buried in paint, glue, glitter, plastic, and more. The table top itself looks like a colorful piece of three dimensional art, but its center also has a heavy duty extension cord for the glue guns, a basket, and a box with work materials. Nearby is a four tier shelf that has see-through plastic boxes with a variety of craft and recycle materials, and a three tier shelf filled with old national geographic magazines and other materials. These shelves separate this area from the writing center. A big newspaper print role leans against the wall and the wall space above the bench is filled with more children's artwork, with contrast as its main focus. From the ceiling hangs another fish net with fish, and a metal string stretches from the window to the back wall. It has the group's St. Nicklaus boots that the children made the week prior.

In the writing area are two trapezoid-shaped tables pushed together with six chairs and two smaller shelves that hold paper, work sheets, pencils, markers, and each child's pencil box. The boxes are color coded red for the girls and blue for the boys, and hold crayons, color pencils, pencils, eraser, a small glue bottle, and scissors. On the wall in the center area hang color wheels around which are colorful student profiles using flat shapes and controlled lines showing information they learned about Henri Matisse. 
In the middle of the room are two large tables that each seat eight children comfortably. On the wall, right across from the teacher's desk, is a cabinet that holds paper and the student's portfolios.

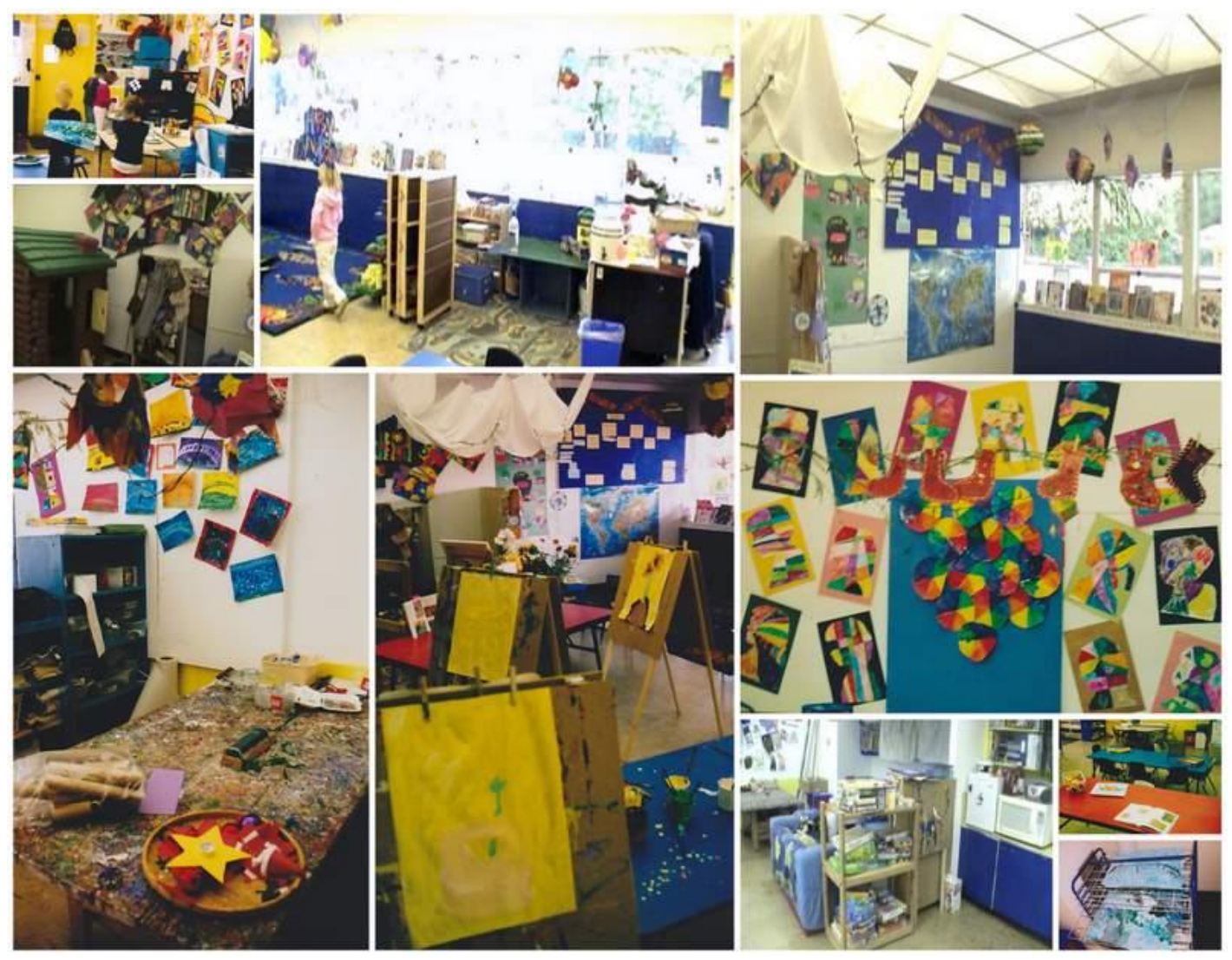

Figure 59. U.S.K.P.: Kindergarten room layout.

\section{Outdoor Area and Playground}

The children's cubbies are outside, and each child has a big blue bag that hangs on a hook with the child's name next to it (see Figure 60). The school yard is big and there is a large world map painted on the asphalt. Six picnic tables are placed at the edge of the yard close to the playground. The playground has several activities and climbing equipment, a swing set with two swings, and a sand box. Just behind the lunch tables is a painted yellow line which marks the end of the preschool schoolyard. On the other side are a basketball field and the remaining school building. 


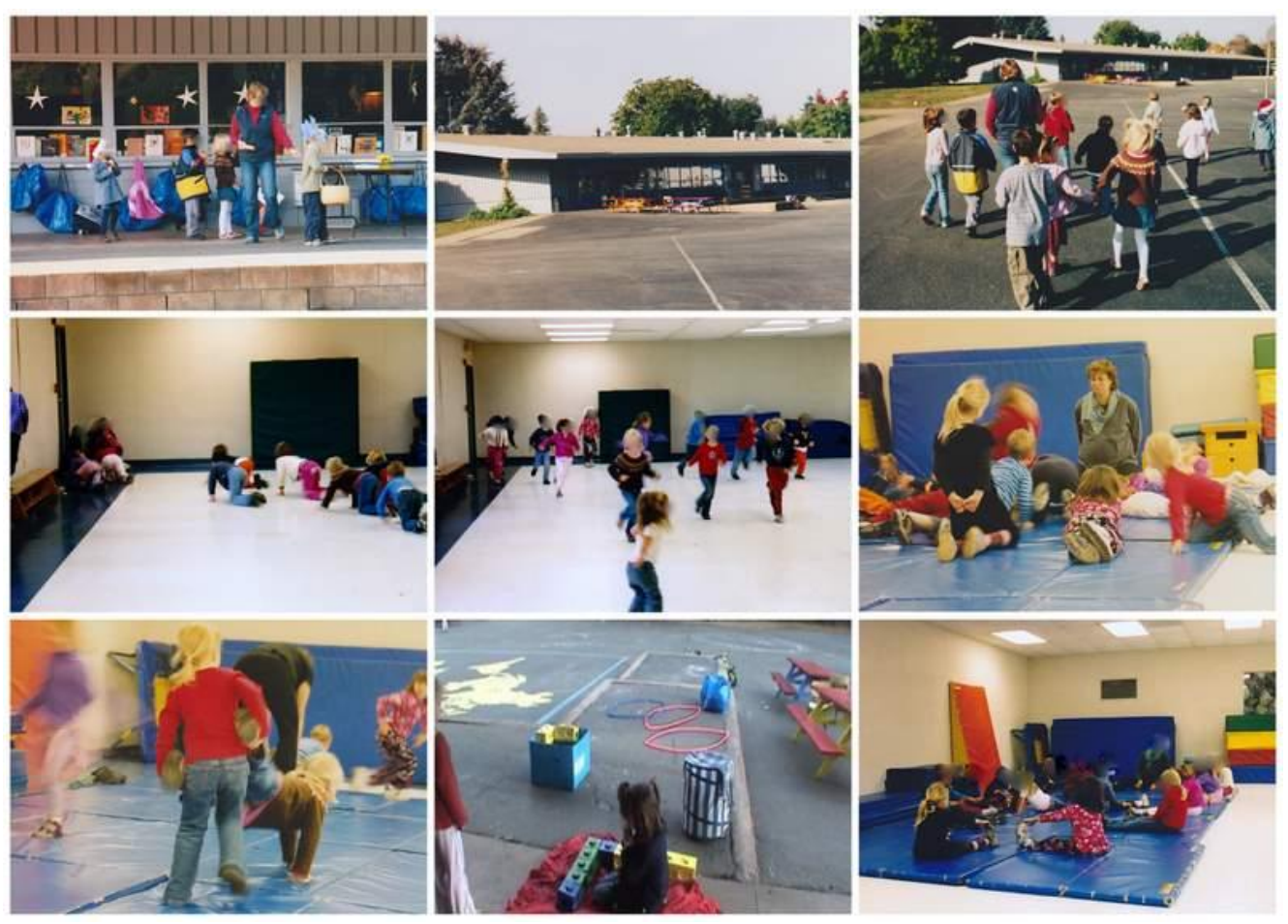

Figure 60. U.S.K.P.: Outdoor area and physical education activities.

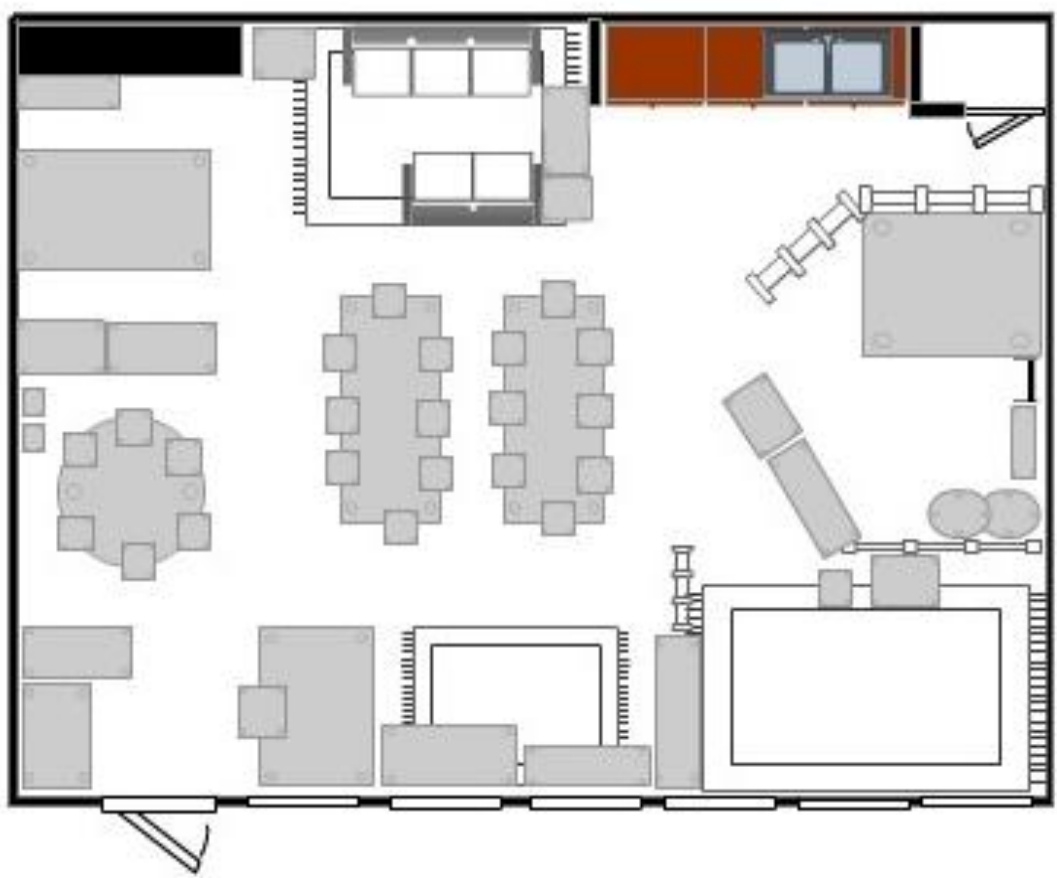

Figure 61. U.S.K.P.: Classroom layout. 


\section{A Typical Day}

Welcome and Arrival Time (8:30 - 8:45 a.m.)

The sound of classical music greets the children as they enter the classroom. The music is vibrant. It feels as if the children should dance a waltz as they come in. Each table has activities. On the blue table is a children's book and Connect Four, and on the red table are pattern blocks with picture cards and a book about art that shows patters (see Figure 62). I can see the parents through the windows as they bring their children to their cubby where they leave their lunch box and jackets. Children talk with other children and parents with parents, most of which are mothers. The teachers are also outside to welcome each child, and have short conversations with their parents.

This morning it is a little chilly and Hannah enters still wearing her cardigan. She seems rather shy, waits, looks around, runs to the circle area, chooses an art book from the window sill, and takes a seat on the carpet. She turns the pages, looking carefully at the pictures. Outside, more and more children arrive and the assistant teacher greets each one. Everyone seems to be very excited because it is the last week of school before the Christmas holidays and many children are flying back to Germany, Austria, and Switzerland.

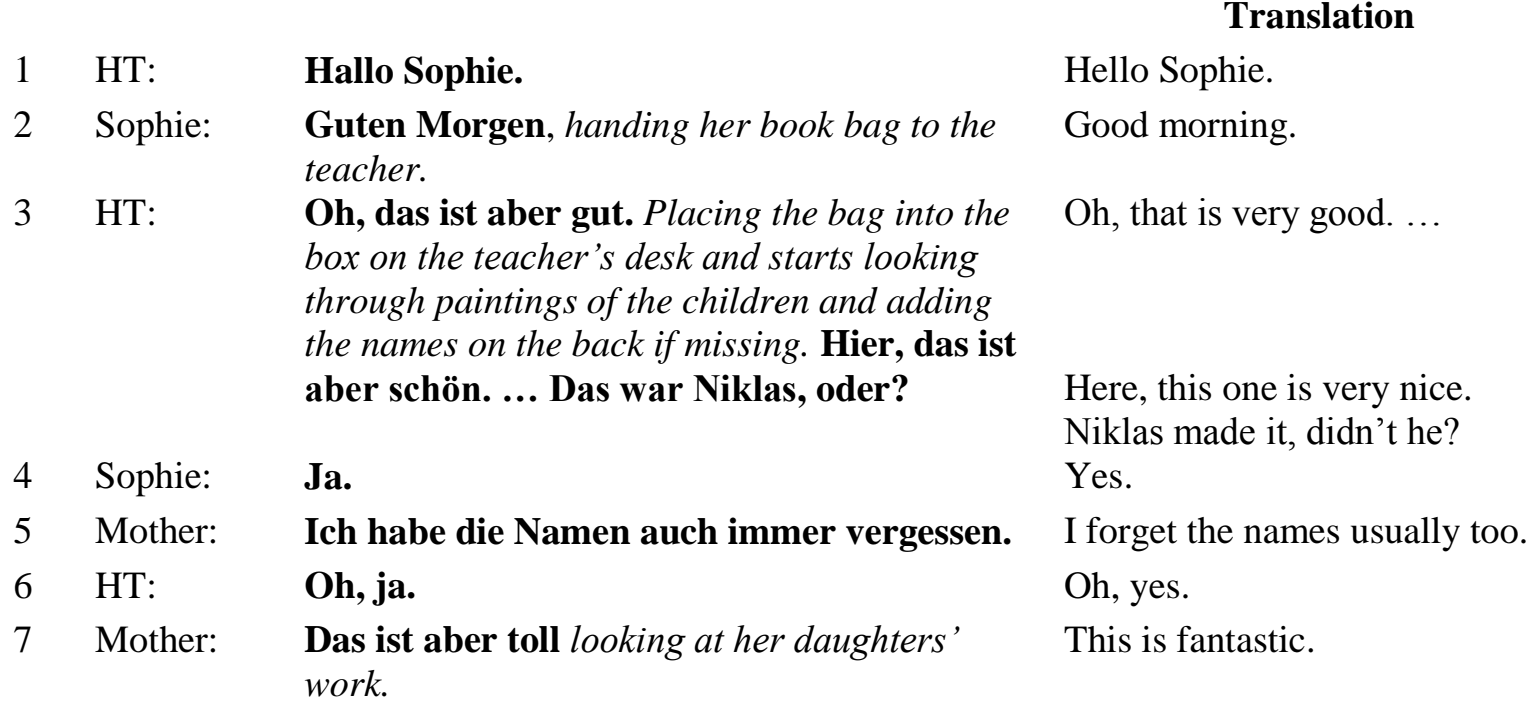

The teacher goes to the circle time area and starts preparing. Sophie's mother has a question and they start talking. Meanwhile Lea arrives and talks to the teacher assistant who is standing outside at the door:
$8 \quad$ Lea: $\quad$ Ich soll noch zwei mal schlafen und hier herkommen, und danach fliegen wir nach Österreich.
9 TA: $\quad$ Feierst du Weihnachten in Österreich?

I have to sleep two more nights and come here, and then we will fly to Austria.

Are you celebrating Christmas in Austria? 
10 Lea:

Jaaa. ... Ist in zwei Tagen Christmas?

11 TA:

12 Lea:

13 HT:

14 Mother:

15 HT:

16 Mother:

17 HT:

18 Sophie:

19 HT:

20 Sophie:

21 Mother:
Nein, noch nicht. Aber in zwei Tagen fährst du nach Österreich und dann must du erst mal ankommen und dann ist bald Weihnachten.

Ach so. Walking into the room to the head teacher, handing her proudly the book bag she was carrying. I bring my book, here.

Hast du es mitgebracht? Toll soll ich es in die Bücherbox hier tun? Pointing to the box on the teacher's desk, then taking the book bag and placing it in the box.

Kannst du dein Buch holen? Asking Sophie who is in the box searching for her bag.

Das hat sie schon gleich beim Reinkommen gemacht.

Ach so. While Sophie shows her the bag.

Hast sie gleich dran gedacht telling the mother and saying to her Hast du selbst dran gedacht?

Saying Ja very carefully while looking at her mom.

Jaaa? Smiling to the mother who is also smiling.

\section{Auch meine Mama.}

Alles ist in meinem Gehirn. Das ist unglaublich. Smiles, kisses Sophie, says good bye to the teacher and leaves the room.
Yesss. ... Is Christmas in two days?

No, not yet. But in two day you'll go to Austria, and you need time to get there, and then Chrismas will be there.

I see.

Have you brought it? Great, do you want me to place it into the book box?

Can you get your book?

She did it when she arrived.

I see.

She remembered as soon as she got here. ... Did you remember yourself?

Yes.

Yeess?

Also, my mom.

Everything is in my head. It is unbelievable.

Lea, Sophie, and Hanna take a seat at the blue table and start playing with the pattern blocks activity. They search for a pattern in the pile of cards, which have English words printed on the bottom. Lisa, Jan, and Marie join the activity. Marie starts to make a frog, Jan a fish, Lisa a ship, Hannah a truck, and Sophie a vase with flowers. Lea holds up a little piece she needed and says proudly in English, "Look what I found." Lisa and the children at the table start saying a couple of times "Englisch raus (English outside)." As Lea noticed what she did, she sighs, "Oh," and turns her head to the back pretending to put it outside where the mothers with a few younger children are talking.

The group is focused on the pattern creation activity, searching the box with shapes one at a time. Leoni and Hannah, who are sitting at the end of the table and have to reach far to get a shape, pull on the box at the same time and Sophie says, "Okay, I will give everyone a piece." No one notices her use of English and after a few seconds she turns to Lea, telling her "Englisch raus (English 
outside)," and turns her head around looking toward the door. Hannah, who is waiting to get the box with shapes, says something that is very difficult to understand. Sophie connects to her prior statement and repeats "Englisch raus. Das habe ich schon gesagt (English outside. I have said that already)." However Hannah says while waving her pattern block card in the air, "Aber ich will auch welche. Ich will auch eins machen. Alle dürfen eins machen (But I want some too. I want to make one too. Everyone can make one)." The teacher supports her argument saying, "Natürlich dürfen alle eins machen, Hannah (Of course, all are allowed to make one, Hannah)." The girl complains, "Ihr lasst mich keine haben (You don't let me have any)." The teacher goes down to the eye-level of the child asking her "Was? (What?)," and while she leans forward and grabs the box with shapes she says, "It goes in the middle." The teacher offers another solution for the problem: "Vielleicht holt ihr euch immer eine handvoll raus (Maybe, you should take a handful each)." Sophia continues to talk in English, explaining what she is looking for, but no one refers to the rule that inside only German is spoken. They continue on their pattern cards and a few start on their second.

Marie's mother has finished her conversation with the parents outside and comes in, goes over to her daughter, and gives her a kiss. Marie gets up, hugs her mother another good-bye, and her mother leaves the room. Emilie and her mother enter and they start talking with the teacher, explaining that Marie has been feeling better and is ready to return to school. The teacher greets Emilie and tells her that she and the group are happy that she is back. Niklas, Leon, and Jonas have been playing with Legos at the shelf behind the tables. Leon states quite loudly, "English raus (English outside)." A smiling Jonas looks somewhat shyly around the room to check if no one noticed. A second later the boys have returned to their play and no sound can be heard. Meanwhile, the children have almost finished their pattern and Hannah is starting her second as the teacher signals with a song that it is circle time.

She sings, "Es kommen alle hier zusammen. Es kommen alle hier zusammen. Wir fangen jetzt an (Everyone comes together here. Everyone comes together here. We will start now)," repeating it a couple of times. Some parents are still inside and others are outside with their children, but when the children hear the song they enter or stop their activities and run to the carpet area in the corner. The teacher has to remind Lea, who continues to work on her pattern card, "Lea?" and the girl replies with "Was? (What?)," not looking up but rather finding the next piece. "Wir haben Kreiszeit gesagt. Was must du denn da machen? (We called for circle time. What should you do then?)," asks the teacher and follows with the answer immediately, "In den Kreis kommen (Join the circle)." Lea looks at her smiling "ja (yes)," and both are laughing as the teachers adds, "Das weißt du ja schon (But you know that already)." 


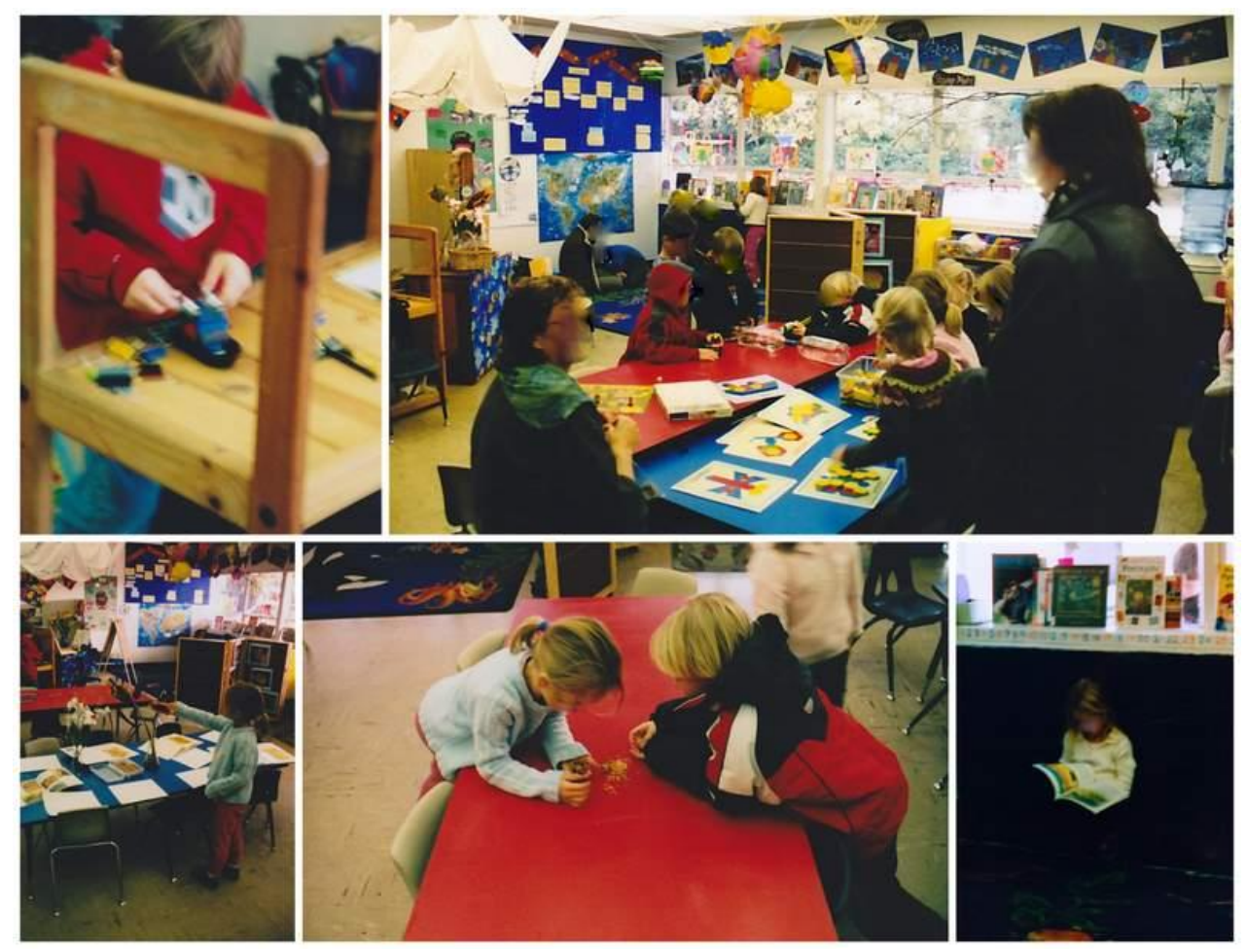

Figure 62. U.S.K.P.: Arrival time activities.

Circle Time and Discussion (8:45 - 9:15 a.m.)

\section{Morning Routine}

The teacher has taken a seat and starts clapping her hands on the thighs. Some children are standing or sitting and echoing the rhythm while others just enter the circle area (see Figure 63). The constant rhythm soon has all of the children clapping, and the teacher notices that they look tired and says with a smile, "Aufwachen, aufwachen (Wake up, wake up).” while clapping. She starts the welcome song:

\section{Song}

Hallo, hallo, schön dass ihr da seid. Hallo, hallo, wir freuen uns so sehr. Die Hacken und die Spitzen, die wollen nicht mehr sitzen.

Die Fersen und die Zehen, die wollen weitergehen.

Hallo, hallo schön dass ihr da seid. Hallo, hallo, wir freuen uns so sehr.

\section{Translation}

Hello, hello nice to see you here. Hello, hello we are so happy.

The heels and the toes cannot sit any longer.

The heels and the toes they want to move on.

Hello, hello nice to see you here. Hello, hello we are so happy.

\section{Movement}

Waving hands.

Move feet from heel to the toes.

Move feet from heel to the toes.

Waving hands. 
The teacher goes on to take attendance and reads the names of the check list as the children raise their hand or reply with "ja (yes)." She says that one child is sick at home and then continues with the calendar time. "Heute werden wir ... Oh, welcher Tag ist heute? (Today we will ...Oh, what day is today?)," she asks, and Sophie raises her hand and says, "Mittwoch (Wednesday)." Then she asks the circle time helper Niklas to turn off the lights and responds to Sophie's answer, "Ja, und wie viele Adventskerzen machen wir an? (Yes, and how many candles will we light?)" Jonas says, "vier (four)," and she asks, "vier? (four?)," while Luca adds, "drei (three)." The teacher agrees and so do the children. Katja calls out, "der dritte Advent (the third of Avent)," and the group repeats saying "der dritte (the third)." The teacher nods, "Ja, der dritte Advent (Yes, the third of advent)." She lights the candles of the advent wreath, then the day candles, counting them with the group to find out what the date is. They stop at "vierzehn (fourteen)" and the teacher says, "Heute is Mittwoch, der 14. Dezember 2005, and which advent? (Today is Wednesday, December $14^{\text {th }}, 2005$ and which advent?)," and the children automatically repeat the date in a chorus. Together, they start a short funny advent poem: "Advent, Advent, ein Lichtlein brennt. Erst eins, dann zwei, dann drei, dann vier. Wenn das fünfte brennt, dann hast du Weihnachten verpennt (Advent, Advent, one light is glowing. First one, then two, then three, then four. When the fifth is burning you overslept Christmas)." Afterwards, she asks the circle time helper to turn on the lights again.

She says, "Wetterfrosch Hannah, komm mal her und erzähl uns wie das Wetter ist (Weather frog Hannah, come here and tell us how the weather is)." The girl gets up, looks outside the window, and goes silently to the weather chart. She turns the handle to the cloudy weather sign and returns to her seat without saying a word, but looking at the teacher who asks her again, "Wie ist denn das Wetter, erzähl mal (Can you tell us how the weather is?)." Finally she says, "nebelich (foggy)." Still shy, she looks outside again and Lea adds, "Ich sehe sonnig (I see sunny)." Then the others try to help her saying "sonnig, sonnig (sunny, sunny)." Jonas says, "Ich sehe Donner und Blitz (I see thunder and lightning)," and starts smiling. Hannah returns to the chart, changes her first thought to sunny, and the teacher asks her again. She turns around with a smile and says, "sonnig und kalt (sunny and cold)," and the teacher agrees.

\section{Speaker Chair}

Marie has been sitting all along on the speaker chair next to the teacher, who finally gives her the word. The girl puts a finger in her mouth showing a big open space. 
1

2

HT:

3 Marie:
reingelegt.
4 HT: Und den Zahn hat sie mitgenommen oder
5 Marie: Dagelassen.

\section{Translation}

\author{
My first tooth fell out. \\ Your fist tooth fell out. \\ What did you do with the tooth? \\ I put it into a box, wrote a letter \\ for the tooth fairy, that she \\ should not take the tooth because \\ I want to keep it. She wrote back \\ and put in a special dollar. \\ Did she take or leave the tooth? \\ Left it.
}

The teacher summarizes Marie's words for the group while some of the children express what the tooth fairy does at their house. The teacher continues to tell the children that the tooth fairy does things differently for every child. Then she asks Jan if he would also like to talk about his tooth. He nods while taking a seat on the speaker chair. He says that the tooth had fallen out during a play date and that all his friends where there. She asks him how many teeth he had lost so far and he says three. Then she inquires about what he had done with his tooth and he tells her he had put it into a box. She repeats that it works differently at every home. He returns to his seat and she asks who else would like to speak. Lea puts her arm up and the teacher asks her to take a seat on the chair. The girl tells the group, "In zwei Tage fliege ich zu Österreich (In two days I fly to Austria)," and the teacher comments excitedly, "Du fliegst nach Österreich! (You are flying to Austria!) There are a lot of children who will be going to Germany or Austria over the weekend. Who is going?" About seven children put their arms up to express that they are going to Germany or Austria. Then she asks who will stay here and puts her arm proudly in the air with the rest of the children.

\section{Main activity}

\section{Introduction and Discussion}

The teacher starts discussing the topic that the group has been working on and asks, "Worüber haben wir denn gesprochen in der letzten Zeit? (What did we talk about the last couple of days?)" Katja says, "Kunst (Art)," and the teacher takes that information and includes it in her next question, "Was über Kunst? (What about art?)” Sophia briefly responds, "ausdücken können (can express)." The teacher takes her thought and expands it to, "Wie können wir uns mit Kunst ausdrücken? Und da waren doch zwei Künstler, die wir schon hatten. Wer war das noch mal? (How 
one can express oneself through the arts? There are two artists we have already learned about, who were they again?)" Marie answers "Matisse" and the teacher praises her and says, "Henri Matisse." Several children call out "van Gogh" and the teacher says, "Ja, richtig. Vincent van Gogh. Könnt ihr das alle mal sagen? (Yes, excellent. Vincent van Gogh. Can you say it together?)" They repeat the name in a chorus several times and enjoy doing so.

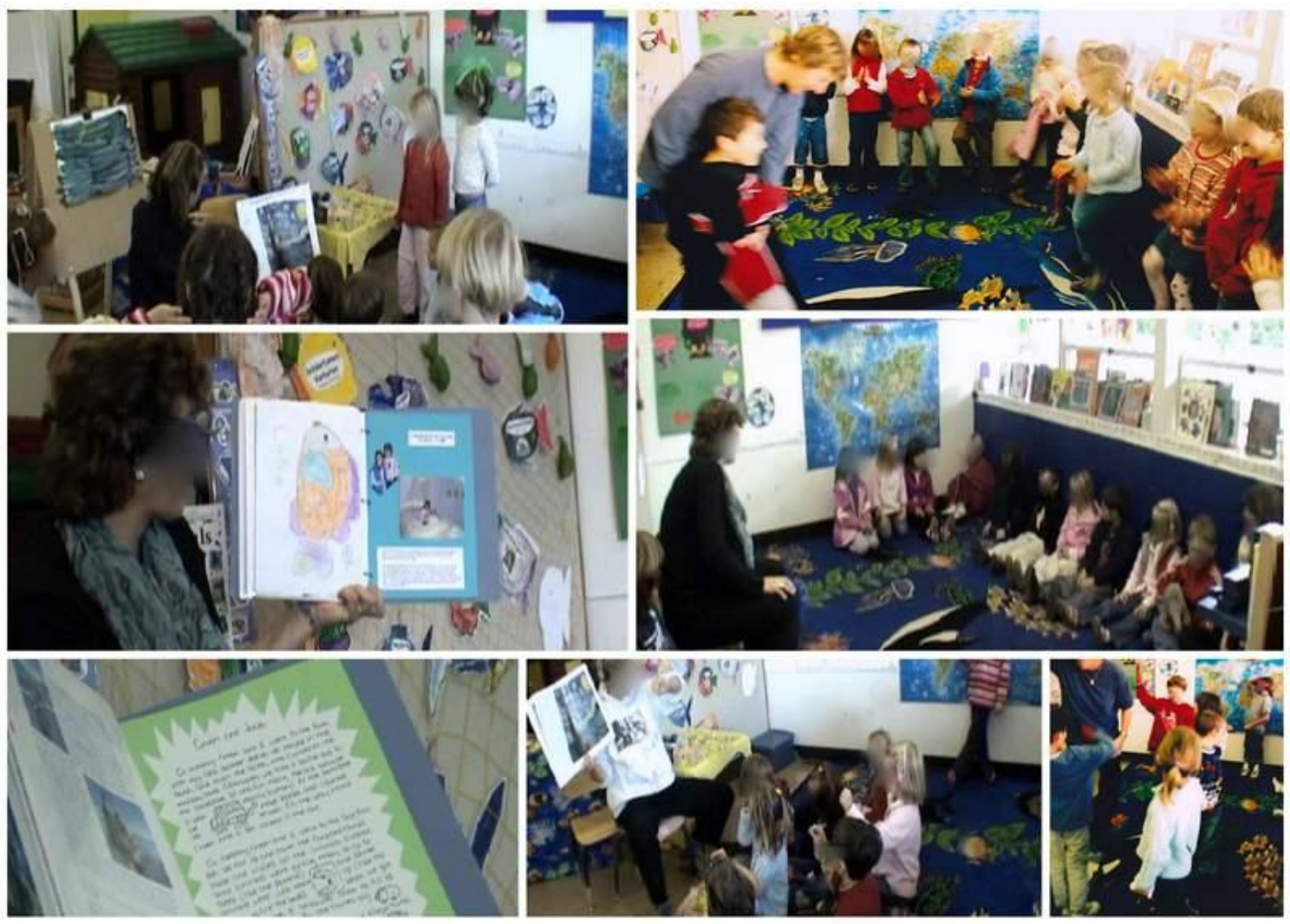

Figure 63. U.S.K.P.: Morning circle.

The teacher moves to the world map showing the children that she attached, as promised yesterday, a picture of van Gogh where he lived. She asks, "Das ist ...? (This is...?)," and Jan says first, "Europa (Europe)," while the others follow him. Leon says, "Da sind Oma und Opa (There are Grandpa and Grandma)." The teacher asks, "In Europa wohnen deine Oma und dein Opa? In welchem Land? (In Europe live your grandma and grandpa? In which country?)," and he answers, "Deutschland (Germany)." Then she shows the children where it is while moving her finger along the border.

"Aber wer weiß, in welchem Land Vincent van Gogh gelebt hat? (Who remembers in which country Vincent van Gogh lived?)" The children mention Paris and the teacher tells them that he moved there later in his live. She says, "Paris ist eine Stadt in Frankreich (Paris is a city in France)," 
while pointing to the city and showing the border of France. "Der kam aus den Niederlanden. Das ist ein bißchen über Frankreich (He was from the Netherlands. That is just above France)," she continues, showing it on the map. "Aber wer kam denn aus Frankreich? (But who was from France?)," and the children call out "Matisse." She asks a few questions which the group can answer with yes or no. Her first question is, "Leben die beiden noch? (Are they still alive?)" The children, shaking their heads, say "Nein (No)" and she says, "Richtig. Sind sie schon eine Weile tot? (Right. Have they been dead for a while?)" "Ja (Yes)," they answer.

She moves over to the time line, which has pictures of Matisse and van Gogh above their birth years, and she shows the children the life span of the artists. She explains, "Ihr seid hier um 2000 geboren, Diana und ich sind hier so geboren, Matisse hier und van Gogh hier (You were born here around 2000, Diana and I are born here, Matisse here, and van Gogh here)." The emphasis is on making certain that the children see the distance between themselves and the artists to learn understand time. She then shows the group, "Van Gogh hatte ein kurzes Leben, aber Matisse ein sehr langes (Van Gogh had a very short life, but Matisse a very long one)." Then she returns to her seat to read a story.

\section{Read-Aloud: Camille and the Sunflowers by Laurence Anholt}

\section{Translation}

1 HT: $\quad$ So, meine lieben Künstler und Künstlerinnen, ich möchte euch jetzt eine Geschichte vorlesen.

2 Leon: Schichte, schichte. Saying happily.

$3 \quad$ Könnt ihr alle kucken.

$4 \quad \mathrm{CH}$ : Ja moving into a theater style seating arrangment.

5 HT Das ist die Geschichte von Camille und den Sonnenblumen holding up the book so that the children can see the picture and looking at the cover opening the first page

Das ist eine Geschichte über Vincent van Gogh. Wer ist das noch mal?

6 Ch: $\quad$ Ein Künstler, Maler...

7 Luca: Der berühmte Künstler der immer..., der nicht in so gute Stimmung ist.

8 HT: Ja, er war ein bisschen launisch. Turns page and starts translating the book in German page by page. Wo Camille lebte, da gab es ganz viele Sonnenblumen und die wurden immer moving her hand into the air immer größer und die sahen aus

So, my dear artists, I would like to read a story for you now.

Meaning story, story.

Can you all see?

Yes.

This is the story about Camille and the sunflowers.

This is a story about Vincent van Gogh. Who was he again?

An artist, painter...

The famous artist who always ... who is not in such a good mood.

Yes, he was a little moody.

Where Camille lived there were very many sunflowers and they grew taller and taller and looked like real suns. 
wie richtige Sonnen. Showing the picture to the children again asking Sehen die aus wie richtige Sonnen?

9 Ch: Ja in a chorus

10 HT: Und ein ganzes Feld voller

Sonnenblumen. Es sah aus als würden die Sonnen brennen. Asking Sieht das nicht aus wie Sonnenblumen, Lea?

11 Lea: Nee, wie Lachblumen.

12 Leon: Nein, nur nach Blumen.

13 HT: Aha, nur nach Blumen repeating and turning the page

14 HT: Jeden Tag nach der Schule rannte Camille durch die Sonnenblumen, um seinen Papa zu treffen, und der war...asking Was war der denn? Was für einen Job hat der gehabt in diesem Ort?

15 Ch: A trainer.

16 HT: Ein Zugführer? Nein, er war kein Zugführer.

17 Luca: Ein Polizei.

18 HT: Ein Polizist war er auch nicht.

19 Niklas: Feuer.

20 HT: Nein, ein Feuerwehrmann war er auch nicht. Er hat Briefe ausgeteilt also war er?

21 Lisa Postbote.

22 Ja, ein Postbote richtig. Continues to read Sein Papa war der Postbote. Zusammen haben sie die schweren Postsäcke vom ... pointing to the train in the picture $\mathbf{Z u g}$ geholt. Asking Was haben sie dann damit gemacht?

23 Ch: Are not saying much...zu dem Haus says one.

24 HT: Die haben die Post sortiert und zu den Häusern gebracht. Continues to read Eines Tages kam ein merkwürdiger Mann mit dem Zug an, in den Ort wo Camille gewohnt hatte. Er hatte einen Strohhut, und einen gelben Bart und ganz schnelle braune Augen. Moving her eyes very fast while turning the page "Ich bin Vincent, der Maler" sagte er, und lachte Camille an. Vincent lebte in einem gelben Haus am Ende von Camille's Straße. Er hatte
Do they look like real suns?

Yes

And an entire field filled with sunflowers. It looked like the suns would burn.

Does that not look like sunflowers, Leas?

No, like laughing flowers.

No, only like flowers.

Aha, just like flowers.

Every day after schoole Camillie ran through the sunflowers to meet his father, and he was...

What was he then? What job did he have in his area?

Made up word

A train conductor? No, he was not a train conductor.

A police.

He was not a police man either.

Fire

No, he was not a fire fighter either. He handed out letter, so he was...?

Mailman.

Yes, a mailman excellent.

His father was the mailman. Together they would lift down the heavy sacks of mail from ...the train. What did they do with them?

To the house

They sorted the mail and brought it to the homes.

One day a strange man arrived with the train, in the place, where Camille lived. He had a straw hat, and a yellow beard, and very fast moving brown eyes.

"I am Vincent, the painter" he said and smiled at Camille. Vincent lived at the end of Camille's road in a yellow house. He had no money... 
kein Geld ...

25 Luca: Where ist der Vincent?

26 HT: Hier ist der Vincent showing him in the pictiure. Der Vincent hatte kein Geld ... und keine Freunde. Turning the page „Lass uns helfen“" hat der Vater von Camille gesagt. So haben sie den Wagen mit Töpfen und Pfannen und Tischen und Stühlen pointing to each one und mit solchen Sachen vollgemacht und haben ihn zum gelben Haus hingefahren. Camille flückte einen großen Strauß Sonnenblumen für den Maler and stellte sie in einen großen braunen Topf. Vincent fand das ganz toll und die beiden wurden super gute Freunde. Turning the page Vincent fragte Camille's Vater „Kann ich dich in deiner besten Postbotenuniform malen?" ...putting the book in her lap and taking the book Van Gogh by Mike Venezia from Getting to Know the World's Greatest Artists series showing the painting of the postman. Hier ist die Geschichte. Jetzt zeig ich euch mal was in diesem Buch drin ist. Opening it to the same picture. Kuck mal hier.

27 Marie Kuck mal hier. Showing another book cover to the teacher which she found on the window sill.

28 HT: Marie zeig mal her. Na du bist ja vielleicht ein Forscher. Schaut mal was die Marie entdeckt hat.

29 Jonas: Dieselbe.

30 HT: Dasselbe Bild.

31 Luca: Alles ist dasselbe Bild.

32 HT: Warum meint ihr ist das in mehreren Büchern?

33 Luca Weil das sind ganz viele Bücher von Vincent van Gogh.

34 Sophie: Und weil der ganz berühmt ist.

35 HT: Aha, und was meint ihr, ob das Bild dann ein berühmtes Bild ist?

36 Ch: Berühmtes Bild.

37 HT: Wenn dich einer malt, was musst du da machen?

38 Sophie: Du musst still bleiben.

39 Niklas: Ganz still bleiben.
Where is Vincent?

Here is Vincent.

He had no money and no friends.

"Let's help" said Camielle's father. Then they loaded the cart with pots, and pans, and tables, and chairs and such things, and brought it to the yellow house.

Camille picked a big bunch of sunflowers for the painter and put them in a big brown pot. Vincent was very pleased and they became wonderful friends.

Vincent asked Camille's father "Can I paint you in your best mailman uniform?"

Here is the story. Now, I will show you what is in this book. Look here. Look here.

Marie, bring it to me. Well, you are quite a discoverer. Look here what Marie found.

The same.

The same painting.

All are the same painting.

Why do you think it is in so many books?

Because these are so many books about Vincent van Gogh.

And because he is so famous.

Aha, and do you think that the painting is a very famous one?

Famous painting

If someone paints you what do you have to do?

You have to keep still.

Keep very still. 
40 HT: $\quad$ Erinnert ihr euch als wir unsere Schülerprofile gemacht haben. Da musstet ihr...da hatten wir doch die Lampe und da musstet ihr auf dem Stuhl ganz still sitzen.

41 Jonas Ganz still.

42 HT: Ich habe bemerkt, als ich euch abgemalt habe, dass sich einige Kinder immer bewegt haben. Moving around on her chair and then continuing to read a few pages

„Man muss aber sehr still sitzen" sagte Vincent. Camille liebte den Geruch der Farben und die kräftigen Töne, die Vincent benutzte. Camille sah erstaunt zu, als das Gesicht seines Vaters wie Magie auf der Leinwand erschien. Asking Was ist eine Leinwand? But when the children don't answer her saying Auf solche Wand malen die Künstler ihre Bilder drauf. Warte mal. going the storage cabinet to get the big canvas.

43 Luca: Gets up looking for the teacher saying Was ist eine Lienenwand?

44 HT: $\quad$ Returning with a sample Das ist eine Leinwand und darauf malen die Künstler ihre Bilder und wir werden nachher auch hier etwas darauf malen.

45 Ch: Getting very excited.

46 HT: Soll ich weiter erzälen? Children are getting quiet. Das Bild war eigenartig aber sehr hübsch. Vincent sagte, dass er gern die ganze Familie malen würde - Camilles Mutter, seinen großen Bruder, seine kleine Schwester ... Und dann auch natürlich Camille. Camille war sehr aufgeregt denn er wurde noch nicht mal fotographiert mit einem Fotoapparat. Explaining Damals gab es gerade die Anfänge von der Kamera. Es war noch nicht wie heute im Computer und ausdrucken. Nicht so wie eure Bilder pointing to the student's profile chart above the area. Camille nahm seine Bilder von Vincent van Gogh mit zur Schule. Damit sie alle sehen konnten. Aber die anderen Kinder mochten seine Bilder nicht. Sie begannen alle zu lachen,
Do you remember when we made our student's profiles? You had to ... then we had the lamp and then you had to sit still on the chair.

Very still.

I noticed when I copied you that some of the children always moved.

"But you have to sit still," said Vincent. Camille loved the smell of paint and the strong shades of color, Vincent used. Camille watched with interest, when the face of his father like magic appeared on the canvas.

What is a canvas?

On such a board artists paint their paintings.

Wait a second.

What is a canvas?

This is a canvas and the artists paint their paintings on it and we will paint on this one later.

Should I continue?

The painting was strange but very pretty. Vincent said that he would like to paint the whole family. Camille's mother, his big brother, his small sister....

And then also Camille. Camille was very excited as he did not even have his picture taken with a camera yet. Back then cameras were just at the beginning. It was not like today in the computer and printing. Not like your pictures...

Camille took his paintings from Vincent van Gogh to school so that everyone could see them. But the other children did not like his paintings. They started to laugh which 
was Camille sehr traurig machte. Nach der Schule ärgerten die ältern Kinder den Vincent.

47 Katja: Interrupting Die zeigen kein Respekt.

48 HT: $\quad$ Nee. Die zeigen überhaupt keinen Respekt.

49 Lisa: Und die lachen ihn aus. Saying very upset.

50 HT: Die lachen ihn aus und was machen sie noch nicht?

51 Sophie: Toleranz

52 Ch: Several children repeat Toleranz.

53 HT: Und was zeigen sie auch nicht?

54 Niklas: Mitgefühl

55 HT: Sie folgten dem Künstler als er zu malen ging. Sogar die Erwachsenen machten sich lustig und fügten hinzu ,Es wird aber Zeit für eine richtige Arbeit, anstelle dass du den ganzen Tag mit Farben spielst."

56 Leoni: Die sind nicht nett, aber.

57 HT: Camille schaute Vincent beim Malen zu. Es war sehr heiß, aber Vincent malte schnell. Er malte die Sonnenblumenfelder und sogar auch die Sonne selbst. „Er ist der Sonnenblumenmann“ sagte Camille zu sich selbst.

Aber es machte nichts wie schwer Vincent arbeitete, er konnte niemals ein Gemälde verkaufen. „Wenn ich viel Geld hätte, würde ich gern alle deine Bilder kaufen" sagte Camille. „Vielen Dank, mein Freund" lachte Vincent.

In dieser Nacht hatte Camille einen komischen Traum. Er sah Vincent im Mondschein hoch über der Stadt stehen. Vincent hatte Kerzen auf seinen Hut geklebt, so dass er sehen konnte. Der Sonnenblumenmann malte die Sterne. Stopping to read. made Camille very sad. After school the older children made Vincent angry.

They do not show respect.

No. They do not show respect at all.

And they laugh at him.

They laugh at him and what else are they not doing?

Tolerance.

Tolerance.

And what else are they not showing? Sympathy.

They followed the artist when he went painting. Even the grown-ups laughed at him and said "It is time for a real job instead of playing with colors all day."

They are not nice, but.

Camille watched Vincent painting. It was very hot, but Vincent painted fast. He painted the sunflower fields and even the sun itself. "He is the sunflower man" Camille said to himself.

But it did not matter how hard Vincent worked, he could never sell a painting. "If I had a lot of money I would buy all your paintings," said Camille. "Thank you very much, my friend" said Vincent smiling. At night Camille had a weird dream. He saw Vincent standing in the moonshine high above the city. Vincent had candles on his hat so that he could see. The sunflower man painted the stars.

\section{Group Painting Discussion and Activity "Starry Night"}

1 HT: So nun möchte ich, dass ihr euch das Bild hier pointing to the story book mal ganz genau anschaut. Dann schaut in diese Bücher und versucht ein ähnliches Bild zu finden. Es ist ein ganz berühmtes Bild. Handing a couple of books to the children who are excited and
Now I would like that you look at this picture very closely. Then search through these books and try to find a similar painting. It is a very well-known painting. 
search through the books.

2 Ch: Finding the painting very fast calling out hier. Hier ist es.

3 HT: Jan, bring mal euer Buch hier. Showing it to the group. Es heißt Starry Night. Was heißt denn das?

4 Luca: Sternennacht.

5 HT: Aha, Sternennacht. Schaut euch mal das Bild an. Was seht ihr denn auf dem Bild?

6 Ch: Sterne, Sterne

7 HT: Wie hat er die Sterne gemalt?

8 Lea: Mit weiß, und gelb.

9 Katja: Mit helle Farben.

10 HT: Mit hellen Farben. Könnt ihr noch was dazu sagen?

11 Emilie: Gut

12 HT: Hat er einen Stern gemalt wie ihr ihn malen würdet?

13 Ch: Nein.

14 HT: Sondern?

15 Leoni: Making circles with her finger saying Kreise.

16 Leon: Rund.

17 HT: Seht mal hier, er hat ganz viele Kreise. gemalt.

18 Jan: Nee, das ist der Mond.

19 HT: Aha, das ist der Mond. Und das? Und das? pointing to the other yellow circles

20 Ch: Sterne.

21 HT: Aha, Sterne. Meint ihr er hat mit seinem Pinsel einfach mal so her gemalt? Making one very long brush stroke.

22 Ch: Nein, Kreise, Muster

23 HT: Ja, Muster. Er hat immer nur ganz kleine Pinselstriche gemacht. Demonstrating brush strokes. Nehmt mal alle euren Finger hoch und zeigt mal euren Pinsel all show their finger Und versucht mal kleine Kreise mit kurzen Strichen zu malen

24 Lea: Nicht so einfach.

25 HT: Ja, gar nicht so einfach. Hat der gleich angefangen die Sterne zu malen.

26 Sophie: Nein, die Farbe muss erst trocknen und dann hat er die Sterne gemalt.

27 HT: Past mal auf, wir kucken uns das mal an hier.

Here. Here is it.

Jan, bring your book to me. It is called "Starry Night." What does that mean?

Starry night.

Aha, starry night. Look at the picture. What do you see?

Stars, stars.

How did he paint the stars?

With white and yellow.

With light colors.

With light colors. Could you add to that?

Good.

Did he paint his star how you would paint it?

No.

But?

Circles.

Round.

Look here, he made a lot of circles.

No, that is the moon.

Aha, that is the moon. And that?

And that?

Stars.

Aha, stars. Do you think he painted with his brush just like that?

No, circles, patterns.

Yes, patterns. He made small brush strokes always. Lift up your finger and show your brush. Und try to make small circles with short strokes.

Not so easy.

Yes, not very easy. Did he start painting the stars immediately?

No, the color has to dry first and then he painted the stars.

Watch, we will examine this here. Placing the book open showing Starry Night on 
her chair and moving the easel that was standing next to her closer into the area. Als erstes hat er sich eine Farbe für den At first he took a color for the Hintergrund genommen. Was hat er genommen?

28 Ch: Dunkle Farben.

29 HT: $\quad$ Painting the background with a big brush quite fast saying Zuerst hat er den Hintergrund ganz dunkel angemalt.

30 Ch: Ja.

31 HT: Wir malen das ganz dunkel. Sieht es jetzt schon so aus wie Vincent van Goghs aus?

32 Ch: Nein.

33 HT: Nee, find ich auch nicht. So und was hat er jetzt gemacht?

34 Sophie: Sterne darauf gemalt.

35 Jonas: Kreise

36 Ch: Kreise

37 HT:

38 Luca:

Luca, komm mal zu mir. Du darfst den Pinsel nehmen. Und mit welcher Farbe hat er die Kreise gemacht?

\begin{tabular}{|c|c|c|}
\hline 38 & Luca: & $\begin{array}{l}\text { Gelb starting to paint while the other children } \\
\text { are trying to see what he is doing. Making } \\
\text { yellow dots very carefully. }\end{array}$ \\
\hline 39 & HT: & $\begin{array}{l}\text { Super, danke schön. Was hat er jetzt } \\
\text { vielleicht noch gemacht? Leon. Komm mal } \\
\text { her. }\end{array}$ \\
\hline 40 & Leon: & $\begin{array}{l}\text { Starts painting and the teacher reminds him very } \\
\text { quietly to use small brush strokes which seems } \\
\text { to be difficult for him. }\end{array}$ \\
\hline 41 & HT: & $\begin{array}{l}\text { Okay, Danke. Hat er nur in Gelb gemalt oder } \\
\text { noch was anderes? Hands go up. Lea? }\end{array}$ \\
\hline 42 & Lea: & $\begin{array}{l}\text { Looking at the painting saying } \mathbf{H m m} \text {. Großes } \\
\text { Haus. }\end{array}$ \\
\hline 43 & HT: & Und was für Farben? \\
\hline 44 & Lea: & Schwarz. \\
\hline 45 & HT: & Sophie, was siehst du noch? \\
\hline 46 & Sophie & Ich sehe Wind. \\
\hline 47 & HT: & Wind, wie hat er denn den Wind gemacht? \\
\hline 48 & Ch: & Mit weiß. \\
\hline 49 & HT: & Leoni, was kannst du noch malen? \\
\hline 50 & Leoni: & $\begin{array}{l}\text { Looking at the painting in the book before } \\
\text { answering. Ein Mond. }\end{array}$ \\
\hline 51 & HT: & $\begin{array}{l}\text { Hat er den Mond mit kleinen oder großen } \\
\text { Strichen gemalt. }\end{array}$ \\
\hline
\end{tabular}

background. What did he use?

Dark colors.

At first he painted the background very dark.

Yes.

We paint this very dark. Does it look exactly like Vincent van Gogh's painting?

No.

No, I agree. So and what did he do now?

Painted starts

Circles.

Circles.

Luca, come over to me. You can take the brush. And with what colors did he make the circles? Yellow.

Great, thank you very much. What else did he do? Leon. Come here.

Okay, thanks. Did he only paint with yellow or another one? Lea? Hmm.

Big house.

And what colors?

Black.

Sophie, what else can you see?

I see wind.

Wind, how did he paint the wind?

With white.

Leoni, what could you add?

A moon.

Did he paint the moon with small or big strokes? 


\section{Ch: Mit kleinen.}

With small.

Leoni tries very hard to use small brush strokes while painting the moon. All children who come up have to concentrate on using small brush strokes. The teacher calls on a few other children before circle time is over.

\section{Free Play, Choice Activities, and Snack time (9:15 - 10:00 a.m.)}

As the circle time ends, the head teacher tells the group their room-the aquarium-is open. Sophie, who studied the picture in the book for a while, takes the brush and the mixing palette and adds to the painting (see Figure 64).

The teacher explains what the children can do today: "Wisst ihr was, die Kinder, die hier weiter malen möchten, können sich hier abwechseln und ein bisschen drauf malen und die anderen Kinder, die können jetzt hier drinnen mit dem Lego spielen, ihr könnt eure Bilder weitermachen, ... (You know what, the children who would like to continue painting, can take turns and add a piece, and the other children can play inside with Legos or you can carry on with your pictures...)." Lisa interrupts asking, "Welche Bilder? (What pictures?)," and the teacher tells her, "Die ihr vorhin angefangen habt, da auf dem Tisch, oder ihr könnt nach draussen gehen (The ones you started earlier, there on the table, or you can go outside)." Lea returns to her picture and so does Marie, while Lisa starts to work on one. Katja seems to work on Hannah's picture. Jan and Emilie are talking about what they will do someone says "draussen (outside)," and Jonas, Finn, Niklas, Leoni, Jan, Emilie, and Katja run outside immediately. Hannah and Marie are slowly leaving the circle time area and start finishing their shape picture.

Luca and Adrian are playing at the Lego shelf while Sophie is still painting. Lea and Marie are going outside and Lea returns in a second saying, "Sophie, Komm, Marie needs your help (come)." When the teacher sees Sophie and Lea standing in front of the easel she gets another brush asking, "Braucht ihr noch einen zweiten Pinsel dazu? (Do you need a second brush?)" She places it by the painting and Lea takes over painting because Sophie went into the creativity corner. Lea paints a thick white line with loops carefully across the painting. Marie asks her, "When you are done can I try?” and she replies, “Okay.” Marie waits very patiently for a few minutes. Meanwhile, Lea adds white dots onto her white line and yellowish ones on the sky.

Luca joins the pattern blocks activity where Hannah is working on her next card, and in the creativity area Katja, Jan, Emilie, Sophie and Lisa are busily creating Christmas presents for their friends and families. Lea, who has just passed on the brush and mixing palette to Marie, is telling her, "I saw a little mouse holding one of those..." when the teacher interrupts her saying, "Lea, Deutsch 
(German)." The girl remains quiet for a few seconds and then says to Marie, "Don't misch it (do not mix)." Marie replies, "Why did you?" "No, I didn’t, Sophie did it. You don't have to misch (mix)." Lea adds to her case and walks off. Marie adds a white line that is connected to Lea's as well as more white dotes. She searches for Lea outside and they talk about what they might do next.

In the creativity recycle area the children are busy gluing and Katja adds a new glue stick to her glue gun. Lisa has chosen part of an egg carton and she adheres red sticks to it. Jan asks Lisa, "Willst du noch basteln? (Are you continuing to craft?)," and she tells him, "Ich will noch das basteln für mich und dann noch eines (I want to make this for me and then another one)." The children accompany their steps with statements which are not connected. Lisa says a couple of times, "Ich bastle gern (I like to do crafts)." Emilie shows her frustration, "Der stick fällt immer raus. Was soll denn das? (The stick is always falling off. What is going on?)" Jan, working next to her, takes a little piece and Emilie tells him, "Das wollte ich gerade benutzen (I just wanted to use that)." Then he places it back on the table and searches the basket for something he likes.

Luca stops the block activity, joins the table, and uses an empty paper roll to glue legs on. He seems to search for glue sticks for the glue gun, but when he cannot find them he asks everyone at the table several times, "Ich brauche mal einen glue stick (I need a...)." No one reacts and he goes to ask the teacher. She fills the box up and leaves again. At the table the German speakers are on the left side and are talking all the time, while the English speakers like Marie, Luca, and Leoni sit on the right. Sophie is pointing to Katja's creation asking her, "Wie hast du das gemacht? (How did you make that?)," and she tells her in German. When Sophie is back at her spot next to Leoni she asks her, "Where did you find it?" meaning a little handmade figurine, and Leoni points to the basket.

Lea returns inside addressing the teacher with, "Weißt du was? (You know what?)" The teacher returns the question, "Was denn? (What is going on?)," and follows her to the door where the girl points to the big blue boxes standing in the corner. Lea says, "Ich möchte, dass da haben. Dadrin (I would like to have that. There inside).“ The teacher asks her, "Die Blöcke möchtest du haben? (You would like the bricks?)," while she adds happily "Ja. (Yes)." The teacher hands her one box after the other, which the girl places outside the door.

Hannah and Marie have been in and out of the circle time area. Marie is painting and Hannah watches her. Both refer to the book, in which the painting can be seen a couple of times. Emilie has finished her creation that she calls "blooby." It is a small piece of white material on which she glued big and small sea shells, a green star bow is glued into the big shell, and a few shiny pieces are scattered about. She gets a marker and asks the teacher, "Wie schreibt man blooby? (How do you spell blooby?)" 


\section{Translation}

1 HT: Pointing to the creation. Das ist schwer darauf zu It is difficult to write on it. schreiben. Pass mal auf. Taking a smaller piece of paper asking her Soll ich dir das mal hier drauf schreiben?

2 Lisa: Ja.

3 HT: Darf ich mal den Stift haben?

4 Lisa:

Ja. Handing the marker to the teacher while Lisa and Jan are watching the explanation.

5 HT: $\quad$ Writing the letter while explaining her action. Ein B. Dann kommt ein L. Blubby?

6 Lisa: Ja.

7 HT: Ein U. Ein B. Genau weiß ich das auch nicht, wie man das schreibt, aber ich würde es mal so schreiben. Ein B und dann kommt noch ein $Y$ dazu. Ja, so würde ich es schreiben. Blubby. Feeling a little unsure how to spell this invented word.
Should I write it on this?

Yes.

Could I have the marker?

Yes.

The letter B. Next is the letter L. Blooby?

Yes.

The letter U. The letter B. I am not a hundred percent sure how to write it, but I would write it like this. Blooby

Emilie starts writing the letters 'blubby' on her creation and checks the teacher's sample for each new letter before returning to the creativity area to add a few more things. In the meantime, Lea and Marie have been playing with the bricks. They placed a red blanket on the ground and now Marie hands Lea the jumbo bricks to build the house. Hannah has joined them but is only observing the girls.

\section{Translation}

8 Maria: Wait a minute. It has to be bigger now.

$9 \quad$ Lea: How? Checking for the teacher in the back, who is not there. Ich brauch noch das nächste. I need the next one.

10 Marie: Adding two bricks to the house.

11 Lea: No, no.

12 Marie: There has to be enough room for me.

13 Lea: Hmmm. Thinking and saying something like. You also have to be on foot.

14 Marie: Is not happy with the answer and stomps her foot

15 Lea: No, it is my house.

Marie turns around, walks to the big blue bow a couple of yards away, takes a seat, and pouts for a while. Hannah also walks off to the playground while Lea remains on the blanket with the 
bricks. They do not talk to each other for a few minutes and Marie, who is still upset, goes inside, takes a book from the window sill, and thumbs through it in the circle time area.

Lisa, Jan, Emilie, and Katja are still working, focusing on their creations without saying much. After a while Marie comes over and checks what they have been doing. Emilie tells Katja, "Das sieht ja so lustig aus (That looks very funny)." Katja responds with a smile. Lisa has finished her egg carton creation and tells Jan, "aber nicht kucken (but no peeking)," referring to the surprise she is making for him. He has gone outside when she asks him, "Kannst du auch noch was für mich machen? (Can you also make something for me?)," not noticing that he is gone. Katja tells her, "Das sieht aber schön aus (This looks great)," and Lisa agrees with her stating, "Ja, das ist fertig. Jetzt muss ich nur noch eines für Jan machen (Yes, this one is done. Now, I have to make one for Jan).”

Jonas and Niklas enter, still talking in English, and when Jonas recognizes it he says "Englisch raus (English outside)," running back to the door to leave it outside. Then he joins the boys at the Lego station. When Hannah comes into the room the teacher engages her asking, "Hannah, was willst du denn jetzt mal machen? (Hannah, what would you like to do now?)" The girl gives a shrug and the teacher suggests that she could work in the writing area, which she does. She searches for a copy in the copy section and takes the color wheel that they have been working on a couple of days ago. The painted wheels are now posted above the writing area and she gets colored pencils and starts coloring the first segment orange.

The boys Adrian, Finn, Jonas, and Niklas talk fast and loudly in English while constructing Lego trucks, airplanes, and the like. The loud talk lasts for only few statements, which are difficult to understand. Luca joins the group of boys.

\section{Translation}

\section{Jonas: I wanna keep it.}

2 Niklas: What is it that?

3 Luca: That ....that..holding his paper roll with two legs on the side and a Christmas tree ball ornament on top.

4 Niklas: What is it that? ... No what did you make.

5 HT: Englisch raus bitte. Saying from behind them. Meine Damen und Herren.

6 Leon: Englisch raus. ...Was hast du gemacht?...

7 Niklas: Was hast du da gemacht.

8 Luca: Eine...hmm das ist eine ...looking at it from all sides ...das ist so ein Ding, wo man kucken kann. Aber dies hier ist es wenn man es dunkel haben möchte.

English outside please. My ladies and gentlemen. English outside. What did you make? What did you make there? A ...hmm that is a ...that is a thing, where you can watch. But this here is it when one wants to have it dark. 
9 Finn: Looking through the roll handing it to Niklas
10 Niklas: Kann ich sehen? Kann ich sehen?
Can I see? Can I see?
11 Luca: Aber es ist für Dunkelheit.
But it is for darkness.
12 Niklas: Carefully looking into it.
13 Luca: Ich möchte es bitte wieder haben. Walking off with the toy.
14 Jonas: Others continue to play for a while and he says
Okay, guys not fair. Stop this is mine.
I would like to have it back.

While the teacher was outside the group spoke in English and Luca returned to the creativity corner to add something to his creation.

Outside, the house is finished and the girls have reconciled. Lea is sitting in the three foot high brick house and an orange blanket functions as a roof. Meanwhile, Leonie, Sophie, and Marie are sitting in the big blue boxes and each have a blanket as their roof. Momentarily, all girls are hiding and it sounds like Leoni is calling "daddy, daddy, come here." Sophie makes the suggestion, "Let's put our hand out." Marie meows, pretending to be a cat, and emerges from under the blanket seconds later along with Sophie and Leoni. Marie starts playing with Lea's roof. She reacts in annoyance with the following question, "Who has their hands on meine Decke? (my blanket?)"

A loud bang fills the room and all children check to see what happened by turning their head in the direction of the bang. Thousands of Lego pieces scatter on the ground everywhere. The teacher asks smilingly, "Und was nun? (And now what?)," and the boys return the smile knowing exactly what to say, "Aufräumen (Cleaning up)." "Na, dann mal los. Alle helfen mit (Let's start then. Everyone will help)," adds the teacher and she and the boys begin to clean up.

After most of the pieces are picked up she asks the group, "Wer möchte kann helfen beim Aufräumen, wir brauchen mal ganz viel Platz hier. Wer kann denn den Tische mit abräumen? (Who would like to can help clean up, we need a lot of space right here. Who will help cleaning up the tables?)" Hannah puts her marker down and helps the teacher, as do Marie, Lea, and Sophie. They put away the pattern block activity, and once they have finished the teacher pulls the tables away from each other. She then goes to the door and calls, "Alle Fische ins Aquarium (All fish into the aquarium)," and turns her head saying into the room, "Alle Fische bitte auf den Teppich kommen (All fish please come onto the carpet)." The children go to the circle time area and wait for the teacher to come. 


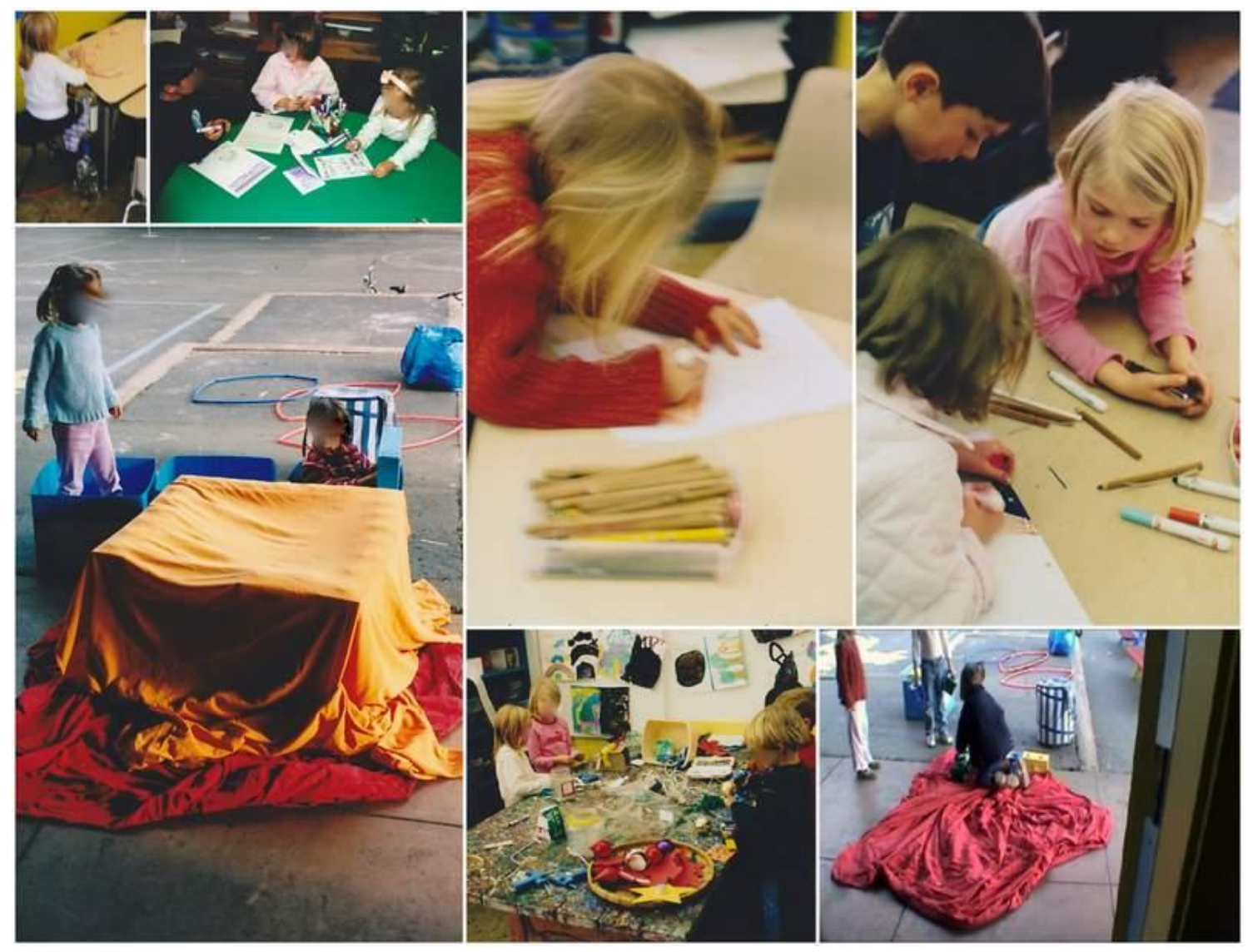

Figure 64. U.S.K.P.: Free play and choice activities

Main Project of the Day (10:00 - 11:30 a.m.)

\section{Painting "Starry Night" Discussion and Instruction}

1 HT: Singing: Es kommen alle hier zusammen. Es kommen alle hier zusammen. Wir fangen jetzt an. Then she adds So meine lieben Fische nun setzt euch mal bitte hin.

$2 \mathrm{CH}$ : The children are taking a seat on their own terms.

3 HT: Wenn wir den Leon noch da haben, dann können wir anfangen. Waiting for him $\mathrm{Oh}$, da bist du ja schon. Praising him. Heute machen wir mal ein Bild in dem Stil von dem Künstler ... Welcher Künstler eigentlich.

4 Sophie: Ah, ich weiß Henri Matisse.

5 HT: Hmm...searching for a different answer.

\section{Translation}

Everyone comes here together. Everyone comes here together. We will start now. ... So, my dearest fish. Please take a seat everyone.

When Leon gets here then we can start. Oh, there you are already. Today, we will create a painting in the style of the artist ... Which artist actually? Ah, I know Henri Matisse.

Hmmm...

No, I know ...tiny 
7 HT: Nicht winzig, aber so ähnlich....

8 Luca: Vin van Gogh

9 HT: Vincent van Gogh. Some children say it with her. Vincent van Gogh. Richtig. Heute machen wir mal ein Bild im Stil von Vincent van Gogh. Wir haben ja hier schon ein bisschen geübt. Pointing to the painting standing behind her. Die Kinder, die das gemacht haben. Was wir heute machen wollen... wir machen mal ein anderes Bild. Meint ihr eures muss genauso aussehen wie seins?

$10 \mathrm{CH}: \quad$ Nein. Looking at the picture she is holding up.

11 HT: Nein, shaking her head, aber was wir machen wollen, wenn ihr nachher malt, das ihr mal versucht, holding up a bigger picture of Starry Night, mit kleinen Strichen Wind oder Sterne zu malen. Showing with her finger Wenn ihr hier schaut ... es ist erst ganz dick and viel Farbe ... hier im Stern, und dann außen rum ... ganz kleine Striche.... Und auch den Wind hat er quer über das Bild gemalt mit ganz kleinen Strichen.

$12 \mathrm{CH}$ : Checking the painting very closely and nodding their heads while sitting or lying in any position or shape on the carpet but watching and listening very carefully.

13 HT: Was ich gemacht habe, damit ihr nicht ein so großes Bild malen müsst. Denn ein so großes Bild dauert ja ganz lange. Deshalb nehmen wir eine Abkürzung heute. Wir machen das alles ein bisschen kürzer. Ich habe euch schon den Hintergrund gegeben und ihr dürft euch gleich mal aussuchen, ob ihr einen ganz dunkelblauen Hintergrund oder einen ganz dunklen schwarzen Hintergrund möchtet. Holding up the paper samples.

$14 \mathrm{CH}$ : Calling out the colors at the same time Blau, dunkelblau, schwarz.

15 HT: Dürft ihr euch gleich aussuchen und dann habe ich gedacht für die Häuser, da machen wir auch eine Abkürzung

16 Luca: Eine Abkürzung. Repeating excited.

17 HT: Da habe ich schon Zettel hier. Holding up a 2

$18 \mathrm{CH}$ : by 2 square. Aber sieht das aus wie ein Haus?

19 HT: Was fehlt denn da noch?
Not tiny, but very similar...

Vin van Gogh

Vincent van Gogh. Well done. Today, we will make a painting in the style of Vincent van Gogh. We practiced a little with this one. The children who made it. What we will be doing today ... we will make a different painting today. Do you think it has to look like his?

No.

No, but what we want to do, when you paint later, is to try to paint the wind and the stars with small strokes. When you look here ... it is very thick and lots of paint ...here inside the star, and then around the outside ... very small strokes. ... And also the wind he painted across the paper with very small strokes.

What I did so that you don't have to paint such a big painting. Such a big painting takes quite a while. Therefore, we will choose a shortcut toady. We will make it a little shorter. I have given you the background already and you can choose in a minute, if you want an entirely dark blue background or a dark-dark black background. Blue, dark blue, black.

You can choose in a minute, and then for the house we will also take a shortcut.

A shortcut.

Here I already have the pieces. But does this look like a house? No.

What is missing here? 
$20 \mathrm{CH}$ : Several children raise their hands and call out das Dach, Dach, ein Dach.

21 HT: Wie bekomme ich ein Dach daraus? Calling on Leoni who was raising her hand.

22 Leoni: Explaining slowly while moving two fingers like a scissor Du könntest mal ein Dreieck ausschneiden.

23 Luca: Repeating the word Ausschneiden.

24 HT: Zum Beispiel, ihr könnt euch überlegen wie ihr es machen wollt. Ich habe hier schon ganz viele kleine Stücke hingelegt ... pointing to the table in the middle of the room und dann könnt ihr hier unten auf das Blatt euch eine Stadt machen. Wie ihr möchtet. Ein paar Häuser oder diesen riesigen Baum hier. Showing the tree in the painting. Zum Teil könnt ihr kleben oder malen. Das einzige, was ich von euch möchte, was ich vorgebe, ist das ihr alle mit kleinen Strichen oder Linien den Himmel, den Wind, und die Sterne malt. Jetzt könnt ihr eure Klebeflaschen und eure Scheren aus den Vorschulboxen rausholen. Dann könnt ihr euch ein Blatt aussuchen und dann könnt ihr anfangen.

Wer sich das noch mal anschauen will, wie man das mit den kleinen Strichen gemacht hat, kann sich die Bilder hier auf dem Bauteppich anschauen.
The roof, roof, a roof.

How do I get a roof from this?

You could cut out a triangle.

Cut out.

For example, the rest of you could think about how you would do it. I have placed here many small pieces ... and then you can create down here on the paper a city. However, you prefer it. A few houses or this big tree here. Practically, you can glue or paint. The only piece that I want you to do, what I request, is that you paint the sky, the wind, and the stars with small strokes or lines. Now, you can get out your glue bottle and you scissors from your preschool boxes. Then you can choose a piece of paper and then you can start.

If you would like to check again how that works with the small strokes then you can check the paintings back here on the carpet.

\section{Painting "Starry Night"}

All children shove and push in front of the shelf in the writing area. The teacher asks the children to step back and calls on the children who can get their box. Then the children find a seat and start choosing from the small, different sized pieces, and placing them in the middle of the table. Slowly the tables fill up and she asks, "Alle Kinder die blau möchten, nehmen bitte die Hand hoch (All children who would like blue, please, raise your hand)." As they get up she places a big piece of construction paper in front of them. A chorus of "Ich will blau (I want blue)" fills the room as the assistant enters. She starts organizing something in the back of the classroom. The teacher hands out black and many children have already started to glue pieces onto their paper or cut the roofs for the houses (see Figure 65).

The teacher asks the children to take out their glue as well as the scissors and to place these under their chairs so that there will be more space. Seeing that some children have problems finding 
scissors, she asks, "Habt ihr alle eine Schere? (Does everyone have a pair of scissors?)," and three children say "Nein (no)" while the others say "Ja (yes)," with Leon adding,"Ich habe scissors (I have...)." She then takes the book with the painting and asks the group, "Was kommt jetzt als nächstes? (What comes next?)" Marie, who raised her hand first, answers "Wir müssen die Stadt machen (We have to make the city)." "Richtig, die Stadt sollt ihr erst machen (Exactly, you should make the city first)," the teacher repeats and tells them to start the activity. Marie is asking, "Wie machen wir das Dach? (How are we making the roof?)" The teacher refers the question to Leoni, who had answered the same question before, and Leoni says twice "ein Dreieck ausschneiden (cut out a triangle)." "Gut, und wie bekommt man ein Dreieck aus dem Viereck? (Right, and how do you get a triangle out of the square?)," she continues to ask the children while observing their work. Seeing what Luca is doing she directs their attention to him. "Schaut mal der Luca hat eine Idee (Watch Luca, he has an idea)," she says while he is cutting the square diagonally. Another child adds that he has also an idea and the teacher praises him. Luca now holds up the two triangles he created and says, "So schneidet man eine Haus aus (That is how one cuts a house)." The teacher praises him for his idea. She continues by checking on the other children, and as she passes Marie, who shows her the same method, she praises her saying, "Da hast du eine gute Idee wie du ein Haus machen kannst (You have a good idea how you can make a house)," and Leon adds "Ich auch (Me too)," and Luca states, while holding a square and a triangle, "So macht man eine Haus (That is how one creates a house)." "Ja, sehr gut. Dann klebe dein Haus auf (Yes, very good. Then glue your house to the paper)," the teacher adds and the children seem to focus on their work, becoming rather quiet.

Some of the children are not using this method but rather cut out of the bigger squares pointed triangles or triangles which are bigger than the body square. It is all in the eye of the beholder and the creativity activity helps practice the understanding of geometrical shapes. The group at the blue table is having a problem as Leoni has almost all of the paper pieces in her possession while Marie and Lea explain to her in English that this is not right. Lea says, "No, no you are not allowed to have that much." And Leoni replies, "Everyone can have as many as they want." The teacher places additional pieces on the table and reminds the children, "Wir teilen und jeder bekommt ein paar Teile (We are sharing and everyone gets a few pieces)." Leoni puts a few pieces of paper back into the middle.

At the red table Leon is says in English, "I making my house in ...," turning his head to the teacher who is saying "Leon" and starts whispering "Englisch raus (English outside)." He turns his head toward the door to leave his words outside. She encourages them to make different kinds of houses and they concentrate on their work for the next few minutes. Then Jonas, who has cut two 
stars out of the squares, says to Leon in English, "look what I cutted out, I made a star," while placing it onto the upper part of his paper. He then turns his head to the teacher holding up a star and saying something that is neither German nor English. It seems like a mix of sounds and after a few seconds he says to her in German, "Schau hier. Ich habe ein Stern ausgeschnitten. Ein Stern (Watch this I have cut a star. A star)." The teacher seems surprised, repeats his statement, and asks him, "Was hatten wir gesagt, was wir mit dem Papier machen wollen? Erinnerst du dich? (What did we say we wanted to use the paper for? Do you remember?)" He nods, saying "Häuser (houses)," and she adds, "Die Stadt. Und womit wollten wir dir Sterne machen? (The city. And how did we want to make the stars?)" Jan, who is sitting next to Jonas, answers "malen (painting)," and Leoni adds "bunte Kreise (colorful circles)."

They continue to work and the assistant walks from table to table checking whether they need materials or help. She opens a couple of glue bottles for the few children who have a hard time getting glue out. On their big construction papers small cities or villages come into existence in different shapes, sizes, and colors. The assistant places brushes on each table and adds one color palette on each table for the children to share. Luca has finished his city and searches in his box under the table for crayons repeating several times, "nachher den Himmel malen (later color the sky)," while Lisa points to the paint in the middle trying to tell him, "Hier mit dem, Luca, hier mit dem (Here with these, Luca, here with these)." He comes up when he hears his name and understands what she is telling him. Then he takes a brush and starts painting while the other children continue to work on their villages.

The children can work at their own pace, and while others have already started painting, Katja is happy to have finished her first house with a door. She searches for the next piece she wants to glue and says, "Mein Haus ist da. Wo ist der Stamm? (My house is there. Where is the tree trunk?)," and Emilie looks at her work. Lea tells the teacher, "Ich habe meine Stadt gemacht (I have made my city)." The teacher answers, "Hmmm, Lea und jetzt? (Hmm, Lea and now?)" Marie adds "Berge (mountains)," then looking at Lea asks, "Did you do the Berge? (mountains?)." Lea returns to the teacher adding, "Ich brauche braun. Darf ich schon anfangen zu painten? (I need brown. Can I start to paint already?)" While at the other tables the children have been using paint for some time, this table is just now finishing their cities. The teacher tells her that it is her work and she can start when she thinks that it is ready. Then Lea decides, "Ich mache jetzt mal einen Star (Now, I will make a star)," and dips her brush into the yellow paint.

While the teacher brings more paint to the table Jan starts telling her: 


\section{Translation}

1 Jan: Mein Opa ist auch ein Künstler

2 HT: Dein Opa ist ein Künstler?

3 Jan: Aber, der ist eigentlich kein Künstler, der ist nicht berühmt aber.

4 HT: $\quad$ Er ist ein Künstler, aber er ist nicht berühmt.

5 Jan: Ja.

6 HT: Ja, aber.... is interrupted by him

7 Jan: Er ist ein Künstler und malt auch, aber die Bilder sind nur für mich.

8 HT: Oh, hast du die in deinem Zimmer hängen?

9 Jan: Ja, und im Buch. Painting with small strokes around the circle of the star.

10 HT: Und im Buch? Hmm. Wondering.

11 Luca: Meine Mama ist berühmt.

12 HT: Deine Mame ist berühmt?

13 Luca: Ja saying smilingly.

14 Jonas: Meine Papa...

15 HT: Die berühmte Anne ist deine Mama?

16 Luca: Ja saying smilingly.

17 Leon: Die berühmte Imke saying smilingly.

18 Jonas: Imke, meine Mama und mein Papa ...is... sind berühmt.

19 Lucas: Meine ganze Familie ist berühmt.

20 HT: Wau....das freut mich, dass ihr alle solche berühmten Familien habt.
My grandpa is also an artist.

Your grandpa is an artist?

But, he is not really an artist, he is not famous or anything.

$\mathrm{He}$ is an artist, but he is not famous.

Yes

True, but...

He is an artist and he paints also, but the paintings are only for me. $\mathrm{Oh}$, are they hanging on your wall?

Yes, and in a book.

Und in a book? Hmm.

My mom is famous.

Your mother is famous.

Yes.

My dad..

The famous Anne is your mom?

Yes.

The famous Imke...

Imke, my mom and my dad ... are famous.

My entire family is famous.

Wow...it pleases me that you all have such famous families.

The group returns to their task and Luca is already finished with his painting though he did not use any small strokes. Katja says, "Imke, ich habe auch Bäume gemacht (Imke, I also made trees)," and she adds that she could also add more houses: "Hier hinten liegt noch mehr, damit alle einfach rankommen (Back here are some more so that you can easily get to it)." The group is getting louder and the children are all talking at the same time when the teacher asks them, "Ich möchte jetzt mal sehen, ob ihr ein paar Minuten mal ganz leise arbeiten könnt (Now, I would like to see, whether you can work very quietly for a few minutes)." Immediately, it is very quiet and Niklas seems to try to ask for music, "Kannst du Musik...(Can you turn Music...)," and stops but his request is not heard. While the teacher reminds the children to speak with a very soft voice, Jonas gets up and checks the reference painting. Leoni does too. When he returns he uses smaller strokes while painting; the starry night painting must have reminded him to do so. 
The children whisper now when they are talking and this lasts a while. The teacher asks Leon to join her at the reference painting, making one long move across the picture and asking him, "Hat er den Pinsel genommen und einmal so gemacht? (Did he take the brush and go like this?)" Marie and Jonas stand behind them and watch. Leon's answer is "nein (no)." She continues, "Wir wollen ja mal versuchen es in der Technik von van Gogh zu malen ... immer mit kleinen Strichen ...Lass mich mal sehen, wie du mit kleinen Strichen malen kannst (We are trying to paint it in the technique of van Gogh ... always with small strokes...Let me see how you can paint with small strokes too)," demonstrating small strokes on the painting. Jonas, who listened to the teacher's suggestion, asks her, "Ich auch? (Me too?)" She tells him, "Ja, du auch (Yes, you too)," while in the background a few more voices can be heard, "Ich bin fertig. Fertig (I am finished. Finished)." She addresses the entire group saying, "Wenn ihr meint, dass ihr fertig seid, dann überlegt noch mal ganz genau, ob ihr noch mehr mit kleinen Strichen machen könnt (If you think you are done then think very hard whether you could use even more small strokes)."

The girls Leoni, Marie, and Sophie are using English with each other, while using German with the teacher. Emilie and Katja are not talking too much, but when they do they use German. At the blue table Leon, Finn, and Jonas use mainly English with each other while Jan and Hannah are not saying much. At the writing table Lisa holds the conversation in German when talking with Luca, Jonash, or Sophia. However, the teacher reminds the children to use German and the children say sporadically "Englisch raus (English outside)."

Lucas, Lisa, and Marie, who were in line holding their paintings to receive feedback from the teacher, all went back to their seats and started adding something here and there. However, the teacher chooses a few more children to come to the book and discuss the brush strokes. The children who are finished spent about 45 minutes on their painting then they get in line at the teacher's desk where she adds the children's names. She sends a few children back to add more to their paintings, while others place their paintings into the drying rack next to the sofa. Jan decides for himself that he would like to add some more and tells the teacher when asked, "Ich male noch ein bisschen (I will paint some more)." He takes his seat. Meanwhile, only Hannah, Finn, Leoni, Katja, Emilie, Niklas, and Sophia are busy working. Jonas, having just placed his painting into the drying rack, asks the teacher, "Jetzt müssen wir was machen? (Now, we do what?)" She tells him to wait one second while helping some children at the drying rack. 


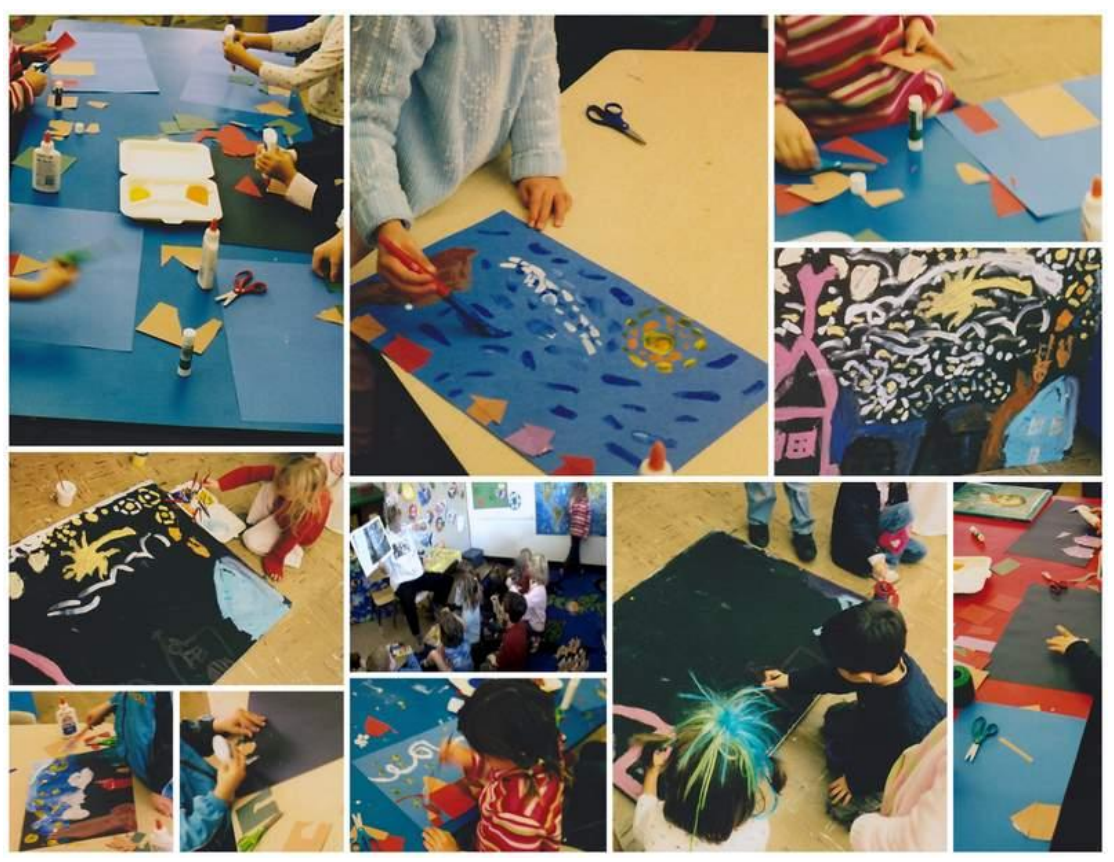

Figure 65. U.S.K.P.: Painting in the style of van Gogh.

\section{Group Painting "Starry Night"}

The teacher announces to the children, "Die Kinder, die jetzt schon fertig sind, die können sich hier einen Farbtopf aussuchen und hier unten auf der großen Leinwand malen. Ihr könnt ein Haus malen, so dass wir am Ende ganz verschiedene Häuser haben. Jeder kann ein Haus oder eine Kirche oder einen Berg malen (The children who are finished already can choose a paint jar and paint on the lower part of this canvas. You can paint a house so that in the end we have many different houses. Everyone can paint a house or a church or a mountain)." The canvas is about three by five feet and the children find a spot around it. Lea and Leon have a problem with the paint and the teacher gets involved in the solution process.

\section{Translation}

1 Leon: Stop, stop. Du hast mich angemalt.

2 HT: Lea, suggesting dann muss ich dir die Farbe leider wegnehmen. Weisst du, du kannst deine Worte benutzten, wenn dir irendwas nicht passt. Aber ein anderes Kind anzumalen, ist nicht okay.

3 Lea: Ich habe ihn nicht angemalt. Ich habe es nicht geseht. Ich habe es nicht geseht.

4 HT: Du hast es gar nicht gesehen? Was kannst du denn jetzt machen mit dem Leon?

5 Lea: Ich weiss es nicht.
Stop, stop. You painted on me.

Lea. Then I have to take away the paint. You know that you can use words when there is something wrong. But to paint another child is not okay.

I did not put paint on him. I didn't see it. I didn't see it.

You didn't see it? What could you do now for Leon?

I don't know. 
6 HT: Kuck ihn mal an. Kannst du mal mit ihm dadrüber reden? Musst du ihm das vielleicht sagen?

7 Lea: Looking at him Ich habe es nicht geseht. Entschuldigung.

8 Leon: Nods his head to accept her apology.
Can you look at him? Could you

talk to him about it? You should maybe tell him?

I didn't see it. Sorry.

The incident is quickly forgotten and the children continue painting their part of the group painting. The teacher reminds the children not to fill up the entire space so that the children who are still working on their painting have some space to add something. Leon paints a big yellow star while Jonas paints a light blue house and says, "Schau das große Haus an. Ich mach das Dach (Look at the big house. I am making the roof)." The teacher is involved in writing the names of the children on the backs of their paintings and misses his statement.

Only children who would like to participate in the group picture need to do so. She announces for the other children, "Wenn ihr euren Platz aufgeräumt habt und eure Vorschulbox weggeräumt habt und die ganzen Schnipsel aufgehoben habt, dann könnt ihr spielen (When you cleaned up your area, and put away your preschool box, and picked up all the clippings, then you can play)." The children are busy cleaning up their belongings while Emilie, Katja, Niklas, and Hannah continue to work on their projects. About fifteen minutes remain until lunch time.

Lea, Luca, and Sophie are still painting parts of the sky, when Luca asks the teacher, "Kann ich weiß und gelb mischen? (Can I mix white and yellow?)" The teacher gives him a mixing palette and says, "Darauf kannst du mischen (You can mix the colors on this)." Leoni joins the group painting activity after she finishes cleaning up her area and belongings. Lisa returns to the creativity area to continue working on her creations and is joined by Jan. Niklas, who has just finshed, says to the teacher, "Ich bin fertig (I am done)," and brings his painting to her so that she can write his name on the back. Leon, Jonas, Finn, and Niklas create something at the Lego station.

All children are engaged in their activities and continue to play, create, or paint for a few more minutes. The assistant teacher starts to wipe off the tables, which takes some time because of all of the glue and paint. In the meantime, Marie, Sophie, and Leoni have moved to the writing area and started writing little notes. Some English is coming from the Lego station and Niklas declares "Englisch raus (English outside)." However, Leoni is checking Sophie's paper saying "that is good," and Sophie is trying to read when Leoni explains "Das ist ein B (This is a B)," pointing to the paper. The teacher comes by asking, "Was macht ihr denn schönes? (What nice things are you doing?)," but they seem not able to express their activity in German. She notices and offers a suggestion, "Ihr bring 
euch schreiben und lesen bei (You teach each other reading and writing)," showing each action with her hands. Sophie replies with "ja (yes)" while the other two nod their heads. Emilie finishes her painting and the teacher encourages her to add something to the group painting. Lea joins the boys at the Lego station, but plays by herself.

\section{Project Feedback Chart}

The teacher, standing at the project feedback chart, calls on the students individually to have short conversations about the painting they were working on (see Figure 66). The children add a happy, neutral, or sad smiley face depending on how they feel about the project. She selects the children who are not overly focused on their activities.

1 HT: $\quad$ Niklas, kommst du mal kurz her? He comes Kannst du deinen Namen finden?

2 Niklas: Pointing to his name. Da.

3 HT: Wie hat es dir heute gefallen, Starry

4 Niklas: Gut.

5 HT: Gut, dann machst du was?

6 Niklas: Ein gutes Gesicht. Making a happy smiley face carefully.

7 HT: $\quad$ Ein glückliches Gesicht. Ja, sehr gut. Luca who has been waiting behind Niklas. So nun bist du daran. Lucas wie hat es dir gefallen?

8 Luca: Gut.

9 HT: Weißt du wo dein Name steht?

10 Luca: Hmmm, ja, über Jonas. Making a happy smiley face carefully.

\section{Translation}

Niklas, can you come over here for a second. Can you find your name?

There.

How did you like to make Starry Night?

Good.

Good, then you make what?

A good face.

A happy face. Yes, very good. Luca, it is your turn. Luca, how did you like it?

Good.

Do you know where your name is?

Hmm, yes, above Jonas.

The teacher thanks him and he returns to his activity while she continues to call the children who need to have not yet added their feedback.

Back in the writing area Leoni and Sophie are checking their names off the list and signing the paper. They show Marie how to do it, exchange the papers, and do it all over again. Their choice of language at the moment is English. Leonie hands Sophie a different piece of paper saying, "Please check on this." They do this back and forth and also include Marie. Sophie tries to hand a marker to Leoni, who is searching for something, saying "Here, you have to try this. It is a very good pen," but Leoni continues searching. Marie returns to the group painting and starts adding a few stars and different colors to the houses. 
The only one still focused on her painting is Katja, taking her time and using small brush strokes while using the paint. Jan, Hannah, Lea, and Lisa are working in the creativity corner and Jan is creating a little box using brown and red construction paper and asking, "Kannst du das einschneiden, so dass die Finger reinpassen? (Could you cut it so that the fingers fit trough?)" Lisa is cutting a red piece of paper and it looks as if she is making a small door. "Kannst du auch ein Dach machen? (Could you also make a roof?)," Lisa says, giving Jan a piece of red paper. Jan replies, “Oh, die Emilie ist schon so weit (Oh, Emilie got that far already)," checking out her house and giving a few suggestions. "So, geht solche Schachtel (That is how you make a box)," Jan says, and he returns to his spot. It seems tricky to glue the houses with the hot glue guns. One child has to hold the corners while the other glues the paper together. the glue does not seem to hold very well, and they try to stabilize the sides with additional paper. Katja moves to the group painting and adds some more brush strokes of color.

The assistant teacher calls for Emilie and Katja to clean up their space so that she can wipe the second table and the teacher says, "Wir wollen jetzt mal alle alles aufräumen, denn wir wollen gleich rausgehen (We will clean up together now, because we will go outside soon)." The children start cleaning up while Lisa says, "Da ist Tesa da (There is tape)," leaving the room to go to the next room and get tape for their construction. The teacher walks around the room and reminds them to clean up the stations. "Lea, es ist Aufräumzeit (Lea, it is time to clean up)," says the teacher while Jonas adds "Aufräumzeit, es ist so weit (Clean up time, it is time)." Then the teacher tells the group which children she sees actually cleaning up. After everything is done the children wait at the door for the sign that they can go outside. The teacher says, "Alle man ab nach draussen (Everyone, let's go outside)," and off run the children with the teacher following behind. 

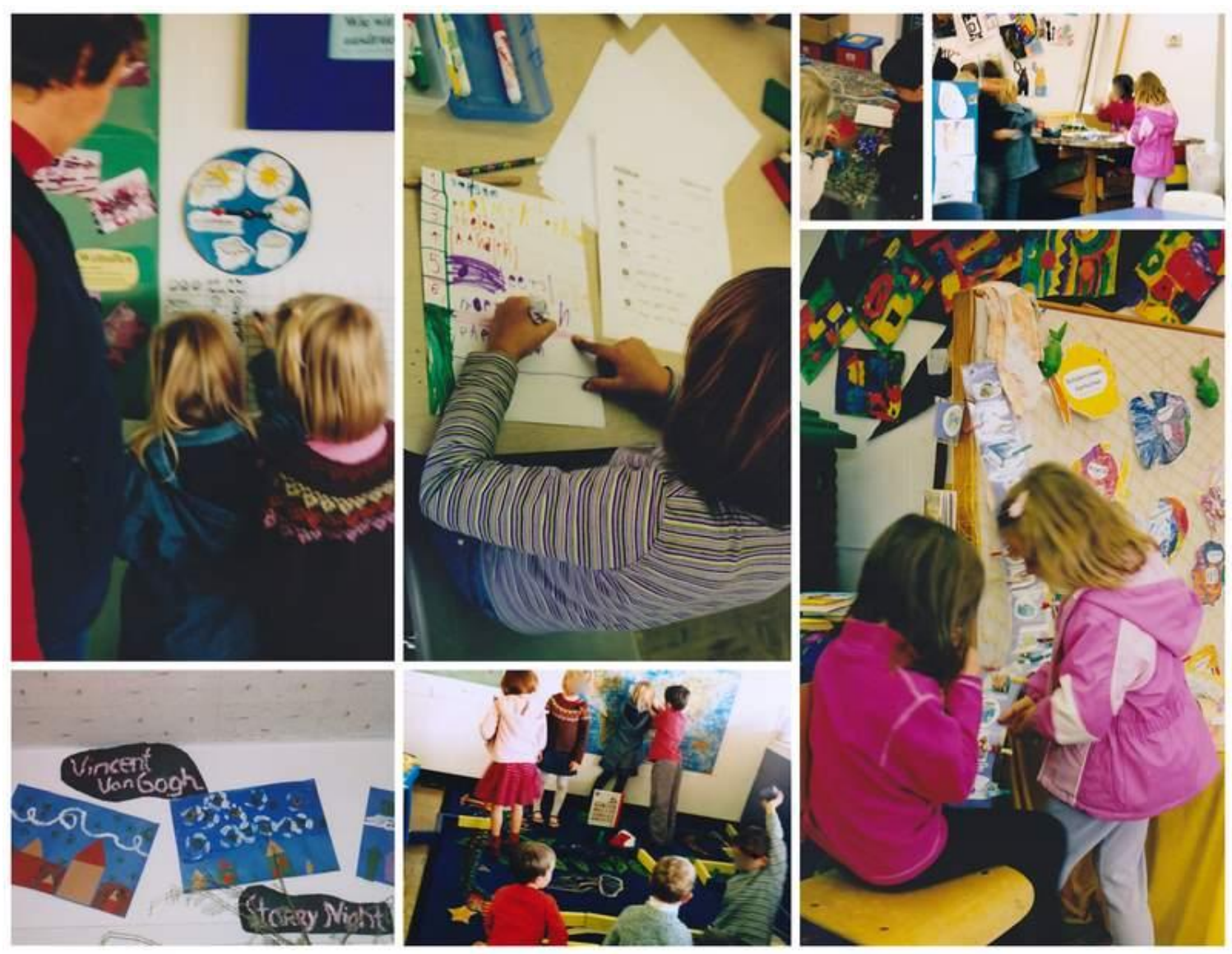

Figure 66. U.S.K.P.: Free choice activities and feedback chart.

Free Play and Choice Activities (11:30 -11:50 p.m.)

While the other children are playing on the playground four are in front of the classroom door. Lisa and Katja jump rope and Emilie and Jan wait for the jungle to open so that they can draw inside. When the teacher passes by she addresses the group.

1 HT: Was wollt ihr hier draußen machen? Was braucht ihr?

2 Jan: Wir warten bis der Jungel wieder auf macht.

3 HT Ihr wollt in den Jungel gehen.

$4 \quad \mathrm{CH}$ : Ja saying very excited.

$5 \quad$ Was wollt ihr da denn machen?

6 Ch: Malen.

7 HT: Wollt ihr denn was mit Farben oder Stiften malen?

8 CH: Mit Stiften.

\section{Translation}

What would you like to do out here? What do you need?

We are waiting until the jungle opens.

You would like to go into the jungle?

Yes

What would you like to do there?

Draw.

Would you like to use paint or markers?

With markers. 
9

10 Jan:

11 Girls: Nein.

12 Wenn du es willst Jan dann hol es dir. Du kannst deine eigene Entscheidung treffen. Oder ihr könnt weiter hüpfen.

13 Katja: Ich bin gestern zu viel gehüft. Papier von drinnen holt, und dann da auf der Bank malt?

\section{Ja.}

Wie ware es, wenn ihr euch die Stifte und

Katja and Lisa place the jump rope back into the cart and together they go inside to get the materials they want. The teacher, who is standing in the middle of the schoolyard, asks everyone loudly, "Möchte denn jemand das Ampelspiel spielen? (Would someone like to play the traffic light game?" The group turns their heads and thinks about it while Katja and Lisa already run excitedly to the teacher. Jan and Emilie go inside and get the markers, colored pencils, and paper. When they return and take a seat at the tables the teacher repeats her question and more children from the playground join the game. She explains to the children, "Ihr müsst euch dort an der gelben Linie aufstellen (You have to line up at the yellow line there)," while pointing to it. The teacher announces the traffic light colors with closed eyes, while the children choose whether to walk or to stay put. If she spots a child moving after opening her eyes, then the child has to go back a step.

Emma says to Jan, "Ich male etwas für Lisa, weil sie etwas Schönes für mich gemacht hat. Und dann noch eins, und noch eins (I will draw something for Lisa because she made something nice for me. And then another, and another)." Jan is listening but thinking about what he could draw. Finn, Luca, and Niklas were playing in the sand pit and are now running with their buckets and shovels across the schoolyard searching for a trash can. Luca repeats several times, "We have to find a trash can." They want to discard the materials they found in the sand box that do not belong there.

The teacher passes the game over, designating Marie as the leader while Lisa, Katja, Jonas, Sophie, Lea, and Leoni wait for the commands. They play a couple more times, changing the leader each time. Katja and Lisa return to the drawing activity, first seeing what has been done, then going inside to get their own paper. Then the game has fallen apart and the children return to the playground or sand pit.

Emilie, Jan, Lisa, and Katja all sit next to each other at the lunch tables with their backs to the sun. They are drawing and Lisa, who is watching what Jan makes, says, "Ich kenne ein blaues Flugzeug. (I know a blue plane)." A kindergarten group walks in pairs across the schoolyard to the school in the back and Emilie says, "Der Kindergarten, da waren wir früher (The kindergarten, we 
were there a while ago)." Katja recognizes the kindergarten teacher, calls her name, and waves to her. Emilie, recognizing that they are breaking one of the preschool rules, says "Hey, Die dürfen über die gelbe Linie (Hey, they are allowed behind the yellow line)." Lisa, a little upset, adds "Und wir dürfen aber nicht (And we are not allowed)." All watch the group walk away. The yellow line is right behind the table and separates the preschool schoolyard from the rest of the schoolyard.

"Jan, sieht das nicht aus wie ein Flugzeug? (Jan, does this not look like a plane?)," asks

Emilie. Jan takes a look, but does not say much. Then Lisa asks, "Wo sind die Fenster und Türen? (Where are the windows and doors?)," and Emilie answers, "Die will ich nicht machen (I won't make those)." Lisa adds, "Dann kann keiner rauskucken and auch keiner reingehen (Then no one can look outside and no one can get on)." Emilie changes her mind, "Ich werde noch hier eine Tür machen (I will make a door over here)."

The children are searching for different pencils in the box when Jan says out of the blue:

\section{Translation}

1 Jan: Solche Idi-oten, solche Idi-oten gibt es in meinem Ort. Solche Idi-oten gibt es in meiner Stadt. Solche Idi-oten.

2 Lisa Was sind I-di-oten?

3 Jan: Idi-oten sind Blöde.

4 Lisa Blöde Leute?

5 Jan: Ja, Blöde Leute, die lassen einfach einen Koffer auf der Straße stehen.

6 Lisa: Und wir haben einen Schatzkoffer.

7 Jan: Ja, aber da war nichts drin. Das sind Idioten.

8 Lisa: Ja, da waren Süßigkeiten drin. Saying to Katja. Doch ich habe die Fee gesehen, die da war. Die Fee hat Süßes reingezaubert.

9 Jan: Malst du ein Jumbo oder ein Flugzeug? Asking Emilie.

10 Emilie: Einfach nur ein Flugzeug.

11 Lisa: Ich fliege mit Lufthansa.

12 Jan: Ich auch.

13 Katja: Meine Oma ist auch in Deutschland, weil Lufthansa ist Deutsch.

14 Jan: Meine Mama will nur mit Lufthansa fliegen.

15 Lisa: Meine Mama will auch nur mit Lufthansa fliegen.

16 Jan: Und ich möchte immer mit British Airways fliegen.
Such idiots, such idiots are in my area. Such idiots are in my city. Such idiots.

What are idiots?

Idiots are stupid.

Stupid people?

Yes, stupid people, who leave a suitcase on the road.

And we have a treasure suitcase.

Yes, but there was nothing inside. These are idiots.

Yes, there were sweets inside. For sure I saw the fairy that was there. The fairy conjured sweets inside. Are you drawing a jumbo jet or a plane?

Just a plane.

I fly with Lufthansa.

Me too.

My Grandma is also in Germany because Lufthansa is German. My mom just wants to fly with Lufthansa.

My mom just wants to fly with Lufthansa also.

And I would like to fly British

Airways. 
The conversation ends and the children continue to draw on their airplanes adding windows, doors, staircases, and things they can think of connected to airplanes and flying. Marie, who is going to her big blue bag hanging on her hook, sings, "Heute ist es Pizzatag (Today is Pizza day)" over and over again and places a few wood pieces into the bag. At the drawing table all children join her singing very excitedly. The singing has spread from the playground area to the lawn area and now also to the writing table. Everyone knows there will be Pizza for lunch. An airplane flies over the area and it is quite loud. The children show no reaction while drawing their planes. Emilie and Katja start a new picture while Jan continues talking about airplanes and how they land, demonstrating that they land with their back wheels first and then with the front wheels touch down. Katja joins the demonstration. A second plane is flying over the area and will land at the airport about 20 miles away. The children look into the sky to spot the plane but it is difficult because they are looking right into the sun. Lisa says, "Das ist mein Fleugzeug (This is my plane)."

\section{Lunch Time (11:50 - 12:20 p.m.)}

The teacher calls for everyone to get ready for lunch, "Händewaschen, Mittagessen (Wash your hands, lunch time)." The children come in from the playground to go to the restroom and wash their hands, then they return they get a plate from the cart and get in the pizza line at the adjacent table. The children wait patiently in line to get their Pizza, which the assistant hands out. There are about five large boxes for both groups. The children then find a seat at the lunch tables and the teacher reminds them to get their drink from their lunch boxes. The teachers eat with the children and some children focus on their food while others tell stories in German or English, though the teachers always use German. They sit and eat in the sun under a blue sky, making this a nice and relaxing lunch time where the children can share stories with their teachers. On the minds of many is Christmas time and their upcoming travel plans are on the minds of many, and the teachers and students share these plans. When the children have finished they can either have another small piece from the pizza that is left or wait until all of the children at the table have all finished. Afterwards they return their plate to the cart and wash their hands before returning to their play.

\section{Free Play and Choice Activities (12:20 -1:15 p.m.)}

After lunch both groups together do a few physical education activities on the basketball field (see Figure 67). The teachers are standing on each side of the field to explain the tasks to the children. Imke runs back and forth on the field, then says, "Vorsichtig, bis zur Eva rückwärts laufen oder gehen (Carefully, run or walk backwards to Eva)." Niklas, Jan, and Emilie remain at the Lunch 
table. "Ihr wollt nicht mitmachen? (You do not want to join?)," asks Imke. Niklas answers, "Ich muss meinen Schuh zu machen (I have to tie my shoe)," and runs off to join the children. Jan says, "Ich möchte nicht (I don't want to)," and Emily just adds "Nein (no)."

Eva tells the group, "Galoppieren bis zur Imke (Gallop to Imke).” Imke says, "Und zurück bis zur Mitte laufen, dann Hüpfen (And run back to the middle, then jump).” The teachers ask the children for suggestions, and they keep running back and forth a few more times.

The teachers ask if they would like to play a game. The children want to play tag and they do for a while. Then one of the children suggests playing "Herr Fischer, Herr Fischer (Mr. Fisherman, Mr. Fisherman)." Imke tells both groups to find a space at the middle line. She chooses Finn to be the Fisherman and he comes over to her. The children call, "Herr Fischer, Herr Fischer welche Fahnen wehen heute? (Mr. Fisherman, Mr. Fisherman, which flags are flying today?)" Finn calls out very loud for the children to hear "Schwarz (black)." The children who are wearing black are safe and can get to the other side without problems. However, Finn tries to catch a child who does not wear black, which would make him the next Mr. Fisherman, and he succeeds by spotting Jonas. Jonas returns to his starting point and the game starts over again. After about 10 minutes of playing the teacher suggests to play another game or to play on the playground, and the children decide on the playground.

Most of the children are playing on the playground, in the sand pit, or on the lawn area and only a few return to the lunch tables to draw, play with the brick house built this morning, or paint at the easels. Katja and Lisa are swinging, Jan and Emilie are drawing more pictures, and Sophie and Lea are starting to paint at the easel station.

In the lawn area the children are examining and playing with the wood pieces left from a tree that had fallen over the previous week. It was cut down and removed, but there are enough interesting pieces left to be recognized by the group. Leon and Hannah were already playing here in the morning. Hannah collects the wood and makes a pile while Leon examines each piece. They start to collect branches and wood chips of all sizes. Leon brings a two foot long branch and says, "Look what I found." Hannah, Leoni, and Marie create a pile and study the bark of the branch. Leoni takes the branch and a big piece of bark comes off. She inspects the bark then places it back onto the area from where it came, but it will not stay so she places it next to the pile of wood and goes to find her own pieces.

The boys Luca, Niklas, and Finn empty their buckets into the trash and return with their empty buckets to the scene of investigation, continuing to dig with shovels to find the still covered roots of the tree. The language used is English and rarely a German sound can be heard. Luca and 
Niklas dig some more and bring their findings to the pile. When they find the roots everyone is very excited: "Look here, we found it"; "Here is the root"; "The root"; and similar statements sound across the schoolyard, and the teacher and a few children come to see. The teacher says, "Das ist aber eine große Wurzel (But this is a big root)," and the children repeat several times, "eine große Wurzel (a big root)." They continue to dig until free play time is over.

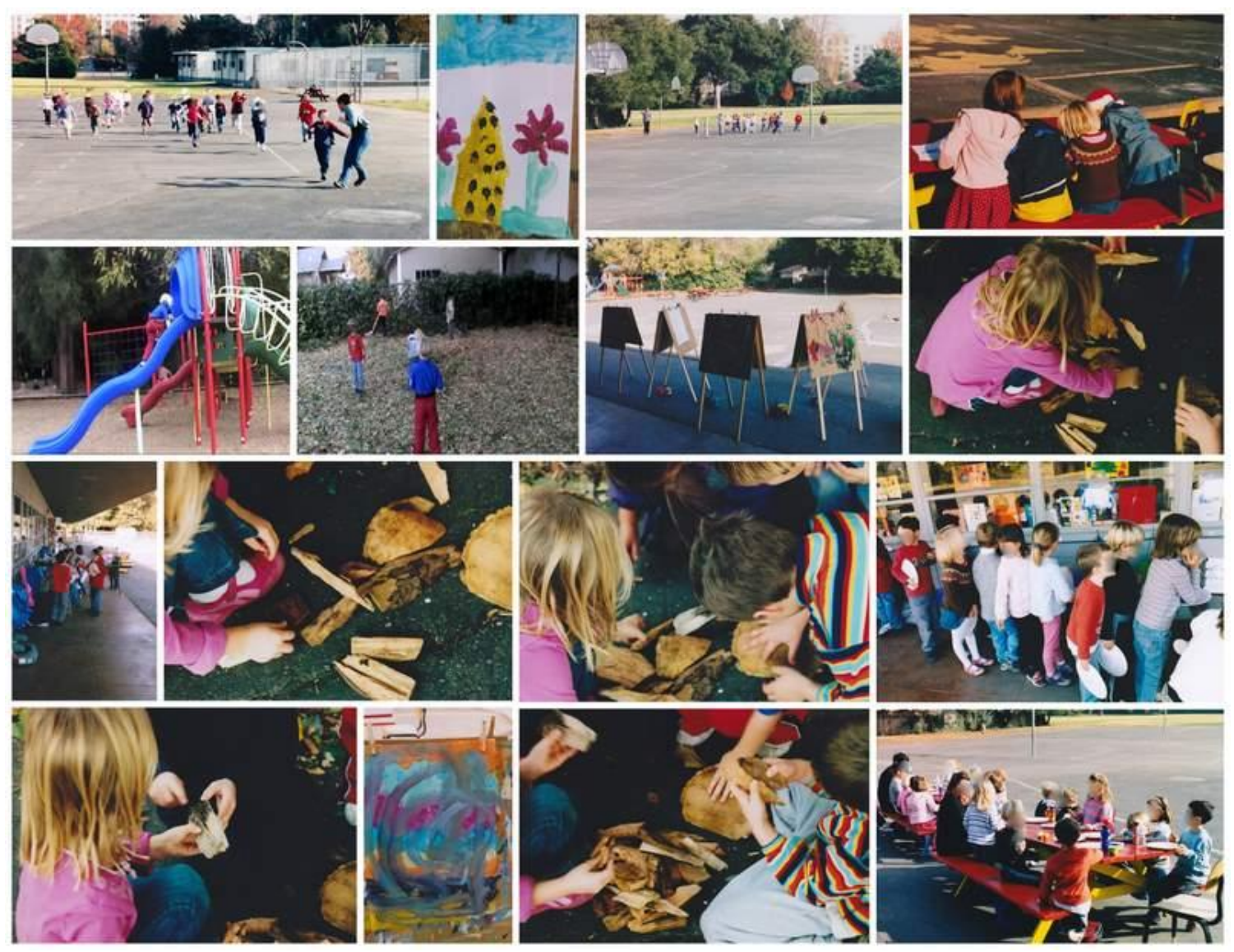

Figure 67. U.S.K.P.: Outside play time impressions.

Clean-up Time (1:15 - 1:20 p.m.)

The teachers walk around and tell the children, "Aufräumzeit es ist so weit (Clean up time, it is time)." Since most of the time was spent outside there is not much to clean up. Jan and Emilie need to return their markers and pencils. The children in the sand pit need to collect the shovels, buckets, and such. The children in the lawn area should also collect the shovels and buckets. The teacher assistant asks Sophie, Lea, and Marie to put the bricks into the boxes. When all is said and done the teacher calls the children inside and tells them to take a seat on the carpet so that circle time can begin. 
Closing Circle (1:20 - 1.55 p.m.)

The children are very exhausted from the playing and physical education activities. The teacher tells them to get a drink of water before circle time begins, and after a few minutes she takes a seat.

\section{Letter}

\section{Translation}

1 HT: Die Eva hat mir heute was gebracht showing a letter together with a picture of monkeys in a sheet protector Wisst ihr was das ist?

2 Finn: Nein.

$3 \quad$ Das ist ein Brief an die Vorschulkinder von Kids Saving the Rainforest. Und hier steht: „Dear Vorschul-Students, thank you very Eva brought me something today. much for your donation to plant and care for a Do you know what it is? No. This is a letter to the preschool children from "Kids Saving the Rainforest." And it says... tree in your name. ...

The teacher reads the entire letter in English to the children. They are learning that their efforts helped to plant more trees and that the goal is to plant over 12000 trees as reforestation and to save the lives of the Mono Titi monkeys, who call the Costa Rican rainforest their home. After she has finished the letter the children seem unsure of what to do. Some are joyous while others are still thinking about the content of the letter.

4 HT: Das sind die Affen pointing to the pictures Und ihr habt mitgeholfen, mit dem Geld, dass ihr verdient habt, einen Baum zu Pflanzen, damit diese Affen dort leben können. Und das ist pointing to the certificate in the back of the letter für euch Vorschulkinder.

$5 \quad$ All: Yeah. The group is more joyous now but a few still seem unsure.

6 Luca: Ist das, das riesen Poster?

7 HT: Eva hatte es versucht an diese Leute zu schicken aber konnte die Adresse nicht richtig finden, dann hat sie etwas anderes rausgesucht. Aber ich glaube wir haben noch genug Geld übrig, dass wir uns noch vielleicht ein großes Poster kaufen können

$8 \quad$ Yeah. The group is very joyous now.

9 Katja: Affen sind meine Lieblingstiere.

10 Finn: Meine auch.
These are the monkeys. Und you have helped, with the money that you earned, to plant a tree so that the monkeys would be able to live there. And this is for you preschool children.

Yeah.

Is this from the big poster?

Eva tried to send it to those people but was not able to find the address and then she found something different. But I believe we might still have enough money to buy a big poster. Yeah

Monkeys are my favorite animals. Mine too. 


\section{Artist Memory}

1 HT: Themawechsel und nun kommen wir zu unseren Künstlern zurück. Ich habe hier eine Memoryspiel. Wer von euch hat schon mal Memory gespielt.

$2 \mathrm{CH}$ : Ich sounds through the room and Jonas, Finn, Sophia, Lea, and Katja raise their hands fast and joyfully.

3 Katja: Ich habe ein großes.

4 HT: Ich habe ein Künstlermemory. Es ist aber noch sehr klein. Wie viele Künstler kennen wir?

$5 \quad \mathrm{CH}$ : Zwei, drei, zwei.

6 Marie: Looking at the pictures above the time line, counting. Eins, zwei, drei... counting also the group's pictures.

7 HT: Euch selber auch noch. Da habe ich vielleicht eine Idee

8 CH: $\quad$ Joyous repetition of Idee, Idee.

9 HT: Vielleicht können wir euch ja als Künstler miteinbringen. Wir haben eure Köpfe, die ihr gemalt habt pointing to the students' profiles across the room. Wir machen von den Profilen und von einem anderen Bild von euch noch Fotos. Kleben das Profil auf eine Karte und das Bild auf die andere. Wer hat mir die Idee gegeben? Marie, du hast doch gesagt, ihr seid auch noch dran, who is smiling das war ein guter Anstoß.

$10 \mathrm{CH}$ : Are very pleased with this idea. Yeah.

11 HT: Showing a card with a painting Welcher Künstler ist das?

$12 \mathrm{CH}$ : Vincent van Gogh

13 HT: Der Vincent van Gogh ist das. Richtig. placing the card up on the floor. Welcher Künstler ist das hier? Showing the card around the circle.

$14 \mathrm{CH}$ : Henri Matisse

15 HT: Woher weißt du das? Asking Katja Du hast das Bild doch noch gar nicht gesehen? Oder kannst du da durchschauen?

16 Katja: Putting her hands to the eyes demonstrating Durchschauen.

17 Marie: While Marie who is sitting in front of the time line shows to the artists above. Kuck mal.

18 HT: Showing a card with a painting Welcher

\section{Translation}

Moving on and now we will return to our artists. I have here a memory game. Who of you has played memory before?

I

I have a big one.

I have an artist memory. It is still very small. How many artists did we learn about?

Two, three, two.

One, two, tree.

You yourself also. Maybe I have an idea about that.

Idea. Idea.

Maybe we can include you as artists. We have your heads which you have colored. We will take pictures of your profiles and from another painting. Glue the profile on one card and the painting on another. Who gave me that idea? Marie you said that it is your turn now that was a good impetus.

Yeah.

Which artist is that?

Vincent van Gogh

Vincent van Gogh is that, well done. Which artist is that?

Henri Matisse.

How do you know that? You did not see the picture yet? Or can you see through it?

See through.

Look here.

Which artist painted that? 
Künstler hat das gemalt?

\section{$19 \mathrm{CH}$ : Vincent van Gogh}

20 HT: Wieso das?

21 Jonas: Weil das ist "Starry Night." While the other children repeat the title several times.

22 HT: Der Vincent van Goh hat das gemacht. Das ist also "Starry Night." Placing the card painting close to the painter on the floor. Welcher

Künstler hat das gemalt? Showing the card around the circle.

23 CH: Henri Matisse
Vincent van Gogh

Why that?

Because that is "Starry Night"

Vincent van Gogh painted that. Thus, it is "Starry Night"

Which artist painted that?

Henri Matisse

They play the short memory game a few times and it is very easy for the children. The teacher repeats the suggestion to add all the children and one of their paintings, which will make the game much harder, but adds a new match for now.

24 HT: Aber hier ist noch ein Künstler, den wir morgen besser kennenlernen. Er heißt Claude Monet und kommt aus dem gleichen Land wie Henri Matisse.

25 Luca: Das ist dann ein Freund von ihm.

26 HT: Richtig.

27 Sophie: Standing at the world map already and pointing to France Das ist hier.

28 HT: Richtig. Wie hieß das Land noch mal?

29 Ch: Frankreich.

30 HT: Ja, Frankreich, aber mehr über Claude Monet lernen wir morgen. Könnt ihr den Namen sagen?

$31 \mathrm{CH}$ : Claude Monet, Claude Monet. Repeating in a chorus

32 HT: Claude Monet hat diese Bild von einer Brücke gemalt.
But here is another artist about whom we will learn more tomorrow. His name is Claude Monet and he comes from the same country as Henri Matisse.

That is then a friend of him.

Correct.

That one.

Good. What is the name of the country again?

France.

Yes, France, but you will learn more about Claude Monet tomorrow. Can you repeat his name?

Claude Monet painted this painting of a bridge.

She adds the cards to the game and they play it twice, but it still seems easy for the children and they enjoy the activity. 
Visit with School Principal

1 HT: $\quad$ Ihr als Künstler dürft euch jetzt mal zu zweit an der Tür aufstellen und jetzt bringen wir mal unser Starry Night Bild, dass wir für den Direktor gemacht haben, und bringen ihm das mal rüber. Ich trage es rüber und ihr könnt es alle zusammen überreichen. Leading the group outside and a short walk around two corners and passing by first grade.

2 P: Oh, wau. Come in.

3 HT: Kommt mal rein.

$4 \quad$ P: $\quad$ Kommt mal rein. Das ist ja Klasse. Was ist

das überhaupt?

5 Ch: Starry Night.

6 P: Das ist "Starry Night." Wer hat das gemalt?

$7 \quad \mathrm{CH}: \quad$ Alle

8 P: Alle von euch. Das ist Klasse. War das der

9 Ch: Ja.

10 P: Das gefällt mir ganz toll. Habt ihr alle eure Namen drauf?

11 HT: Ja, die Namen stehen hier hinten. Es ist noch etwas feucht. Man muss vorsichtig sein.

12 P: $\quad$ So ein schönes Bild für meine neues Büro. Dankeschön

13 CH: Bitte schön.

14 HT: So ihr lieben Künstler nun lauf mal zurück ins Aquarium, wo die Eva und die Papageien vielleicht schon warten.
You as the artists can line-up with a partner at the door and now we will bring our "Starry Night" painting which we made for the principal to him. I will carry it and you can present it to him together.

Come in.

Come in. That is great. What is this actually?

That is "Starry Night." Who painted that?

Everyone.

All of you. That is great. Was this Vincent van Gogh?

Yes.

I like this very much. Did everyone sign it?

Yes, the names are on the back. It is still a little wet. One should be careful.

Such a beautiful painting for my new office. Thank you very much.

You are welcome.

Now, my little artists, please return to the aquarium where Eva and the parakeets might be waiting already. 


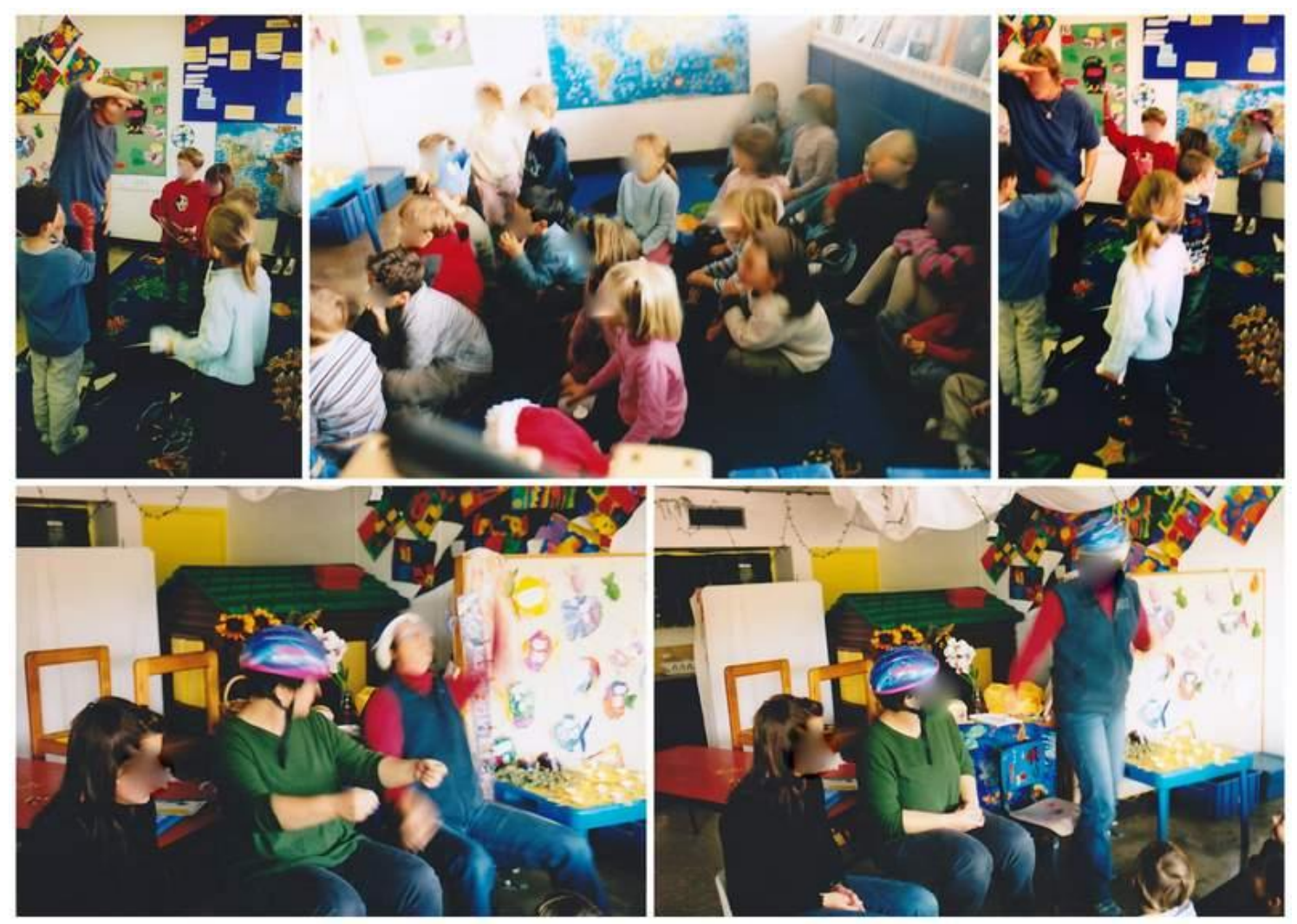

Figure 68. U.S.K.P.: Closing circle impressions.

\section{Storytelling: Christmas Party}

Both kindergarten groups join together for storytelling time, the last part of the circle time (see Figure 68). The parakeets enter quickly and take a seat on the carpet just after returning from their visit with the principal. Their teacher joins the other two teachers and takes a seat in between them. They continue the story from the day before, in which they were talking about the teachers' Christmas party at Eva's house. They mention how they got there in Diana's car with wheels as tall as her, that Imke needs shoes with springs so she can get in, what happened on the way, how they met the Nikolaus, how Diana behaved throughout the year, and what present she received.

1 HTF: Auf jeden Fall hat der Weihnachtsmann, der Weihnachtsmann repeating the word so that the children listen while the other teachers remind the children to listen. However it takes only a few seconds before everyone listens. Der Weihnachtsmann, der hatte da eine Liste in seinem Buch drin opening a book, squeezing the eyes, Das Buch sah ein

\section{Translation}

Anyway, Santa Claus had, Santa Claus ....

Santa Claus had a list in his book. The book he had was much more golden. He checked very carefully over Diana for a while. There were a lot of good things about Diana in the book, and then he went on to Eva 
bisschen goldener aus, dass er hatte. Naja, bei der Diana hat er die ganze Zeit ganz ordentlich gekuckt. All teachers nod in agreement. .... Über die Diana stand ja viel Gutes drin, und dann kam er zu der Eva und fragte ,hast du dich denn immer benommen?"،

HTP: Looking into the air and wonders for a few seconds Kann ich mal schnell überlegen, Nikolaus?...Im Winter waren wir noch gar nicht zusammen. Looking at her group... Im Frühling war ich in der Preschool...Ja, ja. ...Im Sommer hatte ich ganz lang Urlaub. ... Ja, ja, ... und dann fing die Schule an... thinking Ja, ja, ...seems convinced that she always behaved well.

3 TA Nun helft mal der Eva...saying to the children.

$4 \quad \mathrm{CH}: \quad$ Calling Ja

5 HTF: Oder soll ich mal in mein Buch reinschauen. Da...steht reading jeden Mittwoch erzählt die Eva immer Geschichten... asking the children Wißt ihr was da seht? immer die Diana vorweg.

HTP: Ja, weil doch die Menschen sind verschieden Nikolaus. Die einen Menschen sind mutiger. Kennst du die Schülerprofile?

\section{du. Es gibt Menschen, die sind mutiger.} Dann gibt es die Menschen, die immer erst wissen wollen, was passiert, die sind dann vielleicht nicht so mutig, aber vielleicht wissen die dafür mehr. Es gibt ganz viele verschiedene Menschen und die Diana ist halt so ein mutiger Mensch. Deshalb habe ich gedacht...

11 HTF: Pointing to the profiles posted on the wall Riskobereit.

12 HTP: Ja. Genau. Das nennt sich riskobereit und das ist halt die Diana.

13 HTF: Deswegen hast du dich immer hinter ihr versteckt?

14 Ich musste mich irgendwo verstecken, whispering wenn ich Angst habe. Ist das denn nicht so gut? asking her "Did you always behave?"

Can I think about it for a second? In winter we were not together yet, in spring I worked in the preschool. Yes, yes. In summer I had a long break. Yes, yes. And then school started ...yes.

Well, can you help Eva?

Yes

Or should I check my book. It says ... every Wednesday Eva tells stories. You know what it says next?

No.

When there is a problem you always send Diana in front.

Yes, because the people are all different, Santa Claus. Some people are very brave. Do you know the students' profiles?

No.

There are different profiles, you know. There are people who are very brave. Then there are people who want to know what happens first, who are maybe not so brave, but maybe they know a lot. There are so many different people and Diana is a brave person. Therefore, I thought...

Risk-taking.

Yes. Right. That is called risk-taking and Diana does.

That is why you were hiding behind her?

I had to hide somewhere when I am afraid. Is that not so good. 
HTF: Naja, nicht immer. Aber du hast schon viel Gutes gemacht. ...Beim Aufräumen im Kindergarten hast du den da immer mitgeholfen?

16 HTP: Ja, ja immer.

17 HTF: Was meinen die Papageien?

18 Ch: Calling Ja

19 HTF: Naja, da stand eine ganze Menge gute Dinge

20 HTP: Interrupting Nikolaus, kannst du mal bei den Papageien nachschauen, ob da drin steht, das sie manchmal ganz allein aufräumen auch ohne meine Hilfe.

21 HTF: Lass mich mal auf der Seite von den Papageien schauen?

21 TA: Oh, jetzt wird es spannend.

23 HTF: Hier steht drin...Die Papageie haben die Eva nach draussen geschickt, und die musste zählen, und dann hatten die eine Überraschung für die Eva. Die Überraschung war, dass die alles aufgeräumt haben. ...Und kuck mal hier ... showing the book to the other teacher da seht was über die Fische im Aquarium.

24 HTP: Holding the book. Nikolaus, whispering ich kann deine Schrift nicht so gut lesen. Handing book back.

25 HTF: Die Fische im Aquarium, da musste die Imke rausgehn, bis zehn zählen: teachers read it together eins, zwei, drei ...

HTP: Stimmt jetzt sehe ich es auch pointing into the book.

27 Finn: Leans forward trying to check the book too.

28 HTF: ...neun, zehn und dann war immer alles aufgeräumt.

29 HTP: Das ist ja ganz ähnlich. Steht da denn immer? Checking the book. Nee, da steht manchmal.

30 HTF: Ja, da hast du recht. Reading Manchmal haben sich Kinder auch unter den Tischen versteckt und nicht mitgeholfen.

31 TA Oh, wirklich nicht mitgeholfen? Was?

32 CH: Saying separately Ich noch nie. Turning into a chorus of Ich noch nie.

33 HTF: Naja, jedenfalls hat sich der Nikolaus hauptsächlich, um die Eva gekümmert, und festgestellt, dass sie auch was aus seinem Sack kriegen sollte. Dann hat er den Sack da gehabt. Showing the size of the bag with
Well, not always. But you did many good things. Did you always help during clean up time?

Yes, yes always.

What do the parakeets think?

Yes.

Well, there were a lot of good deeds about Eva. And then he took his...

Santa Claus, could you check under the parakeets, whether it says that they sometimes clean up without my help.

Let me check the page of the parakeets.

Oh, now it is getting interesting.

Here it says: The parakeets send Eva outside, and she had to count, and then they had a surprise for her. The surprise was that they had cleaned up everything. And look here there is something about the fish in the aquarium.

Santa Claus, I cannot read your writing so well.

The fish in the aquarium. Imke had to go outside and count until ten: one, two, three...

Right, now I see it too.

Nine, ten and then everything was cleaned up.

That sounds very similar. Does it say always? No, it says sometimes.

Yes, you are right. Sometimes, the children were hiding under the table and did not help.

Oh really, did not help? What?

I never did that.

Well, anyway Santa Claus was mainly concerned with Eva, and decided that she should also get something from his bag. He had the bag right there. Then he put his hand 
her hand and continues to express the word with gesture Dann hat er seine Hand ganz, ganz nach unten in den Sack gesteckt und musste da unten richtig rumwühlen.

Whispering dann kam er raus und hatte ein Geschenk das war so groß. Nicht wie Dianas

HTP: Dianas ist ja so groß. Reaching with her hands over her head showing how big it was.

Und es ist ja gewachsen. Meines ist so klein. Showing the size with four fingers.

35 Ch: Was ist das?

36 HTF: Was ist denn das? Hast du es schon aufgemacht?

37 HTP: Nein. Das steht unterm Weihnachtsbaum.

38 HTF: Sehr gut. Dann hat der Nikolaus es ihr in Hand gegeben und was hat sie dann gesagt?

39

40

Ch: Danke.

HTP: Ich habe gesagt vielen Dank! Moving her intonation up. Nikolaus. Und habe mich so gefreut, dass ich auch ohne Imkes Sprungschuhe ganz hoch gesprungen bin. So... She started jumping very funny up and down, which made the children and teacher laugh.

HTF: Der Nikolaus hat nur gesagt „Eijeijei“ und hat über seinen Bart gestrichen

HTP: Aber ich bin manchmal so neugierig, dass ich es kaum erwarten kann. Aber ich darf es noch nicht aufmachen. Erst an Weihnachten.

Ch: Können wir es sehen? Several children ask very excited.

HTF: Naja, vielleicht nach Weihnachten. Es liegt doch noch unterm Weihnachtsbaum.

HTP: Dann kam die Deutsch-Anke vorbei. Sie kam dann auch noch rein zur Feier. Ihr hättet sie sehen müssen, die hat sich hier überall Federn hingehängt, und die kam reingeflogen. Nee, Anke! Und was hat denn der Nikolaus zu dir gesagt? Weisst du das noch? deep down into it and had to search for a while. Then he appeared again and had a present that was this big. Not like Diana's...

Diana's is that big. And it grew, too. Mine is small like this.

What is it?

What is it? Did you open it already?

No. It is under the Christmas tree.

Very good. Then Santa Claus gave it to her and what did she say.

Thank you.

I said thank you very much. Santa

Claus. And was so happy that I jumped very high even without Imke's jumping shoes.

Santa Claus said while stroking his beard "Goodness, gracious."

But I am very nosy sometimes that I can hardly wait. But I am not allowed to open it. Only at Christmas.

Can we see it?

Well, maybe after Christmas. It is still under the tree.

Then the German-Anke came by. She joined the party too. You should have seen her. She had feathers everywhere and flew inside. Really, Anke! And what did Santa say to you. Do you remember?

First, Santa didn't know that I am the German-Anke. He thought I am a big white Bird with all the feathers. "Okay, if you are a bird, then I will give you a very small package." Well, I thought hmm okay, then I opened the package ... 
HTF: Hhh. Du hast deines aufgemacht? Looking at her.

HTP: Vor Weihnachten? Looking at her very surprised.

GH: Ja, ich war ja ein Vogel. Wisst ihr was im Paket drin war? Asking the children.

All: Nein.

$\mathrm{GH}$ : Vogelfutter.

HTP: Da haben wir doch angefangen zu kichern. Saying smiling to HTF.

HTF: Dann haben wir gefragt, ob wir einen Sonnenblumenkern abhaben können. Continuing laughing at the HTP.

$\mathrm{GH}$ : Und ich war ein bisschen sauer. Ich bin ja kein Vogel. Ich hatte mich ja nur als Vogel verkleidet.

HTF: Naja, und im nächsten Moment haben wir ihr geholfen, haben die Flügel abgemacht, und dann hat der Nikolaus gesagt „Ach ja, du bist ja die Deutsch-Anke." Er hat sein goldenes Buch rausgeholt und dann stand da irgendwas drin... von einem kleinen Stofftier...inviting the children to fill in the name.

Ch: $\quad$ Saying separately Schnuffi. Turning into a chorus of Schnuffi, Schnuffi.

HTF: Da stand drin, dass die Anke, immer den Schnuffi mitbringt. Richtig?

Ch: Ja.

HTF: Und dann stand da noch was...englische Sprache. Was meint ihr wohl, was darüber drin stand? ... Englische Sprache...bei der Deutsch-Anke? ... Answering herself because it is a new idea for the children. Da stand drin, dass bei den Deutschkindern spricht sie nie die englische Sprache. Stimmt das?

Ch: Ja.

HTP: Aber da steht doch noch mehr. ...Bald wird die Deutsch-Anke zur Englisch-Anke. Hmm Wie geht denn das?

\section{GH: Na, da habe ich einen Trick. Soll ich ihn} verraten?

Ch: Ja saying in a chorus while one child adds für die Erstklässler bist du die English-Anke.

$\mathrm{GH}$ : Ja, richtig, da gehe ich rein und spreche Englisch und dann treffe ich draussen Deutschkinder und spreche nur Deutsch.
Hah. You opened yours?

Before Christmas?

Yes, but I was a bird. You know what was in it?

No

Bird seeds.

That is when we started laughing.

Then we asked if we could have a sunflower seed also.

And I was a little upset. I am not a bird. I just dressed up as one.

Well, and in the next moment we helped her, got the wings off, and then Santa said "Oh, you are the German-Anke." He took his golden book out and it said something about a small stuffed animal...

Schnuffi.

It said that Anke always brings Schnuffi. Right?

Yes.

Then it said something else about ... the English language. What do you think it said about that? English language ....Here it says that she never speaks the English language with the German children.

Yes

But there was much more ...Soon the German-Anke will be the English-Anke. Hmm, how does that work?

Well, I have got a trick. Should I tell you?

Yes. For the first grader's you are the English-Anke.

Yes, right, I go into the class and speak English and then outside I meet German children and speak only German. 
65 HTF: Kriegst du kein durcheinander?

66 GH: Manchmal schon, aber ich habe einen Geheimtrick. Wer weiss den Geheimtrick noch von den Deutschkindern?

HTF: Naja, und dann hat er gesagt, für die Deutsch-Anke habe ich auch ein Geschenk. Whispering Dann hat er wieder seinen grossen Sack genommen und ein schönes rausgezogen. Das war so lang und das wurde so hoch, und höher, und höher looking up to the ceiling das sah aus wie ein Rechteck.

72 Luca Das ist vielleicht das gleiche, wie die Diana bekommen hat.

73 HTF: Nee, nee, denn Dianas ist ja gewachsen.

74 HTP: Und war auch rot und grün. Welche Farben hatte deines?

75 GH: Gold und Silber, glaube ich. Mit einer riesigen Schleife.

76 HTP: Das war wieder so eigenartig. Das hatte er wieder aus diesem ziemlich kleinen Sack für so große Geschenke.

HTP: Ja.

HTF: Naja, dann hatte ...

TA: Die Imke kam ganz am Schluss dran.

$\mathrm{GH}$ : Sie war geduldig, aber wurde schon ein wenig ungeduldig.

HTP: Dann hatte er wieder sein Buch genommen, und rein gekuckt und gekuckt und hat gesagt „Imke...aha....aha hmm...ja...Schwimmen also? Schwimmen magst du ganz gern?

83 HTF: Nee, nee nicht mit den Kindern. Wir haben ja hier keinen Swimmingpool.
Are you not getting confused?

Sometimes yes, but I have a secret trick. Who of the German children remembers the trick?

A secret trick should never be revealed.

The school children know it already. They have not told you yet?

No. A button on the head.

Yes, right. I have a button up here on my head. I turn on the English button when I speak English and I switch it back to German when I have to speak German. And then I do not mix it.

Well, and then he said that for the German-Anke he had a present too. Then he took his big bag again and pulled out a beautiful one. It was so wide and got so high, and higher, and higher. It looked like a rectangle.

It is maybe the same one Diana got.

No, no, because Diana's grew, really.

And was red and green too. Which colors was yours?

Gold and silver, I think. With a big bow.

That was very strange again. He got this again out of a small bag for such big presents.

Well, then he had...

Imke was the very last one.

She was patient, but became slowly impatient.

Then he took his book again, and looked and looked into it, and said "Imke, ....aha.....aha ...yes.

Swimming right? Swimming is what you like?

Yes.

But you don't do this with the children here?

No, no not with the children here. We don't have a swimming pool. 
HTP: Ja, ja. Hier steht, dass du immer sehr fleissig bist. Immer früh aufstehst, wenn es noch dunkel ist auch wenn es bitter kalt ist und dann schwimmen gehst. Ganz viele Bahnen. Wie lange schwimmst du denn? Ich hatte ja nie so lange Zeit umzuzucken, hat der Nikolaus gesagt, weil du so lange schwimmen gehst und ich muss ja allen Menschen auf der Erde zu kucken, da habe ich nicht so viel Zeit.

\section{HTF: Ein Stunde am Tag.}

HTP: Das ist aber sehr lange.

HTF: Dann habe ich immer ganz kalte Füsse am Ende.

HTP: Dann seht hier noch, dass du ganz gut für deine Kinder sorgst. Ja, das Frühstück essen sie immer ganz gern von dir, aber dein Abendessen nicht so. Deswegen hilft dir dein Mann ganz viel beim Kochen.

HTF: Kochen ist nicht sowas, was ich sehr gerne mache.

HTP: Aber dafür schwimmst du ganz gut. Talking to the children, Merkt ihr, die Imke ist auch ein Mensch. Manche Sachen kann man ganz gut, und anders nicht so gut. Das ist bei uns allen so.

HTF: Richtig

HTP: Hier steht noch als letztes, dass du ganz viel Spass hast mit den Kindern.

HTF: Haben wir Spass hier? Nein...

Ch: Ja, ja, ja

HTF: Kuck doch mal in deinen Sack rein lieber Nikolaus.

HTP: Da steht hier, dass du manchmal etwas ungeduldig bist. Denkt ihr das da etwas für die Imke im Sack ist?

\section{Ch: Ja, ja, ja}

HTF: Rate mal was das für eine Form hatte?

HTP: Der Nikolaus hat den Sack genommen, sich noch vorn übergebeugt und ganz tief im Sack gegraben.

HTF: Ich dachte, der kommt, da gar nicht wieder raus. So lange hat er gesucht.

HTP: Wo ist es denn? Hat sich da in der Ecke versteckt. Liebe Imke, du bekommst ein
I see. Here it says that you are always hard-working, always getting up early when it is still dark outside, and also when it is very cold then you go swimming. Very many lanes. "How long are you swimming? I never had the time to watch" said Santa "because you are always swimming for such a long time and I have to watch all people on earth, therefore I don't have so much time."

One hour a day. That is very long. In the end, I always have very cold feet.

It also says here that you take care of your children. Yes, they like to eat your breakfast, but not your dinner. Therefore, your husband helps with cooking. Cooking is not something I like to do.

But you can swim very well. Do you see, Imke is also a human. Some things she does well, and others not so well. That is the same for everyone.

True.

It says here too that you have a lot of fun with the children here.

Do we have fun here? No...

Yes, yes, yes.

Dear Santa, can you please check your bag now?

And then it says here that you are sometimes a little impatient. Do you think that there is something for her in the bag?

Yes, yes, yes.

Guess what shape it had?

Santa took the bag, leaned forward, and dug deep down inside.

I thought that he would not get out anymore. He searched for such a long time.

Where is it? Was hiding there in the corner. Dear Imke, you get a very 
ganz besonderes Geschenk. Das Geschenk ist jetzt erst mal ganz klein. Wenn du dein Geschenk unter deinem Weihnachtsbaum legst und dich ganz doll auf die

Weihnachten freust und ans Weihnachtsfest glaubst, wird dein Geschenk größer werden. Wenn du aber keine fröhliche Laune hast, dann wir es kleiner. Handing the present to her.

102 HTF: Kuck mal ist schon gewachsen. Schon wieder. Ich freue mich schon auf Weihnachten. Showing it to the children, who are checking her hand.

103 HTP: Wenn wir uns alle freuen wird es bestimmt noch größer.

104 HTF: Ich stecke es lieber in die Hosentasche. Oh, nein, nein. Present grows in the pocket. Es wird immer größer hoffentlich kriege ich es wieder raus. Taking it out and everyone is laughing while the HTP brings it to the desk. $\mathrm{Na}$, da bin ich mal gespannt, was da drin ist.

105 HTP: Der Nikolaus hat dann noch gesagt „Ich muss jetzt aber weitergehen, weil ich noch so viele Menschen auf der Erde besuchen muss." Und pötzlich war er weg.

106 HTF: Aber die Eva hat dann noch einen Spruch für den Nikolaus gesagt. Sollen wir uns den mal anhören?

107 Ch: Ja

108 HTP: Santi Niggi Näggi, hinterm Ofe stägg-i, bring mer Nuss und Biire, denn kum-i hinte führe.

109 Ch: Was heist das?

110 HTP: Santi Niggi Näggi - ist ein Kosewort für den Nikolaus.... hinterm Ofe stägg-i ...asking a girl from her group who is from Switzerland

111 Girl: Hinter dem Ofen bin ich.

112 HTP: Ja richtig, kannst du auch das nächste? The girl nods her head. bring mer Nuss und Biire ...

113 Girl: Bitte bring mir Nüsse und Birnen. Und dann komm ich wieder vor.

114 HTP: Sehr gut. Dankeschön. Wir sagen es noch einmal kurz zusammen. Santi ... Niggi ... Näggi..., hinterm Ofe... stägg-i, bring ... mer Nuss ... und Biire, denn kum-i .. hinte führe. ....Ja, super war das. Danke smiling very happy to hear this saying from the group, who likes repeating it. special present. The present is still very small. When you put your present under the tree and look very happy toward Christmas and believe in the Christmas celebration then your present will grow. If you are in a bad mood, then it will shrink.

Look it grew already. And again. I am looking forward to Christmas, already.

If we are all merry it will grow for sure.

I will put it in my pocket. Oh, no, no. It is growing hopefully I will get it out again.

Well, I am so curious, what will be in there?

Santa added "I have to move on, because I have to visit so many people here on earth"and just like that he was suddenly gone.

But Eva said real fast an old saying for Santa Claus. Should we listen to it?

Yes.

Santa Claus. I am hiding behind the stove, bring me nuts and pears, and then I'll appear.

What does that mean?

Santi Niggi Näggi is a word of endearment for Santa Claus ... Hinterm Ofe stägg-i I am hiding behind the stove. Well done. Do you know the next line too?

Bring me nuts and pears, and then I'll appear.

Very good. Thank you. We will say it together one more time. Santa

Claus. I am hiding behind the stove, bring me nuts and pears, and then I'll appear. That was wonderful. Thank you 
115 Ch: Says out of the blue Ich weiss, was Dianas Geschenk ist.

116 HTF: Was, du weisst dass schon? Was ist es denn?

117 Ch: Suggested by the several children Eine Blume, ... einWeihnachtsbaum.

118 HTF: Was denkt ihr, was Evas Geschenk ist?

119 Ch: Ein Ring, ein Ei,

120 HTF: Was meint ihr, was bei mir drin ist?

121 Luca: Ein...ein Ballon showing with his hand how it grows.

122 HTP: Ja, vielleicht. Wir können es ja euch im neunen Jahr erzählen. So nun sagen die Papageien den Fischen ,Tschüs“" und wir gehen noch ganz schnell in unser Zimmer.
I know what Diana's present is.

What, you know that already? What is it?

A flower ... a Christmas tree.

What do you think Eva's is?

A ring, an egg.

What do you think is in mine?

A .... balloon.

Maybe so. We could tell you in the new year. So, now the parakeets say bye-bye to the fish and we will go quickly to our room.

The groups say their good-byes and after the parakeets leave the teacher hands out some of the children's craft work before some go outside where a few of their mothers are already waiting. The teacher says, "Schaut mal, meine lieben Fische, was ihr heute noch mit nach Hause nehmen dürft (Look here, my dear fish, what you can take home with you today)." The children stand on the carpet and get their stocking, which they made for December $6^{\text {th }}$-the traditional St. Nikolaus day in the German speaking cultures, when their names are called. Marie reminds the teacher, "Du hast doch gesagt da ist was drin (You said that there is something inside)." The teacher tells her, "Da war doch schon was drinnen. Das habt ihr doch schon rausgenommen. Oder? (There was something inside already. You took it out already. Didn't you?)" Everyone smiles, saying “Nein (no)."

Good-bye and Pick-up (1:55 p.m.)

The teacher waves her hand and it signals the children to begin singing the good-bye song:

Song

Salut, mitein'nand

Schau mitein'nand

Good bye, Auf Wiedersehen.

Salut, mitein'nand

Schau mitein'nand

Good bye, Auf Wiedersehen

Lebe wohl und ade,

bis morgen früh auf

Wiedersehen.
Translation

Bye, bye everyone.

Bye, bye everyone.

Good bye, Auf Wiedersehen.

Bye, bye everyone.

Bye, bye everyone.

Good bye, Auf Wiedersehen.

Good bye and good luck, Wave at each other.

Until tomorrow morning

Good bye.

\section{Movement}

Wave at each other.

Wave at each other.

The children dance to the song while holding their stockings. They dance and sing in the circle time area, and afterward they leave the area and some of the children hug the teacher and the 
assistant good-bye. The teacher says, "Auf Wiedersehen (Good-bye)" and "Tschüs (bye) several times while hugging the children shortly. She follows the children outside to where they greet their families and proudly show their stockings. Jan, Katja, Lisa, and Emma hand all of their creations to their parents and explain what they did. It is loud but in a good way. Most of the children leave with their families while three mothers talk and sit at the picnic table while their children play on the playground. The teachers return inside and clean up, preparing a few things for the next day.
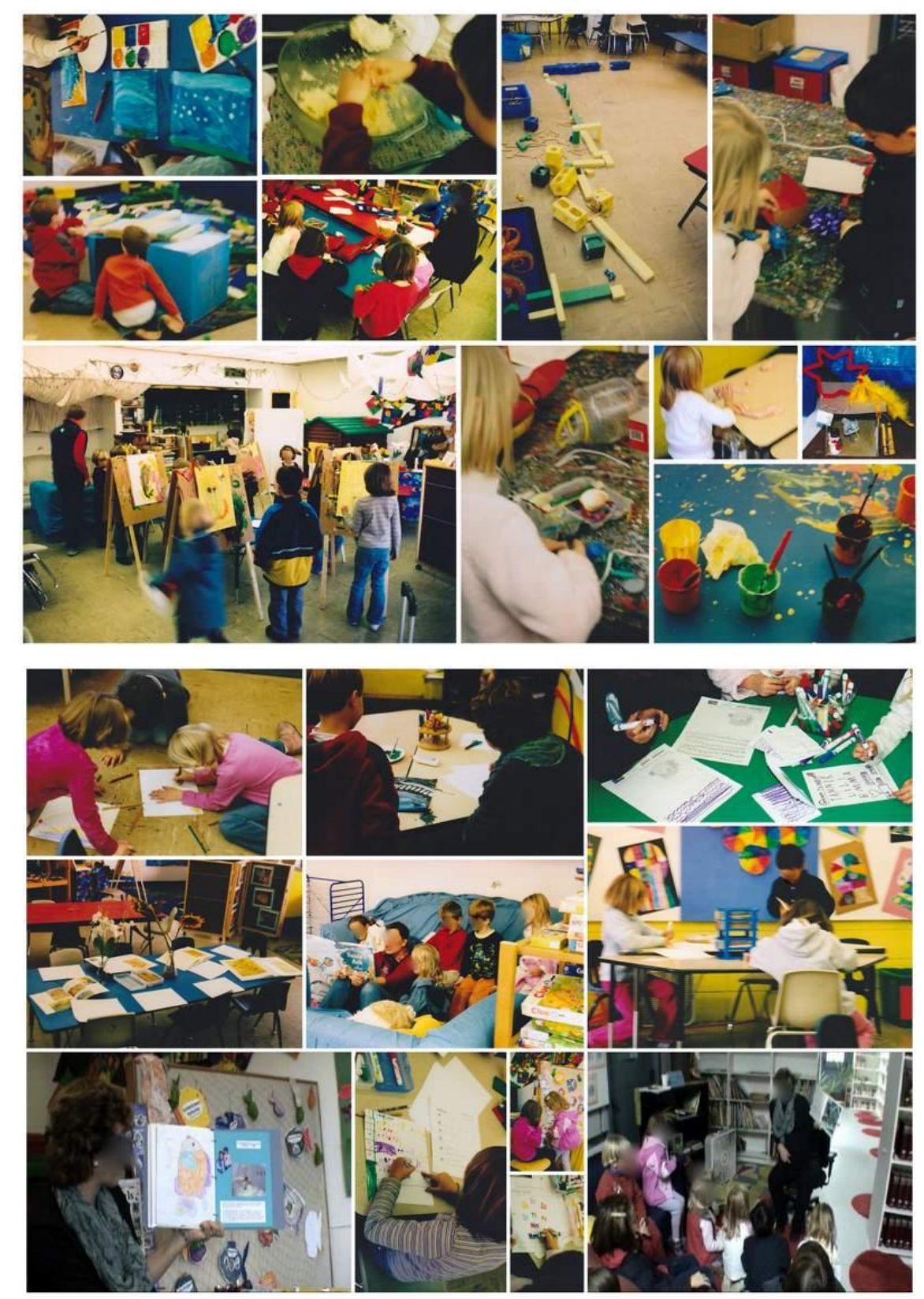

Figure 69. U.S.K.P.: A week in our life-impressions. 


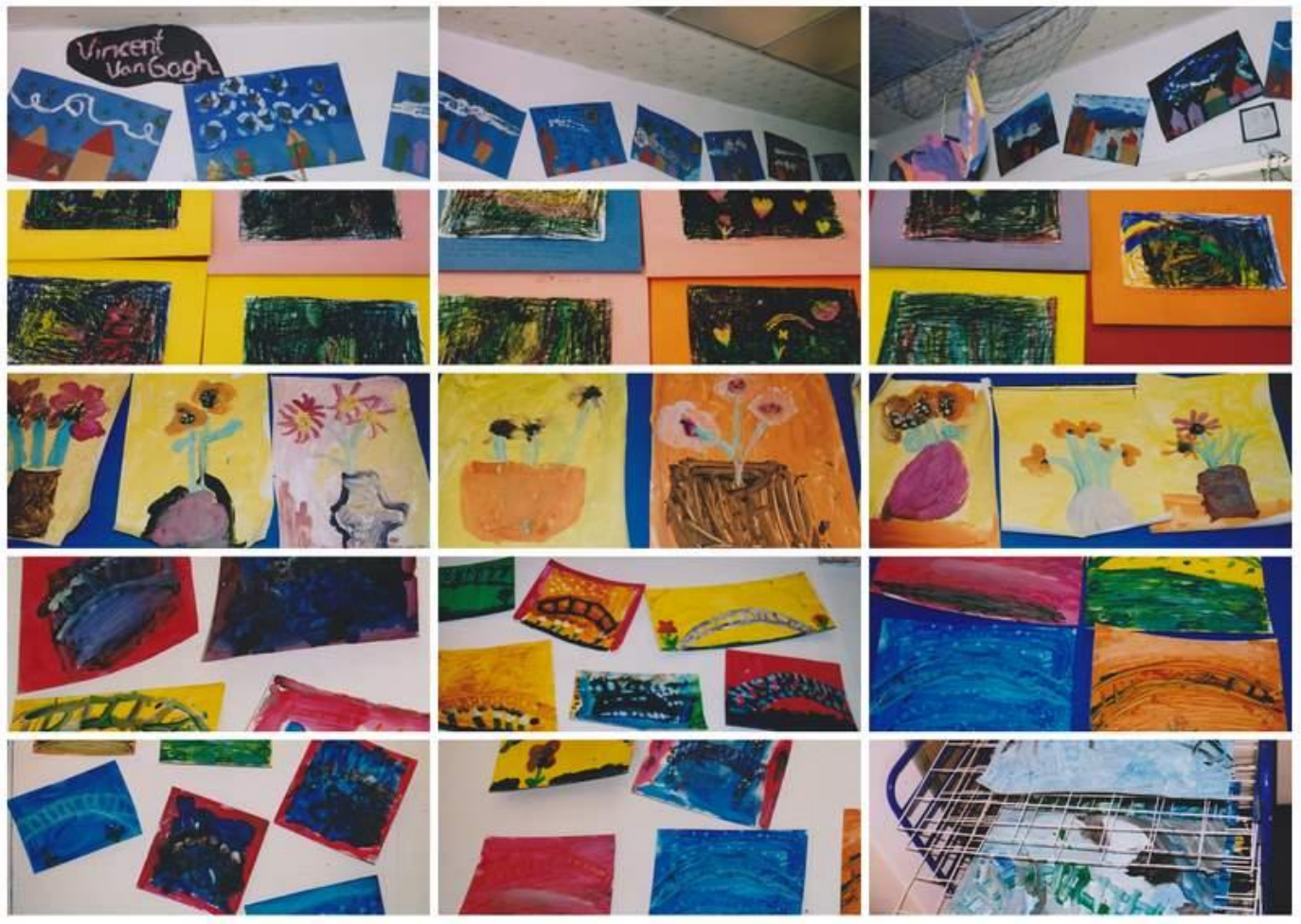

Figure 70. U.S.K.P.: Drawings in the style of artists.

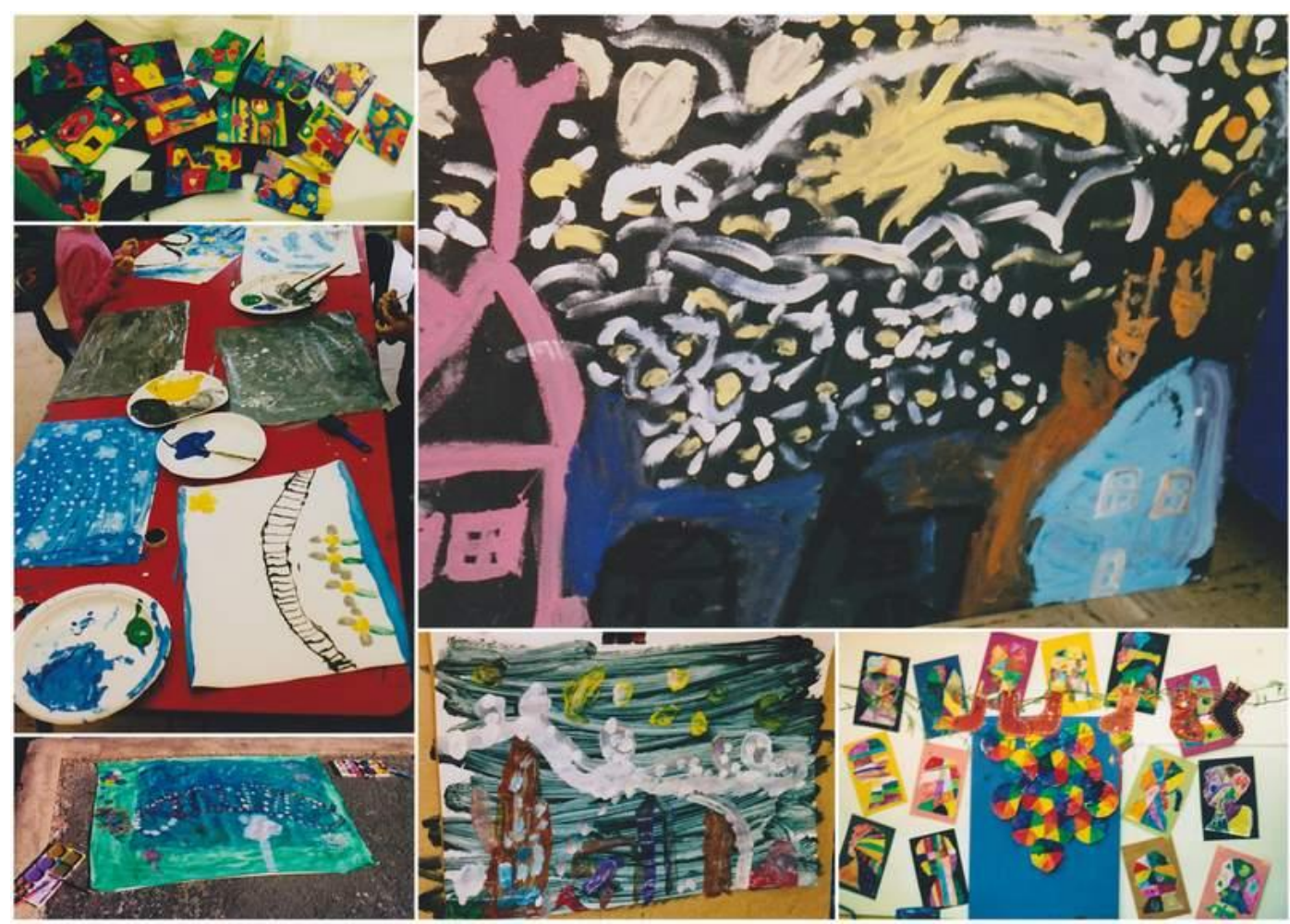

Figure 71. U.S.K.P.: Art work impressions. 


\section{Chapter 7: Analysis and Discussion of Findings}

\section{Introduction}

In my analysis of the different programs, I found that any one learning situation provided a complexity of answers to the multiple research questions that informed this study. For example, the circle times in each program offered instances of strategies and activities that are used to engage students in early childhood language learning. They also provided information about when and how children use their language(s) in early childhood programs, how peer support enhances language learning, what roles teachers and students play in the early language learning environment, and what pedagogical approaches and methods the programs use. Circle time activities answered all these research questions to varying degrees and in an overlapping manner. This can be seen, for example, in the U.S. preschool program when the group is practicing the song "Little Snowflake" (p. 212), or in the practical life activities accomplished in the art room in the Austrian program (p. 99). These situations addressed strategies, activities, children's language application, peer support, and the roles that teachers and students play in language acquisition, among other points. In this chapter I will analyze each program from a holistic perspective rather than question by question to show the complex and overlapping ways all three programs address early childhood language learning.

\section{Austrian Program}

This program used the Montessori Method, which is a longstanding approach in early childhood education, in combination with the immersion approach, which focused on English as the target language and involved materials such as Montessori activities, books, audio-tapes, CDs, and software. Engaging children in the target language was accomplished in part by a rule that required children to speak English inside the kindergarten building. When playing outside, they could use the language they preferred or best fit the given situation. This rule was established in 2001, as the teacher explains in the following interview excerpt:

We used to have the policy that the children could speak to each other in whatever language they preferred. We then discovered that the German speaking children were not really learning much English at all. They have the German all round them, and they would play mostly with German speaking children and really just learn a minimal amount of English.

The Montessori curriculum included subjects such as practical life, mathematics, language and cultural studies. Each of these areas was assigned its own room while the didactic materials of the sensorial curriculum were integrated throughout the other subject areas. The program under study 
added an art room, two small dramatic play areas, and a Lego center to the curriculum, recognizing these to be integral to the field of early childhood education. The teachers prepared each room carefully to provide an interesting, organized, and aesthetically pleasing learning environment according to the Montessori Method.

The applied curriculum followed the theme "From the Milky Way to our city" during the 2004/05 year. This theme was explored from a variety of angles. For example, students learned about the Milky Way by exploring it through visual arts, music, and science. They also studied planet earth by learning about the continents - their locations, geographies, and cultures. While looking at Europe the curriculum focused on the countries that border Austria, Austria itself, and the city the pre-school was located in. By going from the universal to the local, students gained a better understanding of their place in the world and an appreciation for their own culture as well as for how much exists beyond their city's borders.

The schedule was set up with an uninterrupted work period in the morning. Maria Montessori defined this period as a time in which children choose activities according to their interests and needs. The teachers arranged theme-based activities using Montessori materials and engaged the children in structured learning activities. The morning circle brought all children together, shifting the focus to structured activities such as taking attendance, singing the welcome song, and making announcements. The outdoor play time provided free play in a less structured environment. This was followed by group circle times which were conducted according to age groups and offered teacher-structured activities in language and mathematics for the younger children and a more theme-oriented structure for the older children. The children also participated in organizing the circle time by choosing songs they wanted to sing or move to.

\section{Situational Language Application in Circle Times}

During circle time teachers conducted read-alouds and activities that either focused on a topic or on language practice, though this latter focus mainly applied to the blue group, which consisted of 2 to 4 -year-olds. All circle times were preceded by a transition period in which children went to the rest room, got a pillow, and took a seat in the circle, an outline of which had been taped onto the floor in all rooms. These familiar activities made it easy for the students to move from outdoor free play to teacher-structured circle time. As the children approached the circle, they might still be talking with each other in German and the teachers who were finishing the last parts of their preparation reminded them that they needed to use English inside. The transition period was very important for the children 
to readjust not only their behavior but especially their language use, if they had been speaking a language other than English outside.

\section{Circle Time Starting Routine}

Each circle time began with a routine such as handing out name cards, taking attendance, and going over the calendar and the weather. The way these activities were conducted differed according to the age group. For the first couple of weeks at the beginning of the year the teachers would read the names and hand the cards out to all the children, regardless of their age. Thereafter, in the blue group (ages 2 to 4), the teacher would hold up each name card, showing it around the circle and waiting for someone in the group to respond. If no response occurred, she would read the name. The children took their card and placed it in front of them. This allowed all children to recognize each name through daily repetition. Children who were able to read the names were encouraged to use their skill while the others were able to learn the names from hearing and seeing them. In the yellow group (ages 4 to 5), the children would pick a name, read it, and hand it to the person it belonged to. If a child had difficulties the teacher or the peers provided support. In the red group (ages 5 to 6), a different child each day would distribute the name cards.

Attendance was taken in the blue group by the teacher and in the other two groups by a child who was the circle time helper and who received support from a peer or the teacher if needed. The person who took attendance had a clipboard with the attendance sheet and checked off boxes in the corresponding column. When the child's name was called he or she answered with "yes" or a form of the word and turned the card in to the responsible person. Then the name cards were counted in English and everyone joined in. In the red group the children requested counting in other languages, such as Hebrew, German, Spanish or Japanese. By including the different mother tongues in this way, the children were able to share knowledge of their first language while becoming acquainted with the languages of their peers. The attendance activity transferred the teacher's responsibility to the children, requiring each child to establish leadership, organizational, and presentational skills so that their peers would listen to them. The children had an assigned schedule of who was the circle time helper to ensure that every child had a turn. The children looked forward to doing these tasks and accomplished them with care.

Calendar time focused in the blue and yellow group on determining which day of the week it was. The teacher placed cards with the days of the week in a circle on the floor and read the cards out loud for the children to repeat. Then the children guessed which day of the week it was, and also what the preceding day had been and what the next day would be. In the blue group the teacher 
announced the date after counting each previous day while pointing to the wall calendar. This provided a daily visualization and repetition of the days of the weeks and the ordinal numbers. In the yellow group the children guessed the date and the teacher repeated the correct answer, then the children followed her lead by speaking in a chorus. In the red group, two children set the calendar on the wall while selecting the weekday, the date, and the month if it had changed. They expressed the date in a sentence, for example, "Today is Monday, July $11^{\text {th }} 2005$," and added the weekdays for the previous and next day. The children would ask the teacher for support if they had a problem. The calendar time was a good example of how the children progressed over the three-year program. The children started by repeating what the teacher said and developed into second-language learners who were able to collaborate with peers and present answers to a problem in the target language.

The teachers used the kindergarten weather song "What will the weather be?" that the red group would still sing occasionally. During the song a child checked the weather at the window and chose a word from the song that corresponded to the day's weather. The song was accompanied by movement like drawing a sun or cloud in the air or expressing rain or wind through moving fingers. The song provided language beginners with relevant vocabulary and expressed the meaning of the adjectives through a visual representation. Additionally, singing the song each day ensured that all children learned the weather expressions. Children who possessed a wider vocabulary selected different words or phrases about the weather, thereby providing language models that others could learn from. In the red group, after a child had announced what the weather would be, the children sang relevant songs, such as "Rain, rain go away" (p. 124). This showed further acquisition of the language and a joy in the language skills they had learned.

\section{Circle Time Main Project: Blue Group}

The teacher introduced a book called "Monkey Puzzle" and engaged the students in a prereading discussion that provided vocabulary and a short summary of the story while using the book's illustrations as visual support. In this situation the teacher applied short descriptive language supported by gesture, body language, and visualization. The children called out what they saw, repeated vocabulary, and answered the teacher's questions. This informed the teacher about the children's vocabulary knowledge, their ability to construct short phrases, and their understanding of the general context. For the children who had only limited knowledge of English this activity provided crucial vocabulary while giving everyone time to become familiar with the story.

The teacher's use of repetition when introducing vocabulary corresponds to Tabors (2008) description of repetition as a technique "that is used successfully when communicating with second- 
language-learning children" (p. 92). The teacher used repetition to enhance the children's acquisition of vocabulary. Whether or not they guessed the correct word in response to her visual prompt, she validated their responses and repeated the vocabulary word again. She applied these two strategies continuously throughout her work, while allowing the children to choose between verbal or nonverbal participation. The children decided on their own terms when to express a word. Some repeated the new word in an instant while other children, who were newer to the language, needed several repetitions before speaking or chose to remain silent.

While still preparing for the story the teacher showed the first two pages and raised the question, "Does the monkey look happy or sad?" The children called in a chorus, "SAD." She asked the next question, "Why do you think the monkey is sad?" and Almaz offered an answer, "Because he can't smile." The teacher continued, "Why can't he smile?" She waited for a few seconds and told the children that "the monkey is looking for his mommy." Next, the teacher employed the strategy of guided questioning using choice and why-questions to have the students predict what would happen in the story. This raised the children's interest in the story, though some were unable to verbalize what they were thinking. When the teacher recognized that the children had reached the limits of their language competency, she provided answers to her questions or reiterated the short plot.

The teacher read through the story applying various techniques: different voices for each animal, varying intonation, gesturing with hands, and telling the story with her body language. These helped the children recognize the different characters and understand the story. While reading the teacher did not discuss the storyline but instead used the strategy of language presentation and the children heard the story as a whole. Thus the teacher used a longer narration to allow children to hear language structures and to practice their listening comprehension in rich content and in the context of the target language. The children were able to practice words through hearing them and understand the story through body language and gesturing that explained the vocabulary. Language presentations are important for learning and building language structures in early childhood language learning.

During the language presentation one child insisted on using her mother tongue for the word spider (p. 110) but the teacher did not engage further but agreed by non-verbally supporting the mother tongue comprehension the child was advocating. A peer sitting next to her tried repeatedly to teach the word, thereby showing peer support through offering target language expression. The child did not agree and ignored the suggestions trusting her established mother tongue knowledge. One possible explanation of her reaction is that she just learned the German word and made a connection in her mind and the new name puzzled her. She did not show this reaction to any other animalelephant, snake, parrot, frog, or bat-mentioned in the story. The teacher's reaction to the child's 
asserting attitude was based on the knowledge that she was finding her way in her first couple of days in the program and had no prior knowledge of the target language. Further research is needed to explore these situations in depth in early childhood language learning programs through longitudinal studies.

The next segment introduced or reviewed, depending on the children's language competencies, key concepts of the practical life or Montessori activities as well as other subject areas. In the matching color activity (p. 111) the teacher reviewed and introduced the names of colors while pointing to each one on a dice. The children who called out the answers demonstrated their language skills and the non-verbal language participants were introduced or made connections in their mind. She repeated the answers to offer additional repetition. The children practiced the colors by rolling the dice and choosing a corresponding object. The activity was self-corrective in nature because the children saw their dice' color and chose from a mix of different colored objects in the basket until they matched the colors. The teacher accompanied the activity with language prompting each child to express the color, offered the answer if a child applied nonverbal participation, or used the target language reply to non-target language use. Additionally, she taught the key word "hold up" repeatedly by modeling the meaning each time she used the phrase as it was used in the Montessori schedule regularly.

In the music segment, the teacher used the same songs over a longer period of time so that the children learned them through repetition instead of practicing each one line by line. She had one or two songs in mind that were practiced while the others were requested by the group. The children added to the repetition by selecting songs over and over again, which is a common phenomenon in early childhood and very useful for language learning. The songs would be either traditional or modern. The music section had two different segments (p. 112). The first offered modern children's songs that the teacher sang and accompanied by movements. The children decided according to their own readiness to sing and/or move. The application of songs prompted verbal participation practicing language structures and nonverbal participation demonstrating learning through presentation of movement. The children used movement learned only through observation of the presented language models that supported a construction of meaning by connecting movement and language.

The second segment employed a classical music piece and was accompanied by sound or movement. Although the activity in itself did not use language the teacher used the organizational component to involve language learning. The teacher handed out instruments and scarves, and told each child what instrument or type of scarf they got. She applied the strategy of language repetition 
and the children heard the words several times. Some started repeating the vocabulary and could make additional connections while using the objects creating music or movements.

\section{Circle Time Main Project: Yellow and Red Group}

The theme-based main projects drew from the overarching theme "From the Milky Way to our city" and were coordinated between the yellow and red group. The groups explored sub-themes through read-alouds or storytelling and a variety of activities over a three week period. Outings were a regular component in studying sub-themes that offered real-life connections beyond the kindergarten and allowed the children to explore their role as a member in their community. The groups visited art galleries, museums, churches, and cathedrals while also learning about history and legends from a children's guide to the city, which was written in English. The studied information was further explored in exhibitions or museums, allowing children to draw connections between their comprehension and the presented artifacts, as well as offering a rich visualization through the presentation of art from different cultures or the planet system. I had the chance to join the groups on one outing while visiting a landmark cathedral and a history museum.

The current topic focused on the city through learning about different people, stories, historical facts, and living in a metropolitan area. These were set in context during outings, combining knowledge acquired from books with real-world situations by visiting places stories happened and showing traces of the past in the present city living experience. This topic was the last stop on the journey they had taken throughout the year from the Milky Way to their city.

\section{Main Project Yellow Group: Learning through Puppetry and Storytelling}

At the beginning of the week, the teacher had introduced the city's recycling system using an activity set provided by the city for each kindergarten that included a collection of small recycling trash cans, a recycling truck, and other materials. It helped the teacher to integrate the topic of recycling through activities based on play as well as to teach and to demonstrate children's responsibility in keeping the parks and playgrounds clean for the enjoyment of all community members. The teacher used puppetry and storytelling for the presentation (p. 118). Her performance included different voices so that the children could differentiate the person speaking. Previously, she had introduced the puppet as Kasperle and used repetitively the Austrian culture-based phrase "Krawutzi-Kaputzi," which the children found very funny. The children enjoyed and engaged actively in the performance. The presentation allowed the children to draw connections to their daily life experiences in the kindergarten and at home. 
The storytelling began with a language presentation aspect during which the children were passive in their behavior and active in their minds by making cognitive connections between language, actions, and the offered visualization. The teacher gave the puppet the role of leading character, as it told its story about the park and activities it liked to do. All was demonstrated by the props and the movement of the puppet. She used the puppet further as a medium to apply repetition and review. Since the storytelling started with the visit of the puppet and the social rule of greeting a new person in a group, she repeated counting the children and included personal recognition for each child through the puppet. The children were pleased about the visit and listened to every word the puppet said. The teacher used the puppet as the mediator of her information and applied the strategy of an imaginary walk in the park to describe the environment.

The language presentation segment ended when the puppet assumed the function of prompting the children's language use and creating an interactive segment in the storytelling through the development of a dialogue. The children became verbally active participants, constructing and shaping the story as well as demonstrating understanding of the theme. During the language presentation the puppet had applied behaviors that the children viewed as incorrect. In the interactive segment the children were asked to guide the puppet to correct his actions while demonstrating their knowledge of how to behave and act in a public park. For example, Maria explained, "You have to put everything in a Mistkübel (trash can)," and the teacher helped her by rephrasing, "You need to throw everything in a bin, Kasperle." "Yes," said Maria. The girl used code-mixing by replacing the word she did not know with her mother tongue equivalent, demonstrating her flexibility in applying her languages. The teacher then utilized the strategy of target language reply, providing the word while checking her comprehension. Maria agreed with the statement that the teacher made demonstrating that she recognized the word and understood the sentence.

Through the puppet, the teacher provided positive feedback for the children's language application and for helping the puppet to act environmentally friendly and in a community-oriented way. This served to implant rules of behavior in the children themselves. The developed dialogue between the children and the puppet reviewed or taught theme-based vocabulary depending on the knowledge of the individual child. Additionally, it practiced communicative competence and skills. The children's answering of the questions helped the puppet and the children to learn the needed language and content, while taking on the role of teachers and offering indirect peer support. They demonstrated their individual comprehension of the vocabulary and knowledge of the theme. The teacher facilitated the children's ability to learn vocabulary through different senses, in this case touch and sight, and included the strategy of repetition as well as visual representation by modeling each 
phrase through the puppet. This process invited the children to practice the applied language phrases, and it was amazing to see how the group supported the puppet through their words and helped him succeed at the task of cleaning up the park. The combination of puppetry, storytelling, and themebased activity supported the children's active participation and moved the role of teacher into their hands. The teacher became an observer of the language and content competencies. The learning process was supported through the application of repetition, visualization, prompting, and the teacher's storytelling skills.

\section{Main Project Red Group}

The teacher considered the interest and wishes of the children in structuring this part of the circle time (p. 124). The teacher had changed her entire planning for two reasons: the weather and the children's interest. The rain had shortened the playtime in the garden, which created fidgeting and lack of focus in the beginning. Therefore, she changed the order of the circle time segments, demonstrating flexibility and consideration of the group's needs. She started with the last segmentmusic and movement-which had a language learning focus. The first song was the Chicken Song, to which the children danced and moved to let their giggles and wiggles out without having to apply any language skills. The following song, Stir up the porridge, involved the children's verbal language participation. The children's choice and language competence led to some children singing the entire song while others joined only during the parts they were familiar with. They demonstrated their language competencies, combining singing and movement according to the lyrics, without having to focus exclusively on either one.

The next song was the Hokey Pokey as requested by a child. The teacher led the singing without $\mathrm{CD}$ player support and the group joined her. This gave verbal language participation a different role, showing the children's strengths and weaknesses in knowing the lyrics. The children's comprehension was demonstrated by movements that expressed the lyrics. The last song, also reliant upon knowing the lyrics, was Atootytot, which is also known as Singin' in the Rain. The song applied the same activities as the previous one, but the children had to focus on the applied language reduction and those parts were hummed. This demanded a lot of concentration but the children enjoyed the singing very much. The teacher arranged the songs from low difficulty to demanding language competency and from non-verbal to verbal participation aspects. This added an additional transitional segment for the children to concentrate on the circle time activities. The children decided on their level of language participation, choosing when and what to sing or just moving about. Most 
of the children, especially during the last two songs, were both singing and moving demonstrating their language competencies.

The read-aloud segment presented the story The King of Capri. The reading area provided a selection of books about kings, queens, princes and princesses in connection to the city's history, but the children had decided that they would rather hear a different story than one about their city. The teacher began by introducing the story's author and pointing out its location in Italy, then started reading at a comfortable pace for the children to follow. She emphasized certain words, used alternating intonation, and applied different voices for leading characters to help the children concentrate on this long and language demanding story. In the read-aloud, the teacher applied the strategy of language presentation and the children's understanding of the main events in the story was further supported by viewing the illustrations after she had read two pages. The children commented briefly on the pictures or laughed about the funny looking illustrations. She asked only very few short yes or no questions to check the comprehension of the storyline, and occasionally summarized the plot in simple language. The children were comfortable with this format and listened well. They asked questions that reflected their comprehension of the story when finding interesting information. For example, when the story included words in Italian, Mindy asked, "Si means yes?" and the teacher agreed. Teresita joined and explained that it would be the same in Spanish, demonstrating her mother tongue competencies. This discussion showed that the children understood the concept of different languages and that they were interested in learning about them. The children chose to acquire the Italian vocabulary the story offered and repeated the words for themselves.

The teacher ended the story by summarizing the main events. Deeper conversation about the circle time books was conducted in the following read-alouds, initiated by the children who had further interest in the story. This strategy allowed discussion of the books according to the language competencies and addressed specific language needs of the children. It further established one-onone and small group language learning situations during the uninterrupted work time in the morning.

The last part of the circle time was also changed due to the children's interest. The teacher decided to demonstrate a science experiment, prompting language use and involvement of critical thinking skills. She used guided questioning and built on children's language knowledge to introduce the materials. When showing an object she waited for a few seconds so that children were able to apply their language knowledge. For example, the teacher said, "You need ..." and paused before Dileep said, "a balloon." Additionally, she asked yes or no questions to engage the children and to check their comprehension. The teacher did not imply that an answer was wrong but rather viewed the answer from the child's perspective and constructed her reply accordingly. Throughout the 
introduction she provided the possibility to learn through the senses, letting the children touch and explore the materials they were curious about.

During building the object used in the experiment, the teacher applied descriptive language. The explanation of each detail served as a short form of language presentation, and the children observed the process and connected the language to each step. Then she asked each child about their prediction of the experiment's outcome by starting with a more fluent student to set a language model that the children could use in their answers. She helped the children who did not express their own thoughts in the target language by offering a yes or no question. The discussions about the prediction and observation were tailored by using guided questioning to prompt language participation according to the language competencies of each child.

\section{Situational Language Application during the Uninterrupted Work Time}

A child's choice of verbal and non-verbal language participation is influenced by the situational application, ranging from structured to unstructured during the daily schedule. The following examples occurred during the uninterrupted work time and are unstructured to semistructured situations depending on the guidance provided by the teacher. The song matching activity (p. 80) took place in the language room and was conducted by the brothers Dimitar (YG. L1 Bulgarian) and Domonkos (BG, L1 Bulgarian). In this activity the child had to recognize a song in two ways; through listening and through a visual representation. Through the matching activity the child demonstrated understanding of the meaning by choosing a symbol that reflected the key word of the song. Dimitar, the older brother, who was the active participant, showed his listening comprehension by placing the symbol for a song onto the white area of the activity cards that featured a picture connected to the song. This was a non-verbal activity for him because his mind was preoccupied with listening, visualizing, and matching. His younger brother observed and moved to the rhythm of the songs, which included Twinkle, Twinkle Little Star, Baa, Baa, Black Sheep, Humpty Dumpty, and Mary Had a Little Lamb. When Dimitar had selected a symbol, the shape of the blank area would show him whether his choice was right or wrong. This self-correction strategy is part of

the Montessori method and especially applied in the Montessori materials. This activity was played several times individually or in small groups. The children chose either verbal or non-verbal language participation.

The teacher introduced the visual and conceptual matching and sorting of kindergarten objects activity (p. 84) to Johannes (BG, L1 German), who she had observed reading names effortlessly, and Sophia (BG, L1 German). When children were introduced to a new activity, the 
teacher used descriptive language and showed the child where it was located, supporting the child's independence in choosing and returning the activity, another part of the Montessori method.

During the activity the teacher used an adaptation of the three-period-lesson: 1) the teacher associates names with objects, 2) the child recognizes objects, and 3) the child recalls the object's name (Lillard, 2007). The teacher anticipated that the children were familiar with some words, e.g., play dough, because it was used in the art and practical life room regularly. Therefore, she adapted the first step (association) to reading the label only relying on the comprehension of the children without providing any visual support. She followed with the second step (recognition) by going through the picture cards asking, "Is this play dough?" prompting the child's language application through a yes-or-no question. In the third step (recall) she supported the children by reading together the name of the object, which was the initial focus of the activity. When the child could not recognize "cushion," the teacher adapted the lesson from reading to learning vocabulary. She changed her first step to naming the objects in the pictures so that the students were able to recognize the objects and then returned to the typical three-period-lesson. Through this change she accommodated even more repetition. It was surprising that Sophia (BG, L1 German) did not know the word "cushion" because it had been used throughout the group circle time on a daily basis with multiple repetitions in phrases like: "Please get your cushion," "Sit on your cushion," or "Return your cushion to the basket." Perhaps the child just knew what to do by following the model of the other children, or recognized the vocabulary only in the context of the event.

The teacher listed the names of the objects instead of implying that the child was wrong following Montessori's (1912) remark, “...[I]f we should say in correcting the child, 'No, you have made a mistake,' all these words, which, being in the form of a reproof would strike him [or her] more forcibly than others, would remain in the mind of the child...," (p. 226) while negatively influencing the remaining activity. The teacher offered a way of making further connections by pointing out that the cushion is on the line and making a direct reference to the children's experience in the kindergarten. For the children this activity had turned into a vocabulary activity in which they were able to connect the picture of an object with the verbal and written representation.

\section{Individual Reading of Children's Books}

The children practiced emerging reading skills through applying non-verbal and verbal language participation in all the rooms' reading areas. The books on display were the same ones used during read-alouds during the uninterrupted work time and the group circle times. I observed children thumbing carefully through each page of the book. For example, Nanako (RG, L1 Japanese, 
p. 80) was reading individually in the language room while the teacher offered a read-aloud. She read through the books The Bear on a Bike and Aaron's Hair with which she was familiar because these books had been read several times in the language room where she had demonstrated her emergent literacy skills.

Toni (BG, L1 German, p. 91) looked through books in the practical life room in which he participated in the blue group circle time. When reading the jungle book Monkey Puzzle, he recalled a few vocabulary words such as monkey and snake; mainly the words he could recognize from the illustrations. This book had not been read at this point, therefore he was unfamiliar with the storyline and its nice rhyme and rhythm, thus impacting his vocabulary knowledge and storytelling skills. This changed when he selected a different book that had been read during the circle time both the day before and throughout the morning. He read while looking at the cover, "Brown bear, brown bear, what do you see?" Reading this story motivated him to present his own read-aloud while applying the teacher's model that he had observed during circle time. He practiced oral language skills, practiced and reviewed the vocabulary, and demonstrated his knowledge of the story, which was supported by the story's illustrations and rhythm. This language presentation was a tremendous demonstration of a child's language skills since he had learned English as a second language for just one year and was only four years old. I observed this form of emergent reading skills by other children of this age as well, but at varying levels of fluency and story comprehension.

\section{Name Card Activity}

The name cards and name recognition were a constant component of the children's daily schedule. In the cloak room children had to find their cubby by knowing their names, during lunch time they had to know their name to find their seat, and during group circle time they received their name card and had to turn it in when attendance was taken. When children arrived at the kindergarten, they had to take their name card and place it into their group's basket. The baskets were then placed in the language room, providing everyone with access to the cards.

Teresita (RG, L 1 Spanish, p. 82) returned for a month to Austria from her home in Spain and had attended the kindergarten in the previous year. She looked through the name cards of the red group, the group she was part of during group time. Teresita sought the teacher's support for parts of this activity, which provided an English language context through which she slowly found her English voice. She demonstrated her need of support by approaching the teacher every time with the question, "What stands here?" In Teresita's situation the name cards supported the child's recognition of the children she knew, and taught her to read unfamiliar or forgotten names. At the 
same time she moved within the situation from a non-verbal to a verbal language participant not only in reading the names but also by starting to ask questions.

In a different situation, Sophia (BG, L1 German, p. 84) used the name cards to simulate the attendance routine she experienced during circle time and in this way practiced key vocabulary items that were needed to be a verbally active member of the group. During this activity, the child used code-switching because she had exhausted her second language skills but was able to continue for a few numbers in her first language. This situation showed that cognitive skills were applied to either language and that the child returned to the language with more vocabulary knowledge.

The following situation was semi-structured through initiation and guidance by the teacher, who understood the significance of the name cards and name recognition in the program. She explained her experience in the interview:

Their own names are a good place to start doing letters and reading because they are kind of attached to. They very, very quickly learn to recognize their name and also other names. Other programs use little pictures and such things that are absolutely unnecessary. Even two year olds learn to recognize their name very quickly. Even if they only know one or two letters of their name they recognize the pattern and distinguish their name from others. This enables you to gradually move on to other things with names.

Therefore, she encouraged Cloe (BG, L1 German, p. 83), who was three, had little knowledge of English, and had been in the kindergarten only for a couple of days, to participate in reading the name cards and learn to recognize her name. Cloe was interested and invited Paula (BG, L1 German), who also was three, new, had little knowledge of English, and was very shy, to join the activity in German. She used her mother tongue with her friend as Paula did not use German or English at this point, yet Cloe knew that she understood and would follow her lead. Cloe liked to communicate and engaging without using her language seemed difficult for her.

The teacher's goal was that Cloe should find her name while the child demonstrated her understanding by showing her different cards that she read. She followed the teacher's request by applying the model of the children she had observed. Cloe picked up the clues of the Englishspeaking environment and quickly learned its routine. In this activity the name card had meaning to her and she enjoyed being part of an activity or small game with her name card. However, she had not developed the same attachment to her card or name as the other children I had observed during circle time. It seemed a mere piece of paper that she received and turned in again.

Johannes (BG, L1 German) joined the activity when he had heard his name and was excited about his card. After being in the program for longer, the children identified with their name card as 
it was the first word they learned to read. The teacher searched now for Paula's card and Johannes modeled the activity providing indirect peer support and helping the teacher to stay in the target language. When he found Paula's name he handed the card to the teacher. This showed that he had successfully learned to read their names within the last few days through the name cards used during circle time or in this activity. Paula barely looked at it and placed it right away into the red basket. The teacher used descriptive language and visual support, guiding the children's organization of the name cards and offering vocabulary repetition. In this situation the teacher introduced the children to the written representation of their name in order to help them function as independent individuals during certain parts of the day, while at the same time introducing the names of their peers. For example, during lunch time children found their seat by locating their name card on the table. The teacher and students were active participants in this activity, while the girls did not use any verbal language participation.

In another situation the teacher shared the teaching role with Johannes (BG, L1 German), who read the names cards to Alicia (YG, L1 Spanish), offering peer support (p. 82). This gave recognition to the child's skills and supported his self-esteem in the presence of his peers. He shared his knowledge about the rule that children should not bend the cards, allowing the children to review the rule and combining language with a visual representation.

\section{Neighborhood Design Activity}

In the cultural studies room the teacher encouraged Nanako (RG, L1 Japanese) to choose an activity of her interest (p. 97). She selected a partner activity and the teacher asked Teresita (RG, L1 Spanish) to join in an effort to partner children who were of the same age and knew each other from circle time. Teresita and Nanako did not engage in a conversation but rather observed each other's maps carefully to design the same city. They worked well together, following one another's choice and in this way demonstrating that they were taking the other person's perspective into consideration. Both children were shy and did not converse much with the other children during uninterrupted and circle times, which relates to their character and language skills. However, both had English language skills and it was their personal choice to conduct this activity as non-verbal participants. Providing a language model by the teacher would have encouraged the children's verbal language participation. In her feedback she provided a description of the city to acknowledge their creations, which could have led children to describe their cities in more detail. However, the teacher seemed more focused on collaborative work than on language involvement during this exercise. 
A different situation involving oral language application (p. 97) was presented by Adam (YG, L1 English) and Jasni (YG, L1 Malayalam), who had been in the program for one year and had good English language skills. They built similar cities and argued verbally about what would go where, occasionally explaining the reason. The children drew on their imaginations to develop a rich storyline about castles and horses, and did not need any language guidance. Jasni learned from Adam, who indirectly supported his language learning in their daily conversations and discussions. They always conversed in English with each other, and through their communicative nature they practiced their language intensively.

\section{Painting Activity}

In the art room, Molly (YG, L1 English) and Michaela (RG, L1 German) watched three girls (BG) create patterns through the use of different objects and paint (p. 101). Christine (YG, L1 German) had difficulties pronouncing the word "yellow." In this situation I observed a rare occasion;

a child corrected another child's language application by offering peer support. The art room, with its different painting and craft activities, provided a good conversation starter and the big work table invited the children's language engagement. They practiced simple language structures and requests, for example, "Can I have blue?" or, "Pass the yellow." Most children were familiar with this vocabulary through learning from each other's language models.

\section{Person-bound Language Application during the Uninterrupted Work Time}

The Brown Stair is part of the sensorial curriculum, educating the senses by using vision and touch to understand dimensions. Lillard (2007) stated: “....and perhaps even more important, they [sensorial material] also appear to assist the child's concentration, ability to make judgment, move with purpose..." (p. 57). Monika (BG, L1 German), who was new in the program, chose this activity (p. 90). She moved the blocks onto a rug practicing fine motor skills (Montessori, 1914). She explored the material and placed the blocks in a line, like they were found on the shelf. This was part of the Montessori didactic concept for this particular activity. The blocks were out of order rather than showing a constant gradation, thus demonstrating that she needed more practice conducting this activity. Afterwards, she used the blocks creatively by using them as a music instrument. The teacher, who had been observing the child's exploration, gave her time to familiarize herself with the blocks before joining to teach the activity. The teacher had recognized the child's interest and realized that she was not familiar with the activity. She explained that these blocks were the brown stairs and asked her, "Should we build the stairs?" Monika replied in German, "Ja (Yes)." 
The teacher started modeling the Brown Stair activity and the child followed her sample by placing the two "music instruments" apart from each other on the rug. She seemed to want to play with them and put a different block on top. The teacher took the piece off and said, "Let me show you how to build the stairs." She explained using just enough descriptive language to teach the activity and the concept of big and small, and modeled by comparing blocks repeatedly. Monika demonstrated her comprehension by participating in the comparison and building the stairs. The lesson enabled the child to do this activity by herself and introduced the corresponding vocabulary. It ended with an observational walk around the stairs while the teacher repeated the vocabulary that was visualized by the object. Through the teacher's simple language use, repetition, and visualization she invited the child to learn the concept in the target language. After taking the stairs apart the teacher encouraged Monika to practice the activity while she herself retreated from the activity.

The child only used German once with the teacher in the beginning, otherwise she chose the role of the nonverbal language participant, listening and observing the teacher's language and the movement of objects. She seemed to understand that the other children used a different language with the teacher than she was yet capable of. Her language use changed when she invited a few children who spoke the same mother tongue to participate in the activity. Monika became an active language participant while addressing her peer in her mother tongue, using the person-bound language application. She built the brown stairs again and lined up the blocks out of order following her own understanding, but Christine (BG, L1 German) offered peer support while using their mother tongue, explaining and doing the activity with Monika's participation. Another peer, Almaz (BG, L1 Arabic), observed and followed the German explanation. Annina and Christine used English with the teachers and children, following the English language rule but making an exception with Monika who had no English language skills. They offered support and guidance for her in various situations. Both used person-bound English or German if the child had no language skills.

In the address book activity (p. 93), Lucas and Nadine (RG, L1 German) addressed the teacher in English, which they continuously spoke during the observation period. They connected a language with a specific person; this language application was natural for both. While communicating with each other the children often used German in the morning, during transition periods, or when teachers had stepped out of the room. This language connected both students even after three years in the program. Though they had enough language skills to use either language, their mother tongue seemed dominant in their relationship. They used the person-bound language application, and in an interview the teacher stated her perspective on the children's language use: 
Actually, of course, it is for some a really unnatural situation at times comparing it to my situation I have always spoken German to my husband and it would feel very odd speaking English to him, and I am sure it must be for the children. Some of them have known each other since they were born and now they have to speak English to each other.

She understood why they were using their first language and connected it to the person they used this language with. In the previous sample, children worked on the same task and used the person-bound language application, while in the following example the children worked on individual practical life activities in the art room (p. 99). Johannes (BG, L1 German) and Lea (RG, L1 German) decided to cut apples. They joined Rico (RG, L1 German), who worked with a pouring activity, and Lucas, who (RG, L1 German) used the coffee grinder, and were communicating in German. In this situation, the children employed a person-bound language application because they knew German was their common mother tongue and connected English with the teacher. The children who used the German language influenced the children who joined to also use German. The youngest, Johannes, usually used English except in a situation where a child with minimal English language skills approached him in German. When the teachers asked a question, the child replied in English, demonstrating his comprehension and changing the language application to English. She did not have to remind the children to use English; their own interest in the language let them use the target language even if they previously used the person-bound language application. Though the children respected the target language rule, they often returned unaware to the person-bound language application.

\section{Person-bound Language Application during Outdoor Free Play}

Three girls, Michaela, Lea, and Natalie (RG, L1 German), were playing at the small house (p. 104). During this free play activity they used German because it was their mother tongue. Alicia (YG) and Teresita (RG) played in the same area but communicated in Spanish, their mother tongue. They used their common language in the open language environment of the garden. This application allowed their language learning activity and brain a rest by using the language they had more competencies in. When a problem occurred between children with different mother tongues, they opted in this sample for applying non-verbal communication strategies to resolve the issue. Michaela and Teresita were aware of their languages, knowing each other from circle time, and chose to converse in English due to the fact that they had different mother tongues. They decided to use their common language, applying the person-bound language application. During outdoor play, the children had short and quiet conversations as they focused on playing. All languages were present, 
German by its native speakers, Michaela, Lea, Natalie, Cloe, and others, while some like Paula applied non-verbal communication. Spanish was applied by Teresita and Alicia and English was used by its native speakers, for example, Molly, Zach, and Adam. The children applied person-bound language application during their free play activities. In play situations where they did not share the same mother tongue, children used non-verbal communication strategies or English according to their language competencies. The children had the tendency to play in groups of those sharing their mother tongues, especially in the red group which contained older children who were about to start school. The playground was a place for all languages that the children were learning or speaking, and it was a place for them to relax, something very important to language learners of all ages. 
Summary

\begin{tabular}{|c|c|}
\hline & Austrian Program \\
\hline Program & $\begin{array}{l}\text { Language immersion program } \\
\text { English } \\
\text { Target language rule }\end{array}$ \\
\hline \multirow[t]{23}{*}{ Strategies } & Use of English by teacher \\
\hline & Rule of target language inside supported by peers and teachers \\
\hline & $\begin{array}{l}\text { Recognition of L1 language use of monolingual } 3 \text { year-olds or code-mixing while } \\
\text { applying the target language reply }\end{array}$ \\
\hline & $\begin{array}{l}\text { Short code-switching for children who needed guidance or to prevent emotional } \\
\text { upset }\end{array}$ \\
\hline & $\begin{array}{l}\text { Descriptive language in combination with gestures, movement, or body language as } \\
\text { constant component to offer language learning situations }\end{array}$ \\
\hline & $\begin{array}{l}\text { Application of open-reply and providing choices for children to be verbal or non- } \\
\text { verbal language participants } \\
\text { Recognition of readiness to use expressive language }\end{array}$ \\
\hline & Initiation of language models by children with more language competence \\
\hline & $\begin{array}{l}\text { Guided questioning through open-ended, choice, or yes-or-no questions to scaffold } \\
\text { language use }\end{array}$ \\
\hline & $\begin{array}{l}\text { Allowing children to share their personal experience and connections to content in } \\
\text { the target language }\end{array}$ \\
\hline & Repetition of vocabulary, songs, stories, and rhymes and embedded in activities \\
\hline & $\begin{array}{l}\text { Use of visualization through gesture, body language, illustration, materials, and } \\
\text { objects }\end{array}$ \\
\hline & Prompting language application \\
\hline & $\begin{array}{l}\text { Theme-based content and connections to children's life and experiences during } \\
\text { group circle time of } 4 \text { to } 6 \text {-year-olds, and materials in language and cultural studies } \\
\text { room }\end{array}$ \\
\hline & Language focus in circle time of 3 to 4 -year-olds and language room \\
\hline & Flexibility in structure and planning \\
\hline & $\begin{array}{l}\text { Accommodating all learners in the learning styles and through whole, small, and } \\
\text { one-on-one learning experiences }\end{array}$ \\
\hline & $\begin{array}{l}\text { Use of modeling, repetition, review, checking for listening, vocabulary, and content } \\
\text { comprehension }\end{array}$ \\
\hline & Strategies used by children \\
\hline & Call-out replies \\
\hline & Creativity to show understanding \\
\hline & Songs \\
\hline & Use of multi-media to introduce, teach, and practice songs \\
\hline & Use of visualization through gestures and movement \\
\hline
\end{tabular}




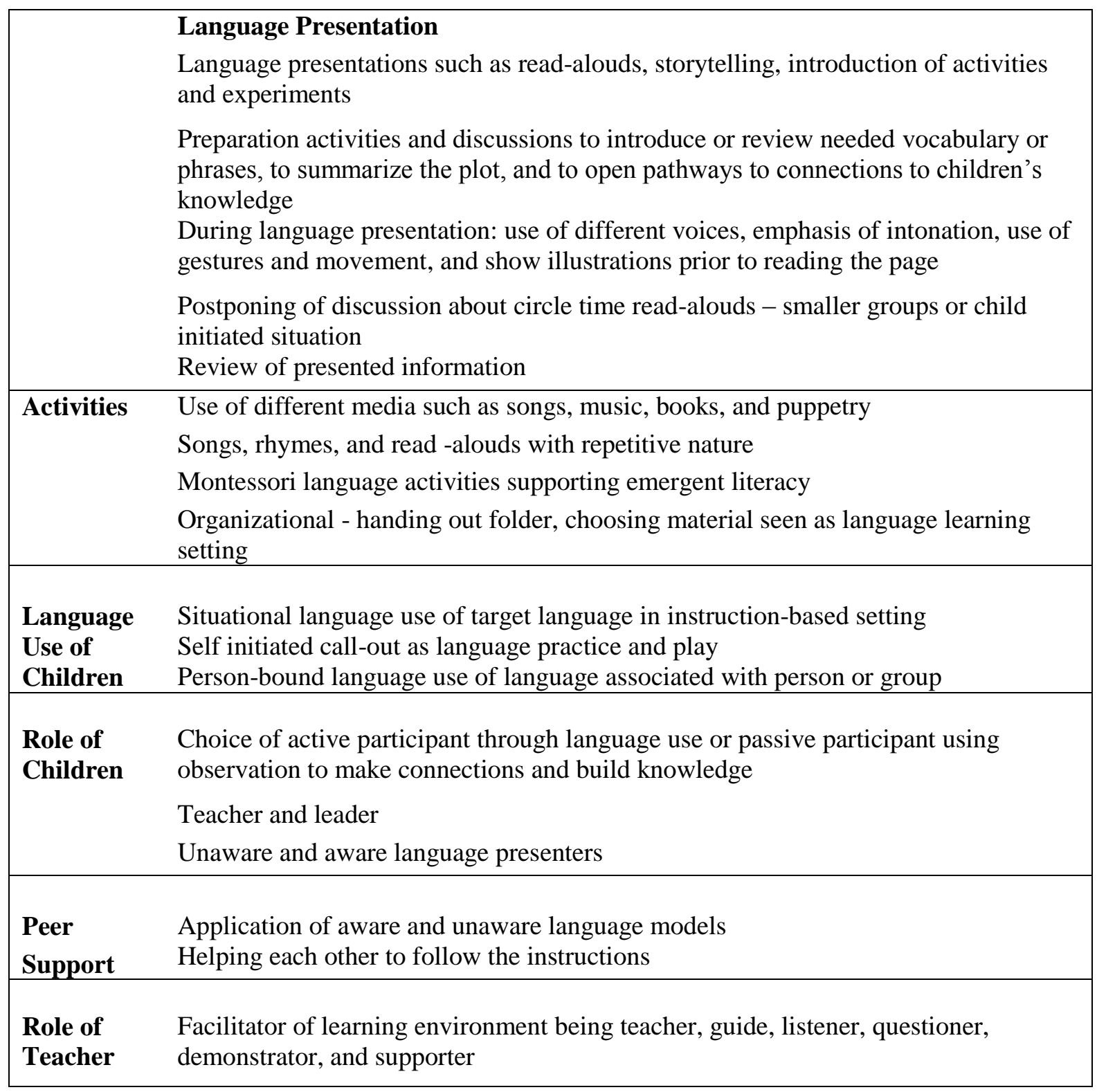




\section{United States Preschool Program}

\section{Situational Language Application during Circle Time}

In the U.S. preschool program, the morning and afternoon circle times were structured flexibly based on the theme 'Winter' that was applied due to the up-coming holiday festival. The following components offered a wide selection of possibilities for language input and practice and promoted language application: read-alouds and storytelling, music and movement activities, songs, and the use of the speaker chair. The teachers applied organizational and theme-based songs throughout the circle times and daily schedule.

\section{Organizational Songs and Rhymes}

The organizational songs and rhymes were the welcome and good bye songs, the counting rhymes, and transitional rhymes for circle or clean up time. The teachers had introduced a variety of welcome songs. These songs had a language focus, which was supported by visualization, movement, and gesture. For the welcome song (p. 211), the teacher provided four symbol cardssun, wind, bird, and child - as visualization of the key vocabulary. The children showed the cards when their symbol appeared in the song. This displayed their comprehension while providing visual support for the other children. Additionally, the children demonstrated their comprehension of the vocabulary words through associating sounds, which helped each child to define their understanding of the content and the key vocabulary. Marc (L1 English, 4 years), Mira (L1 English, 4 years), and Jeth (L1 English, 3 years) confirmed their understanding while Kacey (L1 English, 3 years) needed a cue from the teacher, who offered ample support. The children were able to choose their intensity of participation according to their own language skills. Some children first watched the other children and then made the sounds a few seconds later or enthusiastically sang the parts they knew while singing the others more quietly. The teachers sat spread out between the children so that they were able to better support them. The group finished the song after each child had a turn. The song had a repetitive nature and practiced the words sun, wind, bird, child, and good morning in short phrases, which supported the whole language approach that the teachers applied in their work.

I observed throughout the week two additional welcome songs: Hello, Bon Jour, Buenos Dias, g'day, Guten Tag and Guten Morgen, Wir winken uns zu (Good morning, we wave to each other). The first song applied greetings in other languages, such as French, Spanish, and English, with which some of the children were familiar from their homes. The second song was an action song, repetitive in the lyrics, and the children chose the action they wanted to perform. The children 
expressed their wishes in German and English while the teacher applied the target language reply if needed and modeled the movement. Through movement and visualization, this song aided the children in understanding its content and creating meaning.

The teacher used two transitional rhymes: one for announcing circle time (p. 209), and the other for clean up time (p. 248). These rhymes helped children not only in their transition to the next part of their daily schedule or to start cleaning up, but also gave the children an opportunity to use and practice the target language. Usually, the children paraded joyfully through the room or outdoor areas informing everyone of the next segment. Through this they shared the teacher role and helped to organize and emphasize their daily routine.

The teacher applied counting rhymes (p. 213) to determine which child would do an activity whenever not everyone received a turn. For example, a song might be sung only once, and the rhyme was repeated depending on how many children were needed to conduct the dramatization of the song. However, it was not the direct intention of the teacher to teach the children this rhyme. Rather, it was used as a form of language presentation where children could hear the language as modeled by the teacher. Some of the children joined the counting while others practiced the entire rhyme by reciting it with her. The children made their own choice of using language or listening, and whether they wanted to participate in the activity. The teacher applied three different rhymes throughout the week. I observed children starting to use one during their outdoor play, though they were not yet able to reconstruct the entire rhyme; that would come after repetition the teacher applied.

\section{Theme-based Songs}

The teachers of the preschool program selected traditional German culture-based songs and Frosty the Snowman for their groups' presentation to the families and community at the holiday festival. These songs were practiced on a daily basis so that the children would be able to participate and demonstrate their language skills and comprehension. The teachers of the observed group had introduced the songs one at a time, with two days in between each song, before the observation started. These songs were supported by visualization, dramatization, sound, movement, and gesture, and had a theme-based focus.

\section{Song: Schneeflöckchen, Weißröckchen - Little Snowflake, Little White Snowflake}

In preparation for this song the teacher handed out snowflakes to the children, counting each in German (p. 212). The integrated counting was a review for the children who were still learning to count, and established how many children were in the circle as a form of attendance. When the head 
teacher reached "neun (nine)," Michel (L1 German, 5 years) joined and stopped at 25 demonstrating how far he was able to count and how secure he was in knowing the numbers. However, the teacher continued to count at her own pace giving the children a chance to say the numbers with her. The teachers used descriptive language and commented on everything they did so that the children would be able to connect the language and their actions. This strategy of descriptive language application was a constant component in their work, and helped to achieve the goal of offering the children more language experiences and learning possibilities. This involved a certain amount of repetition throughout the day and week. The children decided what was interesting and what they might learn, while also benefiting from the many unconscious learning situations.

The teacher held up the snowflake and the children followed her model, expecting the song to start. However, she was checking for comprehension with her question; What are these again?. While some children knew immediately, others listened and repeated their peers' answers as the teacher provided enough time for everyone to answer. The children demonstrated through their answers that they had learned the word from the song. It was the teacher's goal to use visual comparison to point out the difference between the model snowflake they had used and the actual snowflake in the song. This seems like a small nuance in the language, but it is important to learn the difference and additionally to know the more commonly used term.

They then started singing and visualizing the story, demonstrating their comprehension through the movement of the snowflake and throwing the snowball on cue. During the song Jeth and Kacey (L1 English, 4 years) watched what the others were doing and followed their movements carefully. These two children, the youngest in the group, learned from observing the older children and imitating their visual interpretation. After everyone had thrown their snowball the children laughed happily and continued the paper snowball fight by taking the balls that landed in front of them. A few of children then got up to find their snow balls, which were still flying around the room. Michel's statement (L1 German, 5 years) provided a language model for Marc (L1 English, 4 years), who repeated it and thus practiced his German language skills. This was a form of peer support that the children with greater language competency offered, unaware of their crucial role for the learners with less language knowledge, who used parts, repeated the phrases, or built onto these phrases.

\section{Song: Kommet her und seht - Come here and see}

The teacher introduced the second song (p. 213) by checking the children's comprehension and attention through making a false statement. The children demonstrated their understanding by 
calling out the right answer, correcting her. She agreed and repeated the answer, offering more language input through repetition. Mira (L1 English, 4 years) and Michel (L1 German, 5 years) were eager to build a snowman. The teacher gave the children a choice of materials for the snowman by offering a blue and a black hat, of which Mira selected the black one. The teacher allowed the child to act on her decision, though this choice did not follow the song's lyrics. She wanted the children to correct this selection through demonstrating their comprehension of the song's lyrics, hoping to observe the problem solving process and to create a learning moment.

After the second verse the teacher stopped and gave the children some time to make a connection between the lyrics and the visual representation. One of the children said, "eines schwarzes Hut (a black hat)," noticing that they were singing about a blue hat in the song. Focusing on building the snowman, Mira and Michel as well as the teacher did not hear the suggestion. The teacher used the strategy of confusion but there was no reaction and they continued singing the song to the end. When the children needed more support she narrowed the problem area by repeating the specific verse and applied guided questioning, which helped the children to find what was wrong. The children used their comprehension of the song to determine the problem the teacher had found. As the teacher had missed one child's earlier remark on this problem, the child became insecure and did not offer the observation again. The group analyzed the content by directly linking the visualization to the meaning of the song, thus supporting their comprehension while reviewing the reason for visualization.

\section{Song: $A B C$, die Katze lief im Schnee - ABC, the Cat Ran in the Snow}

In the introduction to this song (p. 251), the teacher had hoped to tap into the children's imagination, but, because they knew the term and had an understanding of "table cloth," they corrected the teacher by using the open-reply strategy. After a couple of children had established that it was a cloth, the children who had not known joined the chorus, practicing the word several times. The teacher tried not to manifest her opinion but rather continued with the imaginary snowstorm, teaching the concept of high and low and of a snowstorm through the movement of a prop combined with repetition. Marc (L1 English, 4 years) supported the teacher with his remark, "Like winter," and it took only a few seconds before the other children engaged in such imagining. Marc set the sign that the initial position of a table cloth was false, allowing everyone to let their imagination take over and to enjoy the activity. The older children often lead and the younger children would follow or imitate their actions. 
The teacher used an element of surprise for the first dramatization of this song. The dramatization expressed the story of the song and visualized its meaning, helping the children to make connections between the vocabulary and the performance. The idea of putting socks on the child's feet and arms turned out to be challenging, therefore another teacher helped. While the children patiently waited for her to be ready, they practiced the song and simulated another snowstorm through moving the cloth very fast up and down. The children's interest in becoming the cat as part of the dramatization worked well with the teacher's goal of practicing the song.

\section{Read-Aloud: Gingerbread Baby by Jan Brett}

In the read-aloud situation (p. 215), the teacher used a theater style seat arrangement in the circle time area and elevated the book by placing it on the speaker's chair. The selected book had large illustrations, which the children could see while following the story. The teacher explained the reason for the book selection, referring to the winter theme. She then explored whether the children knew the story, and if that would have an impact on the reading and storytelling features. She described the presentation's structure, preparing the children for the mode of language use. After the book's title was introduced she checked their comprehension of key German vocabulary. As a last step, the teacher and children zipped their mouths shut, repeating a familiar behavior rule for presentations. The read-aloud applied these organizational features in order to mentally prepare the children, placing them in a mindset conducive to language acquisition.

The children waited with high anticipation and Jeth (L1 Englisch, 3 years) got on his knees to have a better view of the book's illustrations. The teacher used person-bound language application, talking to Jeth in English and to Cloe and Michel in German. The teacher had explained in an informal interview that using English in moments of organization with children who knew English was the most efficient way to solve problems in big group situations.

The teacher presented the read-aloud as a language presentation through the longer form of narration while reading in English and providing a summarized translation in German with the anticipation that the children would learn based on passive behavior but active minds. It was in this moment that the language should act as a stimulus for observing language as a whole. The teacher used a storytelling voice and rhythm whenever the story melody allowed her to and the children were glued to both the reading of the story and the summarized translation. The children asked a few questions, and were answered if their questions were connected to the story's plot. However, if their questions diverged from the plot the teacher ignored them, maintaining the goal of language presentation. These questions demonstrated that the children followed the story in both German and 
English, engaging their minds, making connections between the storyline and the illustrations, and leading to language acquisition. The children had a chance to check their language comprehension and widen their language knowledge by listening to the story read in English then summarized in German, and following the illustrations throughout. Additionally, the story had a repetitive nature, offering an abundance of vocabulary repetition that supported the children's language acquisition. The teacher used summarized translations rather than translating the story sentence by sentence, helping to maintain the children's interest in both languages.

\section{Music and Movement Segment: Musical Chairs}

In the organizational segment of the musical chair activity (p. 216) the teacher used descriptive language supported by modeling to introduce the instructions, demonstrating the actions and providing translations from German to English. The teacher offered additional assistance to some of the younger children who encountered difficulty. She used translation throughout the instructional aspects of new activities to address the language competencies of all children and shorten the explanation process while setting the focus on the activity rather than the language.

Amy (L1 English, 4 years) said in English that this game is called "musical chairs" and the teacher agreed. But since the teacher developed her own rule she had not introduced the activity under this title with the intention that children would not be confused by the rule change. The child was apparently confused and continued to express the rule she connected with the activity: "Or you have to go out of the game. Right?" Though the child anticipated a supportive response, the teacher did not engage, letting her learn through the experience and anticipating that she would understand the situation through observing the action of others and hearing the descriptive language use.

The activity did not focus on active language use by the children but rather centered on music and movement. However, the teacher accompanied the activity by descriptive language in German and modeled the action to support the children's understanding and participation in the activity. A second descriptive language aspect was added through explanation of the outcome of children sitting on each other's laps, as she added repetitive elements of language structure to an activity that is usually non-verbal. Accompanying the activity with the German language offered language input leading to language acquisition, encouraged children to remain in the language, and prompted language use. The latter was demonstrated, for example, in Amy's statement that four children were sitting on top of each other. She used the German language and had overcome her earlier problem through participation and observation. This shows that not everything has to be explained in detail using a language that otherwise often leads away to more non-target language application. 


\section{Speaker Chair}

The teacher used the speaker chair as a prompt for children's speech production, discussing events or experiences, and organizing the lost and found basket. The children on the chair had the opportunity to share their thoughts in either German or English and practice their communication skills while other children were listening and asking questions. This introduced the children to public speaking. The teacher used guiding questions or summarized the children's thoughts or event. If a child used the English language the teacher applied a target language reply to summarize the statement, responding in German.

The first example concerns the discussion of the holiday festival and the teacher asked the children to express their thoughts or questions (p. 249). The children were familiar with the concept eager to participate, raising their hands immediately. The teacher applied the person-bound language application using English and German with Amy (L1 English, 4 years) and Kacey (L1 English, 3 years). She followed their statements with a German language reply, summarizing each one in order to share the information with the group. It was important to introduce students of all ages to the speaker chair, and undivided attention from the audience helped the speaker to practice his or her role. Michel (L1 German, 5 years) used German, which was his preferred language, and asked a question about the attendees. Through answering his question the teacher reviewed the vocabulary about family members, providing words the children could use in their presentations. Mira (L1 English, 4 years) demonstrated her comprehension of the previous conversation but used her preferred language, English. The children remained within the topic that Michel had started and used more German, even if their preferred language was English, such as with both Cloe and Marianne (L1 English, 4 years). When Cloe talked about her grandmother the teacher rephrased her language choice with the more commonly used word, but she had not yet made connections to this particular word. The teacher did not stress the word, respecting Cloe's choice since the children were just acquiring the general concept of family. Marianne talked about her family members and the teacher corrected her statement by rephrasing and offering a short explanation without referring directly to her statement. The children who wanted to present something in the speaker chair had the opportunity to practice their communication skills while the teacher observed and asked questions to check for comprehension. She also provided corrections through rephrasing parts of the statements.

In the second example, the "detective" basket, the speaker chair gave one child the lead and the teacher provided support if needed to distribute things that had been found (p. 252). The student

practiced questions such as, "Who does this belong to? Where does this belong?" and the children answered, took their belongings, or returned objects where they belonged. Amy (L1 English, 4 years) 
was asking the children and handing out things from the detective basket. The teacher assisted her, but the focus remained on her. The teacher clarified the questions while expressing them in German and English. Amy showed her comprehension through asking the right questions. Marianne (L1 English, 4 years) wished to bring something to the dollhouse, but was confused as she could not find it in the room saying, "Where is the Puppenhaus?" using code-mixing in her statement. The child used the German vocabulary word she knew, demonstrating her beginning language acquisition. During the activity the children had the leading role and also practiced their questioning skills in the target language while the teacher provided support of their language and organization.

\section{Library time}

Once a week, the group visited the school's library which was in the same building (p. 226). A parent participated, sharing the role of the teacher and helping with organizational aspects of the visit. The teacher explained the library rules and the task in German and English. She used both languages to assure all learners understood the procedure and expectations. In the library, the children demonstrated that they were familiar with pre-literacy skills, knew where the children's book section was, and followed the expected process. The second teacher guided Kacey and Jeth (L1 English, 3 years), showing where the shelf for their age group was and using descriptive language to explain the task. Vanessa and Sarina (L1 English, 4 years) selected a book and looked at the illustrations, relying upon their imaginations to understand the story while conversing in German. A mixture of German and English could be heard throughout the library.

The children presented their chosen books to the teacher and she kept record of these selections. The teacher engaged the children who needed more language practice into short one-onone conversations about their selection. For example, Christian (L1 English, 4 years) had a German book about fire stations. The teacher asked guided questions in German and applied the personbound language application through adding the English translation if needed to prompt language production. Christian used mainly English and included a few German words, using code-mixing to demonstrate his German language skills. In another situation, the teacher engaged Daniela (L1 English, 4 years) through the application of guided yes or no questions to check the child's language comprehension and prompt a target language reply. In these short conversations the teacher helped practice communication skills and learned about the interests of the children, helping to guide her work and planning.

The library visits invited the children to become early readers and to understand the mechanics of a library. This was valued in the school as the children had the opportunity to start 
early literacy practices in the same way they learned languages. Additionally, this allowed for German language material at home where parents could read the stories to the children and further support the language learning that occurred in the program. Parents could become an active member of the classroom setting and a role model for the children by supporting early reading. The children had time to choose books they liked, share them with their peers, and engage in discussions about their selections through which they could learn about each other's interests.

\section{German Lesson}

The program offered German lessons for preschool and kindergarten, conducted in small groups that lasted about 45 minutes daily for six weeks. The content had a language focus that considered the interests of the children, and the teacher applied descriptive language to support language application and acquisition.

\section{Warm-up activities}

During warm-up and review (p. 232) the teacher included activities such as songs and rhymes that had been taught in previous German lessons, introduced new vocabulary, and engaged the children in conversations. This phase was additionally seen as a language transition into a German only learning environment. The teacher demonstrated her flexibility through engaging the children's interest and excitement while postponing her action song for a few minutes, allowing the children to share their thoughts. Amy (L1 English, 4 years) addressed the teacher in her preferred language while the teacher used the target language reply, which was an indirect reminder of the German language use. The child recognized the target language application and provided an answer in German. Lea (L1 English, 4 years) provided peer support, offering the whole word because Amy had forgotten the last part. The teacher repeated the word in a sentence, providing a language context while adding an open-ended question to deepen the subject. Amy showed her comprehension by answering and trying to use German, which led her to code-mixing her languages. After the short discussion of the events of the up-coming day, all children and the teacher sang the song and moved according to the lyrics. The children's level of participation demonstrated that they knew the song well and their movements showed their comprehension of the lyrics.

The teacher then transitioned to the current lessons theme, combining the introduction of new vocabulary with movement so that the children could create meaning. The phrase "auf einem Bein (on one leg).," found in the song that the children had learned, reappeared in the main part of the lesson. The teacher asked the children to jump, repeating the word "hüpf (jump)" every time they 
jumped. She demonstrated and the children followed while the word filled the room. Since jumping on one leg was much harder for the children, they focused on the action instead of the target language use. Therefore, the teacher repeated the phrase for each jump, allowing the children to learn through repetition and listening. Mira (L1 English, 4 years) started explaining her problem in the target language. She created a simple sentence but stumbled over the sentence structure and continued in English "because," demonstrating that she was not able to construct the complex sentence structure. The teacher used a target language reply, helping the child to continue to express the long statement and showing her target language competence. At the same time it showed the teacher that Mira needed more practice applying complex sentence structures.

In the next segment, the teacher engaged the children in a discussion about what they would bring on toy day (p. 233). A puppet was used to prompt target language application and seen as a language partner who loved hearing German, while the teacher had the role of a mediator between children and puppet. The teacher expected the children to answer in a sentence. When Sophia (L1 English, 4 years) answered using only one word, the teacher provided the beginning of the sentence, thus prompting her to express an entire sentence. She asked each child prompting an answer with her question and sometimes repeated their statements. As Lea (L1 English, 4 years) expressed what she would bring the teacher repeated the word several times and added visualization, which helped Amy (L1 English, 4 years) to formulate her answer. The teacher respected the children's excitement, allowing them to talk about their plans. Through her flexibility she found an engaging way to integrate the children's interests into the lesson without losing focus on the language learning goal. Each child practiced and demonstrated language competence in expressing a sentence that encouraged the puppet's appearance. The teacher used the puppet to summarize the previous discussion while checking the children's comprehension. The children engaged in their age group's common interests and saw the puppet as their friend. This demonstrated that the puppet was a good prompt, initiating children's language production.

\section{Introduction of a New Action Song}

In the introduction segment of the animal action song (p. 235) the teacher employed the animal puppets as visualization of the song's lyrics to support the children's comprehension. The song began with an animal that the children had previously learned, and the teacher let the children identify this animal. She then used descriptive language and guided questioning, building on the children's answers to discuss the first verse of the song. Lea (L1 English, 4 years) stated that the cat

puppet could speak though this was not a typical feature of cats. This comment prompted the teacher 
to explain how a talking cat assisted in helping the children learn to speak German, the primary goal of the program. Additionally, she included praise for the efforts the children were making to learn the target language. She continued by letting the cat puppet model dancing on one leg, linking back to the children's experience in the lesson's warm-up segment. The teacher sang the song for the children after having established their understanding of the song's beginning. She used different voices to distinguish the animals, applied meaningful intonation to stress the cat's excuses, and expressed the storyline through the movement of the puppets. Then she encouraged the children to dance on one leg while describing the situation and connecting the lyrics to their movements. She continued by singing the first verse again so that the children became more familiar with the song, after which they asked if they could sing with her. The children danced on one leg and sang a few short parts. In the second verse the teacher sang lower and with a different voice for the hare and the group joined loudly with “"'Bitte reich mit deine Tatze! (Please give me your paw)," because the line rhymed well. They demonstrated they had learned the phrase already. She stopped singing to introduce the word "zappelig (fidgety)" while shaking the hare puppet to demonstrate the word's meaning. The teacher checked for comprehension of the verse by asking a question. During the next verse the teacher paused a little before the line "Bitte reich mit deine Tatze! (Please give me your paw!)," giving the children the chance to sing alone and demonstrate their learning. As they went through the rest of the song the children sang more and more parts together with the teacher, showing their learning progress. The teacher selected a repetitive song that substituted only the animals and their characteristics. The children learned the song through repetition and understanding of the lyrics, through the visualization offered by the puppets and demonstration of their corresponding characteristics, and through applied guided questioning. They had the choice of how to participate: actively, involving movement, language, and mind; or passively using mind and observation.

\section{Practicing the Song}

The next segment (p. 237) helped practice the song as the children portrayed an animal using a puppet and singing the line "Bitte reich mit deine Tatze! (Please give me your paw!)." The teacher reviewed the storyline, the animals and their characteristics, and short phrases. By using repetition and movement she encouraged the children to join in the motion. This review supported comprehension of the song and provided more language structures and context for the children's language acquisition and application. The children practiced their lines and the teacher offered support when needed to ensure that the children had a successful language experience. They then went through the song one more time and the children demonstrated that they had a good 
understanding as signified by their singing, movements, and performance. In the end everyone was dancing with a partner and the teacher narrated effectively, offering descriptive language input that the cat was dancing with the tomcat, the dog with the hamster, and the hedgehog with the hare.

\section{Drawing Activity}

The children initiated the drawing activity (p. 238) through showing that they were exhausted from the cognitive work they had mastered during the last 30 minutes. The teacher used the situation as a teachable moment by giving Lea (L1 English, 4 years) the role of the teacher. The child taught the phrase that she had provided demonstrating direct peer support. Afterwards, the group repeated the phrase together, "Können wir bitte malen? (Could we please draw?)" The teacher praised Lea for being a good teacher and the others for being good students to encourage the application of complex structures in the target language and to promote language acquisition. Through this process, the teacher transformed a loud and overwhelming situation into a constructive language learning experience.

In the organizational aspect of the activity, the teacher used a false statement in the form of a question to check the children's comprehension. The group demonstrated their language skills through offering a variety of words. The teacher then checked their recognition of the vocabulary by placing a box with markers and pens on the table asking, "Sind das Stifte? (Are these pens?)" and they agreed, further demonstrating their language competence. This process enhanced the children's language competence while providing a means for success because they were familiar with the vocabulary.

Afterwards, she reviewed the animals the children had learned in a previous lesson by following a copy that the children had in their language folders. The teacher selected a child to give the answer with the aim to observe the children's individual language competencies. Sophia (L1 English, 4 years) did not remember the vocabulary so the other children offered peer support. For example, Lea (L1 English, 4 years) said, "ein Pferd (a horse)," and Sophia repeated the word and Cloe (L1 English, 4 years) recognized the next picture saying, "ein Teddybär," which the entire group repeated. In smaller group situations the children supported each other more because they were learning together, relied on each other, and felt safe in this established environment. Then the teacher continued reviewing the animals that appeared in the song using the text handout with pictures to offer visualization and to check the children's comprehension. This review activity demonstrated that the children had as a group mastered the recognition and recall of parts of the song that they had just begun to learn. 
After the review the teacher returned to the organizational aspect of the activity by asking if someone would like to color pictures of either the song page or a blank piece of paper. The teacher used descriptive language accompanying every activity to prompt the children's language use and practice. This was also applied during the drawing when the children requested a certain color from

the teacher. Repeating the color provided opportunities to practice requests, which seemed natural for the children to do. For example, Cloe (L1 English, 4 years) told her, "Ich brauche rot (I need red)," and the teacher replied, "Rot, bitte schön. Hier ist rot für dich. (Red, here you go. Here is red for you)." The teacher used repetition and set the color into a language context. Since everyone liked several colors the teacher was busy. Mira repeated a couple of times, "Ich brauche pink (I need pink)," and with each repetition her language became more articulate, showing another aspect of the language application in a usually non-verbal activity. Amy asked, "Bitte haben rot, schwarz, orange (Please, have red, black, orange)," and the teacher rephrased her question offering a language model that the child could use. 
Summary

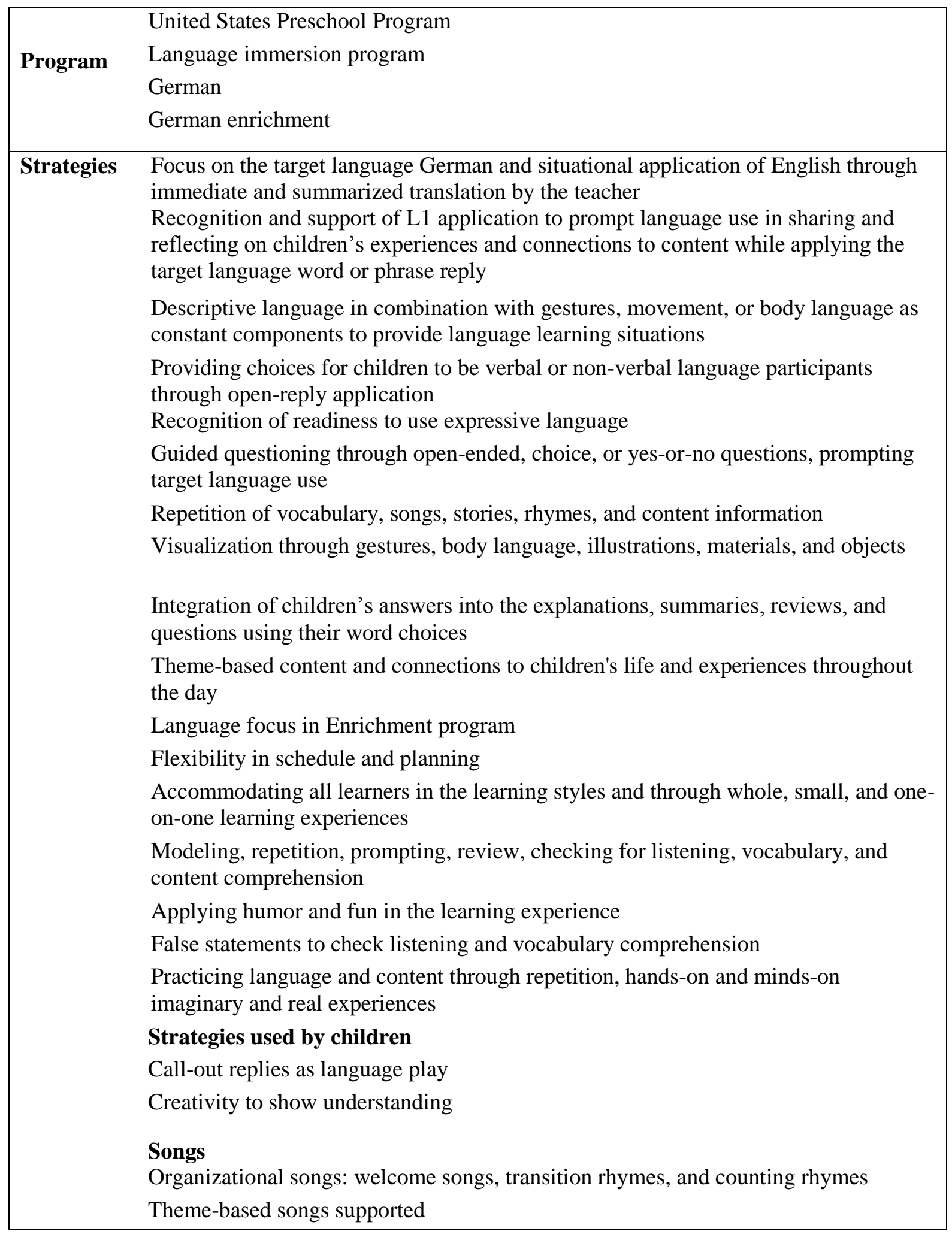




\begin{tabular}{|c|c|}
\hline & $\begin{array}{l}\text { Symbol cards for key vocabulary } \\
\text { Demonstration through gesture, body language, movement, and objects } \\
\text { Dramatization }\end{array}$ \\
\hline & $\begin{array}{l}\text { Language Presentation } \\
\text { Read-alouds, storytelling, and introduction of activities } \\
\text { Short pre-reading activity to set minds on the topic through review } \\
\text { Children's involvement in discussions through guessing and prediction of the } \\
\text { story } \\
\text { Focus on language presentation with application of visualization through gesture, } \\
\text { illustration, body language and without interruptions } \\
\text { Making connections between story and reality } \\
\text { Post-reading activity connected to main topic of the day }\end{array}$ \\
\hline Activities & $\begin{array}{l}\text { Songs, rhymes, and read-alouds with repetitive and authentic nature } \\
\text { Creating art projects } \\
\text { Organizational situations understood as language learning moments } \\
\text { Choice time activities and books }\end{array}$ \\
\hline $\begin{array}{l}\text { Language } \\
\text { Use of } \\
\text { Children }\end{array}$ & $\begin{array}{l}\text { Situational language use of target and L1 language in instruction based setting } \\
\text { Self initiated call-out as language practice } \\
\text { Person-bound and situational language application }\end{array}$ \\
\hline $\begin{array}{l}\text { Role of } \\
\text { Children }\end{array}$ & $\begin{array}{l}\text { Choice of active participant through language use or passive participant using } \\
\text { observation and making connections to build language comprehension } \\
\text { Teacher and leader } \\
\text { Unaware and aware language presenters }\end{array}$ \\
\hline $\begin{array}{l}\text { Peer } \\
\text { Support }\end{array}$ & $\begin{array}{l}\text { Application of aware and unaware language models } \\
\text { Helping each other to follow the instructions }\end{array}$ \\
\hline $\begin{array}{l}\text { Role of } \\
\text { Teacher }\end{array}$ & $\begin{array}{l}\text { Facilitator of language learning environment being teacher, guide, listener, prompter, } \\
\text { questioner, demonstrator, and supporter }\end{array}$ \\
\hline
\end{tabular}




\section{United States Kindergarten Program}

The theme-based curriculum was applied throughout different segments of the daily schedule including circle times, free play and choice activities, and the project time. This allowed children to be involved the entire day in theme-oriented activities.

\section{Circle Time}

The kindergarten circle times included the same components that have been discussed in detail in the preschool program, such as the welcome songs, good bye songs, and transitional rhymes. The kindergarten program used the songs the children had learned during preschool while adding theme-based songs according to the topics they were working on. The weather and calendar were discussed daily. During the advent season the teachers added tea-light candles and an advent wreath as part of the German cultural experience and countdown to Christmas.

\section{Introduction and Discussion}

In the introduction to the main activity (p. 269), the teacher applied the guided questioning strategy to review and explore what the children had learned about the theme they had worked on throughout the last two weeks. She started with an open-ended question, then built on the information given by the children and expanded it to the question, "Wie können wir uns mit Kunst ausdrücken? (How can we express ourselves through the arts?)" This was a leading question in the art unit, "In the footsteps of great artists." She narrowed the focus by asking for people that they had studied. Marie (L1 English, 6 years) answered demonstrating her understanding of the question and the teacher repeated the name in her reply, but continued to search for the artist they were exploring. Then several children connected the question and Marie's answer, calling out "van Gogh." The teacher used repetition to correct and to practice the pronunciation of the name, using choral speaking several times, which the group enjoyed.

In the next step the teacher focused on social studies by discussing some biographical aspects of the artists and where they had lived. She started with the latter and provided rich context through locating the countries on the world map posted on the wall. While the group established the location of the European continent, Leon (L1 German, 5 years) shared his personal connection to the continent as the place where his grandparents lived. The teacher engaged him in a short conversation demonstrating that she valued the children's personal connections. She used this as a teachable moment while showing the country on the world map. Discussions always allowed room for the children to make personal connections that expressed the way they related to themes taught and also 
demonstrated the children's comprehension and language competencies. After this personal excursion, she returned to the main subject focusing on van Gogh's country of origin. The children mentioned Paris remembering parts of his life story that the teacher had introduced the previous day. She reviewed parts of his life story and pointed out the difference between a city and a country, while showing Paris and the border of France. Since this was still a new topic, and she recognized that the children did not know the answer, the teacher gave the answer to her question. The children demonstrated their knowledge while connecting Matisse with the country of France. The visualization of the countries and cities on the map allowed the children to connect their knowledge in context to geography.

After the geographical aspect she asked a few yes or no questions related to the time period. She used a timeline to visualize the concept of time periods, showing the pictures of the artists above their birth years and their life span. Through this introduction the teacher placed the artists into a time and place, showing how these were different than the children's so that they would understand the story and context of the artists' lives. This helped prevent the children from connecting the artists to their own time period. The understanding of time and place are important concepts that the children learned in kindergarten. The teacher supported the information by visualization through the use of the world map and the timeline. The children were making connections through their personal experiences and being included in the demonstration of the timeline. They could choose the role of an active participant, answering questions and offering personal experiences, or a passive participant, using observation to make connections in their minds and build knowledge.

\section{Read-Aloud: Camille and the Sunflowers by Laurence Anholt}

The teacher used the picture book Camille and the Sunflowers written by Laurence Anholt to share more biographical aspects about Vincent van Gogh and to introduce some of his artwork in story form (p. 271). The book was in English and the teacher presented a summarized translation in German. The children sat in theater-style seating to follow the story. She started the read aloud by briefly explaining her goal, the title, and checking the group's knowledge about the artist, who was part of the storyline. While reading, the teacher allowed the children to interact with the story through asking questions, filling in the blanks, guessing, commenting, evaluating, and making connections to their knowledge and learning environment. The teacher held the book so that the children were able to see the illustrations throughout the read-aloud, which helped the children connect the story and the visuals, further building their understanding. Occasionally, she moved the book even closer to the children so that they could look at the illustrations in detail. This was the case 
while posing the question, "Sehen die aus wie richtige Sonnen? (Do they look like real suns?)," and the children took a second look before agreeing with her. The teacher also included gestures and rich intonation in her reading.

In the discussion about fathers' occupations (p. 272, lines 14 to 22) the teacher applied fill-inthe-blank and guessing strategies to check the children's vocabulary comprehension about professions. The teacher was especially interested as this represented a topic that was part of another unit. One child offered the word, "a trainer," combining the word train that she saw in the illustration with the German ending "er," which is used to name professions for males. The teacher understood what the child meant and offered the target language term in her reply. She accepted all answers while applying the target language reply. The children called out their ideas without being concerned about making mistakes and felt safe in this learning environment, supporting their oral language application. The teacher used the words provided by Lisa (L1 German, 5 years) and continued to read a few of sentences before stopping to ask a question about the mechanics of the mail system. When she noticed that it was unfamiliar to the children she integrated the answers in her explanations. She continued the story using the strategy of language presentation for the next few pages, letting the story speak without interruptions while identifying words in the illustrations for visual support.

When one of the illustrations included a painting about the leading character's father (p. 273, lines 29 to 36), the teacher paused reading with the goal of drawing real life connections through demonstrating that the painting could be found in different books. This was an element of surprise for the children, and they could not explain it. Marie (L1 English, 6 years) discovered the picture on yet another book cover and showed it to the teacher, who encouraged her action and asked her to show it to the children. This situation prompted Jonas (L1 English, 5 years) to announce his realization using the German language by telling everyone that these were the same paintings. The teacher offered the right vocabulary choice in her reply, and Luca (L1 English, 5 years) applied it in his comment. She recognized the children's excitement and continued the discussion by inviting the children to express their opinions. This connection between a painting found in a picture book, and the same in non-fiction books, led to a learning moment, in which the children used their second language in a deep and meaningful context, demonstrating their language competencies. The teacher further enriched this moment by making a connection to the children's experience of drawing their own profiles. They discussed what it takes to sit for a painting and the materials artists use to paint, including the canvas, which they had the chance to paint on later.

During the next part of the language presentation the children noticed that the people in the story did not like the paintings the group had just established as beautiful and famous (p. 274, lines 46 
to 54). Some of the children got distressed and upset. This created another rich learning moment initiated by the children and conducted through a discussion showing their opinion, deep understanding, and reflection of personal attitudes and expectations. Katja (L1 German, 5 years) interrupted the story to express her deeply felt opinion, "Die zeigen kein Respekt (They do not show respect)" and Lisa (L1 German, 5 years) repeated a statement from the story through which the children opened up a discussion about behavior. The teacher agreed with their observation and the other children added their views. They compared the behavior and action to the students' attitudes posted on the wall around the circle time area, which the group agreed on and tried to follow. The children selected the ones that suited this situation: the people were not demonstrating tolerance, respect, and empathy. They had discussed attitudes at the beginning of the year and were behaving accordingly. The attitudes were part of the IB program and to be applied in daily lives.

The teacher continued to read, ending the read-aloud when the story showed Vincent painting at night with candles on this hat. The illustration was very similar to Starry Night, which she used to segue into the main project of the day. Throughout the read-aloud the teacher used guided questioning to prompt target language use, explored the comprehension level, and coordinated childinitiated discussions. Learning moments were established and enhanced by teacher and children while drawing real life connections and building on the children's experiences.

\section{Group Painting Discussion and Activity "Starry Night"}

At the beginning of the last segment of the morning circle time the teacher asked the children to observe the children's book illustration that was similar to Starry Night but had a few differences such as the painter, a bigger lake, and the position of the village (p. 275). She asked the group to find a similar painting — building on the children's interest shown earlier. This inquiry was the transition to the discussion of his painting style and colors used. While using open-ended questions she engaged the children in expressing their observations (p. 276, lines 5 to 11). The children offered their main suggestion, "Sterne (stars)." With the next question she wanted the children to go deeper into expressing their observations, and children talked about the colors with Katja (L1 German, 5 years) using the phrase, "Mit helle Farben. (With light colors)." The group had learned about contrast in the previous week, which the teacher referred to while Lea (L1 German, 5 years) expressed how she liked the way the stars were painted. In the next step, the teacher led the children into a comparison between their ideas and the artist's idea of painting a star (p. 276, lines 12 to 36). She emphasized, through connections with their drawing experiences and her guided questions, that there are different ways of making stars. In this exercise the teacher led the children to understand how one 
could paint in the artist's style while practicing with an imaginary brush. The children found it difficult to make the very short brush strokes and Lea commented in German that this was not easy.

The teacher introduced the application phase, explaining the mechanics of painting with an easel, brush, and paint, and emphasizing the idea of background, with which children in general have a difficult time. She painted the background dark, following the children's suggestion. The children guided the teacher's presentation and demonstration through answering the teacher-initiated questions. In the next step the teacher turned the painting practice into a group experience (p. 277, lines 37 to 52). She called the children to the front while discussing their ideas and what each child would add to the painting using small brush strokes, which they continued to find challenging. The teacher was rendered speechless when Sophie (L1 English, 5 years) recognized the wind being expressed in the painting through the white clouds. She applied deep thinking skills, making connections been the wind and the clouds, and noting the impact wind has on clouds. She consequently connected it all to the painting and found it in the artist's interpretation. During the hands-on and minds-on demonstration the teacher applied guided questioning to prompt answers and engage the children in language application, using open-ended or yes and no questions to build on the children's individual experiences. The children decided between verbal participation and silent observation.

\section{Project Time: "Starry Night" Discussion and Instruction}

After free play and choice time the teacher continued with the theme "Vincent van Gogh and Starry Night," introducing the project of the day through instructions. She used descriptive language and visual support in the form of the painting and materials used in the project (p. 283, lines 1 to 24). She asked guided questions to check the children's understanding of the theme. Noticing problems with his name, the group practiced the pronunciation several times. While giving the instructions for the project (lines 13-23) the teacher emphasized that is was important to see the artist's painting as a model and that the children should express their own creativity by using small brush strokes in the style of the painter. It was her intention that the children apply and practice their fine motor skills, which was still very challenging at this age. She used observation and discussion to explain the style, and used descriptive language with visual support. The teacher integrated a mathematical focus in the form of shapes into the painting project and let the students explore rectangles and their characteristics. She showed the children a rectangle and compared it to a house. The children recognized immediately that the roof was missing, demonstrating their understanding of the comparison. Leoni (L1 English, 6 years) used gesture to accompany her statement, which she 
expressed by slowly constructing what she wanted to say. The teacher agreed, leaving her statement untouched so it could resonate with the children while Luca (L1 English, 5 years) practiced the word "Ausschneiden (Cut out)." He created meaning by connecting the word with the action. The teacher planned for the children to explore the characteristics of the rectangles, continuing with the project instructions (line 24). The teacher's emphasis was on the creativity of the children along with the small brush strokes, which depicted van Gogh's painting style. The art project demonstrated the children's understanding of the information presented in the morning and during circle time. She gave direct instructions for the art project, visualizing each step to ensure that the children would have a successful outcome.

\section{Painting "Starry Night"}

The organizational part of the art project (p. 285) was accompanied by language, with the children demonstrating their language comprehension in the decisions they made. While the teacher placed a big piece of construction paper in front of the children, a chorus of "Ich will blau (I want blue)" filled the room. The children enjoyed practicing phrases using choral speaking. This selfinitiated language application can be seen as a group form of language play. The teacher guided the children through the instructions, applying descriptive language and visualizing what she was saying so that the children received additional language input. The children demonstrated their understanding of the teacher's questions through yes or no answers, and Leon (L1 German, 5 years) chose to reply in a statement using code-mixing, showing that the German word was not part of his expressive language competence. The teacher then reviewed the instructions, using the painting as visual support while prompting language application. She asked the children to demonstrate their understanding, requesting that they offer their own explanation of the next step, which was gluing the buildings in place. Maria (L1 English, 6 years) offered the answer, showing her comprehension and language application competence while the teacher repeated parts of her statement and informed the group to start the activity.

While working on the project Marie (L1 English, 6 years) asked a question, demonstrating that she was unsure about how to get a triangle out of the rectangles. She did not want to explore the problem on her own, relying instead on an explanation or model. The teacher referred the question to Leoni (L1 English, 6 years), who had answered the same question before. Leoni's answer was too abstract for Marie, as there was no visualization of the answer and the process was not explained in detail. Therefore, the teacher changed the answer into a specific guided question and continued asking the children while observing their work to find a child who could apply the concept. Seeing 
what Luca (L1 English, 5 years) was doing, she directed attention to him, offering a model and prompting his language application to explain the concept. He had created roofs by moving the two triangles together and apart and saying, "So schneidet man eine Haus aus (That is how one cuts a house)." He demonstrated his knowledge while showing the concept and at the same time received recognition from the group. The teacher used the children's knowledge to provide an answer to Maria's problem by engaging the children in language application and modeling through guided questions. She recognized the other children's ideas while the children remained focused on the activity. This creative project supported and practiced the understanding of geometrical shapes.

During the project time the children used person-bound language application, speaking German with the teacher and English or German with their peers. The group at the blue table encountered a problem because Leoni (L1 English, 6 years) had taken almost all the paper pieces into her possession (p. 286). Marie (L1 English, 6 years) and Lea (L1 German, 5 years) expressed their feelings in English, applying their preferred language while playing with each other during free play time. The teacher placed additional pieces on the table and reminded the children to share, using the target language to solve the problem. Leoni returned a few pieces back into the middle of the table.

Another example of person-bound language application occurred when Jonas (L1 English, 5 years) cut two stars out of the squares (p. 286). He said to Leon (L1 English, 5 years) in English, "look what I cutted [sic] out, I made a star," while placing it onto the upper part of his paper. Though using English with his peer, the language they used together during free play, he used German with the teacher to show his creation of the star. Turning to the teacher and holding up the star he said something that was neither German nor English. He recognized the mix of sounds and became aware that he had used English and that this was not the language used with the teacher or inside in general. After a few seconds he said to her in German, "Schau her. Ich habe ein Stern ausgeschnitten. Ein Stern (Watch this, I have cut a star. A star)." The teacher liked his creativity but wanted him to stay on task by working on the city. She redirected his focus while Jan (L1 German, 5 years) and Leoni (L1 English, 6 years) helped her to restate the steps of the project.

When Luca had finished his city and searched in his box under the table for crayons he repeated several times, "nachher den Himmel malen (later color the sky)." He remembered the phrase from the instructions and practiced it as private speech, keeping himself focused on the task. In this situation the child applied the language through rehearsal language play. He associated the word "malen (to draw)" with the crayons he was searching for, while Lisa (L1 German, 5 years) offered peer support pointing to the paint in the middle of the table and trying to tell him several times 
to use paint. He demonstrated his comprehension by taking a brush and starting to paint. Lisa's constant application of the target language provided both direct and indirect peer support.

The teacher distributed more paint to the tables while Jan (L1 German, 5 years) engaged her in a conversation about his grandfather being an artist (p. 287, lines 1 to 10). This situation was a personal learning moment for Jan, who shared his personal experience while trying to construct the meaning of the terms famous and artist, and understand their correlation. He seemed unsure as to whether artists were always famous. The teacher guided him by explaining that he was an artist, though not yet a famous one. When he understood the concept he restated that he was an artist but painted only for himself, showing his comprehension. Luca, Jonas, and Leon heard the conversation and focused on the word famous (lines 11 to 20). They started playing with the word, constructing simple sentences and thereby practicing application and pronunciation. The teacher supported their language play by repeating the phrases in the form of questions while checking for comprehension. This led to a family member listing contest to which Jonas applied self-correction, noticing that he used the plural of the verb to be. The teacher ended the conversation through acknowledging that all families were famous, helping the children to return their focus to their work.

While looking at the painting, the teacher conducted one-on-one and small group discussions on the techniques van Gogh applied (p. 289). This not only provided the children with a focus on style, but also provided additional language input while the teacher checked the children's comprehension. When some children announced, "Ich bin fertig. Fertig. (I am finished. Finished)," she encouraged the children to critically observe their artwork with the goal of recognizing any improvements they could make. The children's artwork (see right side Figure 72) demonstrated their individual interpretations of Starry Night. The technique of using small brush strokes was applied according to each child's fine motor skills and creativity. The concept of creating a triangle from a rectangle was present in all paintings, showing a variety of different applications. One child demonstrated creative problem solving skills through adapting the concept of using a trapezoid to create the roof for a house. The paintings were hung around to room in order to create a children's art gallery as a visual representation of the learned information and a means of sharing their work with visitors and parents. 


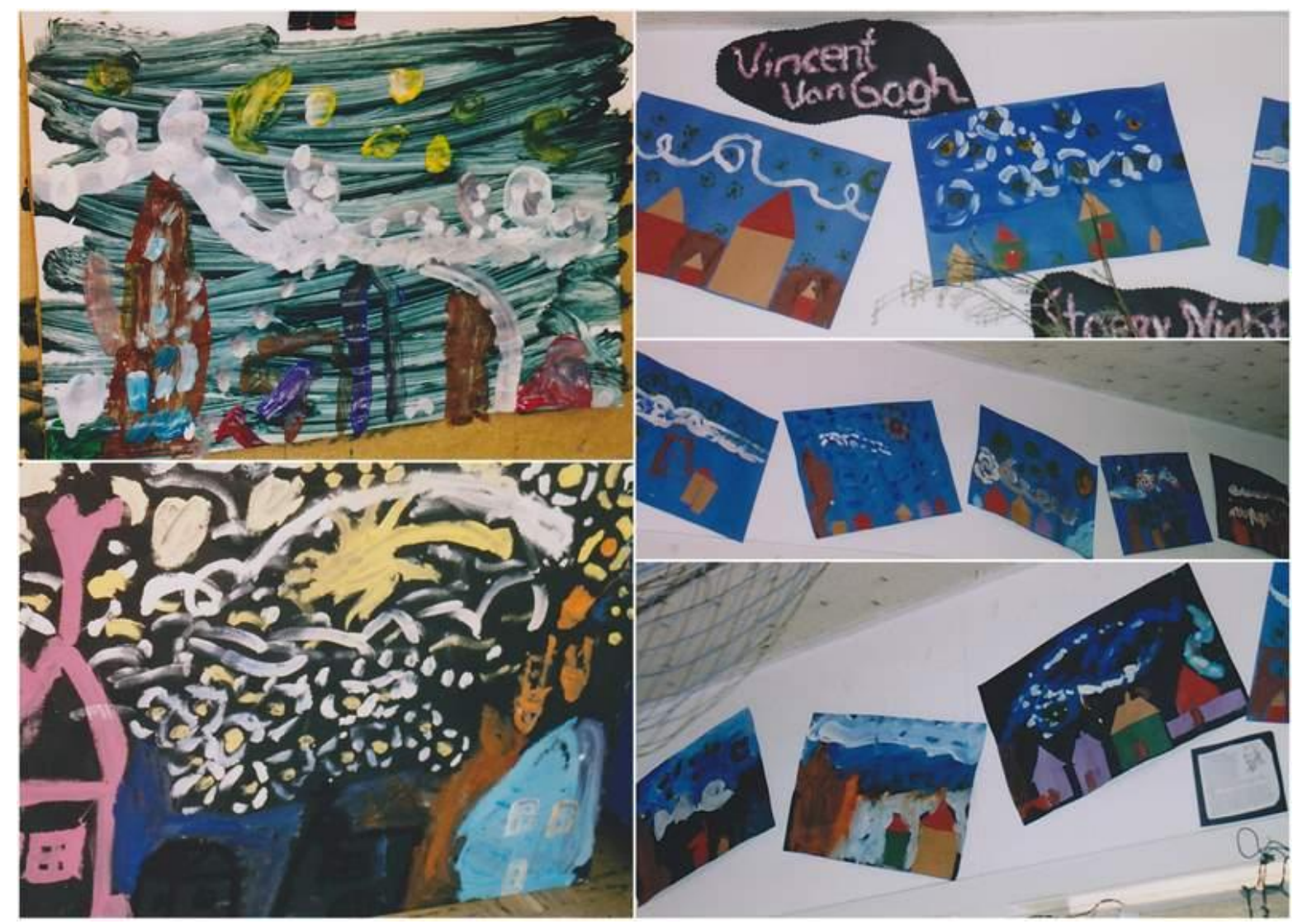

Figure 72. U.S.K.P.: Children's renditions of "starry night:" individual (right), group painting circle time (upper left), and group painting project time (lower left).

\section{Group Painting "Starry Night”}

The teacher included the group painting project (p. 290) to accommodate varying work pace, to promote collaboration, and to share experience while learning from each other as well as taking other views into consideration (see lower left side of Figure 72). She explained the activity using descriptive language, reviewing the instructions and giving the children the choice to participate. The children painted their part of the group painting while learning to collaborate and solving problems that occurred with the help and guidance of the teacher. The children applied their skills and comprehension to the group painting while engaging in short conversations.

\section{Project Feedback Chart}

As an evaluation unit, the teacher applied a project feedback chart that recorded the interests, likes, and dislikes of the children and provided a possibility for the children to reflect on their experience (p. 292). She conducted small individual interviews through which she also observed the 
children's language competencies. The children added a happy, neutral, or sad smiley face depending on how they perceived the project.

\section{Artist Memory and Visit to the Principal's Office}

In the closing circle the teacher returned to the theme-based curriculum, introducing an art memory game that was based on the artists they had studied (p. 301). The children felt that they could be part of the memory game because they saw themselves as artists, and the teacher agreed with their view. She explained how their addition to the game would make it more complex. The teacher demonstrated her flexibility, embracing the children's role in shaping and influencing the curriculum. Through the introduction of the memory game the teacher reviewed information discussed earlier and the children demonstrated their skills through the application of the open-reply strategy. The children could answer questions by calling out the answers, allowing all children to use the target language more frequently and according to their interest and knowledge. The teacher applied this strategy continuously throughout the day. The group played the memory game a few times and it was very easy for the children. Afterwards, the teacher introduced a new artist to prepare and inform the children of what they could expect to learn the next day. She embedded the new information and engaged the children in making connections between the artists and their country of origin by using visual support in the form of the world map and memory cards. Luca (L1 English, 5 years) expressed his understanding of friendship between people from the same country, which showed his deep level of comprehension and created meaning, connecting the information offered with his personal understanding. The teacher then added the memory cards to the game and they played it twice. The activity remained easy and enjoyable for the children.

As the next step in the closing circle the teacher had planned to bring the group painting to the principal to integrate community connections and outside recognition for the students' accomplishments through sharing their knowledge and work. The teacher had systematically spread the theme-based topic throughout the day, enforcing repetition, review, and language input for the children so that they learned both the concept and the language required for its expression. She applied a variety of activities such as review, read-alouds, art projects, and a memory game to create a rich environment for language and content presentation and for knowledge transfer.

\section{Storytelling: Christmas Party}

The storytelling segment (p. 304) provided a language presentation using narration with gestures, props, and body language produced by the teachers on the children's language level. The 
narrations included model dialogues of real-life conversations and were built on actual events, interweaving the medium of humor and exaggeration. Each week the story included moral elements connected to the life of the children and elements that would engage the children in short answers to show their comprehension. The children were able to create their own mental image while listening and watching the performance unfold, learn new language phrases, and observe language being used in the form of a longer presentation, improving their own conversation and communication skills.

\section{Target Language Rule}

The target language rule defined that German was spoken in the classroom and that students should remind their peers to do so with the phrase, "English raus (English outside)." The child would then go to the door or turn to the door to place the language outside. The rule was supported by kinesthetic action which expressed the meaning of the phrase. The rule had been established at the beginning of the year in agreement by children and teachers. Throughout the observation the children used the rule frequently and in a friendly manner. The rule was used more frequently during transitional periods before which the children had used their preferred language, such as arrival to school or following recess.

\section{Children remind Children}

The following example showed the rule being used during arrival time (p. 265). Lea, Sophie, and Hannah (L1 English, 5 and 6 years), who used English with each other as their preferred language, started together the block pattern activity while their minds were still set on English. Lea, happy about finding a certain piece, held her hand up showing what she needed and saying proudly, "Look what I found." Lisa (L1 German, 5 years), who had lived in Germany until a year ago, also worked on the activity and reminded Lea of the rule "Englisch raus (English outside)." and the other children joined her. As Lea noticed what she did, she sighed "Oh," and turned her head to the back pretending to put the words outside. Lisa recognized that English was used because her main language was German and she still had a strong sense of separation between the two languages. Sophia and Hannah were unaware until Lisa's comment and so was Lea, who had to think about her last words to check if the statement was correct. She acknowledged the fact and turned her head to the door to follow the rule.

\section{Self-recognition by Child}

During the same activity several more self-recognition situations occurred, for example, Sophie (L1 English, 5 years) spoke in English but became instantly aware of its accidental use (p. 
266). She wanted to provide a solution to a problem she had observed, which was that not everyone could reach the box with pieces, and stated, "Okay, I will give everyone a piece." The children did not notice her use of English but after a few seconds Sophie turned to Lea telling her "Englisch raus (English outside)," and further turning her head around looking toward the door. She was very proud of her self-recognition but forgot to hand out pieces. Sophie connected to Hannah's statement and repeated, upset, "Englisch raus. Das habe ich schon gesagt. (English outside. I have said that already)." In this situation, Sophia had become aware of her language use while listening to her own words, and corrected her language use by applying the rule.

During morning free play Jonas and Niklas (L1 English, 5 years, p. 281), who used mainly English with each other, entered after playing on the play ground while still talking in English. Jonas recognized that he had broken the rule and said, "Englisch raus (English outside)." He ran back to the door to leave it outside. I observed this natural self-correction several times by different children. The natural self-correction shows not only the children's willingness to follow a rule but also an early commitment to using their second language. 
Summary

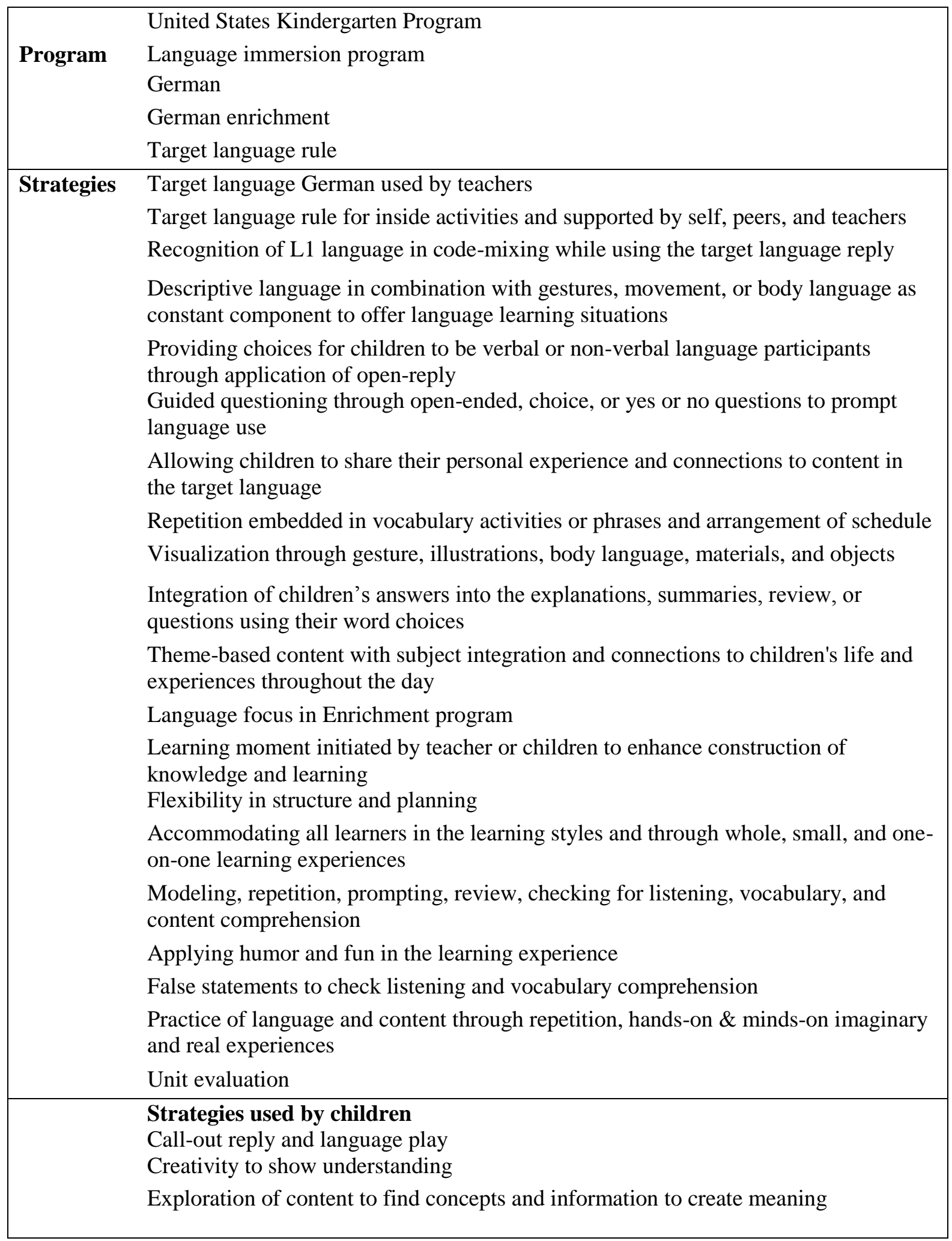




\begin{tabular}{|c|c|}
\hline & $\begin{array}{l}\text { Songs } \\
\text { Organizational songs - welcome songs and transition rhymes }\end{array}$ \\
\hline & Language Presentations \\
\hline & Read-alouds, storytelling, and introduction of activities \\
\hline & Short pre-reading activities to set minds on the topic through review \\
\hline & Children's involvement in discussions through guessing and prediction of the story \\
\hline & $\begin{array}{l}\text { Focus on language presentation with application of visualization through gesture, } \\
\text { illustration, and body language without interruptions }\end{array}$ \\
\hline & Making connections between story and reality \\
\hline & Post-reading activities connected to main topic of the day \\
\hline & Review of presented information \\
\hline Activities & Circle time with songs, read-alouds, storytelling, activities \\
\hline & $\begin{array}{l}\text { Project time - intro short review \& offering instructions while teaching new } \\
\text { vocabulary needed in the context; project - creating a collage using cut-outs and paint } \\
\text { and a group painting of starry night, project evaluation; }\end{array}$ \\
\hline & Organizational situations understood as language learning moments \\
\hline & Choice time activities and books \\
\hline Language & Situational language use of target language in instruction based setting \\
\hline Use of & Self initiated call-out as language practice \\
\hline Children & Person-bound language use \\
\hline & $\begin{array}{l}\text { Language play - construction of simple and not meaningful sentences while using the } \\
\text { phrase or word }\end{array}$ \\
\hline $\begin{array}{l}\text { Role of } \\
\text { Children }\end{array}$ & $\begin{array}{l}\text { Choice of active participation through language use or passive participation using } \\
\text { observation to make connections and build knowledge }\end{array}$ \\
\hline & Demonstration of the comprehension and knowledge through language or artwork \\
\hline & Teacher and leader \\
\hline & Unaware and aware language presenters \\
\hline & Application of guessing, inquirer, risk-taker, thinker and communicator \\
\hline Peer & Application of aware and unaware language models \\
\hline Support & Helping each other follow instructions \\
\hline $\begin{array}{l}\text { Role of } \\
\text { Teacher }\end{array}$ & $\begin{array}{l}\text { Facilitator of learning environment being teacher, guide, listener, questioner, } \\
\text { demonstrator, and supporter }\end{array}$ \\
\hline
\end{tabular}




\section{German Program}

The integration of languages and the focus on English were embedded in the concept of the kindergarten which was based on the view of educating the whole child and on the situational approach emphasizing intercultural learning as one aspect of the methodological framework. The pedagogues used emerging and theme-based situations as well as the established routines to integrate languages. The languages that were applied depended on the children's cultural backgrounds or the languages that children had acquired as well as English, which the pedagogues provided as the special focus of the program. Since the groups were age-mixed the variety of languages changed from year to year according to the cultural backgrounds that the new children brought with them.

In the interviews the pedagogue expressed that the children whose primary language was not German would use their mother tongue outside, during choice time, or in smaller play areas such as the building or dramatic play areas when these children shared the same language. The languages across both groups were Russian, Tibetan, Farsi, Greek, English, and Italian. However, the main language used by all children was German.

The pedagogues recommended that parents use their heritage language with the child while the children would further develop or acquire German and some English in the program as well as learn some vocabulary and understanding of other languages in accordance with the mother tongues of the children in the group. Parents were invited to share their language and culture through activities and short presentations. It was considered an important aspect to see each child in connection to his or her cultural heritage while opening doors to new cultures. I observed that children valued and understood the concept of language, making connections to cultural experiences.

The pedagogues applied open planning and connected the activities to the theme they were exploring. The current theme was city and country life, with an emphasis on the forest. Kindergarten took place in the forest once a month and for an entire week during the summer. The children spent all day in the forest, going about their regular kindergarten routine. The teacher searched for themebased activities that developed German and English language skills. It was important that all language activities were integrated naturally or according to the situation, and applied based on the concept of play or through the arts to facilitate creativity and imagination in the learning process.

\section{Morning Circle Time}

In the morning circle, languages were integrated for greetings, counting the children to establish the number of children present, and the day of the week. The pedagogue greeted the group in English, Italian, Spanish, and German (p. 154). The children repeated each greeting with joy and 
lots of energy. The children would repeat each phrase without having to construct the output, and comprehension was assisted through the inclusion of the German phrase. Since this was a daily occurrence, the children were used to the greeting and enjoyed using different languages in their morning welcome routine.

The attendance component was the next part that integrated languages other than German (p. 156). The pedagogue asked in English, "Who wants to count the children?" and the children showed interest through calling out in German "I want," or by show of hand. They were very eager to conduct the counting activity in English, Russian, and German. However, this was a challenging task because the children had to demonstrate their own language competency by knowing the numbers in various languages. The pedagogue selected Sara (L1 German, 6 years) because she was part of the enrichment group that had English at least twice a week and had learned counting in the setting, Victor (5 years) because his mother tongue was Russian, and Antje (4 years) because hers was German. The children counted slowly so that they had a chance to repeat the numbers, which many children chose to do. All children had the chance to count in German and English throughout the time, and counted alone or with the support of the pedagogues and children depending on their skill level. The children who had these skills in different mother tongues such as Russian, Italian, Tibetan, Arabic, and Farsi were asked and encouraged regularly to share their languages with the group so the other children could learn these skills. This provided experiences and created interest in the mother tongues of the children. The pedagogues had familiarized themselves with the other languages by trusting the native speakers in the group to teach them. They invited parents to come and teach about their languages and cultures if they had the time and interest.

The last segment of the circle time that included English was the conversation about the weekday (p. 156). The pedagogue conducted this in German and asked the group saying, "und heute ist in English ... (and today in English is ...)," and the children filled in the blank using the English "Monday" in a loud and proud chorus. Naturally, they started to sing: "Monday, Tuesday, Wednesday, Thursday, Friday, Saturday, Sunday - every day is a special day." The song had a nice easy rhythm so that it was very easy for the children to learn and the pedagogue struck the chime for each day, adding a pleasant sound. Earlier in the year the pedagogues had taught the weekday song that the children remembered and had integrated into the circle time. The 5 to 6 year-olds usually started the song, the 4 to 5 year-olds then joined the song, and some of the 3 - 4 year-olds sang along while others observed the event. The pedagogues integrated the English name for the weekdays daily, but the song was not always part of the calendar time. This depended on the interest of the children and daily form. 


\section{Read Aloud: We Are Going on a Bear Hunt}

The read-alouds took place during either choice or circle time segments. If an English book was read it was introduced in small group read-alouds, then read during circle time, or introduced in the opposite order, either of which provided repetition for the children. The children decided how many times they wanted to hear a book being read and what vocabulary they wished to remember. In the case of We are going on a bear hunt the pedagogue first introduced the book during choice time to a group of children who chose to participate (p. 160). After the group had explored the front and back cover, establishing the family members in German, the pedagogue introduced each one in English while pointing to each person on the cover. The children were carefully watching her mouth saying these words as she repeated the sentence slowly, with some children repeating the words after her. The children repeated the words as they felt able, expressing the ones they were able to repeat. The pedagogue connected the vocabulary with the illustration on the cover, helping the children to comprehend the new information. She then read the title, We are going on a bear hunt, and translated it into German. This immediate translation provided comprehension of the key phrases that were repeated throughout the story. She continued with a few pre-reading questions in German such as, “where do you go on the hunt for a bear?" or, "Have you been on a bear hunt?" The questions and the pre-reading activities helped prepare for the reading while letting the children predict where the story might take place.

The next step in reading the story involved the pedagogue repeating the title twice. While reading she demonstrated individual words such as "catch" and "big" with gestures or body language, and through her intonation and rhythm she emphasized the melody of the story. She used the strategy of language presentation, through which the children got a feeling for the words and identified the ones they new already. Then she read the page line by line, stopping after each line to discuss the meaning. The children knew the first line already and expressed the meaning as a group. This was a sign of accomplishment and encouraged the children to concentrate and remain focused in their participation. The next line was partially explained by Antje (L1 German, 4 years), "Big ist groß (big is big)," and the pedagogue praised her and offered the translation of the line. The children engaged in the translation process, demonstrating their comprehension and sometimes offering guesses. The pedagogue then built on the given information and provided the complete translation. This brought the children to understand that knowing a word or two can help to construct the meaning as a whole. She followed this structure throughout the book and included the illustrations to demonstrate the meaning of the words and to set them into a visual context. Occasionally, the pedagogue introduced a word such as river or mud before reading the page, supplying the children with the meaning of a key 
word and supporting their comprehension. Anielle (L1 German, 4 years) and Heiko (L1 German, 5 years) started to repeat a few words with the pedagogue, and all children made the movements accompanying the words: catch, big, scared, over it, under it, and through it. She suggested taking a break from the book after a few more pages were read, saving the rest for tomorrow morning.

The children looked exhausted but had enjoyed the read-aloud and agreed to finish the story tomorrow because one of the children would be picked-up after nap time. The pedagogue had used gestures, body language, and movement that supported content comprehension, and connected the meaning of the words with movement, which the children picked up quite fast. According to the pedagogue, using immediate translation supported understanding and helped the children to stay focused on the stories in general. The book was very repetitive in nature, which made it very suitable for this age group, and it also connected with the countryside and forest theme that they had been working on throughout the year.

\section{Getting in Line}

The pedagogues used English during transitions from place to place, such as going to the bathroom (p. 161). According to the pedagogues, this procedure helped with behavior and shifted the focus onto the task at hand. After everyone was in line the pedagogue asked the children in German, "How should we go to the bathroom today?" The children called out different animal names in German and English until the group agreed on ladybug. She told them the English word, and slowly, one by one, they flew off with their arms at shoulder-height while repeating the word. This introduced the children to a variety of animals for which each child created their own movement and repeated the word several times. This technique was applied several times throughout the day for bathroom breaks or after nap time when the children individually came upstairs.. According to the pedagogues, the older children already used more English words due to the English enrichment, while the younger children usually suggested the animals in German unless it was an animal from On the farm, an English song they had learned.

\section{Song Practice: On the Farm}

The action song On the Farm was introduced by using a video that taught the song step by step and included movements and a related story. The pedagogues had explained that the children first watched the story, integrating the song into the narration. They then watched the teaching segment of the song, where children joined the movement and some started singing according to their readiness. After having watched the video and song several times over a period of two weeks, the 
pedagogues shifted to using the CD instead of the video. The groups had been working on the song for about four weeks before this study was conducted. The song was practiced once a day during circle or choice time.

During the morning outdoor choice time, the pedagogues called the children to make a big circle in which both groups joined (p. 166). The circle was comprised of about 50 children and five pedagogues. As the children waited for the $\mathrm{CD}$ player, which took a little while, some children started singing On the farm on their own. Malika (L1 German and English, 6 years) knew the song well. She began, unintentionally leading the singing while providing a model and cue, and thus prompting the children close to her to slowly join in. The pedagogues followed her lead and the group sang the song without CD player support quite well. The children enjoyed performing the gestures and movement. Some of the younger children watched the older ones to see their gestures and movements. By the time one of the pedagogues finally brought the $\mathrm{CD}$ player, the group was toward the end of the song and had no use for it anymore. The pedagogue gave the children a big compliment for how well they were singing and how well they knew the song already. The song included the numbers with which the children were already familiar, and the children were able to connect movement and gestures to the lyrics, which helped them to learn the song as well as the daily practice. The children performed the song for their parents during the summer forest festival, and the parents were quite impressed by the children's language competence. This song was included by the pedagogues because it integrated well with their theme and the enrichment program. Additionally, the 5 to 6 year-old children had visited a farm early in the spring and had learned about farm life, and this song therefore built on prior knowledge while presenting the corresponding English vocabulary.

\section{Edible Flowers}

During the free choice time, the pedagogues integrated English according to the language level of the children. The pedagogues integrated English through situational and person-bound language application, according to the children's familiarity with the language needed in a particular situation and to the person they were working with. In this example, the pedagogue teaching the English enrichment asked the children in German if they would like to try eating the nasturtium flowers she held in her hand (p. 170). Michail, (L1 Russian, 6 years) was a German language learner throughout his three years in kindergarten and also had English enrichment. The pedagogue was aware of his language competencies, and after a discussion about the concept of edible flowers in German she addressed him in English. She asked him the colors of the blossoms she held, offering 
him a choice question and relying upon his knowledge gained from enrichment to answer this question. This person-bound language integration appeared occasionally throughout the day.

\section{Lunch Time}

During lunch the pedagogues shared the table with the children and after the main course the children had fruits that looked fresh, ripe, and delicious - strawberries, cherries, peaches, and apples (p. 175). The conversation had moved to finding the names for each fruit in English and Russian. While the pedagogue offered the English vocabulary, Michail provided some of the words he knew in Russian, his favorites including strawberries, cherries, and mangos. The children repeated the words for strawberries, cherries, peaches, mangos, watermelon, and apples in English and Russian. Each child added their favorite fruit. Similar conversations could be heard on every table. The teacher integrated English into the daily experiences, and when the children saw the fruits they talked about their favorites, using this moment to learn and practice these words in English and the other mother tongues of the children at the table. During lunch the children learned about food and meals in English by discussing the main dish, the dessert, or the table setting, offering a component of daily repetition.

\section{English Enrichment}

During naptime the 5 to 6 year-olds from both groups who spent their last year in kindergarten participated in the English enrichment, offered at least twice weekly by Mrs. R. and supported by Mrs. S. The enrichment followed their daily experience in the program and was rather flexible in nature. The components were warm-up, vocabulary introduction, main activity, choice time, and closing segment. Within these components, the pedagogue used songs, read alouds, arts and crafts activities, and discussions. These were applied according what she hoped to review, practice, or introduce. The children often influenced the order and the content according to their interests and needs.

In this particular example of the enrichment, the observed group gathered on the blue circle time carpet (p. 178, lines 1 to 6). The pedagogue greeted each child in English and asked how he or she was feeling, and most of the children responded using the target language. The pedagogues used only English in this section, offering choices accompanied with gestures from which the children were able to select their answers. Malika (L1 German and English, 6 years) had more experience with English because it was one of her family's languages. Furthermore, she demonstrated her language competencies by constructing whole statements while the other children used one word 
answers. She supported children who needed help by repeating the choices, modeling language structures from which the other children could learn.

The next step focused shortly on the weather, and the pedagogue explained in English that it was very hot that day, using her hand as a fan to demonstrate the meaning (p. 178). She used gestures to support the meaning of her sentence and offered an immediate translation so that the children were able to check their understanding and correct it if necessary. She then used a song as a language warm up, asking the children to sing Head, Shoulders, Knees and Toes while touching the body parts they were singing about. This offered the children language practice and helped place them in an English language mindset.

She continued with a review section, using their English folders as the object by handing them to the children while asking what color their respective folder was. Since both the folders and colors were a constant component, the children knew the color of their folder very well. The teacher referred to the children's artwork as a theme-based review (p. 178). These pictures were displayed on the English bulletin board in the hallway, but the children had not used the vocabulary for a while since they had moved on to the topic of paper, learning about different types and its production. Therefore, the children had a difficult time remembering the words and the pedagogue decided to present the vocabulary while pointing to the drawing to support their comprehension. Some children chose to repeat the words while others listened.

In the next segment the pedagogue combined different goals in the introduction of new vocabulary words and phrases (p. 179). Since Rico could not participate in the outing visiting the sheep herd, the pedagogue used guided questions in German to let the children talk about their experiences. This enabled Rico to create his own picture of the outing, including him in this project of enrichment. In this reflection of the outing she integrated the introduction of English expressions, using repetition and translation throughout while applying a few questions in English to check the student's comprehension. The children could repeat the words as they chose, and the pedagogue encouraged the children to apply the languages they were familiar with in the counting section.

She then reviewed the words she had introduced (p. 180, lines 41 to 68). However, since the children had reflected on their experiences, she had forgotten to introduce the word shepherd, which she had planned and included it in the review section. Since they were talking about animals the teacher reviewed all the animals the children knew through use of a German or English question.

After the review she introduced the project of the day, encountering mixed feelings from the children (p. 181). Some really liked this activity while others had a harder time embracing it. The pedagogue summarized the different experiences, then asked the group to portray their favorite part in 
a picture. Paula's mother picked her up, but she returned as she wanted to participate in the project. The children took a seat at the prepared table and some discussed what they would do. When the pedagogue started handing out the paper she returned to the English language, asking each child what color he or she wanted and giving them this choice each time (p. 182). The pedagogue applied repetition, addressing each child with the choice of color. During the creation of the collage the children focused on their work, conversing in German while the teacher reviewed some of the vocabulary.

The educator listened to the children's explanations about their work. The children who finished early could play or read books. Vivian, Marius, and Niklas thumbed through the pages of On the farm and opened some of the hidden pictures. Michail and Thomas played memory. Paula created a pattern with colorful wooden blocks. Malika and Mario were looking at the book We Are Going On a Bear Hunt. After a few minutes the children joined the pedagogue, who suggested singing the action song On the Farm as closure to the English enrichment. Everyone joined the circle and the pedagogue counted to three then started singing, expressing the meaning with gestures and movement.

Throughout the program and the enrichment the pedagogues applied a mixture of German and English when teaching the English language. The pedagogues explained two reasons for this application: the first being that the children felt uncomfortable with more than segments of English, and the second being that the children had no prior knowledge of the language. Other reasons that I observed were the open-planning application, which did not structure or prepare the enrichment enough, and the connection to a theme-based curriculum that moved weekly to different topics, making it difficult to focus on one theme for a longer period of time. The program's goal was not to lead the children to a high proficiency level in English, but rather to introduce English along with languages in general. The theme-base connection in the enrichment allowed the children to share and reflect on their experiences, using language the children were comfortable with, while placing an English language focus in the background.

In the field of early language learning, the exclusive use of the target language has been supported by researchers such as Curtain and Dahlberg, who stated:

There are two main reasons why language mixing and translation are inefficient. First, if the students know that the teacher is going to use both languages, they will not engage with the target language and will patiently wait for the English [German] "version" to appear. Second, the teacher who knows she or he will be clarifying in or repeating English [German] will not expend as much effort to make the target language comprehensible. (p. 42) 
These mentioned reasons seemed not to apply to this early childhood program's approach, in which the children engaged actively and had interest in applying the English language to songs and stories. In order to apply a single language approach, the pedagogues would have needed a more direct connection between the enrichment and the theme-based curriculum, providing a different structure. However, such an approach would reduce the application of the children's personal experiences. 
Summary

\begin{tabular}{|c|c|}
\hline Program & $\begin{array}{l}\text { Language integration approach } \\
\text { Multiple languages } \\
\text { English focus } \\
\text { English enrichment } \\
\text { GLL support }\end{array}$ \\
\hline Strategies & $\begin{array}{l}\text { Use of German and English languages } \\
\text { Theme-based content and situational connections to children's life and } \\
\text { experiences in the program } \\
\text { Immediate translation } \\
\text { Repetition of vocabulary, songs, stories, and thymes in the form of warm up and } \\
\text { review } \\
\text { Visualization through gestures, illustrations, and body language, } \\
\text { Use of movement } \\
\text { Use of multi-media to introduce and teach new songs or stories } \\
\text { Application of whole or small group settings or one-on-one } \\
\text { Application of target language segments } \\
\text { Dual language use to let students share and reflect their experiences in which the } \\
\text { target language was built } \\
\text { Read aloud } \\
\text { Pre-reading activity in German while teaching new vocabulary } \\
\text { Use of rich intonation and melody } \\
\text { Use of visualization through gesture, illustrations, and body language } \\
\text { Use of immediate translation } \\
\text { Built on children's vocabulary knowledge or their guesses before offering } \\
\text { translation }\end{array}$ \\
\hline Activities & $\begin{array}{l}\text { Greetings, counting of children, and calendar time } \\
\text { Songs, rhymes, and read-alouds with repetitive nature } \\
\text { Creating art projects } \\
\text { Organizational - handing out folder, choosing material --seen as language } \\
\text { learning setting } \\
\text { Choice time activities and books }\end{array}$ \\
\hline $\begin{array}{l}\text { Language Use } \\
\text { of Children }\end{array}$ & Receptive and expressive \\
\hline $\begin{array}{l}\text { Role of } \\
\text { Student }\end{array}$ & $\begin{array}{l}\text { Active participant through expressive language use } \\
\text { Observer } \\
\text { Children as teacher and leader } \\
\text { Unaware language presenters }\end{array}$ \\
\hline Peer Support & $\begin{array}{l}\text { Providing help for children } \\
\text { Unaware through presenting language models }\end{array}$ \\
\hline $\begin{array}{l}\text { Role of } \\
\text { Teacher }\end{array}$ & Facilitator of learning environment -teacher, guide, supporter \\
\hline
\end{tabular}




\section{Conclusion}

This case study of early childhood language-learning programs in Austria, Germany, and the United States has shown that children are aware of their own language competencies as well as those of their peers. This can be seen from their participation in activities such as circle time, in which they engaged either verbally or non-verbally depending on how comfortable they were speaking the target language. The children's application and acquisition of the target language was influenced and facilitated by the teacher's implementation of the curriculum and teaching strategies, by the program's organization, pedagogical approach, and method of language learning, and by the teachers' and children's roles in the learning environment. In structured contexts such as circle time or guided activities the children elected either to use the target language or to be a non-verbal participant, observing, imitating, and gesturing instead of speaking. Awareness of other people's L1 and L2 abilities was evident from the child's language choice in various person-bound contexts. A child with competence in both languages was able to switch from one to the other as required by the context, speaking his or her native tongue with a peer who had little L2 competency and switching to the target language when speaking with the teacher or with peers whose L2 competency was strong or who spoke a different mother tongue.

Figure 73, which illustrates the complexity of early childhood language application and acquisition, shows that the child's position in the learning process is central, and that the child makes the conscious or unconscious choice about which language to speak in a given situation.

\section{Languages and their Application by Children, Teachers, and Programs}

The variety of language combinations involved in the various programs indicates the multifaceted nature of the language environments included in this study. Children attending the programs were monolinguals, bilinguals, or multilinguals who used the majority and minority languages within a given community. According to Genesee et al. (2004), "the majority-minority distinction is not binary but it reflects points along a continuum" (p. 6). The spectrum of minority language communities can range from large to small, and depending on their size and on the time spent in them, their political and societal influences are often limited. Nevertheless, the created complex linguistic and culturally diverse societies require special consideration. The majority language community has to learn the characteristics of their transformed culture. In the three participating early childhood language programs, the children experienced and lived this complexity of languages as a first step in finding their understanding of culture on a daily basis. 


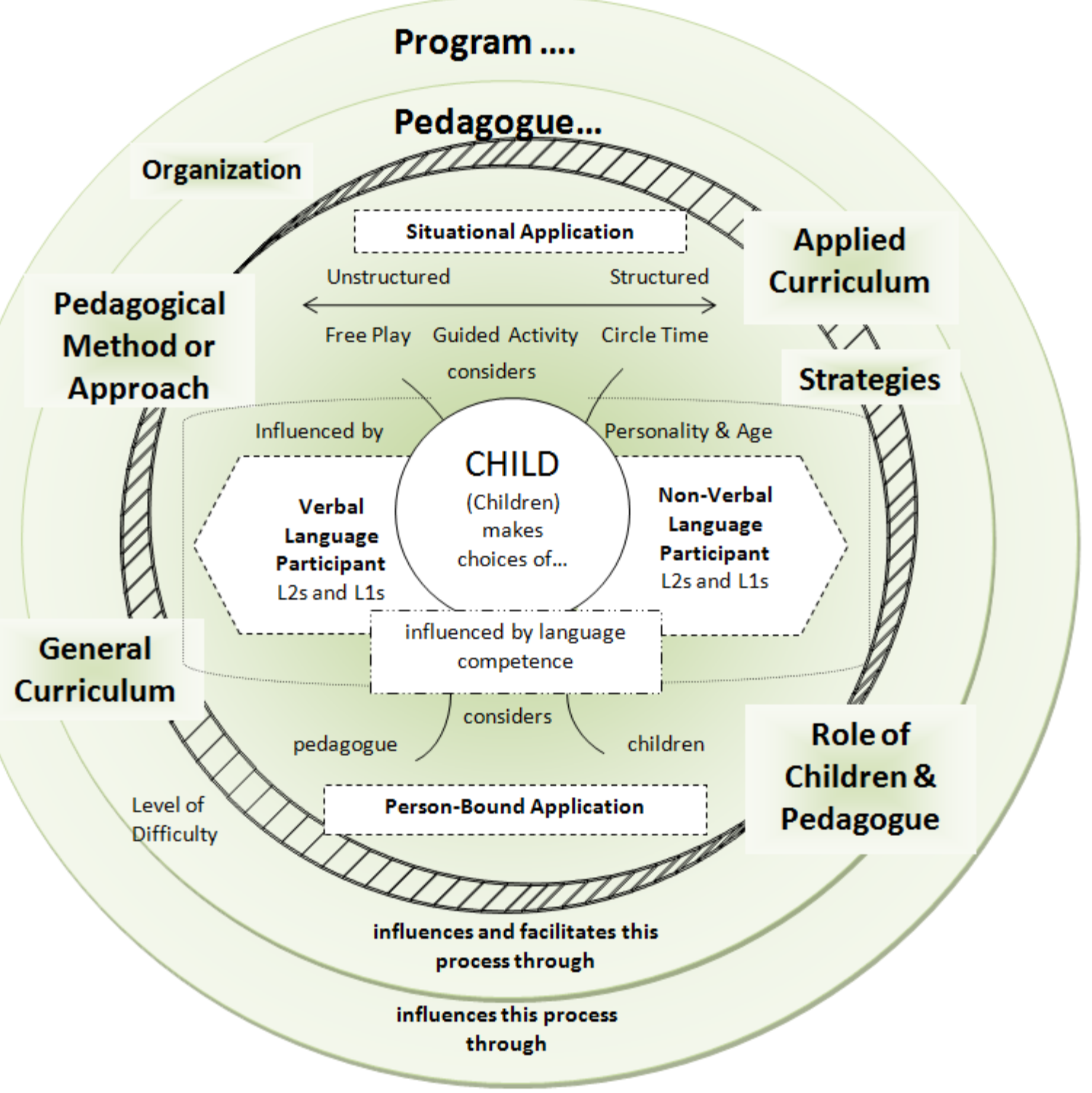

Figure 73. Guiding components and features constructing the complexity of early childhood language application and acquisition

The target language in the Austrian program (A.P.) was English, a minority language of the area. The majority language was German. The program included monolingual children who spoke German, English, or Japanese, bilingual children who spoke German and English, Hungarian and English, or Spanish and English, and multilingual children in Malayalam, English, and German or German, Hebrew, and English. The teachers were English native speakers or second language learners. 
In the United States preschool and kindergarten programs (U.S.P.P. and U.S.K.P), German, a minority language, was the target language and English, the majority language, could also be used by the children and teachers in the preschool setting. The children were monolinguals in German or English, bilingual in English and German or German and Finnish, or multilingual in English, German, and French, or English, German and Chinese. The teachers were native speakers of German. In the U.S.P.P. teachers used German as the main language and applied person-bound and situational English to accommodate all children in the program. The teachers used German in the U.S.K.P.

The Austrian and United States language immersion programs applied a minority language as the target language. Edelenbos et al. (2006) identified immersion as yielding "the highest level of target language proficiency," as did Curtain and Dahlberg (2010). Due to the dominance of the majority language the teachers implemented a target language rule. The rule was applied within the indoor facilities. The A.P. applied it to all children while the U.S.P. applied it to the kindergarten program only. The rule helped children in both programs to learn and use the language. The U.S.P \& K.P. was part of an immersion school and its results built the basis for the next grades and levels. The A.P. did not have this direct connection. Both programs had the goal of making the children become linguistic members of the target language community through acquiring verbal and listening competencies. The programs promoted cultural identities and awareness through the applied curriculum and strategies.

In the German program (G.P) German, the majority language, was the main language. English, the minority and second language, was integrated as well as other minority languages that were connected to the children's cultural heritage or competencies. Edelenbos et al. (2006) described in the report to the European Commission four models of language education for very young learners of which two apply to the German program. These two are 1) the integration of a particular language within a flexible curriculum and 2) "a language awareness model, ...giving access to a number of languages and cultures, in order to develop underlying qualities such as metalinguistic awareness and intercultural sensibility" (p. 11).

The G.P. included monolingual children, who spoke German or Macedonian, and bilingual children who spoke German and Russian, German and English, German and Farsi, or German and Slovak. The teachers initiated the English integration since they themselves have a good foundation of English as a second language and understood the benefits of early childhood language learning. Through the introduction of the intercultural pedagogy by the city's department of early childhood education, language teaching had become an emerging component in the kindergarten's concept. The teachers integrated the minority languages through actively learning them from the children. The 
language integration had the goal of introducing children to their peers' cultures and demonstrating the diversity and complexity of their groups, while creating linguistic and cultural awareness. Additionally, the English language focus was included to introduce a world language and to prepare children for their school experience in which the first foreign language will be English.

\section{Linguistic Diversity}

The children who entered the programs as monolinguals and bilinguals of other languages than the target language(s) were integrated in a non-mother tongue environment after just having established their first language(s). Tabors (2008) studied English language learners in United States preschools that did not make specific language accommodations for the children and were not language programs. She described a developmental sequence for beginning second-language learners that has four stages starting with 1) the application of home language, 2) a nonverbal period, 3) an application of telegraphic and formulaic second language, and 4) the productive language use in communication. Genesee et al. (2004) introduced the interlanguage phase that partly overlaps with Tabors' segments and is defined from the beginning of language production until native speaker competencies are reached.

The children in the participating early childhood language programs illustrated that developmental sequence was an interwoven tapestry of early childhood language application and acquisition. The stages of the sequence can be understood in the tapestry as segments. While the children moved from one segment to another in a somewhat sporadic fashion, their language use was also affected by situational and person-bound language experiences. Hence, the complexity of the groups and individuals involved in the language programs must be kept in mind. Tabors' developmental sequence may only be applicable to individual children or a small group with similar backgrounds and language competencies. Tabors (2008) stated:

It is important to realize, however, that the children learning a second language do not move discretely from one period to the next; in fact, except for the homelanguage use, which is usually eliminated when speaking to those who do not understand it, young children add skills to their repertoire from the next level of language use but maintain the previous techniques as well. (p. 64)

The children created an interwoven tapestry of language use based on their individual language competencies and the situations they found themselves in. Whether or not they spoke in their mother tongue depended on the diversity of languages present. The children had language communities within the programs that impacted their language acquisition and application. The 
influence of the mother tongues and majority language on the process can be seen as a continuum from enhancement to hindrance.

In the A.P. five children who had just started represented the first two segments - application of the home language(s) and nonverbal communication. The latter was signified through attentiongetting and gesturing. In structured situations, the children occasionally applied the third segment, telegraphic and formulaic language production. For example, Cloe (3 years old, L1 German) persistently used her home language with other children and teachers during the interrupted work time, while during circle time and guided activities she was a non-verbal observer who occasionally spoke in her mother tongue. She gathered information about the new language through observation and applied fragments of the new language during songs and rhymes. In the other programs younger children who had only some background in the target language exhibited similar behavior. Children, who had experienced the programs for a year or longer in the A.P. and G.P or for half a year or longer in the U.S.P \& K.P., used the four segments according to their choice and competencies considering the situation and the person. The children's use of the segments supported the applicability of tapestry of. non-verbal and verbal language application

Since Tabors' study was conducted in a general preschool without a specific language focus (Tabors P. O., 2008), more research in the form of longitudinal studies are needed. They should examine the acquisition sequences with a special focus on the relevance of the developmental segments for monolinguals or bilinguals, with no target language competencies in early childhood language programs.

\section{Children's Language Participation}

In the A.P., the children's language choice was influenced by the target language rule. The children embraced the target language and expressed this through enthusiastic and constructive participation in the offered structured situations such as circle times. They demonstrated language competencies through verbal or non-verbal participation. Except when the rule was broken, it transformed the monolinguals and bilinguals whose mother tongue was not the target language into non-verbal language participants. After observing what others were doing and saying, they began to make telegraphic and formulaic utterances in the target language, thereby reflecting Tabors' third stage. Once the non-verbal participants began to imitate what they heard, they entered the segment of linguistic development. Through the use of open-reply strategy all children were able to call out the answers if they felt comfortable doing so. This allowed them to determine the degree to which they participated and constructed a tapestry of verbal and nonverbal language participation within each 
child and the group. This was also true of guided activities where the focus was on one child or a small group of children. The teacher would first teach an activity so that the language needed was familiar to the children. They would then let them choose how they would participate according to their language skills or offer the answer for the child to repeat.

In the U.S.K.P., the structured context included circle and project times and the children's language participation was also influenced by the target language rule that the children followed. Language participation thus resembled the A.P., with the difference that German was the target language. The teacher used the open-reply strategy or called on children if they raised their hands. This supported the children's application choice and did not place them at the center of attention when they were not ready to speak German.

In the A.P. and the U.S.K.P. during unstructured components of the schedule such as uninterrupted and choice time, as well as parts of project time, the children occasionally used personbound language application with their peers when sharing the same mother tongue. When this occurred the children were either aware or unaware of their use. The outdoor play areas were open to all languages. The children employed the person-bound language application while using the target language for children that did not share the same mother tongue.

In the U.S.P.P. the children decided according to their language competencies to apply German or English in both structured and unstructured situations. The children's personality and age together with their language competencies influenced verbal and non-verbal language participation. The teacher used German and the strategy of target language reply for English language comments by the children, which is a form of direct translation. The teachers did not reject any language choice because children's communication should not be hindered by lack of target language competency at this age. This view is shared by Carver-Akers and Markatos-Soriano (2007), practitioners in a language-immersion Montessori program for 3 to 6-year-olds in Chapel Hill, who stated:

When observers inquire about the English they hear in the classroom among the children, we explain that we never tell a child that she [or he] may not talk at our school! New 3-year-olds use English for talking both to their guides and the peers (in most cases, English is the only language they know). We listen to these $3 \mathrm{~s}$, and, from the beginning, we respond to them in simple Spanish or French, using gestures so they can grasp the gist of the meaning and, more importantly, feel heard and emotionally secure. (p. 43)

In the G.P. the teachers and children used German in structured and unstructured situations as the main language. An English language focus along with mother tongues was integrated into the German language context in routines such as attendance, establishment of the week day, greetings, 
and curriculum activities. The English enrichment program offered target language segments and German language-guided activities. The children applied their choices of verbal and nonverbal language participation. The pedagogues explained in the interviews that the children who shared the same mother tongue other than German also applied person-bound language during choice time in more private areas such as the block and dramatic play areas or outdoor play areas.

The programs shared the practice of allowing the children to decide between verbal and nonverbal language participation. These individual decisions were influenced by their language competencies and consideration of situational or person-bound application. Through this either conscious or unconscious process, the children demonstrated complex language awareness. This awareness developed differently according to the children's age. Another important aspect that the programs had in common was the application of the open-reply strategy. It had a significant role in allowing the children to define their language participation. Use of call-on strategy could impact language application negatively. Tabors (2008) recommended the open-reply strategy for ELLs in preschools stating:

Children should be allowed to respond to teachers' questions in unison or on a voluntary basis at circle time. By calling on a second language learner to respond in front of the entire class, teachers may render even the most confident child speechless. (p. 115)

The open-reply strategy created highly productive, language-prompting, lively, and at times somewhat loud learning environments. In these early childhood language learning programs this was a crucial time for language application and practice. The children often waited for a language model to be presented by peers or occasionally for the teacher to express the answer to a question or problem. They connected the presented language model with their own understanding of the concept and presented their answers as repetitions, made small changes, or paraphrased the language according to their needs. In these situations the teacher allocated more time, allowing the children to present their answers and guiding the direction of these answers. Edelenbos et al. (2006) listed as a good quality indicator in teaching languages to very young learners that children should not be forced "to speak, but also not left to be silent for too long" (p. 113). The open-reply strategy was applied with this understanding and proved to work well as shown through the children's participation.

\section{Languages and Curricula}

The teachers applied theme-based curricula for learning the target language in the A.P. and U.S.P. \& K.P programs. In contrast, the G.P. integrated English as their language learning focus while German, the majority language, was used to explore the theme-based curriculum. A theme- 
based focus is supported by Curtain and Dahlberg (2010), Edelenbos et al. (2006), and Cameron (2001). They suggested this approach for young language learners in the elementary school system. Cameron (2001) stated that using theme-based teaching offered exciting learning experiences for students and teachers alike while connecting language learning to the outside world and linking it to the students' interests. The programs demonstrated through their curricula that the same was applicable for early childhood language learning. Additionally, the programs' environments were aesthetically pleasing and carefully prepared by the teachers, supporting the applied curriculum.

These theme-based curricula incorporated different subject areas and art forms such as songs and music, rhymes, literature, storytelling, puppetry, and visual arts. The curricula, in a broader sense, referred to a holistic learning of language and content that is supported by Edelenbos et al. (2006) and Curtain and Dahlberg (2010). Including authentic children's songs, rhymes, and stories in the curriculum supported language learning and introduced the children to to the target language culture. The themes and topics employed culture in a broader sense focusing not only on the target language culture. The A.P. studied the theme "From the Milky Way to our city" and the children explored different continents and their cultures through books, the arts, museums, and the city's heritage. In the U.S.K.P the children studied the unit "In the foodsteps of great artists," through which their and the aritists' world and culture were explored. These two examples show the programs focus on building and promoting a globally-oriented cultural awareness that included the children's multicultural heritage.

Additionally, the curricula incorporated a language focus. The U.S.P \& K.P. offered the focus within the German enrichment. The programs shared the language focus application for classroom management and instruction, both of which were understood to be valueable language learning situations. This has been recognized by Curtain and Dahlberg (2010) and Cameron (2001) who stated that "routines can provided opportunities for meaningful language development; they allow the child to actively make sense of the new language from familiar experience and provide space for language growth" (p.11). Additionally, they offer a good possibility for language application and practice through the repetitive nature of early childhood education.

\section{Languages in Structured to Unstructured Situations}

The programs organized the schedule by alternating the structured language learning situations such as the circle times or enrichment and unstructured language learning situations such as choice time or outdoor play. This allowed for recuperation time between structured situations that demanded high language participation whether verbally or nonverbally and unstructured situations in 
which the children chose the events and play according to their needs and interests. The recuperation time allowed the presented language information to settle, to be practiced in their play, and to make unconscious connections between language and the concepts learned.

The programs' theme-based curricula were the foundation for the structured and semistructured components such as circle and project times. This provided a platform to teach and practice language(s), as well as to promote language application and acquisition in content-rich formats. During unstructured components such as choice or outdoor time the teachers offered guided activities and shared readings. These were semi-structured components that offered language-focus or theme-based situations. The teachers worked with children one-on-one or in small groups and provided specific language support for each child. The children chose to participate according to their interests and needs.

The A.P. followed the Montessori method, starting the day with two and a half hours of uninterrupted work time, a semi-structured component. During this time the children chose from a wide selection of language, mathematic, practical life, sensory, cultural studies, and art activities. The teacher introduced an activity in individual or small group lessons that focused on general learning concepts embedding language application and acquisition. For example, activities based on sorting or matching of pictures or objects with labels supported the visualization of vocabulary and established a concrete context. The cultural studies and language activities allowed children to develop their early literacy skills and enhanced their language learning experience. These language activities have found general acceptence in the American early childhood education. However, the general German and Austrian early childhood education system has not yet made use of them.

Further longitudinal studies are needed to explore the Montessori language concept and materials and their application in the field of early childhood language learning programs.

\section{Strategies for Early Childhood Language Learning and Teaching}

The teachers applied a manifold of strategies such as descriptive communication, guided questioning, open-reply, demonstration, repetition, prompting, and modeling to guide and support the children's language application and acquisition.

The teachers used descriptive language in combination with gestures, movement, body language, or modeling the action with the aim to visualize meaning of speech and to provide comprehensible input. This form of language application was a continuous component in their work, defining each interaction with a child or a group of children as a language learning situation. Tabors (2008) described two similar forms of language use by teachers. She introduced the first strategy of 
buttressing communication as "additional information delivered by a gesture, an action, or a directed gaze adds another dimension that helps the child to tune in to exactly what is being talked about, making it easier to get the message" (Tabors, 2008, p. 92). Second, she mentioned the strategy of "running commentary" in which the teacher accompanies the development of a teacher-guided activity through descriptive language application (Tabors, 2008). The teachers in the A.P, and U.S.P \& K.P. applied these two strategies continuously and in the same learning situation which made differentiation difficult. They received additional dimensions, namely the frequency and overlap of application. The latter was observed also by Tabors (2008). Since there was no term defining this phenomenon the expression descriptive communication evolved. The strategy of descriptive communication is defined by the continuous application of descriptive language in combination with gestures, movement, body language, or modeling an action to visualize the meaning and to present comprehensible input into each interaction with a child or a group of children. Descriptive communication takes full advantage of the moment, recognizing normal interactions as language learning situations..

The teachers incorporated demonstration as a constant factor in their teaching through the descriptive communication strategy as well as through the use of materials, objects, pictures, and illustrations. This strategy employed the goal to learn languages through various combinations of audio, visual, and tactile senses. The demonstrations accommodated an easement of language comprehension through concrete samples of the applied language content. In the A.P. the children explored concepts using the Montessori materials that provided a concrete representation through tactile and visual support and were accompanied by language. Curtain and Dahlberg (2010) discussed supplies, materials, and equipment needed for early language learning programs in schools and recommended their application as visual or tactile support. They stated that these will "provide the means for creating the concrete context that is necessary for meaningful communication. Because young learners require hands-on learning experiences with concrete objects..." (Curtain and Dahlberg, 2010, p. 335). Edelenbos et al. (2006) stated, "for early language learning a visual approach is paramount" (p. 126). The participating programs in this study made meaningful use of materials as visual and tactile support and combed them with language application to enhance early childhood language learning in structured and unstructured situations. The teachers offered pathways to establish connections between materials, objects, visuals, and language to promote and to explore the listening and language comprehension while evaluating a child need for more support as well as offering the teachers the possibility to remain in the target language. 
The teachers used the strategy of prompting to encourage verbal language producation, engaging students as verbal participants in the learning situations through the application of guided questioning, the integration of children's answers, false statements, and allowing children to share their personal experience and connections to content. Guided questioning was a technique that all teachers applied using different types of questions: open-ended, choice, or yes-or-no questions, which helped to scaffold language use according to age and language competencies and the presented content. This technique was usually paired with the open-reply strategy in structured learning situations giving the children the possibility to call out the answers. This process engaged the children in language application and practice. Through the open-reply strategy, the children made their own choices of whether they were ready and comfortable to apply their target language skills in the A.P. and U.S.K.P.

In the U.S.P.P the teachers used the call-on strategy more often because the children had the choice to answer in English or German, the target language. The reason for using both languages was to encourage the children in sharing their personal experience and connections to content as well as general support for language application. The target language competency of the group was very diverse according to their age and time of enrollment in the program. Their mother tongue played another factor in their choice of language use. In the G.P., the children's language competencies were connected to the language integration approach. Therefore, the children had only beginning competencies in English, the target language, and the teacher applied a majority language context, using German in discussions of the content and language translations for comprehension.

In all programs the teachers focused on the integration of children's answers into explanations, summaries, reviews, or questions. In the U.S.K.P. and U.S.P.P. this was emphasized by including the children's word choices. The teachers demonstrated that their answers were meaningful and encouraged more language contributions.

In all programs repetition was found in a plethora of applications to engage the children in productive language situations and to encourage the construction of meaning, leading to language learning. This approach is shared by Cameron (2001), Curtain and Dahlberg (2010), Tabors (2008), and Edelenbos et al. (2006). The repetition of vocabulary, songs, rhymes, stories, and activities were theme-based or language oriented and occurred immediately or gradually over a longer period of time. The teachers constantly used repetition in their language, applying the vocabulary in different contexts and activities. Cameron (2001) supported this application stating that "Vocabulary needs to be met and recycled at intervals, in different activities, with new knowledge and new connections developed each time the same words are met again" (p. 84). The teachers offered immediate practice 
of vocabulary in the form of individual and choral recalls. They built on the children's verbal language choices and the practice was initiated by either teacher or children. Additionally, strategies such as the target language reply, open-reply, and descriptive communication offered platforms for repetition of vocabulary. The children used repetition as a form of language play, showing selfinterest in the presented vocabulary. They applied repetition according to their age and language competence, choosing simple to more complex language structures.

\section{Use of Songs and Rhymes as Instructional Approach}

The teachers in all programs taught songs and rhymes from a holistic point of view, presenting the whole song at once instead of line by line. The songs and rhymes possessed a repetitive nature and varied in their language demands to address all learners in the groups. The U.S.P. and K.P., G.P., and the A.P. used authentic children's songs and rhymes. Additionally, the A.P. and G.P. used a professionally produced song that helped their teaching process and provided learning support. Curtain and Dahlberg (2010) stated that "songs learned in the target language have the double benefit of giving students experience with an important dimension of the target culture and helping them to internalize the sounds, the vocabulary, rhythms, and the structure of the new language" (p. 396). This applied to theme-based songs and rhymes while the organizational songs focused instead on the language learning aspect.

In the U.S.P.P. each song had either an organizational or theme-based purpose. The organizational songs and rhymes were accompanied by gestures or movement and used for routines and transitions with less demanding language and content. The theme-based songs were practiced during circle times and were accompanied by visualization or dramatization of the story or lyrical content, helping children construct meaning and supporting their use of the target language. Children used objects and movement to tell the story of the song or performed the content through dramatization. The U.S.K.P. revisited the children's experiences in the preschool program and applied the same organizational songs and rhymes. However, fewer theme-based songs were integrated due to a topic selection that did not offer a wide variety of children's songs. During unstructured situations such as arrival time and free play, the teacher played background music: modern or traditional children's songs or classical pieces that had a language focus. In the A.P., songs and music were a component of each circle time. The teachers used organizational and themebased or language-focus songs. Music was included to offer a rhythmical experience accompanied by movement, scarves, or instruments. The children across the programs joined the songs or rhymes 
with movement or gestures until they felt ready to become a verbal participant. The teachers selected a variety of songs that addressed all language learners according to their needs.

\section{Language Presentation}

I defined the language presentations as longer narrations and language use by teachers or children that allowed them to hear language structures and practice listening comprehension with rich content and in the context of the target language(s). The children's active cognitive engagement was shown by making connections to their understanding through asking questions and posing problems that occurred when a child tried to integrate new information into his or her current understanding. The language presentations provided a rich platform for the visualization of learning moments initiated by children and set into context by the teacher. I observed these learning moments in all programs. Depending on the situation some were traceable while others were hidden because thinking and thoughts are non-verbal in nature. In the U.S.K.P and in the A.P.'s yellow and red group, these moments were more traceable due to the developmental stage and language competencies. Occasionally, children offered a window into their construction of language comprehension and acquisition through expressing a problem or question. Vygotsky explained that "thought and speech turn out to be the key to the nature of human consciousness" (Vygotsky, 1986, p. 256). The children expressed their thoughts, problems, and questions using the target language, demonstrating their engagement in the language presentation. The active listeners showed passive behaviors resembling Mayer's theory (2009), which explored active and passive participation in the field of learning and instruction while considering high and low activity in both learning and instruction. Mayer (2009) arrived at the conclusion that the constructivist understanding of the learning process "can be caused by passive instructional methods (such as principled presentations) and can be hindered by active instructional methods (such as pure discovery)" (p. 195).

\section{Types of Language Presentations}

The teachers applied read-alouds, storytelling, introduction to activities, experiments and projects, reviews, and songs as types of language presentations. Other types of language presentations are possible depending on the content and context of the learning situation. Additionally, the children's language competence and form of participation might transform a situation for a child into a language presentation. For example, while a group was singing a song, a child or several children may use observation or non-verbal language strategies as a form of participation, transforming this song into a language presentation. 
Read-alouds and storytelling were recurring forms of language presentations and the teachers used them in their daily work during circle or choice time. In the U.S.K.P. and the A.P. these were conducted in the target language, while the U.S.P.P. used the book's language, a summarized translation of the story, or a combination of both. The G.P. used the target language followed by a direct translation after each page. The teachers applied pre-reading activities and discussions to introduce or review needed vocabulary or phrases and summarize the plot. These activities established connections to children's prior knowledge and drew their minds to the topic. During presentations the teachers used different voices, emphasized intonation, gestures, and movement, showed illustrations, and invoked brief discussions through guessing and predictions of the storyline. Showing the book illustrations prior to reading a page or throughout the presentation seemed very important to the children. Otherwise, children who were not able to see would try to change position or somehow get a glimpse of the illustrations.

The A.P.'s blue group read-alouds postponed the post-discussion of the book until after circle time. The discussion was conducted during the uninterrupted time when a child or a small group of children would initiate reading the story again. The teacher tailored the reading and discussion to the needs of the child or group of children.

In all programs the children explored the books read in read-alouds during their free choice time. Teachers repeated stories according to interest and needs over a longer period of time. The educators also made connections between the story and the children's real-life experiences. The theme-based selection of books made it possible to use an aspect or topic from the story as a transition or as a base for activities or projects. The language presentation offered a foundation to introduce, review, and repeat vocabulary while the children had the chance to hear it used in context and construct further understanding.

\section{Role of Teachers and Children}

The teachers in the programs facilitated the learning enviroment by taking roles as teacher, guide, supporter, listener, and questioner. They designed a rich language learning environment that they explored and maintained with the children. The children were responsible for their own learning while making choices among the presented information and influencing the content. The teachers used language presenting strategies and the chidlren decided on engaging cognitively and orally according to their competencies. The children, through their demonstrated competencies, supported the language learning of peers through both conscious and unconscious role modeling. The peer 
support in the programs could benefit from more focus. It would be helpful to teach children strategies so that they could support each other in their journey of language learning.

\section{Implications}

This case study of early childhood language learning programs demonstrated that the programs shared features and characteristics concerning schedule, curriculum, program, instruction, language application, and language and instructional strategies leading to language acquisition and application. Their implementations have been analyzed and discussed. For a summary of the guiding components and features constructing the complexity of early childhood language application and acquisition for early childhood language programs see Figure 73. These components and features can be used in early childhood language learning as well as general early childhood education when working with children of linguistic diversity.

\section{Future Research}

In conducting this study I found that locating research concerning the field of early childhood language learning and corresponding programs proved to be exceedingly difficult. The applied research in this study was connected to either ELLs in non-language settings, or applied to early language learning that is present in elementary schools. The age group of three to six-year-olds needs more scholarly attention. This study offers a starting point through its observational findings and allows future research to focus on specific topic areas and to deepen understanding through additional longitudinal research while considering the language learning process and environment from the view of the teacher, child, and researcher. Early childhood language education and programs are growing and present a wide open arena for research. The future research that I recommend emerged directly through conducting this study and includes:

1. Longitudinal studies of early childhood immersion and language integration programs with the focus of providing deeper insight into the findings of this study and enlarging the body of available research in the field.

2. Longitudinal studies exploring the Montessori language concept and materials and their application in the field of early childhood language learning programs.

3. Longitudinal studies concerning the sequence or tapestry as a whole, with a special focus on the entry of monolinguals or bilinguals with no target language competencies into early childhood language programs are needed to investigate this phenomenon. 
4. Country-wide studies in Germany, Austria, and the United States to collect data for each country in the field of early childhood language learning from birth to school entry.

5. Revisiting the identified strategies to establish a cannon of the strategies that will be used by teacher education programs to prepare early childhood educators and to guide continued training of practitioners in the field.

6. Studies focusing on the understanding of children participating in early childhood language programs to learn about the choice-making process while revisiting the conclusions of this study.

7. Further collaborative studies of practitioners in the field and the research universities to learn current practices and to integrate newly established research findings.

8. Studies focusing on the application of the arts in the field of early childhood language learning.

9. Studies focusing on the aspect of intercultural pedagogy or multicultural education to establish their role in early childhood language programs.

10. Studies focusing on theme-based curriculum application and planning in the field of early childhood language learning programs.

\section{Summary}

This study provided a deep view into the daily experiences of children and teachers in early childhood language learning programs as presented in Chapters 4 to 6 . These experiences, the linguistic competencies and their application by each child, and the analysis of the data led to the representation of my findings as shown in Figure 73. At the center is the child with his or her language competence, age, and personality. Each child makes choices concerning the form of verbal and non-verbal language participation while considering the situation and person in the application. Both teachers and children guide, facilitate, and interact throughout the applied curriculum, strategies, and the program environment. These facets define the child's path on the language difficulty continuum. The paths overlap, creating a tapestry in which the children attempt to become a verbal member of the target language environment. The teachers and children of the participating programs helped to develop this view through sharing their work and experiences and transforming observations into this model and conclusion.

The early childhood language programs have followed the intentions of the European Union which has begun to establish Union-wide support for language learning. Austria and Germany focused on integrating language learning into the elementary school system. The children in this study demonstrated that early childhood language learning, given an environment conducive to this learning, can be both successful and challenging at the same time. 


\section{Bibliography}

AATG. (2010). KLD Overview. Retrieved April 2, 2010, from American Association of Teachers of German: http://www.aatg.org/kinder-lernen-deutsch/182-kld-overview

ACTFL. (2006). ACTFL Position Statements. Retrieved April 2, 2010, from American Council on the Teaching of Foreign Languages: http://www.actfl.org/i4a/pages/index.cfm?pageid=4743

Anholt, L. (1994). Camille and the Sunflowers. Hauppauge, NY: Barron's Educational Series, Inc. Austrian Center for Language Competence. (2004). Förderung des Sprachenlernes und der Sprachenvielfalt: Aktionsplan 2004-2006 der EK, Prioritäten und Umsetzung in Österreich. Graz, Austria: Austrian Center for Language Competence.

Austrian Centre for Language Competence (ÖSZ), Austrian Federal Ministry for Education, the Arts and Culture (BMUKK), \& Austrian Federal Ministry for Science and Research (BMWF). (2009). Language and language education policies in Austria: Country Profil Austria. Vienna, Austria: BMUKK, BMWF, and ÖSZ.

Austrian Federal Ministry for Education, the Arts and Culture, Austrian Federal Ministry for Science and Research, \& Austrian Centre for Language. (2008). Language and language education policies in Austria: Country report Austria. Vienna, Austria: authors.

Austrian Federal Ministry of Economy, Family and Youth (BMWFJ). (2010). Gratiskindergarten und verpflichtender Besuch [Free kindergarten and mandatory attendance]. Retrieved February 1, 2010, from BMWFJ: http://www.bmwfj.gv.at/Familie/Kinderbetreuung/Seiten/Gratiskindergarten.aspx

Bayerisches Staatsministerium für Arbeit und Sozialordnung, Familie und Frauen, Staatsinstitut für Frühpädagogik München. (2003). Der Bayerische Bildungs- und Erziehungsplan für Kinder in Tageseinrichtungen bis zur Einschulung. Weinheim, Germany: Beltz Verlag.

Bennett, C. I. (2007). Comprehensive multicultural education: theory and practice (6th ed.). Boston: Pearson Education.

Berger, M. (2005). Recherchen zum Kindergarten in Österreich: Gestern - Heute - Morgen. (Martin R. Textor) Retrieved March 2, 2010, from Kindergartenpädagogik: Online-Handbuch: http://www.kindergartenpaedagogik.de/1240.html

Blackstone, S. (2001). Bear on a Bike. London, England: Barefoot Books.

Bock, P. (2005, March 6). Infant science. Pacific Northwest - The Seattle Times Magazine .

Brett, J. (2003). Gingerbread baby. New York, NY: Putnam. 
Broner, M. A., \& Tarone, E. E. (2001). Is it fun? Language play in a fifth-grade spanish immersion classroom. The Modern Language Journal , 85 (3), 363-379.

Brooks, J. G., \& Brooks, M. G. (1999). In search of understanding: The case for constructivist classroom. Alexandria, VA: Association for Supervision and Curriculum Development.

Brown, B. (1992). The history of bilingual education in America. Washington, DC: U.S. Department of Education.

Bundesrepublik Deutschland. (2006). 8. Buch Sozialgesetzbuch: Kinder- und Jugendhilfe (SGB VIII). Berlin, Germany.

Caccavale, T. (2007). The correlation between early second language learning and native language skill development. Learning Languages , 13 (1), 30-32.

Cameron, L. (2001). Teaching languages to young learners. Cambridge, UK: Cambridge University Press.

Carle, E. (2003). Brown bear, brown bear, what do you see? London, England: Mantra.

Carver-Akers, K., \& Markatos-Soriano, K. (2007). Our Young Cultural Ambassadors. Montessori Life (2), 42-47.

Ceo-DiFrancesco, D. (2007). A Montessori approach to learing another language. The NAMTA Journal , 32 (1), 197-210.

Charlotte Bühler Institute. (2009). Bundesländerübergreifender BildungsRahmenPlan für elementare Bildungseinrichtungen in Österreich [Countrywide education framework for elementary education institutions in Austria]. Vienna, Austria: Ämter der Landesregierungen der österreichischen Bundesländer, Magistrat der Stadt Wien, Bundesministerium für Unterricht, Kunst und Kultur.

Chomsky, N. (1965). Aspects of the theory of syntax. Cambridge, MA: MIT Press.

Commission of the European Communities. (2005, November 22). Communication from the Commission to the Council, the European Parliament, the European Economic and Social Committee and the Commitee of the Regions: A new framework strategy for multilingualism. COM (2005) 596. Retrieved from EUR-Lex: http://eurlex.europa.eu/smartapi/cgi/sga_doc?smartapi!celexplus!prod!DocNumber\&lg=en\&type_doc $=$ COMfinal $\&$ an_doc $=2005 \&$ nu_doc $=596$

Commission of the European Communities. (2003). Communication from the Commission to the Councile, the European Parliament, the European Economic and Social Committee and the Committee of the Regions: Promoting Language Learning and Linguistic Diversity: An Action Plan 2004-2006. Brussels, Belgium: European Union. 
Commission of the European Communities. (2008, September 18). Communication from the Commission to the European Parliament, the Council, the European Economic and Social Committee and the Committee of the Regions MultiLingualism: an Asset for Europe and a Shared Commitment. COM (2008) 566. Retrieved from EUR-Lex: http://eurlex.europa.eu/LexUriServ/LexUriServ.do?uri=COM:2008:0566:FIN:EN:PDF

Commission of the European Communities. (2005, March 22). Progress towards the Lisbon objectives in education and training. Retrieved from European Commission: http://digm.meb.gov.tr/belge/EU_edu2010_progressreport05.pdf

Cook, G. (1997). Language play, language learning. ELT Journal, 51 (3), 224-231.

Crane-Fisk, C. (1986). Foreign Language Instruction Within a Montessori Environment. Proceedings of the Annual Meeting of the American Council on the Teaching of Foreign Languages. Dallas, TX.

Creswell, J. W. (2007). Qualitative inquiry \& research design: Choosing among five approaches. Thousand Oaks, CA: Sage Publications, Inc.

Croker, R. A. (2009). An introduction to qualitatve research. In J. Heigham, \& R. A. Croker (Eds.), Qualitative research in applied lingustics: A practical introduction (pp. 3-24). London, U.K.: Palgrave MacMillan.

Curtain, H., \& Dahlberg, C. A. (2010). Languages and children: Making the match - new languages for young learners, grades $K-8$ (4th ed.). Boston, MA: Pearson Education.

Curtain, H., \& Pescola, C. A. (1994). Languages and children (2nd ed.). White Plains, NY: Longman Publishing Group.

Decker, C. A., \& Decker, J. R. (2001). Planning and administering early childhood programs (7th ed.). Upper Saddle River, NJ: Prentice Hall.

Deutsches Jugendinstitut e.V. and Dortmunder Arbeitsstelle Kinder- und Jugendhilfestatistik. (2007). Zahlenspiegel 2007 - Kindertagesbetreuung im Spiegel der Statistik. Retrieved from Bundesministerium für Familie, Senioren, Frauen und Jugend: http://www.bmfsfj.de/Publikationen/zahlenspiegel2007/1-kinder-bis-zum-schuleintritt-intageseinrichtungen-und-kindertagespflege.html

Donaldson, J. (2002). Monkey puzzle. London, England: MacMillan Children's.

Doods, D. A. (1999). Sing, Sophie. Somerville, MA: Candlewick Press.

Edelenbos, P., Johnstone, P., \& Kubanek, A. (2006, October). The main pedagogical principles underlying the teaching of languages to very young learners. Languages for the children of Europe Published Research, Good Practice \& Main Principles. Retrieved from European 
Commission, Education and Culture, Culture and Communication: EU Language Policy: http://ec.europa.eu/education/languages/pdf/doc425_en.pdf

Eurydice. (2005). Key data on teaching languages at school in Europe. Retrieved from Education, Audiovisual and Culture Executive Agency (EACEA): http://eacea.ec.europa.eu/ressources/eurydice/pdf/0_integral/049EN.pdf

Eurydice. (2008). Key data on teaching languages at school in Europe. Retrieved from European Commission, Education, Audiovisual and Culture Executive Agency (EACEA), Eurydice: http://eacea.ec.europa.eu/education/eurydice/documents/key_data_series/095EN.pdf

Fairfax County Public Schools. (2010). World Language Immersion Programs. Retrieved February 22, 2010, from Fairfax County Public Schools, High School Instruction and K-12 Curriculum Resources: http://www.fcps.edu/DIS/OHSICS/forlang/partial.htm

Forrest, S. N. (2004). Implications of No Child Left behind on family literacy in a multicultural community. The Clearing House, 78 (1), 41-45.

Fosnot, C. T. (2005). Constructivism revisited: Implications and Reflections. In C. T. Fosnot (Ed.), Constructivism: A psychological theory of learning (2nd ed., pp. 276-292). New York, NY: Teachers College Press.

Fosnot, C. T., \& Perry, R. S. (2005). Constructivism: A psychological theory of learning. In C. T. Fosnot (Ed.), Constructivism: theory, perspectives, and practice (2nd ed., pp. 8-38). New York, NY: Teachers College Press.

Freie Hansestadt Bremen - Senat für Arbeit, Frauen, Gesundheit, Jugend und Soziales. (2005). Rahmenplan für Bildung und Erziehung im Elementarbereich. Bremen, Germany: author.

Freie Hansestadt Hamburg Behörde für Bildung und Sport - Amt für Kindertagsbetreuung. (2002). Sprachförderung in Kindertagesstätten: Mehrsprachigkeit ist eine Bereicherung! Hamburg, Germany: author.

Freire, P. (2001). Pedagogy of the oppressed. New York: Continuum.

García, O. (2009). Bilingual Eudaction in the 21st Century: A global Perspective. Chichester, UK: Wiley-Blackwell.

Genesee, F., Paradies, J., \& Crago, M. B. (2004). Dual Language Development and Disorders (Vol. 11). (S. F. Warren, \& M. E. Fey, Eds.) Baltimore, MD: Paul H. Brookes Publishing Co., Inc. Gilzow, D. F., \& Branaman, L. E. (2000). Lessons learned: Model early foreign language programs. McHenry, IL: Center for Applied Linguistics and Delta Systems Co, Inc.

Gitter, L. L. (1970). The Montessori way. Seattle, WA: Special Child Publications. 
Glaser, B. G., \& Strauss, A. L. (1967). The discovery of grounded theory: Strategies for qualitative research. Chicago, IL: Aldine Publishing Company.

Greenfeldt, B., \& Russel, P. (Winter 2003). Engaging children in language learning: Princton regional schools. NNELL Learning Languages , 8 (2), 11-13.

Hatch, J. A. (2002). Doing qualitative research in education settings. Albany State University of New York Press.

Hatch, J. A. (Ed.). (2007). Early childhood qualitative research. Routledge, Taylor \& Francis Group: New York, NY and Oxon, UK.

Heigham, J., \& Croker, R. A. (Eds.). (2009). Qualitative research in applied linguistics: A practical introduction. London, U.K.: Palgrave MacMillan.

Hessisches Sozialministerium and Hessisches Kultusministerium. (2005). Bildung von Anfang an: Bildungs- und Erziehungsplan für Kinder von 0 bis 10 Jahren in Hessen. Wiesbaden, Germany: author.

Hood, M. (2009). Case study. In J. Heigham, \& R. A. Croker (Eds.), Qualitative research in applied lingustics: A practical introduction (pp. 66-90). London, U.K.: Palgrave MacMillan.

Hovestadt, G. (2003). Wie setzen die Bundesländer den Bildungsauftrag der Kindertageseinrichtungen um? Vom Gesetz zur Praxis. Rheine, Germany: EDU-CON, Strategic Education Consulting GmbH.

Humphryes, J. (1998). The developmental appropriateness of high-quality Montessori programs. Young Children, 53 (4), 4-16.

Hymes, D. H. (1972). On communicative competence. In J. B. Pride, \& J. Holmes (Eds.), Sociolinguistics (pp. 269-293). Baltimore: Penguin Books.

Jackson, F. H., \& Malone, M. E. (2009). Building the foreign language capacity we need: Toward a comprehensive strategy for a national language framework. Washington, DC: Center for Applied Linguistics.

Jampert, K., Best, P., Guadatiello, A., Holler, D., \& Zehnbauer, A. (2007). Schlüsselkompetenz Sprache: Sprachliche Bildung und Förderung im Kindergarten-Konzepte, Projekte und Maßnahmen (2nd ed.). Weimar and Berlin, Germany: verlag das netz.

Jantscher, E., \& Landsiedler, I. (2000). Foreign language education at Austrian primary schools: An overview. In M. Nikolov, \& H. Curtain, An early start: Young learners and modern languages in Europe and beyond (pp. 13-28). Graz, Austria: European Centre for Modern Languages, http://www.ecml.at/. 
Jugendministerkonferenz und Kultusministerkonferenz. (2004). Gemeinsamer Rahmen der Länder für die frühe Bildung in Kindertageseinrichtungen. Gütersloh, Germany.

Khan-Svik, G. (2004, August). The attitude of employees at kindergartens towards mono/bilingual kindergarten children - a survey in Austrian kindergartens. Retrieved from TRANS. InternetZeitschrift für Kulturwissenschaften (15/2004): http://www.inst.at/trans/15Nr/08_1/khan15.htm

Kovács, Á. M., \& Mehler, J. (2009). Flexible learning of multiple speech structure in bilingual infants. Science , 325, 611-612.

Krashen, S. D., \& Terrell, T. D. (1983). The natural approach: Language acquisition in the classroom. Elmsford, NY: Alemany Press/Pergamon Press.

Kubanek-German, A. (2000). Early language programmes in Germany. In M. Nikolov, \& H. Curtain, An early start: Young learners and modern languages in Europe and beyond (pp. 59-70). Strasbourg, France: Counsil of Europe Publishing.

Kuhl, P. K., Conboy, B. T., Coffey-Corina, S., Padden, D., Rivera-Gaxiola, M., \& Nelson, T. (2008). Phonetic learning as a pathway to language: new data and native language magnet theory expanded (NLM-e). Philosophical Transactions of the Royal Society B , 363, 979-1000.

Kultusministerkonferenz der Länder in der Bundesrepublik Deutschland (KMK). (2005). Fremdsprachen in der Gundschule: Sachstand und Konzeptionen 2004. Bonn and Berlin, Germany: KMK.

Land Brandenburg - Ministerium für Bildung, Jugend und Sport. (2004). Grundsätze elementarer Bildung in Einrichtungen der Kindertagesbetreuung im Land Brandenburg. Potsdam, Germany: author.

Land Niedersachsen - Kultusministerium. (2005). Orientierungsplan für Bildung und Erziehung im Elementarbereich niedersächsischer Tageseinrichtungen für Kinder. Hannover, Germany: author.

Land Nordrhein-Westfalen - Ministerium für Frauen, Judend, Familie und Gesundheit. (2001). Wer spricht mit mir? Düsseldorf, Germany: author.

Land Rheinland-Pfalz - Ministerium für Bildung, Frauen und Jugend, Referat "Kindertagesstätten". (2004). Bildungs- und Erziehungsempfehlungen für Kindertagesstätten in Rheinland-Pfalz. Mainz, Germany: author.

Land Saarland - Ministerium für Bildung, Kultur und Wissenschaft. (2004). Bildungsprogramm für saarländische Kindergärten. Saarbrücken, Germany: author. 
Land Sachsen. (2006). Der sächsische Bildungsplan - ein Leitfaden für pädagogische Fachkräfte in Kindergrippen und Kindergärten. Dresden, Germany: Sächsisches Staatsministerium für Soziales.

Land Schleswig-Holstein - Ministerium für Bildung, Wissenschaft, Forschung und Kultur. (2004). Erfolgreich starten - Leitlinien zum Bildungsauftrag von Kindertageseinrichtungen. Kiel, Germany: author.

Landeshauptstadt München-Schul und Kultusreferat (LMSK). (2004). Englisch im Elementarbereich. Retrieved March 2, 2010, from http://www.musin.de/download/kita/englkiga.pdf

Lascarides, V. C., \& Hinitz, B. F. (2000). History of early education. New York, NY and London, UK: Falmer Press, Taylor \& Francis Group.

Lenneberg, E. H. (1967). Biological foundations of language. New York, NY: Wiley.

Lessow-Hurley, J. (2005). The foundation of dual language instruction. Boston, MA, New York, NY, and San Francisco, CA: Pearson Education.

Lightbown, P. M., \& Spada, N. (1999). How languages are learned (revised ed.). Oxford, U.K.: Oxford University Press.

Lightbown, P. M., \& Spada, N. (2006). How languages are learned (3rd ed.). Oxford, U.K.: Oxford University Press.

Lillard, A. S. (2007). Montessori: The Science behind the Genius. Oxford, U.K., New York, NY: Oxford University Press.

Maine State Department of Education. (1997, July). Modern and Classical Languages. Retrieved April 3, 2010, from Maine.gov, Department of Education: http://www.state.me.us/education//res/mcl.htm

Mayer, R. E. (2009). Constructivism as a theory of learning versus Contructivism as a prescription for instruction. In S. Tobias, \& T. M. Duffy (Eds.), Constructivist instruction: success or failure? (pp. 184-200). New York, NY: Routledge, Taylor \& Francis Group.

Mecklenburg-Vorpommern - Sozialministerium. (2004). Rahmenplan für die zielgerichtete Vorbereitung von Kindern in Kindertageseinrichtungen auf die Schule. Schwerin, Germany: author.

Meltzoff, A. N., Kuhl, P. K., Movellan, J., \& Sejnowski, T. J. (2009). Foundations for a new science of learning. Science, 325, 284-288.

Merriam, S. B. (1988). Case study research in education: A qualitative approach. San Francisco, CA and Oxford, U.K.: Jossey-Bass Publishers. 
Merriam, S. (2009). Oualitative Reseach: A guide to design and implementation. San Francisco: Jossey-Bass.

Met, M. (Ed.). (1998). Critical issues in ealry second language learning. Glenview, IL: AddisonWesley Educational Publishers Inc.

Mikl-Leitern, J. (2007, March 16). Mehr Englisch in NÖ Kindergärten [More English in NÖ's kindergarten]. Retrieved from APA-OTS Originaltext-Service: http://www.ots.at/presseaussendung/OTS_20070316_OTS0186

Molfese, D. (1977). Infant cerebral asymmetry. In S. J. Segalowitz, \& F. A. Gruber (Eds.), Language development and neurological theory (pp. 22-37). New York, NY: Academic Press.

Montessori, M. (1914). Dr. Montessori's own handbook. New York, N.Y.: Frederick A. Stokes Company.

Montessori, M. (1967). The absorbent mind. New York, NY: Delta Publishing.

Montessori, M. (1912). The Montessori method. (A. E. George, Trans.) New York, NY: Frederic A. Stokes Company.

Munch, B. (2002). Aaron's Hair. New York, NY: Cartwheel Books.

NCSSFL (National Counsil of State Supervisors for Languages). (2010, March). States with or Considering High School Foreign Language Graduation Requirements. Retrieved April 2, 2010, from www.ncssfl.org: http://www.ncssfl.org/docs/States\%20with\%20Foreign\%20Language\%20Graduation\%20Req uirements\%20-\%20\%20Revised\%202010.pdf

New Jersey State Department of Education. (1999). New Jersey World Languages Curriculum Framework. Retrieved April 2, 2010, from State of New Jersey, Department of Education: http://www.nj.gov/njded/frameworks/worldlanguages/

Nieto, S., \& Bode, P. (2008). Affirming diversity: the sociopolitical context of multicultural education (5th ed.). Boston, MA: Pearson Education, Inc.

NÖN. (n.d.). Schulbegin: Kindergärten sprechen in Zukunft Weltsprache [School start: In future kindergarten speak world language]. Retrieved February 1, 2010, from NÖN (Niederöstereichische Nachrichten): http://www.noen.at/redaktion/schulbeginn/article.asp?Text=241074\&cat=980

ORF. (2009, March 18). Soziales. Retrieved from NOE ORF.at: http://noe.orf.at/stories/349498/ Organisation for Economic Co-operation and Development (OECD). (2004). OECD Country Note: Early Childhood Education and Care Policy in The Federal Republic of Germany. Paris, France: OECD. 
Patton, M. Q. (2002). Qualitative research and evaluation methods (3rd ed.). Oaks, London and New Dehli, India: Sage Publications.

Penfield, W., \& Roberts, L. (1959). Speech and brain mechanisms. Princeton, NJ: Princeton University Press.

Piaget, J. (1970). Genetic epistemology. (E. Duckworth, Trans.) New York, NY and London, U.K.: Columbia University Press.

Piaget, J. (2001). The child's conception of physical causality. New Brunswick, NJ: Transaction Publishers.

Planty, M., Hussar, W., Snyder, T., Kena, G., KewalRamani, A., Kemp, J., et al. (2009). The Condition of Education 2009. (NCES 2009-081). Washington, DC: National Center for Education Statistics, Institute of Education Sciences, U.S. Department of Education.

Pufahl, I., Rhodes, N. C., \& Christian, D. (2000). Foreign language teaching: What the United States can lean from other countries. Washingtn, DC: ERIC: Educational Resources Information Center.

Rhodes, N. C., \& Pufahl, I. (2010). Foreign language Teaching in U.S. schools: results of a national survey. Washington, DC: Center for Applied Linguistics.

Robinson, D. W. (1998). The cognitive, academic, and attitudinal benefits of early language learning. In M. Met (Ed.), Critical issues in early second language learning (pp. 37-42). Glenview, IL: Addison-Wesley Educational Publishers Inc.

Rodriguez, L., Irby, B. J., Brown, G., Lara-Alecio, R., \& Galloway, M. (2003). An analysis of a public school prekindergarten bilingual Montessori Program. Annual Meeting of the American Educational Research Association. Chicago, IL.

Rosanova, M. (1998, Spring). Early childhood bilingualism in the Montessori children's house. Montessori LIFE, 37-48.

Schulausschuss der ständigen Konferenz der Kultusminister der Länder in der Bundesrepublik Deutschland (KMK). (2006). Konzepte für den bilingualen Unterricht - Erfahrungsbericht und Vorschläge zur Weiterentwicklung. Berlin and Bonn, Germany: KMK.

Shrum, J. L., \& Glisan, E. W. (2010). Teacher's handbook: Contextualized language instruction (4th ed.). Boston, MA: Heinle, Cengage Learning.

Singleton, D. (2005). The critical period hypothesis: A coat of many colours. International Review of Applied Linguistics in Language Teaching (IRAL) , 43 (4), 269-285.

Stake, R. E. (2006). Multiple case study analysis. New York, NY: The Guilford Press. 
Tabors, P. O. (2008). One child two languages: a guide for early childhood educators of children learning English as a second language (2nd ed.). Baltimore, MD: Paul H. Brookes.

Taylor-Ward, C. (2003). The relationship between elementary school foreign language study in grades three through five and academic achievement on the Iowa tests of basic skills (itbs) and the 4th-grade Louisiana educational assessment program for the 21st century (leap 21) test. Louisiana State University and Agricultural and Mechanical College, Baton Rouge, LA.

Textor, M. R. (2003). Österreich: der Kindergarten als Dienstleistungs- und Bildungseinrichtung. Retrieved from Kindergartenpädagogik: Online-Handbuch: http://www.kindergartenpaedagogik.de/1090.html

U.S. Department of Education. (2010). A Blueprint for Reform: The Reauthorization of the Elementary and Secondary Education A. Washington, DC: ED Pubs, Education Publications Center, U.S. DoE.

U.S. Department of Education. (2009, September 24). Press release: Secretary Duncan Says Rewrite of 'No Child Left Behind' Should Start Now; Reauthorization Can't Wait. Retrieved April 2, 2010, from ED.gov: http://ed.gov/news/pressreleases/2009/09/09242009.html

Usó-Juan, E., \& Martínez-Flor, A. (2008). Teaching intercultural communicative competence through the four skills. Revista Alicantina de Estudios Ingleses , 21, pp. 157-170.

Verein für Frühe Mehrsprachigkeit an Kindertageseinrichtungen und Schulen e.V. (FMKS). (2010). Address lists. Retrieved February 1, 2010, from http://www.fmks-online.de/bilikitas.html von Glaserfeld, E. (2005). Introduction: Aspects of Constructivism. In C. T. Fosnot (Ed.), Constructivism: theory, perspectives, and practice (2nd ed., pp. 3-7). New York, NY: Teachers College Press.

Vygotsky, L. S. (1978). Mind in Society. (M. Cole, V. John-Steiner, S. Scribner, \& E. Souberman, Eds.) Cambridge, MA and London, England: Harvard University Press.

Vygotsky, L. (1986). Thought and Language. (A. Kozulin, Ed., \& A. Kozulin, Trans.) Cambridge, MA: MIT Press.

Wells, R. (1973). Noisy Nora. London, U.K.: Puffin Books.

Wentworth, R. A. (1999). Montessori for the new millennium. Mahwah, NJ: Lawrence Erlbaum Associates. 


\section{Appendix}

\section{Questionnaire for Parents}

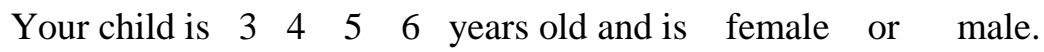

What language(s) are spoken at the child's home?

German

English

other, please name

What language(s) did your child know prior to kindergarten?

___ German ___ English

other, please name

What language(s) are mainly used in conversation with your child?

___ German ___ English

other, please name

What language(s) does your child understand?

German English

other, please name

What language(s) does your child speak?

___ German ___ English

other, please name

What is your child's language preference?

___ German ___ English

other, please name

What do you think is a reason for the preference? Please, explain. 
What are your expectations for your child's world language experience? Please, explain.

In your opinion, how important is world language learning in kindergarten?

very important important neutral not very important not at all important

Have you noticed any changes, since your child started to learn a new language. Please, explain.

In the future how will your child be able to use the languages? Please, explain. 


\section{Teacher Interview Questions}

1. How is language used by the students in the early childhood institution?

- How do students apply their first language or mother tongue (L1) and second language (L2) in the early childhood institution?

- How do students use other "languages" (understood in the Reggio Emilia context)?

- How do peers support language use in the early childhood institution?

2. How does the teacher support and foster language learning in the early childhood institution?

- What has the environment to offer toward enhancing language use and acquisition?

- How are activities and educational material selected, developed and integrated to promote language learning?

- How is language scaffolded in student-teacher interactions?

3. As teacher, how do you support and foster language learning in the early childhood institution?

- How do you create or design an environment that provides support toward enhancing language use and acquisition?

- How are activities and educational material selected, developed and integrated to promote language learning?

- How is language scaffolded in student-teacher interactions?

4. Are there any differences in the children's behavior or actions that you were able to observe after the world language integration?

5. Please, explain why your institution/ district include world language learning.

6. What current implementations of policies have had an impact on your institution / district? Please, explain.

7. What are your expectations of the early childhood education of the future? 


\title{
IRB Approval Letter
}

\author{
West WrginiaUniversity \\ Office of Research Compliance \\ DATE: May 10, 2005 \\ This research will be monitored for re-approval annually. \\ APPROVAL PERIOD: May 10, 2005 to May 9, 2006
}

NOTICE OF APPROVAL EOR PROTOCOL: IRB \#16592

TO: Sandra Schoder

TITLE: World Language Application and Use in Early Childhood Programs in Austria, Germany and the United States: A Descriptive Cross-Cultural Case Study

AGENCY: N/A

The Institutional Review Board for the Protection of Human Research Subjects (IRB) has approved the project described above. Approval was based on the descriptive material and procedures you submitted for review. Should any changes in your protocol/consent form be necessary, prior approval must

be obtained from the IRB.

According to the Code of Federal Regulations, Section 312.32, investigators are required to notify the FDA and the study sponsor of any adverse experience associated with the use of an investigational drug that is serious and unexpected. A

serious adverse experience is considered any event that is fatal or life-threatening, is permanently disabling, requires inpatient hospitalization, or is a congenital anomaly, cancer, or overdose. An unexpected adverse experience is an event that is not identified in nature, severity, or frequency in the current investigator brochure. Any experience reportable to FDA and the sponsor must also be reported immediately to the IRB. If the study is funded, initiation of the protocol may not begin until the contract is finalized.

\begin{tabular}{c|l} 
& Chestnut Ridge Research Building \\
& 886 Chestnut Ridge Road \\
Phone: $304-293-7073$ & PO Box 6845 \\
Fax: 304-293-7435 & Morgantown, WV 26506-6845
\end{tabular}


Date: May 10, 2005

Page -2-

Schoder

IR3 \#16592

A consent form* $\mathrm{X}$ is__ is not required of each subject.

An assent form_ is $\mathrm{X}$ is not required of each subject.

A recruitment ad has__ has not $\mathrm{X}$ been approved.

$A$ consent form waiver has__ has not $X$ been approved.

An authorization form to use PHI has__ has not $\mathrm{x}$ been approved.

A PHI waiver has. has not $\mathrm{X}$ been approved.

Only copies of the consent and/or assent form with the IRB's approval stamp may be used with human subject research. It is the responsibility of the investigator to submit a revised consent form for the IRB's approval should funding be obtained. This stamped consent form must then be used for subjects enrolied. A copy of each subject's signed Consent/Assent Eorm must be retained by the investigator and accessible to federal regulatory authorities for at least three years after the study is completed.

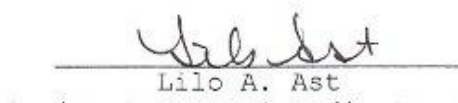

Senior Program Coordinator for

Research Compliance

LAA/baw

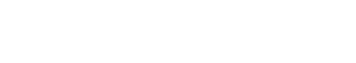

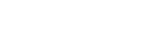

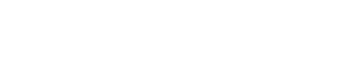

